2019

\title{
What Does A Marginalized Community Say About Its Experiences In A Two-Year, Service- Learning Project?
}

Shanequa Smith

sshanequa@hotmail.com

Follow this and additional works at: https://researchrepository.wvu.edu/etd

Part of the Civic and Community Engagement Commons, Community-Based Research $\underline{\text { Commons, and the Urban Studies and Planning Commons }}$

\section{Recommended Citation}

Smith, Shanequa, "What Does A Marginalized Community Say About Its Experiences In A Two-Year, Service-Learning Project?" (2019). Graduate Theses, Dissertations, and Problem Reports. 3839.

https://researchrepository.wvu.edu/etd/3839 
What Does A Marginalized Community Say About Its Experiences In A Two-Year, ServiceLearning Project?

\author{
Shanequa Smith
}

Dissertation submitted

To the Davis College of Agriculture, Natural Resources and Design

At West Virginia University

Doctor of Philosophy in

Human and Community Development

Peter V. Schaeffer, Ph.D., Chair

Peter Butler, MLA

Amena Oliver Anderson, Ph.D.

Bradley Wilson, Ph.D.

\title{
School of Design \& Community Development
}

\author{
Morgantown, West Virginia \\ 2019
}

Keywords: community members, marginalized, service-learning, engagement, relational practices, voice of the community

Copyright 2019 Shanequa Smith 


\begin{abstract}
What Does A Marginalized Community Say About Its Experiences In A Two-Year, ServiceLearning Project?

\section{Shanequa Smith}

Institutions of higher education are increasingly engaging with communities through service-learning projects to provide students with practice in their chosen fields and assistance to communities. By now, such efforts have been described in a growing body of literature.

However, little has been reported on the perspectives and experiences of community members. The purpose of this phenomenological study is to capture and understand the perceptions and experiences of community members who participated in a two-year service-learning project, with the goal of sharing lessons to improve university-community engagement relationships and practices. A qualitative phenomenology approach, using semi-structured interviews, was the method used to gather data from individuals who participated in a two-year service learning project. Findings highlight the importance of a relational approach to engagement to establish clear expectations and limitations of the engagement between the university and community members.
\end{abstract}


Table of Contents

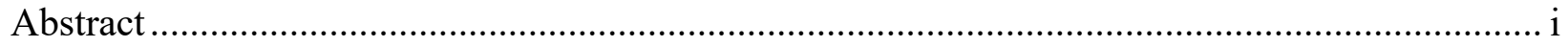

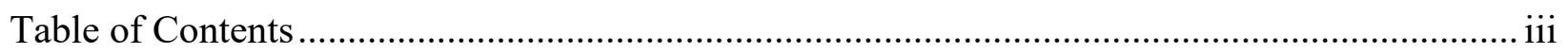

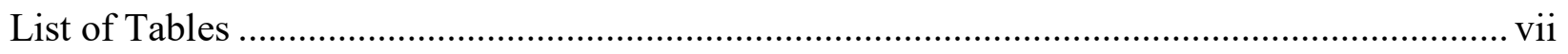

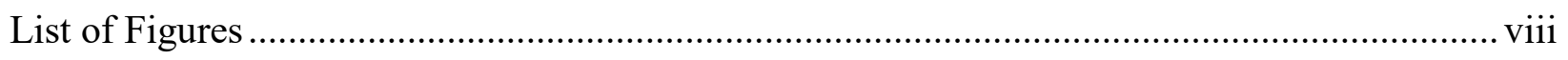

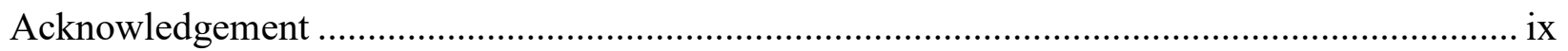

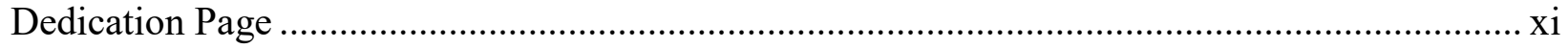

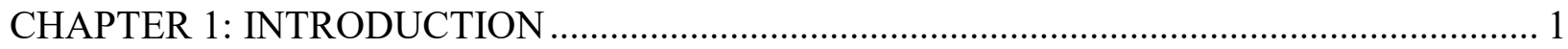

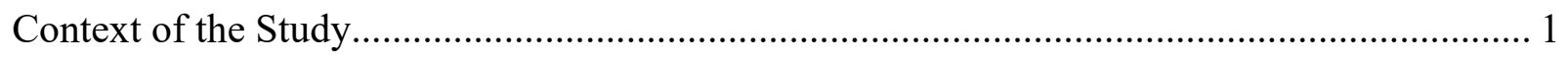

The Fostering Fairmont (FFP) Service-Learning Community Development Project................ 3

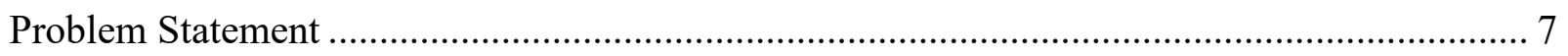

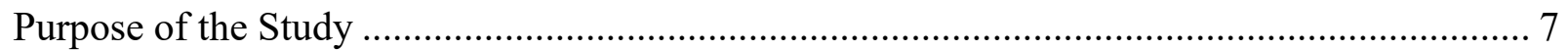

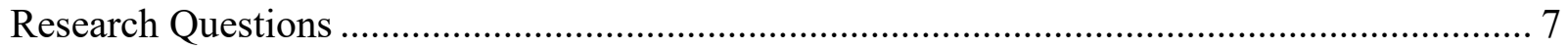

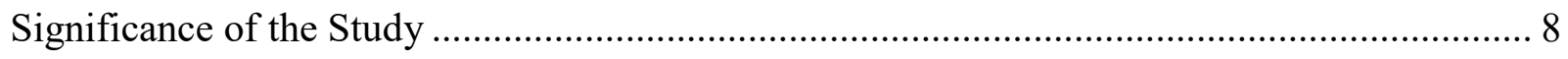

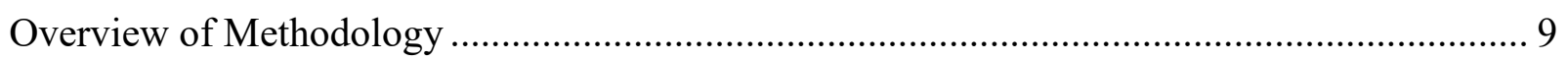

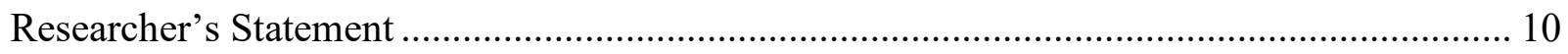

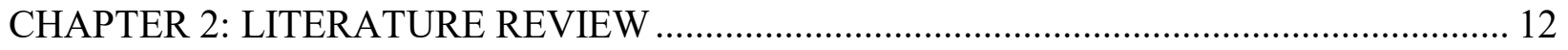

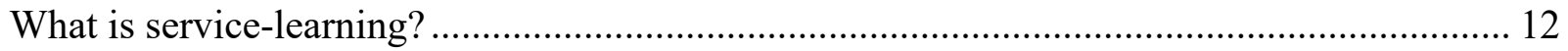

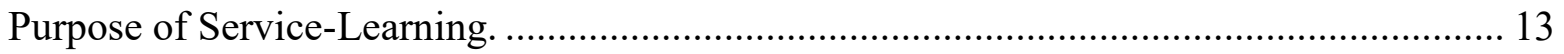

Service-Learning's Theoretical Foundations............................................................... 14

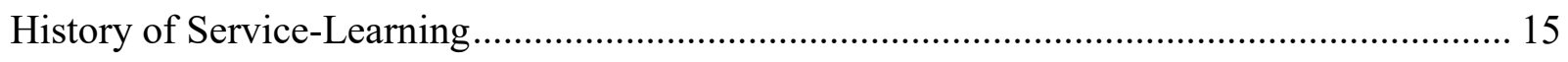

Service-Learning - Traditional Approach ............................................................. 17

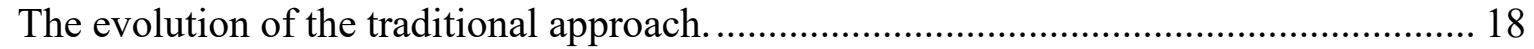

Service-learning as Engagement - The Critical Approach ......................................... 20

The evolution of the engagement approach. .......................................................... 25

Service-Learning in Relationships - Postcritical / Relational Approach ........................... 26

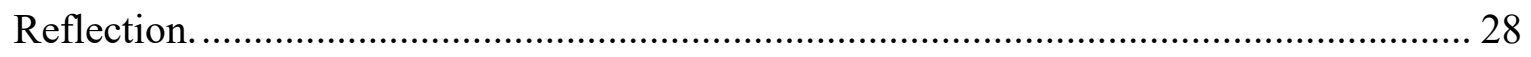

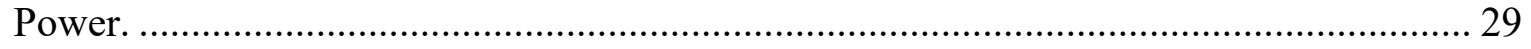

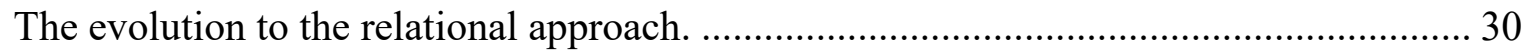

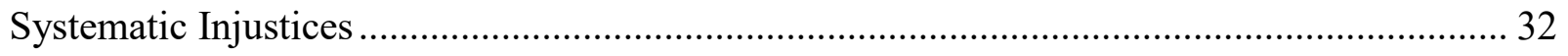

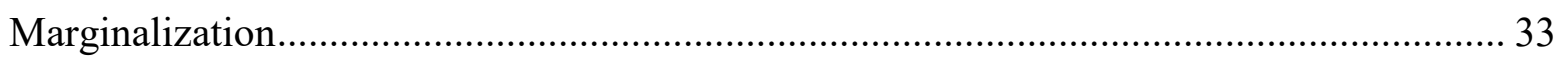

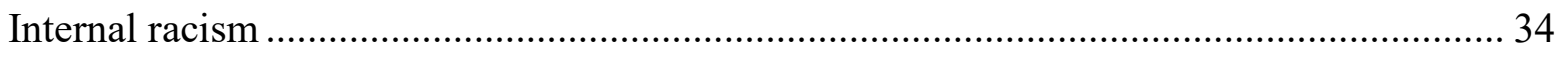


Trauma

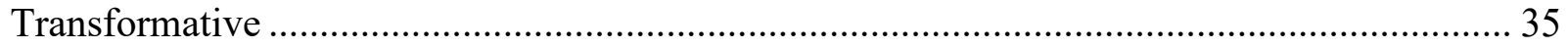

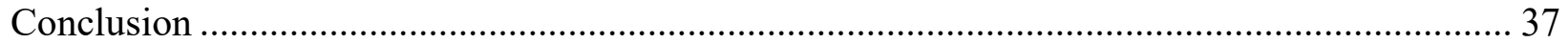

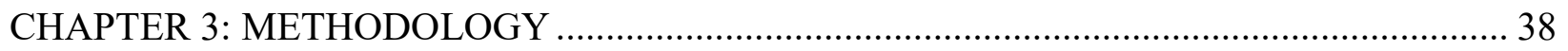

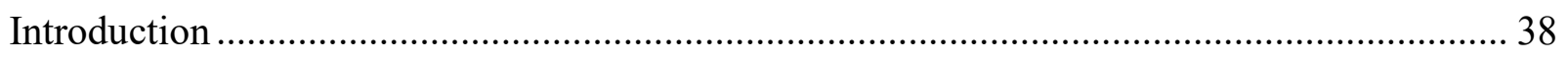

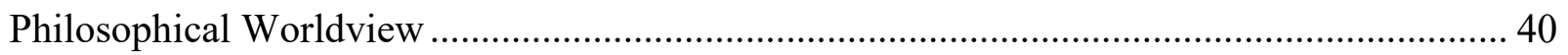

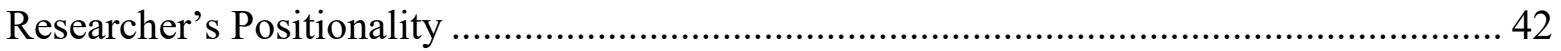

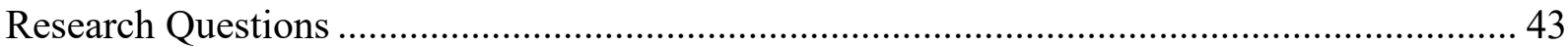

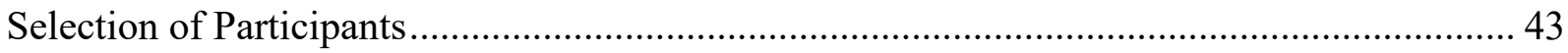

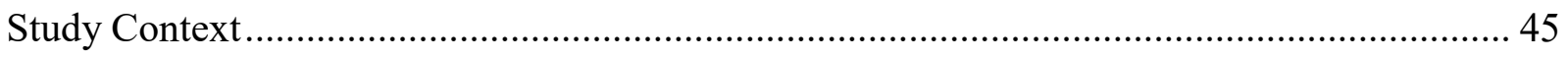

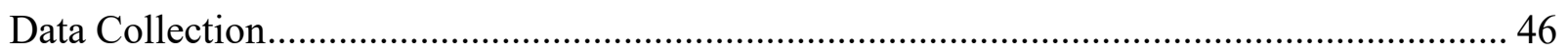

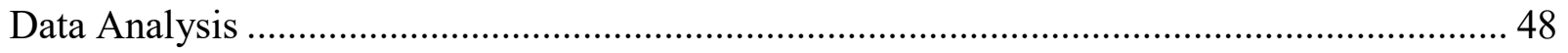

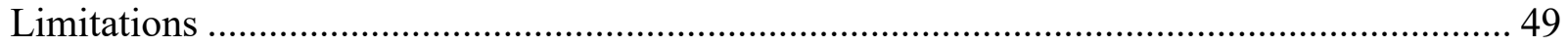

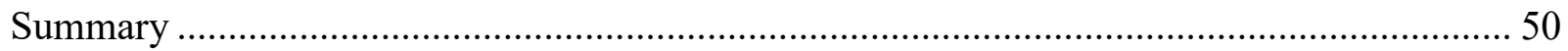

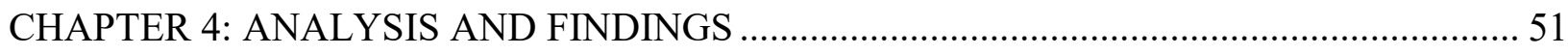

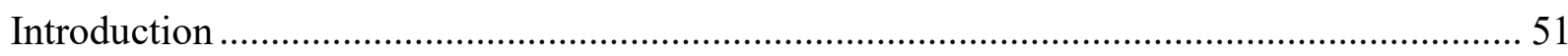

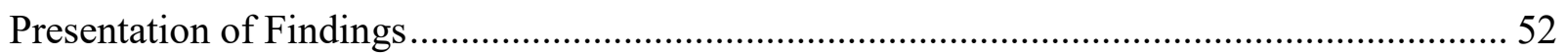

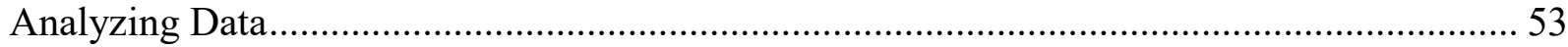

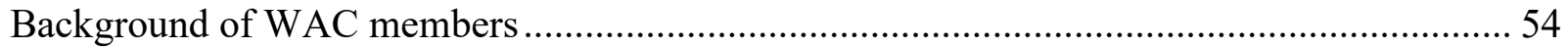

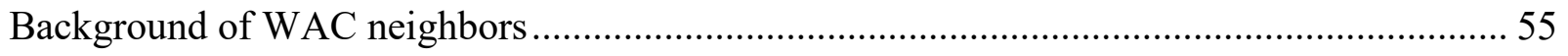

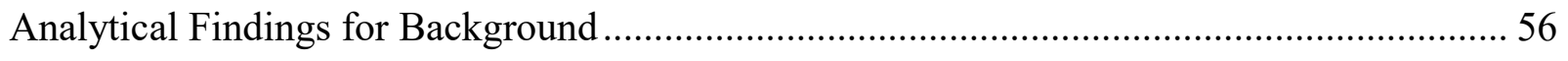

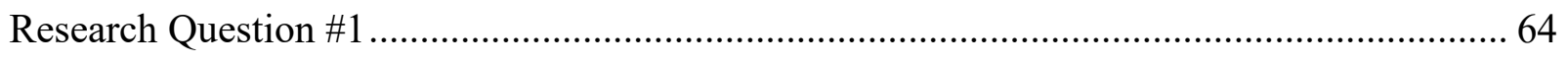

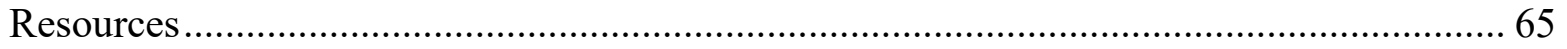

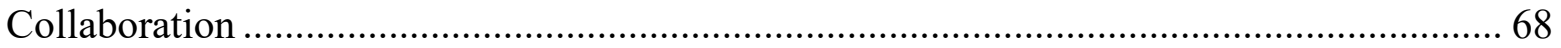

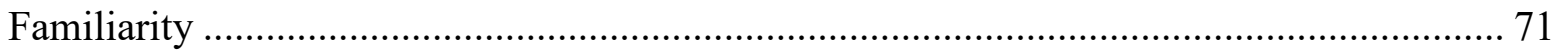

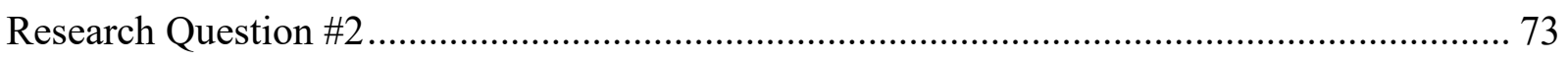

Collaborative Efforts and Knowledge Shared ......................................................... 74

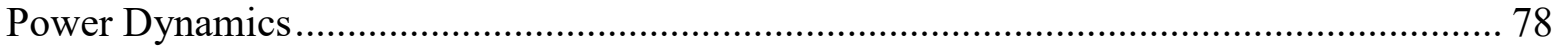

Barriers to/Recommendation for Engagement within their Community......................... 82

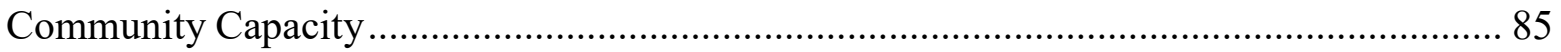

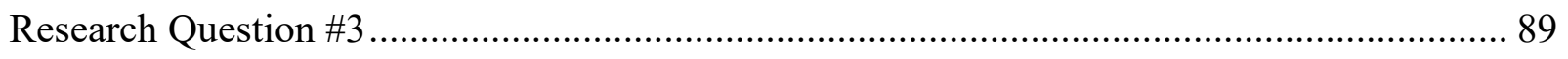

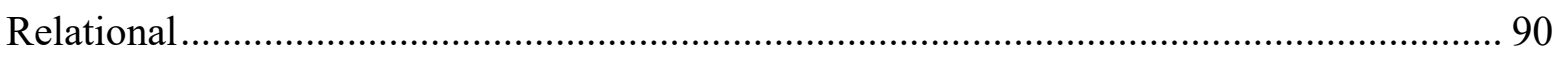




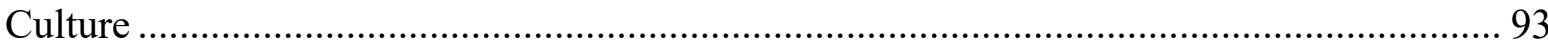

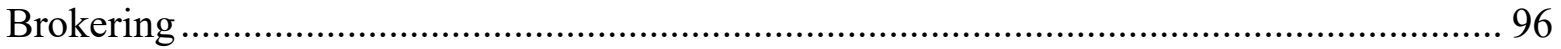

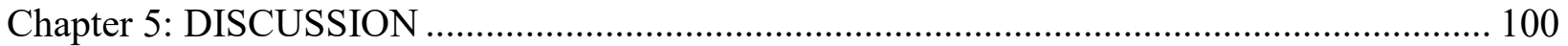

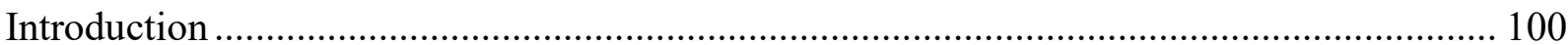

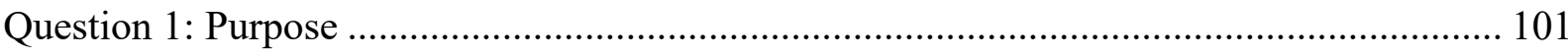

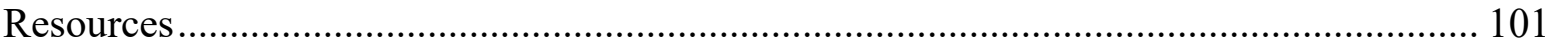

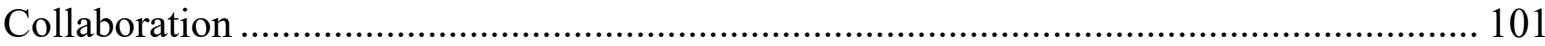

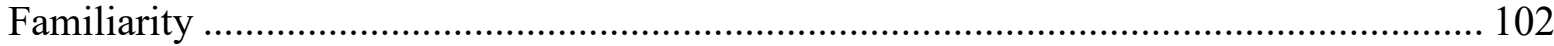

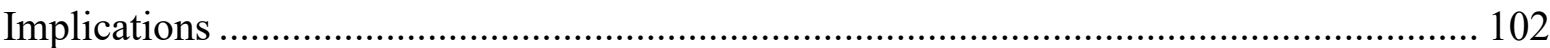

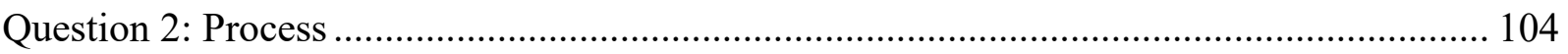

Collaborative Efforts and Knowledge Shared ............................................................. 104

Power Dynamics....................................................................................................... 105

Barriers to and Recommendation for Engagement within their Community....................... 105

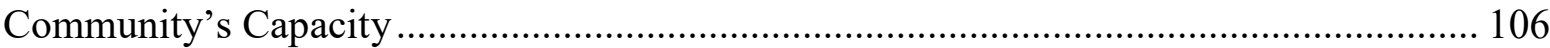

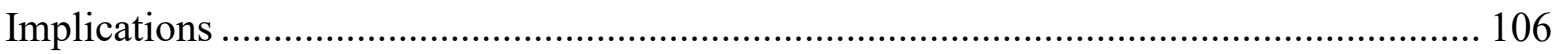

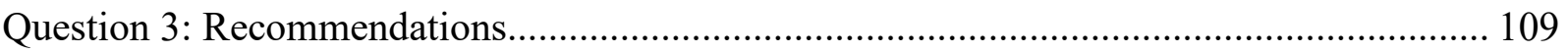

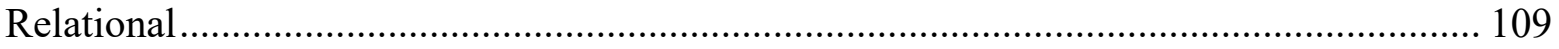

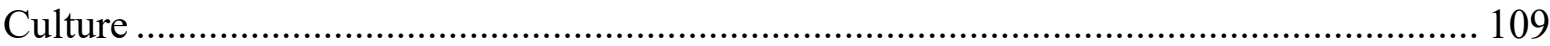

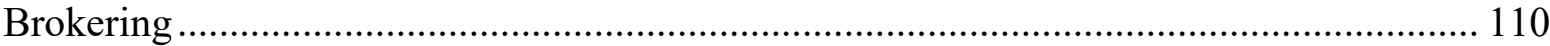

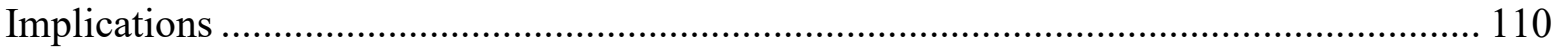

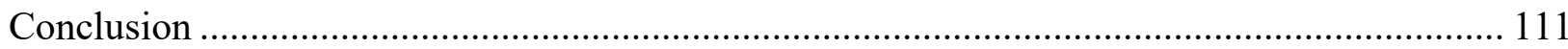

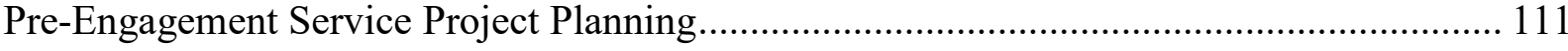

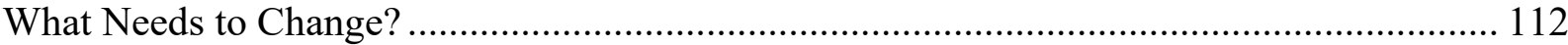

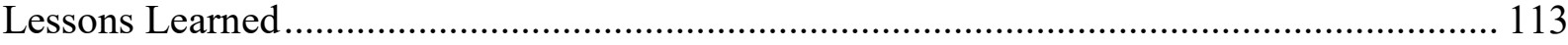

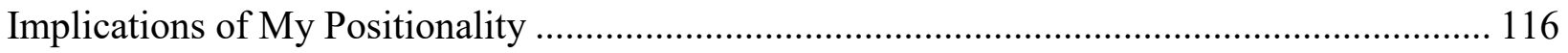

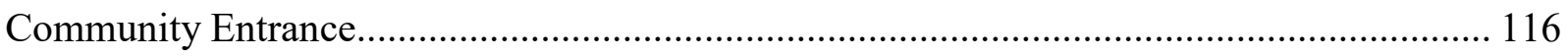

Community Engagement ................................................................................................... 119

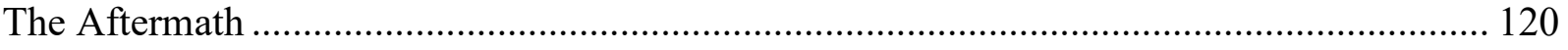

Recommendations for Future Research ............................................................................... 121

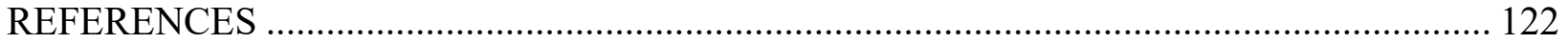

APPENDIX A - Interview Protocol for WAC Members......................................................... 136

APPENDIX B - Interview Protocol for Westside Neighbors ..................................................... 140 
APPENDIX C - Consent for Participation in Interview Research....................................... 143

APPENDIX D - Public Engagement Plan for the Westside Action Coalition......................... 145

APPENDIX E - Community Visioning Conversations Report............................................. 208

APPENDIX F - Community Profile Report.................................................................. 256

APPENDIX G - Community Survey Results Report................................................. 345

APPENDIX H - Community Profile Slides .......................................................................... 372

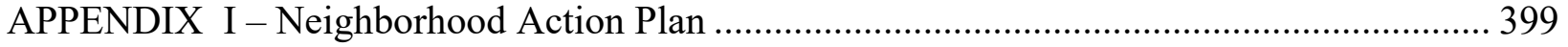




\section{List of Tables}

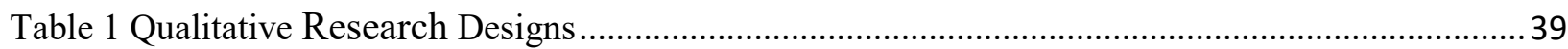

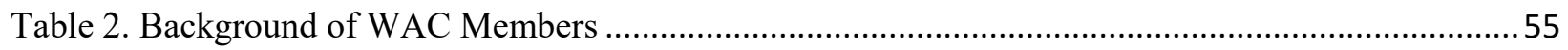

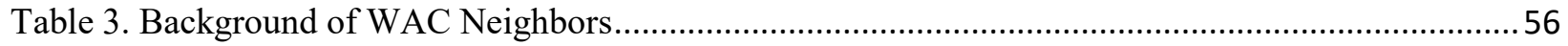

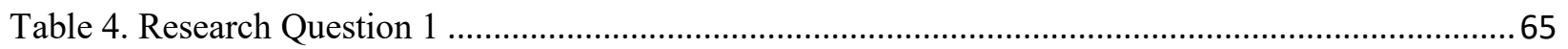

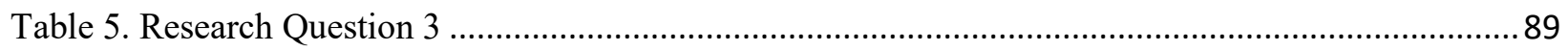




\section{List of Figures}

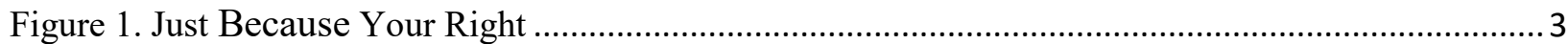




\section{Acknowledgement}

During my academic journey, I was blessed to meet individuals who provided actions of love that enabled me to successfully complete my endeavor. These actions of love had formed tribes of individuals that I will forever be grateful for. I would like to say THANK YOU to my academic tribe, community tribe, and family tribe. Instead of mentioning names and possibly mistakenly forgetting someone, I decided to acknowledge your actions of love that have become the roots of me successful completing this journey.

Thank you for serving as my committee member.

Thank you for serving as the chair of my committee.

Thank you for being a supportive colleague.

Thank you for reading my writings in short time frames.

Thank you for editing my dissertation.

Thank you for being my accountability partner.

Thank you for being my writing partner.

Thank you for connecting me to opportunities that were part of my destiny.

Thank you for being an example.

Thank you for being supportive of my journey when neither of us seen my path.

Thank you for believing in me when I was unsure of myself.

Thank you for listening.

Thank you for allowing me to sleep in your home as I traveled back and forth between

Charleston, Fairmont, and Morgantown.

Thank you for participating in the Fostering Fairmont Project (FFP).

Thank you for allowing me to interview you. 
Thank you for being my financial support system.

Thank you for helping me take care of my children.

Thank you for feeding me.

Thank you for sacrificing with me.

Thank you for loving me.

Thank you for trusting me.

Thank you for being patience with me.

Thank you for being my faith partner.

Thank you for praying with me.

Thank you for praying for me.

Thank you for speaking encouragement into me.

Thank you for talking with me.

Thank you for making flyers for me.

Thank you for being in my life for a season.

And thank you for the laughter and wine. 


\section{Dedication Page}

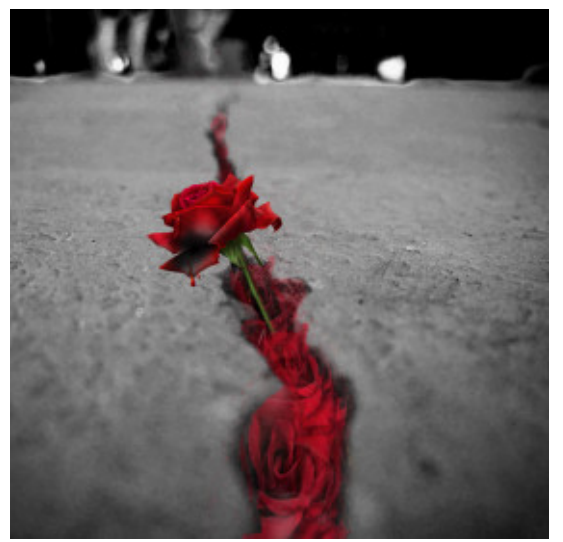

\section{The Rose that Grew from Concrete:}

Did you hear about the rose that grew from a crack in the concrete?

Proving nature's law is wrong it learned to walk without having feet. Funny it seems, but by keeping its dreams, it learned to breathe fresh air. Long live the rose that grew from concrete when no one else ever cared.

\section{By Tupac Shakur}

This dissertation is dedicated to every rose that grew through a crack in the concrete. 


\section{CHAPTER 1: INTRODUCTION \\ Context of the Study}

"Just be genuine. And be sensitive to the needs of the people that you're working with. Like, really understand their point of view and where they're coming from and don't look at them as a project but look at them as people" (Henrietta, personal interview, July 26, 2017).

What does it mean to "just be genuine" ...," sensitive to the needs of the people" ...", to "understand their point of view" ...", and not to "look at them as a project but look at them as people"? How can researchers ethically respond to these questions, while achieving their academic goals? In the opening quote, Henrietta, a community member, provided these recommendations to community engaged scholars, after participating in a two-year servicelearning project. Henrietta's recommendations call attention to the need for community engaged scholars to be mindful to humanize research efforts as we work with community members to address their social justice issues. Humanizing research allows researchers to apply methodologies that seek to "grapple with the tensions that arise from being primary concern about equity and social justice while simultaneously engaging in research" with other individuals (Paris \& Winn, 2014, p. xiii). Balancing the commitments of the academy with desires to humanize research, positions community engaged scholars to acknowledge the need to address this struggle.

Humanizing research seeks first to understand the perspectives and experiences of individuals who have been marginalized, in order to form a collaborative effort against the social justice issues that impede them (Paris and Winn, 2014). A humanizing pedagogy includes acknowledging the power dynamic that influences the interactions between the community 
engaged scholar and the community (Bortolin, 2011; Moore, 2014; Paris and Winn, 2014); and learning how to learn from community members in order to collaboratively expand research and empower communities. Stephen Covey (1992), lists "seek first to understand, then to be understood" (p. 150) as the $5^{\text {th }}$ habit of highly effective people. Freire (1970) states:

No pedagogy which is truly liberating can remain distant from the oppressed by treating them as unfortunates and by presenting for their emulation models from among the oppressors. The oppressed must be their own example in the struggle for their redemption (p. 54).

Community engaged scholars who are learning about and incorporating a relational approach to their research practices with marginalized community members, are realizing that self-reflection, understanding their position of power, and how marginalized people may view or respond to the researcher's power; are part of the process of humanizing research (Bortolin, 2011; Paris \& Winn, 2014).

As community engaged scholars become more aware of their position of power and incorporate relational approaches to working with marginalized community members, scholars and community members synergistically address social change and social justice issues (Clifford, 2017). Learning, understanding and validating knowledge created by others, positions the community engaged scholar to share the power dynamics of the relationship. Figure 1 provides a visual representation of why practicing a relational approach to research when working with marginalized people is important. 


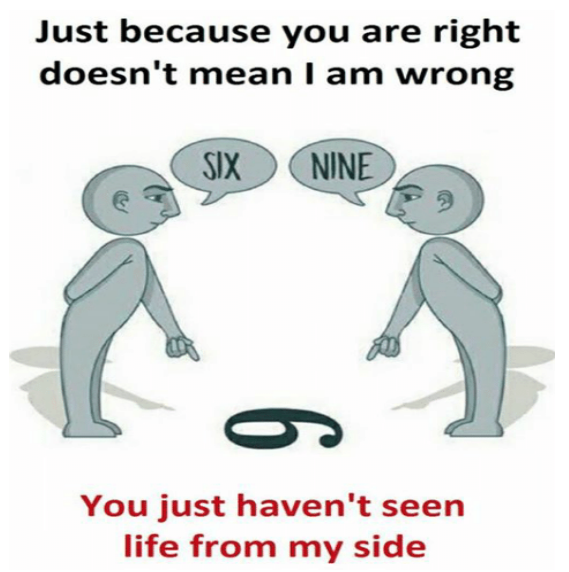

Figure 1. Just Because Your Right

Figure 1 shows how perspectives can differ concerning the same object, which amplifies the need for humanized research. As community engaged scholars increase their involvement in communities to address social issues through their research, learning, understanding, and incorporating community members' perspectives and experiences can further research (Levkoe et al., 2018).

\section{The Fostering Fairmont (FFP) Service-Learning Community Development Project}

In the fall of 2015, the project team leader, graduate students, and myself, as the community engaged scholar, began a two-year service-learning project, through West Virginia University (WVU), with members of a Fairmont community. The two-year service-learning project was identified as the Fostering Fairmont Project (FFP) and it was conducted through a combination of service-learning and participatory action research. The purpose of the FFP was to equip community members with the tools necessary to enhance their neighborhood. The project team designed the FFP using the theory Asset-Based Community Development (ABCD), with a Community Capitals Framework (CCF). The ABCD approach focuses on a community's assets instead of its deficiencies (Kretzman \& McKnight, 1993) and the CCF identifies key capitals that 
contribute to the development of a community (Emery \& Flora, 2009). The CCF capitals identified are the following: natural capital, cultural capital, human capital, social capital, political capital, financial capital, and built capital.

The International Association for Public Participation (IAP2) Spectrum of Public Participation, was coupled with the $\mathrm{ABCD}$ model and the $\mathrm{CCF}$ to guide participatory objectives and techniques. A more in-depth description of how this theory and these frameworks were used in the FFP can be found in the Public Engagement Plan for the Westside Action Coalition (2016), (see WAC Public Engagement Plan for the Westside Action Coalition in APPENDIX). The FFP was structured into four phases, over four semesters, with the goal to assist community members with building community development initiatives within their community. These four phases consisted of community members learning, mobilizing, planning and acting on the strategies necessary to enhance their community (Community Visioning Conversations Report, 2016, see APPENDIX).

The first phase of the FFP started in fall 2015 and was identified as the learning phase (Community Visioning Conversations Report, 2016). During this phase of the project, community members participated in collaborative activities to learn and teach about their community. These collaborative activities was comprised of meetings, workshops, neighborhood tours, and assisting with the gathering of primary and secondary data. Meetings and workshops were conducted to build community capacity and teach them about their local governance, community development and community organizing.

Neighborhood tours were conducted to provide community members the opportunity to share their expert knowledge about their community. Community members also shared rich historical information about their generational connection to the community and they also 
assisted students with the collection of secondary data. Details about these activities can be read in the Public Engagement Plan for the Westside Action Coalition (2016) and the Community Visioning Conversations Report (2016). In this phase, The Community Profile Report (2015), and the Community Survey (2015), were produced to be informational tools to assist community members with their community and economic development initiatives (see Community Profile Report and Community Survey in APPENDIX).

The Community Profile Report (2015) provided information about the history of the neighborhood, assets of the community, and how to organize and develop community resources (Community Profile Report, 2015; Community Visioning Conversations Report, 2016, see attached). The Community Profile Report is also included in this dissertation in PowerPoint slide format to provide a summary of the actual report (see WAC Community Profile slides in APPENDIX). The Community Survey provided information about how community members viewed the institutions in their community, and how they felt about the opportunities and practices available to community members in relation to self-governance and collective action (Community Survey Report, 2015).

The second phase of the FFP began in spring 2016, with a focus to mobilize community members through the establishment of a coalition, facilitate community conversations, and equip community members with a public engagement plan. The coalition was established to build encouragement and assist community members with developing a more collaborative approach to working in their community. The project team leader named the coalition, the Westside Action Coalition (WAC) and its purpose was to form a foundation for community members to learn and apply collaborative approaches to building and sustaining social and economic growth in their community. There was a series of meetings held throughout the community known as 
Community Visioning Conversations. These community visioning conversations were held to identify community members' shared values, visions, and their ideas about community issues and potential action which should be taken. The information captured from these community conversations was compiled into the Community Visioning Conversations Report by the project team leader and her graduate students for community members to use for their community development initiatives. The final objective of this phase was to provide community members with a community engagement plan. This community engagement plan, known as the WAC Public Engagement, was provided to assist WAC members with information on how to get other community members involved.

The third phase of the FFP began in fall 2016, with a focus of developing plans for community members to put into action. Information that was collected from community meetings, along with the data that was collected from the Community Profile, the Community Survey, and the Community Visioning Conversations Report, guided the planning for which projects would be included in the Neighborhood Action Plan (2016), (see Neighborhood Action Plan in APPENDIX). After the accumulation of data from meetings with community members and the combined information obtained in the reports was created, ten community project action plans were developed for community members to implement.

For the final phase of the FFP, the focus was implementing projects from the plan. We worked with community members who were placed into project action teams to work collaboratively to support projects from the action plans. These action plans included legal, technical, and budgetary information that helped guide community members as they implemented their community projects. For details to describe the specific manner in which 
community members engaged in the planning phases, see the Public Engagement Plan for the Westside Action Coalition (2016) in appendix.

\section{Problem Statement}

Through service-learning projects, institutions of higher education are increasing their engagement with community members to address social justice issues. (Clifford, 2017).

Community engaged scholars recognize the need to shift service-learning pedagogies from a product-centered approach to a relationship-centered approach to effectively assist community members with emancipating themselves and their communities from systematic oppressions (Bruce, 2018; Clifford, 2017; Paris \& Winn, 2014). Institutions of higher learning use servicelearning practices to prepare students professionally for the labor market while working with community members to better their communities, but little in the literature relates to what community members thought about the service-learning project, and the benefits for community members (Chupp \& Joseph, 2010; Latta et al, 2018; Levkoe et al., 2018).

\section{Purpose of the Study}

The purpose of this study is to understand the perceptions and experiences of Fairmont WV participants who participated in a two-year service-learning project intended to begin community development initiatives in their marginalized community. This study aims to document and report the perceptions and experiences of community members with the goal of showing the need to humanize research in service-learning and engaged scholarship practices and provide recommendations to improve future community-university relations.

\section{Research Questions}

To meet the purpose of this research, a phenomenological study is used to explore the following questions: 
1. What do Fostering Fairmont Project participants perceive as the purpose of the two-year service-learning project intended to begin community development initiatives in their marginalized community?

2. What were Fostering Fairmont Project participants' experiences with the two-year service-learning project that intended to begin community development initiatives in their marginalized community?

3. What recommendations do Fostering Fairmont Project participants have for universities about engaging community members in service-learning projects?

\section{Significance of the Study}

This study will add to the service-learning literature that seeks to modify service-learning practices that will meet academic research and outreach goals while simultaneously humanizing the research process to understand the insight and plight of marginalized community members (Bruce, 2018; Clifford, 2017; Lindquist-Grantz \& Vaughn, 2016; Paris \& Winn, 2014). Todd (2003) writes that:

The idea that we only need to get to know someone in order to be able to act responsibly (and responsively) toward that person is a common way for people to talk about one of the conditions for ethical interaction. In education in particular, this getting to know the other (e.g., teachers getting to know their students through their experiences, cultural backgrounds.) often becomes the premise for building relationships that better meet the needs of persons involved. Indeed, there is some commonsense appeal to this. How often has each one of us thought that if we had only known the full story, we might have acted differently, been more sensitive, or paid closer attention to the other person? This learning about the Other, however, 
suggests two things: that otherness can be understood and that learning about others is pedagogically and ethically desirable. Attempts to work across differences in social justice education often gain their ethical strength from deconstructing center and margin, inclusion and exclusion, and self and "Other." Framing our ethical attention to difference as a question of knowledge implies that the more we know about "Others," the better we are able to understand how to respond to them, how to be more responsible and how to de-"Other" them. (p. 8).

The results of this study will contribute to understanding the perspectives and experiences of marginalized community members and provide service-learning practice recommendations to improve community-university relations. The community engaged scholar will be able to research how academic theories can be practically applied to help marginalized communities, and the community members can receive institutional support and funding for projects that were too expensive to undertake without assistance. By recognizing the human aspect of this project, community engaged scholars may be able to create a lasting relationship with community members, rather than examining the community as anthropologists would. By focusing on the experiences of the community rather than solely the learning objectives and scholarly output, this project bridges the divide between the theoretical and the practical.

\section{Overview of Methodology}

This study's central focus is the perceptions and experiences of community members who participated in a two-year service-learning project that was intended to generate community development initiatives in their marginalized community. Qualitative inquiry is an appropriate approach to achieve this study's objectives because qualitative research allows the researcher to capture and report the perspectives of individuals (Brinkmann \& Kvale, 2015; Yin, 2014) and 
creates room for in-depth narratives and experiences of individuals to be represented in the building of knowledge (Denzin \& Lincoln, 2013). The methodology was a qualitative phenomenological approach, using semi-structured interviews of community members to gather data. A phenomenological design is appropriate when the focus of the study is to provide a description of an event or occurrence within a real-world environment with the goal of understanding the participants' first-hand perspectives and experiences (Moustakas, 1994). Interviews are an important source used in qualitative research (Yin, 2014) because interviews “attempts to understand the world from the subjects' points of view, to unfold the meaning of their experiences, to uncover their lived world prior to scientific explanations" (Brinkmann \& Kvale, 2015, p. 3).

\section{Researcher's Statement}

As I create and write this document, I am consciously choosing to address the politics of language -- by writing this dissertation in a way that community members can understand. Joseph (2006) argues that, "The politics of language choice become particularly difficult when institutional choices have to be made - in what language or languages the government will conduct its business and communicate with its citizens, and, above all, what the language or languages of education will be" (pg. 10). But what actions should be taken when the language chosen by those in power, is unclear to its citizens?

I have had the privilege of walking the divide between community and academic language. Having the experience of being born and raised in marginalized situations has created a gap between the language I was familiar with and the language of which academia presents its teachings. This experience has created a consciousness in me to not only understand the knowledge that I am presenting, but to also make sure that my knowledge is presented in a way 
that the community of this study can understand. Joseph (2006) states, “A language isn't a thing, and it makes little sense to imagine one English language evolving over many centuries, rather than different English languages existing at different stages" (pg. 9). The knowledge that will be generated in this dissertation is generated within the confines of academia, which is known for presenting information in a technical and/or scientific way, but this knowledge was co-created with individuals who are not part of the academic academy. The very act of using words has political overtones (Joseph, 2006). Therefore, using language that is common to community members presents knowledge that can be shared outside the walls of power which will make the information accessible to everyone involved.

Fairmont community members and even some of my family members have shared an interest in reading the final findings of this dissertation. My brother, who is 36 years old, told me that he has never read a book in its entirety, but he is looking forward to reading my dissertation. Community members I have worked within the community have asked me "what is a dissertation?", "why is it taking so long?", and "will we get a chance to read it?" As I have the power to report the phenomenon that took place with community members, I want to give community members the power to read and understand this knowledge. 


\section{CHAPTER 2: LITERATURE REVIEW}

This chapter examines the literature that creates space for acknowledging the importance of including the community's voice and experiences into the process of service-learning. This literature review concentrates on the following areas: (a) how service-learning came about, (b) the evolution of service-learning theoretical practices, (c) and the necessity of this evolution. This literature review ends with the importance of incorporating transformational approaches to service-learning when conducting research and assisting individuals with meeting their community goals.

\section{What is service-learning?}

Service-learning is a reflective, social-academic practice that creates opportunities for students and community engaged scholars to learn and work with communities, while simultaneously addressing community needs. The hyphen in service-learning emphasizes the equal importance of enhancing both of providing a service and learning in the process (Jacoby, 2003; Jacoby, 2015; Phelps, 2012). The goal of service-learning is to "meet human and community needs in combination with intentional learning goals and with conscious reflection and critical analysis" (Jacoby, 2015, p. 4). This objective of service-learning is what makes it distinctive from other forms of community-based work.

Service-learning differs from other forms of community-based work because it aims to provide a mutual benefit to the university and community (Jacoby, 2015). Community-based works such as volunteering and community service tend to focus on benefitting the community, whereas community-based work (such as internships and fieldwork) tend to focus on benefiting 
the community engaged scholar (Furco, 1996; Jacoby, 2015). Service-learning intentionally seeks to create a mutually-beneficial experience between university and community.

\section{Purpose of Service-Learning.}

Service-learning is a reflective, action-centered, educational approach that integrates academic learning objectives with service to the community (Curwood, Munger, Mitchell, Mackeigan, \& Farrar, 2011; Felten \& Clatyon, 2011). This experience equips university students with skills beyond the classroom and exposes them to the differences of planned versus real-life events. This also positions communities with the opportunity to receive support to achieve community goals. With this intent, service-learning has been used to represent programs, pedagogies, and philosophy interchangeably; yet, they all reflect a different approach (Butin, 2011; Jacoby, 2015; Levkoe, Brail, \& Daniere, 2014). Service-learning as a program focuses on providing a direct service to a community, while fulfilling a learning objective for the student. Service-learning, pedagogically, examines the experiences and teachings of community engaged scholars that guide the direct service and educational objectives of the student. Philosophically, service-learning looks to eliminate the need of the direct service to the community and allowing the community's need to drive the learning objectives (Jacoby, 2015). Though these approaches to service-learning differ, they all indirectly influence one another. For example, a servicelearning pedagogy can influence how a service-learning project is implemented, and actions within a service-learning project will demonstrate its philosophical stance. The research presented her was framed as a service-learning project, and therefore, the literature review will reference the "project" side of service-learning.

A service-learning experience that is well-designed and well-implemented embeds an intent to focus equally on achieving academic and community goals (Bringle, Clayton, \& 
Hatcher, 2013), while incorporating reflective activities (Chupp, \& Joseph, 2010; Coffey \& Lavery, 2015; Karlsson, 2016; Lavery, 2012) to address the dimensions of power within the university-community relationship (Clifford, 2017; Davis, Kliewer, \& Nicolaides, 2017; Hunt, Bonham, \& Jones, 2011). This partnership is created to address diverse civic and social issues of a community (Jenkins \& Sheehey, 2011), while simultaneously providing students with relevant work experiences and practical skills (Edwards, Mooney, \& Heald, 2001; Latta, Kruger, Payne, Weaver, \& Van Sickle, 2018; Levkoe \& Stack-Cutler, 2018). Implementation of a servicelearning experience depends on desired goal(s) of the university and community, the contextual conditions in which the project is preformed, and the constraints of those involved. Though these factors influence why variations exist on how individuals define, approach, and implement service-learning activities, there is a consensus that a good service learning initiative includes the following: the furthering of academic learning, service to a community, and a reflective process that consists of bettering engagement practices among practicing scholar, students, and community members (Bringle et al., 2013, Jacoby, 2015, Levkoe, 2018).

\section{Service-Learning's Theoretical Foundations}

Principles, beliefs, and cultural contexts will affect how service-learning is applied (Bringle et al., 2013). Though service-learning may be interpreted differently among community engaged scholars (Clayton, Bringle, \& Hatcher, 2013; Felton \& Clayton, 2011; Flecky, \& Gitlow, 2011; Jacoby, 1996; Jacoby, 2015, Mitchell, 2008), scholars agree that the theoretical origins of service-learning stem from the work of John Dewey (Flecky, \& Gitlow, 2011; Giles \& Eyler, 1994; Jacoby, 2015; Kolb, 2014; McLaughlin, 2010; Noyes, Darby, \& Leupold, 2015). John Dewey is often viewed as the father of experiential learning; he believed that learning occurs from a combination of experience and reflection (Jacoby, 2015). Service- 
learning roots lie in the notion of combining educational knowledge with reflective real-world experiences to create more experienced professionals, but initially failed to establish considerations for systematic injustices.

This omission of considerations of systematic injustices sparked the evolving theoretical phases that service-learning experienced, and still faces today. This literature review will identify the theoretical periods in which service-learning evolved, and the contributing factors for this evolution. These theoretical periods are framed as the traditional approach, the critical approach, and the postcritical approach (Bruce, 2018), all of which will be discussed below.

\section{History of Service-Learning}

The establishment of land-grant institutions through the Morrill Land-Grant College Act of 1862 was the birth of universities providing "knowledge for the public good" (Groark, 2018, p. 8). Land-grant universities were created to "provide equal access to education and service to communities" (Jenkins \& Sheehey, 2011, p. 5). The Morrill Land-Grant Act of 1862 made provisions for higher education institutions to receive funding and land to prepare individuals to join the workforce (Felten \& Clatyon, 2011). This initiative was strengthened through the second Morrill Land Grant Act of 1890 and the 1914 Smith-Lever Act. The latter received funding from the U.S. Department and Agriculture (USDA) and state governments to support "extension" programs within universities (Groark, 2018). Extension programs were designed by universities to provide agricultural and home economics knowledge to community members (Soska, 2015). This funding support provides land-grant universities with resources to assist community members with the development of their state's communities.

Over the decades, land-grant universities flourished and became major academic research centers, but extension programming did not attract research interest and, thus, it was treated as 
academically inferior compared to other academic disciplines (Soska, 2015). This caused interest in extension programming to shrink, even though traditional monies were being allocated to universities for extension programming. According to Groark (2018), some academics and lawmakers addressed the fact that universities started to perceive this funding support as an "entitlement" (Groark, 2018, p.8) and funding was not appropriately spent to best benefit the community. This caused discontent which, eventually, compelled universities to adopt an approach focusing on more engagement when working with communities through servicelearning.

Universities have a long history of working on communities (Reeb \& Folger, 2012; Stanton, 2008), but are now gradually realizing the importance of working with communities by developing collaborative partnerships through service-learning (Jenkins \& Sheehey, 2011). Service-learning continues to develop and grow in popularity in universities (Beckman, Brandenberger, \& Shappell, 2009; Blouin \& Perry, 2009; Bringle et al., 2013; Bruce, 2013; Chupp \& Joseph, 2010; Groark \& McCall, 2018; Jacoby, 2003 Jenkins \& Sheehey, 2011; Levkoe \& Stack-Cutler, 2018; Schmidt, \& Robby, 2002). Practicing-scholars integrate servicelearning into their curriculum as a tool to bridge theory and practice, develop critical thinking skills, and expose students to diverse cultures (Mitchell, Donahue, \& Young-Law, 2012) in a real-world setting (McLaughlin, 2010). The interest of community engaged scholars continued to grow around the benefits of knowledge transfer rooted in democracy that can be created between universities and communities (Curwood, Munger, Mitchell, Mackeigan, \& Farrar, 2011). As explained by Felten \& Clayton (2011), service-learning has become the go to for: advancing learning goals and community purpose; building capacity among participants through 
collaborative interactions; and using critical reflection to understand and document meaningful service and learning within communities.

\section{Service-Learning - Traditional Approach}

Universities are now playing essential roles in the development of communities (Bryson, Quick, Slotterback, \& Crosby, 2013; Jacob, Sutin, Weidman, \& Yeager, 2015; McLaughlin, 2010). The powerful role of the university created community development opportunities around community engaged scholars' research interest and students' services to a community. Through service-learning, universities are able to connect students to community development service projects that increased research opportunities, while also improving students' interpersonal and leadership skills (Bruce, 2018; Mitchell, 2008). These beneficial factors increased the university's interest in community development relations (Curwood, Munger, Mitchell, Mackeigan, \& Farrar, 2011), but sparked concerns around how these community development relations were in actuality benefiting community members.

Generally, universities have put forth efforts to engage community members in community development initiatives. Service-learning was established to generate involvement from community members, but universities engaged community members around developing the physical aspects of their community and not necessary the development of its social construct. Bhattacharyya (1995) discusses this divide in interest when it comes to defining what should be the aim of community development. The focus of community development can be the physical improvements of a community, or it can be the building up of social relations within a community (Bhattacharyya, 1995). When considering this divide of interest, should the focus of community development be the physical aspects of a community or the developing of the culture of a community? Bhattacharyya (1995) suggests that both aspects of community development 
can be achieved simultaneously through the building of solidarity and agency. Universities were now challenged with creating a more engaged process with community members (Checkoway, 1997; O’Connor \& Lynch, 2011).

Resources grew exponentially to support the rising interest of community engagement through service-learning. In 1985, university presidents and the Education Commission of the States joined together to form the Campus Compact non-profit coalition, whose purpose is to build structures for community engagement (Campus Compact, 2018). In 1990, the U.S. federal government established the Corporation for National and Community Service to provide support and resources for engaging the community through service (Corporation for National and Community Service, n.d.). Universities also started to designate resources to support engaging community members (American Psychological Association, 2018; Campus Compact, 2018; Community Tool Box, 2018; Corporation of National \& Community Service, n.d.; Michigan State University, n.d.; National Education Association, 2017; West Virginia University Center for Service and Learning, 2018). As resources and academic interest grew around servicelearning initiatives (Soska, 2015), criticism stared to arise about how service-learning was being implemented.

\section{The evolution of the traditional approach.}

As universities increased their interest and resources to conduct research within communities, questions started to emerge about what should be the best practices for engaging community members (Karlsson, 2016). Aware of the disconnect between achieving academic goals and addressing a community's social and economic issues within the traditional servicelearning approach (Bortolin, 2011; Karlsson, 2016), criticism started to arise in the literature stating that universities were unaware of community social problems and unprepared to address 
them in constructive ways (Jenkins \& Sheehey, 2011). Universities focused on producing academic gains and not necessarily on strengthening the participating community (Chupp \& Joseph, 2010; Moore, 2014). This university's goal centered approach was also criticized for using a paternalistic European influence (Bruce, 2015; Cook, 2008; Groark, 2018) that positions the actor with the resources (the university) to share with persons perceived as being in need (Jacoby, 2003). The traditional approach to service-learning also failed to disrupt social structures of power (Latta et al., 2018), and did not address the complexities of cultural and political contexts (Bruce, 2013). Along with these critiques, one of the most common critiques of the traditional service-learning approach was that it was a form of charity which did not engage community members to address systemic injustices.

The most substantial critique of traditional service-learning was leveled against its charity model (Bruce, 2013; Clifford, 2017; Heldman, 2011; Jacoby, 2003; Jacoby, 2015), which positions the volunteer to try and solve other people's problems before fully understanding their causes or the person (Jacoby, 2003). Clifford (2017) reiterates Heldman's (2011) statement about the differences between service-learning in charity and service-learning in solidarity in this way:

"With charity work, volunteers conceive of themselves as being above the person or group they are assisting. They see their assistance as one-sided instead of recognizing the benefits they receive in the exchange (e.g., feeling good about themselves, learning from the people they are assisting, living a more meaningful life). Charity workers believe their volunteer work makes them 'good people,", and they expect recognition for it. "... Solidarity work is " solidarity work where volunteers (a) see themselves as equal to the people they are assisting, (b) are able to see how privilege shapes their place in the social/economic hierarchy, (c) 
see a part of themselves in the person they are working with, (d) recognize they

are working for the betterment of both parties, and (e) understand they are working for their own liberation from systems of supremacy that they unconsciously uphold through their everyday actions (p.36).

Following these concerns, criticism also began to focus on how service-learning projects were being implemented. Poor implementation of a service learning project can reinforce stereotypes and paternalistic attitudes (Chupp \& Joseph, 2010; Clifford, 2017), both of which can create an unequal focus between the development of students' skill sets and addressing community needs (Chupp \& Joseph, 2010; Dostilio et al., 2012). This can discourage future community engagement activities and heighten the divide between social and cultural groups (Latta et at., 2018). To address this concern, awareness needs to be developed on how servicelearning projects are implemented. Service-learning projects should expose students to the root causes of social problems and help them recognize their own privilege and power (Chupp \& Joseph, 2010). These critiques caused service-learning practice to expand understanding on how to learn and serve through reflective engagement model, into learning, serving, and engaging around a social justice issues model.

\section{Service-learning as Engagement - The Critical Approach}

Universities were now becoming more aware about the importance of engaging with community members to address social justice issues (Groark, 2018; Stanton, 2008). Universitycommunity partnerships created opportunities to strengthen university-community engagement. Groark (2018) identified university-community engagement as the "process that brings together groups of stake-holders from neighborhoods, city, or region (including individuals, organizations, businesses, and institutions) to build relationships and practical collaboration with 
a goal of improving the collective well-being of the area and its stakeholders" (p. 7). This process of university-community engagement required a more critical approach to engagement (Levkoe, 2018), which was not required with the traditional approach to service-learning.

Critical service-learning differs from the traditional approach to service-learning through its aim of providing equitable benefits to the university and community through reflective engagement, while addressing social justice issues within a community (Coffey \& Lavery, 2015; Levkoe \& Stack-Cutler, 2018). Critical service-learning approaches are based on the belief that there are inequalities in society that need to be addressed through a shared learning approach (Bruce, 2013). A critical service-learning approach focuses on redistributing power, addressing systemic oppressions, and developing authentic relationships (Clayton, Bringle, Senor, Huq, Morrison, 2010; Latta et al., 2018; Mitchell, 2008). This approach to service-learning increased engagement among communities and universities, but it did not address the power dynamics within university-community engagement, where the university was still the one holding the resources and power, while the community was the one needing and receiving the funds and aid, putting them in a weaker position.

Though universities embarked on increasing engagement with community members through critical service-learning, privilege of the university was not considered in these engagement efforts. Bortolin (2011) discusses the conversation of privilege that surrounds university-community engagement. Bortolin (2011) highlights four themes that show the power universities have in the relationship of university-community relationship: "(1) community as a means by which the university enhances its academic work; (2) community as a recipient of influence by the university; (3) community as a place which the university makes better; and (4) community as a factor in the financial interest of the university" (p. 52). These conversations 
exposed the realization that universities prefer to use their privilege to engage community members to produce academic products (Clifford, 2017). This brought attention to the fact that more balance was needed to create equitable gains between achieving academic goals and engaging community members to address social justice issues.

Prioritizing the process of engagement over producing a product, positions universitycommunity engagement to create strong mutually-benefiting collaborative relationships (Clifford, 2017). An engagement approach can be framed as being the byproduct of producing a product, or it can be framed as being the conduit in which products are produced. Clifford (2017) states that engagement practices should expand from public relations to creating changemaking outcomes with community members. Moore (2014) defines engagement as "not as a desired product, but as the necessary process through which the community and university interact to strengthen communities at the local and regional level" (p. 4). This proposal of equitable engagement may pose challenges for universities that have not rooted their service-learning practices in equitable engagement. To address this challenge, universities can employ a broker to help them learn how to implement engagement practices that produce equitable outcomes for the community and university.

Levkoe (2018) states that a broker can be an individual or an organization that helps connect and support relationships while creating a conduit to share knowledge between the community and the institution. Though the concept of brokering is not new, Levkoe (2018) states that there is little scholarly literature about brokering. A broker is a person or an organization who acts with the purpose of strengthening university-community relationships to share knowledge and achieve both university and community goals. This framework was designed to provide an 
analytical tool for academics and community engaged scholars to measure their teaching and community-based relationships. Below are a few examples of brokering initiatives.

An example of a brokering system that has been operational for 30 years was established by the University of Pittsburgh. The University of Pittsburgh established the Office of Child Development (OCD) to create a single point of contact for the university and community members. This establishment incubated mutually-beneficial relationships between the community and university. This relationship building created opportunities for universitycommunity collaborative projects (Groark \& McCall, 2018). Staff was hired to operate OCD and provide technical support and resources that were built around collaborative efforts between the University of Pittsburgh and community members (Groark \& McCall, 2018). In order to help ground the university in the community and balance leadership, a person was hired from the community to help build relationships. In order to have successful partnerships with community members, the partnership with the community needs to have a common purpose with clear achievable goals. Each partner has to have a participatory role in the project. (Groark \& McCall, 2018).

Another example of a brokering initiative was demonstrated through the collaborative efforts of Michigan State University and Ingham County (Davidson, Peterson, Hankins, \&Winslow, M. (2010). This collaborative effort was developed to address the high juvenile crime rate in the Ingham community. Michigan State University partnered with this community to provide technical and financial support, while the community provided the setting and organizational support (Davidson et al., 2010). Through this engagement, underserved juveniles received interventional engagement from Michigan State University faculty and Michigan State University students received valuable, real-world experience from the community (Davidson et 
al., 2010). Brokering initiatives supports engagement that creates beneficial opportunities for both the students and community.

A final example of a brokering initiative involves the brokering position I fulfilled during my two-year service-learning research project. My brokering position was informal and selfestablished, to create a bridge of communication between West Virginia University (WVU) and the community in Fairmont, West Virginia, where the project was being conducted. This twoyear service-learning research project was conducted by WVU and implemented in a marginalized community in Fairmont. Intuitively, I knew brokering was crucial for the completion of this service-learning project to address the barriers to engagement that exist between universities and marginalized communities. Through brokering, I was able to encourage community members to engage and help guide the service-learning process that was hosted by the university. The purpose of brokering is to ensure that university-community engagement is just as beneficial to community members as for universities. As universities continue to develop and implement equitable engagement practices with community members, the question of how community members are being engaged should always influence the engagement initiative.

When engaging community members, the question of how community members are being engaged (Clifford, 2017) needs consideration. Chupp and Joseph (2010) state that university and community engagement can be established to essentially benefit the university. Arnstein (1969) identifies different levels of which community members are engaged, and her illustrations point out the inequality that can be present within university-community engagement. Arnstein (1969) introduces nine levels of engagement, which became known as the ladder of engagement. The nine levels of engaging community members are grouped into three categories. They can be identified as engaging with no power, engaging with agreeance, and 
engaging with power. Attree et al. (2011) also write about the power of universities over the engagement process to help bring attention to this challenge. The concern about how engagement was managed between universities and communities put universities in the position to reexamine their engagement practices with community members.

\section{The evolution of the engagement approach.}

Universities supported the practice of service-learning initiatives to encourage and engage community members with community development initiatives but did not consider the relational inequalities of power in which they were operating. Clifford's (2017) work informs on how inequities were observed to be present within university and community relationships. Service-learning projects were frequently designed in order to benefit the university over the community. According to Moore (2014), universities typically viewed "community as a place to advance university objectives" (p. 11), rather than have a focus on "the process of interacting \{being\} equally as important as the outcome of the interactions" (p. 11). Bruce (2013) notes that service-learning historically benefited universities more than it did community members and Davidson et al. (2010) share how universities construct expert-client types of relationship with community members, which maintains their dominant power within the relationship. This attention to inequalities within university and community engagement prompted universities to evaluate their position of power.

As scholarly critiques questioned the power dynamics between university and community in engagement practice, critiques also arose about the institutional cultural barriers to engagement that exist within universities. The concept of power sharing can be challenging for community engaged scholars and community professionals who are not familiar with sharing power (Tryon, Slaughter, \& Ross, 2015). Jenkins and Sheehey (2011) record how university 
members become frustrated when community members do not become engaged with their service-learning project. Levkoe (2018) argues that when universities do not share relational power with community members, universities are responsible for reinforcing systems of inequalities. The absence of shared power between university and community engagement causes community members to become disengaged and suspicious towards the university's community engagement initiatives (Jenkins \& Sheehey, 2011). The university was also critiqued for measuring the success of service-learning initiatives through the number of hours students contributed to communities, instead of measuring the success of a service-learning initiative through the actual impact it had in a community. Clifford (2017) argues that the success of a service-learning initiatives should be measured by the realness of the university and community relationship. Universities responded to these critiques by exploring a more relational approach to university and community engagement.

\section{Service-Learning in Relationships - Postcritical / Relational Approach}

The need to address universities' power dynamics that construct university-community relationships, and the need for this power to be shared with community members spearheaded a change in service-learning practices that encouraged a deeper level of engagement with community members (Steinberg, Bringle, \& McGuire, 2013). This deeper level of engagement required a relational approach to service-learning (also referred to as the postcritical approach). A relational approach to service-learning identifies relationship building as the key to creating equitable meaningful experiences for community members (Bruce, 2018; Karlsson, 2016). Bruce (2018) claims that the relational approach to engagement positions universities to form collaborative, equitable relationships with community members that expand academic knowledge and also address social justice issues within communities. The relational approach to 
service-learning expands the university's knowledge by learning from community members, and positions community members to become actively involved in deciding how their community is developed.

The relational approach to service-learning requires universities to engage in a deeper level of reflection that questions the culture and practices of university-community engagement (Groark \& McCall, 2018). Such questioning identifies structures of privilege and complicity, and the inherent use of power that inadvertently participates in systemic injustices. The relational approach to service-learning equips universities to work collaboratively with community members to uproot systematic oppressions (Bruce, 2018), create academic agendas around community goals (Reeb \& Folger, 2013), and welcome the voice of the community members to inform future engagement practices (Bortolin, 2011; Bringle et al., 2013). Chupp and Joseph (2010) advocate that "service-learning experience should be carefully designed to expose students to the root causes of social problems, structures of injustice and inequity that persist in society, their own privilege and power, and their potential role as agents of social change" (p. 195). Latta et al. (2018) share how they had "captured" and "deconstructed" (p.32) the theories and practices that perpetuated their position of privilege and power. This level of reflection in the relational approach positions universities to develop an ethical engagement framework that establishes authentic relationships with community members to understand, identify, and dismantle systemic injustices (Bruce, 2018). The practice of reflecting through a relational approach, creates opportunities for service-learning initiatives to become more meaningful and beneficial to community members. 


\section{Reflection.}

Reflecting is identified as a critical and beneficial element in service-learning engagement (Chupp, \& Joseph, 2010; Glazier, Charpentier, \& Boone, 2011; Lu, \& Lambright, 2010). Reflecting helps one examine personal biases, expectations, and traditions within the context of privilege and power. Reflecting increases critical thinking skills and informs how to bracket personal judgments by considering all aspects of a problem at hand (Chupp, \& Joseph, 2010; Mitchell et al., 2012). Latta et al. (2018) share their reflections about learned lessons from engaging a community through service-learning. In their reflections, Latta et al. (2018) write: "we understand this process of self-reflection as one that is ongoing and never complete. This process is guided by the intersections of our identities and positions of privilege we occupy as White practitioners, and we recognize we cannot "speak for that which we have not felt" (Hooks, 2000, p. 50).” (p. 50). Latta et al. (2018) provide an example of how reflecting positions practicing-scholars to critically acknowledge their privilege and power, while engaging with community members to redistribute power and dismantle systematic injustices. Reflecting has been very effective in aiding universities through the process of understanding their position in systematic injustices and how their position of privilege and power affects university-community engagement (Chambers \& Lavery, 2012; Coffey \& Lavery, 2015; Cook, 2008). Without reflection, one does not exam one's personal biases, expectations and traditions (Mitchell et at., 2012). Not having reflective activities to assess engagement can diminish the learning experiences of the service-learning process (Chupp, \& Joseph, 2010; Ellsworth, 1989; Mitchell et at., 2012) by not addressing or perpetuating systems of inequalities. Reflective activities can help ensure that issues of power and oppression are addressed within the university-community engagement. 
Reflective activities that are designed to address issues of power and social injustices are very beneficial for university-community engagement (Bringle et al., 2013; Clifford, 2017). They include writings and recordings (Latta et al., 2018), which can also be used as an assessment tool (Chupp, \& Joseph, 2010; Karlsson, 2016). A reflective writing activity can be the maintaining of reflective journals. When grading students' reflective responses in their journal, Bruce (2018) suggests grading students by the depth of their reflections and critiques, instead of by them providing the "right" response (p. 220). Students should have the freedom to be transparent in their journals (Bruce, 2018), and this can only be achieved if students are not graded by how well they can provide the "right" answer. Bruce (2018) also warns against treating student journals as "mandated confessionals" (p. 217). This can cause students to lose the purpose of reflecting, which can cause an increase in practicing a pedagogy of violence which can be done through coercion and manipulation (Bruce, 2018). The recording of conversations can serve as a reflective activity through analyzing the recorded conversation to gain a deeper understanding of the engagement (Latta et al., 2018). Reflecting can also be applied as an assessment tool that uses the voice of community members to evaluate the effectiveness of the engagement (Jenkins \& Sheehey, 2011). Through reflective activities, university-community engagement can be strengthened, and the dynamics of power can be addressed.

\section{Power.}

The concept of power sharing can be challenging for community engaged scholars and community professionals who are not familiar with sharing power (Schwartz et al., 2016; Tryon, Slaughter, \& Ross, 2015). Historically, universities had power over what was chosen to transpire between the university and community engagement (Bhattacharyya, 1995; Thye \& Kalkhoff, 
2014). The university has the power to build the structures needed to develop collaborative actions with community members (Thye \& Kalkhoff, 2014). An important factor of relational service-learning is for the community to have shared power to decide how their community should be developed (Bortolin, 2011; Bruce, 2013; Coffey \& Lavery, 2015; Davidson et al., 2010). The sharing of power can also position community members to provide feedback to students and community engaged scholars about their involvement (Hunt et al., 2011). Community members can also share their expertise and knowledge about their community, history, and preferred community interest (Hunt et al., 2011) through the sharing of power. Groark and McCall state (2018) that community members may have preferential practices of engagement and the university is expected to work with these preferences to create collaborative equitable relationships. This is an important factor that protects the needs and dignity of community members (Jacoby, 1996). Through the sharing of power, individuals are positioned to create a synergy that nurtures building capacities and producing outcomes that no other way would be able to be created (Clifford, 2017; Davis et al., 2017; McReyolds, 2015).

\section{The evolution to the relational approach.}

The relational approach to service-learning positions universities and communities to develop long-lasting, equity-centered, collaborative relationships, that addresses the inequalities of the systems we live in; but the relational approach is not without its challenges. Relational service-learning is based in uncertainty because of its nature (Bruce, 2018). Individuals are different and will respond differently to the same action. This approach requires communication and conflict resolution at its core. At times, universities and communities may have different goals for their engagement (Karlsson, 2016). For example, the university may desire to further its research knowledge, while a community may desire a specific program. Though these may be 
different goals between the university and the community, Karlsson (2016) states that relationships that are rooted in open communication, respect and collaboration can simultaneously achieve both set of goals.

Another challenge within the relational approach to service-learning is the frequent lack of accolades for faculty for this kind of university-community engagement. Faculty are usually rewarded for furthering the university's research agenda and academic publications. Groark and McCall (2018) suggest that universities develop additional ways to measure and reward community engaged scholars in the service-learning field. Schwartz et al. (2016) suggest different merits should be assigned to community engaged scholars who spend enormous amounts of time implementing relational service-learning projects. Universities should develop guidelines for evaluating the work of community engaged scholars. It becomes a challenge for practicing scholars to dedicate the needed time to develop relational engagement with community members, when their evaluations are based on how many classes they teach and the amount of publications they produce.

The lack of financial support from universities is another challenge for relational servicelearning. Community engaged scholars may not receive the financial resources needed to engage community members at this level, nor do they have access to trainings and human-development opportunities to increase their cultural knowledge. Financial support is needed (Groark \& McCall, 2018) to spend time among community members to understand their experiences of systemic injustices, assist them with the development of their human capitals, and to support their community activities/events. The support of community activities and events can eliminate the semester time-line constraint that universities face when engaging with communities. Giving 
community support between semesters is important to the success of a relational service-learning project (Lester, 2015).

Financial support is also needed to expose community engaged scholars to cultural knowledge that is not traditionally taught in academia. This cultural knowledge is usually learned from community members and organizations that serve these communities. Jackson, Caldwell, \& Sellers, (2012) use the distinction of language to shed light on the importance of understanding a community's culture. Jackson et al. (2012) write "research findings reinforce the significance of understanding cultural influences in the research process. Specifically, early research on language revealed that blacks had a well-developed language form distinctly different from that of white Americans" (p. 4). Freire (2000) describes his approach to teaching farmers how to read. He did not start with teaching the farmers how to read by exposing them to the alphabet letters and sounds. He started teaching them by learning from them. Crotty (1998) writes "Freire does not begin by teaching his peasant groups the alphabet or showing them how to spell words chosen for them to learn. Instead, he spends time with the communities, learning himself the words that are meaningful to the people, words that evoke responses in them.... He wants them to feel that they have power over their words and can exercise power over them" (p. 148). Providing financial resources to support relational service-learning increases the university's research efforts of learning and understanding community members' perspectives, while collaborating with community members to dismantle systemic injustices in their communities.

\section{Systematic Injustices}

This literature review will conclude with a focus on the evolving nature of universitycommunity engagement through service-learning and shed some light on why using a relational approach to engaging community members is crucially important when working with community 
members who have been marginalized by systematic injustices. A relational approach to community engagement positions the university to gain an internal perspective on the results of being systematically marginalized. An internal perspective of systematic injustices reveals the mental, emotional, and economical consequences that are woven into the lives of marginalized individuals.

\section{Marginalization}

According to Merriam-Webster (2018), marginalization is the belittling to an unimportant or powerless position within a society. Marginalization is achieved through racial, social, and economic discriminations (Johnson, 2006). Speight (2007) identifies marginalization as the worst form of oppression, due to the "material deprivation" and the "extermination" of African American people (p. 128). African Americans have experienced decades of marginalization and their culture has been devalued. Knowledge produced by African Americans was deemed inferior; this is what Bhattacharyya (1995) referred to as "agency-robbing knowledge" (p. 61). Agency-robbing knowledge is the devaluing of a community's culture by claiming that European-influenced practices are superior (Bhattacharyya, 1995). This historic attitude towards African Americans has affected how African Americans view their chances of being successful when participating in power-sharing activities.

Understanding how a person views the chances to succeed sheds light on how a person views their self-efficacy. Self-efficacy is a person's belief about the ability to succeed or the chances of failure at a given task (Bandura, 1998). This can provide insight as to why a person may choose to engage, or not to engage (Bandura, 1998) in a service-learning initiative. Factors that shape a person's self-efficacy are the experiences of the individual and her peers, and how those experiences affected them emotionally (Bandura, 1998). Individuals who have been 
marginalized through systematic oppressions, and have seen their peers and ancestors oppressed, tend to believe they will not be successful in their efforts. Historical discriminatory practice has created a byproduct of disengagement and self-distrust that has festered into internal racism.

\section{Internal racism}

William and Williams-Morris (2000) describe internal racism as "the acceptance, by marginalized racial populations, of the negative societal beliefs and stereotypes about themselves" (p. 255). Speight (2007) reiterates the concept of internal racism as the acceptance by marginalized people that this is the "way things are" (p. 129). Freire (2000) describes internal racism as "self-depreciation is another characteristic of the oppressed, which derives from their internalization of the opinion the oppressors hold of them. So often do they hear that they are good for nothing, know nothing and are incapable of learning anything-that they are sick, lazy,

and unproductive-that in the end they become convinced of their own unfitness" (p. 63). External discrimination from society, and the internal devaluating of one's culture; creates depths of trauma that is usually identified as apathy among African Americans.

\section{Trauma}

Trauma can be defined as a mental, emotional response to an event or an experience that is deeply distressing or disturbing (The Center for Treatment of Anxiety \& Mood Disorder, 2017). Merriam-Webster (2018) defines trauma as a mental or behavioral disorder that was caused by severe mental or emotional stress. Trauma can come in forms of child, physical, neglect, sexual, and emotional abuse. Traumas can also be interpersonally transferred through generational and/or environmental factors (Lazatatou, 2017). A person may display signs of being traumatized through their lack of interest, aggressive behaviors, and their lack of trustworthiness and low personal agency (National Institute of Mental Health, 2016). These 
behaviors are commonly identified as apathy, without questioning why individuals possess such behaviors.

\section{Transformative}

The successes of engagement experiences and opportunities of exposure that address and dismantle social injustices, incorporate a relational transformative process that delivers healing and liberation to marginalized people. A transformative process is the certainty that engagement with marginalized people will include an intent to dismantle the systematic injustices that entangles their lives (Creswell, 2014). This requires the use of theories and practices that go beyond engagement to address issues of empowerment, inequality, oppression, domination, suppression, and alienation. Transformative approaches provide guidance to universities on how to engage with community members to build authentic, collaborative, power-sharing relationships through relational service-learning. Creswell (2014) also states that a transformative approach requires the removal of engagement practices and theories that do not benefit marginalized people. Groark (2018) writes about universities being grounded in European influences, which did not develop theories and practices that were beneficially inclusive for all people. A transformative approach ensures that marginalized voices are heard and the university-community engagement relationship is not merely transactional. Clayton (2010) discusses Enos and Morton's (2003) distinction between transactional and transformational relationships. Transactional relationships are short-term with the focus on an exchange, while transformational relationships are long-term with a focus on developing a revolving collaborative process that meets both parties' goals. A transformative process is the glove for the hand of relational service-learning that will protect the community. Transformative 
relational service-learning is how the university and marginalized community members can become as Creswell (2014) states "a united voice for reform and change" (p.38).

\section{Addressing a Gap in Literature}

The purpose of this research is to report the perspectives and experiences of marginalized community members who participated in a two-year service-learning project. Reporting the perspectives and experiences of marginalized people addresses the gap in the scholarly literature that focuses on the benefits community members receive from engagement (Attree, French, Milton, Povall, Whitehead, \& Popay, 2011; Blouin \& Perry, 2009; Cruz \& Giles, 2000; Hunt et al.; Reeb \& Folger, 2012; Schwartz, Weaver, \& Miller, 2016). This research is a transformative action to address systematic injustices by validating and bringing the voices of community members into scholarly conversation, in hopes of gaining transformative actionable attention. Bortolin (2011) writes that the academic literature lacks representation of the community's voice, and Chupp and Joseph (2010) note that there is a desire for more literature to reflect the impact of service-learning.

It is important to be mindful that we live and work within systems that are oppressive to some people, though we may not be a witness or victim to these oppressions. Systematic oppression contributes to social (in)justice issues in communities that universities have focused on addressing for decades. The effects of oppression on people mentally, emotionally, financially and generationally must also be considered. Oppressive systems are still alive and operational today, and through relational service-learning; universities can learn how to become more effective in collaborating with community members to dismantle injustices in our society. 


\section{Conclusion}

In summary, universities have an established history of collaborating with community members to further academic research and better communities. Service-learning was developed to accomplish these goals. Service-learning emerged to provide a structure of engagement between universities and communities. It is a reflective, action-centered, educational approach that integrates academic learning objectives with service to the community. Service-learning connects students to community development projects to achieve research goals, while improving students' interpersonal and leadership skills. Community members benefit from the technical support and resources that the university provides. As universities became more knowledgeable about engaging community members, service-learning began its evolving journey. The acknowledgements of systemic injustices, privilege and power, and the mental, social, and financial results of marginalization, launched service-learning practices on an evolving path. This evolution included three phases of approaches: the traditional approach, the critical approach, and the relational (postcritical) approach. Throughout these phases, universities have consistently engaged community members with an intent to improve engagement relations. Through these efforts, universities are learning to reflect, acknowledge their privilege and power, and engage in authentic relational service-learning projects with community members. As diverse synergies and knowledges are welcomed into community and university relationships, Bruce (2018) states, service-learning will forever be an evolving entity. 


\section{CHAPTER 3: METHODOLOGY}

\section{Introduction}

To begin this chapter, I will provide an explanation of the research design and philosophical worldview that influenced the chosen methodology and methods used to answer the research questions for this research activity. A description of how participants were selected, data was collected, and how the data will be analyzed is also provided in this chapter. Lastly, I will discuss the credibility and limitations of this research initiative at the closing of the chapter.

\section{Research Design}

Qualitative research is the methodological approach chosen to answer the research questions generated from the two-year service learning project. Qualitative research allows the

researcher to capture and report the perspectives of individuals (Brinkmann \& Kvale, 2015; Yin, 2014), and creates a space for in-depth narratives and experiences of individuals to be represented in the building of research knowledge. There are several designs to choose from when designing a qualitative research activity (Creswell, 2014, 2014; Crotty, 1998). Creswell (2014) provides a table to highlight qualitative research designs and the features that influence the choice of selecting a design. 
Table 1 Qualitative Research Designs

\begin{tabular}{|c|c|c|c|c|c|}
\hline Characteristics & Narrative Research & Phenomenology & Grounded Theory & Ethnography & Case Study \\
\hline Focus & $\begin{array}{l}\text { Exploring the life of } \\
\text { an individual }\end{array}$ & $\begin{array}{l}\text { Understanding the } \\
\text { essence of the } \\
\text { experience }\end{array}$ & $\begin{array}{l}\text { Developing a theory } \\
\text { grounded in data } \\
\text { from the field }\end{array}$ & $\begin{array}{l}\text { Describing and } \\
\text { interpreting a culture- } \\
\text { sharing group }\end{array}$ & $\begin{array}{l}\text { Developing an in- } \\
\text { depth description } \\
\text { and analysis of a } \\
\text { case or multiple } \\
\text { case }\end{array}$ \\
\hline $\begin{array}{l}\text { Type of Problem } \\
\text { Best Suited for } \\
\text { Design }\end{array}$ & $\begin{array}{l}\text { Needing to tell } \\
\text { stories of individual } \\
\text { experiences }\end{array}$ & $\begin{array}{l}\text { Needing to describe } \\
\text { the essence of a lived } \\
\text { phenomenon }\end{array}$ & $\begin{array}{l}\text { Grounding a theory } \\
\text { in the views of } \\
\text { participants }\end{array}$ & $\begin{array}{l}\text { Describing and } \\
\text { interpreting the } \\
\text { shared patterns of } \\
\text { culture of a group }\end{array}$ & $\begin{array}{l}\text { Providing an in- } \\
\text { depth understanding } \\
\text { of a case or cases }\end{array}$ \\
\hline $\begin{array}{l}\text { Discipline } \\
\text { Background }\end{array}$ & $\begin{array}{l}\text { Drawing from the } \\
\text { humanities including } \\
\text { anthropology, } \\
\text { literature, history, } \\
\text { psychology, and } \\
\text { sociology }\end{array}$ & $\begin{array}{l}\text { Drawing from } \\
\text { philosophy, } \\
\text { psychology, and } \\
\text { education }\end{array}$ & $\begin{array}{l}\text { Drawing from } \\
\text { sociology }\end{array}$ & $\begin{array}{l}\text { Drawing from } \\
\text { anthropology and } \\
\text { sociology }\end{array}$ & $\begin{array}{l}\text { Drawing from } \\
\text { psychology, law, } \\
\text { political science, } \\
\text { and medicine }\end{array}$ \\
\hline Unit of Analysis & $\begin{array}{l}\text { Studying one or more } \\
\text { individuals }\end{array}$ & $\begin{array}{l}\text { Studying several } \\
\text { individuals who have } \\
\text { shared the experience }\end{array}$ & $\begin{array}{l}\text { Studying a process, } \\
\text { an action, or an } \\
\text { interaction } \\
\text { involving many } \\
\text { individuals }\end{array}$ & $\begin{array}{l}\text { Studying a group that } \\
\text { shares the same } \\
\text { culture }\end{array}$ & $\begin{array}{l}\text { Studying an event, a } \\
\text { program, an } \\
\text { activity, or more } \\
\text { than one individual }\end{array}$ \\
\hline $\begin{array}{l}\text { Data Collection } \\
\text { Forms }\end{array}$ & $\begin{array}{l}\text { Using primarily } \\
\text { interviews and } \\
\text { documents }\end{array}$ & $\begin{array}{l}\text { Using primarily } \\
\text { interviews with } \\
\text { individuals, although } \\
\text { documents, } \\
\text { observations, and art } \\
\text { may also be } \\
\text { considered } \\
\end{array}$ & $\begin{array}{l}\text { Using primary } \\
\text { interviews with 20- } \\
60 \text { individuals }\end{array}$ & $\begin{array}{l}\text { Using primarily } \\
\text { observations and } \\
\text { interviews, but } \\
\text { perhaps collecting } \\
\text { other sources during } \\
\text { extended time in field }\end{array}$ & $\begin{array}{l}\text { Using multiple } \\
\text { sources, such as } \\
\text { interviews, } \\
\text { observations, } \\
\text { documents, and } \\
\text { artifacts }\end{array}$ \\
\hline $\begin{array}{l}\text { Data Analysis } \\
\text { Strategies }\end{array}$ & $\begin{array}{l}\text { Analyzing data for } \\
\text { stories "restorying" } \\
\text { stories, and } \\
\text { developing themes, } \\
\text { often using a } \\
\text { chronology }\end{array}$ & $\begin{array}{l}\text { Analyzing data for } \\
\text { significant } \\
\text { statements, meaning } \\
\text { units, textual and } \\
\text { structural description, } \\
\text { and descriptions of } \\
\text { the "essence" }\end{array}$ & $\begin{array}{l}\text { Analyzing data } \\
\text { through open } \\
\text { coding, axial } \\
\text { coding, and } \\
\text { selective coding }\end{array}$ & $\begin{array}{l}\text { Analyzing data } \\
\text { through description } \\
\text { of the culture-sharing } \\
\text { group and themes } \\
\text { about the group }\end{array}$ & $\begin{array}{l}\text { Analyzing data } \\
\text { through description } \\
\text { of the case and } \\
\text { themes of the case } \\
\text { as well as cross- } \\
\text { case themes }\end{array}$ \\
\hline Written Report & $\begin{array}{l}\text { Developing a } \\
\text { narrative about the } \\
\text { stories of an } \\
\text { individual's life } \\
\end{array}$ & $\begin{array}{l}\text { Describing the } \\
\text { "essence" of the } \\
\text { experience }\end{array}$ & $\begin{array}{l}\text { Generating a theory } \\
\text { illustrated in a } \\
\text { figure }\end{array}$ & $\begin{array}{l}\text { Describing how a } \\
\text { culture-sharing group } \\
\text { works }\end{array}$ & $\begin{array}{l}\text { Developing a } \\
\text { detailed analysis of } \\
\text { one or more cases }\end{array}$ \\
\hline $\begin{array}{l}\text { General } \\
\text { Structure of } \\
\text { Study }\end{array}$ & $\begin{array}{l}\text { - Introduction } \\
\text { (problem, } \\
\text { questions) } \\
\text { - Research } \\
\text { procedures (a } \\
\text { narrative, } \\
\text { significance of } \\
\text { individual, data } \\
\text { collection, analysis } \\
\text { outcomes) } \\
\text { - Report of stories } \\
\text { - Individuals } \\
\text { theorize about their } \\
\text { lives } \\
\text { - Narrative } \\
\text { segments } \\
\text { identified } \\
\text { - Patterns of } \\
\text { meaning identified } \\
\text { (events, processes, } \\
\text { epiphanies, } \\
\text { themes) } \\
\text { - Summary (adapted } \\
\text { from Denzin, } \\
\text { 1988a, 1989b) }\end{array}$ & $\begin{array}{l}\text { - Introduction } \\
\text { (problem, } \\
\text { questions) } \\
\text { - Research } \\
\text { procedures (a } \\
\text { phenomenology } \\
\text { and philosophical } \\
\text { assumptions, data } \\
\text { collection, } \\
\text { analysis, } \\
\text { outcomes) } \\
\text { - Significant } \\
\text { statements } \\
\text { - Meaning of } \\
\text { Statements } \\
\text { - Themes of } \\
\text { meaning } \\
\text { - Exhaustive } \\
\text { description of } \\
\text { phenomenon } \\
\text { (adapted from } \\
\text { Moustakas, 1994) }\end{array}$ & $\begin{array}{l}\text { - Introduction } \\
\text { (problem, } \\
\text { questions) } \\
\text { - Research } \\
\text { procedures } \\
\text { (grounded theory, } \\
\text { data collection, } \\
\text { analysis, } \\
\text { outcome) } \\
\text { - Open coding } \\
\text { - Axial coding } \\
\text { - Selective coding } \\
\text { and theoretical } \\
\text { propositions and } \\
\text { models } \\
\text { - Discussion of } \\
\text { theory and } \\
\text { contrasts with } \\
\text { extant literature } \\
\text { (adapted from } \\
\text { Strauss \& } \\
\text { Corbin, 1990) }\end{array}$ & $\begin{array}{l}\text { - Introduction } \\
\text { (problem, } \\
\text { questions) } \\
\text { - Research } \\
\text { procedures } \\
\text { (ethnography, data } \\
\text { collection, } \\
\text { analysis, } \\
\text { outcomes) } \\
\text { - Description of } \\
\text { culture } \\
\text { - Analysis of } \\
\text { cultural themes } \\
\text { - Interpretation, } \\
\text { lesson learned, and } \\
\text { questions raised } \\
\text { (adapted from } \\
\text { Wolcott, 1994b) }\end{array}$ & $\begin{array}{l}\text { - Entry vignette } \\
\text { - Introduction } \\
\text { (problem, } \\
\text { questions case } \\
\text { study, data } \\
\text { collection, } \\
\text { analysis, } \\
\text { outcomes) } \\
\text { - Description of } \\
\text { the case/cases } \\
\text { and its/their } \\
\text { context } \\
\text { - Development of } \\
\text { issues } \\
\text { - Detail about } \\
\text { selected issues } \\
\text { - Assertions } \\
\text { - Closing vignette } \\
\text { (adapted from } \\
\text { Stake, 1995) }\end{array}$ \\
\hline
\end{tabular}


To answer the research questions generated from this project, a phenomenological research design was chosen. Creswell (2014) states, "a phenomenological study describes the common meaning for several individuals of their lived experiences of a concept or a phenomenon" (p. 76). Cerbone (2014) describes phenomenology as "the experience itself" [which] concentrate[s] on its character and structure rather than whatever it is that might underlie it or be causally responsible for it" (pg. 3). A phenomenological design is appropriate when the focus of the study is to provide a description of an event or occurrence within a real-world environment with the goal of understanding the participants' first-hand perspectives and experiences (Hallberg, 2013; Moustakas, 1994; Steinberg et al., 2012). This phenomenology study uses open-ended semi-structured interviews as the central method of data collection to answer the research questions.

For this study, one-on-one semi-structured interviews were the primary source of data collection. Interviews allow knowledge to be produced between the interviewer and interviewee. Semi-structured interviewing allows the researcher to ask specific questions to gain research information and allows the interviewee to add additional information to the research (Brinkmann \& Kvale, 2015).

\section{Philosophical Worldview}

Creswell (2014), discusses the varied ways theory can be used in a qualitative research. A theory can be developed from research, it can be used as a lens to shape research, a theory can be used to achieve theory building and testing in a mixed research study, or there can be no use of an explicit theory as in the case of phenomenology (Creswell, 2014). The focus of a 
phenomenology study is to build the "essence of experiences from participants" which provides a description of the central phenomenon (Creswell, 2014, p. 100). Though theory application is not a focal goal of phenomenology, philosophical worldview influences the practice of phenomenology (Creswell, 2014).

The philosophical worldview selected for this research is a transformative paradigm. A worldview is "a basic set of beliefs that guide action" (Creswell, 2014, p. 15). A transformative paradigm is informed by theories and pedagogies that share the common themes of emancipation and transformative movements through collective actions for marginalized people (Creswell, 2014). This philosophical worldview foundation stems from an interpretive framework which reflects the philosophic beliefs and actions of the researcher (Creswell, 2014). These philosophical action items are rooted in: participation between researcher and community; cocreating knowledge with multiple ways of learning; respect for indigenous values; and collaborative processes in research (Creswell, 2013). Creswell (2013) lists the features of a transformative paradigm:

- Participatory action is recursive or dialectical and is focused on bringing change in practices. Thus, in participatory action research studies, inquirers advance an action agenda for change.

- It is focused on helping individuals free themselves from constraints found in the media, in language, in work procedures, and in the relationship of power in educational settings. Participatory studies often began with an important issue or stance about the problems in society, such as the need for empowerment.

- It is emancipatory in that it helps unshackle people from the constraint of irrational and unjust structures that limit self-development and self- 
discrimination. The aim of this approach is to create a political debate and discussion so that change will occur.

- It is practical and collaborative because it is inquiry completed "with" others rather than "on" or "to" others. In this spirit, participatory authors engage the participants as active collaborators in their inquires (p.26).

A transformative paradigm is used in this study to ensure that the voices and recommendations of participants are reflected and shared in literature.

\section{Researcher's Positionality}

The research design chosen for this study contributes to the significance of conducting humanizing research, which is research "that privilege the co-construction of knowledge, human agency and voice, diverse perspectives, moments of vulnerability, and acts of listening" (Paris \& Winn, 2014, p.23). Understanding and sharing the perspectives of marginalized community members provides important information to help better equip researchers and practitioners with addressing social justice issues that have historically and systemically created inequities (Chupp, \& Joseph, 2010) in communities. Bruce (2018) quoted Todd (2003) as stating:

Are we (as researchers, teachers, and readers) enacting violences upon others as we engage their stories and narratives of self-identification, despite our best intentions? That is, in seeking to learn about them, can we be negligent of learning from them? And, second, if so, how might we attend to the Other and preserve alterity as a nonviolent alternative while working toward the aim of social justice? (p. 3)

The school of thought behind interpretive is that meaning is constructed (Baxter \& Jack, 2008). Crotty (1998) states "Meaning is not discovered but constructed. In this understanding of 
knowledge, it is clear that different people may construct meaning in different ways, even in relation to the same phenomenon" (p. 9).

\section{Research Questions}

To achieve the purpose of this research, this phenomenological research explored the following questions:

1. What do Fostering Fairmont Project participants perceive as the purpose of the two-year service-learning project intended to begin community development initiatives in their marginalized community?

2. What were Fostering Fairmont Project participants' experiences with the two-year service-learning project intended that to begin community development initiatives in their marginalized community?

3. What recommendations do Fostering Fairmont Project participants have for universities about engaging community members in service-learning projects?

\section{Selection of Participants}

For interviewing people, I used purposeful sampling to select specific individuals. Purposeful sampling is the process of choosing certain individuals that can provide specific information that is relevant to the research question (Maxwell, 2013). Merriam and Tisdell (2015) stated, "Purposeful sampling is based on the assumption that the investigator wants to discover, understand, and gain insight and therefore must select a sample from which the most can be learned" (p. 96). There 36 participants to be interviewed were selected from 225 individuals that had been involved in the two-year service-learning project. These 36 individuals represented the different groups of actors involved in this project. These groups include WAC 
members, WAC neighbors, Students, and Community Stakeholders. The first group of actors, identified as WAC members, were community members who participated for the whole duration of the two-year project. The second group is identified as WAC Neighbors. These were community members who only attended a community conversation meeting, which were the meetings that were held through the neighborhoods for several days to collect input from community members for their Neighborhood Strategic Plan. The third set of actors is identified as Students. These were students who participated for the entirety of the project. Though 29 students participated during at least one semester with the project, there were only 4 students who participated for the whole duration of the two-year service-learning project, and those are the students that were included to be interviewed. The last group of actors are identified as Community Stakeholders. These were individuals who did not live in the neighborhoods yet wanted to assist with community development initiatives for these neighborhoods.

These groups of actors were chosen because they represent different perspectives of individuals who were involved with this two-year service-learning project. I chose to omit the perspectives of the lead project coordinator and faculty members because my research focuses on creating space for the community's voice in academia. Often, the voice of the community gets drowned out by the voice of academia (Swarr \& Nagar, 2010), so I am taking this opportunity to focus on the voice of the community.

For my research, I maintained the Institutional Review Board (IRB) protocol of interviewing participants. Consent forms were discussed and signed by participants prior to conducting the interview. Participants whose interviews were conducted over the phone, provided a verbal agreement for the interview and/or sent an electronic form of consent. All participants interviews were done on a voluntary basis and a pseudonym was provided to protect 
their confidentiality. Participants were based on their participation in the two-year servicelearning project. There were four groups of actors: WAC Member, WAC Neighbors, Community Stakeholders, and Students.

\section{Study Context}

In this section, an overview of the research context will be provided which includes the location of the study, demographics of the community members and West Virginia University (WVU). Providing an overview of the research context helps to understand the larger context of the research.

This two-year service-learning project was conducted with community members that represented five different neighborhoods on the west side of Fairmont, WV, and students and faculty from WVU. Fairmont is located about 20 miles south of WVU, and the five neighborhoods involved represented the service area of the youth community center, which was our entry point to the community. These neighborhoods are home to $40 \%$ of Fairmont's African American population; African Americans represent only $8 \%$ of Fairmont's total population (WAC community profile report, 2015). The neighborhoods in the study area have been historically underserved and marginalized by local and county leaders (Sherry, personal interview, July 26,2017$)$. The focus of the two-year service-learning project was to provide technical assistance to community members for community development projects in their neighborhoods, which is one of the goals of WVU's community development efforts (WVExtensionService, 2018).

As West Virginia's flagship university and a land-grant institution, WVU is committed to "encouraging a campus culture of service" (West Virginia University Center for Service Learning, 2018). In 2013, WVU renamed its Center for Civic Engagement the WVU Center for 
Service and Learning to support the center's new strategic plan to educate students and faculty about the importance of serving surrounding communities and to provide knowledge about the center's resources (West Virginia University Center for Service Learning. 2018). With the creation of the WVU Center for Service Learning, WVU has established support to foster integrated service-learning, which assists professors with matching their coursework to the needs of communities. WVU has constructed a network of Special Projects, which are designed to encourage service-learning participation, and IServe which is an online volunteer management system that informs university members about service opportunities among community organizations (West Virginia University Center for Service Learning, 2018). Through award ceremonies and other recognition events, WVU honors students, staff, and faculty for their volunteer hours and participation in service-learning projects.

WVU is no stranger to receiving recognition for their community engagement and outreach. In 2007, WVU was the recipient of the Presidents Higher Education Community Service Honor Roll, which is the highest federal award a university can receive in recognition of their service-learning and civic engagement (West Virginia University wvutoday archive, 2008; West Virginia University Center for Service Learning, 2018). The Carnegie Foundation for the Advancement of Teaching selected WVU to receive its 2010 Community Engagement Classification, which puts WVU in the six percent of higher education institutions that are recognized for their community involvement (West Virginia University Center for Service Learning, 2018).

\section{Data Collection}

Interviews are an important source in qualitative research (Yin, 2014) and interviews are "attempts to understand the world from the subjects' points of view, to unfold the meaning of 
their experiences, to uncover their lived world prior to scientific explanations" (Brinkmann \& Kvale, 2015). Semi-structured interviewing allows the researcher to obtain the perspective of the interviewee, while receiving desired research information (Brinkmann \& Kvale, 2015).

West Virginia University's Institutional Review Board (IRB) granted approval for the collection of data in Fall 2015. Interviews were conducted at the end of the service-learning project in spring 2017. I conducted a total of 36 one-on-one semi-structured interviews: 13 byphone and 23 in-person. Interviewees were given the choice to have their interview conducted in person or over the phone. There were 12 interviews conducted with WAC members, 12 interviews conducted with WAC neighbors, 8 interviews conducted with Stakeholders, 4 interviews conducted with Students.

An attempt to conduct all interviews in person was made to capture the "embodied communication" associated with interviewing (Brinkmann and Kvale, 2015). According to Brinkmann and Kvale (2015):

A qualitative interview is not simply a function of two or more persons who come together to talk, for their coming together is always mediated by a host of nonhuman factors that could (but not always should) be taken into account, as they may matter analytically. Many things must play together, so to speak, in order for qualitative interviewing to be made possible, and the interview as a context does not just fall from the sky but is the results of numerous actors (some human, others nonhuman) orchestrating this complex episode which we have today come to take for granted (p. 121).

All in-person interviews were conducted at the time and place requested by the interviewee to make them as comfortable as possible in this unfamiliar activity. All WAC members, WAC 
neighbors were interviewed in person except for two individuals who preferred to be interviewed over the phone. All Stakeholder interviews were done over the phone at the request and convenience of the Stakeholders and all Student interviews except one were conducted over the phone because students had left West Virginia to return home.

\section{Data Analysis}

Data analysis consists of the researcher selecting specific information from a source of data and deciding how the data will be displayed and organized to allow a story to be told (Miles, Huberman, \& Saldana, 2014). Creswell (2014) states that data analysis is making sense out of text and image data. Data analysis is a procedure used to evaluate data and interviews will be the main source of data to be evaluated in my research. The procedure chosen to analyze interviews was modeled after Groenewald (2004) condensed usage of Hycner's (1985) process of analyzing interviews in phenomenological research. Groenewald's (2004) process of analyzing interviews consists of five steps: (1) bracketing and phenomenological reduction, (2) delineating units of meaning, (3) clustering of units of meaning to form themes, (4) summarizing each interview, and (5) extracting general and unique themes for all the interviews and composite summary. The first step which is bracketing and phenomenological reduction, is when the researcher acknowledges and compartmentalizes their own personal view in order to report the perspective of the participant. This was accomplished in my process of analyzing interviews through using the original text of the interviews to build meaning for my research. The second step is delineating units of meaning which is identifying common perceptions and experiences among participants. I achieved this by identifying frequent themes from interviewee responses to the semi-structured interview questions. The third step in the process of analyzing interviews is the clustering of units of meaning to form themes. This entails combining frequent statements made by 
participants to form themes. For this research, frequent themes were formed from the answers participants provided to interview questions. The forth step is to summarize each interview. This is accomplished by providing a summary of themes that arise from interviews. I completed this within my research by providing summaries that single out common themes that arose from participants statements. The fifth and final step is to identify general and unique themes for all the interviews and produce a composite summary. For my research, themes that were commonly threaded throughout interviews were chosen for my final summary.

\section{Limitations}

Each study has limitations and the limitations of this study include the choice of methods and researcher's bias. The intent of qualitative inquiry is not to generalize, but to provide themes and descriptions developed in context of a specific site (Creswell, 2014). In order to address the lack of recalling and accuracy of information associated with interviewing, each interview was recorded with the interviewee's permission (Creswell, 2014). Recording the interview allows the interviewer to focus on the conversation and the building of knowledge between the interviewer and interviewee, instead of focusing on taking notes. Miles, Huberman, \& Saldana (2014) describe two sources of bias: "the effects of the researcher on the case, and the effects of the case on the researcher" (p. 296). To address the effects of the researcher on the case, I had prior interactions with some interviewees and relationships with others. This eliminated the "on-stage role" performed by interviewees who may not trust the researcher or did not understand what was to be done with the data collected (Miles, Huberman, \& Saldana, 2014). To address the effects of the case on the researcher, interviews were conducted with different actors to collect different perspectives (Miles, Huberman, \& Saldana, 2014). This prevents the researcher from presenting the data from their preferred view. 


\section{Summary}

In summary, this research employs a qualitative phenomenology study which explores the perceptions and experiences of the residents of Fairmont, WV, who participated in a two-year community development service-learning project intended to begin community development initiatives in their marginalized community through semi-structed interviews. The design and methods that were chosen for this study capture the perceptions and experiences of those who participated in a two-year service-learning project with the goal of providing recommendations to researchers and practitioners. 


\section{Introduction}

\section{CHAPTER 4: ANALYSIS AND FINDINGS}

This chapter discusses common themes that emerged from interviews I conducted with individuals who participated in the Fostering Fairmont two-year service-learning project (FFP). The participants were divided into four groups: WAC (Westside Action Coalition) members, WAC neighbors, students and stakeholders. WAC members were community members who participated for the duration of the two-year service-learning project. WAC neighbors were community members who only attended one community conversation meeting. In addition, I interviewed four university students who completed all four semesters of the service-learning project to gain insights into how they experienced the project. Lastly, stakeholders were individuals who did not live in the community but had an interest in supporting the servicelearning project. By interviewing these people, I received information from individuals with different levels of community commitment and involvement.

Interviews were divided into four sections: background, purpose, process, and recommendations. The background section of the interviews focused on gaining an understanding about community members' residency in the community and prior experiences in community engagement. The other sections of the interviews focused on gathering data to specifically answer one of the three research questions posed in this research. The purpose section of the interviews focused on gathering information that would answer the first research question which is: how do Fostering Fairmont participants perceive the purpose of the two-year service-learning project intended to begin community development initiatives in their community? Community members' perceptions of the two-year service-learning project's purpose was revealed from information about their understanding of the service-learning project's purpose, and their familiarity with the process of conducting a community development 
service-learning project. The process section of the interviews focused on collecting information to answer the second research question: What were the experiences of Fostering Fairmont participants with the two-year service-learning project, which was intended to begin community development initiatives in their community? Interview questions in this part focused on compiling data about community members' experiences relating to their engagement and participation throughout the service-learning project, recommendations to universities for implementing service-learning projects, identifying barriers to engagement within their community, and providing recommendations to engage community members. The recommendation section, which is the fourth and last section of the interviews, addresses the research question and centers on data collection to answer the third and final research question. What recommendations do Fostering Fairmont participants have for universities that engage community members in service-learning projects? The question in this section had the sole purpose of providing recommendations for universities that implement service-learning projects.

Because this study significantly focused on the experience of participants who lived in the community, students and stakeholder's interviews were not structured to answer the first two questions in my research. The first two questions in this research were about the perceptions and experiences of community members who lived in the community. Since students and stakeholders did not live in the community, they were not asked the first two questions. However, students and stakeholders were asked the third research questions about recommendations to universities.

\section{Presentation of Findings}

The findings of this research are presented along the same four parts which made up the interview protocols: background, purpose, process, and recommendations. Each section begins 
with the research question to be addressed, a table to summarize the findings, and a summary of how the interview questions sought to gather data to answer that research question. Each section provides the raw data from the interviews. Raw data "refer to information that is gathered for a research study before that information has been transformed or analyzed in any way" (Lavrakas, 2008, p. 2). Presenting the data in unedited raw form helps the researcher bracket her interpretation. All quotes and information provided in the background section will be presented in the exact wording of community members. The quotes from community members represent the common themes that emerged from community members' responses to interview questions. Following the thematic quotes will be an analytical summary of the findings, which will be the ending of each section.

\section{Analyzing Data}

To analyze the interview data, I used Groenewald's (2004) five step process. This process includes (1) bracketing and phenomenological reduction, (2) delineating units of meaning, (3) clustering of units of meaning to form themes, (4) summarizing each interview, and (5) extracting general and unique themes for all interviews and the composite summary (Groenewald, 2004). Bracketing and phenomenological reduction are when the researcher acknowledges and compartmentalizes her personal view in order to report the perspective of the participant. This was accomplished in the process of analyzing interviews through using the original text of the interviews to build meaning for this research. The second step is delineating units of meaning, which is identifying perceptions and experiences that are common among participants. The third step is the clustering of units of meaning to form themes. This entails combining statements made by participants that share a unified theme. In this research, frequent themes were formed from the answers to interview questions. The forth step is to summarize 
each interview by providing a summary of themes that arise from the interviews. The fifth and final step is to identify general and unique themes for all interviews and produce a composite summary.

\section{Background of WAC members}

This background section provides demographic information for the 12 community members who were WAC members, that is, were community members who participated for the duration of the two-year service-learning project. All WAC members, except for two, lived in the community and/or had decades of family ties to the community. One of the two WAC members who did not live in the community stayed involved in the project with efforts to rebuild relations between the community and their work organization. The second WAC member who did not live in the community saw participating in the project as a way to fulfill a long-held desire to assist the community. All WAC members, except one, were actively involved in organizations in their community. Most WAC members attended church and occupied a leadership position. There were 6 women and 6 men, 10 African Americans and 2 Caucasians, from 25 to 75 years old. To honor confidentiality, pseudonyms are used to protect the identity of community members. 
Table 2. Background of WAC Members

\begin{tabular}{|l|c|l|l|l|l|l|}
\hline $\begin{array}{l}\text { WAC } \\
\text { members }\end{array}$ & Sex & Race & $\begin{array}{l}\text { Age } \\
\text { Range }\end{array}$ & $\begin{array}{l}\text { Length of } \\
\text { Residency in } \\
\text { Community }\end{array}$ & $\begin{array}{l}\text { Involved in a } \\
\text { Community } \\
\text { Organization }\end{array}$ & $\begin{array}{l}\text { Attend Church / } \\
\text { Leadership in } \\
\text { Church }\end{array}$ \\
\hline Brenda & F & Black & $31-40$ & all my life & Yes & Yes /No \\
\hline Bettie & F & Black & $41-50$ & over 40 years & Yes & Yes / Yes \\
\hline Charles & M & White & $41-50$ & 0 years & No & No / No \\
\hline Gal & F & White & $51-60$ & 0 years & Yes & Yes / Yes \\
\hline Henry & M & White & $51-60$ & 25 years & Yes & Yes / Yes \\
\hline Henrietta & F & Black & $41-50$ & all my life & Yes & Yes / Yes \\
\hline John & M & Black & $41-50$ & all my life & Yes & Yes / Yes \\
\hline Larry & M & Black & $71-80$ & over 40 years & Yes & No / No \\
\hline & & & & $\begin{array}{l}\text { born here, moved } \\
\text { back over } 40\end{array}$ & & \\
Mary & F & Black & $71-80$ & years ago & Yes & Yes / Yes \\
\hline Roy & M & Black & $71-80$ & all my life & Yes & Yes / Yes \\
\hline Ron & M & Black & $51-60$ & 24 years & Yes & Yes / Yes \\
\hline Ronda & F & Black & $51-60$ & 24 years & Yes & Yes / Yes \\
\hline
\end{tabular}

\section{Background of WAC neighbors}

This section provides demographic information for the 12 neighbors who were identified as WAC neighbors. WAC neighbors were community members who attended only one of the community conversation meetings that were conducted throughout the community for several days. These meetings were repeatedly held to ensure community members were given multiple opportunities to participate and provide input into the community action plans.

All 12 WAC neighbors have either lived in their community for the entirety of their lives or have returned to Fairmont because of family. Seven of the 12 WAC neighbors were active in a community organization, and all but three WAC neighbors regularly attended church. There were 8 women and 4 men, 10 African Americans and 2 Caucasians, and their ages ranged from 25 to 75 years. 
Table 3. Background of WAC Neighbors

\begin{tabular}{|l|c|l|l|l|l|l|}
\hline $\begin{array}{l}\text { WAC } \\
\text { neighbors }\end{array}$ & Sex & Race & $\begin{array}{l}\text { Age } \\
\text { Range }\end{array}$ & $\begin{array}{l}\text { Length of } \\
\text { Residency in } \\
\text { Community }\end{array}$ & $\begin{array}{l}\text { Involved in } \\
\text { Community } \\
\text { Organization }\end{array}$ & $\begin{array}{l}\text { Attend Church/ } \\
\text { Leadership in } \\
\text { Church }\end{array}$ \\
\hline Bree & F & Black & $71-80$ & $\begin{array}{l}\text { don't right now, } \\
\text { but family ties }\end{array}$ & Yes & Yes / No \\
\hline Barbara & F & Black & $21-30$ & all my life & No & Yes / No \\
\hline Charlene & F & Black & $61-70$ & all my life & No & Yes / Yes \\
\hline Gill & F & Black & $51-60$ & 26 years & No & Yes / No \\
\hline Gary & M & Black & $41-50$ & 5 years & Yes & Yes / Yes \\
\hline Hilary & F & White & $61-70$ & 25 years & Yes & No / No \\
\hline Henry & M & White & $31-40$ & 25 years & Yes & No / No \\
\hline John & M & Black & $41-50$ & 4 years & Yes & Yes / Yes \\
\hline Marlene & F & Black & $61-70$ & all my life & No & Yes / Yes \\
\hline Terry & F & Black & $71-80$ & all my life & No & No / No \\
\hline Wendy & F & Black & $31-40$ & all my life & Yes & Yes / No \\
\hline Will & M & Black & $41-50$ & 26 years & Yes & Yes / Yes \\
\hline
\end{tabular}

\section{Analytical Findings for Background}

WAC members and WAC neighbors share a deep sense of devotion and connection to their community sustained by generational ties to and participation in organizations in their community. An in-depth description of the generational ties, community values, and traditions that hold WAC members and WAC neighbors close to their community was captured in the WAC Community Profile (2015) and the Community Visioning Conversations Reports (2016). WAC members and WAC neighbors have traditionally served multiple leadership roles to support local organizations in their community.

In this community, churches were the central local organizations that supported this community. Churches are known to be the central self-help organizations in African American communities (Jackson et al., 2012); this was also the case in this community. Therefore, I chose to gather data on church participation and leadership separately from participation in other organizations. WAC members and WAC neighbors attended different churches but 
fellowshipped together and served to support community organizations. There were three community-based organizations that were led by WAC members: the Fairmont Community Youth Development Center (FCYDC), Dunbar School Foundation, and the Marion County NAACP Chapter. These organizations shared values and goals for bettering the community but were lacking some of the technical skills necessary to create solutions to address the needs of their community.

Though WAC members and WAC neighbors have a long history of operating their community-based organizations, their efforts were impeded by the absence of technical knowledge among WAC members and WAC neighbors. WAC members and WAC neighbors' community-based organizations did not have the structural and technical support needed to operate their non-profit organizations at their full potential. All three community-based organizations were operated through WAC members' and WAC neighbors' volunteers, and with little administrative support and financial backing. Will, a WAC neighbor, shares how WAC members and WAC neighbors felt towards their local government.

In the past, the community felt like it didn't have a voice, they didn't participate within the community affair, interact with the government.

The perception of the community is that its voice as a community has been historically ignored by its local government, but Sherry, who was a stakeholder in our project, shared that the discrimination this community experiences is a second layer of county-level discrimination that she identifies as Marion County fatalism.

We also suffer from that Apalachee or even Marion County fatalism. Is that we're sort of a county stuck between other places that are really progressive and so we 
get a little bit jealous of how slow things are progressing here and we kind of wonder constantly why things aren't happening at the pace we'd like to see.

Hilary, a WAC neighbor, also made a reference to county-level discrimination during the interview. She referred to Fairmont as being the step-child among the surrounding counties. But there's always been this positioning of Marion County and Fairmont, in between Clarksburg and Morgantown, being the stepchild, being the place that was left out of economic development and modernization over the last 25, 30 years. People tend to feel resentful that their town wasn't favored. Their downtown became depopulated. There's this sense of negativity about what is possible in Fairmont that we encountered when we moved here in 1994. People basically felt that the local government was pretty corrupt, and there wasn't anything you could do about it. If you would push back, you would mostly get the shit knocked out of you, so most people had found a way to ... if they were going to stay here, they would keep their head down and not needle the man, you know what I mean?

Hilary speaks to the inequities she has witnessed around and within her local government since moving to Fairmont twenty-six years ago. She also speaks about the fear that was instilled into community members in order to keep them from challenging their local government. These constraints of control and discrimination clenched down even harder on the African American community I worked in. Terry, a WAC neighbor who has lived in this community for the past 69 years stated this:

There are some places in West Virginia, you'd know not to go by yourself. You'd better take somebody with you. It's changing now, a little bit, by the young kids 
mixing up together, it's starting to change now. For the better. But back in my day, I knew not to go in some neighborhoods. I knew better. They had no business out there. The only way you gonna make it here, you better get in with them white folks. Now you get in with them white folks, you got it made.

Terry reflects on her living experiences in Fairmont by sharing a limitation that African Americans had in Fairmont. In Fairmont, African Americans efforts had to be accompanied with permission in order to not create trouble for themselves. Though Terry shared the fact that Fairmont has become more welcoming to African Americans, there are still deep rooted notions among those who live in Fairmont that perpetuate this discriminatory cycle. Sherry, who was a stakeholder during my research project, grew up in Fairmont outside of the African American community. Sherry shares with us the deep rooted teaching she received about the African American community.

You know, even growing up, my thought was always that the stigma through town was that those were very rundown, and crime ridden areas and they weren't safe and they weren't clean and you know everybody was sort of taught to be afraid of those and we were young. And so I just remember for a long time when we were drive by that neighborhood whomever we were with adults other kids whatever, it was like we have to roll our windows up when we drive by here and we, you know, we want to drive through here quickly. I mean it seems like it's a lot quieter than it used to be when I was in elementary school, middle school, high school. And so it was just always sort of an isolated area that people thought was dangerous and people were just steered clear of it. And I mean, even when folks were talking about windmill park, it was, you know, it's it's scary to drive out 
there to play softball. And so I think a lot of people have that mentality has instilled into them as a young person and now these are your people that are working for agencies like this. Seeing my generation and maybe generation before that, I had these thoughts about it. So really like I said it's a cultural overhaul that needs to happen for people to understand, you know, it's not it is a crime ridden dirty area in Fairmont. People are very nice and they're trying very hard to improve their communities. And I think it's, you know, it's just breaking some of these barriers down and helping people understand that you know these ideas are wrong. Kind of how most people would have seen that community. And you don't you don't realize what it is until you go in it. So I was just always basing my opinions off of what other adults had told me through time. And so once I got out there and started to meet people I realized that so much more than that it is.

Sherry uses the term "cultural overhaul" to point to the need for outside community members to change their perspectives and treatment towards African Americans who lived in Fairmont. Wendy, a WAC neighbor, shares her present day experience with outside communities. I don't even know that the city council was over the park. I didn't know about county commission meetings. Really, it was a secret of how Fairmont ran to most of us in our community. Of course, you have those that definitely knew. Not taking away from them. And I'm not saying that we weren't ... We're very intelligent in our community, it has just been for so many years that we really weren't part of that community. You had your few people that held positions and they held them for years and years and years and years and never let go of them that were of our community. Other than that, the rich people. You know what I mean? The people 
on the East side. So those things were beautiful and they were a way for us to understand that we are a community and see things, you know, differently.

Hilary, Terry, and Sherry shared how African Americans communities have historically experienced marginalization from outside communities, and Wendy shares her present experience with outside communities. Sherry, a stakeholder, supports Wendy's statement from an outsider's perspective:

I feel like those folks in those communities often just feel like they're just left out of everything; they're not invited, that things are not included in things they don't, you know, get the message about things to be able to show up at meetings.

Marginalization has historically impeded the powers and opportunities of this community on different levels. First, this community has been disregarded by its local government, which cuts off this community's power and representation. Secondly, this community has been ostracized by other communities, which intensified the discrimination this community was already facing. And lastly, the perpetuation of this marginalization has caused many community members to internalize this discrimination, which leads to low self-agency and self-efficacy.

Henry, a WAC neighbor, speaks to the results of this perpetuated marginalization, which is a contributing factor to low self-agency and self-efficacy among community members.

Change the narrative, change the perspective, and therefore change the direction of the neighborhoods. Recognizing that this negative feedback loop that was going on. People are told both explicitly and implicitly by the surrounding communities that they're not worth anything. So they start to believe it, so they start to act like it, and then everybody wonders why things have gone downhill and it's just like, wait a second, if we actually treat our neighbors like they're 
valuable and like the neighborhood is valuable, then they'll start acting like it again? Whoa!

Sherry, a stakeholder made this comment:

But, you know, prior to Fostering Fairmont and I don't think the folks in the neighborhood felt like they had a collective voice.

The goals of the FFP centered around community members working together for the betterment of their community. In order for these goals to be achieved, community members were required to apply the technical skills they learned from the FFP and work together to continue what the FFP had started. Ronda, a very involved WAC member, was asked during her interview if she had ever imaged herself doing this kind of work, and she stated:

Now I do. Before then, I didn't but now I do. Those are things that I wanted to do but didn't know how to go about them, or I didn't know how to get the people to come together.

Ronda's statement reflects the viewpoint many community members have shared throughout the FFP. Community members' self-efficacy towards engaging their local government and other outside communities, was dissipated through marginalization. Community members are aware of the barriers that have been created in their community and are also aware of needed solutions. Ron, a WAC member shared how the community views itself.

They haven't ever seen anything ... I should say haven't experienced anything really positive in their community, so they don't think it's possible. And my whole thing is why isn't it possible? Why isn't it? Why can't we have a swimming pool in our community? Why? Why can't we have clean streets and clean neighborhoods 
in our community? Huh? How come we can't get abandoned houses torn down? I mean, they're doing it in the other communities. I tell you this, too, Miss Shanequa. When people see a change, the rec center built, even a swimming pool or whatever, whatever comes out of this, and then they're start buying in. Because some people are not foundation people. They can't get a part of the building process. But when the building's complete, then ... or even growing, they'll get in. Actually, different levels. Some gon' get in when they see it growing. Some won't get in 'til they see the door open. But most people ... most people not foundation people. No vision. A lack of vision, should say.

Marlene, a WAC neighbor, described her community as having "passion but no push". Wendy, a WAC neighbor, made the following comment regarding the community: I think it actually made the community aware that it needs to look at itself and reevaluate a lot of things. I mean, you know, just even starting with the board of directors for the center that I represent. We revamped that whole thing, and we wouldn't have been able to start that if we weren't able to have someone come from the outside to look in and tell us, "Look, you know, these are things that can be possible." Motivate us in a way. So in that it was beautiful.

The community saw FFP as a push and motivator. Henry, a WAC neighbor stated this: I'm enthusiastic for the fact that it's predominately focused, we're predominantly focused on the African American Community in Fairmont because I've long been aware of the fact that there's some obvious inequalities going on. I'm only just beginning to get my toes wet in terms of what the root causes and functions behind those inequalities are. But at the same time, I feel like one of the 
underlying intermediate goals of this work should be to help start crossing those divides in this city because it has not benefited anyone at all.

No interview questions were asked to specifically gather information about the marginalization this community has historically faced. WAC members and WAC neighbors shared the information on their own when questions were asked in reference to their engagement and interactions with the Fostering Fairmont Project (FFP) process. WAC members and WAC neighbors began to share how engaging with the FFP required them to participate and become part of the decision making process, which is something that had not always been afforded to them.

\section{Summary}

This background information provided insight about community dynamics that were unknown before the start of the two-year research project. These unanticipated community dynamics affected the two-year service-learning process and outcomes in ways that the research project was not prepared for. The lack of prior knowledge about the community, coupled with resource constraints, meant that the project was ill-equipped to produce all of its designated goals.

\section{Research Question \#1}

What do Fostering Fairmont Project participants perceive as the purpose of the two-year servicelearning project intended to begin community development initiatives in their community?

The purpose section of the interview focused on gathering data to answer the first research question. The data provided information about community members' understanding of the service-learning project's purpose, and their familiarity with the process of a community development service-learning project. The analysis of the purpose section of the interviews 
showed that resources and collaboration were the common themes. Together they represent the most frequently mentioned themes among WAC members and WAC neighbors. The following table lists the WAC neighbors and WAC members from whose comments the themes have been derived.

Table 4. Research Question 1

\begin{tabular}{|c|c|}
\hline \multicolumn{2}{|c|}{$\begin{array}{c}\text { Research Question \#1 } \\
\text { What do Fostering Fairmont Project participants perceive as } \\
\text { the purpose of the two-year service-learning project intended } \\
\text { to begin community development initiatives in their } \\
\text { community? }\end{array}$} \\
\hline Members & Neighbors \\
\hline \multicolumn{2}{|c|}{ Resources } \\
\hline Brenda & Henry \\
\hline Gal & Barbara \\
\hline Mary & \\
\hline \multicolumn{2}{|c|}{ Collaboration } \\
\hline Bettie & Will \\
\hline Henrietta & Bree \\
\hline & Gill \\
\hline
\end{tabular}

\section{Resources}

A common belief of purpose of the FFP was that it was meant to work with community members to garner needed resources for the community. The FFP operated for two years without a budget and the FFP never made any financial commitments to the community. However, there was a conceiving notion from the FFP that if community members continued to collaboratively learn and participate for the entirety of the project, development in their community would happen. Community members also viewed the engagement, collaborative activities, and the knowledge that was shared, as pertinent resources for the community. Brenda, a WAC member, shared how she believed the FFP was going to benefit the city of Fairmont and her community. 
To enhance the city of Fairmont so that we can build resources and have additional resources for us.

As a community member, Brenda believed that working with the FFP could build enough resources for her community to gain some resources after what would be considered excess resources from the city of Fairmont. Note, Brenda acknowledges her community being awarded secondary after the city of Fairmont, even though it was her and her community members that have worked with the FFP for two years. This acceptance is evidence of shared stories of marginalization of this community. Gal, a WAC member, stated what she perceived as the purpose for the FFP.

It's to support the efforts of the community members and their desire to improve their environment and to provide resources and some leadership initially just to incubate a little bit.

Leadership development, and a supportive system for community-based organization were believed to have stemmed from the two-year participation in the FFP. Mary, a WAC member shared her perspective of the FFP purpose.

My initial understanding was that there were organizations that were needing a connection to a lifeline, particularly a financial lifeline or a building lifeline, something that would get a place for people to do whatever the organization was dedicated to, and it felt like there would be some outside help through the Fostering Fairmont Project because we would have access to one another across the organizations even that we had not really tried to build before in any strong ways. And we'd also have access to the minds of people who knew how to tap 
some of the resources that they would find that we truly did need or do need. So, that was basically what I thought it was going to be.

Mary identified the fact that community members did not have the knowledge to access the resources necessary to better their community, nor did the community-based organizations have an inclination of working together prior to the FFP. Mary also shared the belief that the FFP would empower and support community members as they achieved their desired community goal(s). Barbara, a WAC neighbor shared her understanding of the purpose.

The purpose of the program was to bring the community together to use whatever resource the community has, whether it be the people, the knowledge or financial stuff, the community, that it's now being put towards the betterment of the children in a community.

Henry, a WAC neighbor stated this.

So my understanding of the purpose was to provide resources, leg up, vision in particular, to help the community get a better sense of itself. Really, a portion of the community, get a better sense of itself and how it could put together a plan to develop.

WAC members and WAC neighbors shared the perspective of working with the FFP to connect them to resources and expose them to knowledge needed to better their community. Through participating in the FFP, community members started to believe that if they worked together and acquired the needed technical skills, they would be able to achieve the goals they desired for their community. 


\section{Collaboration}

Community members working together for the betterment of their community is a common purpose that WAC members and WAC neighbors perceived for the FFP. The FFP was a participatory project that required community members to engage throughout the project and continue with the FFP plans after the two-year project had ended. When asked what they thought the purpose of FFP was, many community members including Gill, a WAC neighbor shared what she perceived as the purpose for the FFP.

I guess to upgrade Fairmont Westside, to get the community more active, get people more involved, get the community to excel in different things.

Bettie, a WAC member, shared

It's a project or outreach to bring communities together to work together and collaborate to get things done for the community and their needs.

Henrietta, a WAC member shared

I think it is kind of a support system for all organizations in our community. but causes us to collaborate more to make things happen. And to make it more successful.

Henrietta shared her perception of the FFP as being a support system for the community-based organizations in the community. This community had three community-based organizations that operated without staff and few resources. These community-based organizations did not have executive directors, staff members, or consistent funding streams to administratively support and grow these organizations. For years, community members volunteered their time, talent, and finances to support these organizations, yet the absence of needed technical and financial support 
diminished the potential of each organization. Will, a WAC neighbor, supported Henrietta's viewpoint of the FFP purpose.

The purpose was just to help other organizations, collaborate with other organizations, just empower the community and make them aware ... empower them whether it'd be resources that'd be available to them that they don't know, empower nonprofit organizations, help them better understand and help them better reach out to the community. Just be an intercept between the community and the services that are available to it.

Will shared his perspective of the FFP's purpose as being a mechanism of empowerment for the existing community-based organizations and assist with developing collaborative practices among them. He also spoke to the developmental need of organizational knowledge in order for these organization to meet the needs of their community. Will echoes the voices of community members who shared their concerns about the lack of developmental leadership opportunities and the need for more collaborative efforts among community members in the WAC Community Survey. Additional information about community members' perspectives pertaining to their community can be found in the WAC Community Survey (2015). Bree, a WAC neighbor, pointed us back to a consensus of the FFP purpose which is being a mechanism to get community members engaged for the betterment of their community. My understanding of that is for that people have to be involved. They have to be involved.

The FFP was a participatory service-learning project that presented opportunities for community members to become engaged. Workshops, seminars, planning meetings, and community activities; all took place with the goal of engaging and educating community members for the 
betterment of their community. Henry's comment below reflects his experience relating to the purpose of the FFP.

It forced us community members to engage. Some of us might have been a little confused at first about how things were going, but at least that made us step up, ask questions, volunteer, get involved in a more active way.

The FFP's participatory activities had a purpose of exposing community members to collaborative approaches and technical knowledge that would equip them to work toward their community's goals, but no allowances were made to address unanticipated obstacles within this community. There was a steep learning curve associated with community members becoming familiar with the service-learning community development process and there was the need to help community members unite their voices. Bettie, a WAC member, spoke to the purpose of the FFP is to assist community members with reclaiming their collective voice for their community.

That's really what it's all about, is making your voice heard and knowing that somebody is really hearing you, and understanding you, and feeling what you feel, and passionate with what you're passionate with.

Wendy, a WAC neighbor, shares the pride she felt as community members came together to work collaboratively towards their community goals.

You know, I feel like I'm real proud of the community. We're taking big leaps in a very new territory. I'm proud of us, you know what I'm saying? So I have two, three people come attend a meeting is more than when you didn't have zero. A sense of community pride and togetherness arose from community members working together through the FFP. After two years of working with the FFP, community members started to believe they could effect change in their community because the FFP brought a sense of hope to 
community members. John, a WAC neighbor, spoke to the aspiration community members received from the FFP.

And there's a lot of people in this community, mainly the kids, is depending on this to happen. It's big. It's super big. And just to finish it off with actually getting it up and running, I'll be able to rest in peace when I do rest in peace.

During the FFP, community members built trust around the notion that participating in the FFP would yield benefits they desired for their community. The FFP provided knowledge that empowered community members to finally believe that they could would together to achieve desired community goals. However, the two years during which the FFP was active was not enough time for community members to build the capacity needed to begin and/or continue what the FFP had started in their community. Ronda, a WAC member, comment mirrors how many community members felt after the FFP ended.

Now I'm trying to see so where doI go from here. Okay. So that's what I'm ... yeah.

That's what I'm trying to figure out now. What did I learn from all of this? And how do the two of us work and move forward?

Ronda shared her feelings of wondering what the next steps were for this community. The twoyear FFP ended and community members were left with 10 community plans to implement in their community.

\section{Familiarity}

The FFP was the first time community members had experienced a service-learning community development project that focused on the community's ideas and engagement. Community members had previously experienced a university working in their community, but 
not working with them. John, a WAC neighbor shared the community's prior experiences with universities.

Fairmont State always been in the community, cutting grass, fixing up old cemeteries. They definitely reached out and said, "Hey, we're willing to come back." It just we never had the people to reach out in the way that we need them to reach out. Y'all guys came. Y'all brung the whole template of it's not just one thing, especially when they're dealing with economical development.

Ron, a WAC member, made the following statement during his interview when asked if he had every participated in a participatory practice with a university.

I think you guys have a lot of resources that the community very well needs. And I think that actually should be part of your agenda is to come into the communities. I wish Fairmont State would be more involved in the community.

The FFP process required community members to be engaged within the project to learn, mobilize, plan, and implement the community plans that were developed for their community. The lack of familiarity with the techniques and technical information presented throughout the project, coupled with the existing marginalization of this community, created a gap between what the community was expected to do to maintain the efforts of the project, and what the community actually had the capacity to accomplish. Community members did not have the knowledge, resources, or time to maintain the projects that were initiated in their community. Sherry, a stakeholder who grew up in Fairmont, spoke to community members' experiences prior to working with the FFP.

But you know prior to Fostering Fairmont and I don't think the folks in the neighborhood felt like they had a collective voice. 
Community members' unfamiliarity with the FFP process was matched by the university team's lack of familiarity with the community's culture. The project team was unprepared to handle the gap between what community members needed to do to maintain the project, and what they had the capacity to achieve.

\section{Research Question \#2}

What were Fostering Fairmont Project (FFP) participants' experiences with the two-year servicelearning project that intended to begin community development initiatives in their marginalized community?

The FFP was a two-year service-learning community development project that required the engagement of community members to successfully fulfill its academic community development goals. The FFP was a participatory community engagement process that fostered collaborative approaches among community members who desired to better their community. For two years, the FFP organized meetings, workshops, and activities for community members to attend and engage in.

The FFP also guided community members to establish the WAC with the expectation that it would continue the initiatives started by the FFP. There was also support provided through the FFP to assist community members in their efforts of reviving community events that were missed by their community. Details about the process the FFP set to engage community members through the WAC can be found in the Neighborhood Action Plan (2016) and the Public Engagement Plan for the Westside Action Coalition (2016). The experiences of community members who participated in the two-year service-learning community development project were captured through interviews. 
These interviews were conducted two months after the FFP had ended, and the following quotes in this section reflect the comments of the WAC members who participated for the whole two years. The questions in the process section of the interview focused on understanding the experiences of community members who participated for two years in the FFP. The questions centered around learning about what community members thought about their involvement in the FFP, the barriers faced when trying to persuade other community members to engage, recommendation to engaging other community members, and community members' capacity to continue initiatives started by the FFP.

The comments represent common themes that emerged from WAC members' responses to interview questions. For the following set of themes, WAC members were asked to reflect on what stood out to them from the two-year process. The two themes that emerged were the collaborative efforts among community members and information about the community that was provided to community members from the FFP. WAC members agreed that working together and the amount of information that was presented to them throughout the two years from the FFP, were the two most influential factors concerning the FFP.

\section{Collaborative Efforts and Knowledge Shared}

Collaborative efforts among community members was one of the themes mentioned by WAC members. Ron's, Henrietta's, Henry's, and Charles' statements reflect this. Ron shared: From the conception 'til the near the end is to getting the community to work together, as a unit, a cohesive unit.;

Henrietta:

I like the comradery that I saw. I felt like people were really excited and engaged.; 
Henry:

People actually came, members of the community actually came. I was the only business owner.

Charles:

The quality of information, the research, and then getting everybody into the room together.

The four comments indicate the appreciation that has developed among WAC members for having the experience of collaboratively working together. Prior to the FFP, WAC members were unfamiliar with using collaborative approaches to begin community development initiatives in their community. All WAC members were actively engaged in one or more of the three community-based organizations in their community however, prior to the FFP, these communitybased organizations did not have a history of working together to achieve a common community development goal. Gal's statement below shares her reflection on the FFP process.

[the meetings] were very organized, the spirit of the people. The desire. The genuine desire to make things better. To get to an outcome where it would really have an impact on people's lives and not just a bunch of talk and pretty gestures.

Gal spoke to community members' willingness to learn and work together for the betterment of their community and to the impact that the FFP engagement process had on community members. WAC members engaged with the FFP for two years, with the expectation of learning how to use the information presented throughout the project to better their community. The comment below sums up Mary's experience with the FFP. 
I thought it was interesting. I thought the meeting was interesting. I thought

having that data was helpful and could be helpful in the future, much of it. Data that was collected.

The amount and type of information that was presented throughout the FFP was another common theme that emerged from WAC member's interview comments as being among their most memorable experiences. During the FFP, information about the structure and operation of their local government, generational history about their community, information about the assets in their community, and reports for community projects with legal, technical, and financial information needed to get projects started were made available. John's comment below shared his reflection on how what he learned through the FFP has impacted him.

The data, the planning, the work that went into it, the details that's into it, and y'all cover 40 years-plus of history. Well, two years it's been here, but less than two years. In a year, because the last year is when you all brung out the data. It educated a lot of people. It can educate a lot of people that live in this community, and once they see it, once we can show the community the whole plan that you all put into this work, and even the city manager, even the councilmen, even the people that look at ... We actually have a lot of value in this community. It's amazing because there's a lot of things that I didn't know. There's a lot of stuff that I didn't know. There's a lot of things in there that a lot of other people didn't know about. I think it's time for people to start knowing what our resources is. So I just thought it was a great way that you followed your guidelines just to get everything that y'all needed to do to collect it and to present it. 
John's comment shows how much of the information that was presented to community members through the FFP was unknown to them. Presentations and reports were developed by the team project coordinator and her students to equip community members with the knowledge necessary to continue the community development initiatives the FFP had started. A community survey was produced to inform community members about their shared attitudes towards the community's leadership and local government. A community profile was produced to educate community members about their community's history and assets. An engagement plan was created to provide a step-by-step manual to assist community members with engagement initiatives. A Neighborhood Action Plan along with ten project plans were created to provide community members with the legal, financial and technical skills to implement and sustain successful community development plan. All of these, together, were created to make the community stronger in the collaborative process. Brenda's comment below embodies her experience with the FFP.

They were informative, the resources, the knowledge that was given to us. I think at times one of the cons may have been too lengthy, and people's interests is starting. They're starting to lose interest because of the timeframes that we held them at. I think sometimes having it all day on a Saturday from 10:00 to 3:00 is a bit much. I think maybe if we get them in spurts, little spurts, like an hour here or hour there, we probably would have had more people involved.

Brenda's comment shows appreciation for the information that was shared with community members through the FFP, however, she also mentioned a common feeling that was among community members in relation to how the FFP was structured. Brenda also provided a recommendation on a preferred way of disseminating information in her community. 


\section{Power Dynamics}

The next set of comments is in response to five questions that investigated power dynamics between WAC members and the FFP. First WAC members were asked if there were opportunities for them to share ideas and ask questions during the FFP. WAC members had a consensus response of yes. They wholly agreed that there were always opportunities for them to share ideas and ask questions during the FFP process. Below are comments of WAC members that thematically represent how WAC members viewed available opportunities to share their beliefs and inquires. Henrietta made the following statement:

I think at every setting that was really the whole idea, that everybody participates and that everybody shares their thoughts and concerns and ideas. So I think that that was the major thing in each one of the workshops that we attended.

In all engagement activities hosted by the FFP, the shared knowledge and ideas of community members were encouraged and captured to inform what projects would be chosen for community development plans. The community developed plans would be created for community members by the project team leader and her students. Henry made the following statement in reference to the opportunities presented for WAC members to share beliefs and their inquiries.

Lots and lots to share starting from the very beginning. They were all engaged in sharing their ideas through the whole process.

Bettie's comment confirmed Henry's view.

There were plenty of opportunities. I mean it was just a plethora of opportunities for the community to come together and to share.

Ronda also agreed. 
I think at all the meetings, there were opportunities and if the opportunities weren't really asked for, I think we pretty much went on and took advantage of any space that was there to ask those things. I think it felt open enough to do that. Through these comments we can see that the community felt at ease with the process and the sharing, both aspects that could help the community and individual community members feel empowered. The next set of comments are the answers WAC members shared when I asked them an experience they had within the FFP that made them feel empowered or that added to their skill set. WAC members shared that they had an experience of feeing empowered or increasing their skillset. Ronda's comment reflects that her presence at the meetings added to her interpersonal skillset.

I think just coming to the meetings actually. Sitting and listening and watching how [the project team coordinator] presented information, how you all presented information. I think that helped me. Just watching and listening.

Gal also made a comment that spoke to the increase she noticed with her interpersonal skills. My listening skills increased.

Listening is an important interpersonal skill. Collaboration cannot easily exist when the parties are not able or willing to listen to one another. Bettie's comment below also mentioned an increase in interpersonal skills.

This has helped me be able to be more comfortable with engaging with other people. Henry:

I actually got to do something to help. Henrietta:

To map out what, who our community was. 
Henry's and Henrietta's comments reflect the high engagement and learning that was built into the FFP participatory process. At every meeting, workshop, or event hosted by the FFP, community members received new information about developing their community plans and there were activities promoting collaborative efforts among community members. In her comment, Henrietta mentioned a mapping exercise where WAC members decided which communities would be included in the FFP. The mapping exercise was empowering in that it entitled WAC members to have a voice concerning where the FFP would be represented.

Ronda, Gal, and Bettie mentioned an increase in their interpersonal skills, and Henry and Henrietta shared their sense of feeling empowered through the FFP engagement process. The comments by Brenda and John reflect how their experiences within the FFP have increased their intrapersonal skills. Brenda stated:

The press release and being one of the main faces and focal point of the West Side Action Coalition as well as the Fairmont Community Youth Development Center gave me a sense of feeling important.

John stated:

The beginning. The first meeting we had, stakeholder's meeting, or the first couple stakeholder's meeting. Just the development of it. I felt empowered. When the board said, "Yeah. Let's do it then," I felt empowered because, man, it took a lot of ... Well, you know.

John's statement reflects the feeling of empowerment cushioned in a feeling of helplessness. Without all the people in the room the project would not have gone forward. The community would not have been able to do the project on its own but needed the help of the stakeholders and the university. The next question asked WAC members if they had an experience with the FFP 
that felt disempowering, and all WAC members reported that they did not ever feel disempowered during their engagement with the FFP.

Following the question previously discussed, WAC members were asked to share an experience during the FFP that made them feel like a valuable participant. The experiences that were mentioned in the responses included the sharing of their expert knowledge, receiving recognition, and collaboratively working together to revive cherished community events. Below are comments that illustrate those themes. Bettie, Ron, and Henry's comments show how WAC members felt valued by the sharing of their knowledge.

We were able to go out into the neighborhoods and canvass.

The opportunity to pray over the meetings. I don't know. Just being able to give my input on whatever we thought necessary.

When you guys were doing the interviews, and you took the suggestions and wrote them in, and said we need a businessman's perspective.

Brenda's comment below identifies recognition as to what made her feel valued in the FFP. I think whenever I was chosen for their Community Heroes award is what made this experience valuable. I didn't really realize the impact that I had on the community.

In the next comments, Gal and Henrietta shared that working collaboratively together to restart their traditional community event made them feel valued in the FFP.

The Thanksgiving dinner. The comments that I received from people and just glad that we hosted it here.

I really liked was the thanksgiving dinner. I thought that that was awesome. 
The last question investigating power dynamics between WAC members and the FFP asked if WAC members have had an experience within the FFP that made them feel devalued, and no WAC member reported ever having had such an experience.

\section{Barriers to/Recommendation for Engagement within their Community}

During the two years of the FFP, there was a constant effort to get additional community members to commit to being involved in the project. Though community members would attend meetings or community events, only twelve stayed consistently involved, known as WAC members. These twelve members exerted great efforts to try and convince friends, neighbors, and family members to become involved with the FFP. While their efforts succeeded in encouraging other community members to attend a meeting or two, they were unsuccessful convincing their friends, neighbors, and family members to make a long term participatory commitment to the FFP. This motivated me to ask WAC members about the barriers they faced when they tried to encourage engagement among other community members. Below are their comments. Ron shared:

Apathy. Apathy. No time for that.

Gal comment expresses a similar sentiment.

Apathy. think they don't have a personal connection to it and they don't see the need.

Gal's comment unravels a cause of apathy among community members that contributes to community members lack of participation. In other words, apathy may be a symptom of marginalization.

Mary's comment mentions another barrier to engagement that WAC members faced when trying to get community members engaged in the FFP. 
Yeah. I didn't try real hard because I already know the people. The ones that I thought might show up did show up for the meetings at Mt. Zion. Don't nothing get done at no meetings. Just waste of time.

Henrietta made the following comment

Well, a lack of interest from the community, the skepticism of the community.

Mary's and Henrietta's comments represent the frustration also shared among other community members with not having the necessary technical and financial resources to pursue the desires they share for their community. John's comment conveys how the lack of community development resources has positioned community members.

Community need help because they don't know where to go. There's no resources for them to go anywhere, other than the internet.

John's comment focusses on the absence of knowledge among community members. This deficiency of knowledge has created an internal barrier to engagement. Brenda speaks to this barrier.

Lack of knowledge and understanding. A lot of people didn't understand, weren't knowledgeable, and fearful of the change that we were trying to create.

The lack of familiarity to a service-learning community development practice posed as a barrier to engaging community members. Community members were unfamiliar with what the FFP process entailed and unsure if they could contribute to the goals of the FFP.

Next, WAC members were asked for suggestions on how to encourage other community members to get involved in community development plans. Below are the suggestions they shared.

John, a WAC member: 
Personal. Around here, the best way to do it is if we got to go door to door, that's the best way to do it around here to get people involved.

Brenda, a WAC member:

Door to door, taking flyers.

Henry, a WAC member:

From billboards down to knocking on doors, word of mouth.

Bettie, a WAC member:

Like if I get a piece of paper in my door or in my mailbox that I can actually hold in my hand and see it.

Henry, a WAC neighbor:

Honestly, I do think phone calls and the occasional face to face door knock.

Ron, a WAC member:

I don't know. I think flyers ... flyers ... helps a tremendous amount. And I guess with the social media now, you almost have to do Facebook, 'cause so many people are on it. But flyers ... word of mouth.

Roy, a WAC member:

I used to say church announcements. Then I said, "Well, put it in the paper." Right now it's Facebook and Messenger and everybody lives on their iPad, their tablet and their phone.

Wendy, a WAC neighbor:

Text or email.

Barbara, a WAC neighbor:

A text message. 
Henrietta, a WAC member:

It kind of depends on the community that you're in.

Henrietta's comment offers the best advice: it depends on the community. Some communities do better with face-to-face interaction or going door-to-door, while others may be more efficiently contacted through electronic means such as text messages, social media posts, and emails. The only way to determine which interaction works best for a community is to talk with community members and learn what is their preferred form of communication. This concludes the questions on my interview protocol that focused on answering my second research question.

\section{Community Capacity}

In the second semester of the project, community members were guided to start a coalition which was given the name Westside Action Coalition (WAC). The WAC's purpose was to create a foundation for community members to collaboratively continue the community development initiatives started by the FFP. The WAC consisted of individuals from three community-based organizations, along with leadership from neighborhood churches. During the FFP, I facilitated the WAC meetings and was instructed to end my facilitation and pass it on to a community member when the FFP ended.

The next three questions in the interview protocol seek to understand if community members felt they had the capacity to continue the WAC and the community development plans started by the FFP. These questions also include the comments from WAC neighbors to learn their perspective of the WAC. The first question focused on learning about WAC members and WAC neighbors' perceived capacity to maintain the WAC, and their familiarity of being involved in a coalition. All WAC members and WAC neighbors stated that they had never before 
been involved with a coalition and they were unfamiliar with the collaborative dynamics in which coalitions vitality is rooted.

The second question sought to learn about their understanding of the WAC. Here are WAC members and WAC neighbors' comments.

Charlene, a WAC neighbor:

They're coming in, and they try to make things better.

John, also WAC neighbor:

It seems like they brought attention to the Westside and actually gave us something to work towards that we'll have something on this side of town so necessarily you don't have to cross the bridge to go to everything

Brenda, a WAC member:

is a group of people, organizations coming together that has the same goal, wanting to see change within the community or within a section of town, working towards a common goal.

Will, a WAC neighbor:

My understanding is that it's basically an organization of members within a community, to help collaborate with different organizations to bring them together.

Wendy, a WAC neighbor:

I know that it is a organization that is community-based and it brings a number of different organizations together under one hub to help improve and make changes in the community.

Ron, a WAC member: 
A board, an organization for the betterment of the community. Westside Action Coalition putting action to the words.

Bettie, a WAC neighbor:

I'm still trying to get an overall understanding of it, but I know it's a collaboration of five areas that we're trying to build up and work together as a community would.

Charles, a WAC member:

They've got a lot of hard working individuals that are trying to make changes in their neighborhoods.

Gal, a WAC member:

It's to work cooperatively. These various agencies and these various neighborhoods. To find common goals and then implement them.

WAC members identified the WAC as having a positive effect on their community, but what was surprising is that though WAC members served as the WAC for the past year and a half, not one member identified herself/himself as being part of the WAC. They did not see themselves as the ones driving the WAC. Since there was no WAC without community member participation, therefore, it was surprising for WAC members not to see themselves as the driving force of the WAC.

The final question that was in inquiry about community members' capacity to continue the WAC and the community development projects started by the FFP. WAC members and WAC neighbors were asked if they believed they had the capacity to continue the projects started by the FFP, and these are the comments they shared that represented their common theme. Brenda, a WAC member: 
Not at this point, I don't believe, without support. I think we still need support. Gal, a WAC member:

I would say it's a low capacity. I still think that there's a need for some propping up.

Mary, a WAC member:

I think that it still needs a leadership base. I mean, somebody who communicates. Otherwise, it would just fall apart.

WAC members acknowledged the need for additional support to continue the community development plans started by the FFP. WAC member comments showed their willingness to work and their understanding of the need to help continue these initiatives. Ron's comment helps understand the community members' need for knowledge. Ron, a WAC member: I don't know. I think we have to be aware of grant programs. You have to be aware of ... Actually, we have to be aware what's available. If there's grant monies out there, we need to be aware of it. If there's an organization out there that can come in, and help us as a community, not do it for us. I'm not looking for handouts. But knowledge of what's available. I think that's it, pretty much. Just be knowledgeable what's out there, and what we can do and accomplish.

Knowledge enables people to do better. WAC members were willing to learn and work towards bettering their community, but they needed to know what resources were available to help them. This kind of knowledge is not common in a community, let alone one that has been marginalized. This concludes the questions on my interview protocol that focused on answering my second research question. 


\section{Research Question \#3}

What recommendations do Fostering Fairmont Project participants have for universities about engaging community members in service-learning projects?

The question in this interview section focused on eliciting recommendations for community engaged scholars who work with community members in service-learning projects. Community engaged scholars are scholars who pursue positive transformative outcomes for community members and the continual support for these transformative outcomes may be out of the supportive ability of the community engaged scholar. Therefore, it would be respectful to caution community members that the community engaged scholar endeavors may not have the financial and/or technical support of the university. This was a lesson learned. Below we list the themes that emerged from the analysis of interviewing WAC members, WAC neighbors, students, and stakeholders about providing recommendations to community engaged scholars who engage community members. These themes centered around relationships, culture, and brokering.

Table 5. Research Question 3

\section{Research Question \#3}

What recommendations do Fostering Fairmont Project participants have for universities about engaging community members in service-learning projects?

\begin{tabular}{|c|c|c|c|}
\hline Members & Neighbors & Students & Stakeholders \\
\hline \multicolumn{5}{|c|}{ Relational } \\
\hline Ronda & Marlene & Ron & Yondo \\
\hline Henrietta & Will & Abel & \\
\hline & Terry & & Sherry \\
\hline \multicolumn{5}{|c|}{ Culture } \\
\hline Larry & Alfreda & Ron* & Sean \\
\hline John & Nancy & Abel* & \\
\hline Charles & & & Ronald \\
\hline Brenda & \multicolumn{3}{|c|}{ Brokering } \\
\hline \multicolumn{5}{|c|}{} \\
\hline Henry & Wendy & Laura & Yondo* \\
\hline Gal & Charlene &
\end{tabular}


* same statements from Bob and Chris support relational and culture themes

* same statement from Yondo supports relational and culture themes

\section{Relational}

Having a relational approach when engaging community members was a recurring recommendation to universities from FFP participants. WAC members, WAC neighbors, Students and Stakeholders all spoke to the importance of getting to understand community members and establish relationships before starting a service-learning project. Marlene, a WAC neighbor spoke to the importance of first establishing relationships with community members.

I would tell them if you're going to come into my community, my community, then forget everything you know about anything in the community. Come into my community and live in my community before you can help me, because the word community would mean common and unity.

Every community is different, and each community has dynamics that can only be learned through relationships. Entering a community with the initial purpose of learning from and about community members positions the engaged scholar to make more informed decisions about efficient ways to achieve community and as well as academic goals. Will, a WAC member, spoke to the importance of building relationships by stating:

Learn a little bit about it so you can kind of understand it, forge and build relationships. Just don't come in and say, "Hey, you gotta do it this way, this that," because every community is a little different.

Learning from community members and enabling them to contribute to the development of goals for a service-learning project builds relationships that provide an internal understanding about the community. Community members are experts about their communities, and when their expertise is not considered in the initial stages of deciding what a project will be, community 
members can feel--as Will referred to in his comment--forced to accept whatever is brought into their community. Ron, a student who participated throughout the entirety of the project, mentioned in his recommendation to universities that relationship building is important. Is really engaging people. Understanding what it is that's going on in their life. And having compassion and being able to work with them on that kind of level. Ron spoke to the importance of having an understanding about a community that expands researching and gathering knowledge about its physical place and expanding the focus of knowledge to also learning and understanding who the people are in that community. Understanding community members' self-agency, self-efficacy, and community dynamics can provide knowledge that is helpful with implementing a service-learning project. In reference to building understanding about community members, Ronda, a WAC member, provided this recommendation.

Just to get to know the community. I mean you can ... before you even come in. Do some research before you come into the community. So you come in with maybe a little bit of understanding of the community and that would be my advice.

Community engaged scholars can also utilize this time of relationship building to help community members understand limitations that a community scholar may face. Semester timelines, project end times, and the rotation of students are a few such limitations; without community members having a proper understanding of these limitations communities can develop expectations that community scholars cannot keep. During our interview, I asked Yondo, a stakeholder, to provide a recommendation for the university.

The professor that comes in and works in certain areas and once they get done with that they leave. Universities should stay longer in communities. 
This statement shows that there was a lack of understanding between the community engaged scholar and the community in reference to the expectation of their engagement. A mutual understanding between community members and community engaged scholars is needed to create proper expectations between community members and community engaged scholars.

Henrietta, a WAC member, provided a recommendation to community engaged scholars and universities that speaks to the power dynamics of a university and community relationship. Just be genuine. And be sensitive to the needs of the people that you're working with. Like really understand their point of view and where they're coming from and don't look at them as a project but look at them as people.

Henrietta's comment speaks to the inferior position community members face when decisions are made about what is going to happen in their community, and how the project would be implemented. When community members input is not sought, community members may hesitate to engage with the community engaged scholar. The absence of relationship building magnifies the absence of shared power. Power sharing must be achieved between the community engaged scholar and community members to prevent the latter from feeling that they are only valued as a part of a project.

Terry, a WAC neighbor, provided these recommendations:

To know these people, you better go to their house and visit them. And they'll let you know all about how they feel. Sending a letter out is good, but you still have to knock on their doors and talk to them. Simple as that.

Talking with community members to build trust and understanding creates a space for relationship building. Abel, one of the four students who participated in the project, comments below about the importance of building rapport with community members. Abel suggested 
meetings as a tool to strengthen communication and collaboration and to prepare the minds of those who are engaged.

Perhaps hold meetings with them before going into that community. Core meeting with them at least one, two, three times. That would make the process a little bit easier. Because there is no such communication, there is no such get together, before moving on, people were just like you know. At least, let there be information, let there be understanding, let there be concerns about what the people should expect. That'll prepare their mind.

The building of relationships between community scholars and community members can create a space of awareness to learn about diversity among people. Learning about diversity makes us aware of the importance of understanding different cultures, which was among the recommendations that community members provided to the university.

\section{Culture}

The importance of learning about the culture of community members was another common theme that emerged from the analysis of the interviews. Larry, a WAC member, in a few words stated the importance of culture.

The culture thing. You know, the capacity assessment. You know. From the capacity assessment comes the need assessment.

In a few words, Larry, a WAC member, expressed how having knowledge about a culture provides a door of access to an internal understanding that reflects community members' perspectives about achieving their desires for change, and their ability to make that change happen. Acquiring an internal understanding from and about community members equips the 
community engaged scholar to apply the most appropriate engagement approach for benefiting themselves and the community.

During my interview with Bree, a WAC neighbor, she communicated the importance of learning about community members' culture before trying to help them.

So, just come in, be a part of the community, immerse yourself within the culture and then that, once you understand that then you could help people. You could help lead people or suggest things that they could do to empower them.

Bree acknowledges that when people who want to help the community consider the culture of community members, community members are then positioned to achieve their desired goals. Charles, a WAC member, provides a suggestion to how the culture of a community can be learned.

I guess get to know a little bit about the history coming in.

John, a WAC member, expands on Charles's suggestion.

I think they should know the history of it. I think they should know the overall history of what goes on in this neighborhood and why. I think they should have a lot of questions on why not it ain't working. See it and see why and see the problems and why they don't have something. I think it's important to see what they getting into instead of just reading a book and not knowing where they going to end up at. I think it's important that they get that and go forward.

John's comment points to the necessity of inquiring as to why certain attributes may be present within the culture of a community instead of focusing on how to address an issue that may manifest from the culture of that community. Why is there apathy within a community? Why are community members not empowered to make desired changes in their community? Why is there 
an absence of knowledge and resources needed to germinate change? John suggests that coming into a community with only technical knowledge can leave community members and community engaged scholars with unsuccessful and unplanned endings.

Hilary, a WAC neighbor, and Sherry, a stakeholder, whose comments are listed, suggested speaking to as many community people as possible. This approach would assist the community engaged scholar in answering the type of questions posed in the immediately preceding paragraph. Talking to community members would also provide knowledge about the community that cannot be learned about otherwise.

Definitely that they do a lot of interviewing of local people first. I think you know I think to try to talk to as many people face to face as you can because even sometimes a community that seems really tight and it can be at odds about a lot of things.

Sean, a stakeholder, provides a suggestion for including students in the process of learning about the culture of a community.

Maybe a door to door initiative with the students.

Brenda, a WAC neighbor, provided advice on initiating engagement in her community, and she also shared a reflection she had about the FFP engagement process.

Do their research on the community, talk to some of the leaders first, I think we did that kind of late. is to really know the culture and the community and those dynamics, and how to deal with them before actually going in to deal with them, because it could cause frustrations and setbacks, which I think we did have a few, but we were able to overcome them for the most part. the background understanding, knowing the community and what they're all about. 
During the process of implementing the FFP, it was learned that the techniques that were used to engage the community were proven to be effective, but the culture of this community dictated the level of success these techniques actually achieved. Expanding our learning of a community's culture past the academic setting and taking the time to teach community members about the culture of community engaged scholarship decreases the likelihood of unintentionally applying inappropriate techniques when working in a community.

Brokering is the last common theme that emerged for recommendations to community engaged scholars. Brokering is the designation of an individual or organization to help establish and support relationships between communities and the university and creating a conduit for shared knowledges (Levkoe, 2018). WAC members, WAC neighbors, Students and Stakeholders all understood that constraints limit some efforts of the university; brokering could help alleviate some of the structural constraints that can exist within university and community relationships.

\section{Brokering}

Universities are teaching institutions that support different community engagement initiatives from their scholars. Community engagement initiatives are faced with limitations and constraints that may affect how a community engaged scholar can work with community members. Semester deadlines, the rotation of students, and limited financial resources are among the constraints. To strengthen universities in their efforts in assisting communities, universities may partner with other institutions to create brokering establishments in the community. Laura, one of the students who served in the project, presented a reason why brokering would be beneficial for future university and community relations. 
So what could universities do in terms of outreach? I think provide sustainable longer-term support that makes sense, so that communities don't get the rug pulled out from under them.

Community members may feel, as Laura stated, that the rug was just pulled from underneath them when the university is no longer able to continue its support towards the community. Community members may need additional assistance beyond the available resources of a university. Yondo, a stakeholder mentioned another reason why brokering would benefit university and community relations.

The professor that comes in and works in certain areas and once they get done with that they leave. Universities should stay longer in communities.

Community outreach projects hosted by universities are commonly guided by the university's academic calendar, but sometimes these timelines conflict with support needed by community members. Universities are limited within their structure and community members may need additional time and support to continue and/or maintain the initial outreach project. Brokering can accommodate universities and communities by filling gaps in service and support. Gaps in service and support can also be addressed through partnering with local social service institutions.

Charlene, a WAC neighbor, made the following comment supporting a brokering initiative. Make sure that if they're going to do it, that they have investment from someone who can probably do it full-time. It shouldn't be something like it's a semester long project. It needs to be a full commitment from a person, or from a team that's willing to spend time and understanding those communities before they act within those communities. 
Gal, a WAC member, made the following comment in support to brokering.

That they really stay with someone who's not just academically studied some of these things, but someone who's been hands on actually doing it.

Wendy, a WAC neighbor, also made this comment that supports a brokering initiative. I think that it is very important that you find people who are empathetic to lead this program and come into the community open to understand. If the person that you put in that position is a compassionate person, I think that this program is a beautiful program for communities.

Charlene, Gal and Wendy all recommended individual/institution characteristics desired when establishing a brokering initiative. They spoke of a broker that is patient, compassionate, and willing to spend time in a community and learn about community members. These actions can assist with developing space for the exchange of knowledge, and the sharing of power among community engaged scholars and community members. Creating an environment that allows community members and community engaged scholars to learn each other's culture and understand each other's limitations, builds space for relationships that are understanding and beneficial for community members and community engaged scholars. Henry, a WAC member, comment conveys the importance of reaching all people in a community.

Make it ongoing. this was an example of a good, finite project as far as the university's involvement, direct involvement was concerned. That's still kind of at the lesser end of what I'm talking about. Really that kind of extension like service, ongoing in the community and really on the lowest possible level, and even if it's just encouraging students to actually be members of the community and not just transient residents. 
Starting and maintaining a brokering initiative could supersede the resources a university has towards this initiative. However, through collaborative partnerships, universities and institutions can partner to create sustainable relationships within a community. Ronald, a stakeholder who participated in the FFP, gave this recommendation to identify resources to finance related projects.

Make the bankers get in a room and tell you what they could do for you. They ought to be doing more.

This concludes the findings from the data collected. 


\section{Introduction}

\section{Chapter 5: DISCUSSION}

This research focused on community members' involvement in a two-year servicelearning community development project implemented in their community. The purpose of this research was to learn about and understand the perceptions and experiences of community members who participated in this two-year service-learning project with the goal of sharing lessons learned to improved university-community engagement relationships and practices. The three research questions that guided this study were:

1. What do Fostering Fairmont Project participants perceive as the purpose of the two-year service-learning project intended to begin community development initiatives in their marginalized community?

2. What were Fostering Fairmont Project participants' experiences with the two-year service-learning project that intended to begin community development initiatives in their marginalized community?

3. What recommendations do Fostering Fairmont Project participants have for universities about engaging community members in service-learning projects?

This study used a qualitative phenomenological research design, using semi-structured interviews of community members as the method to gather data. A phenomenological design is appropriate when the focus of the study is to understand the participants' first-hand perspectives and experiences (Moustakas, 1994). Interviews are an important source used in qualitative research "to understand the world from the subjects' points of view, to unfold the meaning of their experiences, to uncover their lived world prior to scientific explanations" (Brinkmann \& Kvale, 2015, p. 3). Throughout this research, my focus remained on reporting the perceptions 
and experience of community members in the goal of providing information that could contribute to better university-community engagement relationships.

This final chapter presents key findings of my analysis, implications of the findings, and recommendations for future service-learning community development practice in marginalized communities.

\section{Question 1: Purpose}

Interview questions used to gather data for my first research question centered on collecting information about community members' understanding of the service-learning project purpose, and their familiarity to the process of a community development service-learning project. After an analysis of the purpose section of my interviews, resources and collaboration were the common themes for community understanding of the FFP purpose.

\section{Resources}

Community members believed the purpose of the FFP was to assist community members and community-based organizations with the knowledge needed to garner their desired resources for their community. Community members believed that their continued collaborative participation in the two-year Fostering Fairmont Project (FFP) would help them develop their leadership and community-based organizational capacity to achieve the goals they desired for their community. Community members also viewed the engagement, collaborative activities, and the knowledge that was shared with them as pertinent resources to their community.

\section{Collaboration}

The FFP was a participatory two-year service-learning community development project that had a goal of exposing community members to collaborative approaches and technical knowledge that would equip them to achieve their desired community goals. Workshops, 
seminar, planning meetings, and community activities all took place to engage and educate community members. During the two years of engagement with the FFP, community members built trust around the notion that participating in the FFP would reap them the benefits they desired in their community. Community members viewed the FFP as a mechanism of empowerment to help community members reclaim their voice, and a support system to help establish more collaborative approaches among community members and community-based organizations.

\section{Familiarity}

The FFP was the first time community members had experienced a service-learning community development project that focused on the community's ideas and engagement. The FFP process required community members to be engaged within the project to learn, mobilize, plan, and implement the community plans that were developed for their community.

\section{Implications}

The FFP focused on providing community development technical assistance to community members so they could have the knowledge needed to achieve their community development goals, but the FFP was unprepared to handle the huge learning curve associated with community members becoming familiar with the service-learning community development information and process. Community members' lack of familiarity with the techniques and technical information presented throughout the project created a gap between what community members were expected to learn and apply in the two-year time frame and what community members actually were able to accomplish. The FFP was not prepared to handle the amount of time and effort needed to equip community members to be successful with their community development initiatives. 
There was also an unmet need between what community members desired as their community development project and what the FFP was structured to provide. Community members expressed their desires for a community center and youth development, but the FFP was structured to create a Neighborhood Action Plan for the community. The participatory structure of the FFP allowed community members' ideas and input to dictate what the neighborhood plans would be, but this did not replace community members original desire for a community center and youth programming. Though community members were aware that their preferred community development project was not the focus of the FFP, they continued to participate in hopes of somehow getting closer to achieving their desired community development goals.

Historically, community engaged scholars had the power to choose what community to work with and what initiatives would take place within that community (Bhattacharyya, 1995; Thye \& Kalkhoff, 2014). In order to ensure that the community engaged scholar create an equitable experience for community members, the sharing of power with community members is necessary. The act of sharing power consists of allowing community members to decide how their community should be developed (Bortolin, 2011; Bruce, 2013; Coffey \& Lavery, 2015; Davidson et al., 2010). Community members may have preferred community development projects and community engaged scholars are is expected to work with community members create collaborative equitable relationships (Groark \& McCall, 2018).

The concept of power sharing can be challenging for community engaged scholar who are not familiar with sharing power with community members (Schwartz et al., 2016; Tryon, Slaughter, \& Ross, 2015). The sharing of power protects the needs and dignity of community members (Jacoby, 1996). Through the sharing of power, individuals are positioned to create a 
synergy that nurtures building capacities and produces outcomes that no other way would be able to be created (Clifford, 2017; Davis et al., 2017; McReyolds, 2015). Reflecting is identified as a critical and beneficial element in service-learning engagement because it helps to exam personal biases, expectations, and traditions within the context of privilege and power (Chupp, \& Joseph, 2010; Glazier, Charpentier, \& Boone, 2011; Lu, \& Lambright, 2010). Reflecting has been effective in aiding the community engaged scholar through the process of understanding their position in systematic injustices and how their position of privilege and power affects their engagement with community members (Chambers \& Lavery, 2012; Coffey \& Lavery, 2015; Cook, 2008). Without reflection, one does not exam one's personal biases, expectations and traditions (Mitchell et al., 2012).

\section{Question 2: Process}

The process section of my interview protocol was designed to answer the second research question. Interview questions used to gather data for my second research question centered on collecting data that provided insight into community members experience with the FFP. These questions aimed to understand community members experiences in relation to: (1) their involvement within the FFP, (2) their perception of the power dynamics within the FFP, (3) barriers faced when trying to persuade other community members to engage and recommendations for engaging community members, and (4) community members capacity to continue the initiatives started by the FFP. The sections below discuss the common themes that arose in these sections.

\section{Collaborative Efforts and Knowledge Shared}

Community members reported that working together and the amount of information that was presented to them throughout the two years from the FFP were the most two influential 
factors that stood out to them concerning the FFP. Community members' genuine willingness to learn and work together for the betterment their community. During the FFP, information about the structure and operation of their local government, generational history about their community, information about the assets in their community, and reports for community projects that consisted of the legal, technical, and financial information, were created and presented to community members.

\section{Power Dynamics.}

Community members reported that in all engagement activities hosted by the FFP, there were many opportunities for community members to share their knowledge and ideas. Experiences reported by community members that made them feel empowered were their increase in interpersonal and engagement skills, and community members participation in the FFP. Experiences that made community members feel valued included the sharing of their expert knowledge, receiving recognition, and collaboratively working together to revive cherished community events. No community members reported to have an experience where they felt devalued or disempowered.

\section{Barriers to and Recommendation for Engagement within their Community.}

Throughout the two years, community members put forth great efforts to try and convince their friends, neighbors, and family members to become involved with the FFP. The following internal barriers to engagement were reported by community members were apathy, no personal connection to the work, and lack of knowledge. To engage community members, community members provided the recommendation of coming into the community and learning what may be the most appropriate form of engagement for that community. 


\section{Community's Capacity}

In the second semester of the project, community members were guided to start a coalition which was given the name the Westside Action Coalition (WAC). The WAC purpose was to create a foundation for community members to work collaboratively together to continue the community development initiatives started by the FFP, but community members reported that they did not have the capacity to maintain the WAC or the FFP projects.

\section{Implications}

Every community is different, and each community has dynamics that can only be learned through building relationships. Entering a community with the initial purpose of learning from and about community members' positions the community engaged scholar to make a more informed decision about the most efficient way to achieve community and academic goals. During the FFP, it was learned early in the implementation of the project that community members did not have the capacity to continue the community development initiatives started by the FFP. The FFP was unaware that what was required of community members to make the project successful was incompatible with the capacity of community members. Before the start of the FFP, there was no clear understanding between the FFP and community members in reference to their capacities and limitations.

The two years that the FFP was active in their community were not enough for community members to build the capacity needed to begin and/or continue the community development projects started by the FFP. The absence of developmental leadership, organizational knowledge, and collaborative approaches towards community development initiatives within the community, impeded on community members' abilities to grasp the information and achieve the actions necessary to implement their community development plans 
within the time allotted. The two-year FFP ended with community members unprepared to continue the work to implement the community development plans they participated two years to see to fruition.

Community members were aware of their lack of capacity to continue the WAC and the FFP initiatives and they voiced their concerns, but the FFP was ill-equipped to address these concerns. The FFP continued to encourage community members to participate in the FFP without having the resources to address community members concerns. One of the biggest concerns about the application of service-learning is the absence of addressing social justice issues that may be present in a community (Chupp \& Joseph, 2010; Coffey \& Lavery, 2015; Levkoe \& Stack-Cutler, 2018). If the service-learning initiative does not have a social justice component, then community engaged scholars should be mindful to research with communities that do not need that consideration. Being unaware and/or unequipped to help address social justice issues within a community, impedes on the success of the service-learning process.

Another concern that lies within the practice of service-learning is ensuring there is a mutually-benefiting collaborative relationship between community members and the community engaged scholars (Attee et al., 2011; Clifford, 2017; Davidson et al., 2010; Moore, 2014). Though the FFP was an engaging process that included community members ideas and inputs, community members ideas and inputs were structured around the preset goals of the FFP and not around their preferred community development initiative. The preset goals of the FFP provide a participatory framework that may benefit community members who understand and are able to apply the actions associated with implementing community development projects but may be harmful to community members who have not developed the capacity to sustain community development projects. Groark (2018) writes about community engaged scholars using 
engagement practices that are grounded in European theories that may include practices that may not be beneficially inclusive for all people. These practices can include the lack of decision making power that is shared with community members and the absence of a relational approach to balance power dynamics.

There is "pre-work" or a "pre-research" that needs to take place before the community engaged scholar decides to work with a marginalized community. This pre-work or pre-research consists of learning about and from community members to assist with selecting the most appropriate engagement approach that will produce a mutually beneficial experience for community engaged scholar and community members. Freire (2000) was assigned to teach farmers how to read and he did not start teaching the farmers by exposing them to the alphabet and its phonic sounds. Instead, he spends time with community members learning the words that were meaningful to them in order to guide his teaching (Crotty, 1998; Freire, 2000). Learning from community members through a relational approach to service-learning can equip community engaged scholars with knowledge that can assist with selecting a mutually beneficial transformative experience for the community engaged scholar and community members.

A transformative experience is a level of engagement between community members and community engaged scholars that delivers healing and liberation to marginalized people. Creswell (2014). A transformative approach ensures marginalized voices are heard and the community engaged scholar and community members relations are more than transactional, there transformative (Clayton, 2010; Enos and Morton, 2003). A transformative approach is rooted in relationship building to balance power dynamics between the community engaged scholar and community members. Clifford (2017) states the success of a service-learning initiative should be measured by the realness of the community engaged scholar and community members' 
relationship. A transformative relational approach to service-learning is how the community engaged scholar community members can become as Creswell (2014) states "a united voice for reform and change" (p.38).

Community engaged scholars can also utilize this time of relationship building to help community members understand the limitation that a community engaged scholar may face. Semester timelines, project end times, and the rotation of students are a few limitations some community scholars may face, and without community members having a proper understanding of these limitations; communities can develop expectations that community engaged scholars cannot keep. The relational practice of establishing mutual understandings between community members and community engaged scholars can create proper expectations between community members and community engaged scholars.

\section{Question 3: Recommendations}

The question in this section of the interviews focused on providing recommendations to community engaged scholar who choose to engage community members in service-learning projects.

\section{Relational}

Having a relational approach when engaging community members, was a recurring recommendation to universities from FFP participants. WAC members, WAC neighbors, Student and Stakeholders all spoke to the importance of getting to understand community members and establish relationships before starting a service-learning projects.

\section{Culture}

The importance of learning about the culture of community members, was another recommendation provided to community engaged scholars. Learning about community 
members' culture from their perspective, can provide an internal understanding to how community members view their self-efficacy and self-agency.

\section{Brokering}

Brokering was recommended to help alleviate some of the structural restraints that can exist amidst the community engaged scholars and community members. Brokering is the establishment of an individual or an organization that helps connect and support relationships between communities and the university (Levkoe, 2018).

\section{Implications}

Talking with community members to build trust and understanding creates a space for relationship building. Creating this kind of space can structure realistic goals and define project limitations between community engaged scholars and community members. Creating an environment that allows community members and community engaged scholars to learn one another's culture, and understand one another's limitations, builds space for relationships that are understanding and beneficial for community members and community engaged scholars. Community members are placed in an inferior position when their input is not included in the initial decisions about what is going to happen in their community. When community members input is not sought after, community members may hesitate to engage with the community engaged scholar. The absence of relationship building magnifies the absence of shared power. Power sharing must be activated between the community engaged scholar and community members to avoid community members feeling as if they are only part of a project.

Community members may feel like the rug was just pulled from underneath them when the community engaged scholar is no longer able to continue with support for community members. Community members may need additional assistance that supersedes the available 
resources of a community engaged scholar. Therefore, to accompany the universities in its efforts of assisting community members improve their community; universities can establish and/or partner with other institutions to create brokering establishment in the community. Brokering can accommodate universities and communities by fulfilling gaps in service and support. This gap in service and support can also be addressed through partnering with local social service institutions. Starting and maintaining a brokering initiative could supersede the resources a university has towards this initiative. However, through collaborative partnerships, universities and institutions can partner to create sustainable relationships within a community.

\section{Conclusion}

This study's findings suggest the necessity of using a relational approach when working with members of marginalized communities. The relational approach facilitates the exchange of knowledge and power-sharing between community members and community engaged scholars. It also facilitates the assessment of both the community's and the community engaged scholar's interests, capacities, limitations, and objectives. The findings alert participants if changes to the service mission and plan of action are necessary. Collaborative efforts to adjust the service mission and plan of action not only exemplify power-sharing between engaged community scholars and community members, but further promote collective agency among community members as they share responsibility for project focus, direction, and outcomes. Absent an intentional embrace to a relational approach, service learning projects may be susceptible to selfserving and/or institution-serving interests.

\section{Pre-Engagement Service Project Planning}

While the Fostering Fairmont Project (FFP) was a participatory process that exposed community members to technical knowledge and collaborative techniques to implement and 
sustain community development initiatives, it lacked awareness of community members' capacity, resources, and limitations that ended up compromising program sustainability. These limitations might have been revealed, addressed, and necessary adjustments made in a collaborative pre-engagement service project plan between community engaged scholars and community members. What this meant in the final analysis of the FFP was that only prerequisite objectives were met - that is, a participative process was facilitated, community members were engaged learners, and a community development plan was developed. The central most objectives — plan implementation and plan sustainability—were unmet.

\section{What Needs to Change?}

When objectives are not met, there's a tendency to look around for who's to blame. Is it the community? The students? The community engaged scholars? All of the above? White (2012) offers community engaged scholars a compelling analysis, ...the way our institutions [colleges and universities] operate often impede us from fully realizing the principles of the asset-based, peer-related, respectful, mutually beneficial, democratic engagement that we profess in our...[community engagement] mission statements...bottom line is this: Institutions don't care...People care...I believe the next great leap in the university-community engagement movement is going to be less about how we change communities or behave as individual professionals and students in communities, and more about how we fundamentally change the way out institutions operate—about figuring out how we temper the institutional forces that impede our civic sensibilities (pp 94-95). 
White's analysis points to structural forces within academia that influence community engaged scholars' practice. In the FFP the most obvious institutional force was time, perhaps the least obvious was productivity. In terms of time, although service-learning project practitioners and scholars consider a two-year long project a substantial time commitment, unmet objectives begged the question, "Given community realities, was two-years ever enough?" In terms of productivity, academics whether in physical science laboratories or communities live by the doctrine of publish or perish. While community engaged scholars overwhelmingly care about the people and communities they serve, they also care about their survival in the academy. The fact is whether a project like the FFP meets all of its objectives or not, community engaged scholars can still commoditize their experience in the community through the production of publications (like this dissertation), which may do nothing to increase their credibility in the community served, but may elevate their status in the academy.

\section{Lessons Learned}

My experience with the FFP has taught me three critical lessons that will enhance my future practice as a community engaged scholar: 1 . Passion without skills is like a hamster on a spinning wheel, 2. We have been playing checkers with chess players, and 3. Good intentions can be wrapped in inappropriate approaches.

The first lesson I learned is "passion without skills, is like a hamster on a spinning wheel”. This saying holds me accountable as a community engaged scholar to engage community members in mutual-benefitting initiatives, and it also holds community members accountable to voice their desires and capacities and to make sure that they are understood. This lesson taught me the importance of diligently doing the pre-engagement work of ensuring that my desired goals for working with community members equally benefits community members. 
Doing the pre-engagement work builds an understanding about the interest, capacities, limitations, and goals that exist between the community engaged scholar and community members so both parties can start and end their engagement in equitable positions. The goals of the FFP were to learn about community members' desires for their community, and then provide them with action plans to achieve them. Though the FFP was successful at keeping community members engaged for two years to complete the community development plans, the FFP was unsuccessful at fulfilling the true desires of community members. Upon entering the community, it was known that community members desired a community center to be built in their community, but the FFP was not structured to accommodate their initial desire. Community members participated for two years in the FFP with the belief that their participation in the FFP would somehow help them achieve their goal of building a community center even though the FFP had a focus of delivering community development action plans. Upon completion of the FFP, community members expressed to me numerous times that they knew they did not have the capacity to continue the initiatives started by the FFP, but they believed that they would receive support until they could take on the initiatives themselves. Community members were aware that the project would end in two years but did not believe the support would abruptly end after the two years were completed. They participated in the FFP for two years. Community members stated to me that they believed they would receive support after the FFP ended or they would not have participated in this process for two years.

I encourage community members to require individuals and institutions who desire to work in your community to take the time to understand your community. This can ensure that the community will receive the skillsets needed to match the passions of the community and achieve its goals. Paulo Freire (2000) stated that community engaged scholars "must take into 
account their [community members'] behavior, their view of the world, and their ethics" (p. 55). It is very important to understand a community prior to working in it.

The second lesson I learned is "We have been playing checkers with chess players". This lesson comes from my lived experience as a member of a marginalized community and a community engaged scholar. I was born and raised in marginalized communities so I have personal knowledge of the effects of being marginalized (only knowing how to play checkers), but through my growth of becoming a community engaged scholar, I learned that marginalization is systematically enforced by chess players (systematic oppressions). Growing up in marginalized environments breeds the belief that this marginalization is the way things are (Speight, 2007) and this belief can have a depleting effect on community members' self-agency and self-efficacy. Individuals who have been marginalized through systematic oppressions, and have seen their peers and ancestors oppressed, tend to believe they will not be successful in their efforts. But, knowledge is power! Providing marginalized community members with knowledge that is appropriate for their liberation, will provide a transformative experience leading towards healing and empowerment for community members (Creswell, 2014).

The final lesson I learned is framed in the following statement: "Good intentions can be wrapped in inappropriate approaches." Though the FFP had good intentions of bettering the community, its pre-structured approach was not a good fit for the community we worked with. This reiterates the importance of doing the "pre-work" of building an understanding to ensure than an equitable experience is created between community members and the community engaged scholar. Community engaged scholar must be willing to listen and learn from community members prior to engaging them. This will inform the community engaged scholar on how to engage community members and achieve the goal of a mutually-beneficial 
relationship. Learning from and about community members can expand the opportunities of cocreating knowledge to expand the learning in the halls of academia and to create new strategic synergies to dismantle the systems that oppress people. Freire (2000) states that for marginalized people to be liberated from systematic oppressions, they must be part of their own liberation process. This encourages me to always learn the perspectives and experiences of community members before I inject what I consider a beneficial factor into their lives. Freire (2000) was assigned to teach farmers how to read and he did not start teaching the farmers by exposing them to the alphabet and its phonic sounds. Instead, he spends time with community members learning the words that were meaningful to them in order to guide his teaching (Crotty, 1998; Freire, 2000). Learning from community members through a relational approach to service-learning can equip community engaged scholars with knowledge that can assist with selecting a mutually beneficial transformative experience for the community engaged scholar and community members.

\section{Implications of My Positionality}

\section{Community Entrance}

After deep reflection I felt it was important to share the significance of my positionality in the FFP. Throughout the FFP, my race, ethnicity, and lived experiences, were the keys for gaining entrance into the community, getting community members to participate for two years in the FFP, and gave personal meaning to my commitment in assisting community members with meeting their community goals that were not achieved through the FFP.

Prior to the FFP, I had a research goal of working with an African American community to implement and/or strengthen youth programming in their community. Youth programming can become a positive influencer for youth in their development, and can provide a safe guard from 
negative factors that exist in a youth's family and/or community. The establishment of positive development factors are crucially important in communities that have been marginalized, which commonly include those of African American people. I am aware of this concern because of my lived experiences of being raised in marginalized communities, and I have witnessed the dire consequences that are created when youth are raised in marginalized environments without the injection of positive factors. These dire consequences are the contributing factors to the external destruction that exist in marginalized communities (ex: crime, drugs, and poverty) and the internal destruction from the results of these factors on community members (ex: trauma, lack of self-efficacy and self-agency). This is why it is important to me to work with youth in marginalized communities because I know that the earlier positive factors are introduced to combat the structures of marginalization, the less damage is done to the community and community members.

Eight months before I had to decide upon a community to complete my dissertation research, I started to ask people I knew on campus if they knew of any African American communities that desired assistance with their youth programming. I asked this because I was unaware of any African American communities nearby where I had to temporary live in order to attend my Ph.D. program. It was important for me to find a community prior to the time I had to start my research because I knew time would be needed to build trust with community members. From my search, I received contact information for the board president of a non-profit organization that desired assistance with their youth programming. I spoke with the board president and was invited to attend their board meeting to learn how they could assist me by allowing me to develop a research project for my dissertation and how I could assist them by strengthen their youth programming. During the board meeting, we quickly learned that neither 
of us had the capacity to provide the assistance each other needed. This non-profit did not have the youth programming structure I needed to conduct my research, nor did I have the capacity to become the executive director of their non-profit organization, which was requested by board members.

Even though we could not meet each other desired goals without assistance, there was an instant desire between the board members and myself to find a way to assist one another. This desire stemmed from our shared identity as African Americans, and my intuitive ability to understand and relate to people who have been marginalized. I informed the board members, who were also community members, that I would seek the advice of my then chair to find how the board members and I could find support to help us work together. My then chair offer to assist the community members and I by bringing the FFP to their community. Though the FFP had a goal to develop community development plans and not a focus on developing and/or implementing youth programming, we, community members and myself, agreed to participate in the FFP with the belief that all of our different desired goals would be met.

The goals of the FFP shifted the youth programming focus that community members and my research interest shared, to a focus on developing and implementing community plans. Community members and I were convinced that participating in the FFP two-year process would position community members to implement and sustain their youth programming goals and provide me with the research I needed for my dissertation. Community members were convinced because they trusted me, and I was convinced because I trusted the FFP process. I then situated my research to evaluate the use of FFP chosen theories to work with community members.

My research interest took another shift midway through the FFP after I reflected on a comment made by a stakeholder who was involved with the FFP. He stated that he was 
impressed with community members' consistent engagement in the FFP because community members had a history of being apathetic. As I reflected on his comment, I wondered why the results of being marginalized is commonly viewed through the lens of apathy? I wondered why marginalized people are viewed as apathetic instead of needing healing from the traumas inflicted on them from marginalization? And though he commented on the change in community members' behavior, from being apathetic to engaged, he did not comment nor question what brought about the change in their behavior. What motivated apathetic people to become engaged? I will tell you what changed their behavior; the fact that they had meet someone in power (myself) who respected, understood, and was willing to help them meet their desired personal goals. I then made the decision to turn my research focus towards expanding the perceptions of individuals and institutions who desire to work with marginalized community members.

I began to realize that the disengagement and behaviors of people who have been marginalized are often framed as being apathetic. According to National Institute of Mental Health (2016), lack of interest, distrust, aggressive behaviors, and low personal agency are signs of trauma. These behaviors are commonly identified as apathy, without the questioning of why individuals possess such behaviors. This brought to my attention the need to call into question who and what factors shape the attitudes of community engaged scholars towards marginalized people, which also calls into question how community engaged scholars choose to engage marginalized community members.

\section{Community Engagement}

My shared identities with community members was foundational in maintaining engagement throughout the FFP. Being an African American woman who was raised in 
marginalized communities positioned me to share an unspoken understanding with community members about the importance of establishing trust and the importance of building relationships to create transformative change. I also knew in order to build trust with community members, I had to build relationships outside of the FFP process. I served on non-profit boards and provided substantial amounts of administrative work to help the organization strengthen its operational structure. I assisted with coordinating and reviving community events that once took place in their community. I attended church services, birthday parties, sporting events, and family celebrations. My presence in their community, outside of the FFP, created a trust between me and community members that encouraged their participation in the FFP. Community members trusted that I had their best interest at heart, and they trusted that I would continue to work with them to help them reach their community development plans.

\section{The Aftermath}

This trust that was built between me and the community members, and the unmet goals of the community after the conclusion of the FFP caused me to continue my commitment of assisting these community members with meeting their community development goals even after the FFP had ended. My research revealed that the FFP was successful in fulfilling its learning goals of the service-learning experiences but did not fulfilling its service goals of the servicelearning experience. After the FFP goals were achieved and the data for my research was collected I would have been justified to "discontinue" my work with the community, according to the University and contemporary scholarship. However, knowing that the community's needs were still unmet, this caused me to question my integrity, and caused me to stay committed to this community until the service part of the service-learning experience is completed. 


\section{Recommendations for Future Research}

A transformative experience is a level of engagement between community members and community engaged scholars that delivers healing and liberation to marginalized people (Creswell, 2014). A transformative approach ensures marginalized voices are heard and the community engaged scholar and community members relations are more than transactional, there transformative (Clayton, 2010; Enos and Morton, 2003). Recommendations for future research based on my findings of this study include: (1) learn from and about community members before entering into their community, (2) use a relational approach to service-learning and (3) establish brokering support networks to support collaborative relational initiatives with community members.

Future research should explore pre-engagement service learning initiatives and their subsequent outcomes, as well as their implications in terms of time. One question to explore might be, "Do the outcomes of pre-engagement planning result in more efficient use of time or do they increase time required to successfully execute projects?" When central objectives are unmet in service-learning projects are there feasible ways for institutions to continue serving marginalized communities? 


\section{REFERENCES}

Ahmed, S. M, \& Palermo, A.S. (2010). Community engagement in research: frameworks for education and peer review. American Journal of Public Health 100(8), 1380-1387.

All Poetry. (n.d.). The rose that grew from concrete. Retrieved from https://allpoetry.com/TheRose-That-Grew-From-Concrete

Attree, P., French, B., Milton, B., Povall, S., Whitehead, M., \& Popay, J. (2011). The experience of community engagement for individuals: A rapid review of evidence. Health \& Social Care in the Community, 19(3), 250-260.

American Psychological Association. (2018). Service learning in psychology. Retrieved from https://www.apa.org/education/undergrad/service-learning.aspx

Arnstein, S. R. (1969). A ladder of citizen participation. Journal of the American Institute of Planners, 35(4), 216-224.

Bandura, A. (1998). Personal and collective efficacy in human adaptation and change. Advances in Psychological Science, 1, 51-71.

Baxter, P., \& Jack, S. (2008). Qualitative case study methodology: Study design and implementation for novice researchers. The Qualitative Report, 13(4), 544-559.

Beckman, M., Brandenberger, J. W., \& Shappell, A. S. (2009). Graduate students and community-based learning. Academic Exchange Quarterly, 13(3), 45-50.

Bhattacharyya, J. (1995). Solidarity and agency: Rethinking community development. Human Organization 54(1), 60-69.

Blouin, D. D., \& Perry, E. M. (2009). Whom does service learning really serve? Community based organizations' perspectives on service learning. Teaching Sociology, 37(2), 120135. doi:10.1177/0092055X0903700201 
Bortolin, K. (2011). Serving ourselves: How the discourse on community engagement privileges the university over the community. Michigan Journal of Community Service Learning, 18(1), 49-58.

Bringle, R. G., Clayton, P. H., \& Hatcher, J. A. (2013). Research on service learning. In Clayton, P. H., Bringle, R. G., \& Hatcher, J. A. (Eds.), Research on Service Learning: Conceptual Frameworks and Assessment (pp. 335-357). Sterling, VA: Stylus Publishing, LLC.

Brinkmann, S. \& Kvale, S. (2015). Interviews: Learning the Craft of Qualitative Research Interviewing. Thousand Oaks, CA: Sage Publications.

Bryson, J. M., Quick, K.S., Slotterback, C.S., \& Crosby, B.C. (2013). Designing public participation processes. Public Administration Review, 73(1) 23-34.

Bruce, J. (2013). Service learning as a pedagogy of interruption. International Journal of Development Education and Global Learning, 5(1), 33-47.

Bruce, J. (2015). On racism and prejudice: Exploring postcritical possibilities for servicelearning within physical education teacher education. Asia-Pacific Journal of Health, Sport and Physical Education, 6(3): 233-244. doi:10.1080/18377122.201 5.1092720

Bruce, J. (2018). Postcritical service-learning: Interruptions to ethnocentric and salvationist discourses. The Wiley International Handbook of Service-Learning for Social Justice, 203-223.

Butin, D. W. (2011). Service-learning as an intellectual movement. In T. Stewart \& N. Webster (Eds.), Problematizing Service Learning: Critical Reflections for Development and Action (pp. 19-35). Charlotte, NC: Information Age.

Campus Compact. (2018). History. Retrieved from https://compact.org/who-we-are/history/ 
Centers for Disease Control and Prevention. (2016). About adverse childhood experiences. Retrieved from https://www.cdc.gov/violenceprevention/acestudy/about_ace.html

Cerbone, D. R. (2014). Understanding phenomenology. Retrieved from https://ebookcentral.proquest.com

Chambers, D., \& Lavery, S. (2012). Service-learning: A valuable component of pre-service teacher education. Australian Journal of Teacher Education, 17(4), 128-137.

Checkoway, B. (1997). Reinventing the research university for public service. Journal of Planning Literature, 11(3), 307-319.

Chupp, M. G., \& Joseph, M. L. (2010). Getting the most out of service learning: Maximizing student, university and community impact. Journal of Community Practice, 18(2-3), 190212.

Clayton, P., Bringle, R., Senor, B., Huq, J., \& Morrison, M. (2010). Differentiating and assessing relationships in service-learning and civic engagement: Exploitative, transactional, or transformational. Michigan Journal of Community Service Learning, 16(2), 5-21.

Clayton, P.H., Bringle, R.G., \& Hatcher, J.A. (2013). Research on Service Learning: Conceptual Frameworks and Assessment. Sterling, VA: Stylus.

Clifford, J. (2017). Talking about service-learning: Product or process? Reciprocity or solidarity? Journal of Higher Education Outreach and Engagement, 21(4), 1-13.

Coffey, A., \& Lavery, S. (2015). Service-learning: A valuable means of preparing pre-service teachers for a teaching practicum. Australian Journal of Teacher Education, 40(7), 86101. 
Community Tool Box. (2018). Section 7. Involving people most affected by the problem. Retrieved from https://ctb.ku.edu/en/table-of-contents/participation/encouraginginvolvement/involve-those-affected/main

Cook, N. (2008). Shifting the focus of development: turning "helping" into self-reflexive learning. Critical Literacy: Theories and Practices, 2(1), 16-26.

Corbie-Smith, G., Thomas, S. B, \& St. George, D.M. (2002). Distrust, race, and research. Archives of Internal Medicine, 162(21), 2458-2463.

Corporation for National and Community Service. (n.d.). Service-learning resources. Retrieved from https://www.nationalservice.gov/resources/service-learning

Corporation for National and Community Service. (n.d.). About CNCS. Retrieved from https://www.nationalservice.gov/about

Covey, S. R. (1992). The Seven Habits of Highly Effective People. London: Simon and Schuster.

Creswell, J. (2013). Qualitative Inquiry and Research Design: Choosing Among Five Approaches. Thousand Oaks, CA: Sage Publications, Inc.

Creswell, J. (2014). Research Design: Qualitative, Quantitative, and Mixed Methods Approaches. 4th edition. Thousand Oaks, CA: Sage Publications, Inc.

Crotty, M. (1998). The Foundations of Social Science Research. New South Wales: Allen \& Unwin.

Cruz, N. I., \& Giles, D. E. (2000). Where's the community in service-learning research. Michigan Journal of Community Service Learning, 7(1), 28-34.

Curwood, S. E., Munger, F., Mitchell, T., Mackeigan, M., \& Farrar, A. (2011). Building effective community- university partnerships: Are universities truly ready? Michigan Journal of Community Service Learning, 17(2), 15-26. 
Dale, A. \& Sparkes, J. (2011). The 'agency' of sustainable community development. Community Development Journal 46(4), 476-492.

Davis, K. L., Kliewer, B. W., \& Nicolaides, A. (2017). Power and reciprocity in partnerships: Deliberative civic engagement and transformative learning in community-engaged scholarship. Journal of Higher Education Outreach and Engagement, 21(1), 30-54.

Davidson, W. S., Peterson, J., Hankins, S., \& Winslow, M. (2010). Engaged research in a university setting: Results and reflections on three decades of a partnership to improve juvenile justice. Journal of Higher Education Outreach and Engagement, 14(3), 49-67.

Dostilio, L., Brackmann, S., Edwards, K., Harrison, B., Kliewer, B., \& Clayton, P. (2012). Reciprocity: saying what we mean and meaning what we say. Michigan Journal of Community Service Learning, 19(1), 17-32.

Darling-Hammond, L. (2015). Social and emotional learning. In Durlak, J. A., Domitrovich, C.

E., Weissberg, R.P., \& Gullotta, T.P, Handbook of Social and Emotional Learning: Research and Practice, (xi-xiii). New York: Guilford Publications.

Edwards, B., Mooney, L., \& Heald, C. (2001). Who is being served? The impact of student volunteering on local community organizations. Nonprofit and Voluntary Sector Quarterly, 30(3), 444-461.

Ellsworth, E. (1989). Why doesn't this feel empowering? Working through the repressive myths of critical pedagogy. Harvard Education Review, 59(3), 297-325.

Emery, M., \& Flora, C. (2006). Spiraling-up: Mapping community transformation with the community capitals framework. Community Development, 37(1), 19-35. 
Enos, S., \& Morton, K. (2003). Developing a theory and practice of campus community partnerships. In B. Jacoby \& Associates (Eds.), Building Partnerships for Servicelearning (pp. 20-41). San Francisco, CA: Jossey-Bass.

Felten, P., \& Clayton, P. H. (2011). Service-learning. New Directions for Teaching and Learning, 2011(128), 75-84.

Figure 1. Just because you are right. (n.d). Retrieved from https://www.google.com/search?q=just+because+you+are+right, + does + not + mean $+\mathrm{i}+$ am +wrong\&rlz=1C1SQJL_enUS781US781\&source=lnms\&tbm=isch\&sa=X\&ved=0ahUK Ewi_8_bc0sDeAhUEVK0KHdx1ApgQ_AUIEygB\&biw=1600\&bih=748\#imgrc=AN91k K8Fu_xgtM:

Flecky, K., \& Gitlow, L. (2011) Service-learning in occupational therapy: Philosophy and practice. Sudbury, MA: Jones and Bartlett Publishers.

Fostering Fairmont Project. (2015). WAC community profile report. Who published this? Public Administration?

Freire, P. (2000). Pedagogy of the Oppressed (30th anniversary ed.). New York: Continuum.

Fulton, W. K. (2012). Community learning: Broadening the base for collaborative action. National Civic Review 101(3), 12-22.

Furco, A. (1996). Service-learning: A balanced approach to experiential education. Retrieved from https://digitalcommons.unomaha.edu/cgi/viewcontent.cgi?article=1104\&context=slceslge $\mathrm{n}$

Furco, A., \& Root, S. (2010). Research demonstrates the value of service learning. Phi Delta Kappan, 91(5), 16-20. 
Giles, D.E., \& Eyler, J. (1994). The theoretical roots of service-learning in John Dewey: Toward a theory of service-learning. Michigan Journal of Community Service Learning, 1(1), 7785.

Glazier, J., Charpentier, A., \& Boone, H. (2011). A transformational journey: A framework for pre-service teachers to learn about diversity through service-learning. Journal of Civic Commitment, 17(1), 1-15.

Groark, C. J., \& McCall, R. B. (2018). Lessons Learned From 30 Years of a UniversityCommunity Engagement Center. Journal of Higher Education Outreach and Engagement, 22(2), 7-30.

Groenewald, T. (2004). A phenomenological research design illustrated. International Journal of Qualitative Methods, 3(1), 42-55. https://doi.org/10.1177/160940690400300104

Hallberg, L. (2013). Quality criteria and generalization of results from qualitative studies. International Journal of Qualitative Studies on Health and Well-Being, 8, 1. doi:10.3402/qhw.v8i0.20647

Heldman, C. (2011). Solidarity, not charity: Issues of privilege in service learning. In C. Cress, D. Donahue, \& Associates (Eds.), Democratic Dilemmas of Teaching Service-learning: Curricular Strategies for Success (pp. 33-39). Sterling, VA: Stylus.

Hunt, J. B., Bonham, C., \& Jones, L. (2011). Understanding the goals of service learning and community-based medical education: a systematic review. Academic Medicine, 86(2), 246-251.

Hycner, R. H. (1985). Some guidelines for the phenomenological analysis of interview data Human Studies 8: 279-303 
Jackson, J. S., Caldwell, C. H., \& Sellers, S. L. (2012). Conceptual and methodological challenges in studies of black populations. In Jackson, J. S., Caldwell, C. H., \& Sellers, S. L. Researching Black Communities: A Methodological Guide (3-30). Ann Arbor, MI: University of Michigan Press.

Jacoby, B. (1996). Service-learning in Higher Education: Concepts and Practice. San Francisco, CA: Jossey-Bass.

Jacoby, B. (2003). Fundamentals of service-learning partnerships. In Jacoby, B. (Ed.), Building Partnerships for Service-learning. (pp. 1-19). San Francisco, CA: Jossey-Bass.

Jacoby, B. (2015). Service-learning essentials: questions, answers, and lessons learned. Retrieved from https://ebookcentral.proquest.com

Jacob, W.J., Sutin, S.E., Weidman, J.C., \& Yeager, J.L. (2015). Community engagement in higher education. In Clayton, P. H., Bringle, R. G., \& Hatcher, J. A. (Eds.), Research on Service Learning: Conceptual Frameworks and Assessment (pp. 1-28). Sterling VA: Stylus Publishing, LLC.

Jenkins, A., \& Sheehey, P. (2011). A checklist for implementing service-learning in higher education. Journal of Community Engagement \& Scholarship, 4(2), 52-60.

Jensen, E. (2016). Poor Students, Rich Teaching: Mindsets for Change. Bloomington, IN: Solution Tree Press.

Johnson, A. G. (2006). Privilege, Power, and Difference. New York, NY: McGraw-Hill Joseph, J. E. (2006). Language and Politics. Retrieved from https://ebookcentral.proquest.com Karlsson, C. (2016). Assessment of Career Development in Community-Based Learning: A Case Study among American University Students. The International Undergraduate Journal for Service-Learning, Leadership, and Social Change, 6(1), 22-35. 
Kretzmann, J. P., McKnight, J. (1993). Building Communities from the Inside Out: A Path Toward Finding and Mobilizing a Community's Assets. Evanston, IL: The Asset-Based Community Development Institute, Institute for Policy Research, Northwestern University.

Kolb, D. A. (2014). Experiential learning: Experience as the Source of Learning and Development. Upper Saddle River, NJ: Pearson Education, Inc.

Kvale, S., \& Brinkmann, S. (2009). Interviews: Learning the Craft of Qualitative Research. California, US: Sage Publications, Inc.

Latta, M., Kruger, T. M., Payne, L., Weaver, L., \& Van Sickle, J. L. (2018). Approaching critical service-learning: A model for reflection on positionality and possibility. Journal of Higher Education Outreach and Engagement, 22(2), 31-56.

Lavrakas, P. J. (2008). Encyclopedia of Survey Research Methods. Thousand Oaks, CA: Sage Publications, Inc. doi: 10.4135/9781412963947

Lazaratou, H. (2017). "Interpersonal trauma: psychodynamic psychotherapy and neurobiology." European Journal of Psychotraumatology, 8(4 ), 2-3. doi:10.1080/20008198.2017.1351202

Lester, S. W. (2015). Melding service learning and leadership skills development: Keys to effective course design. Journal of Experiential Education, 38, 280-295. doi:10.1177/1053825915576196

Levkoe, C., Brail, S., \& Daniere, A. (2014). Engaged pedagogy and transformative learning in graduate education: A service-learning case study. Canadian Journal of Higher Education, 44(3), 68-85. 
Levkoe, C. Z., \& Stack-Cutler, H. (2018). Brokering Community-campus Partnerships: An Analytical Framework. Gateways: International Journal of Community Research and Engagement, 11(1), 18-36.

Levkoe, C. Z., Friendly, A., \& Daniere, A. (2018). Community Service-Learning in Graduate Planning Education. Journal of Planning Education and Research, 0739456X18754318.

Lindquist-Grantz, R., \& Vaughn, L. M. (2016). The journey and destination need to be intentional: Perceptions of success in community-academic research partnerships. Gateways: International Journal of Community Research and Engagement, 9(1), 1-21.

Lovearth Network. (n.d.). The purpose of education. Retrieved from https://www.drmartinlutherkingjr.com/thepurposeofeducation.htm

Lu, Y. \& Lambright, K.T. (2010). Looking beyond the undergraduate classroom: Factors service learning's effectiveness at improving graduate students' professional skills. College Teaching, 58, 118-126.

Maxwell, J.A. (2013). Qualitative Research Design: An Interactive Approach. Thousand Oaks, CA: Sage Publications, Inc.

McLaughlin, E. (2010). The "real-world" experience: Students' perspectives on service-learning projects. American Journal of Business Education, 3(7), 109-118.

McReyolds, M.R. (2015). Developing practitioner-scholars for the future of community engagement. In Delano-Oriaran, B., Penick-Parks, M. W., \& Fondrie, S. (Eds.). The Sage Sourcebook of Service-learning and Civic Engagement. Retrieved from https://ebookcentral.proquest.com

Merriam-Webster. (2018). Marginalize. Retrieved from https://www.merriamwebster.com/dictionary/marginalize 
Merriam-Webster. (2018). Trauma. Retrieved from https://www.merriamwebster.com/dictionary/trauma

Michigan State University. (n.d.). Center for service-learning and civic engagement. Retrieved from https://servicelearning.msu.edu/

Miles, M. B., Huberman, A. M., \& Saldana, J. (2013). Qualitative Data Analysis. Thousand Oaks CA: Sage Publications, Inc

Mitchell, T. D. (2008). Traditional vs. critical service-learning: Engaging the literature to differentiate two models. Michigan Journal of Community Service Learning, 14(2), 5065.

Mitchell, T. D., Donahue, D. M., \& Young-Law, C. (2012). Service learning as a pedagogy of whiteness. Equity \& Excellence in Education, 45(4), 612-629.

Moore, T. L. (2014). Community-university Engagement: A Process for Building Democratic Communities. Retrieved from https://ebookcentral.proquest.com

Moustakas, C. (1994). Phenomenological Research Methods. Thousand Oaks, Calif.: Sage. National Education Association. (2018). Service learning resources. Retrieved from http://www.nea.org/tools/50426.htm

National Institute of Mental Health. (2016). Post-traumatic stress disorder. Retrieved from https://www.nimh.nih.gov/health/topics/post-traumatic-stress-disorder-ptsd/index.shtml

Noyes, E., Darby, A., \& Leupold, C. (2015). Students' emotions in academic service-learning. Journal of Higher Education Outreach and Engagement, 19(4), 63-84.

O'Connor, K., Lynch, K., \& Owen, D. (2011). Student-community engagement and the development of graduate attributes. Education \& Training, 53(2-3), 100-115. 
Paris, D., \& Winn, M.T. (2014). Humanizing research: Decolonizing Qualitative Inquiry with Youth and Communities. Thousand Oaks, CA: SAGE Publications.

Phelps, A. L. (2012). Stepping from service-learning to SERVICE-LEARNING pedagogy. Journal of Statistics Education, 20(3), 1-22.

Porter, L., Slade, C., Butt, A., Rosier, J., Perkins, T., Crookes, L., \& Barry, J. (2015). Partnerships of learning for planning education Who is learning what from whom? The beautiful messiness of learning partnerships/Experiential learning partnerships in Australian and New Zealand higher education planning programmes. Planning Theory \& Practice, 16(3), 409-434. doi:10.1080/14649357.2015.1060688

Reeb, R. N., \& Folger, S. F. (2013). Community outcomes of service learning. In Clayton, P. H., Bringle, R. G., \& Hatcher, J. A. (Eds.), Research on Service Learning: Conceptual Frameworks and Assessment (pp. 389-418). Sterling, VA: Stylus Publishing, LLC.

Schmidt, A., \& Robby, M. A. (2002). What's the Value of Service-Learning to the Community? Michigan Journal of Community Service Learning, 9(1). ttp://hdl.handle.net/2027/spo.3239521.0009.103

Schwartz, K., Weaver, L., Pei, N., \& Miller, A. (2016). Community-campus partnerships, collective impact, and poverty reduction. Community Development, 47(2), 167-180. doi:10.1080/15575330.2015.1128955

Soska, T. M. (2015). University and communities in partnership. In W. J. Jacobs, S. E. Sutin, J. C. Weidman, \& J. L. Yeager (Eds.), Community engagement in higher education: Policy reforms and practice (pp. 105-126). Rotterdam, Netherlands: Sense. doi:10.1007/978-94$6300-007-9$ 
Speight, S. (2007). Internalized racism: One more piece of the puzzle. Counseling Psychologist, 35(1), 126-134. doi/pdf/10.1177/0011000006295119

Stanton, T. K. (2008). New times demand new scholarship: Opportunities and challenges for civic engagement at research universities. Education, Citizenship and Social Justice, 3(1), $19-42$.

Steinberg, K.S., Bringle, R.G., \& McGuire, L. E. (2013). Attributes of high-quality research on service learning. In Clayton, P. H., Bringle, R. G., \& Hatcher, J. A. (Eds.), Research on Service Learning: Conceptual Frameworks and Assessment (pp. 359-385). Sterling VA: Stylus Publishing, LLC.

Swarr, A.L., \& Nagar, R. (2010.) Critical Transnational Feminist Praxis. Albany, New York: State University of New York Press.

The Center for Treatment of Anxiety and Mood Disorder. (2017). What Is Trauma. Retrieved from http:/centerforanxietydisorders.com/what-is-trauma/

Thye, S. \& Kalkhoff, W. (2014). Theoretical perspectives on power and resource inequality. In McLeod, J., Lawler, E., \& Schwalbe, M. (Eds.), Handbook of the Social Psychology of Inequality (pp. 27-47). New York, London, Dordrecht and Heidelberg: Springer.

Todd, S. (2003). Learning from the Other: Levinas, Psychoanalysis, and Ethical Possibilities in Education. Retrieved from https://ebookcentral.proquest.com

Tryon, E., Slaughter, M., \& Ross, J. A. (2015). The need for a paradigm shift in communitybased learning partnerships to evaluate community impacts. In Delano-Oriaran, B., Penick-Parks, M. W., \& Fondrie, S. (Eds.). The Sage Sourcebook of Service-learning and Civic Engagement. Retrieved from https://ebookcentral.proquest.com 
West Virginia University. (2008). WVU named to national community service honor roll. Retrieved from http://wvutoday-archive.wvu.edu/n/2008/05/08/6792.html

West Virginia University. (2013). Center for Civic Engagement changes name to the WVU Center for Service and Learning. Retrieved from http://wvutodayarchive.wvu.edu/n/2013/07/17/center-for-civic-engagement-changes-name-to-the-wvucenter-for-service-learning.html

West Virginia University Center for Service Learning. (2018). Encouraging a campus of culture of service. Retrieved from https://service.wvu.edu/West Virginia University Center for Service Learning. (2018). About us. Retrieved from https://service.wvu.edu/about

White, B. P. (2012). Assets and Community Strengths: Our Struggle to Truly Believe in Them. In Hamerlinck, J., \& Plaut J. (Eds.). Asset-Based Community Engagement in Higher Education. Los Angeles, California: SAGE.

WV Extension Service. (2018). Community Development. Retrieved from https://extension.wvu.edu./community-business-safety/community-development Yin, R. K. (2014). Case Study Research: Design and Methods $5^{\text {th }}$ ed. Thousand Oaks, CA: SAGE Publications. 


\section{APPENDIX A - Interview Protocol for WAC Members}

\section{Fostering Fairmont Project Interview Protocol for WAC Members}

Handout to give to interviewees:

- Consent form

Interview Response Sheet

Interviewee's code name:

Date: Location of Interview:

Time started:

Time ended:

Notes to augment digital recording:

\section{Script}

Hi thoughts and experiences about the Fostering Fairmont Project. Before we start, can you look over and sign the Consent for Participation in Interview Research form (I will also provide an option to read the consent form to interviewee if they desire). This form explains why I have asked you to participate in this interview, and why I am conducting interviews. (I will hand interviewee a copy of the consent form or proceed to read the form).

Do you have any questions? Can you please sign this copy and give it back to me so I can have record that you understand the purpose of this interview and you are willing to participate. Ok, let's get started. 


\section{Background Questions}

1. So how long have you lived in (state name of neighborhood) neighborhood?

a. If no, what is your connection to the Westside neighborhoods

2. What other community organizations are you currently involved with? (ex: Elks, Masons, NAACP, WAC)

a. How long have you been involved in community organizations?

3. What, if any, churches are you an active member of?

a. What leadership or support roles do you hold in your church?

\section{Purpose Questions}

4. What is your understanding of the Fostering Fairmont Project's purpose?

5. Before this, what efforts have you been involved with a university, that focused on getting community members involved in making their community a better place to live?

\section{Process Questions}

6. I see that you attended the community conversation meeting where community members were asked to share their thoughts about the past, present, and future of their community. What stood out to you in that meeting? 
7. Based on what you saw and experienced at these meetings what opportunities were available for community members to share their ideas and ask questions?

8. Tell me about a specific experience that made you feel like a valued participant in this project?

9. Tell me about any experiences that made you not feel like a valued participant?

10. Tell me about a specific experience you had in this project that made you feel empowered or added to your skill set?

11. Tell me about any experiences that did not feel empowering.

12. Ok, so now I would like to ask what was your impression of the following people that facilitated this project, starting with Dr. Stout?
a. Any other professors
b. Shanequa
c. The Students
d. Community members
e. Is there anything about anyone that you'd like to mention more specifically?

13. When trying to get buy in from other community members, what barriers did you experience? 
14. What is your understanding of the Westside Action Coalition, or WAC?

15. What types of coalitions have you been involved in?

16. (Review the List of WAC achievements with interviewee and give them a copy to keep) Here is a list of WAC achievements, do you believe community members have the capacity to sustain these projects?

17. How do you recommend getting neighbors involved with the WAC and community project?

18. What do you believe is the best method of getting information out to community members?

\section{Outcomes Questions}

19. What suggestions do you have for universities that desire to come into communities and work with community members?

\section{Closing}

20. Is there anything I didn't cover that you would like to add?

Thank you so much for your time and sharing your thoughts. I greatly appreciate it. Thanks again! 


\title{
APPENDIX B - Interview Protocol for Westside Neighbors
}

\author{
Fostering Fairmont Project \\ Interview Protocol for Westside Neighbors
}

Handout to give to interviewees:

- Consent form

Interview Response Sheet

Interviewee's code name:

Date:

Location of Interview:

Time started:

Time ended:

Notes to augment digital recording:

\section{Script}

Hi ! Thanks for agreeing to have a conversation with me to share your thoughts and experiences about the Fostering Fairmont Project. Before we start, can you look over and sign the Consent for Participation in Interview Research form (I will also provide an option to read the consent form to interviewee if they desire). This form explains why I have asked you to participate in this interview, and why I am conducting interviews. (I will hand interviewee a copy of the consent form or proceed to read the form).

Do you have any questions? Can you please sign this copy and give it back to me so I can have record that you understand the purpose of this interview and you are willing to participate.

Ok, let's get started.

\section{Background Questions}

1. So how long have you lived in (state name of neighborhood) neighborhood? 
2. What other community organizations are you currently involved with? (ex: Elks, Masons, NAACP, WAC)

a. How long have you been involved in community organizations?

3. What, if any, churches are you an active member of?

a. What leadership or support roles do you hold in your church?

\section{Purpose Questions}

4. What is your understanding of the Fostering Fairmont Project's purpose?

5. Before this, what efforts have you been involved with a university, that focused on getting community members involved in making their community a better place to live?

\section{Process Questions}

6. I see that you attended the community conversation meeting where community members were asked to share their thoughts about the past, present, and future of their community. What stood out to you in that meeting?

7. Ok, so now I would like to ask what was your impression of the following people that facilitated this project. Starting with Dr. Stout?
a. Any other professors?
b. Shanequa
c. The Students
d. Community members 
e. Is there anything about anyone that you'd like to mention more specifically?

8. What is your understanding of the Westside Action Coalition, or WAC?

9. What types of coalitions have you been involved in?

10. What do you believe is the best method of getting information out to community members?

\section{Outcomes Questions}

11. What suggestions do you have for universities that desire to come into communities and work with community members?

\section{Closing}

12. Is there anything I didn't cover that you would like to add?

Thank you so much for your time and sharing your thoughts. I greatly appreciate it. Thanks again! 


\title{
APPENDIX C - Consent for Participation in Interview Research
}

\author{
Fostering Fairmont Project
}

$\mathrm{I}$, , have volunteer to participate in this interview with Doctoral Student Shanequa Smith from West Virginia University. I understand the following:

That the purpose of this study is;

- To gain an understanding through the perspectives and experiences of community members, that were involved with the Fostering Fairmont Project that took place in Fairmont within the Westside neighborhoods from August 2015 to May 2017.

- To gather recommendations for future community initiative involvement.

My participation in this interview is voluntary and I may discontinue my participation at any time.

This interview will be recorded to ensure accuracy of the facts stated and to allow Shanequa to focus on the interview instead of taking notes.

Any information I share will not disclose my identity.

I have read and understand the explanation provided to me. I have had all my questions answered to my satisfaction, and I voluntarily agree to participate in this study.

For further information in regards to your participation please contact:

Shanequa Smith

Phone: 304-590-3713

Email:sqsmith@mix.wvu.edu

Participant's Signature

Date

Shanequa Smith

Date 


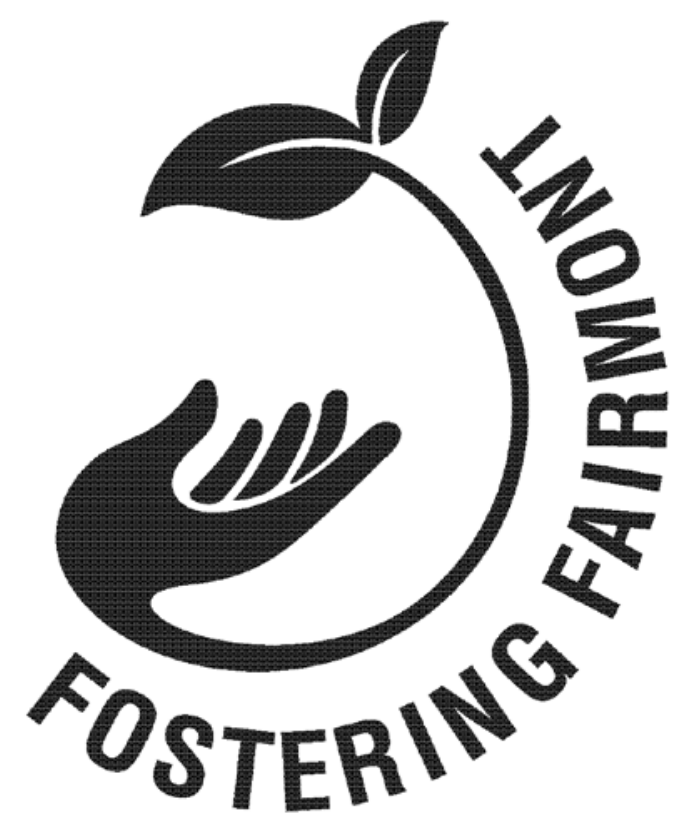

\section{Public Engagement Plan}

\section{for the Westside Action Coalition}




\section{Project Background and Description}

Fairmont, WV is a city operating under a council-manager form of government with professionalized departments that include planning functions focused on a variety of community and economic development purposes. However, the City recognizes the need for communitybased partners in these efforts and wishes to foster their development through grassroots mobilizing efforts. Therefore, in February 2015, the City of Fairmont sought the assistance of Associate Professor Margaret Stout from West Virginia University’s Master of Public Administration (MPA) program and its Area of Emphasis in Local Governance and Community Development (LGCD). Through faculty and student outreach, applied research, and service learning - the Fostering Fairmont Project—-this WVU team hopes to foment community action.

Ideally, the neighborhood chosen to host this initiative would be about two square miles in area, have self-identified boundaries that are commonly recognized, and include at least one public park or other community facility. The Fostering Fairmont project sought out a self-organizing group of community members who share a passion for revitalization and demonstrate sufficient social capital to commit to a two-year schedule of activities that demand community investment of time, effort, and perseverance. The group that responded to this invitation is now called the Westside Action Coalition, which was established by community members affiliated with the MAC (Fairmont Community Youth Development Center), the Dunbar School Foundation, and the Marion County NAACP. These organizations all serve the Fairmont neighborhoods of Jackson Addition, Maple Avenue, Sterling Heights, Shadyside, and parts of Bellview.

An agreement was made in May 2015 to assist the Westside Action Coalition during the academic years 2015-2016 and 2016-2017. Over the course of four semesters, the curriculumdriven and faculty-led service learning and action research activities complete baseline research and capacity building, mobilize and organize residents, facilitate visioning and planning, and support community development project implementation. These activities are designed as a framework for interdisciplinary curricular partnerships across WVU, including:

Graphic Design, Public History, Landscape Architecture, Public Health, Extension Service (Community Resources and Economic Development), Land Use and Sustainable Development Law Clinic, and the Brickstreet Center for Innovation and Entrepreneurship. External partners include the Northern West Virginia Brownfields Assistance Center and the West Virginia Community Development Hub. The WVU team is supported by Ms. Shanequa Smith, who is studying the Fostering Fairmont project for her doctoral dissertation in Human and Community Development. In her action research activities, she is acting as a "cultural consultant" to identify barriers to effective community engagement with this historically African American community.

Funding for the direct costs involved with the project were obtained from a combination of inkind donations procured by the Westside Action Coalition and WVU team. The basic schedule of activities is shown in Table 1. 
Table 1: Schedule of Activities in Four Phases

\begin{tabular}{|c|c|}
\hline $\begin{array}{l}\text { Learning } \\
\text { Fall } 2015\end{array}$ & $\begin{array}{l}\text { - Develop a Community Profile of baseline neighborhood } \\
\text { capitals to be used in strategic planning (secondary data). } \\
\text { - Complete a Community Survey to understand } \\
\text { neighborhood opinions about collaborative governance. } \\
\text { - Build community leadership capacity through a Local } \\
\text { Governance Workshop. }\end{array}$ \\
\hline $\begin{array}{l}\text { Mobilizing and Dialogue } \\
\text { Spring } 2016\end{array}$ & $\begin{array}{l}\text { - Develop a Public Engagement Plan for mobilizing the } \\
\text { community to engage in community events, planning, and } \\
\text { development projects. } \\
\text { - Build community leadership capacity through workshops } \\
\text { on Community Development, Building Social Capital, and } \\
\text { Public Engagement. } \\
\text { - Host public dialogue sessions (Community Conversations) } \\
\text { to develop shared understandings of community issues. }\end{array}$ \\
\hline $\begin{array}{l}\text { Planning and Deliberation } \\
\text { Fall } 2016\end{array}$ & $\begin{array}{l}\text { - Complete primary data collection on neighborhood capitals } \\
\text { to be used in strategic planning. } \\
\text { Facilitate participatory planning sessions to establish a } \\
\text { shared vision and produce a Neighborhood Plan, including } \\
\text { goals, objectives, and action strategies for improving } \\
\text { quality of life. }\end{array}$ \\
\hline $\begin{array}{l}\text { Action! } \\
\text { Spring } 2017\end{array}$ & $\begin{array}{l}\text { - Select three or more action strategies and provide project } \\
\text { development and implementation support. }\end{array}$ \\
\hline
\end{tabular}

The schedule of activities and deliverables, including the community's responsibilities, are outlined below in phases that follow four academic semesters, 2015-2017. All activities share a philosophy of empowered collaboration in support of the three pillars of sustainability: people, place, and profit. Our motto is "working with, not for the community” to build everyone's ability to get things done-both student learning and what we call community capacity.

\section{Phase 1: Learning (Fall 2015)}

In the first phase, we learn about the community and the community learns from us. Community leaders are expected to help form a stakeholder team, actively engage in stakeholder meetings and workshops, support research to gather baseline data for a Community Profile, and help conduct a community survey based on the National Civic League's Civic Index. The latter two activities produce reports for the neighborhood to use in community development activities, including leadership training and organizational development.

The first step is to develop an understanding of the community and economic development process and how we will move through the steps together over the course of two years. To build capacity to engage in that process, we build familiarity with collaborative governance. The term "governance" refers to the complex nature of what happens at the local level of government. Successful cities work closely with neighborhood associations, citizen boards and commissions, business associations, civic groups, nonprofit organizations, school districts, and county and state 
agencies, often with support from federal programs. Therefore, community leaders benefit from initial training on the institutions, powers, and basic operations of local government within its political and economic context, and how to tap into these resources.

\section{Phase 2: Mobilizing and Organizing (Spring 2016)}

Once a core stakeholder group is established, they are supported in mobilizing and organizing other community members, including neighbors and stakeholders in and beyond the neighborhood. The learning process continues with workshops on the importance of active participation in governance processes and the specifics on how to engage neighbors and stakeholders in community building efforts. The group receives a Public Engagement Plan for the neighborhood revitalizing project that provides a model for future engagement activities completed on their own. Community mobilizing and organizing efforts begin with a mapping exercise in which community leaders work with students to identify who to mobilize and devise the best ways to invite them to engage in Community Visioning Conversations about quality of life. From those student-facilitated dialogues, a report is provided as the launch pad for community planning.

\section{Phase 3: Visioning and Planning (Fall 2016)}

In the visioning and planning phase, faculty and students provide the substantive expertise, research data, physical inventories, and process facilitation for neighborhood strategic planning that is conducted with both neighbors and the stakeholder team. Students examine the substantive range of public planning arenas, learning the principles and practices of organizational, program, project, and physical planning with consideration of the political and economic context. They also conduct policy and practice research to develop substantive expertise to contribute in participatory planning exercises with community members and stakeholders. Drawing from this data along with the Community Profile, and Community Survey results, and Community Visioning Conversations results, the university team crafts recommendations for a strategic plan to guide community development activities targeting the quality of life issues identified by participants. A logic model approach is used to support both resource development and evaluation activities.

\section{Phase 4: Action (Spring 2017)}

In the fourth and final implementation phase, activities are designed to leave the neighborhood in action, making sure that plans aren't placed on shelves to gather dust. Students explore the theories, principles, and ethics of economic, environmental, and social sustainability as applied to community and economic development activities. Faculty and students work with community leaders to prioritize and select at least one short-term, one mid-range, and one long-range project. The community participants establish Project Action Teams based on interests and expertise. These teams are given information on using or establishing community-based organizations to carry out projects. Faculty and students then support those teams in project implementation planning. Each plan covers policy and legal issues, technical issues, management and administration needs, budget needs, and resource development plans (including both financial 
and technical assistance resources). Ideally, the short-term project is designed for launch within the semester so that the community is left in motion.

The following sections describe the specific manner in which community leaders, stakeholders, and neighborhood residents will be engaged in the activities in these phases.

\section{Stakeholder Analysis}

In the Community Profile and through a social capital mapping workshop, community stakeholders identified the many community and economic development actors engaging in Fairmont:

- Governments

- Citizen Advisory Bodies

- Education

- Youth Programs

- Community \& Economic Development Organizations

- Housing Organizations

- Social Service Organizations

- Health Organizations

- Civic Clubs

- Faith-Based Organizations

- Active Citizens and Business Owners

- Charitable Funders

- Neighbors

The results of the social capital mapping exercise are provided in Appendix A: Social Capital Mapping Results and Appendix B: Outreach Lists. This diagram and the list illustrate that the Westside neighbors are well-connected to a variety of organizations available to contribute to community and economic development. As shown in the Table 2, students were assigned to work with stakeholder groups in mobilizing these human and organizational resources to engage in the Community Visioning Conversations. 
Table 2: Outreach Teams

\begin{tabular}{|l|l|l|}
\hline Stakeholder Category & Team Member(s) & Email \\
\hline Maple Avenue Residents & Bre Kreutzer & bkreutze@mix.wvu.edu \\
\hline Jackson Addition Residents & Chelsea Slade & cslade@mix.wvu.edu \\
\hline Sterling Heights Residents & Lacie Geary & lgeary1@mix.wvu.edu \\
\hline Shadyside Residents & Ruthana Beezley & rmbeezley@mix.wvu.edu \\
\hline Bellview Residents & Michelle Sloane & masloane@mix.wvu.edu \\
\hline $\begin{array}{l}\text { CommUNITY Cookout } \\
\text { (distribute with Social Capital Survey } \\
\text { administering) }\end{array}$ & $\begin{array}{l}\text { Marissa Angellatta } \\
\text { John Ferguson } \\
\text { Cournti Helmick }\end{array}$ & $\begin{array}{l}\text { mangella@mix.wvu.edu } \\
\text { jfergu11@mix.wvu.edu } \\
\text { crhelmick@mix.wvu.edu } \\
\text { amwong@mix.wvu.edu } \\
\text { dopyoke@mix.wvu.edu } \\
\text { rriddle2@mix.wvu.edu }\end{array}$ \\
\hline Faith Community & $\begin{array}{l}\text { Amy Loomis } \\
\text { Dylan Opyoke } \\
\text { Bob Riddle }\end{array}$ & cbagba@mix.wvu.edu \\
\hline Youth and Educators & Chris Agba & lcunni10@mix.wvu.edu \\
\hline Health Care and Social Services & Ashley Morgan & amorga21@mix.wvu.edu \\
\hline Government Agencies & Gaillynn Bowman & gmbowman@mix.wvu.edu \\
\hline Business Community & Daniel Eades & deades@mix.wvu.edu \\
\hline
\end{tabular}

\section{Community Concerns/Issues}

Issues of concern in the Westside neighborhoods fall into two broad categories: process issues in community development and socio-economic conditions. Please see the Community Profile and Community Survey reports for detailed results summarized herein.

\section{Community Development Process}

Lack of collaboration and consensus. Community members frequently reported disparate visions among and between civic institutions including governments at all levels, business organizations, non-profits, and community organizations. Community development actors were seen as more often competing for resources to support organizational goals rather than focusing on larger community goals. Across entities, residents noted a lack of resident engagement and cross-entity collaboration, resulting in little community vision or a long-term plan to guide development efforts.

Resident input and engagement. The majority of Westside residents did not feel that a diversity of racial, economic, and other groups are involved when it comes to important community decisions, and did not feel that community leadership was reflective of the community's diversity. Residents frequently reported not feeling included in setting organizational or larger community priorities. In many cases this may reflect poor communications between civic institutions and community residents. For example, several residents noted that information important for community development decision making was available but often not accessible. Community leaders especially were criticized for not sharing information and ideas with residents. 
Leadership and vision. Although much of the community's criticism was directed at community leaders, residents acknowledge that many citizens do not take a proactive role in building a strong community. Residents note a dearth of young leaders in the community, limited participation in neighborhood and community organizations, and a lack of engagement and coordination with city/county government, business, and local non-profits. Additionally, many residents note a lack of programs (or awareness of programs) that foster leadership skills at the individual or neighborhood level.

Unity across the Westside neighborhoods and the WAC's organizational capacity to move projects into implementation is an ongoing concern. Therefore, the project will continue to build these community capacities through outreach activities in order to launch successful implementation of community development projects

\section{Socio-Economic Conditions}

Socio-economic issues affecting the Westside neighborhoods are driven by residents' educational attainment, the neighborhood's economic and business climate, these factors' impacts on the built environment.

Education and Human Capital. Schools play an important role in the Westside neighborhood, especially given the WAC's emphasis on the community's youth. Westside neighborhood schools are reflective or the general population and report high poverty rates and a low socioeconomic status (SES) for many students. The community's minority and low SES students often underperform their peers on standardized tests. At both the middle and high school levels, black students underperformed their peers on math and reading assessments (36\% and 39\% proficient vs 51\% and 57\% for total population). Despite underperformance, schools serving the community seem reluctant to accept Title I funds that could provide support to low SES students.

Business and Economy. Although labor force participation and employment in the neighborhood is comparable to the city and county, Westside residents report significantly lower earnings. Median household incomes averaged \$23,667 compared to nearly \$37,000 in Fairmont and over $\$ 40,000$ in the county and state. The Westside neighborhood also reported the largest share of households receiving cash public assistance (4.2\%) and SNAP benefits (23.3\%).

The Westside neighborhoods are primarily residential and business activity is noticeably absent. Based on discussions with community members, several businesses in the neighborhood have shuttered over the past decade, or have relocated within the city, resulting in decreased accessibility to goods and services for residents. Some younger residents, especially young males, are returning to the community following incarceration for drug crimes. Despite the fact that these crimes are often non-violent nature, many are struggling to find employment.

Built Environment. The Westside neighborhoods' Windmill Park is both a built and natural asset for the community. Although the City’s Park and Recreation Master Plan recognizes the importance of Windmill Park to the surrounding neighborhoods, the park and its facilities suffer from disinvestment in comparison to other City parks. To generate increased revenue for 
improvements and better maintenance, the City's recommendations for Windmill Park are to: Create a user fee for leagues and others that use the facilities, the City should operate the concession stand, obtain sponsorship from local businesses for maintaining the fields, and form a shelter rental policy (Park and Recreation Master Plan, 2014). Many in the neighborhood fear that these policies will have a negative impact on residents', especially those of lower socioeconomic status, ability to take full use of park facilities.

Housing. The Westside neighborhoods suffer from a disproportionate number of vacant and dilapidated housing units: Of the total housing units in Fairmont, $13.9 \%$ were identified as vacant by the BAD Buildings team; the Westside had reported a significantly higher rate, nearly $21 \%$. Of these, approximately $40 \%$ were deemed appropriate for demolition. Despite the poor condition of many homes, nearly $40 \%$ of home owners and $75 \%$ of renters in the neighborhood are classified as "cost burdened," spending more than $30 \%$ of their income on housing costs. Appendix C provides a summary of community concerns identified during the Learning phase of the project.

\section{Public Engagement Objectives and Techniques}

In each phase of the Fostering Fairmont project there is a particular purpose that can be linked to specific public engagement objectives and the techniques chosen to achieve those objectives. Table 1 provides a summary of what is planned for the Westside Action Coalition. The various purposes follow the International Association for Public Participation (IAP2) Spectrum of Public Participation: Inform, Consult, Involve, Collaborate, and Empower. At each level the degree of public influence and empowerment is increased:

Inform. Information provides the public with balanced and objective knowledge to help them understand the project as well as alternatives and solutions.

Consult. Consultation allows the public to be engaged through communication so they can offer feedback and raise their concerns.

Involve. Involvement acknowledges public engagement through discussion of concerns and goals. There is a mutual understanding of aspirations, instead of deliberations for decisions.

Collaborate. Collaboration moves from discussion into deliberation. The public is engagement in participatory learning, discussion, deliberation and the decision making process. Throughout collaboration alterative solutions are developed and the ideal solution is identified.

Empower. Empowerment is the final level of public engagement. The authority of the final decision is given to the public participants to decide.

The Fostering Fairmont project will produce a Neighborhood Plan and at least three project or program implementation plans. The Neighborhood Plan will be used by the Westside Action 
Coalition to guide its efforts and its advocacy work with other Fairmont stakeholders. Therefore, residents, property owners, and business owners in the neighborhoods can be fully empowered with decisions regarding its ratification and adoption. The project/program implementation plans will require adoption by the organizations charged with carrying them out. Therefore, community members will be asked to collaborate in their formulation through dialogue and deliberation.

Table 1: Purposes, Objectives, and Techniques of Public Engagement

\begin{tabular}{|l|c|l|}
\hline \multicolumn{1}{|c|}{ Purpose } & $\begin{array}{c}\text { Involvement } \\
\text { Objective(s) }\end{array}$ & \multicolumn{1}{|c|}{ Engagement Techniques } \\
\hline $\begin{array}{l}\text { Work with community leaders to plan } \\
\text { and execute the engagement project }\end{array}$ & $\begin{array}{c}\text { Collaborate/ } \\
\text { Consult }\end{array}$ & $\begin{array}{l}\text { One-on-one work sessions, WAC } \\
\text { meetings, Stakeholder meetings, } \\
\text { capacity building workshops }\end{array}$ \\
\hline $\begin{array}{l}\text { Community Celebration and Project } \\
\text { Launch }\end{array}$ & $\begin{array}{l}\text { Inform/ } \\
\text { Involve }\end{array}$ & $\begin{array}{l}\text { WAC Facebook and website, Flyers, } \\
\text { Press Releases, Fact Sheets, } \\
\text { CommUNITY Cookout }\end{array}$ \\
\hline Community dialogue and visioning & Involve & $\begin{array}{l}\text { WAC Facebook and website, Flyers, } \\
\text { Press Releases, Community } \\
\text { Visioning Conversations }\end{array}$ \\
\hline Community deliberation and planning & Collaborate & $\begin{array}{l}\text { WAC Facebook and website, Flyers, } \\
\text { Press Releases, Planning and Design } \\
\text { Charrette }\end{array}$ \\
\hline Community plan review and adoption & Empower & $\begin{array}{l}\text { WAC Facebook and website, Flyers, } \\
\text { Press Releases, Participatory } \\
\text { Decision Making }\end{array}$ \\
\hline $\begin{array}{l}\text { Project prioritization and selection } \\
\text { develop and implement revitalization } \\
\text { projects }\end{array}$ & Collaborate/ & $\begin{array}{l}\text { WAC Facebook and website, Flyers, } \\
\text { Press Releases, Participatory } \\
\text { Planning and Decision Making }\end{array}$ \\
\hline Project Evaluation and Feedback & Empower & $\begin{array}{l}\text { WAC Facebook and website, Flyers, } \\
\text { Press Releases, Action Teams work } \\
\text { sessions }\end{array}$ \\
\hline
\end{tabular}

\section{Process Facilitation Guides}

Productive meetings encourage continued collaboration; therefore processes are planned in advance in a thoughtful, informed manner. Each activity is designed to achieve a specific purpose (i.e., learn, dialogue, deliberation, decision making, action) through a specific level of influence (i.e., inform, consult, involve, collaborate, empower). Furthermore, common group dynamics are anticipated and accommodated to produce the most fruitful outcomes. 
Facilitation guides include: agendas and schedules; explanations of each activity and the supplies, equipment, and setup required; and instructions and scripts for meeting facilitators and support roles. These instructions design the flow of learning, dialogue, deliberation, decision making, or action so that the meeting is efficient and effective.

The Fostering Fairmont Project has four distinct processes for which facilitation guides have been generated. Each facilitation guide will be used by team members or community volunteers to ensure that even if a process is repeated in multiple sessions, each one is handled in the same fashion so that all participants have a similar experience. An example Facilitation Guide is provided in Appendix E.

\section{Community Conversations}

This process will be designed to allow for guided, open-ended dialogue about the quality of life in the Westside neighborhoods.

All participants will be asked to sign in, indicate where they live on a large scale map to determine overall geographic representation, complete a name tag, and pick up a Meeting Agenda and Project Fact Sheet. Participants with children will be directed to take them to the children's activity area operated by community volunteers.

Each meeting will begin by convening the group as a whole. The WVU Project Team will be introduced, along with any members of the Westside Action Coalition or Stakeholder Team present. A brief overview of the full project will be given, reiterating what is on the Project Fact Sheet and providing a brief update of results to date. This gives participants assurance that previous engagement results were heard and are being used and that they are joining an ongoing project. The agenda for the remainder of the meeting will be reviewed and instructions will be given for finding the first session in a series of small group dialogues.

Facilitators and scribes will be assigned to each group to capture the results of the conversations. An icebreaker exercise will be used to increase participants' comfort before beginning dialogue. Before sending participants home, a team-building exercise will be conducted to emphasize the importance of community connections and collaboration. They will then be asked to complete a participant satisfaction survey and WAC sign-up card if they wish to be on the mailing list.

\section{Planning and Design Charrette}

This two-day process will be designed to allow for facilitated planning in response to the issues found in analysis of the Community Survey and Community Visioning Conversations results. Expert team members will be on tap, not on top, meaning they will be members of issue-based teams alongside community members who share an interest in the issue. Volunteers will be recruited and chosen based on their expertise in the particular issues found in the Westside neighborhoods.

Each day, all participants will be asked to sign in, indicate where they live in the community on a map (to determine degree of geographic representation), complete a name tag, and pick up a 
Meeting Agenda and Project Fact Sheet. On the first day, the group will be convened as a whole and the WVU Project Team will be introduced, along with any members of the Westside Action Coalition present. A brief overview of the full project will be given, reiterating what is on the Project Fact Sheet. Results of the Community Survey and Community Visioning Conversations will be presented in brief to bring everyone up to speed and refresh memories from the previous meetings. This reiterates responsiveness to previous engagement activities.

A draft vision statement crafted from the results of the Community Conversations will be presented, considered, amended if necessary, and ratified. Once this whole group process is completed, the agenda for the remaining elements of the meeting will be read and instructions will be given for finding the first in a series of small group planning activities.

Small group sessions will be organized around each issue identified during the Community Conversations. Facilitators and scribes will be assigned to each group to capture the essence of deliberations. Each planning group will begin with an icebreaker exercise that will serve to emphasize the importance of collaboration in planning and implementation. Facilitated dialogue and deliberation will be designed to capture goals and objectives. Narrative, mapping, and drawing or modeling exercises are likely to be utilized, appropriate to the planning issue at hand.

Alternative activities will be designed to engage youth in planning activities appropriate to their skill levels.

The process will continue the second day with a general assembly during which draft goals and objectives will be presented, considered, amended if necessary, and ratified. Then small groups organized around issue areas will be reconvened for more detailed work in planning teams to identify and craft action strategies. At the end of each planning session, participants will be asked to sign up for potential Action Teams that may reconvene as the Neighborhood Plan strategies are further developed and adopted and project implementation activities begin. These volunteers will receive follow-up communications as the project progresses. Commitment to such a team will ensure ongoing public engagement and ownership of project outcomes.

The small groups will then reconvene in a general assembly to share their results and to complete a large group team-building exercise that will emphasize the importance of community connections and collaboration.

\section{Plan Review and Adoption}

On the third day, a general assembly is convened in the afternoon to present the final results in a draft Neighborhood Plan format: vision, values, goals, objectives, and action strategies. If any recommendations require review and adoption procedures by both the Planning and Zoning Commission and the City Council, representatives from the WVU Land Use and Sustainable Development Law Clinic will explain the process and how they will assist the Westside Action Coalition. Other members of the WVU Project Team will similarly present the manner in which they can support the Westside Action Coalition in the implementation phase. This will include a preliminary schedule of return visits to work with the Project Action Teams. 


\section{Strategy Prioritization and Implementation}

Once the Westside Action Coalition has accepted the Neighborhood Plan, a community meeting will be held to present the Plan and solicit feedback in regard to prioritization as well as to obtain organizational and individual commitments to collaboration in implementation of specified strategies. This meeting will be limited to those who volunteered to engage in Action Teams. This limitation is necessary because at this point, deliberations have been closed and participants must be willing and able to engage in implementation as opposed to simply weighing in on alternatives or trying to reopen deliberations.

All participants in Action Team meetings will be asked to sign in, complete a name tag, and pick up a Meeting Agenda and Executive Summary of the Neighborhood Plan's goals, objectives, and action strategies. While convened as a whole, the WVU Project Team will be introduced and then everyone will introduce themselves. The agenda for the meeting will be read and instructions will be given for finding the first in a series of Action Team activities.

In the first meeting, facilitators and scribes will be assigned to each Action Team to capture the essence of deliberations. Each planning group will begin with reviewing the Plan element(s) pertaining to their interests. The group will first discuss how the action strategies might relate to one another in terms of timing and to place them in phased order, if appropriate. The group will then be asked to use a voting process to prioritize the strategies early in the "critical path." These deliberations will lead to the crafting of three priority community development projects: longrange ( $5+$ years), mid-range ( $2-5$ years), and short-term ( 1 year). At the end of the planning session, each Action Team will set a calendar for convening independently as well as with the WVU Project Team over the semester.

The group as a whole will then reconvene with each Action Team reporting their priorities. The WVU Project Team will then provide feedback as to which projects they are most capable of assisting into implementation. Then the group as a whole will utilize a voting strategy to select the top project in each category among all that they wish to pursue. As always, the process will end with a team-building exercise that will emphasize the importance of community connections and collaboration.

In the second and third meetings, the Action Teams will reconvene for resource development and project implementation activities. The nature of specific Action Team meetings will be determined based on the nature of the community development project involved, but each will be typical inter-organizational collaboration project meetings. A general commitment has been made by the WVU Project Team to help develop implementation plans for three projects, one long-range, one mid-range, and one short-term project. Each implementation plan will include legal and policy findings, technical findings, a budget and resource development options, and a management plan for execution. 


\section{Communications Approach}

Creating a successful communications approach that effectively informs and recruits participants is vital to the public engagement process. A successful communications approach includes recruiting participants in an honest, transparent fashion; providing organized, clear information and education to inform participants; provides concise feedback on community input; and explains the process in which input has been gathered, documented, and utilized for community improvement.

Many strategic tactics will be employed by the Fostering Fairmont Project to produce a successful communications approach. These tactics fall under three different objectives, to engage stakeholders, raise public awareness and inform, and consult and involve the community. Strategic tactics for engaging stakeholders include maintaining contact through phone, email, and physical meetings to disseminate information. For raising public awareness and informing, there are several strategic tactics that require materials to be produced. These tactics involve creating social media accounts and a website and maintaining its information; producing press releases to be distributed to local media outlets; working with the design team to create flyers and web and social media banners; constructing fact sheets and save the dates to be delivered to participants and stakeholders physically and digitally; producing Youtube videos to be circulated on the web and scripts for public service announcements on the radio. Consulting and involving the community includes reports and comprehensive results from public engagement meetings and events providing valuable feedback and information on how to proceed through in-person presentations and YouTube videos. The following table provides an overview of objectives, their corresponding strategic tactics with dates and responsible parties.

\begin{tabular}{|c|c|c|}
\hline Engage Stakeholders & Date & Team Member \\
\hline $\begin{array}{l}\text { 1. Written and telephone correspondence } \\
\text { with the Stakeholder Advisory Team }\end{array}$ & Ongoing & Project Team Leader \\
\hline $\begin{array}{l}\text { 1.1. Email invitations and meeting } \\
\text { agendas }\end{array}$ & $\begin{array}{l}\text { Meeting-1 } \\
\text { week }\end{array}$ & Project Team Leader \\
\hline $\begin{array}{l}\text { 2. Face-to-face meetings with the } \\
\text { Stakeholder Advisory Team }\end{array}$ & Monthly & Project Team \\
\hline $\begin{array}{l}\text { 2.1. Status reports and project information } \\
\text { dissemination through presentations } \\
\text { and handouts in meetings }\end{array}$ & Ongoing & Project Team Leader \\
\hline $\begin{array}{l}\text { 3. Written and telephone correspondence } \\
\text { with Stakeholder Advisory Team } \\
\text { members }\end{array}$ & Ongoing & Project Team \\
\hline Raise Public Awareness and Inform & Date & Team Member \\
\hline 1. Create Facebook Page and Website & Project Start & Communications Team \\
\hline $\begin{array}{l}\text { 1.1. Correspond with design team for } \\
\text { Facebook and web banner }\end{array}$ & & Communications Team \\
\hline $\begin{array}{l}\text { 1.1. Generate posts on the } \\
\text { Facebook/Twitter Pages }\end{array}$ & Ongoing & Everyone \\
\hline $\begin{array}{l}\text { 2. Produce project press releases for } \\
\text { distribution to the media }\end{array}$ & PE Start & $\begin{array}{l}\text { Project Team Leader; } \\
\text { Communications Team }\end{array}$ \\
\hline
\end{tabular}




\begin{tabular}{|c|c|c|}
\hline $\begin{array}{l}\text { 3. Produce Project Fact Sheet, including } \\
\text { known schedule of events }\end{array}$ & Project Start & Communications Team \\
\hline 3.1. Post or link to Facebook and website & Project Start & Project Team Leader \\
\hline 3.2. Distribute in print to the Stakeholders & Meetings & Project Team Leader \\
\hline $\begin{array}{l}\text { 3.3. Distribute digitally to the } \\
\text { Stakeholders }\end{array}$ & Project Start & Project Team Leader \\
\hline 3.4. Distribute in print to the community & Events & Project Team Leader \\
\hline $\begin{array}{l}\text { 4. Produce informational video with } \\
\text { invitation to engage and post links to } \\
\text { YouTube on the Project Facebook Page }\end{array}$ & $\begin{array}{c}\text { PE Start; } \\
\text { Events-2 weeks }\end{array}$ & Communications Team \\
\hline $\begin{array}{l}\text { 5. Announce events on the Facebook and } \\
\text { website and post reminders }\end{array}$ & $\begin{array}{l}\text { Event-4 weeks; } \\
\text { weekly }\end{array}$ & Communicatior \\
\hline $\begin{array}{l}\text { 6. Produce and distribute a Save-the-Date } \\
\text { notice }\end{array}$ & $\begin{array}{l}\text { Event- } 4 \text { or } \\
\text { more weeks }\end{array}$ & Communications Team \\
\hline $\begin{array}{l}\text { 6.3. Ask Fairmont State University } \\
\text { employees to submit to campus news }\end{array}$ & Event-2 weeks & Project Team Leader \\
\hline 7. Produce press release about each event & Event-3 weeks & Communications Team \\
\hline 7.3. Distribute to local media & Event-2 weeks & Project Team Leader \\
\hline 7.3.1. Times West Virginian & & Communications Team \\
\hline 7.3.2. WDTV, WBOY & & Communications Team \\
\hline 7.3.3. WVAQ & & Communications Team \\
\hline 7.3.4. Times Warner Cable & & Communications Team \\
\hline $\begin{array}{l}\text { 8. Retrieve event flyers and poster in both } \\
\text { color and black \& white from design team }\end{array}$ & Event-4 weeks & Communications Team \\
\hline $\begin{array}{l}\text { 8.1.Poster: 11in x 17in } \\
\text { Flyer: 8.5in x 11in }\end{array}$ & “ & Communications Team \\
\hline 8.2.Post links to Facebook and website & Event-2 weeks & Communications Team \\
\hline $\begin{array}{l}\text { 8.3.Distribute electronically to and } \\
\text { through Stakeholders }\end{array}$ & Event-2 weeks & Project Team Leader \\
\hline $\begin{array}{l}\text { 9. Produce script for audio Public Service } \\
\text { Announcement or auto-call systems, } \\
\text { sporting event announcers, radio, etc. }\end{array}$ & Event-3 weeks & Communications Team \\
\hline 9.1.Distribute to appropriate stakeholders & Event-2 weeks & Project Team \\
\hline Consult and Involve the Community & Date & Team Member \\
\hline $\begin{array}{l}\text { 1. Post links to project reports on website } \\
\text { and Facebook }\end{array}$ & PE Start & Communications Team \\
\hline 2. Gather contact information at all events & Events & Communications Team \\
\hline $\begin{array}{l}\text { 3. Produce and disseminate findings from } \\
\text { public engagement events }\end{array}$ & Phase end & Project Team \\
\hline 3.1. Document products of public events & “ & Documentation Team \\
\hline 3.2. Analyze findings and write report & “ & Project Team \\
\hline $\begin{array}{l}\text { 3.3. Edit final report and write executive } \\
\text { summary }\end{array}$ & “ & Project Team Leader \\
\hline 3.4. Present report to Stakeholders & 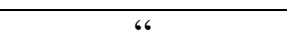 & Project Team \\
\hline Consult and Involve the Community & Date & Team Member \\
\hline
\end{tabular}




\begin{tabular}{|c|c|c|}
\hline Consult and Involve the Community & Date & Team Member \\
\hline $\begin{array}{c}\text { 3.5. Post links to the report on Facebook } \\
\text { and website }\end{array}$ & Communications Team \\
\hline $\begin{array}{c}\text { 3.6. Produce a video recap and post to } \\
\text { YouTube with a link on Facebook } \\
\text { and website }\end{array}$ & $\begin{array}{c}\text { End and } \\
\text { beginning of } \\
\text { each phase }\end{array}$ & Communications Team \\
\hline
\end{tabular}

\section{Documentation Approach}

Legitimacy is ensured through accountability and transparency. The purpose of documentation is to keep a communications, deliberations, and decisions on record. Documentation is used as evidence of the direct input from stakeholders, participants, and decision-makers and should to be traceable from the beginning of the project to its end. Comments might be made in the form of power point presentations on a computer projector onto a screen, posters, flip charts and sticky notes on easels, and storyboard maps and diagrams on the wall. The specific methods used are described in the Facilitation Guides. Input should be documented and align with the outputs produced. Where the two diverge, an explanation must be provided.

The Fostering Fairmont project extends over a two-year period with a variety of team members coming and going from the project. Good documentation will enable everyone to access the history and get up to speed in the project. Taken together, the purposes of documenting project activities and information include:

- Maintain and update a participant contact database;

- Communicate about the project, recommendations, decisions, and next steps;

- Maintain process mapping and navigation;

- Conduct process evaluation for continuous improvement efforts; and

- Ensure accountability and transparency.

Documentation will include the following:

1. Project Documents

a. MOUs and related correspondence

b. Host Evaluation Forms

2. Financial Management

a. Requests for funding and related correspondence

b. Budget

3. WVU Partners

a. External MOUs and related correspondence

b. Internal MOUs and related correspondence

4. Stakeholder Meetings
a. Agendas
b. Sign-In Sheets
c. Handouts
d. Participant Satisfaction Surveys
e. Meeting Notes 
5. Westside Action Coalition Meetings
a. Agendas
b. Sign-In Sheets
c. Handouts
d. Meeting Notes

6. Project Deliverables
a. Community Survey Report
b. Community Profile
c. Public Engagement Plan
d. Social Capital Survey Report
e. Community Conversations Report
f. Neighborhood Plan
g. Project Plans

7. Community Celebration
a. Public relations materials
b. Schedule of activities
c. Evidence of results (selfie station, banner station)

8. Community Visioning Conversations

a. Public relations materials

b. Agenda

c. Facilitation Guide

d. Sign-In Sheets

e. Participant Satisfaction Surveys

9. Planning Charrette
a. Agenda
b. Facilitation Guide
c. Sign-In Sheets
d. Participant Satisfaction Surveys

10. Action Teams (each)
a. Agendas
b. Sign-In Sheets
c. Meeting Results
d. Participant Satisfaction Surveys

11. Public Relations
a. Outreach plans
b. Social Media: Facebook, Twitter, and Instagram profiles
c. Website
d. Press releases
e. Flyers
f. Public Service Announcements
g. Fact sheets about WAC and Fostering Fairmont
h. Media coverage

12. General Correspondence

a. Topics by date

13. Contact Lists

a. Westside Action Coalition 
b. Fairmont Stakeholders

c. Neighbors

\section{Project Evaluation}

The Fostering Fairmont project will be evaluated to capture the perspectives of the WVU Project Team, the Westside Action Coalition and Stakeholder Team, and public engagement process participants. Evaluation methods will include both process and outcomes evaluation. Results from each of these evaluation approaches will be compiled by the WVU Project Team and used to determine what's working and what needs improvement. However, we also offer the Stakeholder Team some evaluative questions to consider in evaluating the success of the public engagement plan:

1. Were there ample opportunities for input that matched the level of community involvement the project sought?

2. Was the leadership structure clearly defined and both decision-making and implementation responsibilities determined?

3. Were various public involvement and communication techniques and styles used?

4. Were the opportunities for public input scheduled within the early phases of the project?

5. Were there different ways for people to provide input into the project?

6. Was there public feedback about the involvement process? Did participants express their opinions about how the process was working? Did themes emerge from the comments themselves?

7. Was the process transparent and well-documented? Can the public see how it may have influenced the outcomes produced?

8. Does the outcome reflect a general consensus? Is the final product generally acceptable to the public?

9. Was adequate information provided to the stakeholders?

10. Do the decision-makers believe the public involvement process helped to make a better decision? 


\section{Project Team}

Debriefing sessions will be completed by the WVU Project Team after each fieldwork visit. These will be conducted in the tradition of service learning and action research, including journal reflections, discussion, and compilation of group consensus points. These reflections will be utilized by the Project Team for continuous improvement efforts in all activities. This type of process evaluation ensures that as issues or concerns are identified, they can be addressed to immediately improve project outcomes. This evaluation is primarily for use by the Project Team, but may also be shared with the Westside Action Coalition when appropriate.

\section{Westside Action Coalition and Stakeholder Team}

The "client" in this case is the community host, the Westside Action Coalition. However, the stakeholders that they recruit to the Fostering Fairmont project are equally important to its success. Therefore, both groups will be asked for their perspectives on deliverables. This evaluation form is shown in Appendix F.

\section{Meeting Participants}

All those attending Fostering Fairmont project meetings and events will be given a satisfaction survey with which to provide feedback on the meeting attended. This participant satisfaction survey is shown in Appendix G. We will also use sign-in sheets to track who and how many participated, the rate of return for satisfaction surveys, and similar quantitative data.

\section{Project Schedule and Task List}

The overall project schedule extends through two years across four semesters:

$\left.\left.\left.\begin{array}{|c|l}\hline \text { Learn } \\ \text { Fall 2015 }\end{array}\right\rangle \begin{array}{l}\text { Mobilize } \\ \text { Spring 2016 }\end{array}\right\rangle \quad \begin{array}{c}\text { Plan } \\ \text { Fall 2016 }\end{array}\right\rangle \begin{gathered}\text { Act } \\ \text { Spring 2017 }\end{gathered}$

Project management software was used to manage tasks.

\section{Project Budget}

The Westside Action Coalition will be responsible for covering project related costs above and beyond equipment and supplies required for meetings. 


\section{APPENDICES}

Appendix A: Social Capital Mapping Results

Appendix B: Outreach Lists

Appendix C: Process Facilitation Guides

Appendix D: Public Relations Materials

Appendix E: Evaluation Forms 


\section{Appendix A: Social Capital Mapping Results}

Stakeholders identified WAC’s social network during a mapping exercise. Green lines represent strong connections. Red lines represent weaker connections. A black line represents a connection of unspecified strength. 
Appendix A: Social Capital Mapping Results

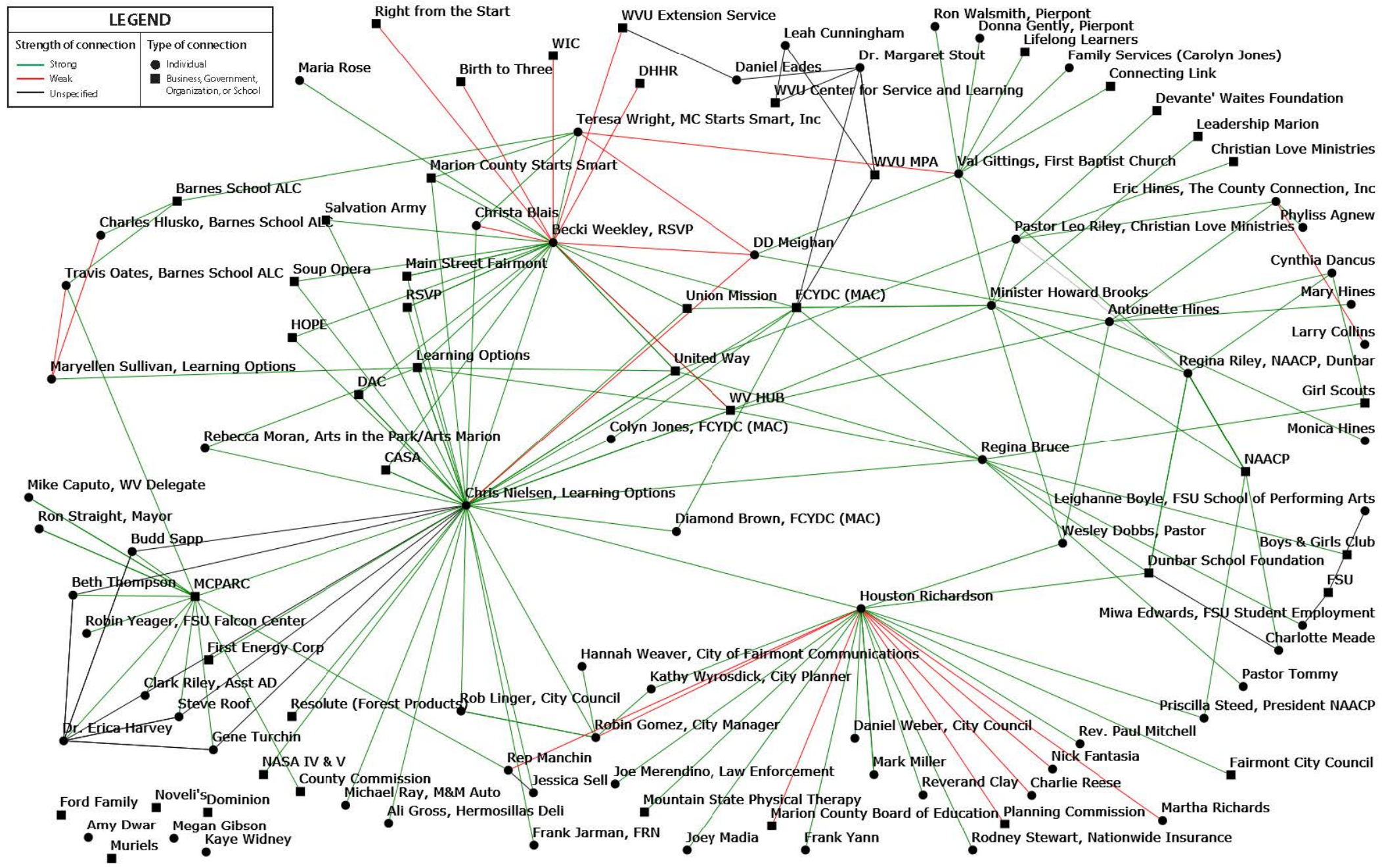




\section{Appendix B: Outreach Lists}

This symbol indicates that a group is a Westside Action Coalition member.

\section{Governments}

City of Fairmont

200 Jackson St., 3rd Floor

Fairmont, WV 26554

http://www.fairmontwv.gov/

304-366-6211

\section{City Council}

Marianne Moran, District 1

Frank Yann, District 2

Robert Linger, District 3

William (Bill) Burdick, District 4

Fran Warner, District 5

Daniel Weber, District 6

Philip Mason, District 7

Thomas Mainella, District 8

Ronald J. (Ron) Straight, District 9 (Mayor)

\section{City Manager}

Robin Gomez

304-366-6212, Ext. 315

rgomez@fairmontwv.gov

\section{Communications}

Hannah Weaver

304-366-6212, ext. 340

hweaver@fairmontwv.gov

\section{Planning and Development}

Martha Richards

304-366-6212, Ext. 318

mrichards@fairmontwv.gov

\section{Police Department}

Chief Steve Shine

500 Quincy St.

Fairmont, WV 26554

304-366-9280 
Fire Department

Chief James Emerick

500 Quincy St.

Fairmont, WV 26554

304-363-7620

jemerick@fairmontwv.gov

\section{Public Works}

Ron Miller

1030 Minor Ave.

304-363-3883

rmiller@fairmontwv.gov

\section{Citizen Advisory Boards and Commissions}

1. Arts \& Humanities Commission

2. Board of Zoning Appeals

3. Fairmont Airport Authority

4. Fairmont Audit Committee

5. Fairmont Building Commission

6. Fairmont Parking Authority

7. Fairmont Parks Commission

8. Fairmont Sanitary Sewer Board

9. Fairmont Water Board

10. Fairmont/Morgantown Housing Authority

11. Fairmont-Marion Transit Authority

12. Fire Civil Service Commission

13. Historic Landmarks Commission

14. Historic Preservation Review Committee

15. ICC Board of Appeals

16. Marion County Parks \& Recreation Commission

17. Marion County Public Library Trustee Board

18. Personnel Appeals Board

19. Planning \& Zoning Commission

20. Police Civil Service Commission

21. Safety Review Board

22. Urban Renewal Authority

\section{Marion County Commission}

Kris Cinalli, County Administrator

200 Jackson St., 4th Floor

Fairmont, WV 26554

304-367-5425

kcinalli@marioncountywv.com

http://www.marioncountywv.com/departments/county_commission/ 
Randy Elliott, West Augusta District

relliott@marioncountywv.com

Rick Garcia, Middletown District

rgarcia@marioncountywv.com

Ernie VanGilder, Palatine District

evangilder@marioncountywv.com

Marion County Parks and Recreation Commission (MCPARC)

Tony Michalski, Director

1000 Cole Street, Suite B

Pleasant Valley, WV 26554

304-363-7037 or 800-903-2994

Tmski44@aol.com

info@mcparc.com

http://www.mcparc.com/

\section{Marion County Board of Education}

Members: President Richard Pellegrin, Dr. Babette Sims, Janette Crespenzi, Thomas Dragch, and Mary Joe Thomas

200 Gaston Avenue

Fairmont, WV 26554

Phone: 304-367-2100

http://www.marionboe.com/

Marion County Health Dept.

300 2nd Street

Fairmont, WV 26554

Phone: 304-366-3360

Fax: 304-363-8217

marionlhd@wv.gov

http://www.marioncountywv.com/departments/health_department/

WV Senator Roman Prezioso

State Capitol Complex

Room 223W, Building 1

Charleston, WV 25305

304-357-7961

roman.prezioso@wvsenate.gov 


\author{
WV Senator Robert Beach \\ State Capitol Complex \\ Room 204W, Building 1 \\ Charleston, WV 25305 \\ 304-357-7919 \\ bob.beach@wvsenate.gov \\ WV Delegate Linda Longstreth \\ State Capitol Complex \\ Room 6U-A, Building 1 \\ Charleston, WV 25305 \\ 304-340-3124 \\ linda.longstreth@wvhouse.gov \\ WV Delegate Tim Manchin \\ State Capitol Complex \\ Room 151R, Building 1 \\ Charleston, WV 25305 \\ 304-340-3331 \\ tmanchin@manchininjurylaw.com
}

WV Delegate Mike Caputo

State Capitol Complex

Room 258M, Building 1

Charleston, WV 25305

304-340-3249

U.S. Senator Joseph Manchin III

230 Adams Street

Fairmont, WV 26554

Phone: 304-368-0567

info@joemanchinwv.com

http://www.joemanchinwv.com/home

U.S. Senator Shelley Moore Capito

172 Russell Senate Office Building

Washington, DC 20510

202-224-6472

U.S. Congressman David McKinley

412 Cannon HOB

Washington, DC 20515

202-225-4172 


\section{Education}

Watson Elementary School

1579 Mary Lou Retton Drive

Fairmont, WV 26554

304-367-2156

West Fairmont Middle School

110 10th Street

Fairmont, WV 26554

304-366-5631

\section{Fairmont Senior High School}

1 Loop Park Drive

Fairmont, WV 26554

304-367-2150

Barnes School Adult Learning Center

Charles Hlusko \& Travis Oates

100 Naomi St.

Fairmont, WV 26554

304-367-2127

Pierpont Community \& Technical College

Donna Gentry

Ron Walsmith

School of Workforce Development

503 Morgantown Ave, Suite 125

Fairmont, WV 26554

304-366-6762

ron.walsmith@pierpont.edu

donna.gentry@pierpont.edu

\section{Lifelong Learners}

Continuing Education Department

Pierpont Community \& Technical College

320 Adams Street, Suite G.01

Fairmont, WV 26554

304-367-4920

\section{Fairmont State University}

Miwa Edwards

Student Employment Advisor

Turley Student Services Center, Room 222A

Phone: 304-367-4836 or 304-657-0788

medwards@fairmontstate.edu 
FSU Falcon Center

Robin Yeager, Director

316 Student Affairs Suite

304-367-4783

ryeager@fairmontstate.edu

West Virginia University

Margaret Stout, Associate Professor

Department of Public Administration

325 Willey Street, Rm 103

304-293-7978

Margaret.Stout@mail.wvu.edu

WVU Center for Service Learning

Leah Cunningham

Leah.Cunningham@mail.wvu.edu

http://service.wvu.edu/

\section{Youth Programs}

The MAC (Fairmont Community Youth Development Center)

Colyn Jones, President

Diamond Brown, Athletics/Intern

612 Madison St

Fairmont, WV

304-534-8316

fcydc2014@gmail.com

https://www.facebook.com/FCYDC.THE.MAC/

\section{Girl Scouts}

Pat Vincent

304-365-0922

\section{Learning Options}

Chris Nielsen

305 Songbird Lane, Fairmont, WV 26554

304-366-3722

304-657-7252

cnielsen@learningoptionsinc.org

http://www.learningoptionsinc.org/

Mary Ellen Sullivan

mesullivan@learningoptionsinc.org

304-795-4388 


\author{
Boys and Girls Club of Marion County \\ 1025 Fairfax St \\ Fairmont, West Virginia \\ 304-376-2627 \\ https://www.facebook.com/BoysandGirlsClubsofMarionCountyWV/
}

West Side Robotics

717 Fairmont Ave

Fairmont, WV 26544

304-612-7100

westsideroboticsfwv@gmail.com

http://westsideroboticsfwv.wix.com/westsiderobotics\#!about1/c1x1t

Community \& Economic Development Organizations

The Dunbar School Foundation

Houston Richardson

101 High St

Fairmont, West Virginia

304-692-8820 or 304-363-7062

https://www.facebook.com/DunbarSchoolFoundation/

\title{
Main Street Fairmont
}

206 Adams Street

Fairmont, WV 26554

304.366.0468

http://www.mainstreetfairmont.org/

\section{BAD Buildings Team}

Luke Elser, Northern WV Brownfields Assistance Center

Luke.Elser@mail.wvu.edu

\section{Habitat for Humanity}

Teri Dalton, Executive Director

103 12th St, Fairmont, WV 26554

PO Box 721 Fairmont, WV 26555

304-363-4244

director@marionhabitat.org

Fairmont-Morgantown Housing Authority

http://www.fmhousing.com/

103 12th Street, P.O. Box 2738

Fairmont, WV 26555

Phone: 304-363-0860

Fax: 304-366-0469 
Fairmont Community Development Partnership

300 2nd Street, Suite 2, Fairmont, WV 26554

304-366-7600

info@fcdp.com

http://www.fcdp.com/

West Virginia Community Development Hub

103 Adams Street, Suite 200

Fairmont, WV 26554

Phone: 681-404-6053 or 6122

http://wvhub.org/

Social Service Organizations

Marion County Family Resource Network

Frank Jarman

112 Adams Street Room 204

Fairmont WV 26554

304-366-4445

marioncountyFRN@gmail.com

WVU Extension Marion County

314 Monroe Street, Room 202

Fairmont, WV 26555-1628

304-367-2772

http://marion.ext.wvu.edu/

MCPARC Master Gardeners

Diana George

304-278-7576

georged333@live.com

Marion County Smart Start, Inc.

Teresa Wright

304-366-5067

greter91@comcast.net

https://www.facebook.com/MCSSBSS

Retired Senior Volunteer Program (RSVP)

Rebecca Weekley

304-816-1250

rweekley@unitedwaycwv.org

https://www.facebook.com/MarionCountyWVRSVP 


\author{
Connecting Link, Incorporated \\ Eric Hines \\ 205 Fairmont Ave. \\ Fairmont, WV 26554 \\ 304-363-4882 \\ http://www.connectinglinkwv.com
}

Marion County DHHR

416 Adams St., Suite 307

Fairmont, WV 26554

304-368-4420

www.wvdhhr.org

Birth to Three

$304-558-5388$

Fax: 304-558-2183

http://www.wvdhhr.org/birth23/Default.asp

Right from the Start

1-800-642-8522

Fax 304-558-7164

http://www.wvdhhr.org/rfts/

Women, Infants and Children (WIC)

304-366-2387

532 Pennsylvania Avenue

Fairmont, WV 26554

www.wvdhhr.org

North Central West Virginia Community Action

1304 Goose Run Road

Fairmont, WV 26554

304-363-6869

Court Appointed Special Advocates (CASA) Marion County

121 Adams Street \#203

Fairmont, WV 265554

304-366-4198

www.wvcasa.org/local-programs/9-local-programs/8-casa-of-marion-county

Disability Action Center

102 Benoni Ave. Fairmont, WV

304-366-3213

jsole@disabilityactioncenter.com

http://disabilityactioncenter.com/ 


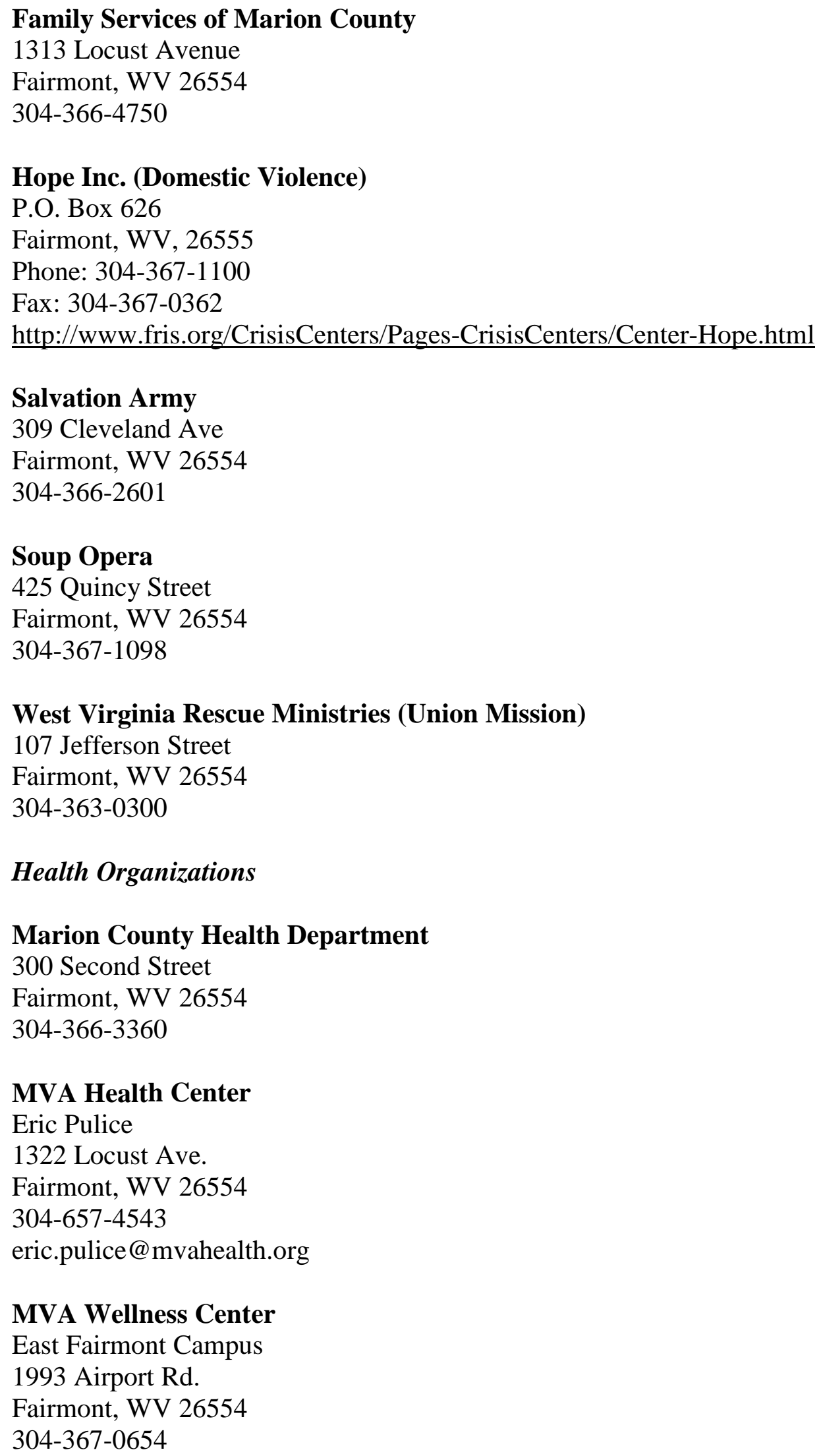




\section{Civic Clubs}

Marion County NAACP

Priscilla Steed

304-657-9684

steed.priscilla@yahoo.com

https://www.facebook.com/Marion-County-NAACP-naacp-112674915473500/

Elk Lodge No. 294

419 Adams St

Fairmont, WV 26554-3105

304-363-4300

\section{Faith-Based Organizations}

\section{Christian Love Ministries}

Pastor Leo Riley

Pastor Regina Riley

410 Morgantown Ave.

Fairmont, WV 26554

304-367-9570

304-366-9552

leoriley01@gmail.com

christianlovemin@gmail.com

Mount Zion Missionary Baptist Church

135 Maple Avenue

Fairmont, WV 26554

304-363-0669

Morning Star Baptist Church

Pastor Wesley Dobbs

100 McKinney St.

Fairmont, WV 26554

304-363-2978

wesleyqdobbs@yahoo.com 
Dash Ministry

Tommy Baron

304-363-8237

dashministry@yahoo.com

\section{(Whurch of God MPGT}

Pastor Eric Hines

900 Lewis St.

Fairmont, WV 26554

304-363-1233

681-753-1230

erichines705@yahoo.com

First Baptist Church of Fairmont

Pastor Valerie Gittings

901 Fairmont Avenue

Fairmont, WV 26554

304-366-2391

304-365-1073

vjgittings@comcast.net

New Beginnings Worship Center

Pastor Robert Clay

1815 Sunnyview Ln.

Fairmont, WV 26554

304-365-0202

304-612-5074

pastorrwclay@yahoo.com

Greater Fairmont Council of Churches

DD Meighan

3 Park Dr.

Fairmont, WV 26554-2401

\section{(V) Trinity Assembly of God}

Pastor Tommy

70 Maranatha Drive

White Hall WV 26554

trinity@tagchurch.org 
Trinity United Methodist

4407 Cleveland Avenue

Fairmont, WV 26554

TrinityUMCFMT@gmail.com

Temple of Christ Church

320 Fitzgerald Ave

Fairmont, WV 26554

Active Citizens and Business Owners

\author{
bid \\ Tracy Evans \\ 304-365-9010 \\ tracysellandlistshomes@yahoo.com
}

M\&M Merrifield Auto

Michael Ray

801 Pennsylvania Ave.

Fairmont, West Virginia 26554

304-363-1860

\title{
Muriels
}

1742 Fairmont Avenue

Fairmont, WV 26554

304-363-3190

muriales@aol.com

\section{Hermosillas Deli}

Ali Gross

919 Morgantown Ave

Fairmont, West Virginia

304-680-4376

Nationwide Insurance

Rodney Stewart

304-363-5400

613 Fairmont Ave

Fairmont, WV 26554-4116

Mountain State Physical Therapy

719 Fairmont Ave, Ste. 102

Fairmont, WV 26554

304-363-8543 
Ford Funeral Home

201 Columbia St, Fairmont, WV 26554

304-363-3130

\section{Charitable Funders}

\section{Devante' Waites Foundation}

Lakisha and Charles Elders

P.O. Box 718

Fairmont, WV 26555

304-365-2568

devantewaitesfoundation@gmail.com

lakisha.elders@gmail.com

Marion County United Way

Nicky Osborne, Executive Director

112 Adams Street, Room 201

Fairmont, West Virginia 26554

304-366-4550

304-680-0275

nicky@uwmarion.org

\section{Dominion Foundation}

701 East Cary Street, 20th Floor

Richmond, VA 23219

Daphne.Johnson@dom.com

https://www.dom.com/corporate/our-commitments/community/charitable-giving-and-thedominion-foundation

\section{FirstEnergy Foundation}

Allen Staggers

304-534-7356

https://www.firstenergycorp.com/content/fecorp/community/firstenergy_foundation.html

NASA IV \& V

NASA IV\&V Facility

100 University Dr.

Fairmont, WV 26554

304-367-8200

http://www.nasa.gov/centers/ivv/home/index.html 


\section{Novelis}

1800 Speedway St,

Fairmont, WV 26554

304-367-5000

http://novelis.com/?s=charitable+giving

\section{Resolute Forest Products}

702 Afr Dr,

Fairmont, WV 26554

304-368-0900

http://www.resolutefp.com/Sustainability/Community_Involvement/Corporate_Philanthropy/

\section{Neighbors}

\begin{tabular}{|l|l|}
\hline Maple Avenue Residents & $\begin{array}{l}\text { Vanessa Bryant } \\
\text { vanessalyn614@gmail.com } \\
\text { Diamond Brown } \\
\text { iyceis100404@hotmail.com } \\
\text { Antionette Hines } \\
\text { antoinette.hines@fairmontstate.edu }\end{array}$ \\
\hline Jackson Addition Residents & $\begin{array}{l}\text { Pastors Leo and Regina Riley } \\
\text { leoriley01@gmail.com } \\
\text { christianlovemin@gmail.com } \\
\text { Colyn Jones } \\
\text { Colyn.Jones94@gmail.com }\end{array}$ \\
\hline Sterling Heights Residents & $\begin{array}{l}\text { Houston Richardson } \\
\text { hsrmoney@aol.com } \\
\text { Chris Nielsen } \\
\text { cnielsen@learningoptionsinc.org }\end{array}$ \\
\hline Shadyside Residents & $\begin{array}{l}\text { Howard Brooks } \\
\text { juniebrooks1965@gmail.com }\end{array}$ \\
\hline Bellview Residents & $\begin{array}{l}\text { Regina Bruce } \\
\text { reglynbruce@gmail.com } \\
\text { Ronnie Williams } \\
\text { rwilliams1@woodforest.com }\end{array}$ \\
\hline
\end{tabular}




\section{Appendix C: Process Facilitation Guides}

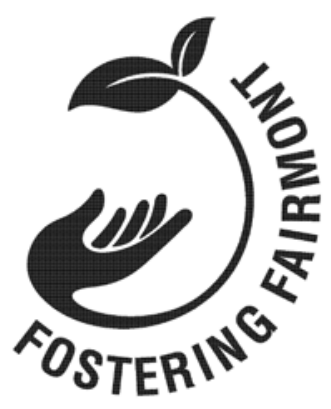

\section{Community Visioning Conversation Facilitation Guide}

The Fostering Fairmont project will host community visioning and planning sessions to develop a Neighborhood Quality of Life plan-a document that will guide the work of the Westside Action Coalition. These Community Conversations are the first step toward developing a shared vision.

\section{AGENDA}

Registration (allow 5 minutes late start)

- Sign-in

- Map your residence

- Receive and complete name tag (color coded random group assignment)

\section{Assembly (15 minutes)}

- Welcome and Introductions

- Housekeeping Notes

- Project Overview

- Review of the Agenda

Small Group Sessions (30 minutes)

- Ice breaker introductions

- Treasured Moments and Places

\section{Break (10 minutes)}

\section{Small Group Sessions (1 hour)}

- Paths to Progress (3 rounds)

- Team Building Exercise (yarn web)

- Participant evaluation

- Return forms and pens to the facilitators at the door-thank them for participating! 


\section{SET UP}

\section{Outside}

Post way-finding signs all over from street to parking to entrance door to meeting room and bathrooms.

Supplies needed:

- Blank signs

- Black Markers and Yellow Highlighters

- Blue tape

\section{Meeting Room Setup}

1. Registration table with 3 chairs at the entrance door

2. Kid's table with 6 chairs near the registration table

3. A screen or blank wall at the front with a table for supplies

4. A table for the projector sufficiently far from the wall with no obstructions

5. Five sets of square/round participant tables with 8-10 chairs at each one-one area empty for facilitator and scribe

6. A snacks and beverages table far into the room somewhere

7. Easels with Rules of Engagement posted at front and sides of room for easy reference from all locations

8. Two easels with flip charts at every table

Registration Table Supplies:

- Sign in sheets and two pens

- Map with yellow sticky dots for where people live

- Scissors to cut name tags into individual tags

- Color-coded name tags to be given randomly (to break up parties who came together)

- Black markers for name tags

- Give away trinkets (wristbands)

- Agenda/Fact sheets (2-sided)

- Bowl of candy

- Extra surveys and information cards

- T-shirts for sale by WAC

Kids’ Table Supplies:

- Paper

- Art supply and activities box

- Someone assigned to watch table (WAC member?)

Presentation Supplies:

- Projector, laptop, cables, speakers, power cord 
Facilitation Supplies for each Participant Table:

- 2 easels

- Blank sticky flip charts

- Pre-labeled no-stick charts: Idea Parking Lot; Useful Terms; Information Needs; Future Agenda Items

- Blue tape (1 roll)

- Treasured moments timeline chart

- Treasured places map

- Paths to Progress chart

- Multi-color marker sets (2)

- Ball point pens (15)

- Sticky notes (5 pads)

- Red dots for "problem" places and barrier voting (50)

- Yellow dots for "treasured" places (50)

- Green dots for "promising" places and ideal characteristics voting (50)

- Blue dots for overall assessment voting (50)

- 1 ball of yarn

- Rubber bands for rolled up charts

- 15 coins with a variety of dates

- Bowl of candy

- Participant Evaluations (10)

- Social Capital Survey (10)

- Westside Action Coalition Sign-Up Cards (10)

- Paper clips for sticky notes 


\section{REGISTRATION}

Welcome and Instructions - (1 greeter, 1 sign-in, 1 mapper, 1 directions)

Welcome people at the door as they come in and ask them to sign in — don't let them bypass the table if possible. Make sure table facilitators have the right color name tags!

Sign-in helper ask them to sign in and make a name tag-first name only. Mapper ask them to map where they live so we know how well distributed participants are. The map dots will be anonymous. Directions helper hand them an agenda/fact sheet and direct them to their colorcoded table.

\section{ASSEMBLY}

Welcome and Introductions_-WAC member present (3 minutes)

A WAC member will welcome community participants, explain the history of the Westside Action Coalition (WAC), and introduce other members present, along with the WVU Team. All WVU team members will be on hand at the front of the room. If WAC members are present who participated in a previous Community Conversation session, ask them to give a motivating assessment of the experience.

Housekeeping Notes—facility host representative or WAC member (2 minutes)

Provide information about bathrooms, parking, snacks, etc.

Project Overview—Margaret Stout (8 minutes)

Thank you for joining us! This meeting is one of four identical sessions being conducted this weekend. Your involvement now and in forthcoming Fostering Fairmont meetings is critical to ensure that the plans created reflect the community's vision. It takes the whole community to make change and improvements!

I'm going to use a presentation to provide an overview of the project, but you've also received a project Fact Sheet to take home with you (hold up).

Complete the project overview presentation...

Review of the Agenda—Margaret Stout (2 minutes)

OK, now that you have an idea of what we're up to, if you turn over the Fact Sheet to the Agenda, you'll see that our next activity is to work in groups at our tables. The rest of the meeting will be held in these smaller groups, so many thanks for your participation! I hope you enjoy your Community Visioning Conversation-I will be back sometime in May to report our results. So, watch the Westside Action Coalition Facebook page for meeting announcements! 


\section{BREAKOUT SESSIONS}

Even if you are familiar with facilitation techniques, you should become thoroughly acquainted with steps in this guide for activities which have been specifically designed for Fostering Fairmont. Please read these instructions carefully and familiarize yourself with them. This will ensure the work produced by your group is consistent with other groups.

Each small group will be assigned a facilitator and a scribe and will be given necessary supplies. Each small group will ideally have a maximum of 12 to ensure everyone can actively participate. Larger groups will need to be divided into smaller groups in which case each group leader will have to perform both Facilitator and Scribe functions. As a Facilitator, it is your responsibility to:

- Ensure the process goes smoothly

- Keep participants focused on the task at hand

As a Scribe, it is your responsibility to:

- Record the work of your group accurately and legibly (instructions below)

- Keep track of time and give three minute warnings

It is important to stay on schedule and not go over the time allotted for each activity. However, if you find that you have finished an activity in less than allotted time, move on to the next activity.

\section{Chart Writing Instructions}

- Label every flip chart using a black marker and small lettering:

- $\quad$ Last Name, Date, Time, Group Color, Exercise, Page \#

- If using an easel, angle it slightly so that it is legible but does not require you to turn your back fully to the group. Stand slightly to the side as you write so you don’t obstruct the chart as you write.

- Alternate natural colors that read well for most notes (blue, green, brown, purple).

- Use red, orange, and yellow to highlight or emphasize only (difficult to read).

- Letters should be 1-1.5 inches high—use block lettering.

- Minimize abbreviations and icons or be certain they are understood by participants and future recorders.

- Do not edit content or meaning — endeavor to use the same language as the participants. Ask for clarification if necessary to capture it correctly.

- Ask for a pause if necessary at any time for labeling or scribing.

- As charts are completed, move them to a wall to remain on display if possible.

- When the session is finished, place the charts in order and roll and rubber band to transport for later recording. 


\section{DIALOGUE SESSION SCRIPT}

\section{Welcome (2 minutes)}

Thank you for joining us for this Community Visioning Conversation. My name is and my partner scribe is . My role as facilitator is to make our work go as smoothly as possible.

On this chart are some ground rules we'd like to use to keep our conversation productive. I'd like to ask each one of you to agree to these rules or offer suggestions for changes or additions. (Read only the bolded words aloud and ask for agreement to each one-making eye contact for nods.)

\section{Rules of Engagement (3 minutes)}

- Be present - turn off cell phones and refrain from distracting side conversations.

- Participate as you feel comfortable-listening, talking, writing, or drawing.

- Share time - try to be brief.

- Show patient attention as others form and express their thoughts.

- Expect differences and seek understanding.

- Actively listen and ask questions.

- Challenge ideas, not people.

- Respect one another - there are no wrong perspectives or bad ideas.

- Respect the purpose - dialogue, not deliberation, or decision making.

- Be inquisitive - remain open to alternative perspectives and change.

- Seek creative, integrative ideas.

- Explore the boundaries of agreement for common ground.

- Volunteer, don't delegate others.

- Others?

Can we agree to these ground rules? Terrific!

We'll take a 10 minute break during our work together, but if anyone needs to step away for any reason, please feel free to do so. 


\section{Remember Exercise (10 minutes)}

OK, let's get started! We will begin with a fun exercise to get to know one another. It's called "I Remember." We're going to take a trip down memory lane.

(Scribe hands out coins, paying some attention to the date to be sure the person was probably alive then.)

1. First, look at the year on the coin. Take a minute to think about what you were doing when that coin was minted. Were you in school? Were you a child? Where did you work? Were you married? Where did you live? What was going on in your life at that time? What was the music of the day? If you were not yet born or prefer not to discuss anything during that year, please trade coins with someone else.

2. After you have had some time to remember what was happening then, we will share our memories. Let's take a few minutes to reflect. (Scribe times 3 minutes.)

3. Are we all ready? OK, I'll begin and then let's go around the circle and share our names and our memories! (Facilitator begins, Scribe goes next, round-robin.) 


\section{Treasured Moments Exercise (10 minutes)}

Thank you so much for sharing some things about your lives! This leads us right into our first visioning exercise, called "Treasured Moments." (Scribe lays out the timeline chart on the table or the wall, if available.) Our purpose is to learn about particular times in Fairmont's and the Westside neighborhoods' history that are important and hear some things that you all would like to see continue into the future.

(Facilitator hands out pens and 3 sticky notes to each participant.)

What I'd like you to do is think of at least three moments in time when something happened in the neighborhoods or Fairmont that you would like to see happening now or in the future. Please put the year or date at the top of the sticky note, then a brief, legible explanation of what happened. As you think of something, please place it on the chart in date order. As you can see we are moving from Fairmont's founding in 1843 to today, but feel free to mark events earlier in history if you'd like. If you need to move notes around to keep things in chronological order, that's fine. Also, please feel free to use both top and bottom of the chart.

(Scribe stays at the chart and helps people with chronological placement. Scribe times a total of 3-5 minutes if needed and gives people a 1-minute warning.)

OK, let's have a look at what we have here so that we are sure to understand your meanings!

(Facilitator reads each sticky note and asks for confirmation of understanding from the group.)

(Scribe replicates the list on a flip chart (re-writes) and clarifies as needed.)

This is wonderful!!!

Now we're going to do a very similar exercise, but instead of thinking about time, we're going to think about places. So, this exercise is called "Treasured Places."

(Scribe takes away the timeline chart and lays out a large map as Facilitator is introducing the exercise.) 


\section{Treasured Places Exercise (10 minutes)}

(Facilitator hands out strips of yellow, green, red, and blue sticky dots and more sticky notes if needed to each participant.)

Now our task is to think about places in the Westside neighborhoods that are important for different reasons. First, I'd like you to think about the places you most treasure. Please place a yellow dot on the map and write on a sticky note why you treasure that place. On the note, please name the location in some way, like street corners, neighborhood, place or landmark name, or address.

\section{(Scribe times about 3-5 minutes and provides a 1-minute warning.)}

(Facilitator places a number on each dot and corresponding sticky note and hands to the Scribe.)

(Scribe notes the number and replicates the reason given on the sticky note on the chart named Treasured-Yellow.)

Now let's think about places in the Westside neighborhoods that are troublesome. Please use a red dot and sticky note to indicate the place on the map and why it is a problem. On the note, please name the location in some way.

(Scribe times about 3-5 minutes and provides a 1-minute warning.)

(Facilitator places a number on each dot and corresponding sticky note and hands to the Scribe. Start numbering from 1 again.)

(Scribe notes the number and replicates the reason given on the sticky note on the chart named Problem-Red.)

Last, let's think about places in the Westside neighborhoods that have potential. Please use a green dot and sticky note to indicate the place on the map and why you think it could be even better than it is. On the note, please name the location in some way.

(Scribe times about 3-5 minutes and provides a 1-minute warning.)

(Facilitator places a number on each dot and corresponding sticky note and hands to the Scribe. Start numbering from 1 again.)

(Scribe notes the number and replicates the reason given on the sticky note on the chart named Potential-Green.) 
Wow! Great work! Let's take a 10-minute break. Please feel free to stretch your legs, grab a drink and a snack, or just chat with one another. We will begin the next exercise promptly in ten minutes!

\section{Break (10 minutes or less to stay on schedule) \\ Paths to Progress Dialogue (30 minutes)}

Now we'd like to turn to some of the issues we heard about on the Community Survey last fall. As was noted during the Assembly, it takes the whole community to make a place the best it can be-especially in an economy like ours where everyone has to pitch in to get things done. So we're going to think about what we can all do to make the Westside neighborhoods the very best they can be.

The purpose of this exercise is to explore Paths to Progress. Our job is to gather ideas and perspectives, not to judge them in any way. I will help keep the conversation moving in that direction, but let's all please remember our Rules of Engagement (point to the chart).

We have about 30 minutes, so we will be keeping time and it will be important to share time fairly so that everyone has a chance to participate.

(Scribe puts up Paths to Progress for Quality of Life on one easel and prepares to write lists on the other easel while Facilitator introduces.)

(Facilitator hands out some more sticky notes if needed.)

\section{Step One}

The first thing we'd like to talk about is the quality of life in the Westside neighborhoods. I want you to imagine that it's 10 years from now and the Westside Action Coalition has been hard at work in community development... What are our neighborhoods like now? Take a minute or two to write down some ideal characteristics on your sticky notes. Use one sticky note per idea.

(Give about 3 minutes for this activity.)

Is everyone about ready? OK, let's go around the circle and share your top three ideal characteristics. If we have time, we'll go around again. If not, we'll collect and use your sticky notes.

(Scribe notes list as Ideal Characteristics until finished. Use an asterisk to identify any duplicative ideas. When discussion is finished, move the list to the wall next to the poster diagram's “Ideal Characteristics.”) 


\section{Step Two}

OK, now please use one of your yellow sticky dots to vote for the characteristic you feel is most important. As you do this, please give us any sticky notes we might have missed so we're sure to have everything documented.

(Facilitator helps them place dots on the flip chart list so that all votes can be counted.)

(Scribe collects sticky notes and stacks them for documentation.)

Let's look at what we've identified as priorities...

(Facilitator points out which ideas have the most votes to frame next step)

\section{Step Three}

Thank you! Now, let's think about today... where do we stand in reaching these ideal characteristics? I want you to take a blue sticky dot and place it on the arrow where you rank the community on Quality of Life today:

1 means "Doing poorly, needs immediate action"

2 means "Needs improvement"

3 means "Average performance"

4 means "Doing well” and

5 means "Doing very well; a strong asset"

(Scribe helps people place dots on arrow so that all votes may be counted. Dots may go anywhere on or between a number. Do not stack dots.)

(When everyone is finished, Facilitator guides dialogue.)

Let's look at how we’ve ranked our community...

(Facilitator points out which ideas have the most votes to frame next step)

\section{Step Four}

Now let's talk about why these ratings were given. What are the barriers to progress?

(Facilitate discussion—no sticky notes this time.)

(Scribe notes list as Barriers to Progress until finished. Use an asterisk to identify any duplicative ideas. When discussion is finished, move the list to the wall under the poster diagram's “Barriers.”) 


\section{Step Five}

Which of these barriers seem to be the most problematic? Please use one of your red sticky dots to vote for the barrier you feel is most problematic.

(Facilitator helps them place dots on the flip chart list so that all votes can be counted.)

(Facilitator points out which ideas have the most votes to frame next step)

\section{Step Six}

Considering these barriers, what could we do differently to overcome them?

(Facilitate discussion—no sticky notes this time.)

(Scribe notes list as Ideas for Action until finished. Use an asterisk to identify any duplicative ideas. When discussion is finished, keep the list on the flip chart easel.)

\section{Step Seven}

Which of these ideas for action have the most immediate potential? Please use one of your green sticky dots to vote for the action you feel is most productive.

\section{(Scribe helps them place dots on the flip chart list so that all votes can be counted.)}

(Facilitator points out which ideas have the most votes to frame future steps)

Thank you for contributing to these community visioning conversations! As you can see, we have many terrific ideas just from our discussions together. There are four other sessions with more groups of neighbors and stakeholders who care about the Westside, so you can imagine how much input we will have to report back to you in May! If you've left us an email address at sign-in, you will receive an email with details for future dates as long as you signed in and provided an email address. 


\section{Team Building Exercise (10 minutes)}

The next thing we'd like to do is set the stage for community members to begin working together over the summer as we get ready for planning in the fall.

For this exercise, we all need to stand up in the circle. How this works is that each one of us is going to say one thing we love about the Westside neighborhoods, then take this ball of yarn, unravel a bit of it and hold onto the string of yarn while tossing the ball to another person in the circle. That person will repeat the process until we've all had a chance to share.

(Facilitator begins while the Scribe helps as needed while the process is completed. Scribe goes last. When everyone has finished, facilitator makes sense of it with them.)

OK, so what do we see here? As neighbors, all of us contribute to the web of life we share. We are already a team brought together by our shared history and places, our shared concerns and hopes, and the many things we love about the Westside neighborhoods. Individually, a single strand is weak, but as a collective, we form a strong web that can catch opportunities. If we think about these relationships and work to strengthen them, we can do great things together. So hold this in mind over the summer, engage in the Westside Action Coalition activities you are invited to join.

(Do not drop the web!)

\section{Process Evaluation (10 minutes)}

Before we drop the web, I do have one more thing to ask of you... Please complete this evaluation form and survey (hold up both) and drop them off at the registration table on your way out. If you are interested in receiving emails about the project as it moves along, also fill out one of these information cards (hold up). All of this information is important for us to be able to do good work with you!

Afterwards, you turn those in, we'll give you a wristband to thank you for your participation today. Let's go ahead and drop the web so you can fill those out!

(Drop the web)

(Scribe hands out evaluation form, social capital survey, and WAC email list sign-up cards.)

\section{EXITING (5 minutes)}

Thank you!-(two students)

(Collect evaluations, surveys, information cards, and pens. Hand out wristbands and say thank you! T-shirts will also be available for sale by WAC members.) 


\section{PREPARE FOR NEXT SESSION/CLEAN UP}

- Ensure that every flip chart is properly labeled.

- Roll every page of charts in order into one roll and rubber band together.

- Write the date, time, and facilitator \& scribe name on the outside in marker.

- Return all pens and supplies to their containers.

- Bring all charts and supplies to the sign-in table for storage until departure. 


\section{Appendix D: Public Relations Materials}

\section{Media Contacts}

Times West Virginian

Email: timeswv@timeswv.com

Editor: Misty Poe

304-367-2523

Web: http://www.timeswv.com/site/contact-us.html

WBOY TV

Fax: (304) 623-9269

Newsroom: (304) 326-6758

Web: http://www.wboy.com/category/224266/about-wboy

WDTV

Email: news@wdtv.com

Fax: (304) 842-4604

Phone: 304-848-5000

Web: http://www.wdtv.com/wdtv.cfm?section=Contact-Us

WVAQ 102 (FM)

Email: publicservice@wvradio.com

Web: http://wvaq.com/submit-a-psa/

Time Warner Cable (Clarksburg)

https://www.connectamillionminds.com/request-support

Fairmont State University

eNews listserv 


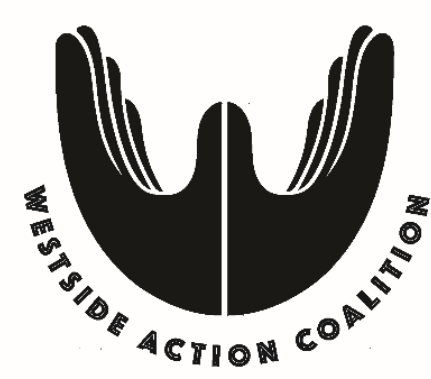

\section{Who are we?}

Residents in five Fairmont neighborhoods:

- Jackson Addition

- Maple Avenue

- Sterling Heights

- Shadyside

- Bellview

The Westside Action Coalition is working to make our neighborhoods a better place to live! Join the team-we're building unity in the community!

Each member stands ready to help the effort, but we need to know more about what we all want and need. Let's make an action plan and work together to create a better future for our Westside neighborhoods!

For more information, please contact Diamond Brown: wac2015wv@gmail.com.

\section{Stay posted! Get involved!}

\section{Find us on $f$}

Westside Action Coalition Fairmont, W.Va

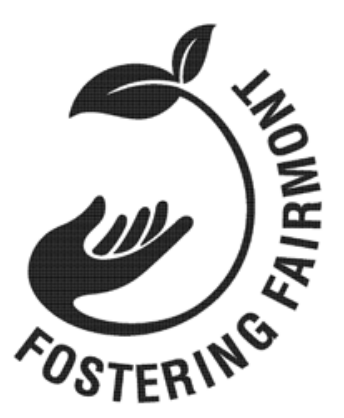

What's happening?

West Virginia University faculty and students are doing outreach and service learning work in support of the Westside Action Coalition over four semesters (2015-2017):

1. Learn about the Westside neighborhoods, Fairmont, and Marion County;

2. Mobilize and organize neighborhood residents, business owners, and nonprofits while inviting other Fairmont stakeholders to the table;

3. Help the Westside Action Coalition vision and plan for the neighborhoods' future; and

4. Start projects and programs that will help realize the shared vision.

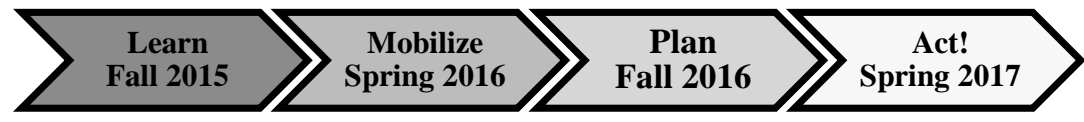

For more information, please contact Margaret Stout: margaret.stout@mail.wvu.edu

\section{Find us on $f$}

Westside Action Coalition Fairmont, W.Va
WACFairmont.wix.com/site 


\section{What's Next?}

Community Celebration

April 2, 2016 (April 9th Rain Date)

Windmill Park

Noon to 4:00 p.m.

Community Visioning Conversations

April 29 \& 30

See flyer for locations and times!

WAC Event

June

Locations and times TBD

WAC Event

July

Locations and times TBD

Community Services and Jobs Fair August

Locations and times TBD

Welcome Back WVU Team

September

Location and time TBD

Neighborhood Planning

October

Locations and Times TBD

Neighborhood Plan Presentation December

Location and Time TBD

Project Prioritization and Selection February 2017

Location and Time TBD

Action Team Meetings

March, April 2017

Project 1 Groundbreaking May 2017

\section{What's Next?}

Community Celebration

April 2, 2016 (April 9th Rain Date)

Windmill Park

Noon to 4:00 p.m.

Community Visioning Conversations April 29 \& 30

See flyer for locations and times!

WAC Event

June

Locations and times TBD

WAC Event

July

Locations and times TBD

Community Services and Jobs Fair August

Locations and times TBD

Welcome Back WVU Team

September

Location and time TBD

Neighborhood Planning

October

Locations and Times TBD

Neighborhood Plan Presentation December

Location and Time TBD

Project Prioritization and Selection

February 2017

Location and Time TBD

Action Team Meetings

March, April 2017

Project 1 Groundbreaking

May 2017 


\section{CommUNITY Cookout Outreach Email}

Subject: Fostering Fairmont

Hello,

The Westside Action Coalition was formed by residents from five Fairmont neighborhoods: Jackson Addition, Maple Avenue, Sterling Heights, Shadyside, and Bellview. The members of this volunteer community group are joining together to make these neighborhoods a better place to live- they are building unity in the community!

The Coalition will kick off with a CommUNITY Cookout in Windmill Park on April $2^{\text {nd }}$ from noon to 4:00 p.m. (rain date of April $9^{\text {th }}$ ). This event will not only let neighbors know what's happening on the Westside, but it will be fun for the whole family. The event is free and everyone is encouraged to attend!

I'm a graduate student at WVU participating in a service learning project in Fairmont. We are supporting the WAC and my goal is to encourage [youth, businesses, etc.] to get involved. May we count on you as one of our supporters? We would appreciate your help in getting the word out. Attached is a flyer to pass out or forward by email.

Many thanks for your assistance!

PS...Like us on Facebook and follow us on Instagram and Twitter! 


\section{CommUNITY Cookout Press Release}

Diamond Brown

Westside Action Coalition

Fairmont, WV

304-282-6588

NEWS RELEASE

DATE: March 18, 2016

FOR IMMEDIATE RELEASE

Westside Action Coalition to Host "CommUNITY Cookout"

FAIRMONT, W.Va. - Residents from five Fairmont neighborhoods_-Jackson Addition, Maple Avenue, Sterling Heights, Shadyside, and Bellview-have joined together to make their neighborhoods a better place to live. The Westside Action Coalition will kick off their efforts with a “CommUNITY Cookout” on April $2^{\text {nd }}$ from 12:00 p.m. to 4:00 p.m. in Windmill Park on Ogden Avenue. This family event is free and open to the public.

The volunteer community group will work with the City of Fairmont, Marion County, and a variety of community-based partners to develop projects and programs, including the MAC (Fairmont Community Youth Development Center), Dunbar School Foundation, Marion County NAACP, Main Street Fairmont, Fairmont Community Development Partnership, and Learning Options. The Coalition is also partnering with a team of West Virginia University faculty and students to develop a community-driven action plan over the coming year. This "Fostering Fairmont” project is being led by Margaret Stout, Associate Professor of Public Administration.

The Westside Action Coalition invites neighbors to join the team and watch for upcoming meetings.

For more information about joining the Westside Action Coalition or attending the CommUNITY Cookout, please contact Diamond Brown at 304-282-6588. 


\section{Community Visioning Conversations Press Release}

Margaret Stout

Associate Professor, WVU Department of Public Administration

304-293-7978

margaret.stout@mail.wvu.edu

NEWS RELEASE

DATE: April 14, 2016

FOR IMMEDIATE RELEASE

\section{Westside Action Coalition to Hold “Community Visioning Conversations”}

FAIRMONT, W.Va. - The Westside Action Coalition, a volunteer group comprised of neighbors from Fairmont's west side_-Jackson Addition, Maple Avenue, Sterling Heights, Shadyside, and Bellview, will hold “Community Visioning Conversations” on Friday, April 29 and Saturday, April 30. These conversations are the first steps in a year-long, community-driven process designed to create a neighborhood plan and develop projects and programs that will help make the Westside a better place to live. That's why everyone’s voice needs to be heard.

While each session will be identical, four options will be offered to meet people's scheduling needs: Friday from 2-4 p.m. in the Dunbar School Annex building at 101 High Street; Friday from 6-8 p.m. in the Morning Star Baptist Church at 100 McKinney Street; Saturday from 10 a.m. - 12 p.m. in the United Methodist Church at 204 Highland Avenue; and Saturday from 2-4 p.m. in the Dunbar School Annex building at 101 High Street. These meetings are open to all Westside residents, property owners, and business owners. Children and youth are welcome to join their parents. Each conversation will be facilitated by a team of faculty and graduate students from West Virginia University. The aggregated results will be reported in May at a public meeting to be announced.

The Westside Action Coalition invites neighbors to join the team in its efforts to make the Westside community a better place to live. Their CommUNITY Cookout in Windmill Park 
on April $2^{\text {nd }}$ drew about 300 neighbors and stakeholders together to celebrate community and launch their efforts. In addition to working with West Virginia University, the Coalition is working with a variety of community-based partners, including The MAC (Fairmont Community Youth Development Center), Dunbar School Foundation, Marion County NAACP, Main Street Fairmont, Fairmont Community Development Partnership, Learning Options, the City of Fairmont, Marion County, MCPARC, and Fairmont State University. For more information about the Westside Action Coalition, please contact Diamond Brown at 304-282-6588 or wac2015wv@gmail.com or find them on Facebook and the internet. For more information about the Community Visioning Conversations, please contact WVU Associate Professor Margaret Stout at 304-293-7978 or margaret.stout@mail.wvu.edu. 


\section{Public Service Announcement: Community Visioning Conversations}

Diamond Brown here from the Westside Action Coalition. Join us in making Fairmont's

Westside neighborhoods a better place to live! We're building unity in the community and

making a plan for action. So join one of our Community Visioning Conversations on April $29^{\text {th }}$ or $30^{\text {th }}$ and make your voice heard! Check us out on Facebook or the web: That's Westside, all one word, Action Coalition, Fairmont W.Va! 


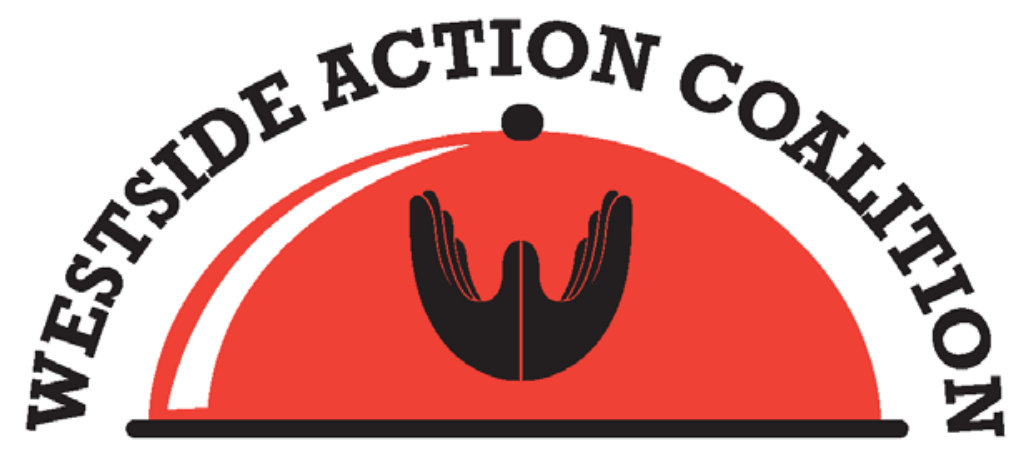

Sterling Heights | Jackson Addition

Maple Avenue | Bellview | Shadyside

COMMUNITY
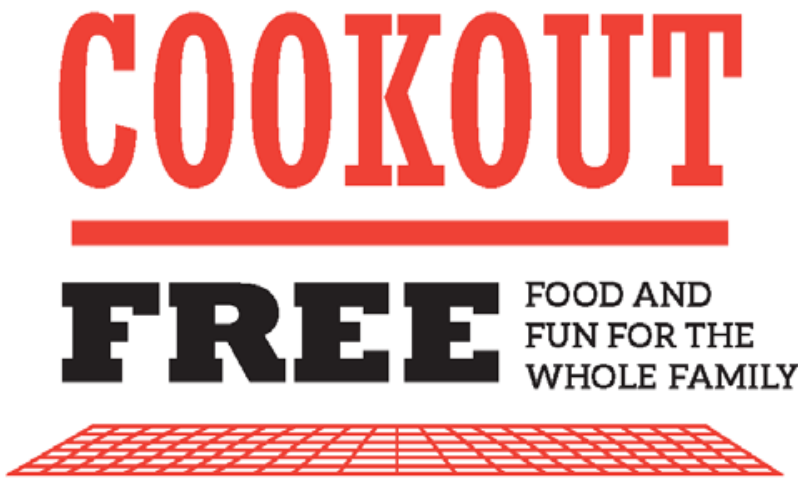

\section{April 2ND | 12-4 ${ }^{\mathrm{PII}}$}

\section{Windmill Parlz}

Ogden Avenue, Fairmont, WV

Rain Date: April 9th

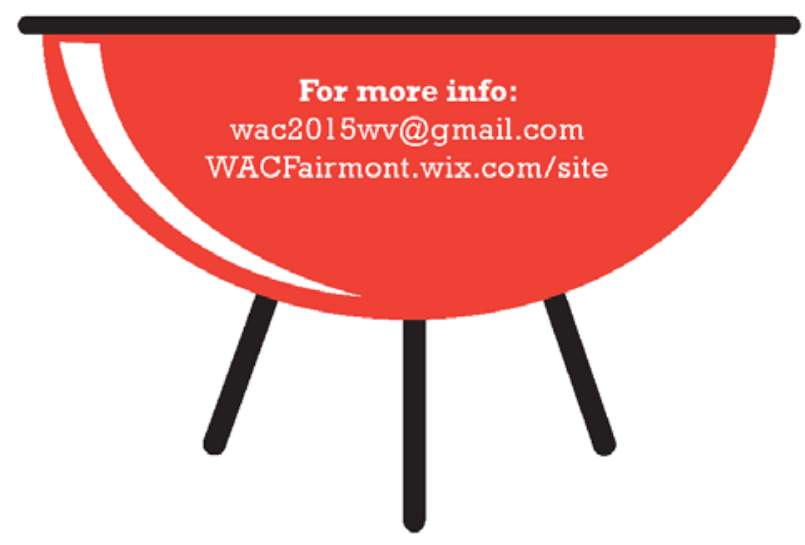


What do you want to see in our neighborhoods-this year, in five years, in ten years? Help shape the vision the Westside Action Coalition will pursue with its partners!

Choose a session that fits your scheduleChildren are welcome!

Friday April 29

2:00-4:00 p.m.

Dunbar School Annex

101 High Street

6:00-8:00 p.m.

Morning Star Church

100 McKinney Street

\section{Saturday April 30}

10:00 a.m.-Noon 2:00-4:00 p.m.

United Methodist Dunbar School Annex

204 Highland Ave. 101 High Street

\section{COMMUNITY VISIONING CONVERSATIONS}

Each repeating session will be facilitated by a team of faculty and graduate students from West Virginia University. They will report the results in May.
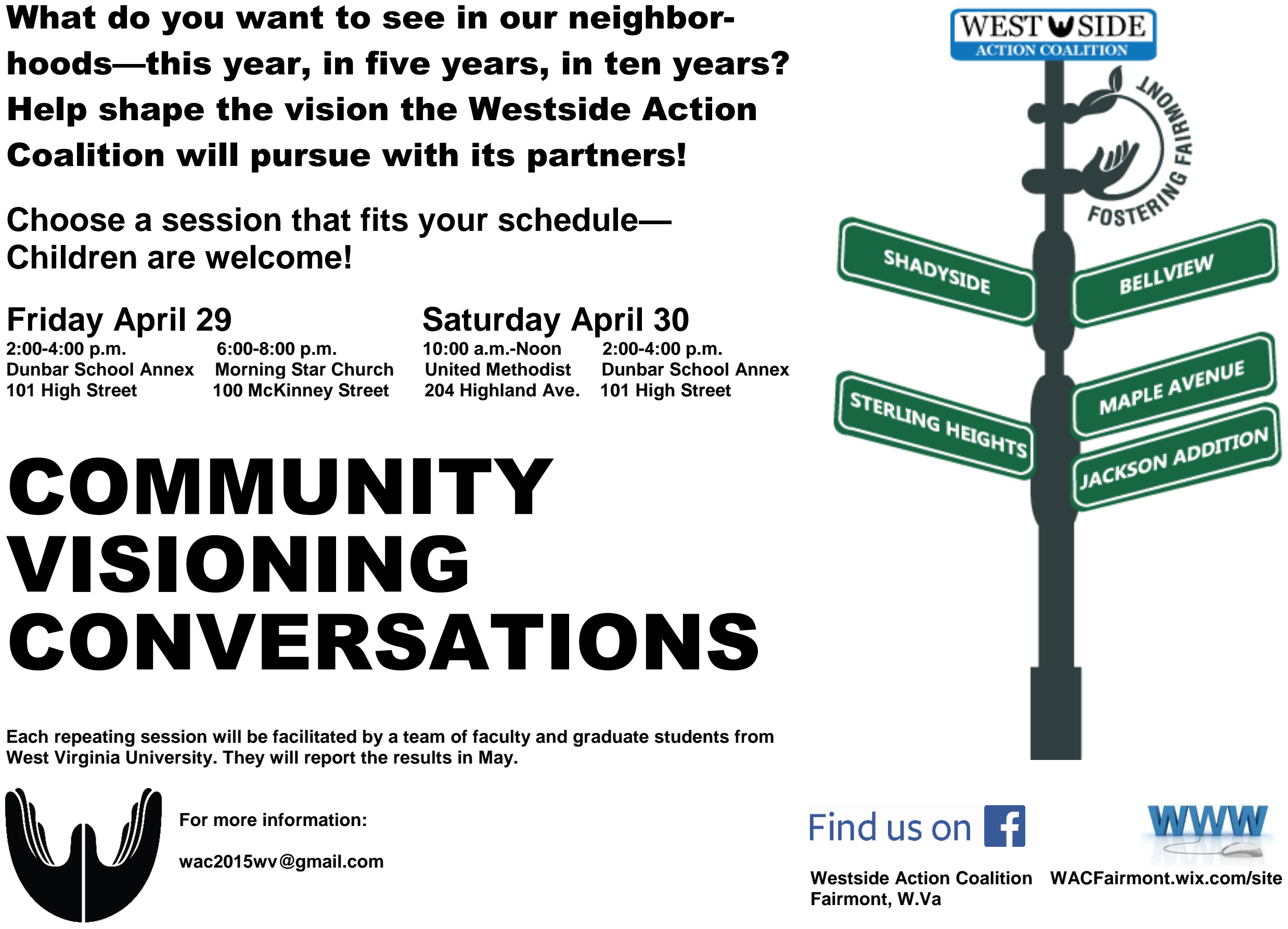

For more information:

wac2015wv@gmail.com 
Social Media Login Credentials

\section{Twitter}

Handle: @WACFairmont

Password: Fairmont123

Instagram

Handle: @WACFairmont

Password: fairmont123

Facebook.com

Westside Action Coalition Fairmont, W.Va

Email: fosteringfairmont@gmail.com

Password: fairmont123

Website: wix.com

http://www.WACFairmont.wix.com/site

wac2015wv@gmail.com

WACfairmont

Youtube

wac2015wv@gmail.com

westsideac

Hootsuite

wac2015wv@gmail.com

WACfairmont 


\section{Appendix F: Evaluation Forms}

\section{West Virginia University Department of Public Administration}

\section{Service Learning Evaluation Form}

Instructions: Please fill out the evaluation form to provide the professor and the students with feedback on your experience with the service learning project. Specific comments and suggestions would be appreciated in the space below. This form will be shared with the students and contributes to their final grade for the course. If there are additional comments you wish to provide you can email them to me separately. Please return the form to Margaret Stout (margaret.stout@mail.wvu.edu) by DATE.

\section{Name of Community:}

\section{Your Organizational Affiliation:}

\section{Activity and Date:}

\begin{tabular}{|c|c|c|c|c|c|c|c|c|}
\hline Evaluation Criteria & N/A & & llent & & isfa & & & \\
\hline & & A & A- & $\mathrm{B}+$ & $\mathrm{B}$ & B- & $\mathrm{C}+$ & $\mathrm{C}$ \\
\hline $\begin{array}{l}\text { Professor led the service project in a } \\
\text { professional manner (organized, } \\
\text { understandable, transparent) }\end{array}$ & & & & & & & & \\
\hline $\begin{array}{l}\text { Students acted in professional manner } \\
\text { (prompt, maintained appropriate contact) }\end{array}$ & & & & & & & & \\
\hline $\begin{array}{l}\text { Professor and students had sufficient } \\
\text { knowledge to meet project purposes }\end{array}$ & & & & & & & & \\
\hline $\begin{array}{l}\text { Professor and students actively listened to } \\
\text { community needs and suggestions }\end{array}$ & & & & & & & & \\
\hline $\begin{array}{l}\text { Extent to which the deliverable fulfilled the } \\
\text { terms of the Memorandum of Understanding } \\
\text { (MOU) }\end{array}$ & & & & & & & & \\
\hline $\begin{array}{l}\text { Professionalism of the final report } \\
\text { (style, appearance, grammar) }\end{array}$ & & & & & & & & \\
\hline $\begin{array}{l}\text { Organization of the final report } \\
\text { (easy to follow and find key information) }\end{array}$ & & & & & & & & \\
\hline $\begin{array}{l}\text { Persuasiveness of the conclusions and } \\
\text { recommendations in the report }\end{array}$ & & & & & & & & \\
\hline Overall quality of the in-person presentation & & & & & & & & \\
\hline $\begin{array}{l}\text { Overall evaluation of the quality of service } \\
\text { delivered }\end{array}$ & & & & & & & & \\
\hline
\end{tabular}

\section{Comments and Explanation for Ratings:}




\section{Participant Satisfaction Survey}

Please take a moment to provide us with some feedback regarding your experience. Your input is important to continuous improvement of public meetings. You can use the back of the sheet for additional comments if needed. Thank you for your time!

1. Please check the box that applies to indicate your rating of each item:

Meeting Location

\section{Poor}

\section{Good}

\section{Excellent}

Meeting Day

Meeting Time

Meeting Facilities

Refreshments

Topic

Materials/Handouts

Presentations

Facilitators

Group Size

Length of Meeting

2. What did you like most about this experience? (Please print.)

3. What would you change? (Please print.)

4. Should this type of gathering be used in the future? Yes $\square$ No $\square$ Why? (Please print.)

5. Please provide us any other comments to assist in improving this process or project (please print). 


\section{COMMUNITY \\ VISIONING \\ CONVERSATIONS}

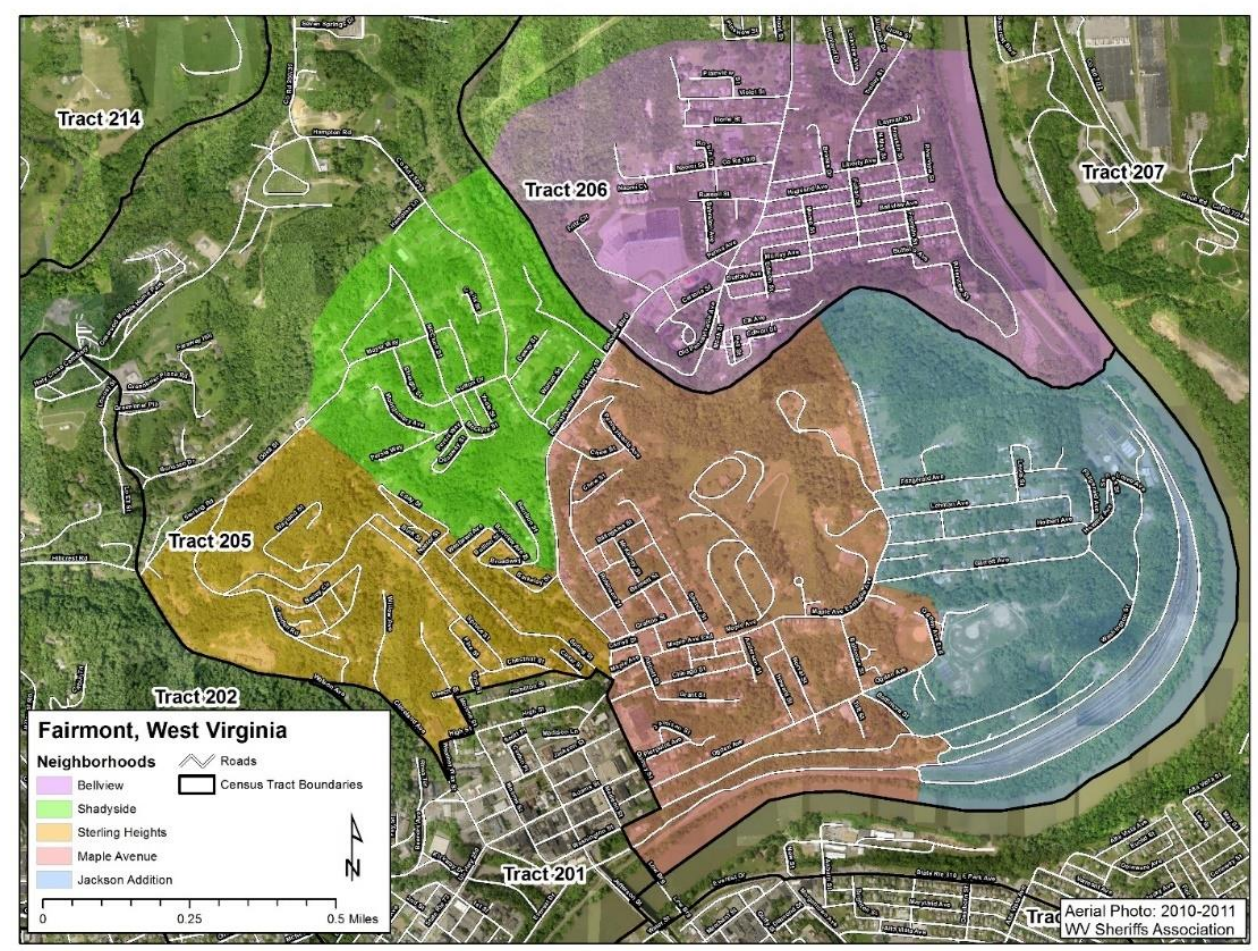

Fairmont's Westside Neighborhoods

This report summarizes the results of Community Visioning

Conversations held April 29th and $30^{\text {th }}$ of 2016 . The comments are organized using the community capitals model. The themes were used to craft Vision and Value statements that will guide forthcoming neighborhood action planning efforts. 
Submitted by:

Margaret Stout

Associate Professor

Department of Public Administration

John D. Rockefeller IV School of Policy and Politics

West Virginia University

PO Box 6322 / 325 Willey Street

Morgantown WV 26506-6322

304-293-7978

Margaret.Stout@mail.wvu.edu

\section{Student Facilitators:}

Chris Agba

Marissa Angellatta

Ruthana Beezley

Gaillynn Bowman

Leah Cunningham

Daniel Eades

John Ferguson

Lacie Geary

Courtni Helmick

Breanna Kreutzer

Amy Loomis

Ashley Morgan

Dylan Opyoke

Robert Riddle

Chelsea Slade

Michelle Sloane

Shanequa Smith 


\section{Community Visioning Conversations}

\section{FAIRMONT'S WESTSIDE NEIGHBORHOODS}

\section{PROJECT BACKGROUND}

In spring 2015, a group of community members from the west side of Fairmont decided they wanted to improve the quality of life in their neighborhoods. These community members realized that if they received the technical assistance needed to guide their passion for improving their community, they could become a driving force for community and economic development. Collectively, these group members also serve on the boards of the Fairmont Community Youth Development Center, the Dunbar School Foundation, and the Marion County NAACP. This core group formed the Westside Action Coalition (WAC), an expanding group of neighbors and representatives from community-based organizations who are willing to work together in a collaborative effort to build community and economic sustainability within their community. The area of focus includes several Westside neighborhoods: Jackson Addition, Maple Avenue, Sterling Heights, Shadyside, and parts of Bellview. The WAC invites other community members, businesses, agencies, and government representatives to join this growing movement to foster community and economic development in these neighborhoods.

The WAC is receiving technical assistance through a two-year agreement with West Virginia University (WVU) faculty and students who specialize in community and economic development. This initiative is called the Fostering Fairmont project, which is designed to assist community members who want to see the assets in their community be put to better use. The project's purpose is to equip neighbors with the tools necessary to enhance their neighborhood through learning, mobilizing, planning, and then acting on the strategies necessary to enhance their community. The Fostering Fairmont project includes four phases:

- The first phase began in fall 2015. Activities focused on learning about the community through community stakeholder meetings, neighborhood tours, and secondary research. This information was compiled in a Community Profile report, which is a powerful tool for learning about the community's assets and conducting resource development. Workshops were also provided to build community capacity on understanding local governance, community development, and community organizing.

- The second phase was initiated in spring 2016 with a dual focus. The first objective was to equip the WAC with a Public Engagement Plan that contains information about the Fostering Fairmont project, guidance on how to effectively engage community members, and a list of stakeholders and resources that can assist residents with their community enhancement initiatives. The second objective was to document the vision residents have for their neighborhoods. This was achieved by facilitating Community Visioning Conversations. The results identified shared values, visions, and ideas about community issues and potential action.

- In fall 2016, the third phase will bring community members, businesses, agencies, and government representatives to the table with experts on tap to develop a Neighborhood Action Plan, which will be used to guide residents and partners in their collaborative efforts to strengthen their community socially, economically, and physically. This phase includes field inventories guided by community stakeholders.

- In spring 2017, the fourth phase will focus on action. Community stakeholders will prioritize the strategies in the Neighborhood Action Plan, select projects to launch, and work collaboratively to implement them. Stakeholders will learn about how they can work together effectively and what part they can play in making the community's vision a reality. 
The Fostering Fairmont project is designed to follow the theory of asset-based community development $(A B C D)$. The $A B C D$ approach establishes a positive outlook by focusing on capacities rather than deficiencies, empowers residents to create positive change within their community "from the inside out", and emphasizes the importance of relationships in achieving shared purpose (Kretzmann \& McKnight, 1996). The successful implementation of a neighborhood action plan depends on the level of community capacity, which is the synergy created by combining human, social, organizational, and political resources (Chaskin, 2001). Therefore, building community capacity through training and technical support is key to the success of any community development initiative. Leader mentoring, community meetings, and learning workshops are used to build community capacity. This community development approach employs inclusive, participatory, and collaborative methods that are most democratic and effective (IAP2, 2007; Kaner et al., 1996). The technical assistance providers work with the community, rather than simply doing things for it, or worse, to it.

To understand a community's capacity, the $A B C D$ approach begins with assessing community assets, emphasizing the human and social capacities in place. The Fostering Fairmont project uses the more comprehensive community capitals framework (CCF) (Flora, Flora and Fey, 2003), which identifies and analyzes the key elements that contribute to a community's vitality and provides insight to how each asset can be used to grow and strengthen other assets within a community (Emery \& Flora, 2009). The CCF works well in participatory practice because both planners and community stakeholders identify community assets, combining inside and outside perspectives.

Specifically, we consider the CCF capitals: natural; cultural; human; social; political; financial; and built types. Following comprehensive community initiatives (Chaskin, 2001) and collaborative approaches to community development list (Chrislip, 2001), we add organizational capital to this set. Natural capital consists of environmental resources, geographic location, natural beauty, and climate. Cultural capital comprises the history, traditions, worldview, and language of residents. Human capital includes the skills and abilities used to access knowledge and resources, identify effective practices, and provide leadership that "leads across difference" in an inclusive and participatory manner. Social capital represents the relational connections among individuals and organizations that enable communities to function more cooperatively and effectively. Political capital includes the access to power and the ability to influence public policy either directly or through representatives. Organizational capital includes the collective capacity for action of groups serving the community. Financial capital includes the resources available to invest in development. Built capital is the man-made infrastructure within a community, including buildings, roads, sidewalks, and utilities.

The community capitals framework was used in the Community Profile to provide information about the neighborhoods and was used to guide development of the Public Engagement Plan. This framework was also used to analyze the responses from participants in the Community Visioning Conversations.

\section{References}

Chaskin, R., (2001). Building community capacity: A definitional framework and case studies from a comprehensive community initiative. Urban Affairs Review, 36, 3, 291-323.

Chrislip, D. D. (2002). The Collaborative Leadership Fieldbook. San Francisco: Jossey-Bass.

Emery, M., \& Flora, C. (2006). Spiraling-up: Mapping community transformation with the community capitals framework. Community Development, 37, 1, 19-35.

Flora, C. B., Flora, J. L., \& Fey, S. (2003). Rural communities: Legacy and change. Boulder, CO: Westview Press. 
International Association for Public Participation (IAP2). (2007). Spectrum of public participation. Louisville, CO: International Association for Public Participation.

Kaner, S., Lind, L., Toldi, C., Fisk, S., \& Berger, D. (1996). Facilitator's guide to participatory decision-making. Gabriola Island, BC: New Society Publishers.

Kretzmann, J. P., McKnight, J. (1993). Building communities from the inside out: A path toward finding and mobilizing a community's assets. Evanston, IL: The Asset-Based Community Development Institute, Institute for Policy Research, Northwestern University. 


\section{FACILITATED DIALOGUES}

On April $29^{\text {th }}$ and $30^{\text {th }}$ of 2016 , community residents and stakeholders of Fairmont's Westside neighborhoods were invited to share their past experiences and future desires for their community in a series of Community Visioning Conversations. The purpose of these sessions was to gather information to identify shared values and develop a shared vision for the Westside neighborhoods. This information will also be used to determine what type of expertise and resources are needed to develop a Neighborhood Action Plan to strengthen the assets within these neighborhoods and realize the community's vision. A series of conversations were held in different neighborhoods, on several different days, and at various times to accommodate participants' scheduling needs. Each session was designed to be as identical as possible, with facilitators using the same guide for presentations and activities. A total of 42 community members from around the neighborhoods participated in the five sessions held (see Figure 1).

\section{FIGURE 1: COMMUNITY VISIONING CONVERSATIONS PARTICIPANTS}

\section{Community Visioning Conversations}

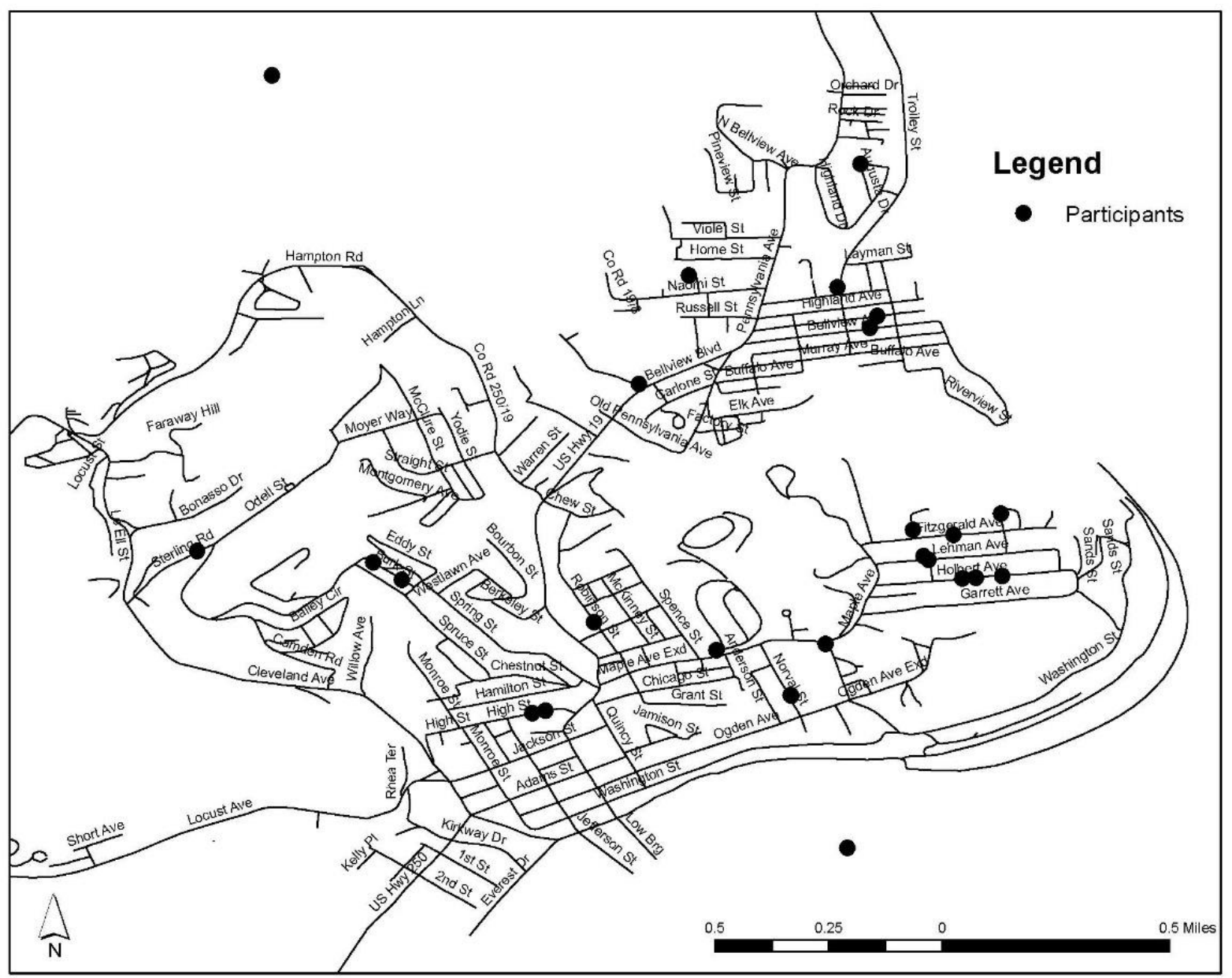

While this is a relatively small turnout, we acknowledge that participatory practices are unfamiliar in this community. Skepticism is to be expected when people haven't experienced their voice influencing decision makers. Trust builds slowly in such situations, and it may require ongoing proof. However, the willingness to try 
can be inspired by the residents themselves. As one Conversation participants noted, mobilizing requires "Talking to community members while out in public (grocery stores, sporting events, bowling alley, etc.) to try and get them involved with community instead of handing out flyers and using social media". While adequate communications were made in the newspapers, on the radio, through internet web sites and social media, flyering to homes, businesses, and churches, and emails to stakeholders, public outreach alone will never be enough. The only successful tactic in community organizing is word of mouth from family, friends, and neighbors, along with encouragement from community and church leaders. In short, so long as the Fostering Fairmont project team continues its community-driven responsiveness, future success is largely in the hands of the Westside Action Coalition members.

The dialogue exercises were designed as open-ended conversations, divided into three parts: (1) a sense of history dialogue, (2) a sense of place dialogue, and (3) a paths to progress dialogue. The sense of history dialogue is designed to capture historical events that participants value and would like to see continued or reinstated in their community. The sense of place dialogue pinpoints places that participants view as treasured, troublesome, and promising. The paths to progress dialogue is used to identify characteristics of an ideal community, where the community stands in achieving those ideals, barriers to progress, and ideas about action steps that can be taken to overcome identified barriers and sustain or develop desired ideal community characteristics.

Appendix A provides the results of the Participant Satisfaction Survey that was distributed at each of the Community Visioning Conversations sessions. The results show a very high level of satisfaction with the process and a desire to continue using this approach as the project moves forward. So, the Fostering Fairmont team knows that it is using the right practices.

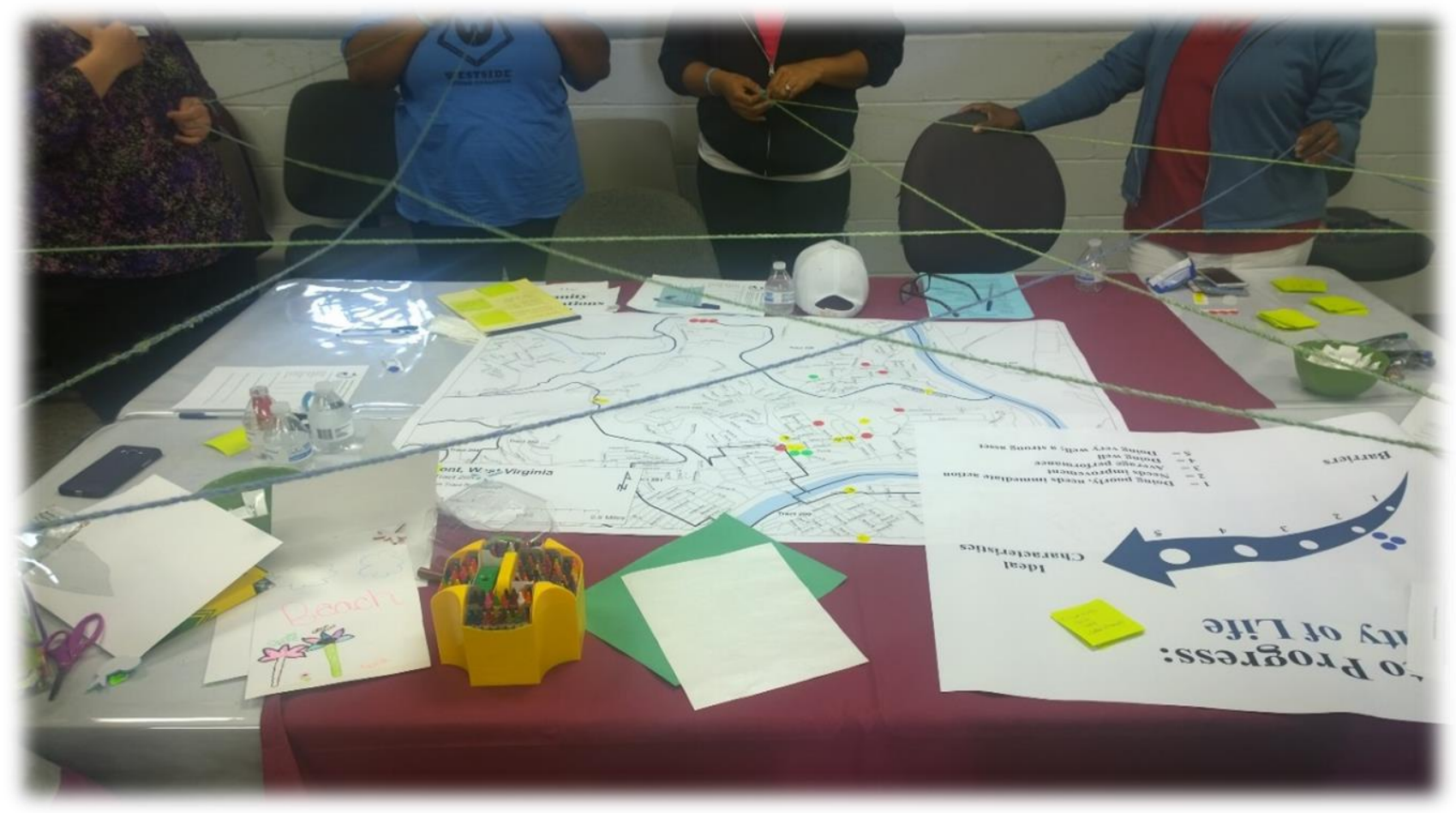




\section{SENSE OF HISTORY DIALOGUE RESULTS}

\section{Treasured Moments}

After a fun icebreaker exercise designed to get people thinking about the past, the Treasured Moments exercise asked participants to share important historical moments that they would like to see continue into the future. As shown in Appendix B, the historical events mentioned reveal community members' deep historic roots in their neighborhoods and valued memories of a more vibrant community than exists today. These treasured moments also demonstrate the importance of actively investing in community capitals and the impact community capitals have on the quality of life.

The value of social capital was evident in the many comments that spoke of family life and family homes. Many of the most treasured moments were of community events that brought neighbors together, such as carnivals, fairs, and art activities at Windmill Park, holiday parades, Taste of Fairmont, community Thanksgiving services and churches, and the Elks Club. Of particular note were stories about neighborhood block parties and mutual aid: "People in the community made provisions for food and provided them to families in need." In the Bellview neighborhood, both the closure of Barnes Elementary and the restoration of the park-twice-brought neighbors together to fight for what they value. Both the ravages of drug use and its diminishment were noted periods in the neighborhoods' history.

Nearly as frequent were comments made about the built capital of the neighborhoods. While some comments referred to commercial areas in downtown and beyond, there was a clear wistfulness for neighborhood businesses that have since been lost: "People didn't have to leave the neighborhood to go get things, mostly everything they needed was there." Participants also noted the importance of public investment in transportation infrastructure and recreational facilities.

Pride in the neighborhoods' unique cultural capital as a historically largely African American community was evident in numerous references to "Black owned" businesses like the "fish market outside of people's homes the business was run out of the kitchen" and Dunbar School, while acknowledging the importance of desegregation and positive race relations in Fairmont as evidenced in the "first Black-White football game played in WV at East-West Stadium amidst tension following Brown-Topeka, Kansas Supreme Court [decision]". Comments also reflect appreciation for the opportunities for arts and cultural activities ranging from the Opera House and concerts in Windmill Park to Gabe's nightclub and live music venues. Finally, participants made note of the neighborhood's Woodlawn Cemetery "which has historic significance as the burial ground for politicians and civil war heroes" and a general appreciation for Fairmont's historic character.

In terms of human capital, it is clear that participants highly value education and educational attainment. Both formal education through the public schools and Fairmont State University were noted, in addition to many different types of formal and informal youth development opportunities, from "People learned things on the playground (swimming, chess, tether ball, etc.)" to "Rocket Competitions with science department @ Dunbar."

In regard to financial capital, comments focused on small local enterprise and employment, alongside large employers such as coal mining (past) and oil and natural gas (current), manufacturing such as Phillips Lighting, Aluminum, and Owens Illinois (past) and the West Virginia High Tech Center (current), and government jobs with Marion County, as Fairmont is the County Seat. 
Organizational capital was noted in several groups that serve the Westside neighborhoods, including the Fairmont Community Development Partnership, the Family Resource Network, and the BAD (Brownfields, Abandoned, and Dilapidated) Building Team.

An appreciation for political capital was evident in comments about a visit from President John F. Kennedy as well as the City of Fairmont's efforts to inform residents through the Fairmont 101 program and its Facebook page.

Natural capital was not left out of the history, with participants noting events at Windmill Park, Bellview Park, and Palatine Park. 


\section{SENSE OF PLACE DIALOGUE RESULTS}

In this dialogue, participants were asked to describe and mark on a large-scale map particular types of places, including those that are treasured, troublesome, or are promising (see Figure 2). Comments explained why each place was identified in these categories. These results provide guidance to field inventories in the planning process.

\section{FIGURE 2: SENSE OF PLACE DIALOGUES}

\section{Sense of Place Dialogues}

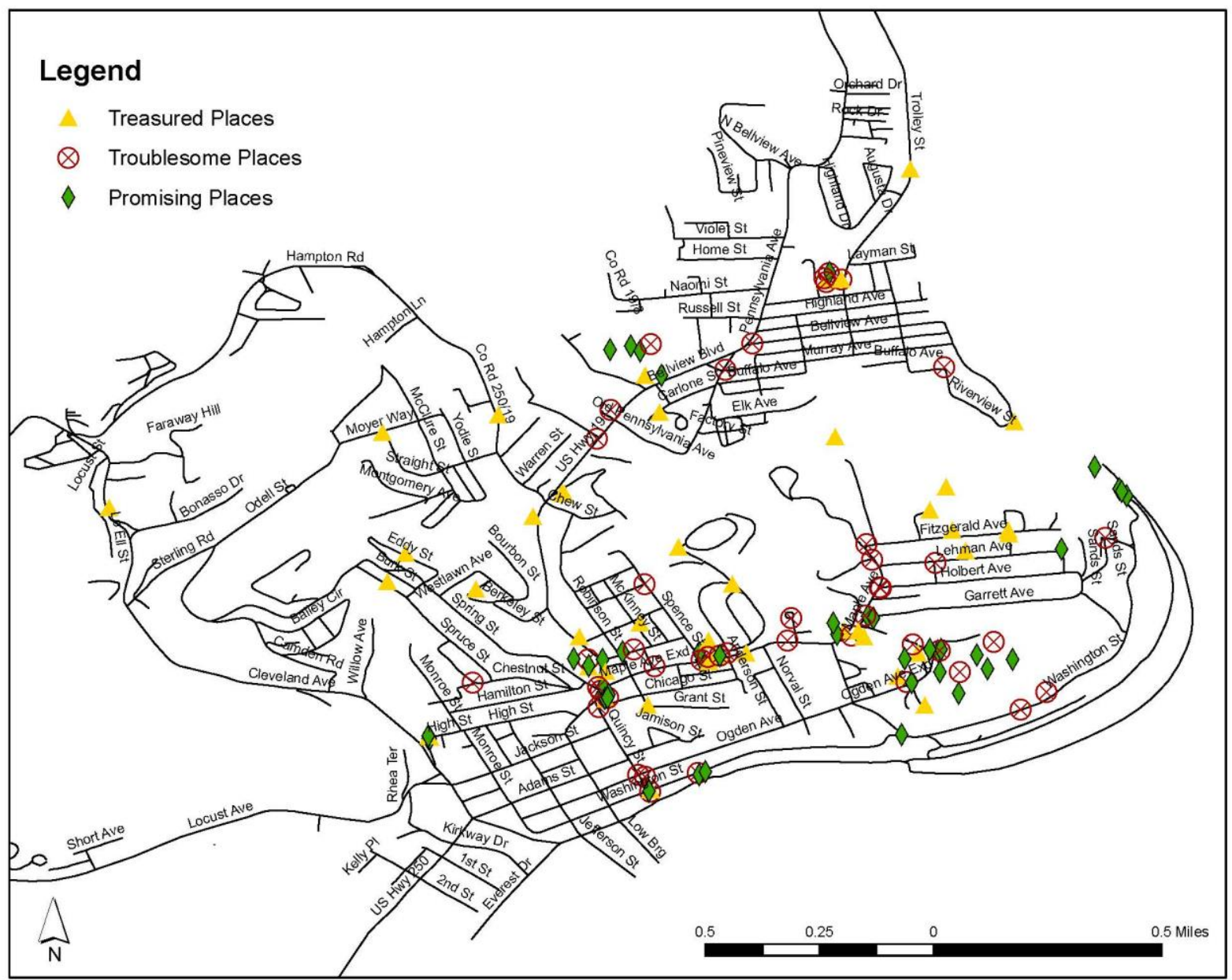

\section{Treasured Places}

Beginning with the Treasured Places dialogue, participants were asked to identify places they cherished, and provide some background as to why they are valued. As shown in Appendix $C$, the representation of community capitals within participants' responses reveals the impact capitals have on residents' quality of life.

The most frequent comments described built capital, with an emphasis on both public and private recreational facilities that create opportunities for sports (football, basketball, track, and swimming), gymnasiums and playgrounds, bowling alleys, skating rinks, and dancing. Neighborhood businesses again featured 
prominently, including Colasessano's and the Westside's "downtown" on Maple Avenue: "Didn't have to go anywhere else." Again, investments in public infrastructure were noted, including recreation and transportation facilities.

The next category in terms of the number of comments is human capital. While both ongoing and closed public schools were mentioned (including Fairmont State University), numerous comments referred to Dunbar School, which is clearly held very dearly: "Dunbar School, considered 'Home away from home' as it provided a dedicated place for African American students." Similarly, the Fairmont Community Youth Development Center (612 Mac) was mentioned several times.

Social capital has a strong showing in terms of community gathering spots and venues, including both formal and informal locations, from Windmill Park to 'High Street: A 'Disneyland for local kids.' Anthony's dad bought a basketball hoop for the kids on the street. Many of the kids would spend their days playing basketball and having a good time. They had a TV outside for N64 competitions. The kids would jump rope, listen to music and partake in a variety of activities with both other kids and their parents." Families gathered on Shadyside neighborhood porches and the rooftop of Hill's Department store alike to watch Independence Day fireworks.

In terms of organizational capital, comments noted the importance of the Fairmont Community Youth Development Center (612 Mac), but also the many neighborhood churches, the West Virginia Rescue Ministries, the Family Resource Network, the WVU Extension Service Marion County office, and the City of Fairmont Police Department.

Sources of financial capital noted were employers located in the area, including paper routes, government offices, and the "CSX Yard/Creek Banks - old industrial center of neighborhood, settled by B\&O Railroad as economic hub."

Natural capital is treasured, including both public parks as well as the banks of Buffalo Creek as well as the Monongahela River where people swim and fish. The neighborhood also boasts cultural capital in the form of the historic Woodlawn Cemetery.

\section{Troublesome Places}

The purpose of the Troublesome Places dialogue was to locate and gather information from participants about places that are viewed as negative or problematic. As shown in Appendix D, the troublesome places often reveal a lack of investment in community capitals.

The most frequent comments were about issues related to a lack of social capital-when people feel disconnected from others, they disregard caring, ethical, and lawful rules of behavior. Dangerous nuisances such as vehicular speeding in the neighborhoods, litter and junkyards, unleashed and aggressive dogs, loud parties, gambling, vandalism, and generally suspicious activities figured prominently. However, of frequent note were more serious concerns about drug-related issues of substance abuse, dealing, and burglary.

The second most frequent category noted was the lack of investment in built capital. Comments tell the story of a pattern of disinvestment by the City of Fairmont and private property owners alike. Many blocks throughout the neighborhoods were noted for dilapidated and abandoned houses and buildings, many of which need to be demolished and some of which need to be rehabilitated. Similarly, Windmill Park has been left to deteriorate, including outbuildings, concession stands, and sports facilities. The historic African American cemetery is overrun with brambles and nearly unidentifiable. Finally, the neighborhoods have suffered a loss 
of commercial space as well as important connector streets. Most other streets lack sidewalks and street lighting to make pedestrians safe.

Interestingly, in terms of political capital, City Hall and the County Courthouse were noted as troublesome places because of what goes on inside of them. Comments referred to a lack of equitable distribution of resources and a lack of consultation regarding development decisions.

\section{Promising Places}

The Promising Places dialogue was designed to gather information from participants about places that are viewed as promising within the community and why these areas are viewed as promising. As shown in Appendix $E$, promising places indicate where participants feel investment in community capitals will be of benefit.

The most common category noted was built capital, most particularly in regard to recreational facilities. Opportunities at Windmill Park include upgraded sports fields and track, connections to walking and biking trails over a Monongahela River pedestrian bridge, and a partnership with the YMCA to develop a recreation facility. Paired with these opportunities were comments about the adaptive reuse of Dunbar School as a community and cultural center. Also frequently noted was the need for more owner-occupied housing development in the many relatively flat, vacant areas of Jackson Addition. Its streets with views of the River were also noted as valuable assets. The vacant Miller School building was called out as an opportunity for adaptive reuse. While many comments referred to downtown Fairmont, a nearly equal number pointed to areas where neighborhood businesses could once again thrive: "Mom and pop stores - bring them back like the old days."

Following from the noted desire for improved recreational facilities and a community center, in regard to human capital, comments pointed to opportunities for youth and senior development programs at Windmill Park, Dunbar School, Miller School, and the Fairmont Community Youth Development Center (612 Mac). The new Culinary School on Pennsylvania Avenue was held up as an example for other entrepreneurship programs.

In support of social capital, places providing opportunities for community service efforts were noted, including vacant land, greenspace, Windmill Park, and Bellview Park. 


\section{PATHS TO PROGRESS DIALOGUE RESULTS}

The Paths to Progress Dialogue is designed to gather information from participants about their ideal community characteristics, where they are in achieving those ideals, barriers to progress, and ideas about action steps that could address those barriers and achieve the desired community characteristics. As shown in Appendices $E, F$, and $G$, these ideas were ranked through voting and priorities are indicated in bold text, while asterisks indicate items mentioned more than once in a given dialogue group. This exercise is a preview of the approach used in the planning process and provide guidance in determining which experts to bring to the team.

\section{Ideal Characteristics}

In the Ideal Characteristics exercise, participants were asked to imagine and describe what their neighborhoods would be like after ten years of community revitalization efforts coordinated by the Westside Action Coalition. These characteristics are shown in developmental order in Appendix F. In this exercise, the natural environment was not mentioned. However, recreation featured prominently in discussion of built improvements.

In regard to human capital, the need for education was noted, particularly for minority entrepreneurship and youth development, mentoring, and training for the new economy as well as life preparedness. It is clear that participants wish to reclaim "youthfulness" and a sense of "hope and opportunities." Mention was also made of the need for ex-felon re-entry programs.

Social capital, figured prominently in ranked preferences. Specifically, participants envision community collaboration, unity and pride in the community, and community change that would enable continued thriving while eliminating the drug culture and associated lack of safety present in the community. Participants want to feel that Fairmont is "actually being the 'really' friendly city" through an increased sense of trust, honesty, and being "more neighborly." In short, they want neighborhoods that are "a great place to live and raise a family."

Cultural capital continued to be mentioned, in terms of valuing the past through African American owned businesses and the intended Black Culture and History Museum.

In terms of political capital, participants called for more civic awareness and knowledge, along with "better communication between government and community, in particular when government listens to community needs instead of making decisions without their input." One comment also noted the importance of improved code enforcement in their neighborhoods.

Participants mentioned a need for better responsiveness in terms of organizational capital in terms of "prioritization of needs."

In regard to financial capital, the desire for employment opportunities was restated, adding to this the desire for alternative energy sources to increase housing affordability. A request for more investment in community infrastructure was made, even suggesting a willingness to pay higher taxes to ensure reinvestment.

The same themes reappeared in regard to built capital: the need for better recreational facilities, owneroccupied homes, improved roads and sidewalks, and revitalized neighborhood commercial areas for small local business. Desired park amenities included a swimming pool and indoor recreational facilities like a gym, bike trails, an ATV track, a dog park, and community gardens and composting. Participants also want to see a community center in the neighborhoods, suggesting the possibility again for a YMCA at Windmill Park. The 
priority in regard to housing is the redevelopment of blighted properties and infill development for increased home ownership, rather than "projects" and "low-income housing developments that outside organizations attempt to build in the neighborhood." Participants reiterated the desire for increased walkability through both sidewalks and lighting, as well as improved roads. Participants want more local basic goods and service businesses and opportunities for neighborhood enterprise that is now preventing by zoning ordinances. In general, participants envision a clean, beautiful, well-maintained neighborhood where residents are "taking pride in surroundings \& shared responsibility", noting particular concerns with unleashed pets and trash.

Once the ideal characteristics were identified and prioritized, participants were asked to assess where the community is in achieving those ideal characteristics. The aggregated rankings of where the neighborhoods stand today clustered between 1 and 2 on the following scale, indicated much room for improvement:

$1=$ "Doing poorly, needs immediate action"

$2=$ "Needs improvement"

$3=$ "Average performance"

4 = "Doing well"

$5=$ "Doing very well"

\section{Barriers to Progress}

In the Barriers to Progress exercise, participants were asked to identify what prevents the community from achieving its ideal characteristics. Once ideas were gathered, participants prioritized the barriers by voting. As shown in Appendix G, each group's priorities are indicated in bold text, as well as by asterisks for multiple responses from participants.

The results show the most significant barriers to be human, social, cultural, and political in nature, following by financial barriers. These results indicate a clear understanding among participants that without community building, development improvements to the built and natural environment through organizational and financial capital investment are not likely.

The human capital barriers included poor educational opportunities: "people can't get jobs or make a community difference, because a lack of education" that lead to a "sense of hopelessness of the youth; the feeling of "no way out'". This is exacerbated by "parental apathy and lack of involvement toward getting involved with their children's activities and education".

The social capital barriers included "broken relationships with the community", "citizens not able to reach agreement", and a "lack of unity within the community; people don't work together". Participants also noted a lack of community awareness, a lack of knowledge, and a lack of vision, noting that "knowledge is power" and "with no vision, you perish". Participants complained that neighbors are apathetic and "don't participate to make a change" or are "resistant to change". But they also described a deep sense of hopelessness in the community and "no sense of agency", describing "fatalism", "cynicism", and "negativity". It is difficult for people to get involved when they "work multiple part-time jobs. As a result, "people have given up and exhausted their efforts"; "people are tired of trying and seeing no results".

In this historically largely African American community, it is important to consider these results in light of comments pertaining to cultural capital. Comments referred to stigmatization based on lifestyle, gender, race, 
and economic class. Participants noted a clear "cultural divide" within the city, in terms of "East versus West sides" and "Black and White communities". They called out unequal social and economic classes, noting "The man with the gold makes the rules".

These barriers are accentuated by the barriers noted in regard to political capital. Participants stated that the community is not given "a voice" because there are "no minorities" on City Council and there is a "need for better representation of all people". They specifically pointed to the fact that the Westside neighborhoods are divided across three voting districts, making it virtually impossible for an African American candidate to win a seat at the table. However, "politics at all levels of government" were noted as a barrier to progress. More broadly, organizational capital is not responsive to community needs.

Not surprisingly, participants claimed there is a "lack of money for developing the community" from both public and private resources. In neighborhoods with high levels of "poverty" and "little opportunity" and "low paying jobs", the community relies on public and nonprofit investment of financial capital, but "funds are not allocated to the Westside".

Without sufficient capacity in these community capitals, the built capital is suffering. Participants reiterated the problem of abandoned buildings, but here noted that the ability to use eminent domain is a barrier to resolving the issue. They also noted that "laws and zoning prevent better development from forming". This "lack of control within the community" is a barrier to leveraging the potential of the built (and natural) environment. Participants also reiterated the need for improved commercial areas and affordable housing.

Combining the human, social, cultural, and political barriers, there appears to be a causal relationship at play in this community-neighbors do not have the capacity to make effective change within the political and economic context, and so they become alienated and lose hope. To make matters worse, instead of working together to overcome these barriers they often lay blame on themselves and at the feet of their neighbors: "Pride prevents us from facing the consequences of our own actions."

\section{Ideas for Action}

In the Ideas of Action exercise, participants were asked to identify actions that would address the barriers to progress noted, better positioning them to achieve their ideal community characteristics. As shown in Appendix $H$, each group's priorities are indicated in bold text, as well as by asterisks for multiple responses from participants.

The most frequently noted action strategies fell in the social capital category. Participants stated that to mobilize and organize, neighbors need to reach out to one another informally to motivate action- "Don't say it... DO IT!!!" They understand that to "become united as one with one voice", they need to "open minds to new ideas". Participants want to use the WAC to organize for community action, starting with "a vision that is championed by youth who are under the age of 40 ", developed through a "Comprehensive community meeting where everyone involved in the project is present (option to live stream)". By everyone, they noted that this needs to include both residents - including youth and seniors-and stakeholders beyond the neighborhoods in order to "play to people's strengths". From there, they recommended forming "Action Boards" to move into action. In short, the Westside neighbors understand that success is largely in their own hands.

To build the capacity to engage more productively, ideas for developing human capital were reiterated. Focusing in on youth, participants noted that they need all types of education and development to prepare not only for jobs and entrepreneurship in the new economy, but for personal life and civic engagement. They 
specifically pointed toward the need for apprenticeships and mentorship, particularly from "black men and women role models who can provide hope for black youth, such as those who own businesses". Previous storytelling in WAC stakeholder meetings highlighted the deep impact of the loss of such role models when Dunbar School was desegregated and later closed, moving students into schools with few African American teachers and administrators. Similarly, the loss of African American businesses that could not compete after desegregation exacerbated this lack of role models. Participants acknowledge that both youth development programs and actual involvement of youth in community affairs are necessary to "Instill sense of urgency of pride within youth".

In regard to political capital, the need to improve representation was restated, both on the City Council and City boards and commissions. Participants also acknowledge that Westside neighbors need to increase their understanding of the "social and economic system and civic participation" and that they can learn from city officials. Furthermore, they feel personal responsibility for taking political action, not only by getting out the vote, by getting involved in the political process and ensuring "community presence @ City Council events" and well as "economic and housing development decisions and planning".

Similar sentiments were noted in regard to financial capital. Participants feel as sense of responsibility for learning more about funding and resources available for neighborhood improvement, as well as the need to participate in creating jobs, including those that can contribute to other neighborhood objectives: "Create jobs out of tearing down old buildings and advertising those jobs".

Participants also envisioned ways to invest in the neighborhoods' built capital by engaging in "community beautification" through volunteerism and coordination with the City. Participants are willing to help find resources "to help tear down or revitalize abandoned places, and add sidewalks for improved walkability". But they also acknowledge the need for government resources and policies to support these activities.

In this dialogue, the only organizational capital that was mentioned is one that is particularly important in the Westside neighborhoods - the faith community. While the WAC has had little success engaging the many churches in the neighborhoods in action thus far, one suggestion was that the faith community form a "Council of Churches who will coordinate programs for volunteers and the dissemination of information benefitting the community". 


\section{COMMUNITY VALUES AND VISION}

As shown in Appendices $\mathrm{B}-\mathrm{H}$, the comments made during each of the dialogue exercises were interpreted and categorized using a community capitals framework. In this interpretation, subcategories were identified based on the type of characteristic revealed. Positive characteristics were interpreted as values, while negative characteristics were interpreted in reverse to identify other values. This asset-based approach keeps the focus on what the community members want to achieve together. Many values (and their nuanced meanings) reappear from dialogue to dialogue, indicating the strength of those values.

As shown in Appendix I, those values include: an appreciation for the natural environment of the neighborhoods' waterways, the largely African American population in the neighborhoods and the rich history and culture it connotes, educational opportunities and attainment supported by strong youth development programming and activities, a sense of community, hope, safety, and active civic engagement, adequate political representation and active political participation, community-serving organizations that are responsive to community needs and priorities, adequate income from both employment and business ownership paired with equitable public and private investment, and thriving neighborhood commercial and residential areas supported by adequate public infrastructure and recreational facilities.

From these results, draft value statements were proposed as a starting place for consideration by neighborhood residents-both those who participated in the Community Visioning Conversations and all others who have signed in to WAC meetings over the course of the Fostering Fairmont project to date. The feedback received to these value statements was overwhelmingly positive and no amendments were suggested.

\section{Naturall Capital}

- We value both neighborhood and regional parks and open spaces for recreation.

\section{Culturall Capitall}

- We value Fairmont's historic character and sites.

- We value our history as a largely African American community.

- We value ample opportunities for arts and entertainment.

\section{Human Capitall}

- We value formal educational opportunities and attainment, including training for entrepreneurship.

- We value lifelong learning through both youth and senior development programs.

\section{Sociall Capital}

- We value our families and home lives.

- We value a sense of community supported by spaces and opportunities for community activities.

- We value a sense of safety and security supported by adequate law and ordinance enforcement.

\section{Organizationall Capital}

- We value the public and community-based organizations serving our neighborhoods. 


\section{Politicall Capital}

- We value civic education opportunities and adequate information about what local government is doing.

- We value adequate political representation and influence over public decision making.

- We value productive government-community relations.

\section{Financiall Capital}

- We value adequate employment opportunities, including small business ownership.

- We value equitable and adequate investment from public and nonprofit partners in the Westside neighborhoods.

\section{Built Capital}

- While we value regional shopping opportunities and activities in downtown Fairmont, we deeply value neighborhood-based businesses.

- We highly value quality public recreation facilities.

- We value home ownership and well-maintained residential neighborhoods.

- We value well-maintained circulation infrastructure for both people and cars.

\section{Vision Statement}

Together, these values tell a story about what the Westside neighbors envision for their future-a target for neighborhood action planning:

We envision neighborhoods with adequate and equitable investment in both people and place, so that our youth will enjoy the quality of life that we enjoyed several decades in the past-one with family-owned homes; small local businesses serving our basic needs; neighborhood schools and churches; excellent community, parks, and recreation centers; ample employment and entrepreneurship; and pride in our shared history as a largely African American community.

Again, the draft Vision Statement was distributed for consideration by neighborhood residents-both those who participated in the Community Visioning Conversations and all others who have signed in to WAC meetings over the course of the Fostering Fairmont project to date. The feedback received to this vision statement was overwhelmingly positive and no amendments were suggested.

With these Value and Vision Statements in hand, we will turn to the next step in the Fostering Fairmont project: community-driven neighborhood action planning. 


\section{APPENDIX A. PARTICIPANT SATISFACTION SURVEY RESULTS}

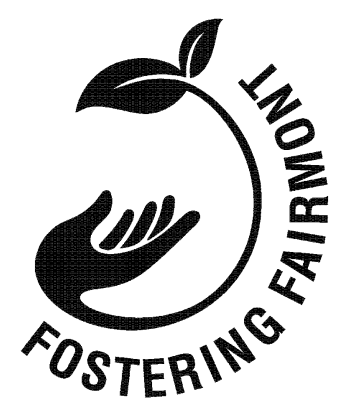

\section{Community Visioning Conversation Satisfaction Survey} April 29-30, 2016

Please take a moment to provide us with some feedback regarding your participation experience. Your input is important to continuous improvement of public meetings. You can use the back of the sheet for additional comments if needed. Thank you for your time!

Respondents $=34$

1. Please check the box that applies to indicate your rating of each item:

$\begin{array}{lccc} & \text { Poor } & \text { Good } & \text { Excellent } \\ \text { Meeting Location } & 0 & 8 & 25 \\ \text { Meeting Day } & 0 & 17 & 17 \\ \text { Meeting Time } & 0 & 15 & 19 \\ \text { Meeting Facilities } & 0 & 16 & 18 \\ \text { Refreshments } & 1 & 17 & 16 \\ \text { Topic } & 0 & 9 & 25 \\ \text { Materials/Handouts } & 0 & 12 & 22 \\ \text { Presentations } & 1 & 9 & 24 \\ \text { Facilitators } & 0 & 10 & 24 \\ \text { Group Size } & 4 & 12 & 18 \\ \text { Length of Meeting } & 2 & 12 & 20\end{array}$

2. What did you like most about this experience? (Please print.)

- Great to see visitors/ neighbors

- Meeting people who are interested in the community of Westside

- Small group size

- Being able to share ideas/dialogue

- Seeing other community members share ideas

- Getting information and being heard

- Meeting people

- Information

- Hearing ideas from diverse people

- I liked the group's diversity

- Input from groups

- Open points of view

- Communicating ideas

- Hearing from different people that have the same concerns with cleaning up the community 
- Wonderful facilitators, great materials and prompts, nice organizations/set up

- The information that was shared

- Seeing people outside of community trying to help other communities

- Info

- Take time to listen

- Everyone participated

- Share ideas

- Hearing other's ideas

- Getting to meet and find out how other's feel

- Opening up

- The group perspective. Having the open conversation.

- The opportunity to voice opinions and concerns

- Being able to share thoughts and discuss decisions share vision.

- Very informative

- Feeling enthusiasm from others

- Listening to others

- IDEAS!

- Learning (not legible) view

3. What would you change? (Please print.)

- Nothing

- More people who are impacted by change

- Nothing

- Nothing/It was great

- Nothing

- Liked the direction

- More folks at the table

- This felt like kindergarten

- Time and more money

- Nothing

- Bigger groups if possible

- The facilitator's should know the information instead of reading straight from the paper

- Nothing

- Not a thing

- Keep meeting

- Nothing

- Nothing

- Nothing

- Have more information about where our money goes

- Just getting more community participation somehow

- Would ask for detailed suggestions on specific programs

- Start on time

- None

- More folks

- Earlier break for coffee etc.

- More community involvement

- Not a thing 
4. Should this type of gathering be used in the future? Yes: 33 No: 0 No response: 1 Why? (Please print.)

- Was easy and fun

- It gives people a chance to share their perspectives

- Getting to know each other and ideas

- Very worthwhile- Thought provoking and informative

- It's needed more often

- (not legible) and thinking forward. Think out of the box.

- The feedback is very informative and beneficial

- It helps with giving our information out

5. Please provide us any other comments to assist in improving this process or project (please print).

- Need more time for sessions

- Could be a little shorter

- Invite more community leaders

- Would like to host a walk-around of the neighborhood

- It was all good.

- Think more

- Good experience

- I think the concept is valuable!!

- Thanks!

- N/A

- More analysis of how to broaden participation

- Break out room to eliminate noise

- These are nice sessions for this to go forward 


\section{APPENDIX B. TREASURED MOMENTS}

\section{Natural Capital}

\section{Value: neighborhood and regional parks}

2005 Played co-ed softball at Windmill Park

2012 Bellview Park community-driven renovation, then fire, then renovation again

2015 Palatine Park redeveloped (Park off the Mon River)

\section{Culturall Capitall}

\section{Value: historically African American community}

Sept 30, 1954 First Black-White football game played in WV at East-West Stadium amidst tension following Brown-Topeka, Kansas Supreme Court reflecting pride in the positive community reaction

1955 Desegregation of schools (i.e. Dunbar High School)

1956 Was able to eat at an old restaurant "The Palace" and the food was nothing special

1960's Fish market outside of people's homes the business was run out of the kitchen. Many different sides were offered: coleslaw, cornbread, potato salad. The food was offered at a moderate price. The fish was caught from Buffalo Creek (Porgy, catfish, bass, perch).

1975 Black owned businesses (stores and restaurants) gave community members a place to work and meet 1980 No prejudice within Fairmont

\section{Value: arts and entertainment}

1900-1940 Development of cultural institutions in Fairmont (i.e. opera house)

1972 Fairmont's Virginia Theater and adjacent shops burned down, reflecting the loss of a favored community asset

1976 Fairmont Theater because it was a beautiful place and it was torn down

1980s -1990s Going to the movie theater in downtown Fairmont

1991 Used to go to the theater downtown with my middle school friends.

1985 Visited Gabe's [a bar] for the first time

2000 Used to have more bars and clubs with live music downtown

2015 Palatine Park redeveloped (Park off the Mon River)

1960s-1970s Fairs and concerts at Windmill Park. The Fairmont theatre was involved with the concerts. Whisperers, a popular musical groups in the U.S, played at a carnival at Windmill Park. The event was also free

\section{Value: historic character}

1890 Woodlawn Cemetery built which has historic significance as the burial ground for politicians and civil war heroes

1904 Development of Downtown buildings of Fairmont (i.e. courthouse)

1910-1920 Booming era in Fairmont: beautiful homes and architecture in Fairmont built 


\section{Human Capital}

\section{Value: youth development opportunities}

1950s Used to be able to play around supervisors with crafts and games that were sponsored by the county at Windmill Park.

1960 People learned things on the playground (swimming, chess, tether ball, etc.)

1970 Learning dance, skating, and playing cards

1996 Biked safety programs at Windmill with police. The police gave out helmets, bike safety tips and checked bikes to make sure they were safe.

2006 Anthony played in the High School State Football Semi-Finals in Martinsburg for Fairmont Senior High School

2002 Egg drop and Rocket Competitions with science department @ Dunbar

2009 camps and activities at Fairmont State University

2010 Children's court was established which allowed kids to gain insight on the criminal justice process

\section{Value: educational opportunities and attainment}

1979 Ms. Riley graduated from High School

1988 Pastor Riley graduate from Fairmont State

1990 Antoinette graduated from Fairmont Senior High School

1990s Barnes Elementary School closed; it had been the heart of the Bellview neighborhood, and neighbors came together to try to keep the school open, reflecting a sense of community pride

1998 Graduated from FSC

2002 Fairmont State College became Fairmont State University

2014 Son graduated from high school

\section{Sociall Capitall}

\section{Value: family and home}

1950 Monarch bicycle, as a gift from an uncle

1960s Grew up on Merchant Street

1966 Houston Richardson was married

1970 Paw Paw Fair brought the community together

1971 Houston Richardson's first son Jason was born

1973 Started my family in Fairmont

1975 Antoinette's little sister was born and she felt like she was a mother to her.

1981 Connie got married at mother's house in Fairmont across the street from current house.

1981 Rileys were married

1981 Houston Richardson's second son Justin was born

1984 Would come up to Fairmont State to pick up my brother and move him when he'd get kicked out of housing

1988 Keith Robinson's son was born and passed

1988 Keith Robinson's daughter was born

1988 Connie's daughter was born.

1992 Connie moved into home on High St in Westside

2007 Lauren comes to Fairmont 
2012 Keith Robinson's grandmother passed

Value: community events that brought people together

1940s There were carnivals and fairs at Windmill Park that my grandparents used to tell me about

1940-1950 Halloween parade in Downtown Fairmont to celebrate Halloween. This brought the community together. Children's costume contest

1950s Boom in Downtown Fairmont: (i.e. Elks Club)

1950s-1960s Fairs at Windmill Park- brought the community together

1960s-1970s Fairs and concerts at Windmill Park. The Fairmont theatre was involved with the concerts. Whisperers, a popular musical groups in the U.S, played at a carnival at Windmill Park. The event was also free

1970s -1980s Back to school picnics/block parties. During this event there was a "Taste of Fairmont" where people would make food and share it will others. The food was locally grown and raised.

1990s Fairmont churches used to have a community Thanksgiving service

1998 Seth (Burton) Fest (deceased) festival to raise funds for youth projects, disc golf

2015 Art in the Park: community initiative to help bring community cohesiveness and gather people together

Value: sense of community and neighborhood efforts

1960s-1970s Block Parties- brought the community together.

1970s There used to be big block parties.

1980 Westside neighborhood had love and unity

1980s Unity in the community. People in the community made provisions for food and provided them to families in need. Alice also shopped downtown in downtown Fairmont during this time at Hartley's Golden Brothers and Murphy's stores. Food provisions by neighbors for families in need

1990s Barnes Elementary School closed; it had been the heart of the Bellview neighborhood, and neighbors came together to try to keep the school open, reflecting a sense of community pride

1998 Effort to keep Barnes Elementary (Bellview) open brought neighbors together

2012 Bellview Park community-driven renovation, then fire, then renovation again

2001 community yard sale- brought the community together

1990 Drugs took over the community and destroyed unity

2000 Drugs declined within the city of Fairmont

\section{rganizationall Capital}

Value: organizations serving the neighborhoods

1912 Fairmont Branch of Church of Jesus Christ of Latter-Day Saints was founded

1992 FCDPartnership

1999 Family Resource Network's established

2014 Bad Building Program established - neighbors involved

\section{Political Capital}

Value: political access and adequate information about what local government is doing

1904 Development of Downtown buildings of Fairmont (i.e. courthouse)

1963 John Kennedy came to Fairmont to speak 
2013 Fairmont 101 began

2014 City of Fairmont got a Facebook

\section{Financiall Capital}

\section{Value: small local enterprise}

1970s -1980s Back to school picnics/block parties. During this event there was a "Taste of Fairmont" where people would make food and share it will others. The food was locally grown and raised.

1975 Black owned businesses (stores and restaurants) gave community members a place to work and meet

2003 Bellview Brite Wash Laundromat built. Our participant's business is a current source of livelihood.

\section{Value: employment opportunities}

1977 Executive Director, OIC

1980 Coal mining was booming in Fairmont

1980 Phillips lighting was in business and provided many jobs

1980 Aluminum business provided many jobs for the community

1980 Owens Illinois employed a lot of people from Fairmont

1982 Pastor Riley started work at UPS

1999 WV High Tech Center established; high paying jobs in the area

2000 Oil and gas jobs began to boom again

2009 Became a pastor in Fairmont

2012 Started a part-time job with Marion County.

\section{Built Capital}

\section{Value: vibrant downtown}

1950s Boom in Downtown Fairmont: shops and restaurants established (i.e. Adams Office Supplies)

1970 Thriving downtown business area in Fairmont

1980 Thriving downtown business area in Fairmont

1980s Fairmont thrived: More retail and restaurants in the community

2011 lunch downtown, pizza and subs - the restaurant closed after the DHHR building downtown was vacated

2015 Busy Beaver on County Club Rd opens; another hardware store option

\section{Value: neighborhood businesses}

1960s Fish market outside of people's homes the business was run out of the kitchen. Many different sides were offered: coleslaw, cornbread, potato salad. The food was offered at a moderate price. The fish was caught from Buffalo Creek (Porgy, catfish, bass, perch).

1962 Variety stores in Jackson Addition. The stores offered common necessities and was like a convenient store. People didn't have to leave the neighborhood to go get things, mostly everything they needed was there

1975 Black owned businesses (stores and restaurants) gave community members a place to work and meet

1998 Bellview Foodland closed (one of our participants was the owner) - reopened as Save-A-Lot, reflecting the change from local business ownership to the arrival of corporate/regional retail chains.

1983 Used to buy furniture from Hartley's store with my parents 
Value: regionall shopping

1979 Great shopping at Middletown Mall.

1980s -1990s Shopping at the local stores at the mall. The stores are either gone now or not what they were back then

2007 New Wal-Mart was built in Fairmont

2009 visiting Middletown Mall

Value: transportation infrastructure and circulation

1957 Fairmont traffic pattern changed the way people navigate through the city

1970 First part of I-79 completed 5 miles from Middletown Mall to East Fairmont, connecting Fairmont to economic opportunities in the state

Late 1990s Historic High Level Bridge (aka Million Dollar Bridge), a main thoroughfare to Downtown Fairmont from the connector, was closed for renovation

1998 Fixing the High Level bridge (to the connector) into downtown Fairmont

2010 New connector opened

2012 Connector bridge was finished

2014 Connector constructed to I-79 (roundabouts)

Value: public recreation facilities

1932 Finished east west stadium complex

1940-1950 Windmill park had a swimming pool 


\section{APPENDIX C. TREASURED PLACES}

\section{Natural Capital}

Value: natural open spaces for recreation

- Windmill Park*

- Bellview Park: took children there to play

- $\quad 5^{\text {th }}$ Street Park: Playing basketball and an organic mentorship between younger and older kids. The Fairmont Sr. gym was here and there were also a lot of events at this park.

- Buffalo Creek: Area for children to go swimming

- Buffalo Creek- Fishing Trips/ Spot

- Fishing and outdoor recreation area - below Washington St.

- Coal Run Hollow - nice creek and wilderness area

\section{Culfural Capital}

Value: historic sites

- Woodlawn Cemetery, Dan Weber's brother's grave who was shot down at age 17

- Woodlawn Cemetery- Family connections with those who are buried there

- Woodlawn Cemetery - Galen's church worked to clean the Black portion for two years (weeding and maintenance)

- Conley Farms/Indian Caves - in the area, little known

\section{Human Capital}

Value: neighborhood schools (more so than regionall schools)

- Neighborhood Schools- important for the youth of the neighborhood

- Butcher School: great neighborhood school

- Miller School Maple Ave section. DD attended school through 6th grade then went to

- Dunbar School: important part of Fairmont history. Used to show movies there, prom, and social dances

- Dunbar School, considered "Home away from home" as it provided a dedicated place for African American students

- Dunbar School as a center for social experience and education

- Dunbar (School) for 7th and 8th grade.

- West Fairmont High School

- Fairmont State University - education

Value: youth development opportunities

- $\quad 612$ MAC * - Youth Education and Programs

- MAC building

- $5^{\text {th }}$ Street Park: Playing basketball and an organic mentorship between younger and older kids. The Fairmont Sr. gym was here and there were also a lot of events at this park.

- Trolley St. - flat and safe road for teaching kids how to ride bikes 


\section{Social Capital}

\section{Value: social gathering spots}

- Bowling Alley *- Socialization with other community members.

- Windmill Park - gathering and sports activities

- House in Chesapeake neighborhood on 2nd street: Keith's grandmother lived there ("first place I knew in West Virginia"), reflecting positive connections with Fairmont although he is originally from Detroit (This area falls outside of the Westside neighborhoods)

- High Street: A "Disneyland for local kids." Anthony's dad bought a basketball hoop for the kids on the street. Many of the kids would spend their days playing basketball and having a good time. They had a TV outside for N64 competitions. The kids would jump rope, listen to music and partake in a variety of activities with both other kids and their parents

- Shadyside: Summer visits, $4^{\text {th }}$ of July, sat on porches and watch fireworks

- Hill's department store: This was located in Bellview. On the $4^{\text {th }}$ of July people gathered for activities and watched the fireworks.

\section{Organizationall Capital}

Value: social services

- 612 MAC * - Youth Education and Programs

- WV Rescue Ministries (Union Mission of Fairmont) corner of Jefferson and High level bridge - provides 3 meals day everyday

- The Penny Pincher Thrift Store for Union Mission also provides free clothing and furniture to those in need

- Family Resource Network offices - 112 Adams St.

- WVU Extension offices - 314 Monroe

Value: community safety

- Old police station

\section{Value: places of worship}

- Morning Star Church: Commemoration of Martin Luther King

- Little church in Chesapeake neighborhood, the site of Keith's first Easter egg hunt; this reflects positive childhood memories (This area falls outside of the Westside neighborhoods)

- Fairmont Christian Assembly, Fulton St, reflecting another center of faith in the neighborhood

- Trinity United Methodist Church: Connie's home church. The church provided family and friendship for her.

\section{Financiall Capitall}

\section{Value: employment opportunities}

- CSX Yard/Creek Banks - old industrial center of neighborhood, settled by B\&O Railroad as economic hub

- JR's home and work on Lewis St.

- Courthouse: Connie worked here on Jefferson St. It was like a second home for her 
- FSU - Galen taught as a Physics professor work in 1994 (This area falls outside of the Westside neighborhoods)

- Adam's Street: Anthony found what he wanted to do with his life watching his mom work at the courthouse when she worked at the City Clerk's office. He sat on a computer at her work and learned about a career in IT.

- Old paper route: Shadyside, Maple Ave, Jackson Ave - DD delivered 160 morning papers from 10th through 12 th grade starting at 4:00am

- 230 Adams St. - places where we work and play

\section{Built Capital}

\section{Value: recreational facilities}

- East/West stadium - used to be where every school in the county played

- Windmill Park - used to be a good spot for youth sports and programs

- Windmill Park - gathering and sports activities

- Windmill Park holds memories childhood sporting events, including meeting Willie Mays

- $5^{\text {th }}$ Street Park: Playing basketball and an organic mentorship between younger and older kids. The Fairmont Sr. gym was here and there were also a lot of events at this park.

- High Street: A "Disneyland for local kids." Anthony's dad bought a basketball hoop for the kids on the street. Many of the kids would spend their days playing basketball and having a good time. They had a TV outside for N64 competitions. The kids would jump rope, listen to music and partake in a variety of activities with both other kids and their parents

- History of his family his Father \& Uncles were track champions

- Windmill Park carnival and swimming pool

- Morris Park- swimming pool

- $12^{\text {th }}$ Street: Local pool, Anthony spent 4 years playing sports there playing Football

- Brickyard playground

- Bellview Park: took children there to play

- Bowling Alley *- Socialization with other community members.

- Bellview Skating Rink: Near here and an area for recreational activities.

- Fairmont Hotel- there used to be dancing and school parties there

- Pal Park- (Larry left before he could elaborate on this location) [Palatine Park]

- Veteran's Square- Downtown Fairmont, military recognition, and it was a community gathering place

\section{Value: neighborhood businesses}

- Collasessano's restaurant

- *Colasessano's because of its atmosphere, kid's games, pin ball machine, and KISS music

- Bellview Brite Wash Laundromat - 603 Bellview Blvd (Galen's business)

- Neighborhood Store- Local business. Noted for selling soda icees.

- Maple Avenue was the downtown on my (Houston's) block: "Didn't have to go anywhere else." This reflects the once walkable and integral center of community within the neighborhood as opposed to the separate Fairmont downtown. 
Value: investment in infrastructure

- Testa Fairgrounds renamed as Windmill Park, possibly signifying the transfer of ownership from family to the City.

- Million-dollar bridge

- High Level Bridge: engineering feat

- "Connector"- roundabouts. Connects both sides of Fairmont

- First Fairmont TV station erected on top of street in 1954 (UHF Channel 35), Grant St Fairmont Maple Ave section. 


\section{APPENDIX D. TROUBLESOME PLACES}

\section{Social Capital}

\section{Value: safety through law enforcement}

- Bellview/Murray Avenue (speeding - needs 4 way stops)

- Bellview Ave- Speeding

- Maple Ave: Speeding and big trucks coming through

- High Street: Speeding and increasing traffic traveling through to Bellview

- Big Apple- Regina described this area as the "Big Apple" and listed speeding as an issue

- Road to Bellview

- Maple Avenue near the Water Plant- people drive too fast

- Corner of Spring/Pennsylvania/Maple- Traffic and Drugs

- Locust Ave: A lot of college students commuting and there is too much traffic

- ATVs riding on roads in Bellview - no helmets, unsafe

- Adams St. - Mid city parking lot - area is increasingly unsafe and rarely used; homeless/transient population

- $4^{\text {th }}$ Street area: Trouble with crime

- FCYDC - Summer Nights- drinking \& dice (gang relations)

- Fairmont Hills Apartments: troublesome area, police are there a lot

- Bellview Park- vandalism in the park

- Bellview Blvd.: Too much beer, alcohol, and tobacco places

- Windmill Park entrance, Ogden Ave, where illicit activities are known to occur.

- Windmill Park is perceived to be troublesome because of the neighborhood.

- Grafton Street, which in the past was known for clubs and a "red light district" but is now improved, evidenced by the presence of churches.

- Bellview Park - teenagers hanging out, maybe drugs or other bad behavior; not safe for young children

- Playground off of Fulton St and parking lot of Fairmont Christian Assembly is a regular hangout for problem kids, drug dealers, and break-ins nearby

- Locust Ave at View Ave is considered very dangerous for lots of addiction and couch surfing activity, slumlords who rent to university students, dilapidated buildings, and drug sharing. (This area falls outside of the Westside neighborhoods)

- Virginia Avenue between 8th and 9th street, characteristic of frequent police calls, drugs, and audible fighting (This area falls outside of the Westside neighborhoods)

- Maple Avenue- Problems with drugs and gambling

- Windmill Park - drugs are an issue and it also needs revitalized.

- "Bad area" - homeless/transient population; drug-use

- Maple Avenue - drugs

- Virginia Avenue: Known for drug activity

- $4^{\text {th }}$ Street: Mountaineer Mart- high drug activity ("crackmart").

- Minute Mart - "Crack Mart"

- Corner across from Maple Avenue, which was known as drug traffic corner, and continues to be, years later. 
Value: safety through ordinance enforcement

- Jackson Addition: unleashed dogs, unlit areas and no sidewalks

- Jackson Addition: unleashed dogs using restroom and not being picked up after

- Vicious dogs - letting dogs run lose all night long, people are afraid to walk around

- Hollburt Avenue - garbage is thrown everywhere and not being picked up

- Ravine just to the side of Fairmont Christian Assembly overgrown and unsafe

- Maple Ave (all over): Music too loud, too late at night

- Hollburt Avenue - no where to park

\section{Politicall Capitall}

\section{Value: good government}

- Court house and city hall - the people who are in charge of the city

- Downtown Fairmont: Lack of equality for resources

Value: community input to decision making

- Maple Avenue (corner of Maple and Spence), where three multi story housing units were erected without community input

\section{Built Capilall}

\section{Value: community beautification}

- Abandoned/dilapidated housing - most are owned but not taken care of - Corner of Holbert and Perry Alley specifically mentioned

- Abandoned houses - 170 in the Westside community

- Corner of Maple and Fitzgerald Ave- abandoned buildings and junkyard

- Woodlawn Cemetery is neglected and there is an abandoned house nearby

- Chicago Street, renovations needed on older houses

- Spring Street, renovations needed

- Holbert Ave, renovations needed

- $4^{\text {th }}$ Street: Butcher School, dilapidated, kids can enter and get hurt.

- Ogden Avenue: Messy blighted homes

- Monroe Street: Worst blighted home

- Houses in area need of demolition

- Jackson Addition/Windmill Park

- Miller School: Vacant and not being used, need of repair, currently an eye sore in the neighborhood

- Fairmont State University college area: de-appreciation of property and disrespect of neighbors

- Cemeteries

\section{Value: quality recreational facilities}

- Windmill Park: Maintenance and activities, needs to be revitalized **

- Windmill Park - good location, fix accessibility, complete renovations and upgrades

- Windmill Park - underutilized and needs upgrades

- Windmill Park and the parking lot need renovating 
- Pavement of track at Windmill park

- Jackson Addition/Windmill Park

Value: thriving commercial areas

- CVS Pharmacy was removed from Bellview Plaza, and the plaza has remained economically depressed. The addition of Teleperformance has improved Bellview Plaza slightly

Vallue: connectivity

- Washington Street: Does not connect to Jackson Addition

- Washington Street - road caved in back in the ' 80 s, cut off park/town access to residents and the neighborhood and business activity declined (dried up)

- Washington Street: Streets have fallen in to the point where it's not feasible to fix

- Jackson Addition: unleashed dogs, unlit areas and no sidewalks 


\section{APPENDIX E. PROMISING PLACES}

\section{Human Capital}

Value: youth and senior development programs

- Windmill Park offers a place for youth activities and community programming *

- Windmill Park: Organized art display area for Youth to come and contribute.

- Dunbar School has the opportunity to serve as a space for both youth and senior activities.

- The efforts of Fairmont Community Youth Development Center (The MAC) offers potential for youth betterment and enhancement through its activities and engagement in the community

- 612 Building

- 612 Mac*- Heart of the community, great place for the youth to stay safe and learn

- Youth Center: Enhancing Youth programming.

- Boy Scout troops should be chartered by community organizations throughout all Westside neighborhood

\section{Sociall Capitall}

Value: spaces for community activities

- Maple Ave has potential for creating gathering places for community events

- Greenspace: Potential to unify communities

- Bellview Park: Potential to unify communities

- Windmill Park: Potential to unify communities

- Maple Ave: Clean up day monthly, Keep neighborhood nice

- $12^{\text {th }}$ Street: High schools have events, Need more events, For ALL the public, Walkathons, Physical challenge courses, Day of service for admission

- College area: Potential for more community service opportunities

\section{Financiall Capital}

\section{Value: neighborhood businesses}

- Pennsylvania Ave: Culinary School, Practice Arts, Turn into restaurant, Interns into entrepreneurs, More businesses

- Mom and pop stores - bring them back like the old days

- Jackson Addition: Clear abandoned homes, more homes that are individually owned, lots of space, some type of convenient store

- Potential store front

- Fairmont Ave: Dry Cleaner

Value: entrepreneurship

- Pennsylvania Ave: Culinary School, Practice Arts, Turn into restaurant, Interns into entrepreneurs, More businesses 


\section{Built Capital}

\section{Value: recreational facilities}

- Windmill Park ***. Could bring in activities and programs, it just needs fixed up

- Windmill Park has potential to become a great recreational

- Windmill Park has received more attention than it had for a long time.

- Windmill park walking trail - paved trail for "senior" recreation opportunities

- Soccer Field (MCPARC) - needs upgrades, lighting and equipment, but has potential and is used by residents

- Windmill Park. Robin Gomez, the City Manager has experience with recreation work in Clearwater, FL and participants would like to see him apply the same recreation potential to Windmill Park

- Windmill Park: Needs attention because it is a wide open space

- Beautiful vacant land - opportunity to build something for community use

- Area across from Windmill Park: YMCA, Children could play in park while parents used the Y

- Madison Street has potential for recreation center that is possibly going in the White Hall area to be placed here

- Fairmont Ave: Possible business or YMCA

- Old B\&O Roundhouse on Buffalo Ave, a former train station is a large area for growth and recreation opportunities along the river.

- Pedestrian bridge across Mon River is an opportunity for Rails to Trail and economic development

- Abandoned rail road for rail trail - want bike route to expand travel opportunities and recreation

- Bike route proposal - want bike route to expand travel opportunities

- ATV trails - want ATV trails near Coal Run Hollow for recreation

- Ogden Avenue - scenic overlook and picnic area

- Youth center - potential location with skating and senior citizen center

- Conley Farms - archaeological significance asset

- Arcade - used to be where nail salon in Bellview Plaza is now - provided something for the youth to do

\section{Value: housing development}

- Large area with development potential (relatively flat, open, available)

- Jackson Addition has potential for more development

- Jackson Addition: Clear abandoned homes, more homes that are individually owned, lots of space, some type of convenient store

- Maple Ave, Jackson Addition has potential for housing restoration

- Maple Ave and Spruce Ave could have more housing development

- Garrette Ave. area has new homes being built and there is an availability of flat land

- Maple Avenue is where renovations have already started

- Ogden Ave has potential for river-view development

- River View area has potential for nice housing development

- Riverfront development: Great location with good scenery

- Miller School: Potential for Senior Citizen Building

- Miller School: Existing building that can be used (currently in the process of rehabilitation)

- Chesapeake neighborhood area - in need of support but has potential for development 
Value: neighborhood community centers

- Dunbar: Recreational Center a Senior Citizen Housing

- Dunbar School and its Cultural Center - Museum

- Dunbar school - community center

- Community education development in the area, such as a 2-year technical college like Pierpont. Perhaps the old Miller School can be put to reuse for this purpose.

- Youth center - potential location with skating and senior citizen center

Value: downtown commercial development

- Downtown Fairmont has several resources, including state buildings, parking garage, organizations, and businesses.

- Downtown Fairmont: New organizations, new small offices \& small businesses, dry cleaner

- Downtown Fairmont offers opportunities for economic growth and locally-owned businesses

- Downtown Fairmont: Re-development opportunities

- Downtown buildings could be better utilized for housing and business

- State building - place for expanded community opportunities

- Madison Street has potential to extend development into the Downtown area

- Off Garett Ave. but needs cleanup

- Abandoned lot (gravel lot across from Chamber) could make for great park [discussion that City may have plans for community garden at this site]

- Mid city parking lot could be better utilized 


\section{APPENDIX F. IDEAL CHARACTERISTICS}

\section{Cultural Capital}

Value: African American businesses

- Small businesses coming back, Black owned businesses, Too hard now with zoning and taxes. *

- Education grants available for minority owned businesses, etc. *

- Valuing the past and the future: The Black Culture and History Museum

\section{Human Capitall}

Value: educational opportunities and attainment

- Educated Community

- Sustainable growth from within the local community as supported by education **

- Education grants available for minority owned businesses, etc. *

- Science ability: Focus on technology more than oil and gas and sustainable resource building *

- New education for new jobs

- Educational and training opportunities

- Educational and training opportunities for the youth including an entrepreneurship program

- Better graduation rates, less drop outs

- Have more neighborhood schools

Value: youth development programming

- Senior and youth entrepreneurial center- work together and learn from each other *

- Mentorship programs for the youth

- Organized youth activities

- Activities for the youth

- Academic excellence for youth: Provide tools, Life preparedness lessons, Life skills as well as Summer programs.

- After school support: Mentorship for youth and activities such as skating, swimming and programs

- After school and day programs for the youth

- Hope and opportunities for the youth

- Youthfulness brought back

- Valuing the past and the future: The Youth Center

Value: support for ex-felons

- Prisoner reentry program

\section{Sociall Capitall}

Value: community action

- Community Collaboration**

- Unity in the community and gaining power with more people involved. *

- More pride and unity in the community- all of Fairmont* 
- Continued thriving through change in the community *

- More collaborative project

- Community yard sales- good for socialization as well as bringing the community together.

- Strong sense of community

Value: high quality of life

- Safety: Feel safe and secure $* * * *$

- Safer and drug free community within Fairmon**

- Thriving Community*

- A great place to live and raise a family

Value: trust and reciprocity

- Honesty - people who share and take ownership of their faults

- Trust - allow all stakeholders to participate fully

Value: neighborliness

- More neighbors to know each other*

- Social: Better engagement of neighbors and be more neighborly

- Sense of belonging to a community

- Actually being the "really" friendly city - feel as if they are marketed as a friendly city, but it's not necessarily true

\section{Organizationall Capital}

Value: responsiveness to community needs

- Prioritization of needs

- Extended bus hours for people to get around.

\section{Politicall Capitall}

\section{Value: productive government relations}

- Better communication between government and community, in particular when government listens to community needs instead of making decisions without their input*

- Good communications with the city of Fairmont

- Communication with City Council \& community members.

- Better communications between community and city council

Vallue: equitable government services

- Active code enforcement of properties including a more rapid response time for all neighborhoods equally (currently there is a perceived or real difference in response time)

\section{Value: civic awareness}

- Informed Community - what do I need to get to where I want to go etc 


\section{Financial Capital}

\section{Value: employment opportunities}

- Job opportunities *

- Upwardly mobile environment. Everyone contributes to the community and people are employed

- Locally-based opportunities for work

- Funding for WAC programs

- CEDA program (Community and Economic Development Association)

- Investment in the community

- Providential planning

\section{Value: housing affordability}

- Power, more individual homeowners with solar panel/other power sources as to not keep monopolies afloat*

\section{Value: public investment}

- Higher taxes that are then invested in community infrastructure

\section{Built Capital}

\section{Value: recreational facilities}

- Windmill Park in better shape, including having a swimming pool *

- Rec Center*

- Health amenities - more recreation*

- Windmill Park to be lively, clean, active, and welcoming

- Recreation spaces - bike trails, better parks, gyms

- More recreational places in the Westside (especially seasonal options for cold weather)

- More nice outdoor areas/parks downtown

- More shared use of recreation assets between community and Falcon center and local schools

- Free recreational activities for all

- ATV track @ Bellview Park

- Dog Park

- Community Gardening/Composting

Value: community centers

- Community Center in Bellview - maybe Bellview Plaza**

- Community Center/YMCA at Windmill Park **

- Active community center *

Value: housing development

- Rehabilitated or replaced (as condition and funds allow) structures/buildings

- Old houses demolished and valuable properties kept in better shape

- Strategic demolition in order to be left with usable lots

- Fix/upgrade/Remove Old Buildings 
- Blighted buildings taken care of

- New developments

- Better homes

- New, Single-family homes built. As opposed to apartment buildings

- New homes built for residents that are not "projects", referring to the undesired low-income housing developments that outside organizations attempt to build in the neighborhood

- New Riverview developments

\section{Value: circulation infrastructure development}

- Lights and Sidewalks and get homeowners on board with this. *

- Walkability: More sidewalks created **

- Repairs to sidewalks and a more walkable downtown

- More street lights in neighborhood like Downtown Fairmont

- Improved roads

- Bridge from I-79 to Route 19 to promote economic development

- Commuter rail to Pittsburgh - Train, where you could work or see a baseball game in Pittsburgh

\section{Value: neighborhood commercial areas}

- Small businesses coming back, Black owned businesses, Too hard now with zoning and taxes. *

- Thriving downtown complex with shops and restaurants*

- Health amenities -more doctors*

- More local business

- Variety Stores back in the community

- Convenience stores in the neighborhood

- More grocery store options - in both products and competition

- Have more retail, grocery stores, and affordable housing

\section{Value: neighborhood beautification}

- Community pride: Taking pride in surroundings \& shared responsibility. **

- Clean neighborhood: Trash pickup and clean environment*

- Decrease in loose animals (i.e. feral cats) *

- Beautiful: Neighborhood pride and spirit, curb appeal

- Pride in the community

- Community takes ownership of their own area

- Personal responsibility

- Clean up \& recycling programs could be utilized for art too 


\section{APPENDIX G. BARRIERS TO PROGRESS}

\section{Cultural Capital}

Value: social and economic equity

- Perception of lifestyle, neighborhood, and gender ***

- Difference/cultural divide within city, particularly East versus West sides *

- Segregation - of the Black and White communities*

- Economic and social breeding creates unequal social classes

- Differences in social status: "The man with the gold makes the rules"

- Stigmatization

Value: adequate entertainment opportunities

(1) Little opportunity - for jobs and entertainment**

Value: history

- People aren't educated on the history of Fairmont, such as Willie Mays visiting Windmill Park

\section{Human Capitall}

Value: education

- Education - people can't get jobs or make a community difference, because a lack of education

- Disconnect between education and available jobs

- Lack of man power

Value: youth development and involvement

- Sense of hopelessness of the youth; the feeling of "no way out"

- Boredom as experienced by the youth

- Lack of, or limited access to, summer/after school programs and childcare

- Poor youth involvement

- Need of mentors for the Youth.*

- Parental apathy and lack of involvement toward getting involved with their children's activities and education

\section{Sociall Capital}

Value: a sense of unity in the community

- Broken Relationships within the community***

- Citizens not able to reach agreement **

- Collaboration as a community education is needed on how to work together

- Lack of unity within the community; people don't work together

- More unity is needed within the community

- There's been competition instead of collaboration

- Too much self-interest. 
- Varying opinions of importance, different opinions

- Trust

\section{Value: civic engagement}

- Complacency (attitude, mentality), exhibited by complaints without action **

- Lack of vision. "With no vision, you perish" *

- Lack of community awareness of what is happening in the community

- Communication, people not showing up to meetings

- Ignorance and lack of knowledge and tools. "Knowledge is power"

- People finding solutions elsewhere instead of staying the Westside and creating them

- Community involvement - people don't participate to make a change

- Aging population/homeowners/residents leads to disinterest in citizen engagement

- Lack of proactive community members

- Not engaging retired community

- Apathy of adult residents in general, evidenced by a lack of action or initiative to improve one's situation; a lack of proactive community members

- People work multiple part-time jobs (hard to volunteer/get involved)

- People are resistant to change, have lost hope

- Resistance to change

- Pride prevents us from facing the consequences of our own action

Value: hope and optimism

- Resident apathy: No sense of agency **

- Fatalism

- Cynicism *

- People have given up and exhausted their efforts.*

- Exhausted Efforts: people are tired of trying and seeing no results.

- Unseen results-failure to deliver on promises

- Follow through with actions plans, don't just talk about it

- Negative mentality - living down the old way of thinking

- Negativity in the community, uncertainties about what the future holds for the neighborhood

- Community attitude "half empty" - people here aren't positive, they only see the negative

- Community itself people don't have the want to change and contribute to it.

- People are resistant to change, have lost hope

\section{Organizationall Capital}

Value: responsiveness to community needs

- Lack of listening to potential (and current) businesses needs and wants

\section{Politicall Capitall}

Value: adequate politicall representation and influence

- Poor communication (giving community a voice) ** 
- City Council "A BIG BARRIER." No minorities on the board and need for better representation of all people. *

- Districts of City Council, not matching up with the neighborhood map. 3 Districts for the Westside [should all be in one] *

- City government - not helping the citizens of Fairmont*

- Lack of communication: nothing is getting done between agencies, the City of Fairmont and us

- Lack of listening to the neighborhood from the city side

- Politics at all levels of government

- Favoritism in funding from the City

\section{Financiall Capital}

Value: equitable and adequate investment in the Westside neighborhoods

- Lack of money for developing the community*

- Lack of funding *

- Little opportunity - for jobs and entertainment**

- Money - there is not enough money to accomplish our goals*

- Money

- Lack of funding *

- Lack of funding. Funds are not allocated to the Westside. *

- Access to funding and having it properly allocated with the city.

- Funding doesn't meet needs, no state funding

Value: employment opportunities

- Little opportunity - for jobs and entertainment**

- Lack of jobs in Westside community *

- Lack of good paying jobs

- Low paying jobs - that don't attract the youth to stay in the community

- Poverty

\section{Built Capital}

Value: development control

- Abandoned buildings/houses

- Ability to use eminent domain

- Laws and zoning prevent better development from forming

- Lack of control within the community

Value: thriving commercial areas

- Lack of thriving downtown area

- People avoid downtown because they feel there is no parking

Value: affordable housing

- Access to affordable housing is low (vouchers expire before homes are available) 


\section{APPENDIX H. IDEAS FOR ACTION}

\section{Human Capital}

Value: educational opportunities

- Companies train youth so that they can be equipped with skills and knowledge

- Education

- Financial education for the youth

- Developing career tract and vocational schools for Fairmont Residents

\section{Value: youth mentorship}

- Training and mentorship program geared toward the young, including entrepreneurship and apprenticeships **

- Strengthen youth center for youth mentorship. ***

- Mentorship programs - Seniors in the community helping mentor Youth*

- Mentoring: Especially for the youth *

- Black men and women role models who can provide hope for black youth, such as those who own businesses

- Role models for the youth

- Focus on positively influencing the youth

Value: youth development programs

- Hands on activities to engage youth (community cleanup, scheduled events and activities with childcare) $* * *$

- Activities and programming for the youth

- Reawaken the Westside Robotics program, a youth robotics program based at Dunbar School Annex which has recently gone dormant and is in need of leadership.

- After school programs

- More funding for after school childcare programs

\section{Value: youth involvement}

- Instill sense of urgency of pride within youth and promote volunteerism

- Develop service opportunities for children

\section{Sociall Capital}

\section{Value: community organizing}

- Informally reaching out to the community***

Talking to community members while out in public (grocery stores, sporting events, bowling alley, etc.) to try and get them involved with community instead of handing out flyers and using social media

- Motivate for action-Don't say it.... DO IT!!! ***

- Open minds to new ideas. ***

- Become united as one with one voice. * 
Value: community action

- Develop a vision that is championed by youth who are under the age of $\mathbf{4 0}$ and under: Visioning, Issues, Planning, Resources

- Comprehensive community meeting where everyone involved in the project is present (option to live stream)

- Working with non-profit and non-governmental groups during the planning and development process

- Motivate for action-Don't say it.... DO IT!!! ***

- Play to people's strengths

- More involvement in the WAC

- WAC meetings at convenient times and to have higher involvement

- Build Action Boards

- Neighborhood watch: community effort group

- Close Windmill Park gate at night for better security against drug activity

Value: civic engagement

- Civic groups need to reach out to younger people, the boards are aging

- More individual involvement and volunteering from Fairmont residents

- More community engagement

- Engage retired community

Value: a sense of community

- God as center **

- Leaning on others and trying to collaborate. ***

- Asking for the help you need. ***

- "Knowing when you are drowning"

- Show pride MYSELF- self-ownership in my community

- More social gatherings to bring the community together

\section{Organizationall Capital}

\section{Value: interfaith cooperation}

- Council of Churches who will coordinate programs for volunteers and the dissemination of information benefitting the community *

\section{Politicall Capitall}

\section{Value: adequate political representation}

- Changing the voting districts *

- Support diverse candidates for city council

- Diversify city boards and commissions

- Change requirements for serving on city commissions

- Terms for serving on council and commission need changed, six year terms are not designed for average citizens

- Expand borders for greater reach: include more people to serve on boards 
Value: civic education opportunities

- Educate ourselves on programs and possibilities ***

- Education on social and economic system and civic participation

- Education: from city council to the people in the community

Value: political action

- Engage with leaders - community presence @ City Council events *

- Encourage people to vote. $* * *$

- Community members should get involved in the political process, including voting

- Neighborhood members attend city council meetings*

- More involvement by community residents in economic and housing development decisions and planning

\section{Financiall Capital}

Value: capacity for resource development

- Research for available funding *

- Better know what resources are available

- Look for grants to fund neighborhood improvements

\section{Value: sufficient income}

- Create jobs out of tearing down old buildings and advertising those jobs*

- Job creation

- Creating jobs - Higher paying jobs, and more attractive jobs for all

\section{Built Capitall}

\section{Value: neighborhood beautification}

- Engage in community beautification **

- Make it more attractive to people who are out of town so that people and businesses move in

- Coordinate with the city for trash pick-up

- Organize groups for cleaning

- Church involvement in cleaning and maintaining the neighborhood

Value: quallity development and redevelopment

- Tear down abandoned buildings in Fairmont***

- Find more government agencies to help tear down or revitalize abandoned places, and add sidewalks for improved walkability

- Laws and zoning need changed

\section{Value: improved walkability}

- Find more government agencies to help tear down or revitalize abandoned places, and add sidewalks for improved walkability 
Value: basic goods and services

- Targeted recruitment of another grocery store chain for neighborhood

Miscellaneous

- Increased advertising of downtown parking options, specifically the garage, to encourage more residents to come downtown

- Don't raise downtown parking meter rates 


\section{APPENDIX I. VALUES DRAWN FROM RESULTS}

\section{Nalurall Capital}

- neighborhood and regional parks

- natural open spaces for recreation

\section{Culturall Capitall}

- historic character

- historic sites

- historically African American community

- African American businesses

- arts and entertainment

- adequate entertainment opportunities

\section{Human Capitall}

- educational attainment and opportunities

- educational opportunities and attainment

- educational opportunities

- youth development opportunities

- neighborhood schools (more so than regional schools)

- youth mentorship

- youth involvement

- youth development opportunities

- youth development and involvement

- youth development programming

- youth development programs

- youth and senior development programs

- entrepreneurship

- support for ex-felons

\section{Sociall Capitall}

- family and home

- neighborliness

- trust and reciprocity

- high quality of life

- sense of community and neighborhood efforts

- a sense of community

- a sense of unity in the community

- community organizing

- community action

- community action

- civic engagement

- civic engagement 
- hope and optimism

- spaces for community activities

- community events that brought people together

- social gathering spots

- safety through law enforcement

- safety through ordinance enforcement

\section{Organizationall Capitall}

- organizations serving the neighborhoods

- social services

- community safety

- places of worship

- interfaith cooperation

- responsiveness to community needs

- responsiveness to community needs

\section{Politicall Capital}

- civic awareness

- civic education opportunities

- political access and adequate information about what local government is doing

- political action

- adequate political representation

- adequate political representation and influence

- community input to decision making

- productive government relations

- good government

- equitable government services

\section{Financiall Capital}

- employment opportunities

- employment opportunities

- employment opportunities

- small local enterprise

- housing affordability

- public investment

- equitable and adequate investment in the Westside neighborhoods

- capacity for resource development

\section{Built Capitall}

- vibrant downtown

- thriving commercial areas

- thriving commercial areas

- downtown commercial development 
- regional shopping

- neighborhood businesses

- neighborhood businesses

- neighborhood businesses

- neighborhood commercial areas

- basic goods and services

- transportation infrastructure and circulation

- investment in infrastructure

- circulation infrastructure development

- connectivity

- improved walkability public recreation facilities

- recreational facilities

- quality recreational facilities

- recreational facilities

- recreational facilities

- neighborhood community centers

- community centers

- community beautification

- neighborhood beautification

- neighborhood beautification

- housing development

- housing development

- affordable housing

- development control

- quality development and redevelopment 

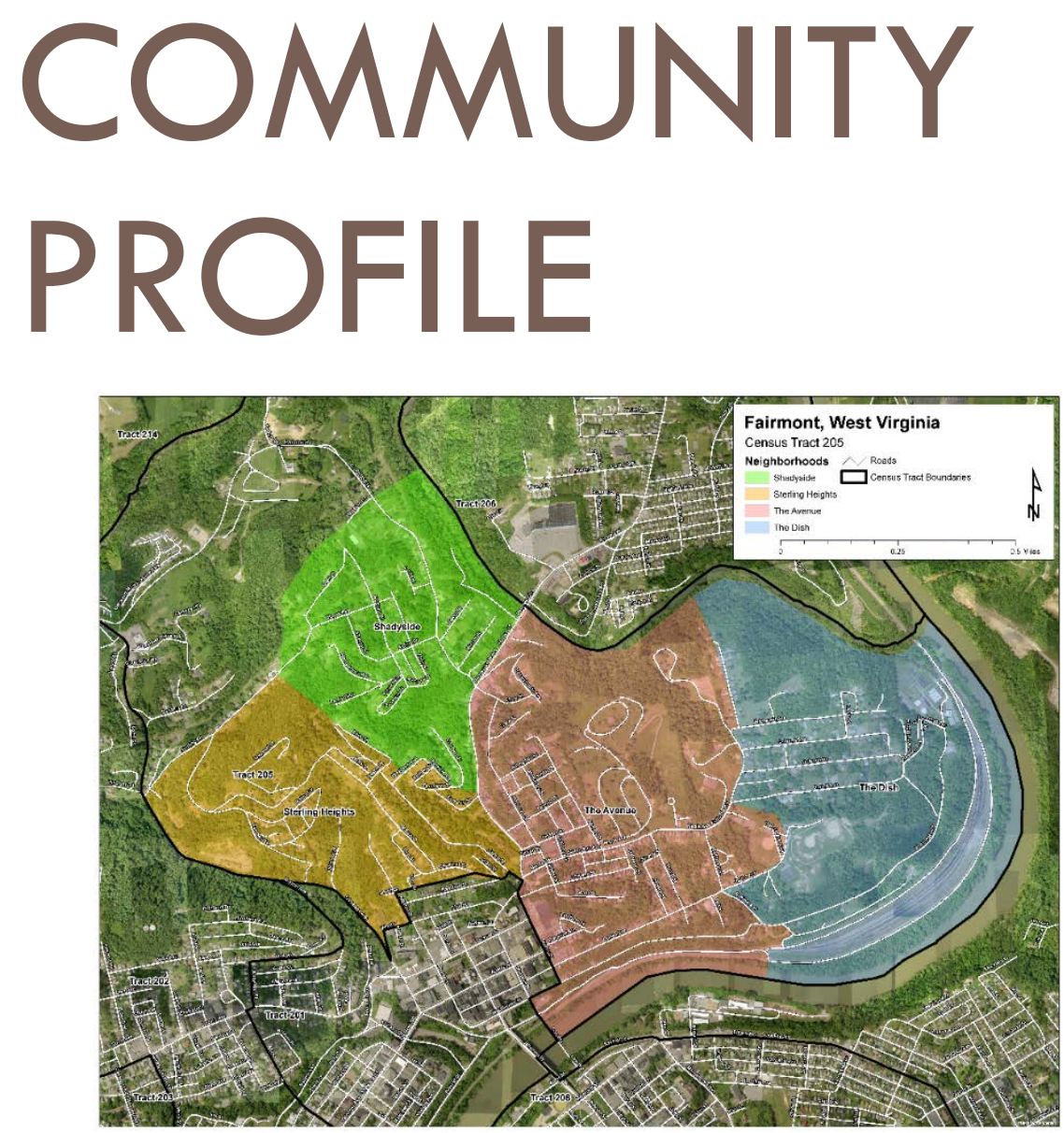

\section{$12 / 5 / 2015$}

\section{Fairmont's Westside Neighborhoods}

This report provides a snapshot of the various community capitals available to these neighborhoods, including: natural environment; cultural; human; social; political; organizational; financial; and built environment capitals. This profile provides baseline data for community visioning and planning efforts. 


\section{Community Profile}

\section{FAIRMONT'S WESTSIDE NEIGHBORHOODS}

\section{PROFILE BACKGROUND}

\section{Margaret Stout}

In May of 2015, representatives of the Westside Action Coalition in Fairmont, WV agreed to work with faculty and students from West Virginia University to mobilize and organize the community toward collaborative strategic planning and project implementation. These outreach activities are being conducted through a combination of service learning and action research activities led by Associate Professor Margaret Stout and the graduate students enrolled in Master of Public Administration courses and outreach programs offered by other academic units.

One of the most important foundations of successful strategic planning and implementation is community capacity. The term community capacity refers to a geographic area's collective ability to foster and sustain positive change. The "collective" includes individuals and both informal and formal groups, organizations, networks (Chaskin, Brown, Venkatesh, \& Vidal, 2001). In sum, these people are the community's human and institutional assets (Kretzmann \& McKnight, 1993).

Capacity as a potential means the abilities, commitment, and resources needed to take any type of community action. It is described by concepts like conditioning influences (Chaskin et al., 2001), orientation (Denhardt \& Glaser, 1999) or preparedness (Perry \& Lindell, 2003). In fact, the readiness aspect of capacity has been explored in community development and resiliency research (Chazdon \& Lott, 2010; Foster-Fishman, Cantillon, Pierce, \& Van Egeren, 2007; Miller, 1990). In short, these studies show that if a community lacks sufficient capacity to take advantage of outside assistance, the project will likely fall short of desired outcomes.

The factors that contribute to community capacity are often described as community capitals, including: natural environment; cultural; human; social; political; organizational; financial; and built environment types (Flora \& Flora, 2007). All of these capitals are interrelated and boundaries are not always clear, but when they are mutually supportive, all elements of community sustainability-environmental, economic, and social vitalityare fostered (Fey, Bregendahl, \& Flora, 2006). For this reason, community capacity is often understood as resilience (Perrings, 1998).

Community capacity can be measured at the start of an outreach project through needs and assets assessments that determine the readiness and potential for positive change. These evaluations can consider any or all of the community capitals, as shown in this Community Profile. The following sections describe preliminary information about Fairmont's Westside neighborhoods, drawing primarily from secondary data sources, as opposed to field inventories, observations, or interviews. These and other capitals will be explored further during forthcoming visioning and strategic planning processes. However, this initial snapshot will help guide outreach and participatory planning activities. 


\section{References}

Chaskin, Robert J., Prudence Brown, Sudhir Venkatesh, and Avis Vidal. 2001. Building Community Capacity. New York: Aldine de Gruyter.

Chazdon, S.A., and S. Lott. 2010. "Ready for engagement: using key informant interviews to measure community social capacity." Community Development no. 41 (2).

Denhardt, Robert B., and Mark A. Glaser. 1999. "Communities at Risk: A Community Perspective on Urban Social Problems." National Civic Review no. 88 (2):145-153.

Fey, Susan, Corry Bregendahl, and Cornelia Flora. 2006. "The Measurement of Community Capitals through Research: A Study Conducted for the Claude Worthington Benedum Foundation by the North Central Regional Center for Rural Development." The Online Journal of Rural Research and Policy no. 1 (1):1 28.

Flora, Cornelia, and Jan L. Flora. 2007. Rural Communities: Legacy and Change. 3rd ed. Boulder, CO: Westview Press.

Foster-Fishman, Pennie G., Daniel Cantillon, Steven J. Pierce, and Laurie A. Van Egeren. 2007. "Building an active citizenry: The role of neighborhood problems, readiness, and capacity for change." American Journal of Community Psychology no. 39:91-106.

Kretzmann, John P., and John L. McKnight. 1993. Building Communities From the Inside Out: A Path Toward Finding and Mobilizing a Community's Assets. Chicago: ACTA Publications.

Miller, Mark Alan. 1990. Exploring rural community readiness for participation in community and natural resource development extension education programs, Agricultural Education, Ohio State University.

Perrings, Charles. 1998. "Resilience in the dynamics of economy-environment systems." Environmental and Resource Economics no. 11 (3-4):503-520.

Perry, Ronald W., and Michael K. Lindell. 2003. "Preparedness for emergency response: Guidelines for the emergency planning process." Disasters no. 27 (4):336-350. 


\section{ENVIRONMENTAL CAPITAL}

\section{Bob Riddle and Lisa Lagana}

Fairmont, West Virginia is located in north-central West Virginia in the eastern portion of Marion County, between the metropolitan cities of Morgantown ( $\sim 20$ miles) and Clarksburg ( $\sim 23$ miles) along the I-79 corridor.

The Westside neighborhoods are bounded on the east and a portion of the south by the Monongahela River, to the north by Buffalo Creek, and to the west by Route 250. As identified by residents, the neighborhoods are generally known as Shadyside, Sterling Heights, the (Maple) Avenue, and the Dish (Jackson Addition). As shown in Figure 1, these comprise the majority of U.S. Census Tract 205.

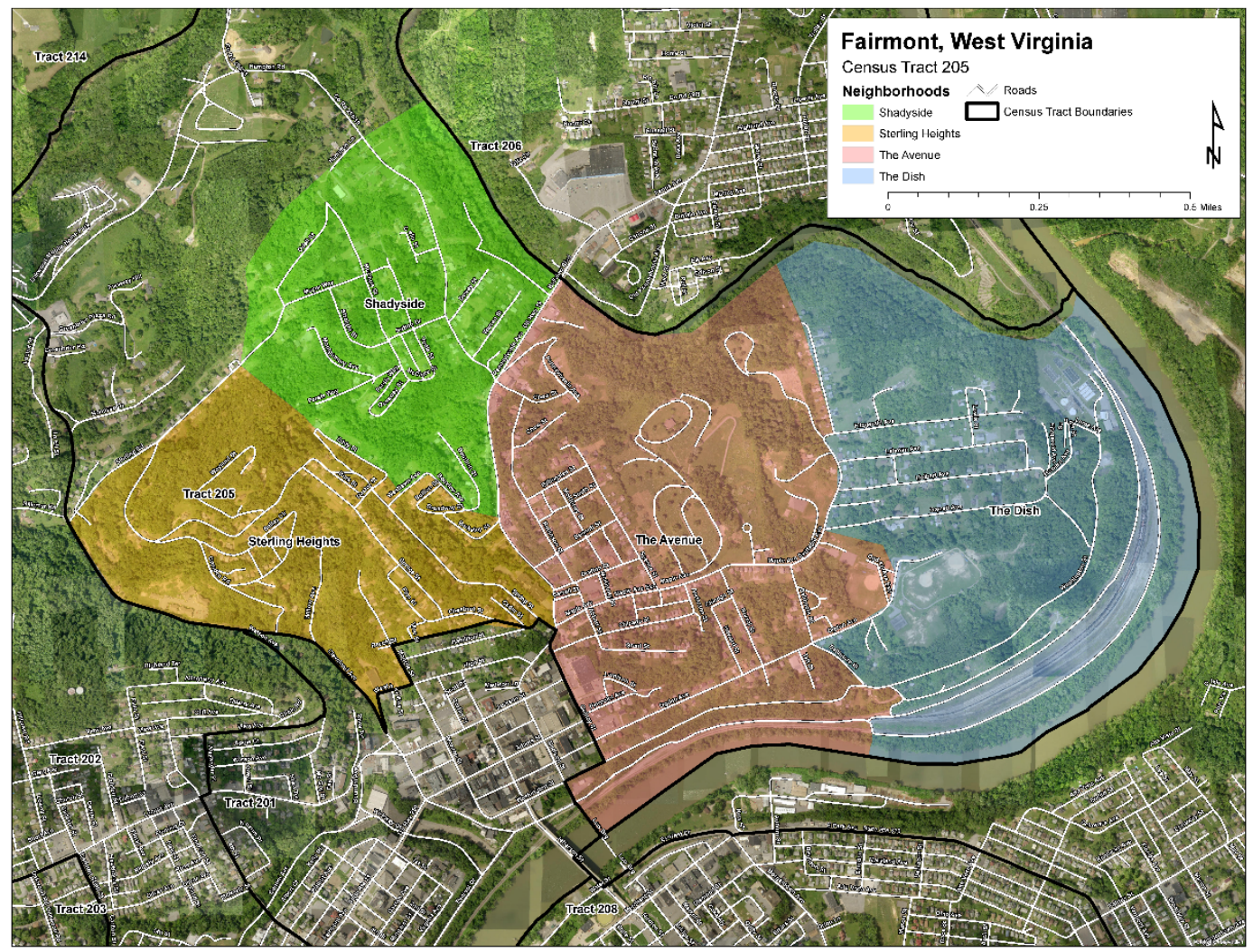

FIGURE 1: RESIDENT-IDENTIFIED NEIGHBORHOODS. SOURCE: STRAGER (2015).

\section{Topography}

Topography shows relief features and surface configurations such as bodies of water and the slope of the land. This information is vital to determine a variety of uses for land such as walking and biking or gardening, identifying potential construction sites, and determining where flooding might be likely. The topography of this area has gentle to strong slopes, making some areas more difficult for development. The individual neighborhoods can be broken down into the following topographical grades:

- Shadyside - $15-35 \%$ slope

- Sterling Heights - $15-35 \%$ slope 
- The Ave - $15-25 \%$ slope

- The Dish - 3-8\% slope

A steep grade, such as that found in the Shadyside and Sterling Heights, can create challenges for construction. As can be seen in the existing neighborhood, homes have to be built on a smaller scale, narrow, or terraced to follow the contour of the hills. With a lesser incline, the Avenue and the Dish areas have a greater potential for larger homes, multifamily buildings, and businesses.

\section{Soill}

These neighborhoods are associated with Monongahela-Zoar Allegheny soils, which can be described as moderately to well-drained acidic soils (USDA NRCS Soil Conservation Service, 1977). The soil in the area is very shallow with bedrock close to the surface. The soils in the neighborhoods can be generally categorized:

- Shadyside - Westmoreland Silt Loam

- Sterling Heights - Culleoka \& Westmoreland Silt Loam

- The Avenue - Urban Land Culleoka

- The Dish - Allegheny Silt Loam

Shallow soil can be prone to erosion, but the silt loam soil type is well drained and favored in gardening and urban farming. This soil is considered ideal in retaining nutrients and with the more acidic $\mathrm{pH}$ of the area, these neighborhoods are perfect for woodland, pasture, and shrubs with shallow root systems. For example, if there is interest in home or community gardens, blueberry bushes would allow neighbors to consume more fruits that are higher in antioxidants, popularly called "superfruits". This produce could create an economic benefit with berries being sold as a seasonal product at the local farmers' market or independent green grocer.

\section{Climate}

A region's climate can determine building types such as stucco versus brick, landscaping choices such as foliage types, and overall community design. The Westside neighborhood has an average yearly temperature low of 42 degrees and a high of 62 degrees, typical for West Virginia. The average precipitation for the year is 39 inches of rainfall and 31 inches on average of snowfall. The humidity averages $76 \%$ and wind speeds average $19 \mathrm{mph}(26555,2015)$. The growing season, as counted above 32 degrees, is an average of 144 days as recorded over a 10 year period (USDA, 1977). These statistics are common for West Virginia's moderate growing season, as most plants require at least 90 days to produce fruit. This area is not suitable for longer growing seasons without a greenhouse, but traditional crops such as carrots, squash, and salad greens would do well.

The area has relatively larger seasonal temperature differences, with humid hot summers and cold winters, which can lead to higher chances of plant fungus and household molds or allergens. Furthermore, this means builders must take moisture maintenance, drainage, and ventilation into account when determining building styles and materials. For example, the potential for severe weather in the winter with moderate snowfall leads to homes with a gable roof that can withstand the weight of accumulation or strong winds. 


\section{pen Space}

There are many integrated open spaces in the Westside community. It could be possible to retain some vacant lots left after demolition of abandoned and dilapidated buildings as open space. Those locations could be used as community gardens or pocket parks to serve immediate neighbors (Fairmont Vacant Properties Map, 2015). Windmill Park gives the neighborhoods roughly 20 acres of open space for the use and enjoyment, including baseball, football, and soccer fields, a basketball court, playground, and covered picnic area. The football field even has a concession stand for use during games.

There are plans in place to connect Windmill Park to the rail trail that will connect to the system that runs throughout the region. The Mon River Trail South travels from Morgantown to Prickett's Fort State Park, about five miles from Fairmont. The trail is a resource for hiking, walking, or biking and acts as a gateway to other rail trails in North Central West Virginia, Southwestern Pennsylvania, Maryland, and Washington, D.C. The proposed plans create the Marion County Connector Trail, which will provide access to this and other trails in Marion County.

Bodies of water and their banks provide additional open space opportunities. The Monongahela River and its tributary Buffalo Creek bound the Westside neighborhoods of Fairmont. The United States Geological Survey recorded statistics for the Monongahela River over the last five years. The river has an average depth of 9.49 feet and a temperature of 61 degrees Fahrenheit. The "Mon" offers a diverse ecosystem for fishing, boating, kayaking, and swimming. According to the Monongahela River Biological Monitoring Study, its waterways are home to many species of fish including: Crappie, Bluegill, Catfish, Carp, Drum, Largemouth Bass, Gar, Sauger, Smallmouth Bass, Muskellunge, and Perch. The River Towns program works to promote kayaking, canoeing, motor boating, and fishing activities within communities along the Monongahela River and could potentially be a resource for Fairmont and its Westside neighborhoods.

\section{Naturall Resource Extraction}

The state of West Virginia has long been characterized by its extraction of coal and other natural resources from the land. There is evidence of mining within the Westside neighborhoods where Windmill Park, Maple Avenue, and Jackson Addition meet. According to residents, strip mining had previously occurred at the location. Upon completion of mining the area, the land was filled with leftover material from the mining. Subsidence (an area of land that sinks or caves in) occurred on the parcel and has been left unmaintained and no land reclamation or remediation has occurred on the site.

The Fairmont Coke Works was located across the Monongahela River from the neighborhoods, operating from 1918 to 1979. Coke is a high carbon fuel product made from bituminous coal. After the factory shut down, two landfills have sat dormant for two decades, likely containing environmental waste. In 1993 the federal Environmental Protection Agency in coordination with the West Virginia Department of Environmental Protection began a comprehensive cleanup of the site. The cleanup is nearly complete and the City is now in the final stages of approving future development plans for the property; possibly an indoor water park and resort called Volcano Island.

\section{Environmentall Quallity}

Environmental factors that directly affect human health are regulated in the United States with agency standards as they affect the quality of life, happiness, and wellness. In regard to air quality for the overall Fairmont area, particulate matter of $10.3 \mu \mathrm{g} / \mathrm{m}^{\wedge} 3$ (micrograms) meets the National Ambient Air Quality Standards of $12 \mu \mathrm{g} / \mathrm{m}^{\wedge} 3$ over a three year period as declared by the EPA for highest weighted annual 
mean concentration (National Ambient Air Quality Standards (NAAQS, n.d.). However, this measurement should be closely watched as high micrograms of particulate matter lead to a higher percentage of asthma, which is a chronic lung condition that has affected 13\% of adult West Virginians as of 2012 (DHHR Fact Sheet, 2013).

Soil and water quality is also of particular concern in West Virginia due to resource extraction activities. The primary concerns of water quality on the Monongahela River and its tributaries are Acid Mine Drainage, Eutrophication (nutrient accumulation from agricultural runoff), and invasive species. The EPA has compiled a list of many chemicals that have contaminated both soil and water sources in the Monongahela River watershed including: phenol, ammonium sulfate, benzene, coal tar, tolvene, xylene, and coke oven gas. The United States Wildlife and Fisheries does advise that consumption of fish exposed to carcinogens like these be limited. However, the water quality of the Monongahela River varies by section and the exact statistics are not currently available for the section flowing through Fairmont and the Westside neighborhoods.

\section{References}

26555 Zip Code Weather. (2015). Retrieved November 8, 2015 from

\section{http://www.weather.com/weather/tenday/1/Fairmont+WV+26555:4:US}

DHHR Fact Sheet. (2013). Retrieved November 8, 2015 from

http://www.dhhr.wv.gov/bph/Pages/default.aspx

Fairmont Vacant Properties map. (n.d.). Retrieved November 8, 2015 from

https://www.google.com/maps/d/viewer?mid=zMe2nKax9Cas.kEIC2nsgO4RI

National Ambient Air Quality Standards (NAAQS). (n.d.). Retrieved November 8, 2015 from

http://www3.epa.gov/ttn/naags/criteria.html

USDA. (1977). Soil Survey of Marion \& Monongalia Counties of WV. [National Cooperative Soil Survey]. Washington, D.C.: USDA NRCS Soil Conservation Service. 


\section{CULTURAL CAPITAL}

\section{Amy Loomis and Chris Agba}

Fairmont is an old city with a Historic Downtown District preserving hundreds of structures that provided an economic and social center to neighboring communities. It was established as Middletown by the Virginia legislature on the farm of Irish immigrant Boaz Fleming on January 19th, 1820. Fleming parceled off his 254acre farm and sold the lots to form a new town. The city became the Marion County seat in 1842 and its name was changed to Fairmont in 1843.

The city was named for its beautiful overlook—or "fair mount"- of where the West Fork River, Tygart River, and Monongahela River come together. Fairmont's rivers are tied to the city's identity and serve to define many of its neighborhoods. From the 1800s through the Industrial Age, navigable waterways, early railroad development, and resource extraction contributed to a bustling economy. High-quality bituminous coal was its leading industry. Other industries included timber, glass, natural gas, railroad, and river transport.

\section{Influx of Culturally Diverse Workers}

Regional industries provided jobs to European immigrants and African Americans migrating from the south. Irish immigrants came in response to the Potato Famine of 1845. Many Italian, German, Russian, and Hungarian immigrants came in response to extreme poverty across Europe and World War 1. After the Civil War in the late 1800s, many African Americans came to West Virginia to support the coal industry. Coal remained the source of employment for many African Americans and European immigrants, but the industry suffered from many economic problems following World War 1 and later, the Great Depression. Many workers came to support the industries, including railroads and local factories.

The Monongah Mining Disaster of 1907 is remembered as the worst industrial disaster in American History. At least 361 miners perished in the accident at Manongah Mine No. 8, leaving 252 widows and 1,000 fatherless children in need of assistance (McAteer, 178). To remember fathers everywhere, and to honor her own late father, Grace Golden Clayton and the Central United Methodist Church held a special service as the Father's Day. Many of the victims were Italian immigrants (Marion County Historical Society, 2011). No known African Americans perished in this inciden. Subsequent disasters have provided the Westside community with a cultural attachment to Father's Day. In 1927, an explosion at Federal \#3 mine in nearby Everettville killed at least 91 men, including several African American men. In 1968, the Consol \#9 mine explosion in Farmington trapped and killed 78 men including James Jones, a Jackson Addition resident (Ezelle, 2015). James Jones was grandfather to Colyn Jones, a board member of the Fairmont Community Youth Development Center (James, 2015).

Following World War II, African Americans flocked to Fairmont's outlying coal mining towns to seek economic opportunities during a post-war coal "boom." However, during the late 1970s, the coal industry suffered a severe recession and unemployment reached all-time highs. Many West Virginians left the state in large numbers at that time.

Each immigrant group brought a legacy of their own cultural heritage to the community. For example, Italian immigrant and coal miner Giuseppe "Joseph" Argiro invented the pepperoni roll-a regional favorite to this day (Mozier, 79). According to local lore, from 1908 to approximately 1921, the ltalian organized crime units known as the Black Hand Italian Mafia and Famalie Vagabonda were headquartered in East Fairmont. The Black Hand operated brothels, dealt narcotics, and was involved in extortion and murder. According to 
community reports (James, 2015), the large department stores in Downtown Fairmont were once mafiaaffiliated. When the mafia members died out, no family heirs were able carry on the dangerous nature of the business. This may have contributed the withering of downtown's commerce. The narcotics trade history may also have contributed to the rise in drug use and the subsequent decline of Westside neighborhood in the late 70s through 80s. Today, descendants of the Black Hand and other mafia group families have gone into legitimate business within the community of Fairmont. Family names like Spadafore, Alloi, lquinta, and others are still commonly related to the mafia (Brooks, 2015).

In regard to black immigrants from the southern states, as shown in Figure 2 the current racial demographic in Fairmont overall is about $8 \%$ Black, as compared to around 3\% for the state overall. However, in the Westside neighborhoods (as represented by Census Tract 205), Black residents represent over $40 \%$ of the population. As shown in Figure 3, this is complimented by over $56 \%$ White and a small percentage of other and mixed races.

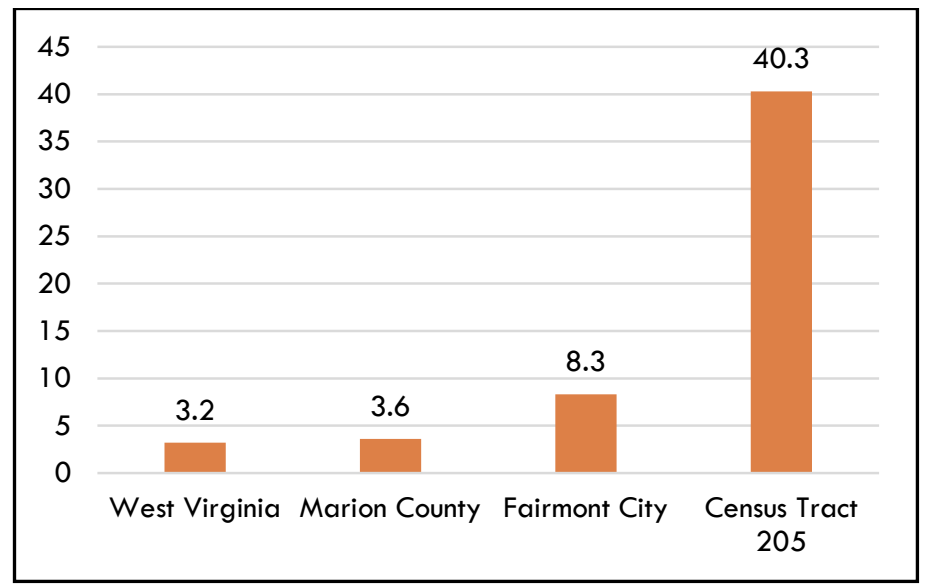

FIGURE 2: RACE IN COMPARISON AREAS. SOURCE: U.S. CENSUS (2013).

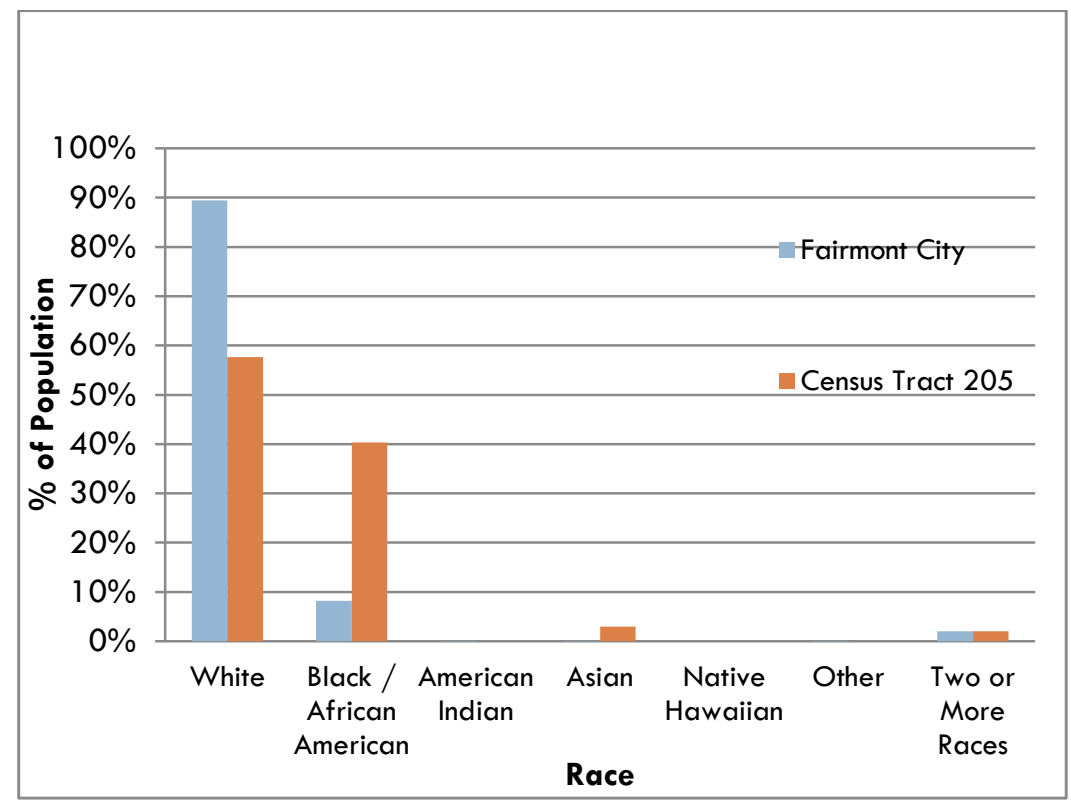

FIGURE 3: RACE CENSUS TRACT 205. SOURCE: U.S. CENSUS (2013). 
The Westside includes a number of neighborhoods with a substantial African American population: Shadyside, Sterling Heights, the Maple Avenue area, and Jackson Addition (see Figure 1). According to Ezelle (2015), the Maple Avenue area was historically a predominantly white settlement for industry elites. The exact reason for the barons' occupation of Maple Avenue can only be speculative, but this may have been motivated by its strategic location next to downtown or hillside views. Jackson Addition was established as African American families settled on the outskirts of the Maple Avenue area (Ezelle, 2015). Jackson Addition was also home to many first generation Italians. In the early 1960s, the first African American family moved to 128 Maple Avenue. Today, Maple Avenue is predominantly African American. Shadyside has always been an AfricanAmerican neighborhood, while Sterling Heights was once predominantly white. Today, Sterling Heights is home to a mix of races.

Just to the north of these neighborhoods is Bellview, which was once home to upper class white residents. Older African Americans gave Bellview the nickname of "Ku Klux Town" although no known Klan or other malicious activities are known to have occurred. It is speculated that this nickname is due to the concentration of upper class white residents and the neighborhood's inaccessibility to African American community members. However, as white residents died or moved away, homes fell into disrepair and black renters moved in. Today there are several African American homeowners in Bellview.

Residents report that although races were informally divided by neighborhood and formally divided by school segregation, interactions between races remained civil. According to Ezelle (2015), prior to the Civil Rights Act, members of the group Clover 13 went downtown to Murphy's lunch counter to place an order. The order was not accepted and the group left. Clover 13 returned a second time and was denied service. On the third attempt, the group was offered seats without fuss.

Similarly, on September 30th 1954 , the all-black Dunbar High School and all-white Fairmont Senior High School teams met on the football field for the first time in local history (Hensley, 2014). The match at EastWest Stadium was framed by racial tension, months after the Supreme Court Decision to end segregation. Local law enforcement was placed on to high alert. The game went without incident, with a final score of 7 to 6 by Fairmont Senior High School. Players were familiar with each other, having played in the park together after school. This friendly competition and familiarity between players eased racial tensions.

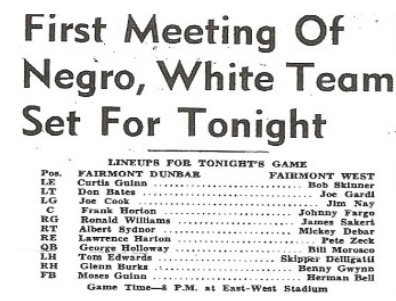

FIGURE 4: DUNBAR V. FAIRMONT WEST LINE-UP. SOURCE: WV PUBLIC BROADCASTING (2014).

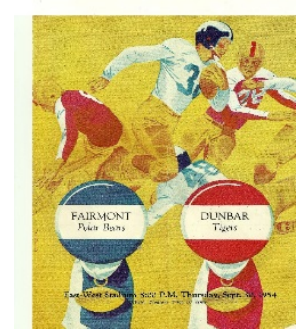

FIGURE 5: PROGRAM FLYER. SOURCE: WV PUBLIC BROADCASTING (2015). 


\section{Economic Activities}

Historically, the Westside has been a predominantly African American community, giving the neighborhood a unique cultural character. According to Nembhard (2015), the resourceful attitude of African Americans to improve their socio-economic condition in the face of slavery and discrimination led to a culture of selfsufficiency through individual and group efforts. As she notes:

While the powerful are gaining more and more power over the centuries, they're also leaving holes and gaps so that the people who are exploited are figuring out at least small ways to do alternatives. Even if we take enslaved African-Americans as an example: people who didn't own their own bodies, didn't own their labor, weren't paid-were totally exploited. Yet, on the one day they had off, on Sunday, they would farm small gardens together. Some actually hired themselves out if they had skills. They found alternative ways to make sure they could feed their families and have some dignity. (Nembhard, 2015)

African American communities have long been built upon a tradition of helping, caring, and sharing community of mutual aid systems and a charitable spirit (Martin, 1985, p. 91). Traditional African American culture emphasized communal solidarity such as mutual aid, respect, and support. This parallels the roles that Westside churches, civic and social organizations, and Dunbar School have played over time. These institutions are examples of how the helping tradition has knit the Westside neighborhoods together.

The history of small business ownership further contributes to the idea that community members serve their community through mutual interest and a strong work ethic. The African American community learned to cater and provide for its own through collaborative efforts, such as sacrificing time and money together to build schools to educate their children; and at most times through singular act of providence by residents who had some additional capacity (Meade, 2015).

In the past, Westside residents supplemented their household income with low-paying part-time job. Some residents worked as seamstresses, maids, cleaners, and other low wage jobbers. Some worked as neighborhood handymen who performed maintenance and chores for a fee (Davis, 2015). The Fairmont Country Club, a membership club offering golf and social activities, was also a source of employment (Brooks, 2015).

Today, the Westside is home to cottage industry businesses. Home-based entrepreneurs offer services such as lawn care, accountancy, hair and beauty care, and children's day care (Brown, 2015). Ms. Charlotte, "the candy lady", lives across the street from Morning Star Baptist Church and sells candy, snacks, and sodas. Neighbors speak nostalgically about Ms. Ann's snow-cone business, which operated up until the last year out of a small building in front of her Norval Street home.

A few African Americans operated longstanding businesses along Pennsylvania Avenue near Maple Avenue during the 1940s through 1960s. Businesses included the Parker Beauty School; Whit's Restaurant, owned by Yancy Whitman; a filling station near Billingslea, owned by Clyde Williams; a blacksmith by the name of Bragg; and various petty stores and juke joints (bars). From the late 50s into the 70s, African American businesses such as a gym, Mr. Fat's Restaurant, a record shop, several groceries, barbers, and beauty shops operated within the Westside (James, 2015). The Saw Robeson convenience store was known for fresh fish and offered a truck service that delivered around town. In the late 1960s, African American professionals such as doctors, lawyers, and dentists lived on the Westside and had offices downtown (Ezelle, 2015). By the 
70s, neighborhood business owners retired, the businesses were not replaced and the buildings went into disrepair.

According to current residents, other family businesses operated along Maple Avenue toward Jackson Street from the 30s to the 50s, most of which were owned by Italian families (Brooks, 2015 and Ezelle, 2015). These businesses included a corner store which offered concessions and school supplies, a clothing cleaner and press shop, a shoe repair shop, and the now-shuttered Norwood Street Groceries, which is referred to colloquially as "the store" or Jack's Grocery Store. Debatos Store was a private home business in which the living room was stocked with lunchmeat, produce, and convenience items. Pacifico's Italian had a reputation for offering the best meat in the county, drawing customers from afar. Marty's was a popular Greek-owned business that offered sandwiches, candy, and draft beer. Pharmacist Leonard Mylan operated a drugstore and a beer garden. After Mylan died in 1958, the businesses along Maple Avenue slowly disappeared and the buildings went into disrepair.

\section{Sociall Activities}

Historically, churches have played an intricate cultural and social role in African American communities. Despite denominational differences, their common goal is to knit together religion, home, and community (African, n.d.). According to Robert Hill (1999), "many studies have revealed that a strong religious orientation and spirituality are major contributors to enhancing the resilience of African American individuals and families" (150). Indeed, involvement in the church has been described by residents as the basis of Westside living (Ezelle, 2015). Churches like Morning Star Baptist church, Mount Zion Baptist Church, Temple of Christ, Church of God Militant, Trinity United Methodist Church, Christian Love Ministry, African and Methodist Episcopal Church provide training, food, shelter, clothing, counseling, education, information, spiritual needs, peacemaking, and other services to the neighborhood (Brooks, 2015).

Trinity United Methodist Church on 407 Cleveland Avenue was founded in 1869. Its charter members included the Meade family (Hensley, 2014). At 146 years old, it is one of the oldest churches in the city of Fairmont and was once one of the leading churches in the community with congregations, reaching a size of 200 faithful. However, today's congregation is only between 25 and 40 people. Morning Star Baptist Church on 100 McKinney Street now has the largest congregation of all Westside churches. According to one resident, church attendance has declined with the passing of older worshippers and younger people pursuing opportunities further afield (Ezelle, 2015).

Churches have the capacity to engage in cooperative activities and serve as incubators for community economic development projects (Wallace, 2003). However, according to W. James (2015), Westside churches have not been at the center of community action since the 60s. In the past, multiple church congregations convened annually for a church picnic at Morse Park on the Eastside, drawing people from as far as Charleston. These events no longer occur, suggesting that churches are playing a less active role in building community beyond their own congregations.

Centers of the community were not limited to church organizations. A settlement house located between Maple Avenue businesses provided community services. Other centers of community included civic and social organizations such as Elks Lodge \#148 and its affiliate Daughter Elks, an African American fraternity, as well as the Black American Legion. The Elks offered a small downstairs restaurant with alcohol, an all-ages dancehall where live music was offered every weekend, and a boarding house (James, 2015). Patrons did not need an Elks membership to participate. Organizations such as the Elks and the Black American Legion offered robust social activities and benevolent programs throughout 80 s and 90 s, including scholarships, social 
dances, and holiday events (Ezelle, 2015). The Elks building, located at Everest Drive downtown, fell into disrepair and no longer stands today (Byrd, 2008).

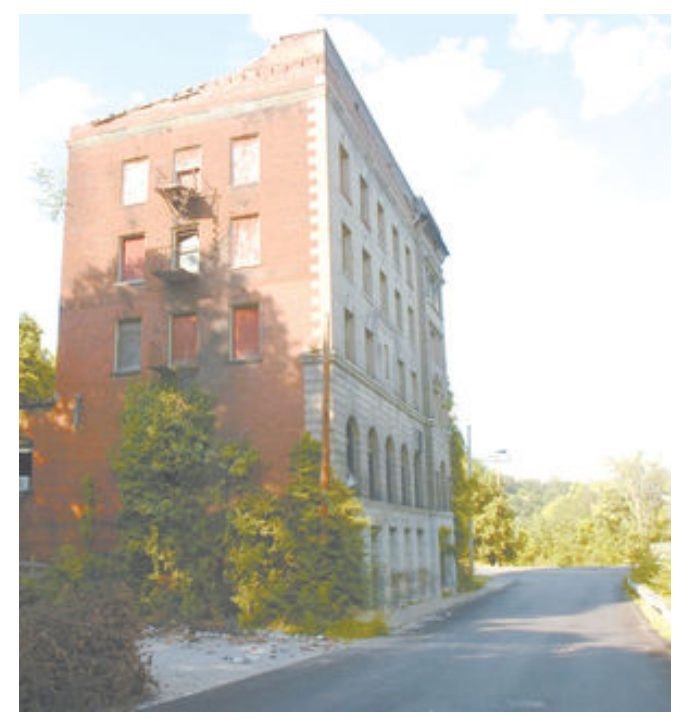

FIGURE 6: ELKS BUILDING. SOURCE: TIMES WEST VIRGINIAN (2015).

Fairmont was also home to businesses that were vibrant meeting spots for African American residents. During the 1930s and 1940s, the African American-owned Rose Tea Room operated alongside other "red light" businesses on Water Street, offering companionship, prostitution, and bootlegging activity. This area is now Palatine Park on the east side of the river (Ezelle, 2015). Through the 70s, Westside meeting places included Club Modi's, Ann Ford, and Mary Phillip's Chatterbox. These hot dog and candy stands served the community as popular after school meeting places.

For entertainment, locals attended Fairmont Theater, Lee Theater, and Virginia Theater to see live acts and moving picture shows. Throughout 40s and 60s, the Fairmont Theater along with the WV Armory hosted famous acts such as Count Basie, Cab Calloway, the Ink Spots, Jerry Lee Lewis, and others (McMillan, 1996). None of the theater buildings stand today: to the dismay of many residents, the dilapidated Fairmont Theater building was razed in 2012 to build a West Virginia State Building in its place.

Windmill Park, located at 900 Ogden Avenue in the Jackson Addition neighborhood, has been and still is the Westside community's primary venue for outdoor social and recreational activities. Historically, the park was managed by neighborhood residents. Formerly called the Testa Fairgrounds, the park hosted events yearround including baseball games, the circus, and the County Fair (Brooks, 2015 and Ezelle, 2015). These festivals were later moved to Palatine Park and further afield. The fairgrounds were acquired by the City of Fairmont in the 1960s and renamed Windmill Park (James, 2015). The park features a children's playground, covered picnic and barbecue areas, a baseball field, a basketball court, and a football field with bleachers and concession stand.

It is rumored that hangings or other executions may have occurred at the park in the distant past, although no one has been able to confirm this. Over time, the park has seen documented foul play. In 1974, a triple homicide case was left unsolved for 38 years (Smith, 2013). In 2014, a police officer was struck head-on by an ATV. The driver was later charged with one felony count of maliciously wounding a police officer (Shriver, 2014). Subsequently, the basketball court was moved to the more secluded location of the previous tennis court. Drug dealers began trafficking drugs after the new court was installed and neighbors report that youth 
loiter at the park to drink and get high (Brooks, 2015). Despite these incidents, neighbors contend that the park has been a safe place prior to and following these incidents (Ezelle, 2015).

Youth sports have figured prominently in Westside social life. In the 60s, a national movement for youth football fueled by "Pop" Warner gave rise to three high-school aged football teams in Fairmont. The Hills (Department Store) Bulldogs, based in the Westside, the Moosejets, overseen by the Fraternal Order of Police (F.O.P.), and the Idamay Black Diamonds of Monongah, formed in 1962 (James, 2015). Youth sports in continue their legacy today at Windmill Park (Brooks, 2015). In the late 80s, Minister Herschel Walker founded 612 MAC (Madison Avenue Center), a community-based youth development organization, and revived the Bulldogs as a youth football team for low-income children (Ezelle, 2015). Through mismanagement over time, the football program was dropped (Brooks, 2015). In 2014, Brian Curry came on as executive director and the organization's name was changed to the Fairmont Community Youth Development Center (FCYDC). Today, FCYDC regularly hosts the Bulldogs youth league football games with their cheerleading squad. On October 1 1, 2015, with support from FCYDC board members, the City of Fairmont dedicated the football field to Frank Hines, an advocate for youth activities and early education on the Westside.

\section{Historic Places}

Marion County has 22 properties listed in the National Register of Historic Places, 16 of which are located in Fairmont. Three of these sites are located in the Westside neighborhoods: Dunbar School, Thomas C. Miller Public School, and Woodlawn Cemetery (National Register of Historic Places, 2015). Interestingly, the Marion County Historic Society does not list any of these under "places of significance," however the National Register offers some background and information on each.

\section{Dunbar School}

Dunbar School is the most recent addition of the three to the National Register of Historic Places, listed on April 28, 2015. Located at the foot of the Sterling Heights neighborhood at 103 High Street, the architectural style is described as Colonial Revival; building materials include brick, sandstone, wood, and an asphalt roof.

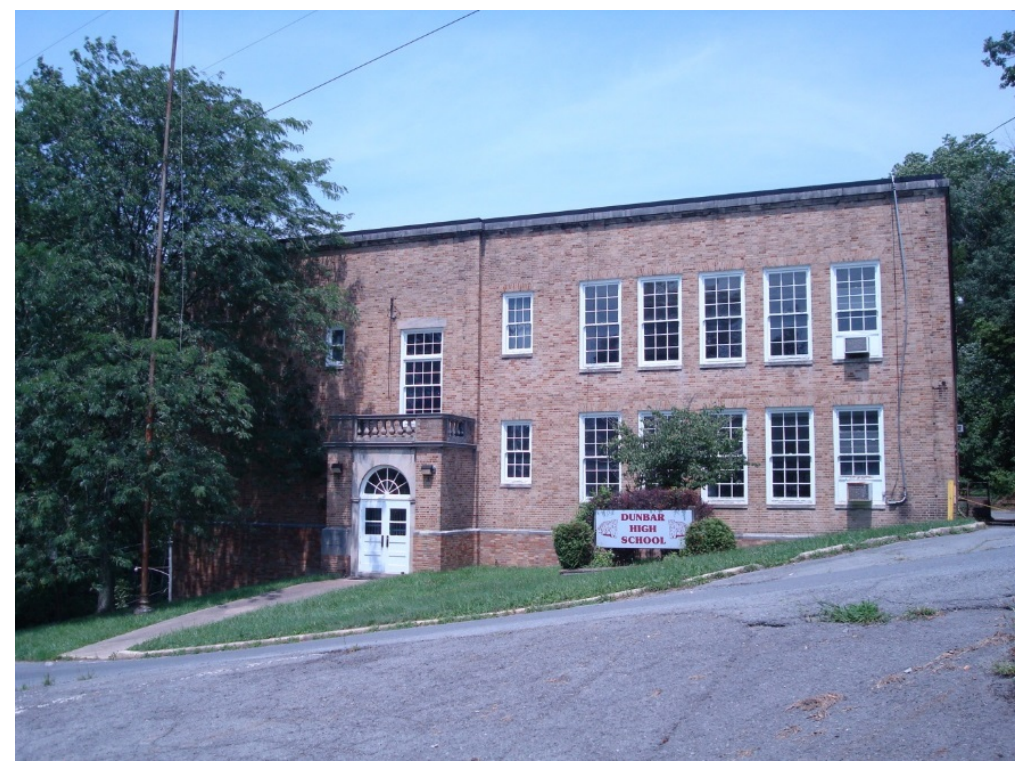

FIGURE 7: DUNBAR SCHOOL. SOURCE: NATIONAL REGISTER OF HISTORIC PLACES (2015). 
Constructed in 1928, it is a historically significant landmark in Fairmont's African American history, as it was the first African American school in Fairmont, and one of the first African American schools in all of West Virginia. It served students from elementary through grade 12 until it closed in 1956 due to desegregation. According to local historian, Charlotte Meade (2015), in the 1860s, Black population began to increase in the area then called Middletown. That population came with differing skills, seeking work, housing, equality, a place to worship, a place to educate their children, and the opportunity to be in fellowship and community. In 1867, the Board of Education purchased a lot between Jefferson and Madison Street in Meredith Alley, later referred to as Dunbar Alley. The black community contributed time and labor in the construction of a fourroom school building and later added a small wood-frame addition to accommodate the increasing enrollment. This building was referred to as "The Colored School" for 42 of its 61 years.

In 1909, as a result of a student contest, the school was named Dunbar in honor of the eminent Black poet and writer, Paul Laurence Dunbar of Dayton, Ohio. In 1912, William O. Armstrong, a Boston native and a recent graduate of West Virginia Colored Institute in Institute, WV, (now West Virginia State University) was hired to teach and serve as acting principal of Dunbar. Although the name had changed, this was still the school for the "colored" and as the population continued to increase, the enrollment soon exceeded the capacity of the building.

On January 9, 1928, the Marion County Board of Education awarded a contract for the construction of a new building at the corner of Weatherwax and High Streets; the cornerstone was laid on April 15; the building was dedicated in December of 1928. The new building provided education for African Americans from $1^{\text {st }}$ through $12^{\text {th }}$ grade. The new school, with 18 classrooms and a gym, had a capacity of 600 students but enrollment reached $700+$ by 1940 . Dunbar High School was rightly known as a school of excellence, a member of the North Central Association for Secondary Schools and Colleges and the Dunbar Elementary School achieved the rating of "Model School."

Dunbar's last segregated class graduated in 1955 (Ezelle, 2015). After integration, the school was temporarily closed. High school students were dispersed to Fairmont Senior High School. Junior high school students were dispersed to Miller. Elementary school students were dispersed to J. N. and Watson Elementary Schools. Dunbar's teachers did not all receive new placements by the Board of Education, a matter that is still a point of contention to the African American community.

In 1963, Dunbar School was reopened as the Fairmont Junior High School Annex, offering classes up to sixth grade. In the 1970s, a group of concerned citizens petitioned the Board of Education with a request to restore the name Dunbar School to the building. As a result, Dunbar was reopened in 1971 as an elementary school. The school was permanently closed in 2007. Since 2008, the Dunbar School building has been owned by the Dunbar School Foundation, which seeks to restore the building to serve as a community center (Dunbar School, 2015).

\section{Thomas C. Miller Public School}

The Thomas C. Miller Public School was added to the National Register on May 8, 2013. Located at 2 Pennsylvania Avenue, it features the Colonial Revival architectural style with Jacobethan detailing; materials include brick, stone, concrete, and a synthetic/rubber roof. It was listed due to its embodiment of the period's style and distinguishing characteristics. 


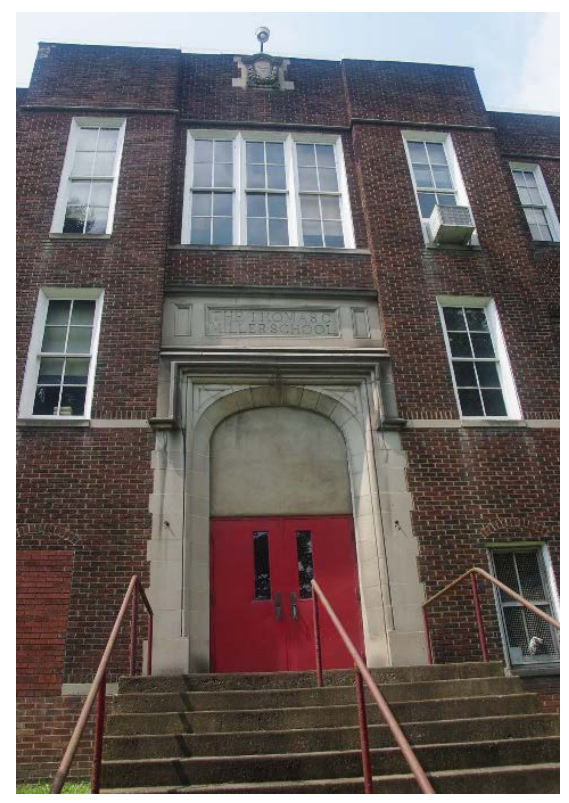

FIGURE 8: THOMAS C. MILLER SCHOOL. SOURCE: NATIONAL REGISTER OF HISTORIC PLACES (2013).

The school was constructed in 1914 and an annex was added in 1928. Distinguishing features include three water fountains with green tile backsplashes with different motifs: cattails, fish, and underwater plants. The school's construction is a reflection of Fairmont's population growth in the early $20^{\text {th }}$ century; the population nearly doubled between 1900 and 1910 (Thomas C. Miller Public School, 2013). Recently, the FairmontMorgantown Housing Authority announced that it would be converting the school into affordable housing for seniors in a partnership with Augusta Development Corporation and Miller School Associates, funding the project in part through historic tax credits and low income housing credits from the West Virginia Housing Development Fund (Fairmont-Morgantown Housing Authority, 2015).

\section{Evergreen Cemetery}

Evergreen Cemetery was established by John Williams adjacent to what is now Windmill Park (Ezelle, 2015). Williams, a railroad worker transferred by B\&O Railroad from Richmond, Virginia, formed an agreement with his supervisor to purchase land parcel by parcel. The land sat vacant until Evergreen Cemetery was established in 1935. Williams saw a need for an African American Cemetery in Fairmont and named it after an African American cemetery in Richmond. Prior to Evergreen, African American burials were limited to the crowded City Cemetery or in neighboring Harrison County at Shinnston or Enterprise.

\section{Woodlawn Cemetery}

Woodlawn Cemetery opened in 1875 as a private burial ground, designed to incorporate the natural beauty of the surrounding landscape in a park-like setting (Woodlawn Cemetery, 2007). The site has been listed in the National Register of Historic Places since April 14, 2004 (National Register of Historic Places, 2015) and in 2009 it joined the Civil War Trails program as a marked site (Historic Woodlawn Cemetery, 2012). Architectural styles assigned to the cemetery include the Rural Cemetery Movement, Egyptian Revival, NeoClassical Revival, Art Deco, and Four-Square. Materials used in the cemetery include concrete, brick, sandstone, marble, granite, and asphalt. 


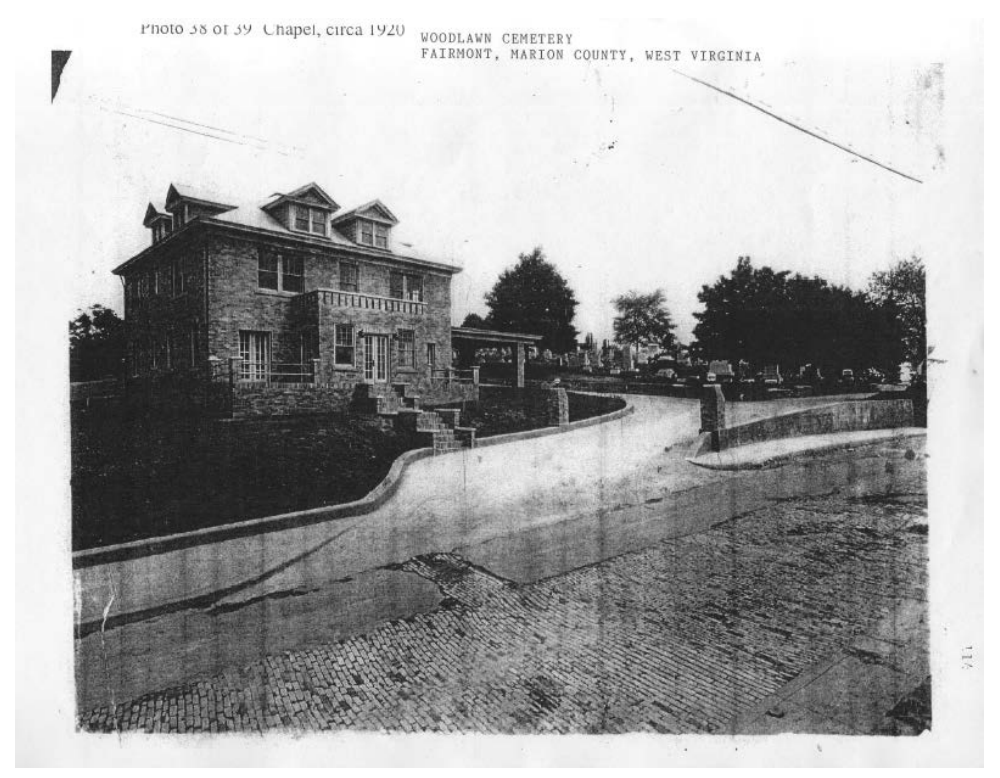

FIGURE 9: WOODLAWN CEMETERY. SOURCE: WEST VIRGINIA DIVISION OF CULTURE AND HISTORY (2007).

Located at 335 Maple Avenue, the cemetery spans 425 acres, encompassing two buildings that contribute to the historic distinction (the abbey and the chapel) and five structures (four family mausoleums and the entrance gate). The cemetery holds over 15,000 graves, including Francis Harrison Pierpont, two governors, national and state legislators, and veterans dating back to the Revolutionary War (Wagaman, 20). Cemetery policy prevented African American burials until integration (Ezelle, 2015). New graves may be added today, however they must comply with the original design intent. The Friends of Historic Woodlawn actively pursue financial support to upkeep the "perpetual care" required by an early $20^{\text {th }}$ century endowment (Historic Woodlawn, 2012).

\section{Historic People}

\section{Fairmont Black History Museum}

Fairmont has a rich African American History. This museum is under development by Charlotte Meade, with plans for installation in the historic Dunbar School (James, 2015). Her family has been prominent in Fairmont, establishing one of the oldest churches in Fairmont; Trinity United Methodist Church (Ezelle, 2015). Notable African American Fairmonters include John Darcus and Fred Stubbs, the only two African American union organizers of the United Mine Worker's Union. W. O. Armstrong was a public school teacher and principal employed by the Board of Education in Fairmont, and other educators came from the Chamberlain family.

\section{Dewey W. Fox}

While actually a Jefferson County native, Dewey Fox helped organize the Fairmont branch of the NAACP (Jefferson, 2009) and as an educator in Marion County, he was active in working toward desegregation and the continued employment of African American teachers in integrated schools (Bracey and Meier, 1995).

\section{Gregory T. Hinton}

Gregory Hinton is a lawyer and professor at Fairmont State University who teaches a popular course on Race, Class, and Gender. "A lifelong resident of Marion County, Hinton has distinguished himself in service to his community in a wide variety of roles. He was elected to the Fairmont City Council in 1977 and served on 
the council for nine years. During his tenure, he became the first African-American to be elected mayor of a major city in West Virginia. After his term, Hinton served as City of Fairmont Building Commissioner for one year" (Wilson, 2009). In 2003, the West Virginia Martin Luther King Jr. Holiday Commission gave Hinton the "Living the Dream" Award for scholarship and his dedication to education and he was honored with the 2009 Governor's Civil Rights Day Award. That year he helped form the Dunbar School Foundation and he remains active in community building efforts.

\section{George S. "Spanky" Roberts}

According to Lonely Eagle (n.d.), Spanky Roberts was born in London, West Virginia, September 24, 1918 and went to elementary and high school in Fairmont, WV, graduating in 1934 at age 15. He went on to graduate from WV State College at age 18 with a BS Degree in Mechanic Arts in 1938. He began CPT training in 1939 at WV State and entered military service as the first Negro Aviation Cadet in July, 1941. He graduated in the first class of five Cadets, March 7, 1942 and was commissioned as a 2nd Lt. and pilot at the Tuskegee Air Field, Alabama. As one of the Tuskegee Airmen, he led a decorated military career, including serving as a Flight Instructor in the Advanced Flight Training School, a fighter pilot, and senior Air Corps ROTC instructor at the Tuskegee Institute, and Dean of the School of Military Science. In 1950, he reported to Langley Air Force Base as the first Black to command a racially mixed unit in the Air Force. In 1952 he earned a Masters' Degree from the U.S. Army Command and General Staff College. Ending his military career as a Colonel, he returned to civilian life as an active citizen engaged in a variety of community service.

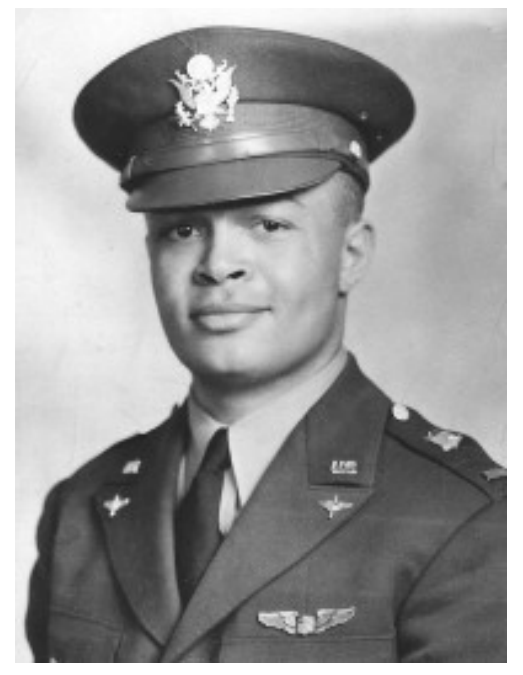

FIGURE 10: CADET GEORGE S. "SPANKY ROBERTS". SOURCE: LONELY EAGLE (N.D.).

\section{Johnnie Johnson}

Johnnie Johnson was born July 8, 1924 in Fairmont. As a teenager he joined the United States Marine Corps. He was one of the first 1,500 African Americans in the Marines. During World War Il, he served in the Marshall Islands in a company band called "The Barracudas." After the war, Johnson worked and performed with Chuck Berry, Eric Clapton, Keith Richards, Albert King, John Lee Hooker, Bonnie Raitt, Bob Weir and Ratdog, the Kentucky Head Hunters, and many others. In 2007, he was inducted into the Rock and Roll Hall of Fame (n.d.). The Johnnie Johnson Jazz and Blues Festival is an annual music festival held at Palatine Park in July (Society, 2015). 


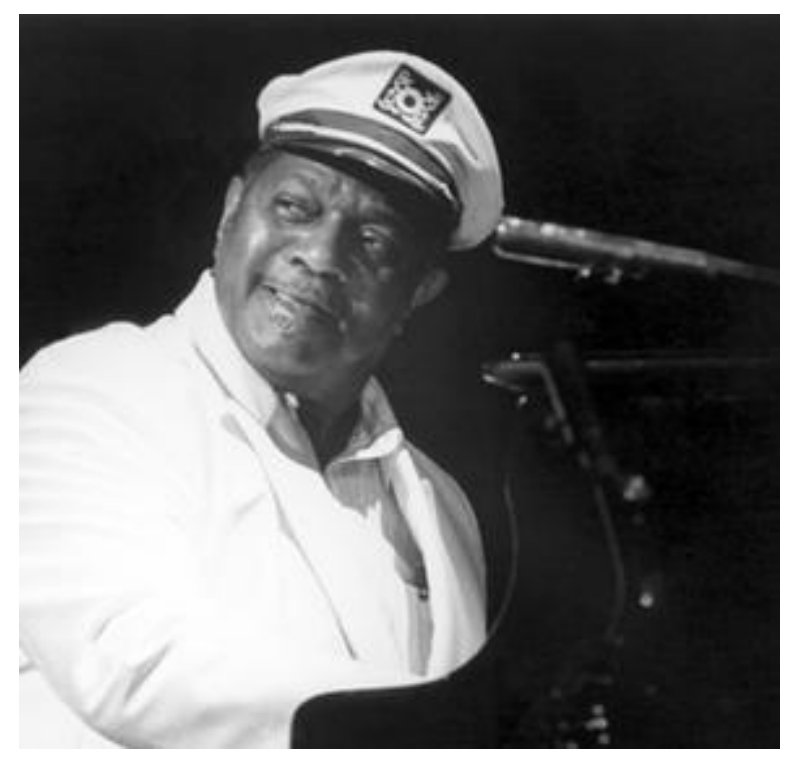

FIGURE 11: JOHNNIE JOHNSON. SOURCE: ROCK AND ROLL HALL OF FAME (2015).

\section{"Toothpick" or "Sad" Sam Jones}

While Sam Jones he lived in The Bottom in Grant Town, he played football and basketball at Fairmont High School. After Army service, he played for the Cleveland Buckeyes of the Negro American League. In 1948 he went to the Kansas City Royals, a touring Negro League squad handpicked by Satchel Paige and later that year played for the Spur Cola Colonites in Panama. In 1949, the Negro National League had disbanded and the Negro American League was waning, so Jones signed with the Rochester Royals, a semi-pro league. By the end of the year he was playing for the Cleveland Indians. On February 26, 1950 he married his high school sweetheart, Mary Beans. In 1954 he was traded to the Chicago Cubs, and the next year Jones was the first African American major leaguer to throw a no-hitter; against the Pittsburgh Pirates. This earned him a spot on the National League All-Star team-and a gold toothpick from Cubs' TV announcer Harry Creighton. In 1956 Jones was traded to the St. Louis Cardinals. He was later traded to the San Francisco Giants and played a second All-Star Game in 1959. After that, Jones played in American, Puerto Rican, and Dominican leagues, ending his career in 1967 with the Columbus Jets. He returned home to Monongah, WV to establish a carwash business. Battling cancer in 1971, Jones died November $5^{\text {th }}$ while undergoing treatment at West Virginia University Hospital in Morgantown and was buried in Woodlawn Cemetery.

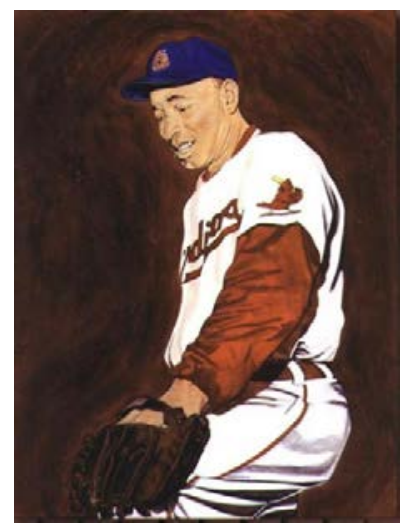

FIGURE 12: "TOOTHPICK" OR "SAD" SAM JONES. SOURCE: SABR (N.D.). 


\section{Ted Echols}

Ted Echols was a two-sport standout for Fairmont State University (Cochran, 2014). He was a three-year letter-winner for the Falcons basketball team and helped lead FSU to an impressive 81-13 record (.861) during those three seasons, one WVIAC title, and an NAIA National Tournament appearance. During the spring, Echols played first base for the Falcons in baseball and twice earned first-team All-WVIAC honors. He was drafted by the Chicago Cubs in the 25th round of the 1972 Major League Baseball Draft. He was inducted into the Fairmont State Athletic Association Hall of Fame in 2013.

\section{Professional Footballers}

According to Database Football (n.d.) a number of African American Fairmonters played in the National Football League. Calvin Eugene Turner played for West Virginia University and was drafted by the Tampa Bay Buccaneers for the 1987 season. Rashod Kent played for Rutgers State University of New Jersey and was drafted by the Houston Texans for the 2003 season. Kerry Marbury, an All-American player for West Virginia University went on to the Toronto Argonauts in the Canadian Football League in 1973-1974, then was drafted by the New England Patriots and traded to the Cleveland Browns, but was cut before playing again.

\section{References}

African American Registry (n.d.). The Black Church, A Brief History. Retrieved October 15, 2015, from: http://www.aaregistry.org/historic events/view/black-church-brief-history

Baker, C. (2014, February 10). Dunbar School still a beloved Fairmont landmark. Retrieved October 19, 2015, from http://www.timeswv.com/news/local news/dunbar-school-remains-a-belovedlandmark/article $117 a 689$ e-a5d3-5fdb-8316-87968e3b78e2.html

Bracey, John H. Jr. and Meier, August. (1995). Papers of the NAACP: Part 3. The Campaign for Educational Equality. Series D: Central Office Records, 1956-1965.

Brooks, H. (2015). Personal Interview.

Brown, D. (2015, November 4). Personal Interview.

Byrd, B. (2008, July 15). Officials fear collapse of old Elks Building. Times West Virginia. Retrieved, November 15, 2015, from http://www.timeswv.com/news/local news/officials-fear-collapse-of-oldelks-building/article 8963abe0-9c55-5957-aca3-473177945909.html

Cochran, Duane. (2014). Seven Selected To FSAA Hall of Fame. Retrieved 12-2-2015 from: http://www.fightingfalcons.com/news/2014/9/26/CVT 10518.aspx?path=baseball

Database Football. (n.d.). DatabaseFootball.com. Retrieved 12-2-15 from: http://www.databasefootball.com/players/player bystate.htm? state=WV

Davis, A. (2015, November 4). Personal Interview.

Ezelle, N. (2015, November 8). Personal Interview.

Fairmont-Morgantown Housing Authority. (2015). Development of the Miller School - Fairmont, WV [Press release]. Retrieved from: http://www.fmhousing.com/news detail T2 R6.php

Fairmont Opera House. (n.d.). History of the Fairmont Opera House. Retrieved October 19, 2015, from http://www.fairmontoperahouse.com/History.php 
Hensley, S. L. (2014, September 25). Sixty Years Ago: Black and White at East-West. Retrieved November 8, 2015, from http://wvpublic.org/post/sixty-years-ago-black-and-white-east-west/

Hensley, S. L. (2014, October 29). The Cloud of Witnesses: A Reminder to Tell the Story. Retrieved November 8, 2015, from https://witnessmonvalley.wordpress.com/2014/10/29/the-cloud-of-witnesses-areminder-to-tell-the-story/

Hill, R. (1999). The Strengths of African American Families. Lanham, Maryland: University Press of America.

Historic Woodlawn (2012). Historic Woodlawn Cemetery, Fairmont, WV. Retrieved November 9, 2015, from http://www.historicwoodlawncemetery.org//

James, W. (2015). Personal Interview.

Jefferson County Black History Preservation Society, Inc. (2009). African Americans of Jefferson County. Charleston, SC: Arcadia Publishing.

Johnson, K. C. (1999, July 2) "Way to go, Johnnie, go... Piano legend Johnnie Johnson, 75, is finally getting recognition as the real father of rock." St. Louis Post-Dispatch (Missouri), Everyday Magazine, p. D1.

Koon, T. J. (2013, May 30). "Fairmont." e-WV: The West Virginia Encyclopedia. Retrieved 19 October 2015, from http://www.wvencyclopedia.org/articles/2231

Lonely Eagle. (n.d.). Tuskegee Airmen. Retrieved 12-2-2015 from: http://escort332.org/?s=spanky

Marion County Historical Society (2011). Miscellaneous History. Retrieved November 14, 2015, from http://www.marionhistorical.org/pages/miscellaneous.php

Martin, J. \& Elmer P. (1985) The Helping Tradition in the Black Family and Community. Washington, DC: NASW Press.

McAteer, D. (2014). Monongah the tragic story of the 1907 Monongah mine disaster, the worst industrial accident in U.S. history. Morgantown: West Virginia University Press.

McMillan, D. B. (1996). An ornament to the city: historic architecture in downtown Fairmont, West Virginia. Terra Alta: Headline Books.

Meade, C. Personal communication, November 3, 2015.

Mozier, J. (1999). Way out in West Virginia: A must-have guide to the oddities and wonders of The Mountain State. Charleston, WV: Quarrier Press.

National Register of Historic Places. (1995). Fairmont Downtown Historic District (95001008). Washington, DC: U.S. Government Printing Office.

Nembhard, J. G. (2015, September 28). Thinking about a next system with W.E.B. Du Bois and Fannie Lou Hamer. Retrieved November 8, 2015 from: http://thenextsystem.org/thinking-about-a-next-systemwith-w-e-b-du-bois-and-fannie-lou-hamer/

Rock and Roll Hall of Fame. (n.d.). Johnnie Johnson Biography. Retrieved November 8, 2015 from: https://rockhall.com/inductees/iohnnie-johnson/bio/

Shriver, T. (2014, July 27). Officer struck head-on by ATV. The Times West Virginian. Retrieved November 8, 2015, from http://www.timeswv.com/officer-struck-head-on-by-atv/image a 2510c70-39c5-54158990-8eae5dcb7c69.html 
Smith, J. (2013, February 11). The Windmill Park murders: A detective's side of the story. West Virginia MetroNews. Retrieved October 18, 2015, from http://wvmetronews.com/2013/02/11/the-windmillpark-murders-a-detectives-side-of-the-story/

SABR. (n.d.) Sam Jones. Society for American Baseball Research. Retrieved 12-2-2-15 from: http://sabr.org/bioproi/person/b2f99b7e

Society. (2015). The Johnnie Johnson Blues \& Jazz Society, Inc. Retrieved November 8, 2015 from: http://www.johnniejohnsonbluesandiazz.com/

Thomas C. Miller Public School. (2013). National Register of Historic Places Registration Form. National Park Service, U.S. Department of the Interior. Retrieved from: http://www.nps.gov/nr/feature/places/pdfs/13000263.pdf

National Register of Historic Places. (1995). Fairmont Downtown Historic District (95001008). Washington, DC: U.S. Government Printing Office.

National Register of Historic Places. (2015). National Register of Historic Places: Listed properties [excel database]. Retrieved from: http://www.nps.gov/nr/research/index.htm

U.S. Census Bureau. (2010). Washington, D.C.: Government Printing Office. U.S. Census Bureau. Race and Hispanic or Latino Origin 2010. Retrieved from http://www.census.gov/

U.S. Census Bureau. (2010). Washington, D.C.: Government Printing Office. U.S. Census Bureau. Profile of General Population and Housing Characteristics: 2010 Census Summary File 1. Retrieved from http://www.census.gov/

Wagaman, G. (2007). Fairmont's Cemeteries. Charleston, SC: Arcadia Publishing.

Wallace, S. (2003) Committed "Armies of Compassion": African American churches building and sustaining community. The Review of Black Political Economy, 30(4), p. 83.

Wilson, Katie. (2009). Gregory Hinton Honored Thursday. Fairmont, WV Times. Retrieved 12-2-2105 from: http://www.timeswv.com/news/local news/gregory-hinton-honored-thursday/article b7577760a 17e-5c27-bb0b-e56668abde36.html 


\section{HUMAN CAPITAL}

\section{Leah Cunningham and Marissa Angellatta}

While the Westside of Fairmont could be considered all neighborhoods west of the Monongahela River and north of downtown, the focal point of the community hosts are the neighborhoods around Windmill Park, Dunbar School, and the Fairmont Community Youth Development Center. The bulk of these areas comprise U.S. Census Tract 205, which is shown in Figure 13. According to these community representatives, these neighborhoods are considered the traditionally African American neighborhoods in Fairmont. Judging by the population statistics, this is most true for Census Tract 205, as compared to adjacent Tracts 206, 21 4, and 202 (201 is a commercial district). Therefore, population statistics available at the Census Tract level will consider 205 only.

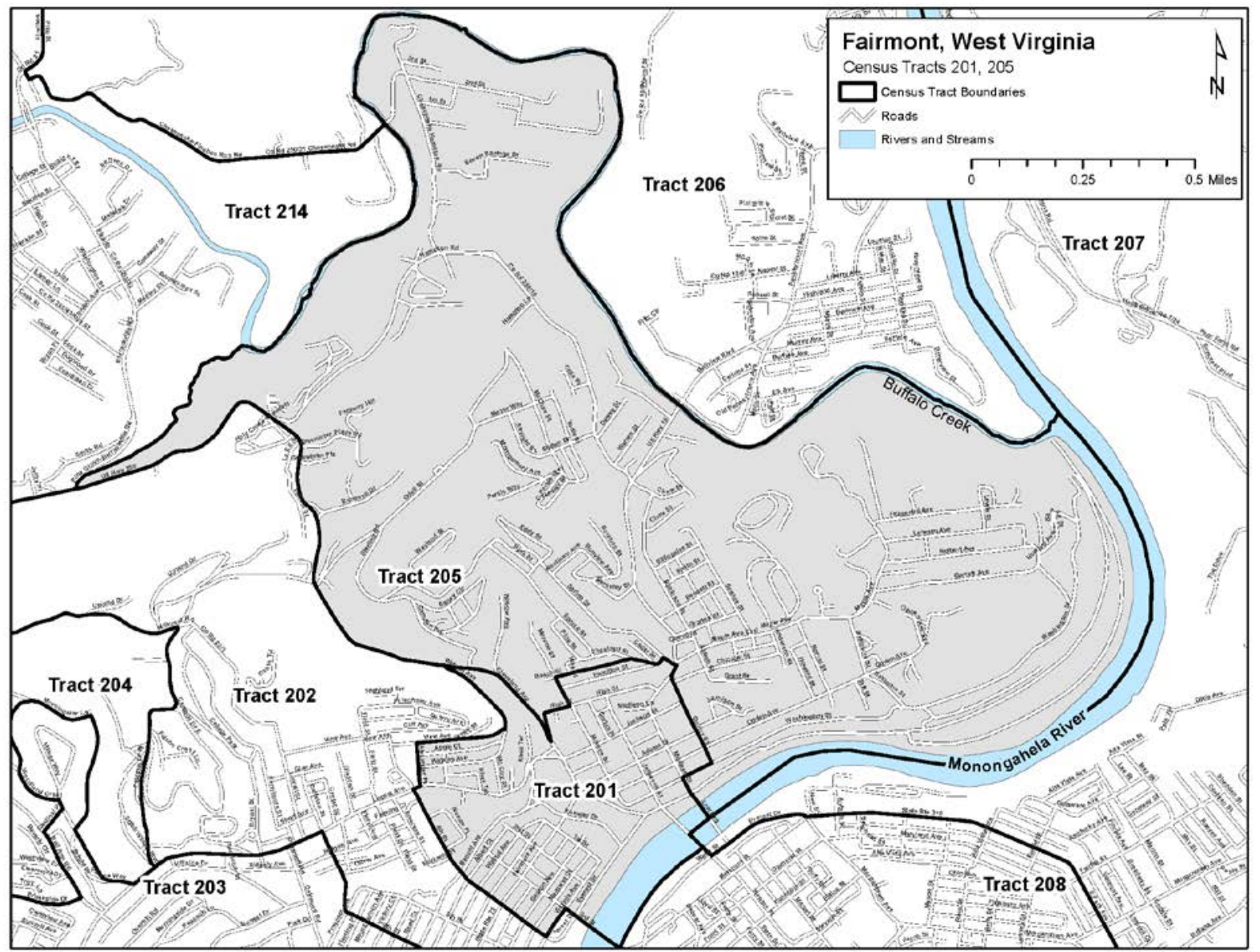

FIGURE 13. PROFILE AREA CENSUS TRACTS. SOURCE: U.S. CENSUS (2013).

\section{Population Statistics}

At 40.3 percent, the percentage of African Americans in the neighborhoods is significantly larger in comparison to the city, county, and state; higher than Fairmont overall by over $30 \%$. This verifies the neighborhoods' identity as a historically African American community. 


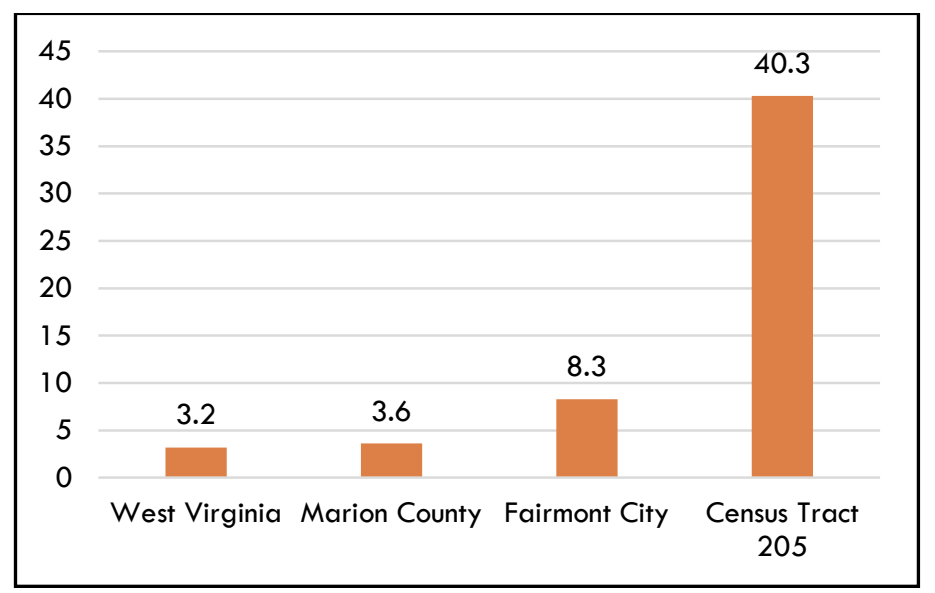

FIGURE 14. AFRICAN AMERICAN POPULATION PERCENTAGE. SOURCE: U.S. CENSUS (2013).

The population of the City of Fairmont has decreased since 1970, but has been fairly stable since 2000. The high poverty level and low wages may be connected to this decrease. We might conclude that many people moved as a result of economic downturn in the area and those who stayed either do not wish to leave or are unable to leave. The exodus phenomenon is commonly described as "brain drain"; when the highest skilled workers leave for better opportunities, leaving the least educated individuals behind (Fiore et al. 2015).

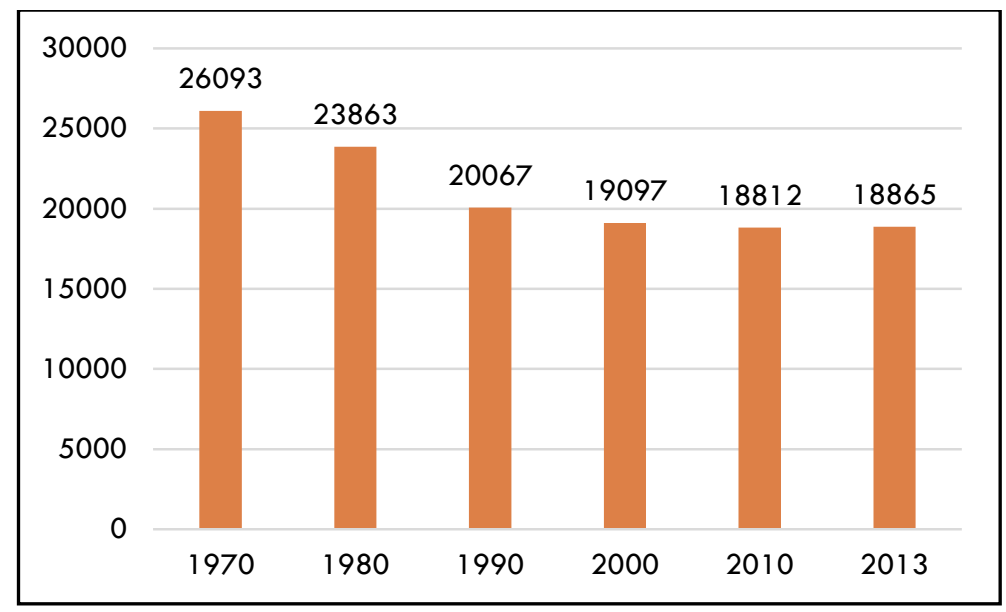

FIGURE 15. POPULATION. SOURCE: U.S. CENSUS (1970-2013).

The median age of 33.7 in the neighborhood is slightly younger than that of West Virginia and Marion County but not significantly different from the median age in Fairmont. We can infer from this data that age is not a significant factor for the issues identified by the neighborhood. 


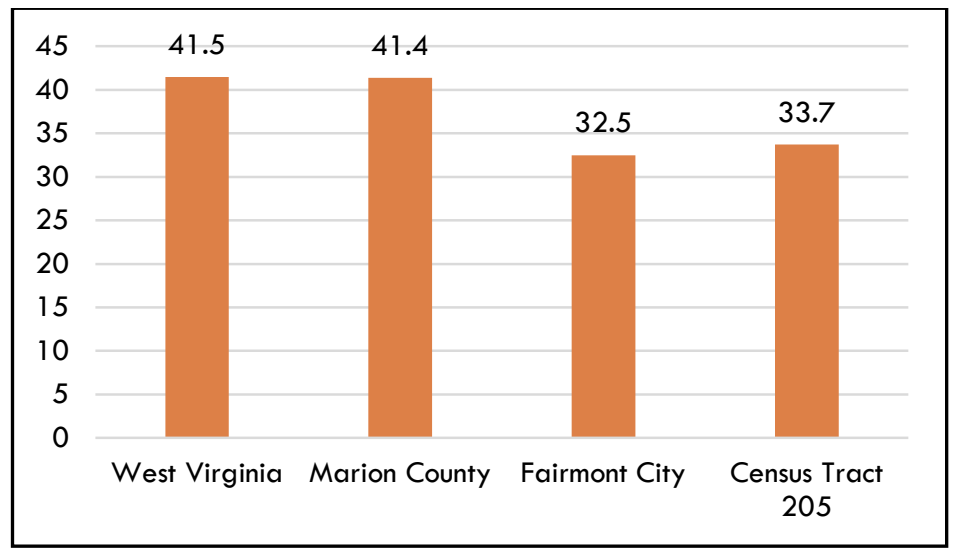

FIGURE 16. MEDIAN AGE. SOURCE: U.S. CENSUS (2013).

The employment rate of 55.3 percent is much higher than West Virginia as a whole, but slightly lower than Fairmont as a whole.

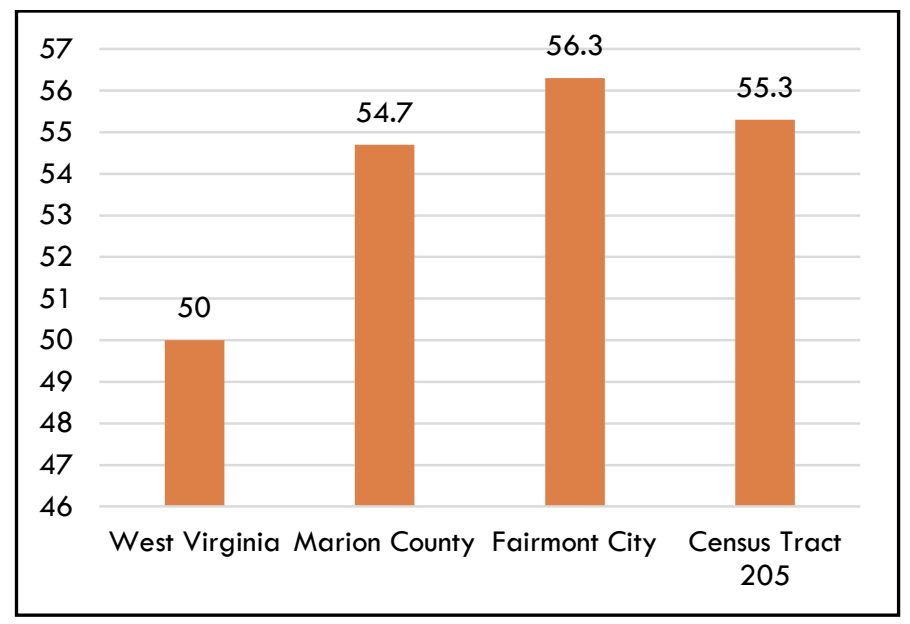

FIGURE 17. EMPLOYMENT RATE. SOURCE: U.S. CENSUS (2013).

At 33.6 percent, the poverty rate in the neighborhoods is higher than in the state, county, and city as a whole. This may be due to low wages and educational attainment factors that will be addressed below.

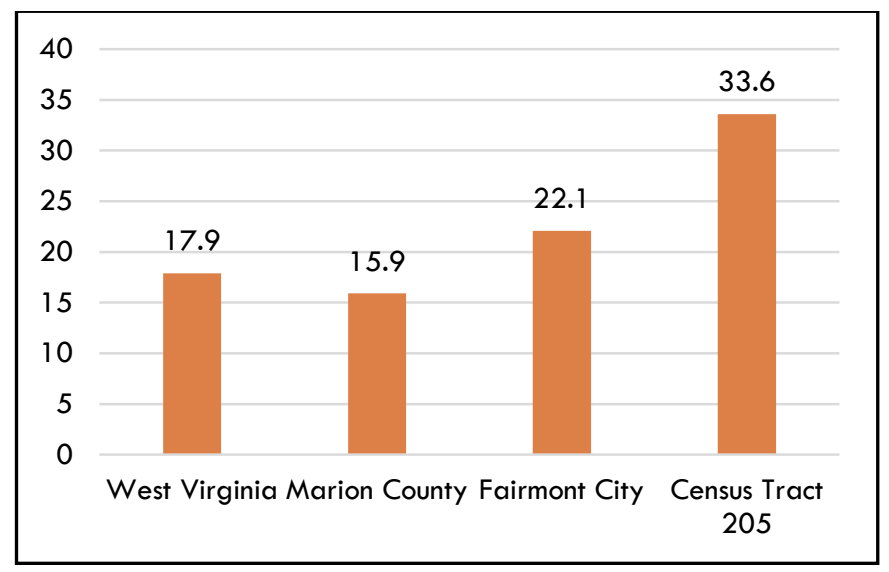


FIGURE 18. POVERTY RATE. SOURCE: U.S. CENSUS (2013).

Just over $47 \%$ of the population under 18 is below the poverty level. Youth living in poverty are consistently shown to have more quality of life challenges, especially those associated with educational attainment.

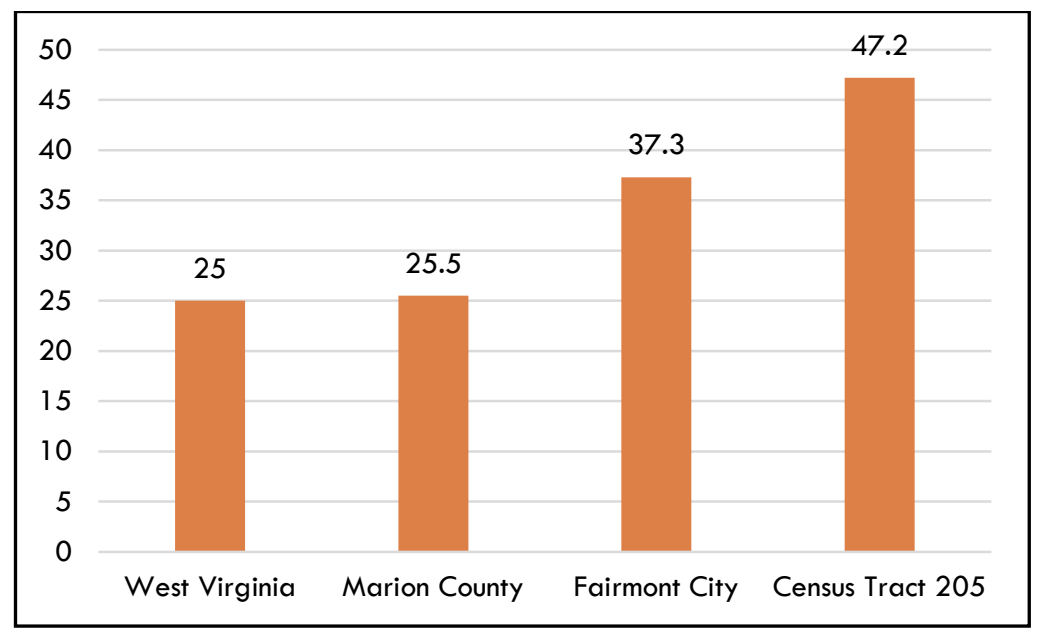

FIGURE 19. POVERTY RATE. SOURCE: U.S. CENSUS (2013).

\section{Educationall Attainment}

Educational attainment is a key indicator of human capital in that higher levels of completion and success are associated with greater social and economic capacity. High school dropouts are on a direct pathway to poverty. Workers with a high school diploma or less bore the brunt of the recent recession's job losses. Job gains in the recovery are confined to those with education beyond high school. In the US, $5 \%$ of children with parents who have not graduated from high school will graduate from college (Lumina Foundation, 2015).

The high school graduation rate for students in Census Tract 205 is slightly higher than both the West Virginia, and national average.

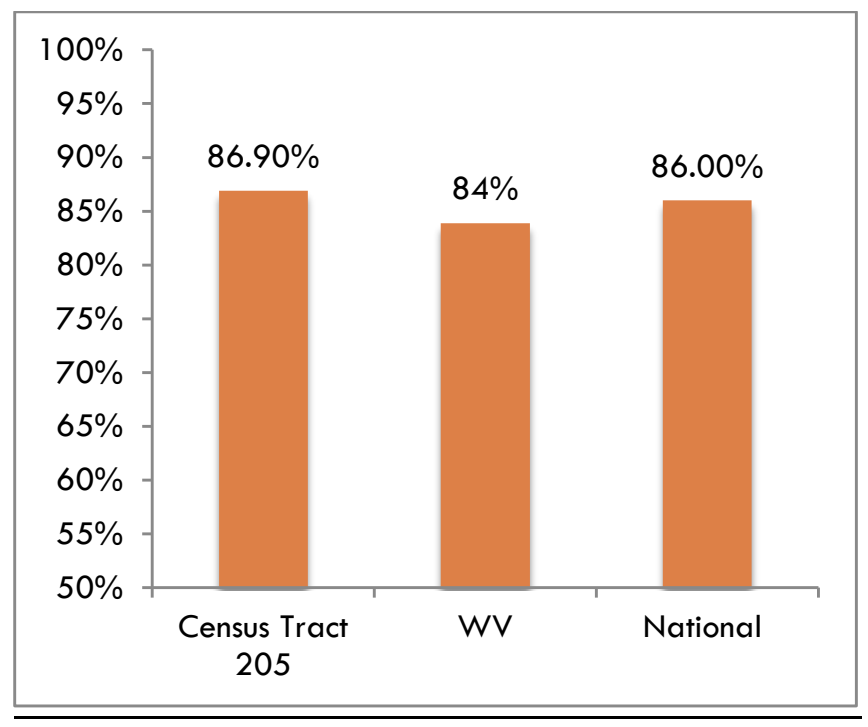


FIGURE 20. HIGH SCHOOL GRADUATION RATES. SOURCE: U.S. CENSUS BUREAU (2009-2013).

The percent of residents pursuing and completing a degree in higher education is significantly less than the national average in both Census Tract 205 and West Virginia. We might attribute the slightly higher percentage in these neighborhoods to the accessibility of Fairmont State University and Pierpont Community College.

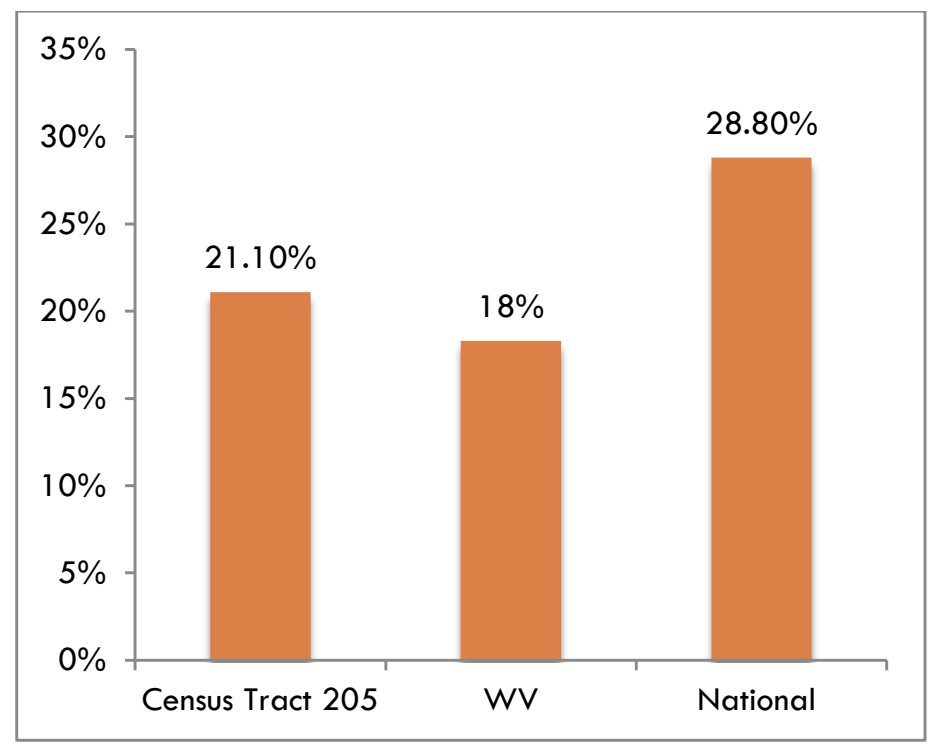

FIGURE 21. PURSUIT OF HIGHER EDUCATION. SOURCE: U.S. CENSUS BUREAU (2009-2013).

\section{School District Characteristics}

The youth in Census Tract 205 attend Watson Elementary, West Fairmont Middle School, and Fairmont Senior High School, all of which are operated by the Marion County Board of Education. Contact information is provided in Appendix A.

School performance is assessed by the West Virginia Board of Education through standardized testing. Over the last ten years, WV has shifted from the WESTEST to WESTEST 2 with APTA, and now uses the West Virginia Summative Assessment. The West Virginia Next Generation Standards are a set of higher expectations in mathematics and ELA that were developed by state leaders to ensure every student graduates from high school prepared for the future. These new standards replace West Virginia's former set of expectations for students.

The West Virginia Accountability Index (WVAl) assigns points to schools for multiple measures of student performance (Annual Measurable Objectives or AMOs) on the statewide general assessment and other summative assessments of reading/language arts and mathematics, graduation rates for high schools, and attendance rates for elementary and middle schools. 
Based on these scores, schools receive a School Designation, including:

- $\quad$ Success - The school has met its target score, and the majority of its student subgroups are making academic progress.

- Transition - The school has met its target score or has demonstrated that a majority of its subgroups are making academic progress.

- Support - The school has not meet its target score and has not demonstrated that a majority of its subgroups are making sufficient academic progress.

The majority of services for schools identified as a Transition school will be led by the local school district, with capacity building support from the Regional Education Service Agency (RESA) and limited WVDE support. A Transition school has some flexibility in determining necessary interventions based on the leadership provided by the local school district. Local schools systems may partner with RESAs and other external providers to provide professional development, technical assistance and interventions, and to implement school improvement strategies (WV Dept. of Education, 2015). Specific expectations for Transition schools include completing a targeted Strategic Plan and participating in limited ESEA monitoring.

It is recommended that Support school implement the USDE Turnaround Principles, which align to the WV Standards for High Quality Schools (WVBE Policy 2322). The local school system and the Regional Education Service Agency (RESA) will partner to provide professional development, technical assistance and interventions. Specific supports/resources to implement the Support school improvement plans will be developed through collaborative efforts of all partners (WV Dept. of Education, 2015). Specific expectations include: completing an extended Strategic Plan; receiving annual progress reviews by their local school district and board of education; and receiving ESEA monitoring during the regular monitoring cycle to review progress.

In addition to state standards and programs for instructional support, federally-designated Title I schools are those with at least 40 percent of students from low-income families. These schools may use Title I funds, along with other federal, state, and local funds, to operate a schoolwide program to upgrade instructional quality for the whole school, thus helping close the gap between low-income and other students. The purpose of this program is to ensure that all children have a fair, equal, and significant opportunity to obtain a high-quality education and reach, at a minimum, proficiency on assessments based on state academic achievement standards. The schools serving youth from Census Tract 205 vary in terms of their Title I status and academic performance.

Watson Elementary School serves grades Pre-K through fourth grade, and receives Title I funding due to the majority of students with Low SES. A little over half of the white students attending Watson Elementary have Low SES. With African Americans, that number jumps to over three-fourths, and for multi-racial students it reaches $81 \%$. 


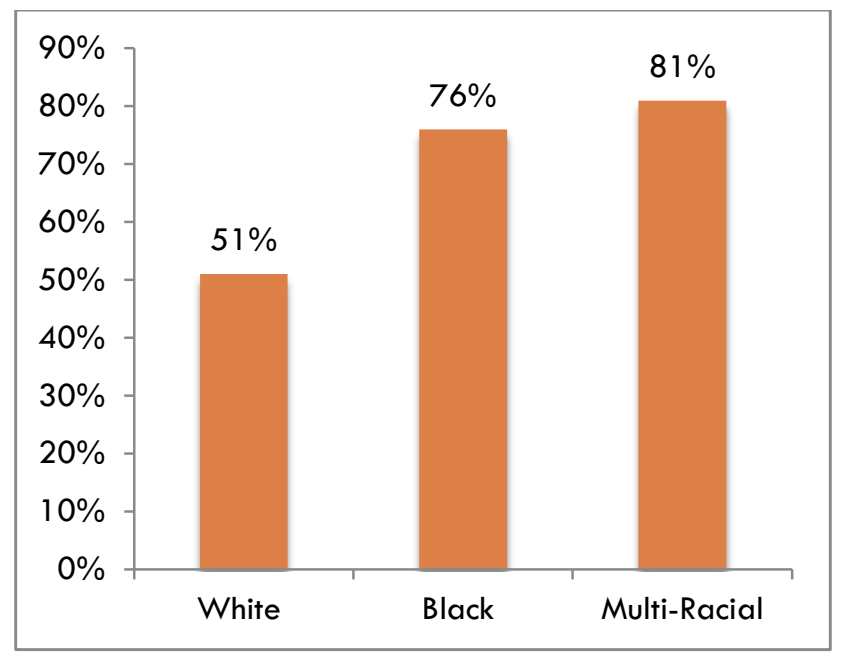

FIGURE 22. LOW SES STUDENTS BY RACE. SOURCE: WV DEPT. OF EDUCATION (2013-2014).

Overall, the enrollment composition at Watson Elementary is predominantly white, however, there is a significant number of both African American and Multi-Racial students.

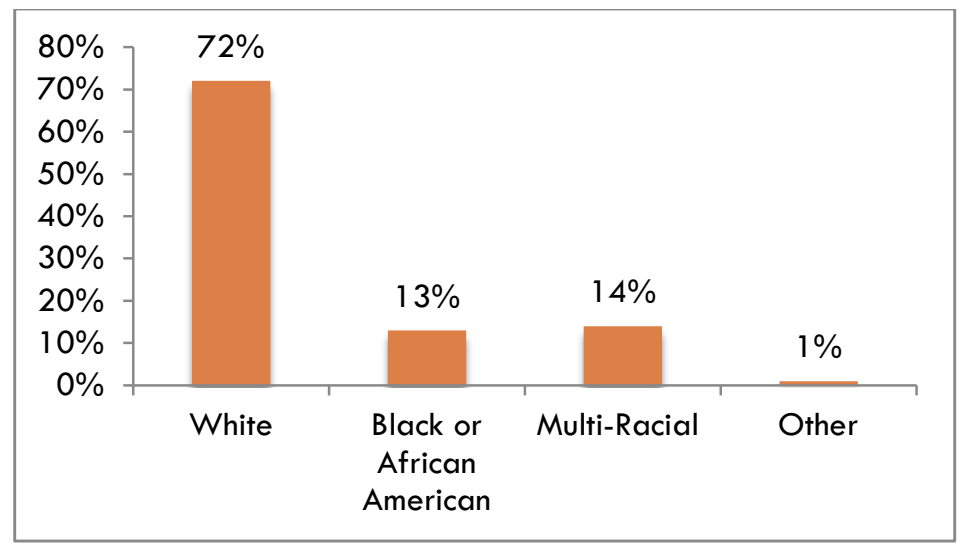

FIGURE 23. ENROLLMENT BY RACE. SOURCE: WV DEPT. OF EDUCATION (2013-2014).

Watson Elementary is designated is designated a Success school by the West Virginia Accountability Index, meaning the school has met its target score and the majority of its student subgroups are making academic progress. The school ranks far above the West Virginia state average for the percentage of students meeting grade level expectations. It is important to note, however, that nearly half of the students are not meeting grade level targets in math and reading, leaving much room for improvement. 


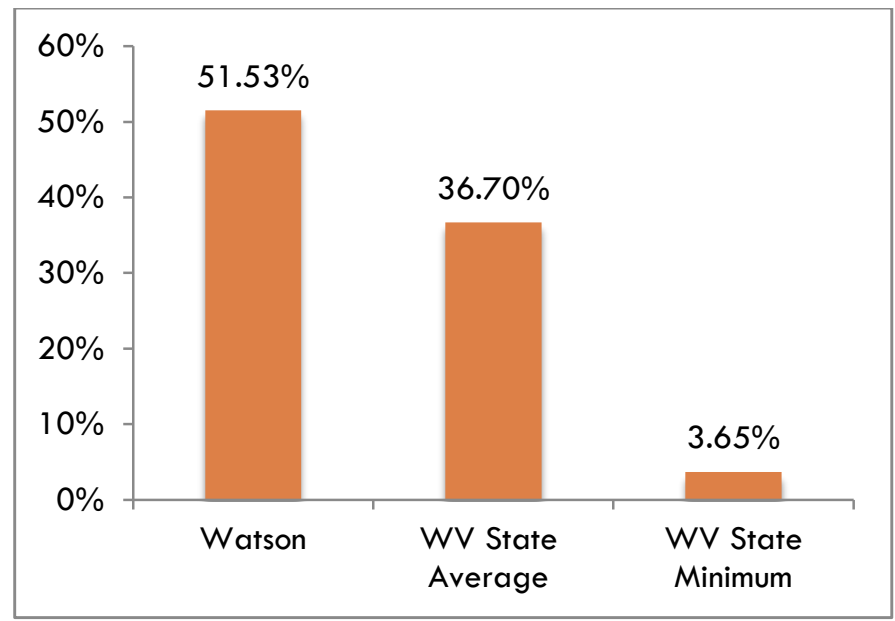

FIGURE 24. STUDENTS MEETING GRADE LEVEL EXPECTATIONS. SOURCE: WV DEPT. OF EDUCATION (2013-2014).

West Fairmont Middle School serves fifth through eighth grade students. While the percentage of students with Low Socioeconomic Status (Low SES) is around $47 \%$ at West Fairmont Middle School, the school does not receive Title I funds. The percentage of students with Low SES is significantly higher for Black and Multi-racial students, which make up a smaller proportion of the population than at Watson Elementary.

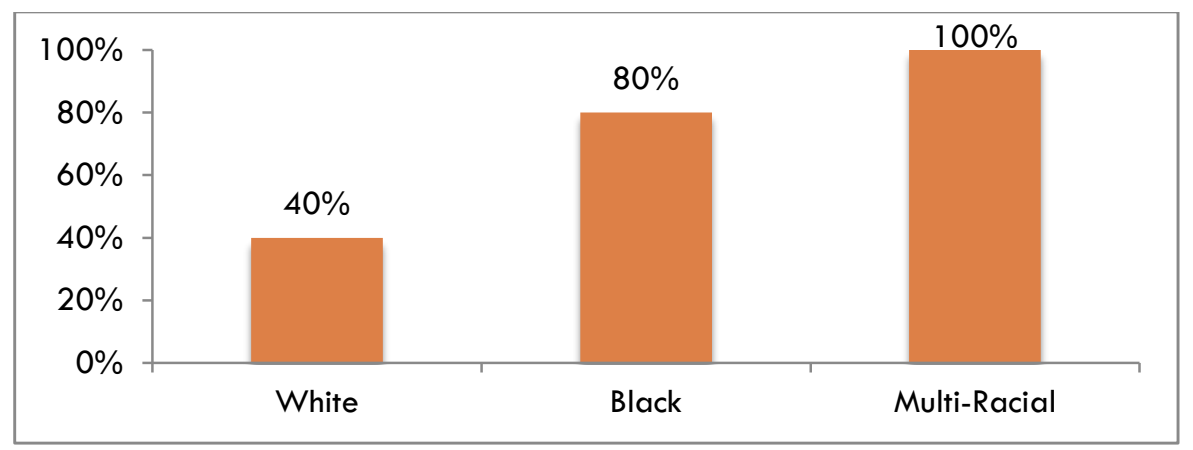

FIGURE 25. LOW SOCIOECONOMIC STATUS BY RACE. SOURCE: WV DEPT. OF EDUCATION (2013-2014).

Overall, the enrollment composition at West Fairmont Middle School is predominantly white, however, there is a significant population of African American students. The proportion decreases as several other elementary schools consolidate into the middle school. 


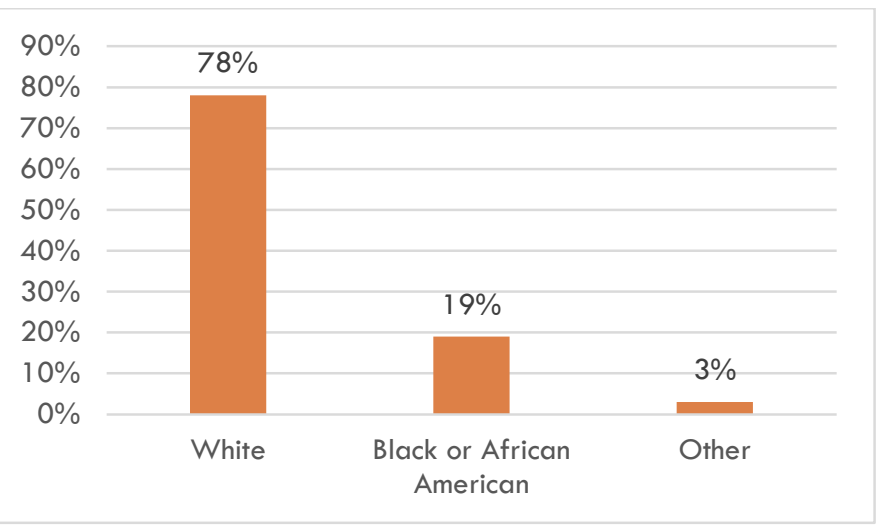

FIGURE 26. ENROLLMENT BY RACE. SOURCE: WV DEPT. OF EDUCATION (2013-2014).

West Fairmont Middle School is designated a Transition school by the West Virginia Accountability Index, meaning the school has not met its target score or has not demonstrated that a majority of its subgroups are making academic progress. Around half of the students are hitting the target scores for mathematics and reading. When broken down by race, it is clear that African American students are scoring much lower than their White peers.

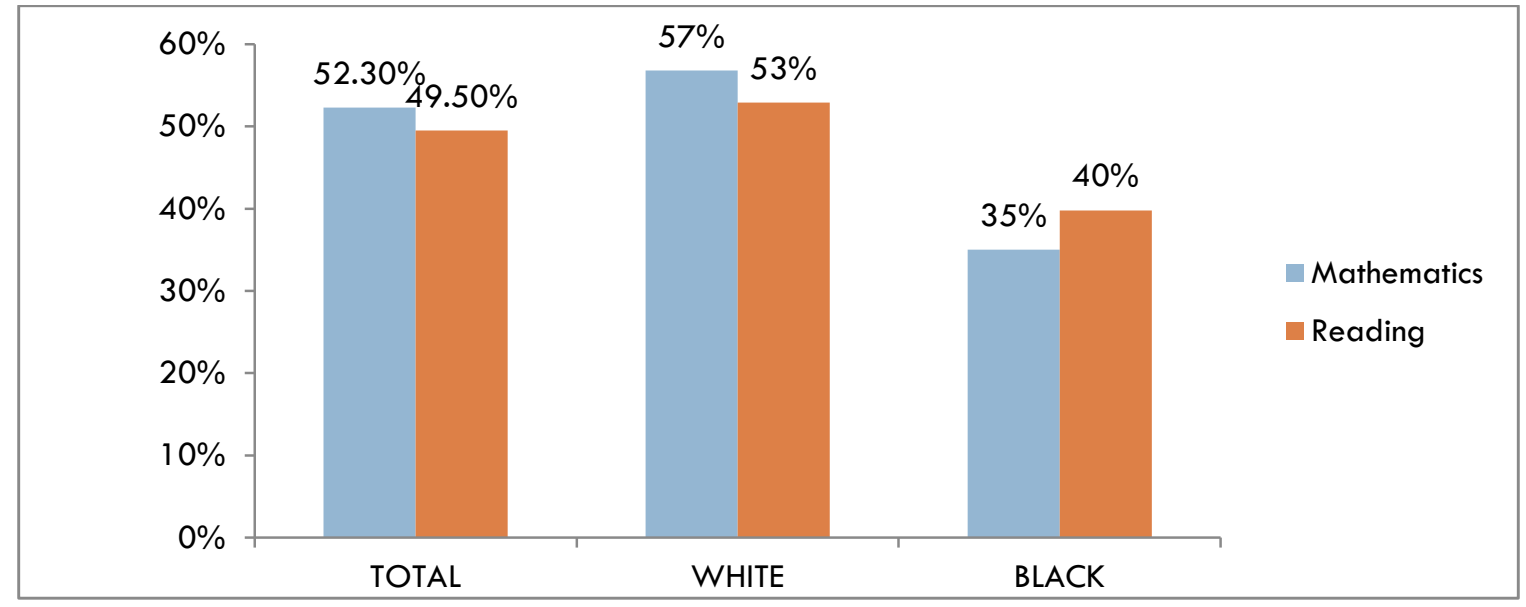

FIGURE 27. PROFICIENCY RATE BY RACE. SOURCE: WV DEPT. OF EDUCATION (2013-2014).

Similarly, students with Low Socioeconomic Status (Low SES) perform far worse than students who are not classified as Low SES in both mathematics and reading. Only about a third of the students with Low SES are reaching target scores, while the average for regular students is more than half. 


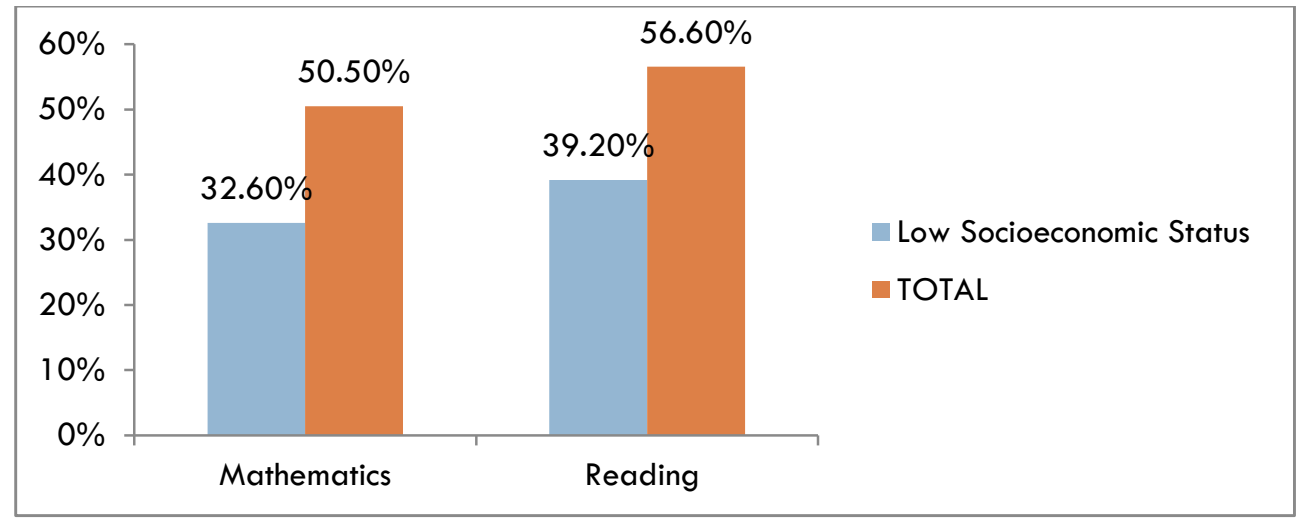

FIGURE 28. PROFICIENCY RATE BY STATUS. SOURCE: WV DEPT. OF EDUCATION (2013-2014).

Fairmont Senior High School serves ninth through twelfth grade students. While the percentage of students with Low Socioeconomic Status (Low SES) is $40 \%$, the school does not receive Title I funds. The percentage of students with Low SES is significantly higher for Black students, which make up a smaller proportion of the student body than at West Fairmont Middle School.

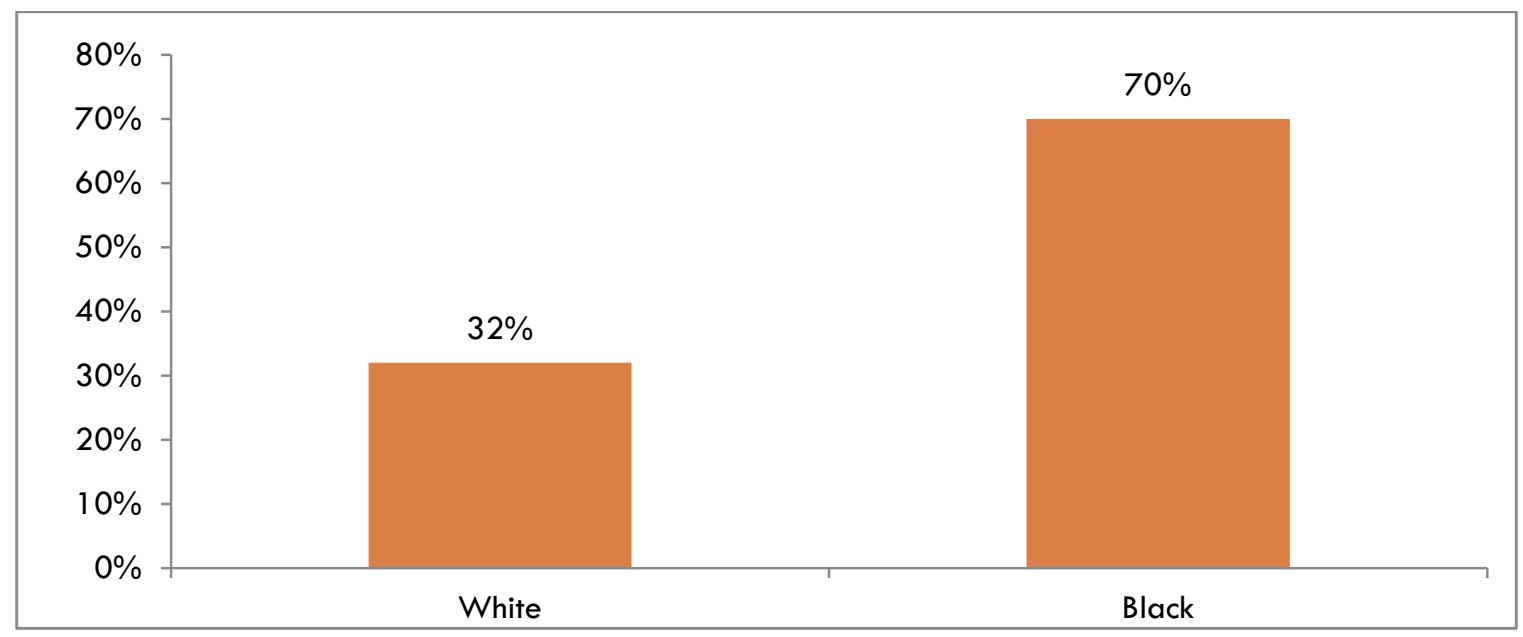

FIGURE 29. LOW SOCIOECONOMIC STATUS BY RACE. SOURCE: WV DEPT. OF EDUCATION (2013-2014). 
The enrollment composition at Fairmont Senior High School is predominantly white, however, there is a significant number of African American students. The proportion decreases as several other middle schools consolidate into the high school.

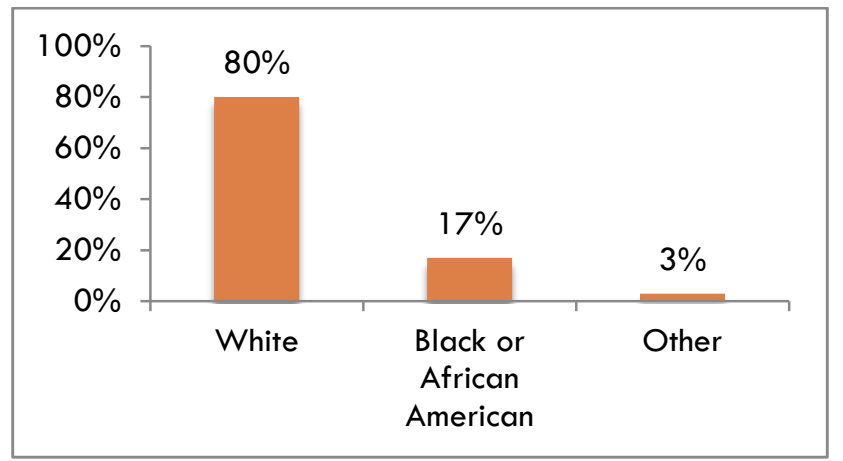

FIGURE 30. ENROLLMENT BY RACE. SOURCE: WV DEPT. OF EDUCATION (2013-2014).

Fairmont High School is designated a Support school by the West Virginia Accountability Index, meaning the school has not met its target score and has not demonstrated that a majority of its subgroups are making sufficient academic progress. Around half of the students are hitting the target scores for mathematics and reading. When broken down by race, it is clear that Black students are scoring much lower than their White peers.

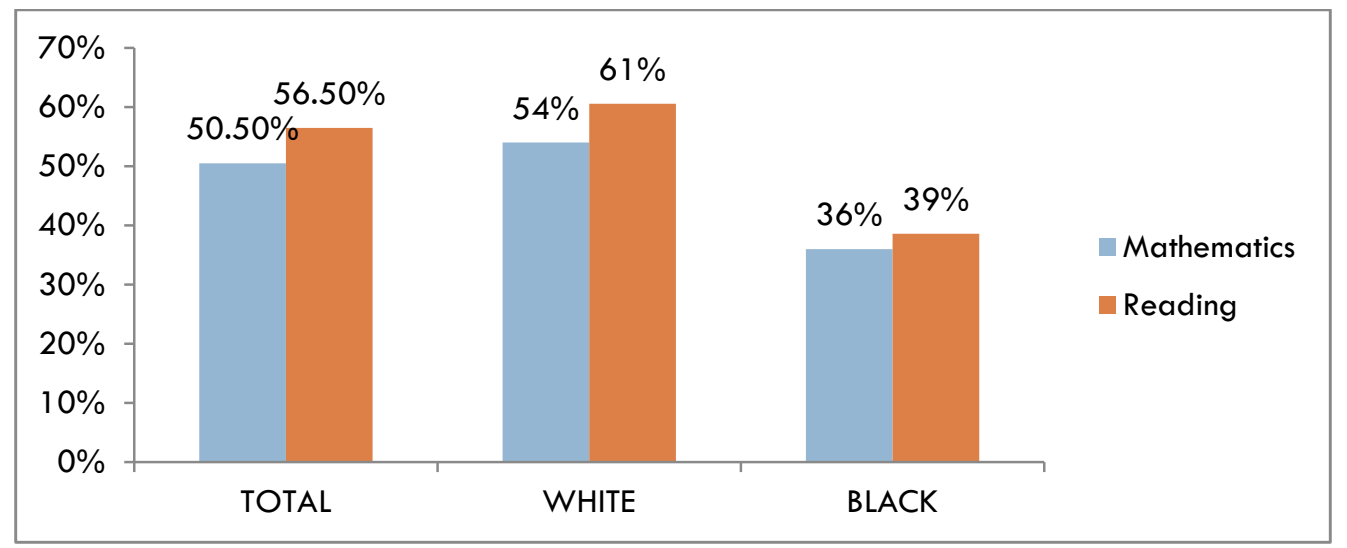

FIGURE 31. PROFICIENCY RATE BY RACE. SOURCE: WV DEPT. OF EDUCATION (2013-2014).

Students with Low Socioeconomic Status (Low SES) perform far worse than students who are not classified as Low SES in both mathematics and reading. Only about a third of the students with Low SES are reaching target scores, while the average for regular students is more than half. 


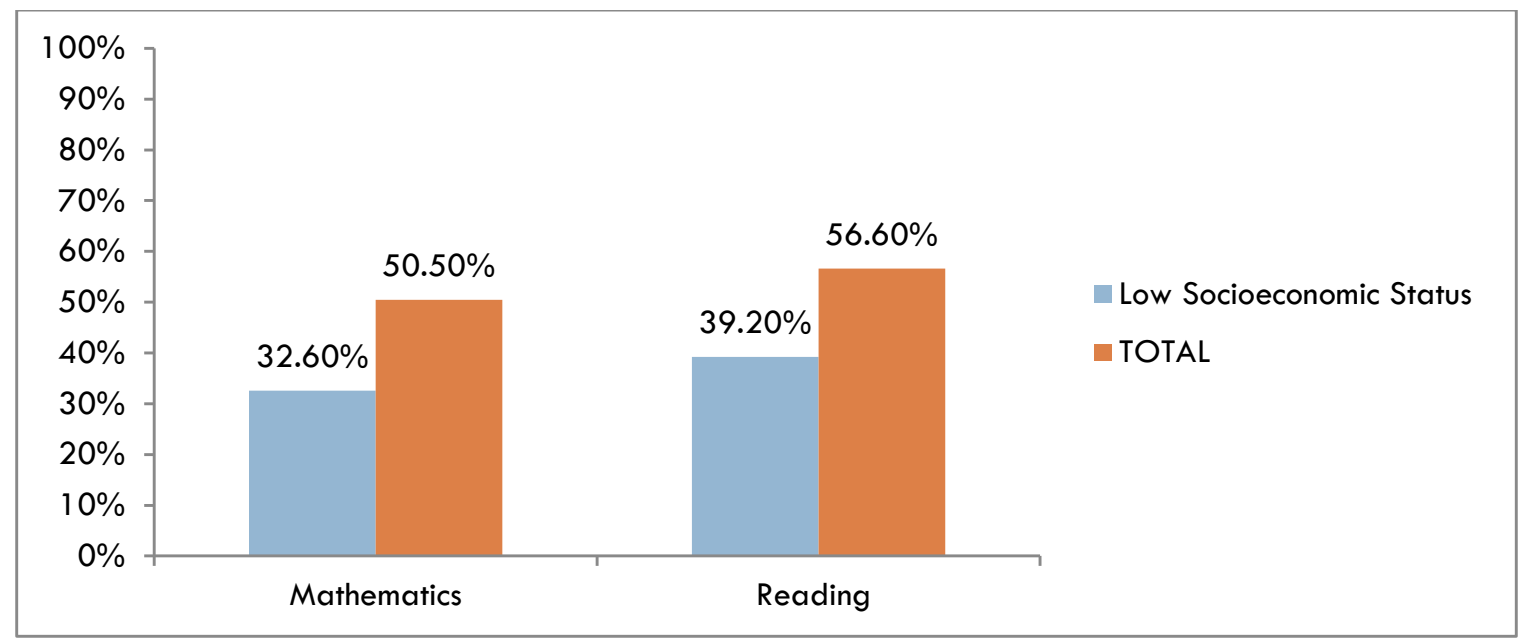

FIGURE 32. PROFICIENCY RATE BY SES. SOURCE: WV DEPT. OF EDUCATION (2013-2014).

The High School graduation rate for students at Fairmont Senior High School is slightly higher than both the West Virginia and national average.

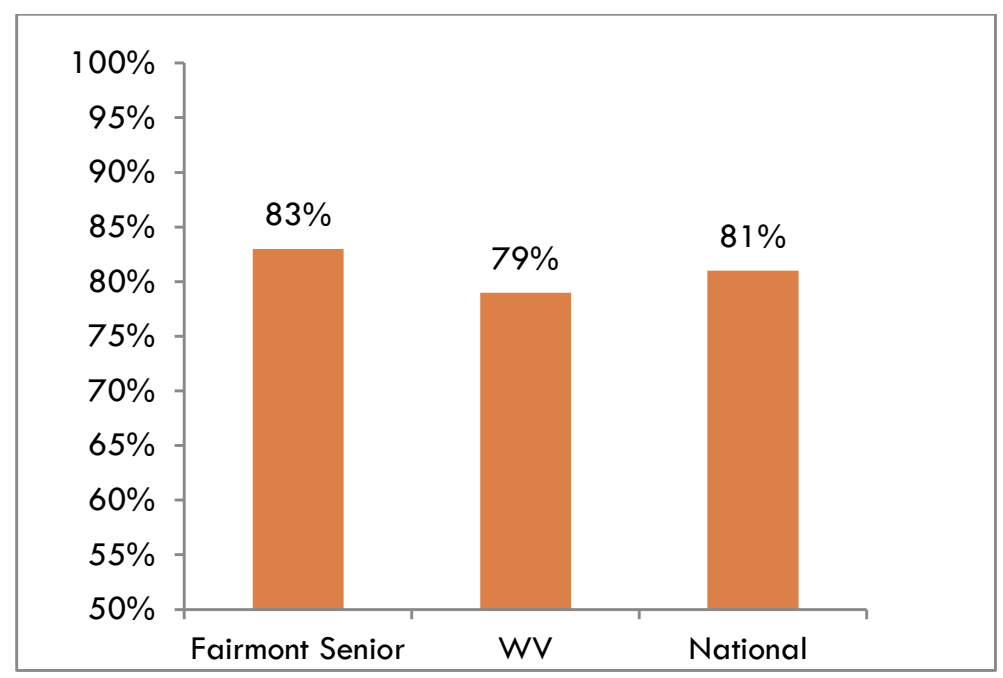

FIGURE 33. HIGH SCHOOL GRADUATION RATE. SOURCE: NATIONAL CENTER FOR EDUCATION STATISTICS (2012)

\section{Conclusions}

Westside residents describe their neighborhoods as the traditionally African American part of Fairmont. This identity is borne out by the relatively high proportion of African American families concentrated in Census Tract 205. As noted in the discussion of Cultural Capital, this offers a unique character that greatly influences the Human Capital of this community.

Comparing to other areas, employment is relatively higher in these neighborhoods; but the poverty rate is even more so, suggesting these residents earn substantially lower wages than those in other areas of the community (see Financial Capital for further discussion). The rate of youth in poverty is substantially higher for the families in these neighborhoods. These economic challenges may be linked to educational progress and attainment. 
Indeed, the data suggest an interesting trend in student progress among those from Census Track 205. Watson Elementary is a Title I school and has the Success performance designation from WVPI. Both West Fairmont Middle School and Fairmont Senior High School do not receive Title I funding and school performance goes from moderate to poor, especially for minority students and those with low socioeconomic status. The data suggest that Title I support may be linked to academic performance for these students. As these supports end after fourth grade, alternatives may be required to boost educational achievement and attainment for students from Low SES families.

\section{References}

Fiore, A. M., Niehm, L. S., Hurst, J. L., Son, J., Sadachar, A., Russell, D. W., Seeger, C. (2015). Will they stay or will they go? Community features important in migration decisions of recent university graduates. Economic Development Quarterly, 29(1), 23-37.

Lumina Foundation. (2015). A Stronger Nation Through Higher Education. Retrieved November 1, 2015 from http://strongernation.luminafoundation.org/report/

National Center for Education Statistics (2012). High School Graduation Rates 201 2. Retrieved November 1, 2015 from http://nces.ed.gov/ccd/schoolsearch/school detail.asp?Search=1 \&SchoolID=540072000553\&ID=5 40072000553

U.S. Census Bureau. (2009-2013). 5-Year American Community Survey: Census Tract 205.

U.S. Census Bureau. (2013). Employment Census Tract 2013: Census Tract 205. Retrieved November 1, 2015 from http://factfinder.census.gov/faces/tableservices/isf/pages/productview.xhtml?pid=ACS $13 \quad 5 Y R \quad$ S2 301\&prodType $=$ table

U.S. Census Bureau. (2013). Median Age Census Tract 2013: Census Tract 205. Retrieved November 1, 2015 from http://factfinder.census.gov/faces/tableservices/isf/pages/productview.xhtmlepid=ACS 13 5YR SO 101\&prodType $=$ table

U.S. Census Bureau. (2013). Race Census Tract 2013: Census Tract 205. Retrieved November 1, 2015 from http://factfinder.census.gov/faces/tableservices/isf/pages/productview.xhtmlepid=DEC $10 \mathrm{PL} P 1$ \& prodType $=$ table

U.S. Census Bureau. (1970-2013). Population Census Tracts 1970-2013: Census Tract 205. Retrieved November 1, 2015 from http://factfinder.census.gov/faces/tableservices/isf/pages/productview.xhtml?pid=ACS $13 \quad 5 Y R \quad$ BO 1003\&prodType $=$ table

U.S. Census Bureau. (2013). Poverty Census Tract 2013: Census Tract 205. Retrieved November 1, 2015 from http://factfinder.census.gov/faces/tableservices/isf/pages/productview.xhtml?pid=ACS 13 5YR S1 701\&prodType $=$ table

West Virginia Department of Education. (2013-2014) - ZOOM WV Data Dashboard 2013-2014. Retrieved November 1, 2015 from http://zoomwv.k12.wv.us/Dashboard/portallHome.jsp 
West Virginia Department of Education (2015). ESEA Flexibility Waiver. Retrieved November 1, 2015 from, https://wrde.state.wv.us/esea/support/Documents/Support $\% 200$ ne $\% 20$ Page $\% 20$ Brief Final.pdf 


\section{SOCIAL CAPITAL}

Social Capital will be assessed in forthcoming phases of this project. 


\section{POLITICAL CAPITAL}

\section{Dakota Morris}

This section will discuss federal and state, county, and municipal governments and government officials which make decisions that impact the neighborhoods that this profile will serve. The goal is that readers come away with a better understanding of how these institutions and officials impact their lives at the various levels of government. Readers may refer to Appendix B for the contact information for organizations and officials within the federal, state, and local governments serving them.

\section{Federall and State Representation}

Marion County and the City of Fairmont are represented by United States Senators Joseph Manchin III (Who has a Fairmont Office at 230 Adams St.) and Shelley Moore Capito. In the United States House of Representatives, Marion County and the City of Fairmont are represented by Congressman David McKinley of the first Congressional District of West Virginia.

The western half of Marion County is represented in the second senatorial district of the West Virginia Legislature by Senators Jeffery Kessler and Kent Leonhardt. The second senatorial district encompasses not only the western portion of Marion County, but also a larger portion of northern and central West Virginia. The eastern portion Marion County, to which the city of Fairmont belongs, is represented in the thirteenth senatorial district in which Senators Roman Prezioso and Robert Beach reside. This senatorial district also encompasses the City of Morgantown and portions of Monongalia County.

In the House of Delegates of the West Virginia Legislature, Fairmont and most of Marion County is represented in the fiftieth House District by Delegates Linda Longstreth, Tim Manchin, and Mike Caputo. One other delegate, Delegate Amy Summers, represents a small portion of eastern Marion County as part of the forty-ninth House District.

\section{County Government Characteristics}

Marion County is governed by a commission style of government. The commission consists of three members which each serve six year rotating terms. Each commissioner must reside in a different Magisterial District. These include Palatine, Middletown, and West Augusta. The Commission currently meets in the county seat of Fairmont in the J. Harper Meredith Building every Wednesday at 10:00 AM, and the meetings are open to the public.

Marion County is also governed by an assessor, a sheriff, and a county clerk. The Assessor determines the value of all real and personal property each fiscal year within the boundaries of Marion County. The Sheriff serves as the chief law enforcement officer of the county, as well tax collector and treasurer. The County Clerk issues marriage licenses, hunting and fishing licenses, certified copies of vital records such as birth, death, and marriage certificates and also handles voter registration and election results, bookkeeping, accounts payable, and fees.

The Marion County Health Department handles public health issues and provides various health services and programs within the county. These include: women's health and family planning services, community health services, immunizations, HIV/AIDS and STD services and various other issues of concern to public health. The Marion County Department of Homeland Security and Emergency Management, located in Fairmont, helps organizations within the country to prepare and cope with disasters and other emergencies as they occur. 


\section{Marion County School District}

The Marion County School District is managed by the Marion County Board of Education. This board is an administrative arm of the State Board of Education, although county boards do have decision making power as well. The Marion County Board of Education consists of five elected members which meets in Fairmont on the first and third Mondays of each month at 6:00 PM. Current membership includes: President Richard Pellegrin, Dr. Babette Sims, Janette Crespenzi, Thomas Dragch, and Mary Joe Thomas. The Superintendent of Schools is Gary Price.

\section{Municipal Government Characteristics}

The City of Fairmont employs a Council/Manager system of government. The City Council, headed by a Mayor chosen by the Council from among its members, governs the city. The City Manager executes and administers municipal ordinances and manages the city's administrative departments. As shown in Figure 34, there are nine voting districts within Fairmont. The members of the Council are nominated by the people who reside in their individual district, but they are elected by the voters at large. The Westside area neighborhoods are included in District 4, represented by Bill Burdick, and District 5, represented by Fran Warner.

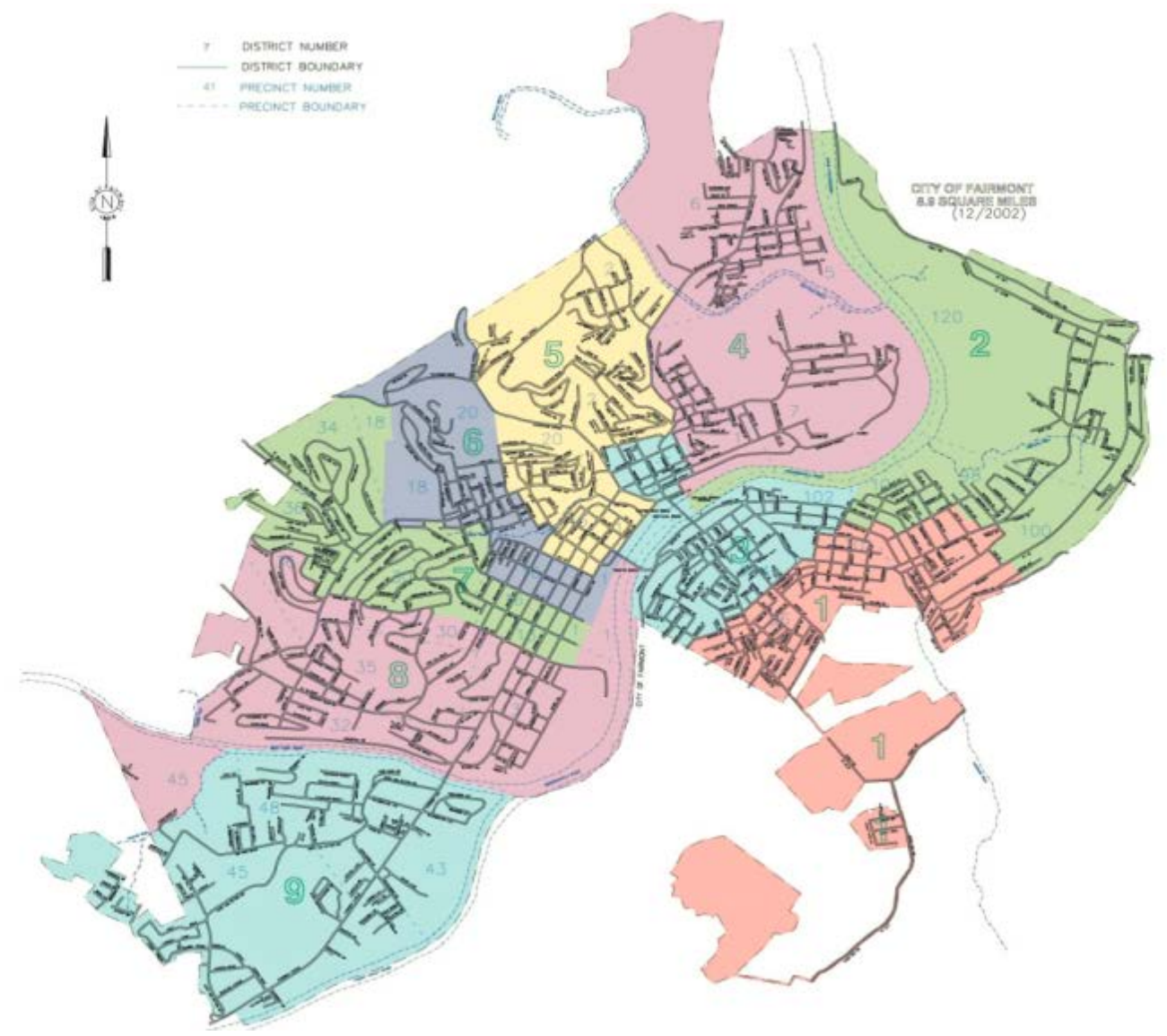

FIGURE 34: MAP OF COUNCIL DISTRICTS. SOURCE: CITY OF FAIRMONT (N.D.).

At the beginning of each new Council term, the Council elects from among its membership, someone to serve as Mayor and someone to serve as Deputy Mayor. The Mayor presides over the Council meetings and serves 
as the head of government for ceremonial purposes. The Deputy Mayor fulfills the Mayor's duties when the Mayor is unable to do so. Ron Straight is the current Mayor.

As shown in Figure 35, the Council appoints a City Manager to execute the ordinances and manage the administration of the city government. The current City Manager is Robin Gomez. The Council cannot interfere directly with city staff, whom fall under the City Manager's control, though they may discuss matters of administration freely with the City Manager. The City Manager appoints all city employees and keeps the Council informed on the administration of the City, including its financial health. The City Manager also prepares proposed agendas for Council meetings and participates in deliberations with no voting power.

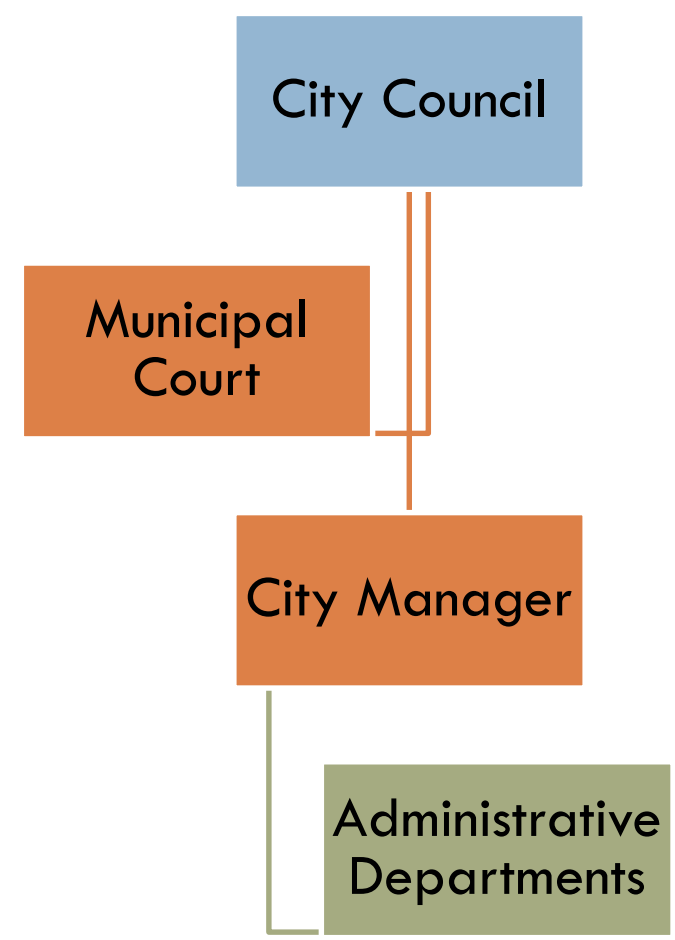

FIGURE 35: FAIRMONT ORGANIZATION CHART

Administrative departments and offices of the city include: the Department of Building Inspection and Rental Registration, the City Attorney, the City Clerk, Marketing and Communications, Customer Service, Finance, Fire and Police Departments, Human Resources, Planning and Development, Public Works, Purchasing, and Utilities.

The Department of Building Inspection and Rental Registration administers enforcement of building codes and rental ordinances as adopted by the Council, issues building permits, and provides necessary forms and applications. The City Attorney, currently Kevin Sansalone, provides legal opinion for the city, prepares and reviews contracts and agreements, serves as legal counsel, and researches and prepares city ordinances. The City Clerk, currently Janet Keller, provides staff support to the Council, takes minutes of meetings, files and stores important information such as ordinances and minutes, publishes notices, provides clerical service to Police and Fire Civil Service Commissions, and also serves as the Chief Election Official of Municipal Elections. Marketing and Communications, currently led by Hanna Weaver, keeps updates on upcoming events of the city as well as up to date information on news related to the city. The Finance Department, headed by Director Eileen Layman, handles business licensing, taxation, and city service fees. The Police and Fire Departments provide essential police and fire services. The current Police Chief is Steve Shine and the current 
Fire Chief is James Emerick. The Human Resource Department manages city employment. The Planning and Development Department, led by City Planner Mark Miller, works with the Council, the Planning Commission, and Urban Renewal Authority on zoning and land use regulations, comprehensive city planning, and also prepares and manages grants and other funding opportunities for the city. Public Works, directed by Ron Miller, manages and maintains city streets, conducting repairs, construction, and signage. Purchasing, led by Paula Friend, manages bids, and Wastewater manages sewer systems and wastewater filtration. The Wastewater department is managed by Superintendent Billie Johnson.

\section{Municipall Court}

The Fairmont City Charter provides for the establishment of a Municipal Court to be overseen by a Municipal judge appointed by the City Council. The Judge must be an attorney in good standing of the Marion County Bar Association.

The Judge serves a four-year term and maintains criminal jurisdiction over City ordinances. The Judge also holds the criminal jurisdiction of a West Virginia magistrate within the City and Fairmont Police Department jurisdictions.

\section{City Boards and Commissions}

The Fairmont's City Charter notes that the "Council may by ordinance create, combine, change or abolish offices, boards, commissions, departments or agencies, other than those established by this Charter" (City of Fairmont, 1976). The City has expanded the number of boards and commissions since its original charter to include a range of issues from arts and humanities to public safety. Fairmont City Council and the City Manager make board and commission appointments. Fairmont currently has 22 boards, commissions and authorities, of which 14 are defined within the Code of Ordinances (Drane Conway Greene, 2015). A summary of Fairmont's Boards, Commissions and Authorities are listed here.

\section{Planning Commission}

Fairmont created the Planning Commission in 1968, to ensure the present and future well-being of the city. The Planning Commission oversees the Board of Zoning Appeals and the Urban Renewal Authority. Meeting monthly on the third Wednesday, the Commission works to improve the welfare of the residents and develops long-term plans for health, education, recreation, utilities, and transportation systems that promote economic growth and efficient use of public funds. The Commission consists of nine Fairmont residents, who possess knowledge and experience in city development and represent area businesses, industries, and labor. Threefifths of the members are required to have at least ten years' residency. One member of the Commission must also serve on the City Council, and another member must serve in the City's administrative department.

\section{Sanitary Board}

In 2005, Fairmont created the Sanitary Board to supervise and control the sewer system, including maintenance, acquisition, improvements, and collection of revenues. The Sanitary Board consists of the City Manager, serving as the Board chairman, and two other individuals, of whom one is a registered professional engineer, serving for a three-year term. 


\section{Building Commission}

As a result of West Virginia Code in 1985, Fairmont created the Building Commission, with the authority to accept conveyance of City property. The Board consists of five residents appointed by City Council. Initially, appointments ranged from a one-year term to a five-year term. As each term expired, subsequent appointees served five-year terms which overlapped, causing a yearly renewal of at least one membership.

\section{Urban Renewal Authority}

Fairmont created the Urban Renewal Authority in 2004 to address the issue of urban blight, as defined by West Virginia Code. The Authority works to promote redevelopment of distressed areas to ensure improved health and wellbeing of city residents.

\section{Fairmont Parks Commission}

The Fairmont Parks Commission, established in 2007, consists of seven residents serving for a term of six years, and appointed by the City Council. Notably, no more than three City Council members can serve as Parks Commissioners.

\section{Fairmont Water Board}

The Water Board controls all aspects of Fairmont's water system. Established in 2010, the Water Board consists of three board members serving three-year terms, one of whom is the City Manager, and the two remaining City Council appointees are residents.

\section{Records Commission}

Preservation of vital local government records is the goal of the Records Commission. Established in 1975, the City Manager serves as the City Records Administrator. Composed of the following members: The Clerk, Finance Director, the City Attorney, Municipal Judge, and the City Manager, the Records Management and Preservation Advisory Committee provide the Administrator advice regarding records conservancy.

\section{Arts and Humanities Commission}

The Arts and Humanities Commission, founded in 1993, consists of eleven resident members appointed by the City Manager and confirmed by Council. The members serve three-year terms, and advise the City Manager and Council on measures to foster arts in Fairmont. The Commission conducts research regarding expansion of the performing and creative arts in the city. Additionally, the Commission works to encourage artistic freedom of expression and the use of local resources and cultural institutions, both public and private, for the development of the arts.

\section{Board of Zoning Appeals}

The Board of Zoning Appeals (BZA) is comprised of five members with the position of president and vice president holding the highest authority. Each one of the members on the board is a resident of Fairmont. BZA meets the first Thursday of each month to look at individual zoning inquires pertaining to nonconforming uses, conditional uses, and variances, that have, for instance, either been denied a permit for construction or have some unusual aspect afflicting the project. BZA exists so that a person who has been denied a permit or license to build a structure on his or her property due to city zoning code restrictions can come before the board to present his or her case. The board has the power to approve or deny the appeal. 


\section{Fairmont Parking Authority}

The Fairmont Parking Authority is comprised of five members appointed by the City Manager and confirmed by Council. Each member serves a three-year term. The City Manager holds administrative authority and acts as the chief executive officer. The Parking Authority has plenary power to approve expenditures, issue bonds, approve contract bids, grant power to erect or construct new facilities, lease and sell facilities and the air space they inhibit all by means of approval of the Council.

\section{The Fairmont-Marion Transit Authority}

The Fairmont-Marion Transit Authority is comprised of five members nominated by the City Manager and appointed by the Council. Both the City and the County jointly appoint one member and two members are appointed by the County Commission. Each member serves a three-year term. The Fairmont-Marion Transit Authority is considered a public corporation and acts accordingly to the authorization of West Virginia Code Article 8-27.

\section{Human Rights Commission}

The Human Rights Commission is composed of nine members appointed by the City Manager and approved by the Council. Each member is to be a resident of the City of Fairmont. Eight of the members are to represent differing racial, religious, and ethnic groups within the city. The final member completing the commission is to be a duly licensed attorney who is a practicing member of the Marion County Bar Association. The Commission seeks to encourage mutual respect and understanding within all racial, religious, and ethnic groups within the City. It also seeks to eliminate discrimination in employment and places of public accommodations as well as eliminate discrimination in the sale, purchase, lease, rental or financing of a home or other property.

\section{Historic Landmarks Commission}

The Historic Landmarks Commission consists of five members appointed by the City Council by the recommendation of the City Manager. Each member is to be a resident of the City of Fairmont and is expected to serve a three-year term. Vacancies within the commission are filled for any member who does not fulfill his or her full term. All commissioners serve without pay but are reimbursed for any reasonable expenses incurred in the fulfillment of his or her role. At the first meeting of each year, a Chairman and Vice Chairman are selected by and from the members of the Commission. The Commission is to hold at least one meeting per year and any additional meetings will be at the discretion of the Chairman. The Commission has plenary power and authority within the jurisdictional boundaries of the City to create surveys of and designate historic structures, prepare a register of these structures, mark these structures, acquire structures, lease or sell property, and adopt rules and regulations deemed necessary for the functioning of the commission.

\section{Historic Preservation Review Commission}

The Historic Preservation Review Commission is made of up five members appointed by the City Council upon the recommendation of the City Manager. Each member is to be a resident of the City of Fairmont who owns a business in a designated historic district and who has demonstrated special interest, education or experience in history, architecture, real estate, law, or planning. All commissioners are to serve a three-year term. Commissioners are served without pay but are compensated for any reasonable expense incurred in the fulfillment of his or her role. At the first meeting of each year a Chairman and a Vice Chairman are elected. The Commission is required to hold at least one meeting per year and any following meetings throughout the year are called at the discretion of the Chairman. The Historic Preservation Review Commission has plenary power within the jurisdictional boundaries of the city of Fairmont. The Commission also holds power to review 
applications for certificates in accordance with the procedures set in place by the Commission, establish rules and standards for the preservation of historic landmarks as well as rules and regulations concerning the operation of the Commission. Finally, the Commission holds power to employ assistants, technical personnel and consultants as necessary.

\section{References}

City of Fairmont, WV. (2015). "City Webpage". Accessed November 1, 2015 from: http://www.fairmontwv.gov/

City of Fairmont (n.d.). "Map of Council Districts". Accessed November 1, 2015 from: http://www.fairmontwv.gov/327/Council-Districts

City of Fairmont, WV. (1976). "Charter of The City of Fairmont, West Virginia". Accessed November 1, 2015 from: https://ecampus.wvu.edu/bbcswebdav/pid-2512335-dt-content-rid$64205591 /$ courses/star88605.201508/City\%20of\%20Fairmont\%20Charter.pdf

Drane Conway Greene. (2015). “Municipal Code Library”. Accessed November 3, 2015 from http://whdrane.conwaygreene.com

Marion County Board of Education. (2015). "Members". Accessed November 1, 2015 from: http://www.marionboe.com/page/about-us/board-of-education/members

Marion County, WV. (2015). "County Webpage". Accessed November 1, 2015 from: http://www.marioncountywv.com/index.php

The West Virginia Legislature. (2015). "District Maps". Accessed November 1, 2015 from: http://www.legis.state.wv.us/Districts/maps.cfm\#HDO 1 


\section{ORGANIZATIONAL CAPITAL}

\section{Gaillynn Bowman and Bre Kreutzer}

Nonprofit organizations and civic clubs work to improve quality of life for particular groups and the community at large. Community-based organizations play a fundamental role in the revitalization of Fairmont, including the Westside neighborhoods. Many of these organizations are already engaging in the Westside Action Coalition, formed to address the needs of Fairmont's historically African American neighborhoods. A list with contact information is provided in Appendix $C$.

\section{Faith Community}

Churches in the Westside neighborhoods serve the community, through activities such as youth programming and outreach to seniors. The denominations include Morning Star Baptist Church with the Women of Purpose Ministry, Mt. Zion Baptist, Temple of Christ, and Church of God MPGT. Nearby churches that also hold a significant cultural connection to the African American community include Christian Love Ministry and Trinity United Methodist.

\section{Civic Organizations/Chapters}

The Westside neighborhoods once hosted an African American lodge of the Freemasons civic organization. The African American Order of the Eastern Star is still active in the community, meeting twice a month during the summer. Founded nationally in 1874, the Order "is the oldest sorority-based Black women's organization in America" ("Welcome To "Voices," 2000).

The local Marion County branch of the NAACP (National Association for the Advancement of Colored People) is active in the community, holding its annual Freedom Fund Banquet in October. The chapter is planning a Martin Luther King Day Celebration, January 17, 2016, to be held at the Morning Star Baptist Church.

\section{Community-Based Organizations}

Several community-based organizations specifically serve the interests of these neighborhoods, including the Dunbar School Foundation, which is working to preserve the heritage of the community school built in 1928 and permanently closed in 2007. In 2008, the community members formed the Foundation under the leadership of Houston Richardson and purchased the building in 2009. The Foundation currently seeks to renovate and preserve the historic building to house inclusive community activities: education, mentoring, community seminars, community dialog, leadership training, visual arts, performing arts, sports, recreation, concerts and plays. The Foundation is also developing a repository to establish a Marion County African American History Museum to be housed in the Dunbar School building (Richardson, n.d.).

Dunbar School's ancillary building currently provides space for non-profit, community based organizations such robotics programming. Created in 2009, West Side Robotics (WSR) offers support to robotics clubs and teams from the Westside neighborhoods that participate in competitions. By providing training, support, and equipment WSR aids Fairmont's youth in science, technology, engineering, and math (STEM) education.

The Fairmont Community Youth Development Center (FCYDC), previously known as the 612 MAC (Madison Avenue Center), offers youth programming. This community center operates out of a house donated by a local doctor in the Jackson Addition neighborhood. During 612 MAC's early years as the vibrant heart of the community, Minister Herschel Walker started the Bulldogs, a youth football team. With the help of Frank 
Hines, Lawrence Horton, and Anna McWright, the organization offered after-school tutoring and reading. Executive Director Anna McWright also piloted an award-winning music program after securing a $\$ 5,000$ grant for instruments. This grant was overseen by United Methodist Church (Ezelle, 2014). Through mismanagement over time, these programs were dropped and 612 MAC ceased operations in 2011.

In 2014, Brian Curry came on as executive director and the center was reopened and the organization was rebranded in 2014 as the Fairmont Community Youth Development Center (FCYDC). The youth football program was restored and the building began extensive renovations (Brooks, 2015). The mission of the Center is to provide children with a safe place to spend time with other youth during leisure time. The Center offers tutoring and studying sessions and also has a small convenience store for children to buy snacks and drinks.

FCYDC partners with other organizations to fulfill its mission. For example, Fairmont State University's Black Student Union supports the Westside Coalition neighborhood through free tutoring and donated school supplies. The Miles Chapel Church provides food scarcity backpacks through the Rising Star program. The Fraternal Order of Police (FOP) provides funding for clothing/supplies to the area youth and the Fire Department/Ambulance/Dare Officer provide educational activities at Windmill Park, with approximately 90 children attending the most recent event. Reflective of its origins, the Center continues to support their local youth football team, the 612 MAC Bulldogs.

West Side Robotics is an after-school club established in 2009 by Willie James, a previous resident of Fairmont. Robotics activities enhance STEM (science, technology, engineering, and math) education. The club provides training, support, and equipment to youth who wish to participate in robotic competitions such as the LEGO League tournaments. Youth mentors are recruited from Fairmont Senior High School to work with youth from Jayenne Elementary and West Fairmont Middle School. The program operates out of Dunbar School ancillary building.

\section{Nonprofit Development Agencies}

The Fairmont Community Development Partnership (FCDP) formed in 1992 to address the need for quality, affordable housing in the Westside neighborhoods. The first meeting of the occurred at the Westside home of Asa Davidson, and the organization embodies the neighborhood's vision for revitalization. FCDP is a NeighborWorks America strategic partner, seeking to stabilize and improve Fairmont's neighborhoods through support from the Federal Home Loan Bank, US Housing and Urban Development, USDA, and the WV Development Office. FCDP builds both owner-occupied and rental housing, and provides services "from homeownership counseling and new home construction, to the purchase \& rehabilitation of homes and the revitalization of commercial properties" ("Fairmont Community," 2013).

The Fairmont-Morgantown Housing Authority, FMHA, is a regional housing authority serving Fairmont and Morgantown, as well as Monongalia, Marion, Preston, and Taylor counties. The FMHA, a quasi-governmental agency, "brings government assisted programs, private partners, and community service programs together" to provide rental assistance, residential property management, community development supports, housing counseling, housing rehabilitation services, new housing construction supports, and commercial real estate services ("Fairmont-Morgantown Housing," 2015).

A recent FMHA project includes a collaboration between Augusta Development Corporation and Fairmont's Miller School Associates "to adapt and reuse the Fairmont Miller Junior High School Building at 2 Pennsylvania Avenue into affordable housing for seniors" ("Development," 2015). The 6.2 million dollar project will pair historic tax credits with Low Income Housing Tax Credits from the West Virginia Housing Development Fund. 
Marion County Habitat for Humanity, headquartered in Fairmont, is an affiliate of Habitat for Humanity of West Virginia. Its mission is to put God's love into action by bringing people together to build homes, communities, and hope. Habitat builds and remodels affordable housing and is active in the Westside neighborhoods.

Fairmont's volunteer, community-based BAD (blighted, abandoned, dilapidated) Buildings Team has mapped dilapidated and vacant properties in an effort to create an inventory of structures that need to be demolished or renovated. The volunteers have formed GO Teams, which include leaders, owner outreach representatives, and sub-committee leaders, which work to beautify the community and provide homeowners assistance in collaboration with neighborhood associations such as Neighbors in Action. Fairmont's BAD Buildings Team has worked to move the Community Investment and Transformation Initiative (CITI) from a concept to a successful strategy ("BAD," 2015).

\section{Colleges and Universities}

Institutions of higher learning often provide faculty outreach and student service learning to communities. Five colleges and universities are within forty-five minutes of Fairmont, including West Virginia University, Salem International University, Alderson Broaddus College, Fairmont State University, and Fairmont State Community and Technical College (Pierpont). ("Colleges," 2015).

Pierpont Community and Technical College has a campus in downtown Fairmont. It offers affordable tuition and two-year degree programs geared toward good paying jobs as well as successful transfer to four-year institutions. Its academic programs include: Business, Aviation \& Technology; Health Careers; Human Services; and Workforce Education.

Fairmont State University is located in south Fairmont and offers a wide variety of Bachelor's degree programs. It also offers several Master's degrees: Education and Teaching, Criminal Justice, Business Administration, and Architecture. Various departments conduct community outreach and service learning. For example, the faculty and students in the Architecture degree program conduct design studios for community planning and the Black Student Union contributes tutoring and donated school supplies to Fairmont Youth Community Development Center.

\section{References}

BAD Buildings Group, Fairmont, WV. (2015). Retrieved November 3, 2015 from http://www.fairmontwv.gov/392/BAD-Buildings-Group/

Colleges. (2015). Retrieved November 3, 2015 from http://www.fairmontwv.gov/DocumentCenter/Home/View/48

Development of the Miller School. (2015). Retrieved November 3, 2015 from http://www.fmhousing.com/news detail T2 R6.php/

Dunbar School. (2015). National Register of Historic Places Registration Form. West Virginia Division of Culture and History. Retrieved from: http://www.wvculture.org/shpo/nr/pdf/marion/15000188.pdf

Fairmont Community Development Partnership. (2015). Retrieved November 3, 2015 from 
Fairmont-Morgantown Housing Authority. (2015). Retrieved October 26, 2015 from http://www.fmhousing.com/

Friends of Downtown! (2015). Retrieved October 15, 2015 from http://www.mainstreetfairmont.org/

Richardson, H. (n.d.) Won't You Join Us in Preserving the Heritage of Dunbar School Fairmont, WV? [Pamphlet] Fairmont, WV: Dunbar School Foundation.

Welcome To "Voices That Guide Us". (2000). Retrieved October 16, 2015 from http://www.aaregistry.org/ 


\section{FINANCIAL CAPITAL}

\section{Daniel Eades and Courtni Helmick}

Financial Capital is the community's monetary resources and access to funding. It includes income, savings, credit, grants, tax revenue, and other monetary resources available for investment in capacity building, underwriting business development, supporting civic and social entrepreneurship, and investing for wealth accumulation to support future development initiatives (Emery, Fey, and Flora, 2006).

\section{Household Income and Sources}

The primary source of financial capital in the community is residents' income. Approximately $80 \%$ of households in Census Tract 205 reported some earnings (see Table 1). Although this rate exceeded other geographic areas, earnings were significantly lower. As a result, median household incomes were lower, averaging $\$ 23,667$ in Census Tract 205 as compared to nearly $\$ 37,000$ in Fairmont and over $\$ 40,000$ in the county and state. Furthermore, Census Tract 205 reported the largest share of households receiving cash public assistance $(4.2 \%)$ and SNAP benefits $(23.3 \%)$.

TABLE 1: HOUSEHOLD INCOME AND SOURCES IN SELECTED GEOGRAPHIES, 2009-2013. SOURCE: U.S. CENSUS BUREAU (2015).

\begin{tabular}{|l|r|r|r|r|}
\hline & Census Tract 205 & Fairmont & Marion County & West Virginia \\
\hline With earnings & $75.9 \%$ & $71.2 \%$ & $68.6 \%$ & $70.2 \%$ \\
\hline Income from Source & $\$ 38,940$ & $\$ 51,698$ & $\$ 59,554$ & $\$ 59,300$ \\
\hline With Social Security & $29.9 \%$ & $34.7 \%$ & $38.4 \%$ & $37.9 \%$ \\
\hline Income from Source & $\$ 12,772$ & $\$ 16,243$ & $\$ 16,490$ & $\$ 16,714$ \\
\hline With retirement income & $15.8 \%$ & $21.9 \%$ & $23.6 \%$ & $25.4 \%$ \\
\hline Income from Source & $\$ 9,602$ & $\$ 14,540$ & $\$ 14,128$ & $\$ 17,154$ \\
\hline With Supplemental Security Income & $4.0 \%$ & $6.0 \%$ & $7.7 \%$ & $5.8 \%$ \\
\hline Income from Source & $\$ 6,083$ & $\$ 7,782$ & $\$ 8,679$ & $\$ 8,601$ \\
\hline With cash public assistance income & $4.2 \%$ & $2.0 \%$ & $2.3 \%$ & $1.1 \%$ \\
\hline Income from Source & $\$ 4,403$ & $\$ 1,993$ & $\$ 2,445$ & $\$ 2,848$ \\
\hline & & & & $12 \%$ \\
\hline With Food Stamp/SNAP benefits & $23.3 \%$ & $14.9 \%$ & $15.3 \%$ & $12.7 \%$ \\
\hline Median Household Income & $\$ 23,667$ & $\$ 36,917$ & $\$ 42,152$ & $\$ 41,043$ \\
\hline Poverty Rate & $33.6 \%$ & $22.1 \%$ & $15.9 \%$ & $17.9 \%$ \\
\hline
\end{tabular}

More than half (52\%) of the households in Census Tract 205 reported household incomes below $\$ 25,000$. For perspective, the U.S. Census Bureau's poverty thresholds and U.S. Department of Health and Human Service's Federal Policy Guidelines use a household income of $\$ 24,250$ for a family of four as the threshold for eligibility in government programs targeted to low income families. Poverty rates in Census Tract 205 were estimated at $33.6 \%$, nearly double the state average of $18 \%$. The neighborhood's low household incomes and high poverty rate present opportunities for participation in federal and state programs that serve low income populations, as listed in Appendix D. Furthermore, charitable agencies and in some cases private 
companies, such as utilities and pharmaceutical companies, use federal poverty guidelines to allocate resources and services.

\section{Employment}

The labor force participation rate in Census Tract 205 averaged $57 \%$ between 2009 and 2013. This rate was comparable to the city and county, which reported labor force participation rates of $60 \%$ and $58 \%$, respectively. Unemployment was significantly lower, averaging $2.7 \%$ versus $6.5 \%$ and $5.3 \%$ in the city and county.

Low unemployment rates suggest that residents are taking full advantage of local employment opportunities. Unfortunately, these jobs are in low-paying service sectors with limited opportunities for advancement or income potential (see Table 2). The largest sectors include educational, health care, and social services (28\%); professional, scientific, and management, and administrative and waste management services (16\%), arts, entertainment, and recreation, and accommodation and food services (14\%); and retail trade (12\%). In line with secondary data, conversations with local stakeholders identified in-home health providers (Fairmont General Hospital Home and REM West Virginia), nursing homes, and business management companies (Teleperformance and Jak Telemarketing) as key employers for local residents.

Growth in information and other "high-tech" jobs along the I-79 Technology Corridor could provide an opportunity for increased incomes for neighborhood residents. The 4Fairmont initiative identified both activating neighborhoods and the local educational pipeline as key challenges for the community. Local community development organizations in Census Tract 205 and the surrounding Westside neighborhoods are encouraged to form relationships with representatives from local development organizations such as the High Technology Foundation and local education institutions (Pierpont Community and Technical College, Fairmont State University) in order to prepare the local workforce to take advantage of future employment opportunities. 
TABLE 2. INDUSTRY EMPLOYMENT IN SELECTED GEOGRAPHIES, 2009-2013. SOURCE: U.S. CENSUS BUREAU (2015).

\begin{tabular}{|c|c|c|c|c|}
\hline & $\begin{array}{c}\text { Census Tract } \\
205\end{array}$ & Fairmont & $\begin{array}{l}\text { Marion } \\
\text { County }\end{array}$ & West Virginia \\
\hline $\begin{array}{l}\text { Agriculture, forestry, fishing and } \\
\text { hunting, and mining }\end{array}$ & $1.6 \%$ & $2.6 \%$ & $5.2 \%$ & $6.6 \%$ \\
\hline Construction & $5.4 \%$ & $4.7 \%$ & $6.5 \%$ & $5.6 \%$ \\
\hline Manufacturing & $7.8 \%$ & $6.9 \%$ & $8.4 \%$ & $7.3 \%$ \\
\hline Wholesale trade & $0.0 \%$ & $1.8 \%$ & $2.1 \%$ & $1.6 \%$ \\
\hline Retail trade & $11.6 \%$ & $12.1 \%$ & $12.5 \%$ & $11.6 \%$ \\
\hline $\begin{array}{l}\text { Transportation and warehousing, } \\
\text { and utilities }\end{array}$ & $6.3 \%$ & $3.6 \%$ & $5.3 \%$ & $5.0 \%$ \\
\hline Information & $0.0 \%$ & $2.8 \%$ & $1.8 \%$ & $2.2 \%$ \\
\hline $\begin{array}{l}\text { Finance and insurance, and real } \\
\text { estate and rental and leasing }\end{array}$ & $1.0 \%$ & $4.2 \%$ & $4.4 \%$ & $4.1 \%$ \\
\hline $\begin{array}{l}\text { Professional, scientific, and } \\
\text { management, and administrative } \\
\text { and waste management services }\end{array}$ & $16.0 \%$ & $11.8 \%$ & $7.7 \%$ & $8.7 \%$ \\
\hline $\begin{array}{l}\text { Educational services, and health care } \\
\text { and social assistance }\end{array}$ & $27.7 \%$ & $27.8 \%$ & $26.3 \%$ & $26.9 \%$ \\
\hline $\begin{array}{l}\text { Arts, entertainment, and recreation, } \\
\text { and accommodation and food } \\
\text { services }\end{array}$ & $14.4 \%$ & $11.1 \%$ & $8.9 \%$ & $9.4 \%$ \\
\hline $\begin{array}{l}\text { Other services, except public } \\
\text { administration }\end{array}$ & $1.6 \%$ & $3.9 \%$ & $4.4 \%$ & $4.8 \%$ \\
\hline Public administration & $6.7 \%$ & $6.8 \%$ & $6.5 \%$ & $6.2 \%$ \\
\hline
\end{tabular}

\section{Locall Businesses}

Local businesses also serve as financial resources through donations and volunteerism. The Westside neighborhoods are primarily residential. As a result, opportunities to engage businesses in community development initiatives are limited. The Reference USA database contained records for only 15 businesses and service agencies located in the neighborhoods. (See Appendix E for name, address, contact information, and business description).

\section{Lending Institutions}

In 2010, the U.S. Census Bureau identified 19 commercial bank and saving institution offices/branches in Marion County. Deposits at these lending organizations totaled $\$ 705$ million. Reference USA database identified eight institutions active in Marion County (see Appendix F for name and contact information).

In 1977, Congress passed the Community Reinvestment Act to encourage banks and savings institutions to meet the needs of low and moderate income borrowers. Table 3 details loan originations by Census tract, loan amount, and recipients income categories. 
TABLE 3. 2014 CRA SMALL BUSINESS LOANS IN MARION COUNTY BY CENSUS TRACT AND AMOUNT. SOURCE: 2014 CRA MSA AGGREGATE REPORT.

\begin{tabular}{|c|c|c|c|c|c|c|c|c|}
\hline \multirow[t]{2}{*}{ Loan Amount } & \multicolumn{2}{|c|}{$\begin{array}{l}\text { Less than } \\
\$ 100,000\end{array}$} & \multicolumn{2}{|c|}{$\begin{array}{l}\$ 100,000- \\
\$ 250,000\end{array}$} & \multicolumn{2}{|c|}{$\begin{array}{l}\text { More than } \\
\$ 250,000\end{array}$} & \multicolumn{2}{|c|}{$\begin{array}{c}\text { Loans to Businesses with Gross Annual } \\
\text { Revenues Less than } \\
\$ 1 \text { Million }\end{array}$} \\
\hline & $\begin{array}{l}\text { Num } \\
\text { ber }\end{array}$ & $\begin{array}{c}\text { Amoun } \\
t \\
(\$ \times 1 \\
000)\end{array}$ & $\begin{array}{c}\text { Numb } \\
\text { er }\end{array}$ & $\begin{array}{l}\text { Amount } \\
(\$ \times 1,0 \\
00)\end{array}$ & $\begin{array}{l}\text { Num } \\
\text { ber }\end{array}$ & $\begin{array}{c}\text { Amoun } \\
t \\
\left(\begin{array}{l}\$ \\
0\end{array}\right. \\
000)\end{array}$ & Number & $\begin{array}{c}\text { Amount } \\
(\$ \times 1,000)\end{array}$ \\
\hline \multicolumn{9}{|l|}{ Low Income } \\
\hline 0201.00 & 29 & 393 & 0 & 0 & 2 & 1,124 & 11 & 1,313 \\
\hline $\begin{array}{l}\text { Subtotal for } \\
\text { Income Group }\end{array}$ & 29 & 393 & 0 & 0 & 2 & 1,124 & 11 & 1,313 \\
\hline \multicolumn{9}{|l|}{$\begin{array}{l}\text { Moderate } \\
\text { Income }\end{array}$} \\
\hline 0202.00 & 36 & 589 & 2 & 401 & 2 & 596 & 15 & 1,173 \\
\hline 0205.00 & 11 & 60 & 1 & 125 & 0 & 0 & 6 & 140 \\
\hline $\begin{array}{l}\text { Subtotal for } \\
\text { Income Group }\end{array}$ & 47 & 649 & 3 & 526 & 2 & 596 & 21 & 1,313 \\
\hline \multicolumn{9}{|l|}{ Middle Income } \\
\hline 0206.00 & 7 & 121 & 0 & 0 & 0 & 0 & 4 & 106 \\
\hline 0207.00 & 30 & 380 & 0 & 0 & 0 & 0 & 10 & 185 \\
\hline 0208.00 & 30 & 298 & 2 & 375 & 1 & 860 & 11 & 159 \\
\hline 0209.00 & 51 & 976 & 6 & 1,116 & 0 & 0 & 11 & 686 \\
\hline 0213.00 & 9 & 92 & 0 & 0 & 0 & 0 & 3 & 27 \\
\hline 0216.00 & 18 & 191 & 0 & 0 & 0 & 0 & 10 & 148 \\
\hline 0217.00 & 13 & 173 & 1 & 150 & 0 & 0 & 8 & 80 \\
\hline 0218.00 & 7 & 44 & 0 & 0 & 0 & 0 & 2 & 10 \\
\hline $\begin{array}{l}\text { Subtotal for } \\
\text { Income Group }\end{array}$ & 165 & 2,275 & 9 & 1,641 & 1 & 860 & 59 & 1,401 \\
\hline \multicolumn{9}{|l|}{ Upper Income } \\
\hline 0203.00 & 38 & 351 & 2 & 375 & 0 & 0 & 19 & 264 \\
\hline 0204.00 & 16 & 93 & 0 & 0 & 0 & 0 & 6 & 41 \\
\hline 0210.00 & 14 & 200 & 0 & 0 & 1 & 275 & 7 & 377 \\
\hline 0211.00 & 23 & 175 & 1 & 250 & 0 & 0 & 5 & 96 \\
\hline 0212.00 & 96 & 1,586 & 5 & 756 & 15 & 7,643 & 27 & 1,344 \\
\hline 0214.00 & 4 & 86 & 0 & 0 & 0 & 0 & 2 & 77 \\
\hline 0215.00 & 14 & 156 & 0 & 0 & 0 & 0 & 11 & 137 \\
\hline $\begin{array}{l}\text { Subtotal for } \\
\text { Income Group }\end{array}$ & 205 & 2,647 & 8 & 1,381 & 16 & 7,918 & 77 & 2,336 \\
\hline TOTAL & 446 & 5,964 & 20 & 3,548 & 21 & $\begin{array}{c}10,49 \\
8\end{array}$ & 168 & 6,363 \\
\hline
\end{tabular}

Small businesses in the community are able to access funding from institutions beyond those with a physical presence in the county. Table 4 provides data on other institutions lending to individuals and small businesses in the county. 
TABLE 4: BUSINESS LOANS FROM INSTITUTIONS ACTIVELY LENDING IN MARION COUNTY. SOURCE: 2014 CRA MSA AGGREGATE REPORT.

\begin{tabular}{|c|c|c|c|c|}
\hline \multirow[t]{2}{*}{ Institution } & \multirow[b]{2}{*}{ Number } & \multirow[b]{2}{*}{$\begin{array}{c}\text { Amount } \\
(\$ \times 1,000)\end{array}$} & \multicolumn{2}{|c|}{$\begin{array}{l}\text { Loans to Businesses with } \\
\text { Gross Annual Revenues } \\
\text { Less than } \$ 1 \text { Million }\end{array}$} \\
\hline & & & Number & $\begin{array}{c}\text { Amount } \\
(\$ \times 1,000)\end{array}$ \\
\hline American Express & 38 & 346 & 17 & 77 \\
\hline Bank of America & 8 & 82 & 3 & 52 \\
\hline Bofl Federal Bank & 2 & 60 & 2 & 60 \\
\hline Branch Banking and Trust Co & 56 & 5,637 & 31 & 1,166 \\
\hline Capital One Bank (USA & 72 & 380 & 22 & 187 \\
\hline Chase Bank USA & 21 & 178 & 0 & 0 \\
\hline Citibank & 26 & 152 & 13 & 79 \\
\hline Citizens Bank & 1 & 1,000 & 0 & 0 \\
\hline Discover Bank & 8 & 37 & 3 & 20 \\
\hline FIA Card Services & 15 & 110 & 7 & 74 \\
\hline First Community Bank & 1 & 188 & 0 & 0 \\
\hline First National Bank of Omaha & 11 & 158 & 1 & 4 \\
\hline First United Bank and Trust & 1 & 40 & 0 & 0 \\
\hline GE Capital Bank & 1 & 125 & 0 & 0 \\
\hline John Deere Financial & 12 & 135 & 0 & 0 \\
\hline JPMorgan Chase Bank & 6 & 868 & 0 & 0 \\
\hline Peoples Bank & 3 & 332 & 2 & 272 \\
\hline Pinnacle Bank & 1 & 20 & 1 & 20 \\
\hline PNC Bank & 4 & 590 & 3 & 90 \\
\hline S\&T Bank & 1 & 888 & 0 & 0 \\
\hline State Farm Bank & 4 & 65 & 1 & 5 \\
\hline Stearns Bank & 1 & 76 & 0 & 0 \\
\hline Summit Community Bank & 1 & 400 & 0 & 0 \\
\hline Synchrony Bank & 75 & 237 & 0 & 0 \\
\hline TD Bank & 2 & 50 & 2 & 50 \\
\hline Texas Capital Bank & 37 & 177 & 0 & 0 \\
\hline The Huntington National Bank & 31 & 3,665 & 17 & 1,714 \\
\hline United Bank & 12 & 1,341 & 12 & 1,341 \\
\hline US Bank & 32 & 242 & 22 & 183 \\
\hline Wells Fargo Bank & 2 & 370 & 1 & 50 \\
\hline
\end{tabular}

\section{Economic Development Organizations}

Because employment and business development opportunities in the neighborhood are limited, stakeholders are encouraged to work cooperatively with city, county, and regional economic development entities that serve the community and work to attract business and industry to the region. Active development organizations include: The Marion County Chamber of Commerce, Marion Regional Development Corporation, I-79 Development Council, High Technology Foundation, Fairmont Renaissance Corporation, Vandalia 
Heritage Foundation, Vandalia Redevelopment Corporation, the Fairmont Urban Renewal Authority, and Main Street Fairmont. (See Appendix G for contact information.)

Of particular interest is Main Street Fairmont, a non-profit organization fostering economic and community development and improvement in the overall quality of life in historic downtown Fairmont. Accredited through Main Street West Virginia and the National Main Street Center, Main Street Fairmont is volunteer-driven and takes an innovative approach to community and economic development ("Friends of Downtown!" 2012). Main Street Fairmont is working with the Westside Action Coalition to connect the neighborhoods with businesses to revitalize Windmill Park.

\section{Charitable Organizations Working Fairmont, WV}

The organizations listed below have made substantial charitable gifts to Fairmont nonprofit organizations. (See Appendix $\mathrm{H}$ for contact information and areas of giving):

- Raymond Brooks Vanscoy Testamentary Trust

- United Way of Marion County

- Fairmont State Foundation

- Connecting Link

- Fairmont State University

- West Virginia University Foundation

- Sobrania

- Community Foundation of North Central West Virginia

- Moore-Church Scholarship Trust

- Fairmont Senior High School Foundation

- Cub Scout Pack 52 Endowment Fund

- Pricketts Fort Memorial Foundation

- The James Gabriel Family Foundation

- West Virginia High Technology Consortium Foundation

- West Virginia Rescue Ministries

- Literacy Volunteers, Monongalia County

- Marion County Parks and Recreation Commission

- North Central West Virginia Community Action Association

- Pierpont Community and Technical College

- Clark Opportunity Foundation

- Marion County Foundation

- Caritas House

- Robert H. Mollohan Family Charitable Foundation

- Morgantown Housing Authority

- Marion County Board of Education

- Community Foundations: Growing Philanthropy Close to Home

- Education Alliance-Business and Community for Public schools

- Regional and Racial Variation in Health Care Among Medicare Beneficiaries

- George M. Cruise Charitable Funders

- Claud "Bud" Mick, Jr. Education Scholarship Foundation

- Promising Practices: Supporting Transition of Youth Served by the Foster Care System 


\section{References}

Emery, M., Fey, S., \& Flora, C. (2006). Using community capitals to develop assets for positive community change. CD Practice, 13, 1-13.

Infogroup, Inc. (2015). ReferenceUSA database. Retrieved October 19, 2015 from

http://www.referenceusa.com/

U.S. Census Bureau. (2015). American Community Survey, 2009-2013. Table DP03-Selected Economic Characteristics.

Federal Financial Institutions Examination Council. (2015). Community Reinvestment Act, CRA Data Products.

Retrieved November 1, 2015 from https://www.ffiec.gov/cra/craproducts.htm

U.S. Department of Health and Human Services. (2015). Frequently Asked Questions Related to the Poverty Guidelines and Poverty. Retrieved November 1, 2015 from http://aspe.hhs.gov/frequently-askedquestions-related-poverty-guidelines-and-poverty\#differences 


\section{BUILT CAPITAL}

\section{Michelle Sloane and Ashley Morgan}

The built environment shapes and augments the natural environment, providing spaces for both indoor and outdoor activities. Land use and zoning laws, in turn, shape what is allowed in the built environment. This built capital also relies on the physical infrastructure that makes living, working, and recreating possible. This section describes the infrastructure, utilities, roads, and buildings that support the quality of life in the Westside neighborhoods.

\section{Water and Sewer System}

The Water Filtration Plant is located on the Eastside of Fairmont. In 2003 the Water Filtration Plant in the City of Fairmont became one of largest ultrafiltration membrane water treatment plants in the United States, an upgrade that cost $\$ 30$ million (Filtration, 2015). The treatment plant produces between 10-15 million gallons of water each day (ZeeWeed 1000, 2013).

The City also operates a sewer system and wastewater treatment plant that purifies the water released into the Monongahela River; it is located on the Westside of Fairmont on Washington Street. The Fairmont Wastewater Treatment Plant fulfills the goals of water treatment outlined by the state of West Virginia and they has also won awards for excellence (Wastewater, 2015).

\section{Utillities}

The City of Fairmont contracts out utilities to different service providers. First Energy provides electricity. Dominion Hope provides natural gas. Residences have options for phone, Internet, and cable. The primary sources of communications are Frontier and Xfinity, while broadcast options include Dish and Time Warner Cable (Staff, 2015).

\section{Solid Waste Management}

The City of Fairmont has a contract with Republic Services to provide garbage collection for those within the city limits. As a resident of Fairmont you must apply for the garbage collection service by filling out the City Service Application on the Fairmontwv.gov website. There is a $\$ 20$ deposit associated with this service. The deposit is fully reimbursed after one full year of payment (New City, 2015).

The only recycling services that the City offers is a partnership with Wheels for Wishes that benefits the Make-a-Wish Foundation. Wheels for Wishes recycles cars, motorcycles and boats that are not wanted (Recycling, 2015). The Marion County Solid Waste Authority has 10 recycling drop off locations throughout the county. The drop off location nearest to this neighborhood is at the U.S. Post Office, 331 Madison St, which is right down the street from the Fairmont Community Youth Development Center (FCYDC). The Marion County Solid Waste Authority accepts cardboard, newspapers/magazines, plastics designated as \#1 or \#2, aluminum cans and steel cans (Marion County, 2015).

\section{Streets and Circulation}

State Route 250 and Route 19, the two collector routes serving the neighborhoods, are maintained by the state of West Virginia Department of Highways. The remaining neighborhood streets are maintained by the City of Fairmont and are considered to be in good condition (Public Works, 2015). The City of Fairmont charges residents and non-resident employees a street maintenance fee. The Public Works Department cares 
for the streets by sweeping, patching, paving, removing snow and ice, and repairing and maintaining street signs and traffic lights (Street Paving and Maintenance, 2015). The department sweeps each street twice a month beginning in the spring and ending in late fall (Street Sweeping, 2015).

The City of Fairmont has three main bridges over the Monongahela River, which collectively serve 23,000 vehicles each day (Comprehensive Plan, 2000). Downtown Fairmont is considered to have traffic circulation and congestion problems (Comprehensive Plan, 2000). However, this assessment was made when the Gateway Connector to I-79 was under construction. A major goal of this project was to help the flow of traffic in the downtown area by creating alternate routes into downtown but also to I-79.

The City of Fairmont operates the Fairmont Municipal Airport-Frankman Field, which mainly serves as a local cargo, flight instruction, and small air hangar facility. It is located three miles south of the city (Fairmont Comprehensive Plan, 2005). Two other airports are located near Fairmont: North-Central West Virginia Airport in Bridgeport and Morgantown Municipal Airport, which serve major airlines and handle most regional passenger and cargo services, connecting the area to Charleston, WV and Washington, DC (Fairmont Comprehensive Plan, 2005; North-Central West Virginia Airport, 2015).

\section{Zoning and Land Use}

Zoning ordinances are the laws that designate allowed land uses on specific properties. The Westside neighborhoods include six zoning districts, according to Fairmont's Zoning map (2015): General Residential, Neighborhood Residential, Recreation, Main Corridor Commercial, a slice of City Center, and a sliver of Industrial running alongside the Monongahela River. Figure $\mathbf{3 6}$ shows this section of the zoning map. The Main Corridor Commercial zone "provides for the sale of general merchandise and limited office employment" (City of Fairmont Planning and Zoning Code, 2015). In the Westside neighborhoods it is found along part of Highway 19 as well as a swath of land between Washington Street and the Monongahela River.

The conditional use of essential services, home occupations, childcare services, and bed and breakfast inns are permitted within Neighborhood Residential, and General Residential also permits some of these services. These allowances, coupled with the observation of apparently vacant buildings from our neighborhood tour, indicate opportunities for entrepreneurial activities and a potential for business growth in the neighborhood. Indeed, some residents in the Westside neighborhoods own cottage businesses. Home-based businesses include day care services, beauty services, lawn care, and candy stores. However, according to Westside neighbors, City zoning changes in the early 1990s might have had an impact on the commercial landscape (Jones, 2015). 

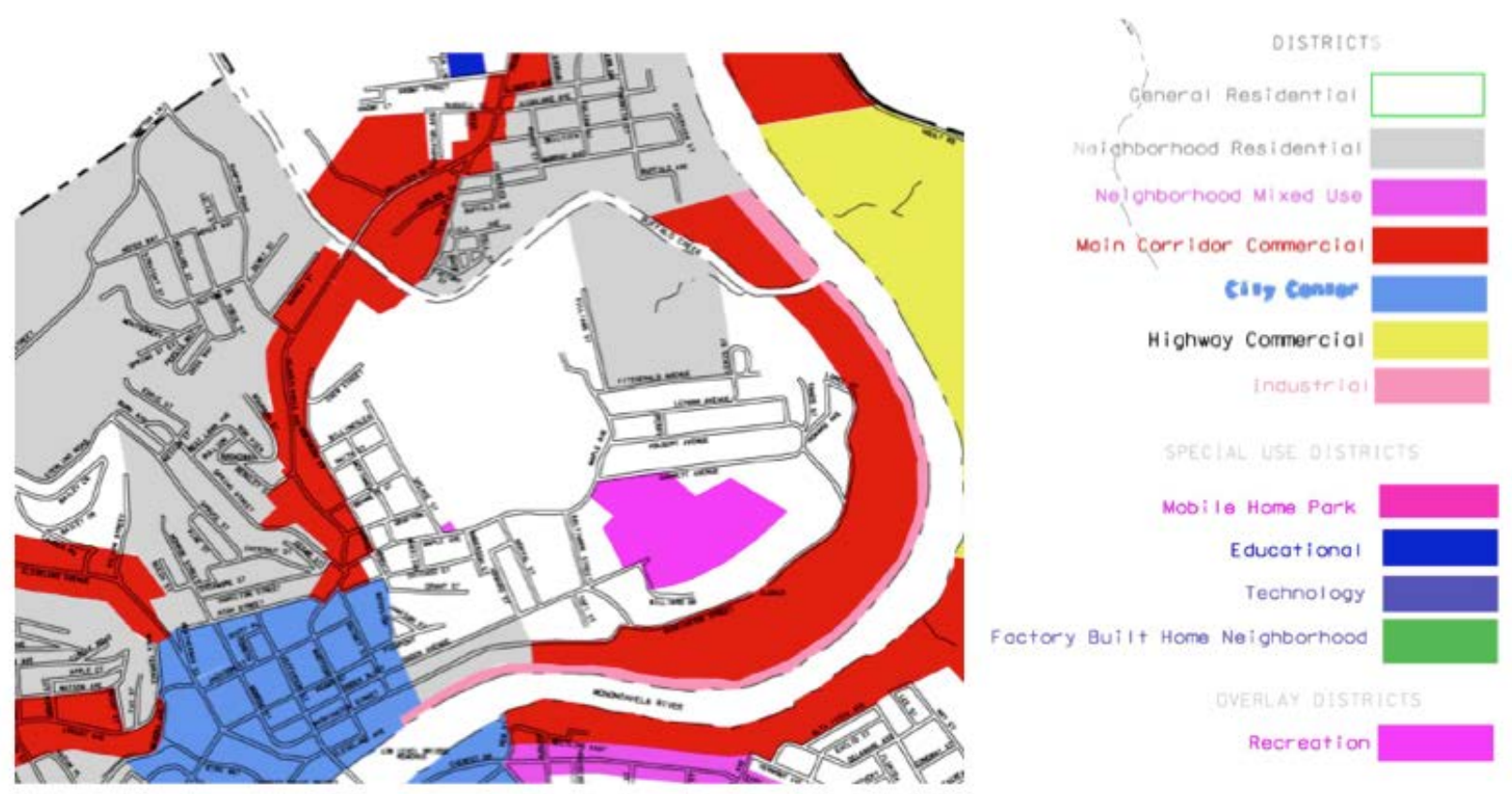

FIGURE 36: FAIRMONT ZONING MAP AND KEY (EXCERPT). SOURCE: PLANNING AND ZONING CODE (2015).

\section{Basic Goods and Service Businesses}

In addition to employment, businesses provide for the basic goods and services needed by a community. Basic goods and service businesses are those that meet resident needs for typical daily, monthly, and annual activities. Fairmont has a mix of restaurants, both fast food chains and local establishments and a few grocery stores, however these are clustered in certain neighborhoods and there is a dearth in the Westside neighborhoods. Based on discussions with community members, several businesses in the neighborhood have shuttered over the past decade, or have relocated within the city, resulting in decreased accessibility for these residents.

\section{Goods}

In terms of basic necessities, Fairmont residents have sufficient access to food, although choices are limited. There are a few big box discount retail and grocery options, such as two Shop 'N Saves, two Save-A-Lots, a Food Lion, a Dollar General, and several convenience stores. The only grocery located near the Westside Coalition neighborhoods is one of the Save-A-Lots, but it is located across Buffalo Creek in the Bellview neighborhood. There is also a Walmart and a third Shop 'N Save located at the border of South Fairmont, in Whitehall, WV by the relatively empty Middletown Mall. There are no grocery options within reasonable walking distance.

Alternative food options include a natural foods and organic produce store downtown called All Things Herbal and a weekly farmer's market on Tuesday afternoons at Veteran's Square, also located downtown. There is a community garden off Oliver Avenue, whose mission is to "educate and promote local healthy food options in our area" (Community Garden, 2015). While it is not located in the Westside neighborhood, the garden is open to all residents of Fairmont. 
As for pharmaceutical needs, according to community members, the CVS used to be located within the Westside neighborhoods but has since relocated to the other side of downtown, where there is also a RiteAid. Another RiteAid is located on the east side of the city.

Options are few in terms of clothing; there is a bridal shop and a consignment store in the downtown area and there is the Walmart in Whitehall. The quality of these basics is of great concern to the possible retention and recruitment of outside talent and individuals. Young professionals and residents of any age must travel to Morgantown or Clarksburg for a wider and higher quality selection.

\section{Services}

Other basic services are provided in town. In terms of beauty and hair care, residents have access to approximately 30 beauty salons, which include services for hair styling, nails, and tanning, however many women in the neighborhood also go to unofficial stylists nearby for hair services. There are six barbershops within city limits, however searches via Yelp, Google Maps, and Yellow Pages result in zero services of this type located in the Westside neighborhoods. Most of the men go to Arthur's Barber Shop on the east side. Fairmont has eight laundry facilities; the closest to the community is in Bellview.

\section{Medical Services}

For medical services, residents of Fairmont can turn to Fairmont General Hospital, which is adjacent to Fairmont State University's campus. Additionally, there is a MedExpress urgent care clinic in the VirginiaGaston neighborhood south of downtown, and the Fairmont Clinic across the river on the east side. The MedExpress is located about a mile from the Westside neighborhoods and the hospital is located 1.5 miles to the west along Locust Avenue.

There are a few assisted living centers in the city, such as Helping Hands Home Health, which is located in the Westside neighborhoods. Two homes providing affordable living for seniors are located in the neighborhood, and the Fairmont-Morgantown Housing Authority recently announced that it will also be converting the historic Miller School into senior housing, however this is not necessarily a welcome addition to the neighborhoods, as gauged by reactions to the news by the community members who would like to see more services geared toward younger people.

\section{Professional Services}

Fairmont has approximately ten traditional banks and four credit unions, including Mountain Valley Bank, First Exchange Bank, Huntington Bank, BCBank, WesBanco, BB\&T, First Exchange Bank, Woodforest National Bank, and the Fairmont Federal Credit Union. These are widespread throughout Fairmont and the surrounding areas. The only one located in the Westside neighborhoods is a Fairmont Federal Credit Union, which is one of the fastest growing local credit unions in the state of West Virginia (Fairmont Federal Credit Union, 2015). The mix of local and national banks helps keep the small town character while allowing residents from outside the area to have access to national banking systems. The wide range of banks and credit unions shows that the economy is flourishing.

Fairmont has more than 15 law offices that specialize in a range of law services. Insurance agents include Mountaineer Insurance Group, State Farm Insurance, and Nationwide Insurance, along with others that provide all types of insurance services. 


\section{Entertainment}

Fairmont has a few restaurants, and a few are well known throughout the region, such as Muriale's, Poky Dot, Colasessano's, and Country Club Bakery. Indeed, the city is known for originating the pepperoni roll. There are two Mexican restaurants, while the rest offer American or Italian American fare. The downtown area features the newest offerings, such as the trendy coffee shop Joe ' $n$ Throw, and at least two are in process of opening in the South Side district. Aside from Colasessano's and a Subway, however, in speaking with the Westside Coalition members, we learned that there are little to no dining options within their neighborhood, leaving much to be desired.

\section{Accommodations/Hotels}

Fairmont has eight hotels and motels for those visiting the area. Visitors have the option to stay at a Days Inn, Red Roof Inn, Microtel Inn, Fairfield Inn and Suites, Super 8, Quality Inn, the Inn at Pettyjohn, and Clarion Inn. Having a variety of accommodations in Fairmont indicates that the community is a regional destination.

\section{Housing Characteristics}

The majority of the Westside neighborhoods are zoned for either General Residential or Neighborhood Residential, with the main commercial, industrial, and mixed uses at the peripheries of the neighborhoods (see Figure 36). While touring the neighborhood, we noticed several vacant or dilapidated buildings, mostly in Shadyside, Sterling Heights, and along Ogden Avenue.

\section{Number and Type of Units}

Fairmont offers a variety of housing options. There are older, larger homes, smaller residences, multifamily housing units, and mobile home parks. There are 8,930 housing units in Fairmont and 943 units in Census Tract 205. Table 5 shows the breakdown of housing types comparing Census Tract 205 and Fairmont overall. Some of the multi-unit apartments are facilities for seniors offering various levels of assistance and health care. There are marked differences in the breakdown of unit types when comparing to Fairmont as a whole. While the percentage of one-unit homes, whether attached or detached, matches that of Fairmont overall, there are half as many multi-unit housing structures in Census Tract 205 than in Fairmont, and there are seven times as many mobile homes.

TABLE 5: TYPE OF HOUSING UNITS. SOURCE: U.S. CENSUS BUREAU (2013).

\begin{tabular}{|c|c|c|}
\hline Units in Structure / Type & Census Tract 205 & City of Fairmont \\
\hline 1-unit, detached & $73.5 \%$ & $75.2 \%$ \\
\hline 1 -unit, attached & $1.5 \%$ & $1.4 \%$ \\
\hline 2 or more units & $10.7 \%$ & $21.4 \%$ \\
\hline Mobile homes & $14.3 \%$ & $2.0 \%$ \\
\hline
\end{tabular}

\section{Vacancy Rates}

Of the total housing units in Fairmont, 13.9\% are vacant. Census Tract 205 has a much higher rate, as 20.9\% of units in this neighborhood are vacant. 


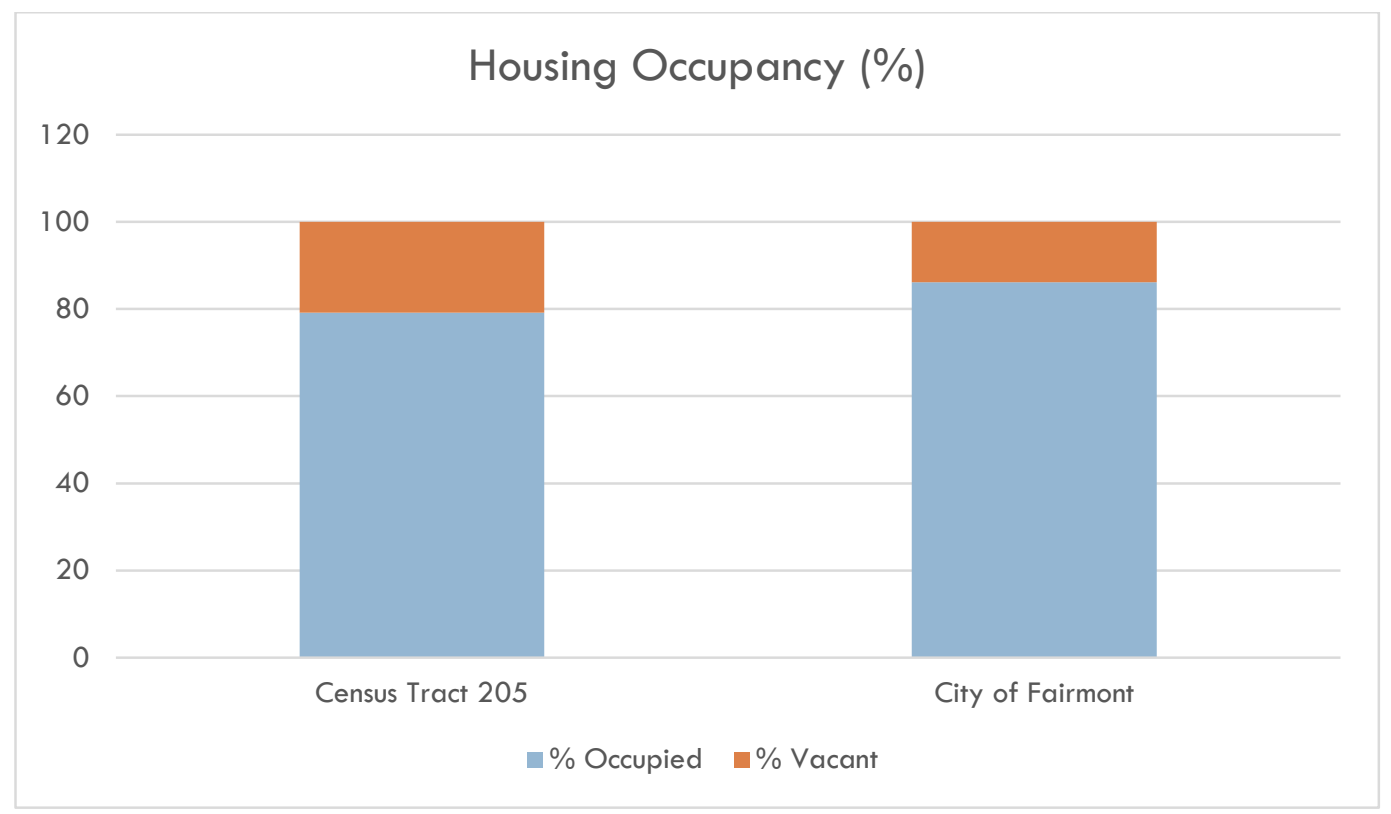

FIGURE 37: OCCUPANCY FOR CENSUS TRACT 205 AND FAIRMONT OVERALL. SOURCE: U.S. CENSUS BUREAU (2013).

\section{Ownership Rates}

The majority of residents in Census Tract 205 own their homes, with $27.9 \%$ of households renting their homes. In fact, home ownership is higher in these neighborhoods than in Fairmont overall: $72.1 \%$ as compared to $67.5 \%$.

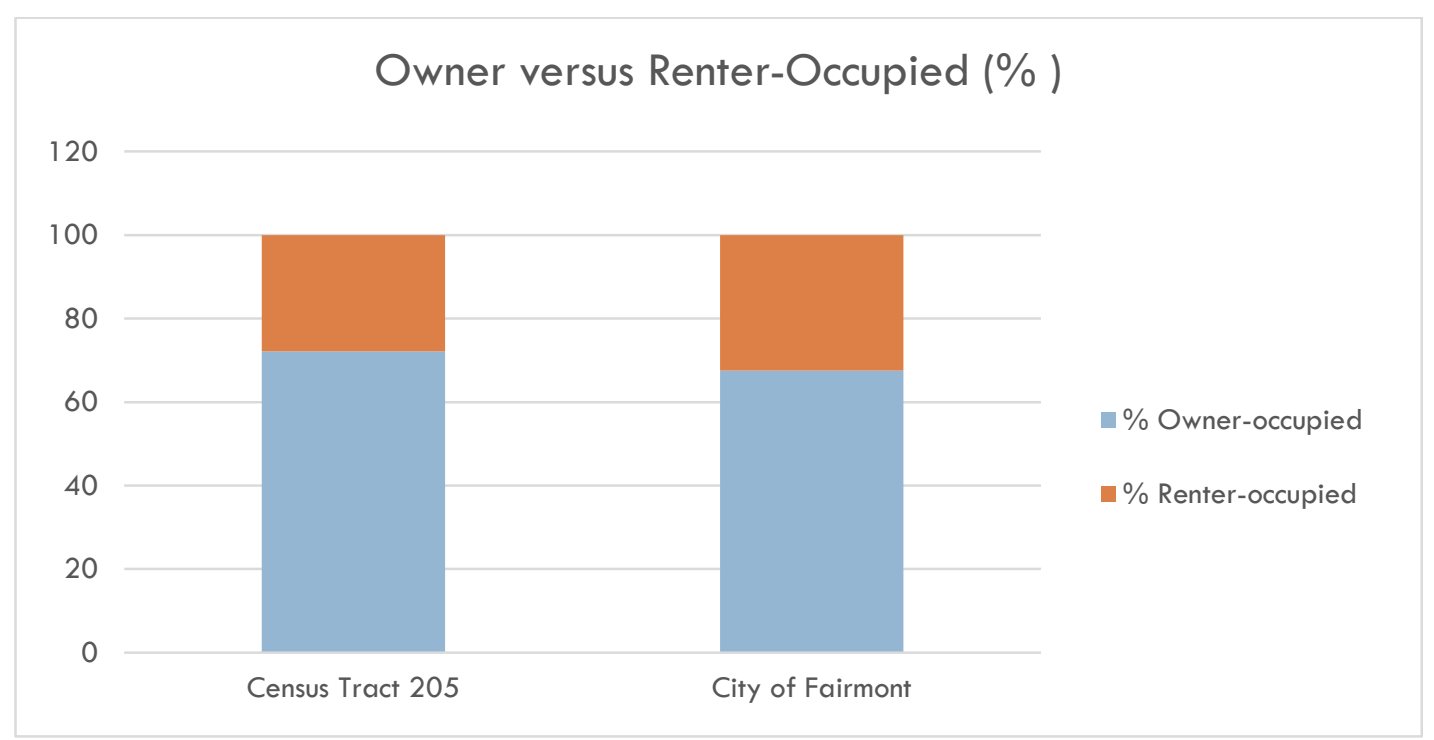

FIGURE 38: RENTAL AND OWNERSHIP RATES FOR CENSUS TRACT 205 AND FAIRMONT OVERALL. SOURCE: U.S. CENSUS BUREAU (2013).

\section{Price and Affordability}

As shown in Figure 39, the largest group of home values in Census Tract 205 falls between a value of $\$ 50,000$ to $\$ 99,000$ which is similar for Fairmont overall, however Fairmont's next largest group of homes are valued between $\$ 100,000$ and $\$ 199,999$ while the next largest group for Census Tract 205 is for homes 
valued at less than $\$ 50,000$. Fairmont as a whole also has a larger percent of homes valued in the two highest brackets (U.S. Census Bureau, 2013). It is clear that Census Tract 205 is less affluent than the rest of Fairmont overall.

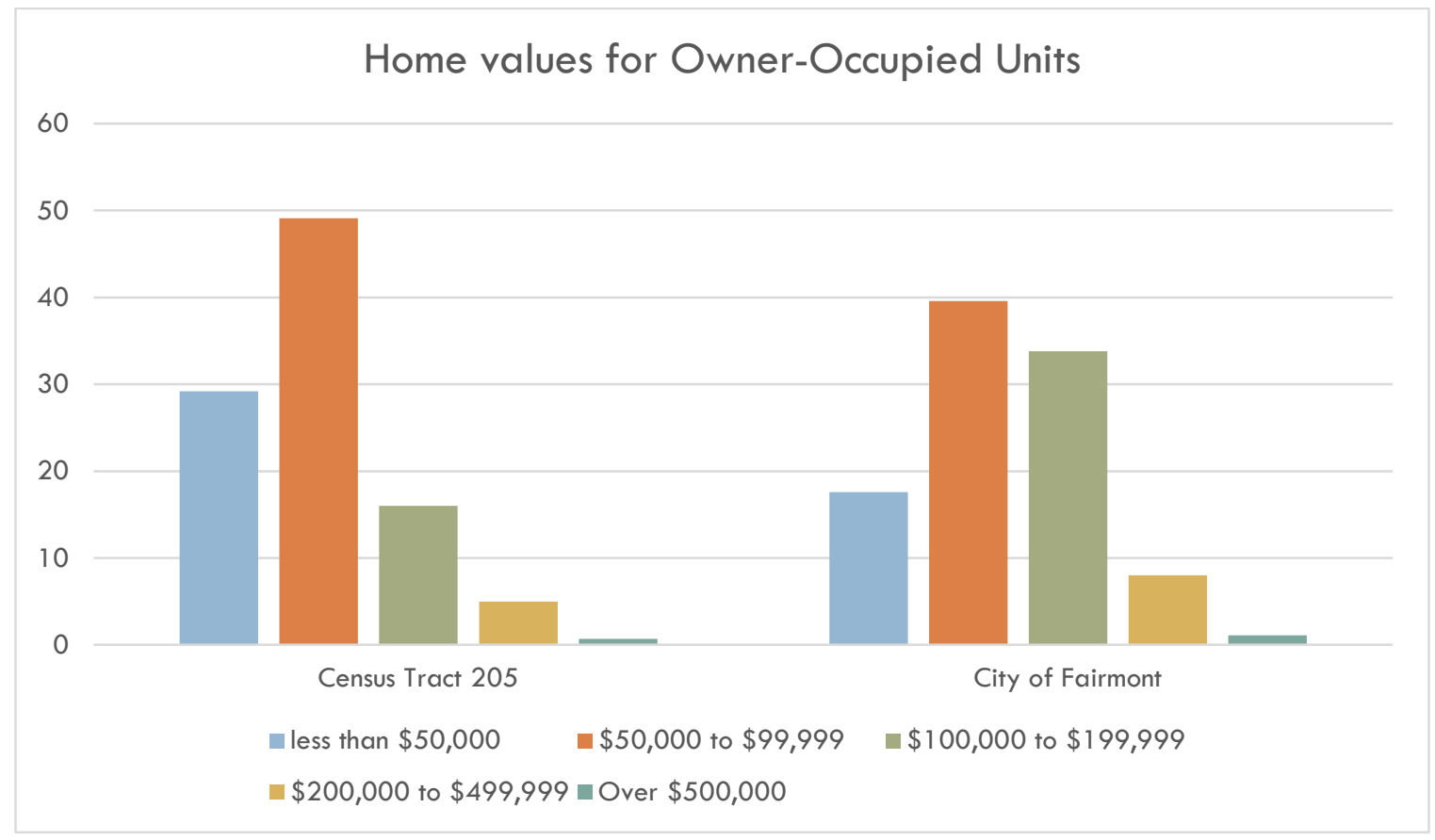

FIGURE 39: HOME VALUES FOR OWNER-OCCUPIED UNITS. SOURCE: U.S. CENSUS BUREAU (2013).

While a lower cost bracket of housing values might seem indicate more affordability, a closer look at how much residents are spending on housing offers another picture. According to the U.S. Department of Housing and Urban Development (HUD), "families who pay over 30 percent of their income for housing are considered cost burdened and may have difficulty affording necessities such as food, clothing, transportation, and medical care" (HUD, 2015). Of the housing units with a mortgage in the Westside neighborhoods, over a third of owners pay $30 \%$ or more of household income toward housing costs in Tract 205, while in Fairmont overall, significantly fewer homeowners spend this much of their income on housing as illustrated in Table 6 (U.S. Census Bureau, 2013). Similarly, although median gross monthly rent for Census Tract 205 is estimated at $\$ 582$ as compared to the median mortgage payment of $\$ 864$, for those who rent, a large majority spends $30 \%$ or more of their income on rent. As nearly a third of Tract 205 are renters and the majority spends over $30 \%$ on housing, it is apparent that neighborhood residents bear this burden and will have trouble being able to afford other necessities.

TABLE 6: MONTHLY HOUSING COSTS AS A PERCENT OF HOUSEHOLD INCOME. SOURCE: U.S. CENSUS BUREAU (2013).

\begin{tabular}{|l|c|c|}
\hline $\begin{array}{c}\text { Those who spend } \mathbf{3 0} \% \text { or more of } \\
\text { income on housing costs }\end{array}$ & Census Tract 205 & City of Fairmont \\
\hline Mortgage-paying homeowners & $39.4 \%$ & $20.1 \%$ \\
\hline Renters & $73.5 \%$ & $61.0 \%$ \\
\hline
\end{tabular}




\section{Building Age}

As shown in Figure 40, nearly a third of the homes in Tract 205 were constructed before 1940, which matches Fairmont overall. This is likely due to the city's history as an industrial town, which peaked in the mid-1 $9^{\text {th }}$ century (Comprehensive Plan, 2000). While the Westside neighborhoods do not boast the oldest and newest buildings in the inventory, the oldest property identified in this neighborhood was built in 1890 and the newest was built in 1953. The average age of the properties for which this information was available was 101 years, which is consistent with Fairmont overall.

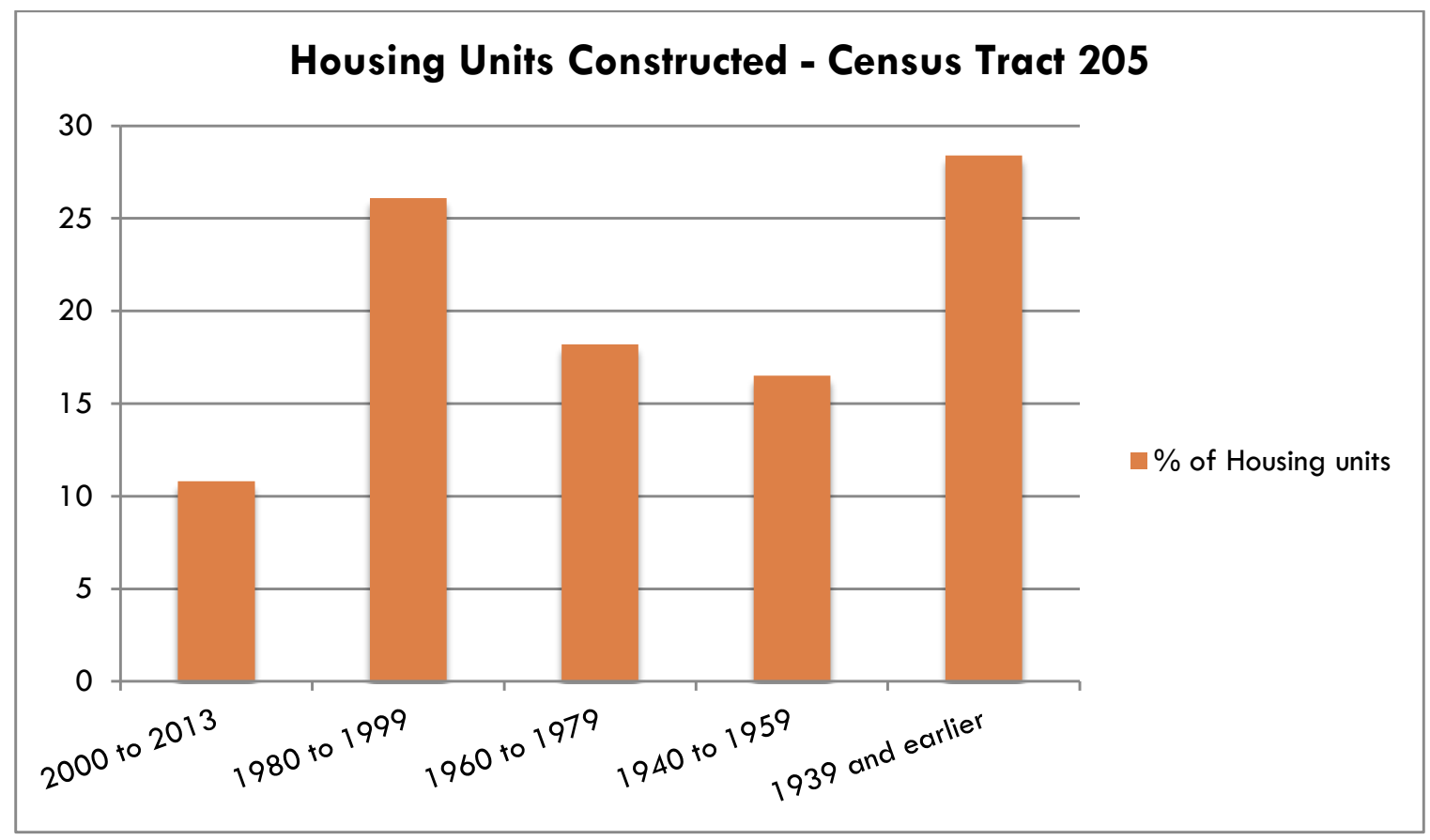

FIGURE 40: YEAR OF HOUSES BUILT IN CENSUS TRACT 205. SOURCE: U.S. CENSUS BUREAU (2013).

\section{Building Condition}

Fairmont has numerous abandoned and dilapidated buildings. In 2014, a group of concerned Fairmont citizens formed the BAD (Brownfield, Abandoned, Dilapidated) Buildings team to address problem properties. Volunteers conducted a community-wide property survey to identify, research, and develop a priority action plan for the properties. A total of 337 properties are listed in the inventory, $73.3 \%$ of which are residential. Of these, $88.7 \%$ are single-family units. Fifty-one percent of the total were indicated vacant, while $10.1 \%$ were occupied. The remainder (39.2\%) was unknown, however a majority $(56.4 \%)$ had vacancy indicators listed: posted notice, boarded up, yard neglect, excess mail, for sale sign, missing structure, burnt or deteriorated, vandalized, or other (BAD Buildings, 2014).

A total of $19.6 \%$ of these properties are in the Westside neighborhoods, second only to the Eastside Norwood neighborhood. Figure 41 shows a comparison of BAD Buildings across neighborhoods. Of the Westside properties, $66.7 \%$ were single-family homes, $10.6 \%$ were duplexes, and one was a multifamily home, while $21.2 \%$ were listed as unknown. Thirty-six percent of the Westside properties in the inventory were identified as vacant, however the rest were unknown, and none were listed as occupied. In this inventory, Jackson Addition/Spring includes the buildings found in the Westside neighborhoods. 


\section{Number of BAD Buildings by Neighborhood}

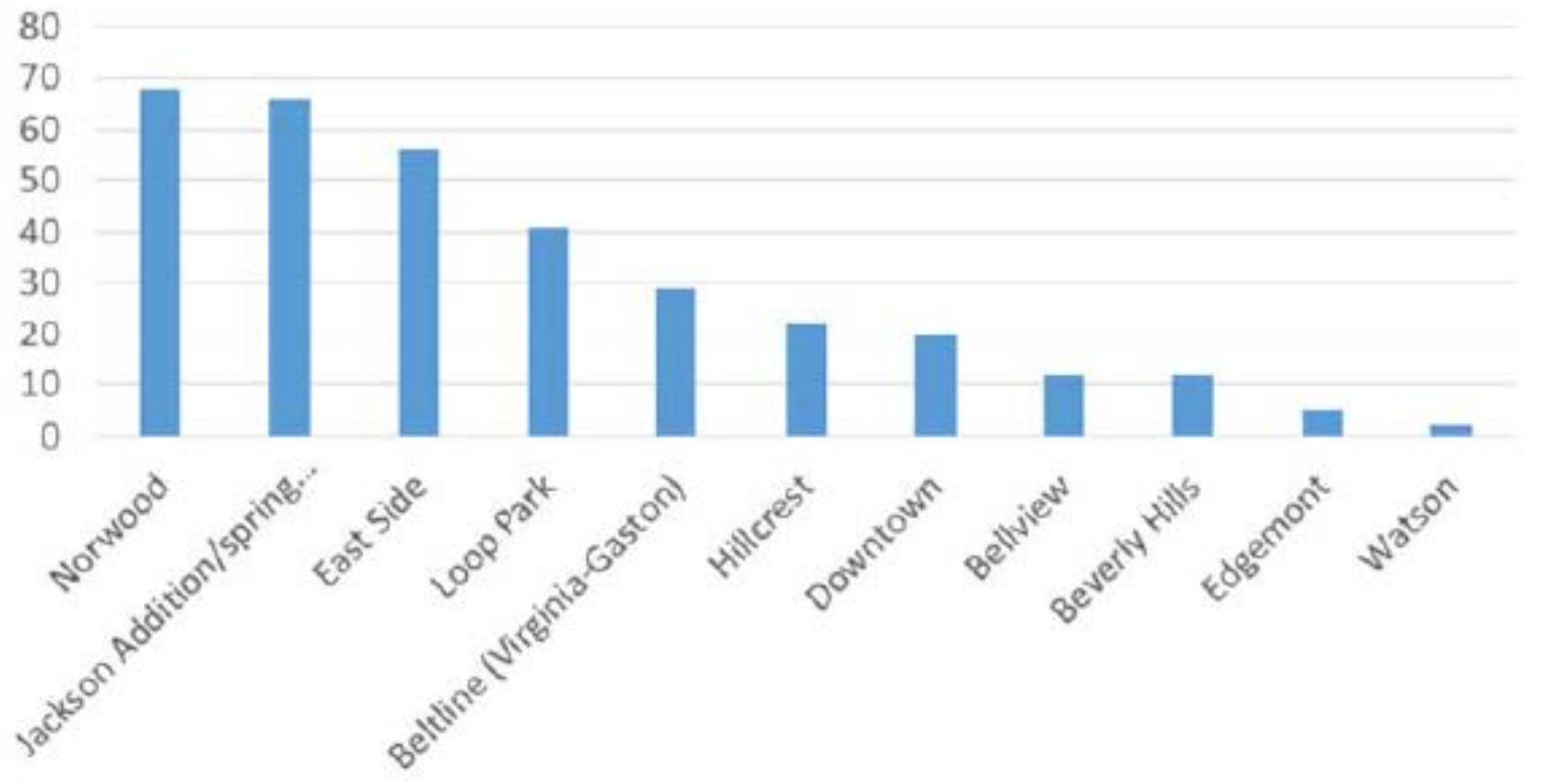

FIGURE 41: ABANDONED/DILAPIDATED BUILDINGS BY NEIGHBORHOOD. SOURCE: NBAC (2015).

Regarding property condition, as illustrated in Figure 42, 9.1\% were deemed good or fair, $16.7 \%$ were deemed poor, and $40.9 \%$ were deemed appropriate for demolition. Since the survey was completed, a few properties from this neighborhood have been purchased and rehabilitated.

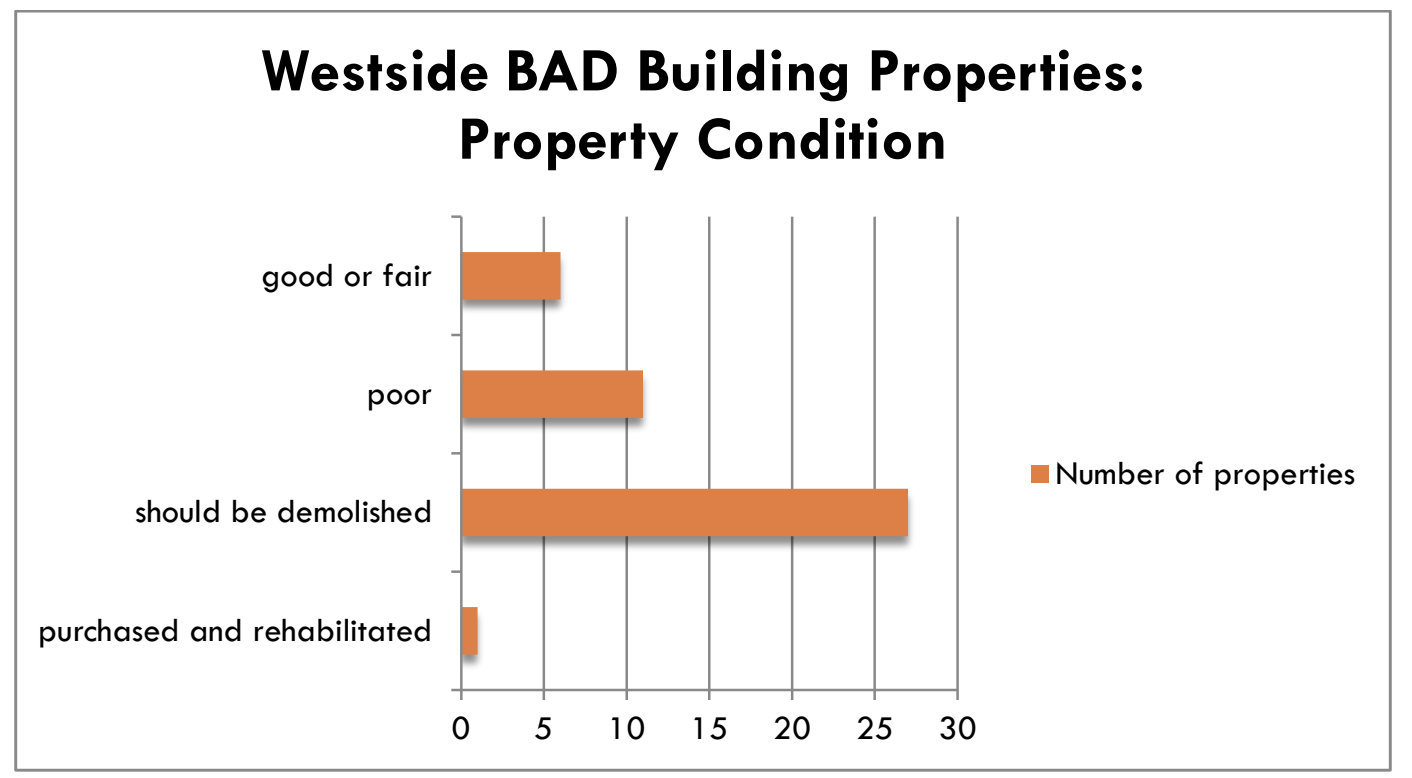

FIGURE 42: PROPERTY CONDITION OF BUILDINGS IN THE WESTSIDE NEIGHBORHOODS BASED ON A VOLUNTEER SURVEY. SOURCE: BAD BUILDINGS (2014). 
The Fairmont BAD Buildings team discovered that certain areas within neighborhoods contained concentrations of blight. In the Westside neighborhoods, Ogden Avenue had the most properties in the inventory (16.7\%); followed by Spruce Street (9.1\%); and Pennsylvania Avenue, Robinson Street, and Spring Street which each accounted for $7.6 \%$ of the neighborhood properties. The map in Figure 43 shows the BAD Buildings properties in the Westside neighborhoods.

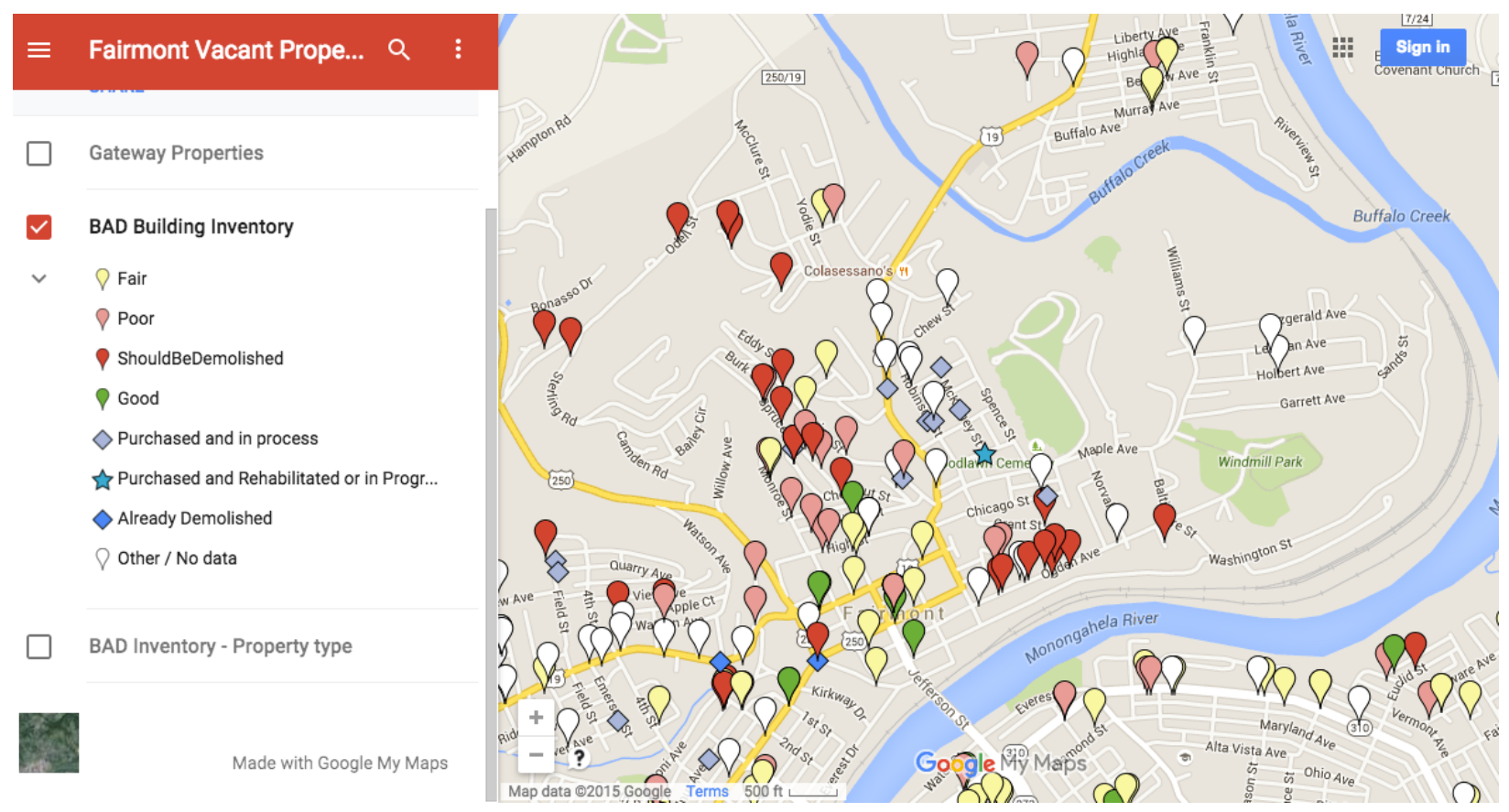

FIGURE 43: FAIRMONT BAD BUILDINGS INVENTORY MAP (EXCERPT). SOURCE: NBAC (2015).

\section{Basic Housing Utilities}

As shown in Figure 44, it is also striking that according to U.S. Census figures, as compared to housing units in Fairmont overall, a higher percentage of houses in Tract 205 were lacking in basic housing utilities such as plumbing or telephone service (U.S. Census Bureau, 2013). 


\section{Basic Housing Utilities}

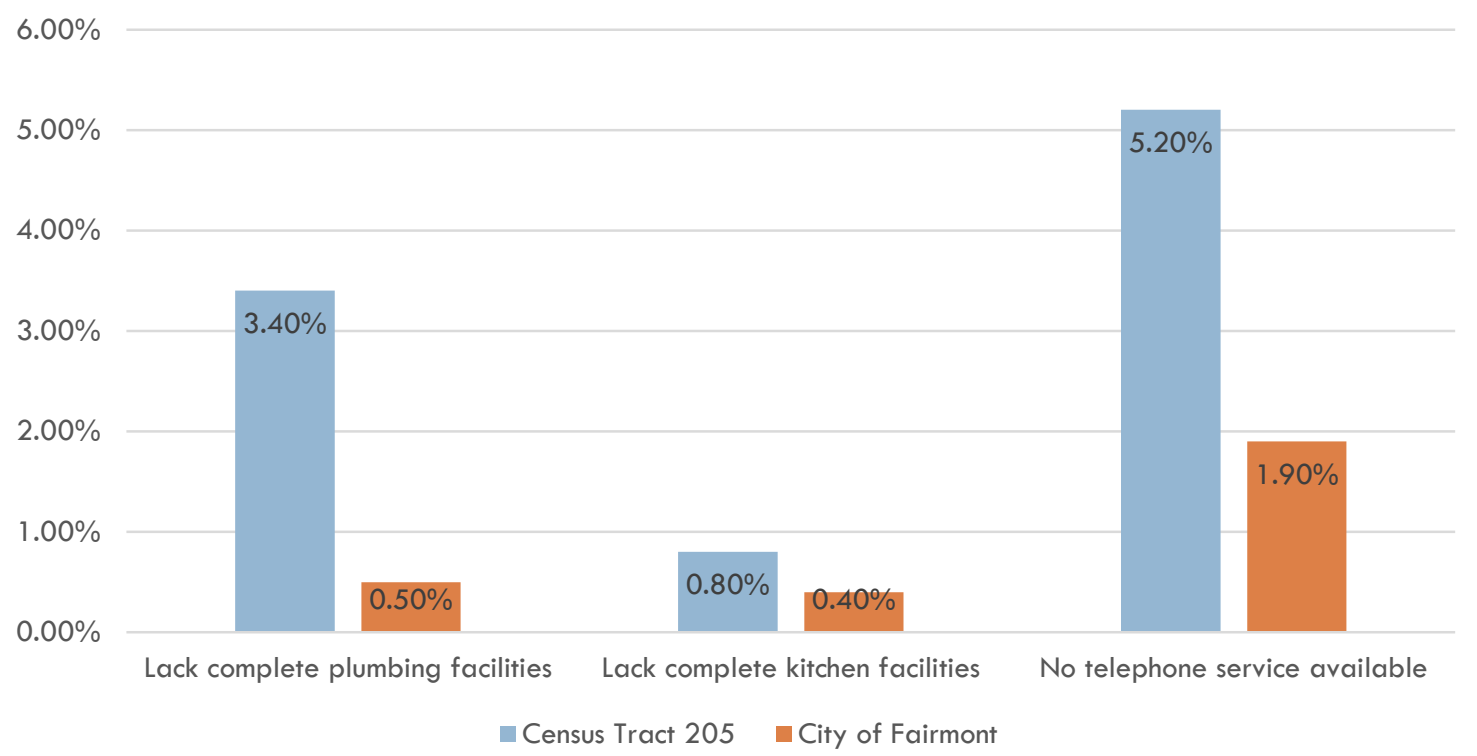

FIGURE 44: HOMES LACKING BASIC UTILITIES. SOURCE: U.S. CENSUS BUREAU (2013).

\section{Recreationall Facilities}

Fairmont has nine parks within the city limits. These parks include the $5^{\text {th }}$ Street Park, Bellview Park, the Gateway Connector Park, Morgantown Avenue Park, Morris Park, Norwood Park, Palatine Park, Veterans Square and Windmill Park (Facilities, 2015). Park amenities include basketball courts, picnic tables and shelters, playgrounds, bike trails, tennis courts, disc golf courses, concession stands, fields, and a boatlaunching ramp in Palatine Park. There are also County and State parks within the area that offer activities such as whitewater rafting, trails, and historical drama.

The Westside neighborhoods' Windmill Park has a lot of meaning and value to the community, and the Fairmont Community Youth Development Center (FCYDC) supports youth baseball and football leagues that use the fields. FCYDC currently operates the concession stand during games in order to raise funds for programs.

However, the park and its facilities suffer from disinvestment in comparison to other City parks. The 2012 Park and Recreation Master Plan, adopted into the Comprehensive Plan in February 2014 was developed through a process that included workshops for children held at the parks across the city (Park and Recreation Master Plan, 2012; Comprehensive Plan, 2000). The importance of Windmill Park to the neighborhoods surrounding the park is noted. Children stated that they liked the merry-go-round, slide, monkey bars and swings. The children disliked the older equipment, the smaller size of the playground, the lack of seating, and the itchy grass. To generate increased revenue for improvements and better maintenance, the City's recommendations for Windmill Park are to: Create a user fee for leagues and others that use the facilities, the City should operate the concession stand, obtain sponsorship from local businesses for maintaining the fields, and form a shelter rental policy (Park and Recreation Master Plan, 2014). 


\section{PARKS AND RECREATION SURVEY}

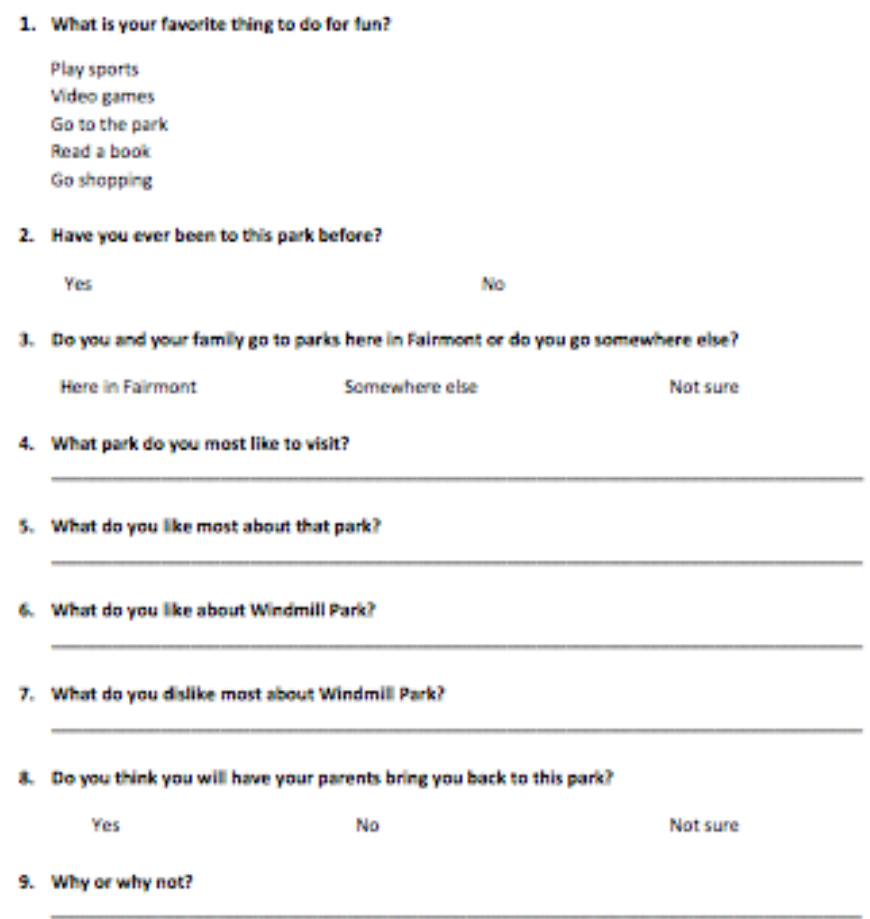

FIGURE 45: PARKS AND RECREATION SURVEY. SOURCE: PARKS AND RECREATION MASTER PLAN (2014).

In addition to parks, the City of Fairmont is expanding recreational trails throughout the community, including one connecting downtown Fairmont and Windmill Park. The Connectivity Plan for the City of Fairmont was created in June of 2014 (Main Street Fairmont, 2014). This plan focuses on creating a healthy environment, a safer environment for pedestrians, and increasing the availability of trails throughout the city. This would increase economic value of this area as well as improve access via alternative modes of transportation. A Health Impact Assessment conducted by the School of Public Health at West Virginia University considered the potential effect of implementing the Connectivity Plan, however, the report stated that there was a lack of response from the residents of Westside neighborhood (Abildso, Bias, Coffman \& Vasile, 2014). 


\section{References}

Abildso, C., Bias T., Coffman, J. \& Vasile, E. (2014). Fairmont Connectivity Plan Rapid Health Impact Assessment. West Virginia University School of Public Health - Health Research Center. Retrieved from: http://www.fairmontwv.gov/DocumentCenter/Home/View/1307

Affordable Housing. (2015). U.S. Department of Housing and Urban Development. Retrieved on October 16, 2015 from: http://portal.hud.gov/hudportal/HUD?src=/program offices/comm planning/affordablehousing/

BAD Buildings Team. (2014). BAD Buildings Inventory. Fairmont, WV: City of Fairmont.

City Code. (2015). Fairmont, WV: City of Fairmont. Retrieved from: http://whdrane.conwaygreene.com/NXT/gateway.dll? $f=$ templates\&fn=default.htm\& vid=whdrane:W VFairmont

Community Garden. (2015). Facebook. Fairmont, WV: Fairmont Community Garden. Retrieved from: https://www.facebook.com/FairmontCommunityGarden/info/?tab=page info

Comprehensive Plan. (2000). Fairmont, WV: City of Fairmont. Retrieved from: http://www.fairmontwv.gov/158/Comprehensive-Plan

Facilities. (2015). Fairmont, WV: City of Fairmont. Retrieved from: http://fairmontwv.gov/Facilities? clear=False

Fairmont Community Youth Development Center (Personal Communication, October 5, 2015).

Fairmont FCU. (2015). Fairmont, WV: Fairmont Federal Credit Union. Retrieved from: https://www.fairmontfcu.com/

Filtration. (2015). Fairmont, WV: City of Fairmont. Retrieved on October 16, 2015 from: http://www.fairmontwv.gov/167/Filtration-Plant

FMHA. (2015). Development of the Miller School - Fairmont, WV [Press release]. Fairmont, WV: FairmontMorgantown Housing Authority. Retrieved from: http://www. fmhousing.com/news detail T2 R6.php

Frankman Field. (2015). Fairmont, WV: Fairmont Municipal Airport-Frankman Field. Retrieved from: http://www.airnav.com/airport/4g7

Jones, C. (2015). Personal communication, September 26.

Main Street Fairmont. (2014). Fairmont, WV Connectivity Plan: Connecting Today to Tomorrow. Fairmont, WV: Main Street Fairmont. Retrieved from: http://www.fairmontwv.gov/DocumentCenter/Home/View/1306

Marion County Solid Waste Authority. (2015). Retrieved on October 16, 2015 from: http://marioncoswa.org/

NBAC. (2015). Fairmont BAD Buildings Inventory Executive Summary. Morgantown, WV: Northern West Virginia Brownfields Assistance Center. 
New City Service Customers. (2015). Fairmont, WV: City of Fairmont. Retrieved on October 16, 2015 from: http://fairmontwv.gov/295/New-City-Service-Customers

North-Central West Virginia Airport. (2015). Retrieved from: http://www.flyckb.com/

Park and Recreation Master Plan. (2012). Fairmont, WV: City of Fairmont. Retrieved October 16, 2015 from: http://www.fairmontwv.gov/DocumentCenter/Home/View/1308

Planning and Zoning Code. (2015). Fairmont, WV: City of Fairmont. Retrieved October 16, 2015 from: http://www.fairmontwv.gov/DocumentCenter/View/1450

Public Works. (2015). Fairmont, WV: City of Fairmont. Retrieved October 16, 2015 from: http://fairmontwv.gov/258/Public-Works

Recycling and Waste Management. (2015). Fairmont, WV: City of Fairmont. Retrieved on October 16, 2015 from: http://www.fairmontwv.gov/395/Recycling-and-Waste-Management

Staff. (2015). Personal Communication, September 26. Fairmont, WV: City of Fairmont.

Street Paving and Maintenance. (2015). Fairmont, WV: City of Fairmont. Retrieved on October 16, 2015 from: http://www.fairmontwv.gov/308/Street-Paving-Maintenance

Street Sweeping. (2015). Fairmont, WV: City of Fairmont. Retrieved on October 16, 2015 from: http://www.fairmontwv.gov/400/Street-Sweeping

Talotta, L. (2015, Oct 5) Nonprofits Seek State Funding for Old Miller School Renovation Project in Fairmont. WBOY News. Retrieved October 16, 2015 from: http://www.wboy.com/story/28575313/nonprofits-seek-state-funding-for-old-miller-schoolrenovation-project-in-fairmont.

Thomas C. Miller Public School. (2013). National Register of Historic Places Registration Form. Washington, D.C.: National Park Service, U.S. Department of the Interior. Retrieved October 16, 2015 from: http://www.nps.gov/nr/feature/places/pdfs/13000263.pdf

U.S. Census Bureau. (2013). American Fact Finder. Retrieved October 16, 2015 from: http://factfinder.census.gov/faces/tableservices/isf/pages/productview.xhtml?pid=ACS 13 5YR DP 04\&prodType=table.

Wastewater. (2015). Fairmont, WV: City of Fairmont. Retrieved on October 16, 2015 from: http://www.fairmontwv.gov/171/Wastewater

ZeeWeed 1000 Features. (2013). GE Water \& Process Technologies. Retrieved on October 16, 2015 from: http://www.gewater.com/products/zeeweed-1000-membrane.html 


\section{APPENDIX A: SCHOOLS SERVING THE WESTSIDE NEIGHBORHOODS}

Watson Elementary School

1579 Mary Lou Retton Drive, Fairmont, WV 26554

304-367-2156

Grades: Pre-K through $4^{\text {th }}$ grade

Total Students: 429

Total Teachers: 29

Student/Teacher Ratio: 14.79

Title I School: YES

WVAI Designation: Success

\section{West Fairmont Middle School}

110 10th Street, Fairmont, WV 26554

304.366.5631

Grades: 5-8

Total Students: 662

Total Teachers: 45

Student/Teacher Ratio - 14.71

Title I school: NO

WVAI Designation: Transition

\section{Fairmont Senior High School}

1 Loop Park Drive

Fairmont, WV 26554-2599

304.367.2150

Grades: 9-12

Total Students: 732

Total Teachers: 42.5

Student/Teacher Ratio: 17.22

Title I School: NO

WVAI Designation: Support 


\section{APPENDIX B: GOVERNMENT CONTACT INFORMATION}

\section{U.S. Senator Joseph Manchin III}

306 Hart Senate Office Building

Washington DC, 20510

Phone: 202-224-3954

Fax: 202-228-0002

230 Adams Street

Fairmont, WV 26554

Phone: 304-368-0567

Fax: 304-368-0198

\section{U.S. Senator Shelley Moore Capito}

172 Russell Senate Office Building

Washington, DC 20510

Phone: 202-224-6472

\section{U.S. Congressman David McKinley}

412 Cannon HOB

Washington, DC 20515

Phone: (202) 225-4172

Fax: (202) 225-7564

WV Senator Roman Prezioso

Capitol Office:

Room 223W, Building 1

State Capitol Complex

Charleston, WV 25305

Capitol Phone: (304) 357-7961

Home:

1806 Dogwood Drive

Fairmont, WV, 26554

Home Phone: (304) 366-5308

roman.prezioso@wvsenate.gov

\section{WV Senator Robert Beach}

Capitol Office:

Room 204W, Building 1

State Capitol Complex

Charleston, WV 25305

Capitol Phone: (304) 357-7919 
Home:

P.O. Box 1620

Morgantown, WV, 26501

Home Phone: (304) 932-7170

bob.beach@wvsenate.gov

WV Delegate Linda Longstreth

Capitol Office:

Room 6U-A, Building 1

State Capitol Complex

Charleston, WV 25305

Capitol Phone: (304) 340-31 24

Home:

804 Ohio Avenue

Fairmont, WV, 26554

Home Phone: (304) 366-5251

linda.longstreth@wvhouse.gov

WV Delegate Tim Manchin

Capitol Office:

Room 151R, Building 1

State Capitol Complex

Charleston, WV 25305

Capitol Phone: (304) 340-3331

Home:

1543 Fairmont Avenue, Suite 203

Fairmont, WV, 26554

Home Phone: (304) 363-5613

Business Phone: (304) 367-1862

tmanchin@manchininjurylaw.com

WV Delegate Mike Caputo

Capitol Office:

Room 258M, Building 1

State Capitol Complex

Charleston, WV 25305

Capitol Phone: (304) 340-3249 
Home:

P.O. Box 585

Rivesville, WV, 26588

Home Phone: (304) 278-5419

Business Phone: (304) 363-7500

mike.caputo@wvhouse.gov

\section{Marion County Commission}

Commissioners: Randy Elliot, Rick Garcia, and Ernie VanGilder 200 Jackson Street, Room 403

Fairmont, WV 26554

Telephone: 304-367-5400

\section{Marion County Assessor's Office}

Assessor: James P. Priester

200 Jackson Street

Fairmont, WV 26554

Telephone: (304) 367-5410

Fax: (304) 366-6532

\section{Marion County Sherriff's Department}

Sherriff: Joseph N. Carpenter

316 Monroe Street

Jacobs Building 1 st Floor

Fairmont, WV 26554

Phone: (304)367-5300

Fax (304) 367-5304

\section{Marion County Clerk}

Clerk: Janice Cosco

Physical Address: 219 Adams Street

Fairmont, WV26554

Mailing Address: PO Box 1267

Fairmont, WV 26555-1267

Telephone: (304) 367-5440

Fax: (304)367-5448 


\section{Marion County Health Dept.}

$3002^{\text {nd }}$ Street

Fairmont, WV 26554

Phone: 304.366 .3360

Fax: 304.363.8217

marionlhd@wv.gov

\section{Marion County Board of Education}

Members: President Richard Pellegrin, Dr. Babette Sims, Janette Crespenzi, Thomas Dragch, and Mary Joe Thomas

200 Gaston Avenue

Fairmont, WV 26554

Phone: 304-367-2100

\section{Fairmont City Council}

Members: Marianne Moran, Frank Yann, Robert Linger, William Burdick, Fran Warner, Daniel Weber, Phillip Mason, Thomas Mainella, and Mayor Ronald J. Straight 200 Jackson St.

Fairmont, WV 26554

Mailing Address:

P.O. Box 1428

Fairmont, WV 26555-1428

Ph: 304-366-6211

\section{Fairmont City Manager}

City Manager: Robin Gomez Physical Address 200 Jackson St. 3rd Floor

Fairmont, WV 26554

Mailing Address

P.O. Box 1428

Fairmont, WV 26555-1428

Ph: 304-366-6212, Ext. 315 


\section{Fairmont City Clerk}

Clerk: Janet Keller 200 Jackson St.

J. Harper Meredith Building

Room 312

Fairmont, WV 26554

Ph: 304-366-6212, ext. 329

Fx: 304-366-0228

\section{Fairmont Marketing and Communications}

Manager: Hanna Weaver

200 Jackson St.

J. Harper Meredith Building

Room 312

Fairmont, WV 26554

Ph: 304-366-6212, ext. 340

\section{Fairmont Finance Dept.}

Director: Eileen Layman

200 Jackson St.

Room 301

Fairmont, WV 26554

Ph: 304-366-6212 ext. 328

\section{Fairmont Human Resources}

Contact: Debbie Erdie

Phone: 304-366-621 2 ext. 324

\section{Fairmont Purchasing Dept.}

Coordinator: Paula Friend

Physical Address

200 Jackson St.

3rd Floor, Room 305

Fairmont, WV 26554

Mailing Address

P.O. Box 1428

Fairmont, WV 26555-1428

Ph: 304-366-6212, Ext. 310 


\section{Fairmont Planning and Development}

City Planner: Mark Miller

Physical Address

200 Jackson St.

3rd Floor

Fairmont, WV 26554

Mailing Address

P.O. Box 1428

Fairmont, WV 26555-1428

Ph: 304-366-6212, Ext. 249

\section{Fairmont Public Works}

Director: Ron Miller

Physical Address

1030 Minor Ave.

Fairmont, WV 26554

Mailing Address

1030 Minor Ave.

Fairmont, WV 26554

$\mathrm{Ph}:$ 304-363-3883

\section{Fairmont Utilities}

Utility Manager: David Sago

$\mathrm{Ph}: 304-366-6231$, ext 232

\section{Fairmont Water Filtration}

Superintendent: Chip West

Phone: 304-366-1461

\section{Fairmont Wastewater}

Superintendent: Billie Johnson

bjohnson@fairmontwv.gov

Fairmont Dept. of Building Inspection and Rental Registration 


\section{Fairmont Police Department}

Chief: Steve Shine 500 Quincy St.

Fairmont, WV 26554

Ph: 304-366-9280

Fx: 304-366-5533

Dispatch: 304-366-4200

Emergency: 911

\section{Fairmont Fire Department}

Chief: James Emerick 500 Quincy St.

Fairmont, WV 26554

Non-emergency office phone: 304-363-7620

Emergency: 911

200 Jackson St.

Fairmont, WV 26554

$\mathrm{Ph}: 304-366-6212$, ext. 303

Fx: 304-366-0228

\section{Fairmont City Attorney}

City Attorney: Kevin Sansalone Pn: 304-366-621 1

\section{City Boards and Commissions}

Contact information:

City of Fairmont

200 Jackson St.

Fairmont, WV 26554

Mailing Address:

P.O. Box 1428

Fairmont, WV 26555-1428

(304)-366-6211 


\section{APPENDIX C: NONPROFIT ORGANIZATIONS AND CIVIC GROUPS}

\section{Faith-Based Organizations}

Christian Love Ministry

410 Morgantown Ave, Fairmont, WV 26554

(304) 367-9570

Morning Star Baptist Church (Women of Purpose Ministry)

100 McKinney Street, Fairmont, WV 26554

(304) 363-2978

Mt. Zion Baptist

135 Maple Avenue, Fairmont, WV 26554

(304) 363-0669

Pentecostal Church of God MPGT

900 Lewis Street, Fairmont, WV 26554

(304) 363-1233

Pentecostal Temple of Christ

322 Fitzgerald Avenue, Fairmont, WV 26554

(301) 367-0578

Trinity United Methodist

407 Cleveland Ave, Fairmont, WV 26554

(304) 363-1928

\section{Civic Organizations/Chapters}

African American Order of the Eastern Star

506 Second Avenue, Fairmont, WV 26554

(304) 363-3568

Marion County Branch NAACP

1759 Fairmont Ave, Fairmont, WV 26554

(304) 376-7379

\section{Community-Based Organizations}

Dunbar School Foundation

P.O. Box 1370

101 High Street

Fairmont, WV 26555

Dunbarschoolfoundation.org 
Fairmont Community Youth Development Center 612 Madison Street, Fairmont, WV 26554

(304) 534-8316

West Side Robotics

717 1 $/ 2$ Fairmont Ave, Fairmont, WV 26544

(304) 612-7100

westsideroboticsfwv@gmail.com

http://westsideroboticsfwv.wix.com/westsiderobotics\#! about 1/c1 x 1 t

\section{Nonprofit Development Agencies}

Fairmont Community Development Partnership $3002^{\text {nd }}$ Street, Suite 2, Fairmont, WV 26554

(304) 366-7600

Fairmont Housing Authority

10312 th St, Fairmont, WV 26554

(304) 363-0860

Habitat for Humanity

Teri Dalton, Executive Director

103 12th St, Fairmont, WV 26554

PO Box 721

Fairmont, WV 26555

(304) 363-4244

director@marionhabitat.org

http://marionhabitat.org/

BAD Buildings Team

200 Jackson St.

$3^{\text {rd }}$ Floor

Fairmont, WV 26554

(304) 366-6212

Universities and Colleges

Alderson Broaddus University

101 College Hill Drive

Philippi, WV 26416

(304) 457-6321

Pierpont Community and Technical College

1201 Locust Ave

Fairmont, WV 26554

(304) 367-4907 


\section{APPENDIX D: FEDERAL PROGRAMS USING HHS POVERTY GUIDELINES FOR ELIGIBILITY}

\section{Department of Health and Human Services}

- Community Services Block Grant

- Head Start

- Low-Income Home Energy Assistance Program (LIHEAP)

- Hill-Burton Uncompensated Services Program

- AIDS Drug Assistance Program

- Children's Health Insurance Program

- Medicare - Prescription Drug Coverage (subsidized portion only)

- Community Health Centers

- Migrant Health Centers

- Family Planning Services

- Health Professions Student Loans - Loans for Disadvantaged Students

- Health Careers Opportunity Program

- Scholarships for Health Professions Students from Disadvantaged Backgrounds

- Job Opportunities for Low-Income Individuals

- Assets for Independence Demonstration Program

\section{Department of Agriculture}

- Supplemental Nutrition Assistance Program (SNAP) (formerly Food Stamp Program)

- Special Supplemental Nutrition Program for Women, Infants, and Children (WIC)

- National School Lunch Program (for free and reduced-price meals only)

- School Breakfast Program (for free and reduced-price meals only)

- Child and Adult Care Food Program (for free and reduced-price meals only)

- Expanded Food and Nutrition Education Program

\section{Department of Energy}

- Weatherization Assistance for Low-Income Persons

\section{Department of Labor}

- Job Corps

- National Farmworker Jobs Program

- Senior Community Service Employment Program

- Workforce Investment Act Youth Activities 
Department of the Treasury

- Low-Income Taxpayer Clinics

\section{Corporation for National and Community Service}

- Foster Grandparent Program

- Senior Companion Program

\section{Legal Services Corporation}

- Legal Services for the Poor

\section{Other Federal and State Income Dependent Programs}

- Supplemental Security Income (SSI)

- Earned Income Tax Credit (EITC)

- State/local-funded General Assistance (in most cases)

- Some parts of Medicaid

- Section 8 low-income housing assistance

- Low-rent public housing 
APPENDIX E: BUSINESSES LOCATED IN THE WESTSIDE NEIGHBORHOODS

\begin{tabular}{|c|c|c|c|}
\hline Company Name & Phone Number & Address & Primary SIC Description \\
\hline Affordable Quality Svc & $\begin{array}{l}(304) 367- \\
9525\end{array}$ & 313 High St & Services NEC \\
\hline Aspire Uniqueness Boutique LLC & $\begin{array}{l}(304) 363- \\
7860\end{array}$ & 300 Chicago St & Boutique Items-Retail \\
\hline Bonasso, F David DDS & $\begin{array}{l}(304) 366- \\
9833\end{array}$ & 100 Greenbrier Plz & Dentists \\
\hline Colessano's Carry Out & $\begin{array}{l}(304) 363- \\
9713\end{array}$ & 506 Pennsylvania Ave & Pizza \\
\hline De Bellis Construction Inc & $\begin{array}{l}(304) 363- \\
2527\end{array}$ & 229 Pennsylvania Ave & Construction Companies \\
\hline Fairmont Hills & $\begin{array}{l}(304) 366- \\
2226\end{array}$ & 788 Cleveland Ave & Apartments \\
\hline Furbee, Mary & $\begin{array}{l}(304) 366- \\
9833\end{array}$ & 100 Greenbrier Plz & Dental Hygienists \\
\hline $\begin{array}{l}\text { George F Mc Elroy Auto } \\
\text { Brokers }\end{array}$ & $\begin{array}{l}(304) 366- \\
5718\end{array}$ & 31 Holbert Rd & $\begin{array}{l}\text { Automobile Dealers-Used } \\
\text { Cars }\end{array}$ \\
\hline H \& H Property Management & $\begin{array}{l}(304) 816- \\
6266\end{array}$ & 401 Lehman Ave & Heating Contractors \\
\hline J G Lampkin Funeral Home & $\begin{array}{l}(304) 366- \\
3890\end{array}$ & 26 Pennsylvania Ave & Funeral Directors \\
\hline Karen's Kountry Store & $\begin{array}{l}(304) 366- \\
4567\end{array}$ & 3088 E Grafton Rd & Convenience Stores \\
\hline Rich Oil & $\begin{array}{l}(304) 363- \\
5045\end{array}$ & 536 Pennsylvania Ave & $\begin{array}{l}\text { Service Stations-Gasoline \& } \\
\text { Oil }\end{array}$ \\
\hline Times West Virginian & $\begin{array}{l}(304) 367- \\
2500\end{array}$ & 300 Quincy St & News Dealers \\
\hline West Fairmont Head Start & $\begin{array}{l}(304) 363- \\
2781\end{array}$ & 111 Maple Ave & $\begin{array}{l}\text { Schools-Nursery \& } \\
\text { Kindergarten Academic }\end{array}$ \\
\hline WIC-Women Infants \& Children & $\begin{array}{l}(304) 366- \\
2387\end{array}$ & 532 Pennsylvania Ave & Government Offices-County \\
\hline
\end{tabular}




\section{APPENDIX F: LENDING INSTITUTIONS IN MARION COUNTY, WV}

\begin{tabular}{|l|l|l|}
\hline Name & Phone Number & Address \\
\hline BC Bank & $(304) 367-9100$ & 936 E Park Ave, Fairmont, WV 26554 \\
\hline Branch Banking and Trust (BB\&T) & $(304) 368-3200$ & 120 Fairmont Ave, Fairmont, WV 26554 \\
\hline & $(304) 368-3236$ & 108 Gaston Ave, Fairmont, WV 26554 \\
\hline Fairmont Federal Credit Union & $(304) 363-5320$ & PO Box 2139, Fairmont, WV 26555 \\
\hline First Exchange Bank & $(304) 367-1700$ & 216 Fairmont Ave, Fairmont, WV 26554 \\
\hline Huntington National & $(304) 363-5800$ & 103 Adams St, Fairmont, WV 26554 \\
\hline MVB Bank & $(304) 363-4800$ & 301 Virginia Ave, Fairmont, WV 26554 \\
\hline Wes Banco & $(304) 363-5000$ & 301 Adams St, Fairmont, WV 26554 \\
\hline Woodforest National Bank & $(304) 363-1525$ & 32 Tygart Mall Road, Fairmont, WV 26554 \\
\hline
\end{tabular}




\section{APPENDIX G: ECONOMIC DEVELOPMENT ORGANIZATIONS IN MARION} COUNTY

\begin{tabular}{|l|l|l|}
\hline Name & Phone Number & Address \\
\hline $\begin{array}{l}\text { The Marion County Chamber of } \\
\text { Commerce }\end{array}$ & (304) 363-0442 & 110 Adams St, Fairmont, WV 26554 \\
\hline $\begin{array}{l}\text { Marion Regional Development } \\
\text { Corporation }\end{array}$ & $(304) 333-6732$ & $\begin{array}{l}\text { 1000 Technology Drive, Suite 1230, } \\
\text { Fairmont, WV 26554 }\end{array}$ \\
\hline I-79 Development Council & $(304) 677-9961$ & PO Box 5099, Fairmont, WV 26555 \\
\hline High Technology Foundation & $(877) 363-5482$ & $\begin{array}{l}1000 \text { Technology Drive, Suite 1000, } \\
\text { Fairmont, WV 26554 }\end{array}$ \\
\hline Fairmont Renaissance Corporation & & $\begin{array}{l}314 \text { Adams St, Suite 102, Fairmont, WV } \\
26554\end{array}$ \\
\hline Vandalia Heritage Foundation & $(304) 368-1555$ & PO Box 1349, Fairmont, WV 26555 \\
\hline $\begin{array}{l}\text { Vandalia Redevelopment } \\
\text { Corporation }\end{array}$ & (304) 363-3547 & 830 Walnut Ave, Fairmont, WV 26554 \\
\hline Fairmont Urban Renewal Authority & (304) 366-621 1 & PO Box 1428, Fairmont, WV 26555 \\
\hline Main Street Fairmont & (304) 366-0468 & 206 Adams Street, Fairmont, WV 26554 \\
\hline
\end{tabular}


APPENDIX H: MARION COUNTY CHARITABLE FUNDING ORGANIZATIONS

\begin{tabular}{|c|c|c|c|}
\hline Name & Phone Number & Address & $\begin{array}{l}\text { Areas of } \\
\text { Giving }\end{array}$ \\
\hline $\begin{array}{l}\text { Raymond Brooks Vanscoy } \\
\text { Testamentary Trust }\end{array}$ & $\mathrm{N} / \mathrm{A}$ & $\begin{array}{l}\text { PO BOX } 1152 \\
\text { Fairmont, WV, } 26555\end{array}$ & Education \\
\hline $\begin{array}{l}\text { United Way of Marion } \\
\text { County }\end{array}$ & (304) 366-4550 & $\begin{array}{l}112 \text { Adams ST \# } 205 \\
\text { Fairmont, WV, } 26554\end{array}$ & Non-profits \\
\hline Fairmont State Foundation & (304) 534-8786 & $\begin{array}{l}1300 \text { Locust Avenue } \\
\text { Fairmont, WV, } 26554\end{array}$ & Education \\
\hline Connecting Link & (304) 363-4882 & $\begin{array}{l}109 \text { Fairmont Avenue } \\
\text { Fairmont, WV, } 26554\end{array}$ & Low-income \\
\hline Fairmont State University & $(304) 367-4000$ & $\begin{array}{l}1201 \text { Locust Avenue } \\
\text { Fairmont, WV, } 26554\end{array}$ & $\begin{array}{l}\text { University } \\
\text { education }\end{array}$ \\
\hline $\begin{array}{l}\text { West Virginia University } \\
\text { Foundation }\end{array}$ & (304) 284-4000 & $\begin{array}{l}\text { PO Box } 1650 \\
\text { Morgantown, WV, } \\
26507\end{array}$ & $\begin{array}{l}\text { Education; } \\
\text { University } \\
\text { education }\end{array}$ \\
\hline Sobrania & (304) 367-1098 & $\begin{array}{l}425 \text { Quincy Street } \\
\text { Fairmont, WV, } 26554\end{array}$ & $\begin{array}{l}\text { Human } \\
\text { services; Low- } \\
\text { income }\end{array}$ \\
\hline $\begin{array}{l}\text { Community Foundation of } \\
\text { North Central West Virginia }\end{array}$ & $(304) 694-2666$ & $\begin{array}{l}1000 \text { Technology Dr. } \\
\text { Suite } 2230 \text { Fairmont, } \\
\text { WV, } 26554\end{array}$ & Foundations \\
\hline $\begin{array}{l}\text { Moore-Church Scholarship } \\
\text { Trust }\end{array}$ & (717) 852-301 & $\begin{array}{l}1100 \text { Wehrle Drive, } \\
\text { 2nd FI. Amherst, NY, } \\
14221\end{array}$ & Education \\
\hline $\begin{array}{l}\text { Fairmont Senior High School } \\
\text { Foundation }\end{array}$ & (304) 376-2150 & $\begin{array}{l}\text { PO Box } 91 \text { Fairmont, } \\
\text { WV, } 26554\end{array}$ & Education \\
\hline $\begin{array}{l}\text { Cub Scout Pack } 52 \\
\text { Endowment Fund }\end{array}$ & (304) 594-1275 & $\begin{array}{l}4 \text { Candlelight Drive } \\
\text { Morgantown, WV, } \\
26508\end{array}$ & $\begin{array}{l}\text { Youth } \\
\text { development }\end{array}$ \\
\hline $\begin{array}{l}\text { Pricketts Fort Memorial } \\
\text { Foundation }\end{array}$ & $(304) 363-3030$ & $\begin{array}{l}88 \text { State Park Entrance } \\
\text { Road Fairmont, WV, } \\
26554\end{array}$ & $\begin{array}{l}\text { Historic } \\
\text { preservation }\end{array}$ \\
\hline $\begin{array}{l}\text { The James Gabriel Family } \\
\text { Foundation }\end{array}$ & $1(800)$ 458-6546 & $\begin{array}{l}55 \text { Scott Avenue } \\
\text { Morgantown, WV, } \\
26508\end{array}$ & Education \\
\hline $\begin{array}{l}\text { West Virginia High } \\
\text { Technology Consortium } \\
\text { Foundation }\end{array}$ & (304) 363-5482 & $\begin{array}{l}1000 \text { \# } 1000 \text { Galliher } \\
\text { Drive Fairmont, WV, } \\
26554\end{array}$ & $\begin{array}{l}\text { Economic } \\
\text { development; } \\
\text { technology }\end{array}$ \\
\hline
\end{tabular}




\begin{tabular}{|c|c|c|c|}
\hline Name & Phone Number & Address & $\begin{array}{l}\text { Areas of } \\
\text { Giving }\end{array}$ \\
\hline $\begin{array}{l}\text { Literacy Volunteers, } \\
\text { Monongalia County }\end{array}$ & (304) 296-3400 & $\begin{array}{l}235 \text { High Street \# } 317 \\
\text { Morgantown, WV, } \\
26505\end{array}$ & Education \\
\hline $\begin{array}{l}\text { Marion County Parks and } \\
\text { Recreation Commission }\end{array}$ & $(304) 363-7037$ & $\begin{array}{l}\text { PO Box } 1258 \text { Fairmont, } \\
\text { WV, } 26555\end{array}$ & $\begin{array}{l}\text { Local } \\
\text { governments } \\
\text { and agencies }\end{array}$ \\
\hline $\begin{array}{l}\text { North Central West Virginia } \\
\text { Community Action Association }\end{array}$ & $(304) 363-6869$ & $\begin{array}{l}1304 \text { Goose Run Road } \\
\text { Fairmont, WV, } 26554\end{array}$ & $\begin{array}{l}\text { Human } \\
\text { services; low- } \\
\text { income }\end{array}$ \\
\hline $\begin{array}{l}\text { Pierpont Community and } \\
\text { Technical College }\end{array}$ & (304) 367-4892 & $\begin{array}{l}1201 \text { Locust Avenue } \\
\text { Fairmont, WV, } 26554\end{array}$ & Education \\
\hline $\begin{array}{l}\text { Clark Opportunity } \\
\text { Foundation }\end{array}$ & $(304) 775-0950$ & $\begin{array}{l}24 \text { Outlook Road } \\
\text { Fairmont, WV, } 26554\end{array}$ & Education \\
\hline Marion County Foundation & $\mathrm{N} / \mathrm{A}$ & Fairmont, WV, 26554 & $\begin{array}{l}\text { Community } \\
\text { improvements; } \\
\text { Foundations }\end{array}$ \\
\hline Caritas House & $(304) 985-0021$ & $\begin{array}{l}391 \text { Scott Avenue } \\
\text { Morgantown, WV, } \\
26508\end{array}$ & Low-income \\
\hline $\begin{array}{l}\text { Robert H. Mollohan Family } \\
\text { Charitable Foundation }\end{array}$ & $(304) 333-6783$ & $\begin{array}{l}100 \text { Technology Drive } \\
\text { Suite } 200 \text { Fairmont, } \\
\text { WV, } 26554\end{array}$ & Education \\
\hline $\begin{array}{l}\text { Morgantown Housing } \\
\text { Authority }\end{array}$ & $(304) 363-0860$ & $\begin{array}{l}10312^{\text {th }} \text { Street } \\
\text { Fairmont, WV, } 26554\end{array}$ & $\begin{array}{l}\text { Housing } \\
\text { development; } \\
\text { Local } \\
\text { governments } \\
\text { and agenicies; } \\
\text { low-income }\end{array}$ \\
\hline $\begin{array}{l}\text { Marion County Board of } \\
\text { Education }\end{array}$ & (304) 367-2100 & $\begin{array}{l}200 \text { Gaston Avenue } \\
\text { Fairmont, WV, } 26554\end{array}$ & Education \\
\hline $\begin{array}{l}\text { Community Foundations: } \\
\text { Growing Philanthropy Close } \\
\text { to Home }\end{array}$ & $(304) 367-3423$ & $\begin{array}{l}1310 \text { Fairmont Avenue } \\
\text { Fairmont, WV, } 26554\end{array}$ & Non-profits \\
\hline $\begin{array}{l}\text { Education Alliance-Business } \\
\text { and Community for Public } \\
\text { Schools }\end{array}$ & $(304) 342-7850$ & $\begin{array}{l}\text { PO Box } 3071 \\
\text { Charleston, WV, } 25331\end{array}$ & Education \\
\hline $\begin{array}{l}\text { George M. Cruise Charitable } \\
\text { Funders }\end{array}$ & $\mathrm{N} / \mathrm{A}$ & $\begin{array}{l}\text { PO Box } 1152 \text { Fairmont, } \\
W V, 26554\end{array}$ & Foundations \\
\hline
\end{tabular}




\begin{tabular}{|l|l|l|l|}
\hline Name & Phone Number & Address & $\begin{array}{l}\text { Areas of } \\
\text { Giving }\end{array}$ \\
\hline $\begin{array}{l}\text { Claud "Bud" Mick, Jr. } \\
\begin{array}{l}\text { Education Scholarship } \\
\text { Foundation }\end{array}\end{array}$ & (734) 434-7582 & $\begin{array}{l}6775 \text { Carpenter Road } \\
\text { Ypsilanti, Ml, 48197 }\end{array}$ & Education \\
\hline
\end{tabular}




\section{COMMUNITY SURVEY RESULTS}

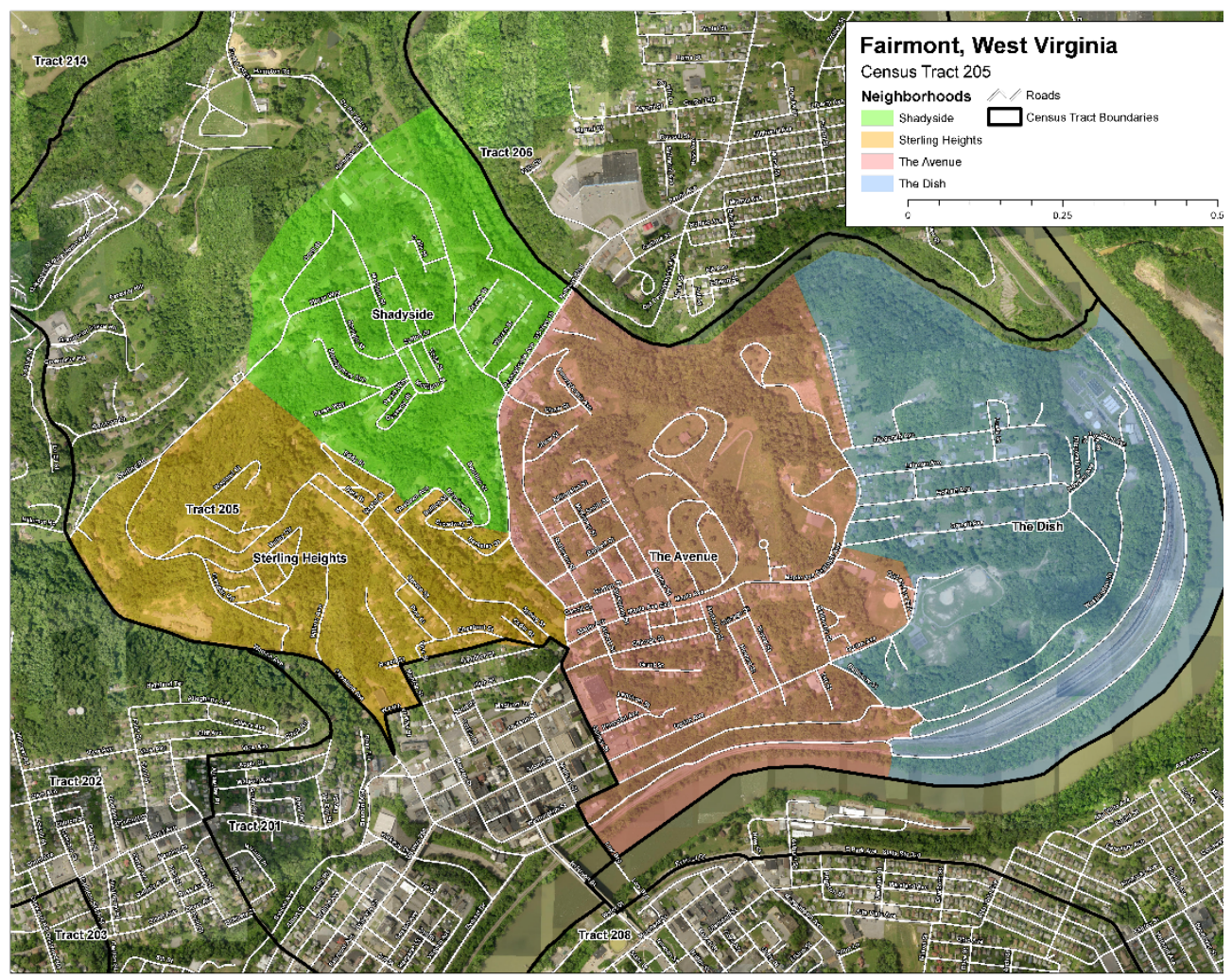

\section{Resident Opinions about Civic Infrastructure}

Drawn from the National Civic League's Civic Index tool, this survey gathered resident opinions on various aspects of civic health, with an emphasis on the Westside neighborhoods. The findings indicate room for improvement, as well as efforts already underway to begin development. 


\title{
Community Survey Results
}

\author{
RESIDENTOPINIONSABOUTCIVIC INFRASTRUCTURE
}

\section{SURVEY BACKGROUND}

\section{Margaret Stout}

In May of 2015, representatives of the Westside Action Coalition in Fairmont, WV agreed to work with faculty and students from West Virginia University to mobilize and organize the community toward collaborative comprehensive planning and project implementation. These activities are being conducted through a combination of service learning and action research efforts led by Associate Professor Margaret Stout and the graduate students enrolled in Master of Public Administration courses and outreach programs offered by other academic units.

Every community has what can be called "civic infrastructure"- the institutions, opportunities, and practices for community members to engage in self-governance and collective action. The National Civic League defines civic infrastructure as "formal and informal processes and networks through which communities make decisions and attempt to solve problems" (League 1999, 13). Strong civic infrastructure contributes to a community's economic, social, environmental, and governance vitality.

Indicators of a vital community include: a shared community identity and vision for the future; interactive roles for residents, government, community organizations, and businesses; bridging group boundaries of all types; cooperating by sharing information, reaching agreement, and learning from experience; and educating community members and developing leadership from all walks of life. The National Civic League's Civic Index is a tool designed to help community groups explore these characteristics.

\section{LEARNING ABOUT FAIRMONT'S WESTSIDE}

\section{Margaret Stout}

Because the Westside neighborhoods are preparing to enter into the collaborative process of community planning and development, a written Community Survey was used to begin assessing the human, social, organizational, and political capitals of Fairmont. Questions were drawn from the National Civic League's Civic Index. This Community Survey was distributed in September and October of 2015 through a variety of stakeholder groups and an online survey web link. Distribution was coordinated by the Fairmont Youth Community Development Center board members. The survey link was posted to its Facebook page and distributed on flyers to churches and other neighborhood leaders via email. Hard copies of the survey were hand distributed at a neighborhood youth football game, a community-wide Halloween event, and by one neighbor to her neighbors. A total of 105 surveys were returned, only three of which were submitted online. Respondents included 68 who identified themselves as Westside residents and 37 who were Fairmonters outside those neighborhoods. While this return rate is less than hoped for, it gives an idea of what active residents are thinking. The results and an interpretation of their meanings follow. 


\section{NEIGHBORHOOD VISION}

\section{Lisa Lagana}

1. My neighborhood clearly knows its unique identity and seeks to preserve it.

\section{$53 \%$ Agree}

$31 \%$ Disagree

16\% Don't Know

2. My neighborhood has a shared vision that guides what we do.

$41 \%$ Agree

43\% Disagree

$16 \%$ Don't Know

3. My neighborhood has a long-term plan that includes most people's ideas.

$28 \%$ Agree

45\% Disagree

$27 \%$ Don't Know

\section{Comments and Ideas}

- I live on the outside of the neighborhood but I grew up in "the ave." and I'm been connected with the neighborhood

- some know some don't care some don't know

- I think as a community we need more collaboration. I don't think my neighborhood sees the value it has

- Fairmont does not want to do anything different or take care of what they already have

- I live on please help heavy drug use

- Fix our park (windmill) and gove it a legit football field

- My neighborhood need improvements in our park where my grandchild play and better housing

\section{Interpretation}

Communities with a clear sense of their past and a shared sense of identity are able to plan inclusive activities around shared desires that reflect their standards and values. Communities with a strong neighborhood vision are able to face challenges with focused action steps that follow a timeline of completion. This encourages citizens to engage in proactive problem solving and take collective action, continuously building upon the community's foundation for its future.

The majority of all survey respondents agree that their neighborhood clearly knows its unique history and identity and seeks to preserve it, but the rest of the Fairmont community was significantly higher than the Westside respondents in this percentage. These numbers were supported by comments in the survey that identified Windmill Park as having a unique identity that Westsiders seek to preserve. However, the majority of respondents disagreed that their neighborhood has a shared vision that guides what they do. The comments reflected a lack of a clear sense of direction and the need for more community collaboration. These answers showed the same difference between Westside and other neighborhood residents. When it comes to a longterm plan, the majority of respondents disagreed that they had one that included most people's ideas. These responses were also higher in the Westside than in the other Fairmont neighborhoods. Comments reflected 
these numbers, indicating that Fairmont does not want to do anything different or take care of what is already has.

\section{Recommendations}

The comments included starting points for a neighborhood vision, including improvements to Windmill Park, better housing, and addressing drug abuse problems. The next steps for Fairmont neighborhoods should include visioning and long-term planning to create action steps that follow a realistic timeline for implementation. An inclusive plan would allow each neighborhood to face the challenges mentioned within the survey and plan activities that reflect those values. By showing pride in community values, citizens will have an incentive to come together to address issues formally and establish a proactive problem-solving foundation, instead of waiting for the City of Fairmont to address their concerns. 


\section{NEW ROLES FOR RESIDENTS}

\section{Courtni Helmick}

1. Most people who live here participate in neighborhood or community organizations.

$41 \%$ Agree

\section{3\% Disagree}

\section{$16 \%$ Don't Know}

2. All people who live here have equal opportunities to participate in community decision-making.

\section{$51 \%$ Agree}

$37 \%$ Disagree

$12 \%$ Don't Know

3. People who live here work with government, business, and nonprofits to solve community problems.

$29 \%$ Agree

45\% Disagree

$26 \%$ Don't Know

4. People who live here believe it is honorable to serve in public office and respect those that do.

\section{$39 \%$ Agree}

\section{$34 \%$ Disagree}

$27 \%$ Don't Know

\section{Comments and Ideas}

- Info isn't always made available to the commonly. So a lot of times people don't know. Need to involve them more.

- Some of the older people work with government. We need to invite younger people in the meetings.

- I work in a nonprofit agency here and we have minimal community help or interest.

- Seems same people have held same positions for years. See same faces running community organizations. These people are important but anything benefits from fresh and new ideas.

- The govern bodies aren't looking for the common people to have a voice by separating ideas and values to incorporate police power.

- A lot of improvement needed for community.

- We as a community need to do more.

\section{Interpretation}

In order to have a strong civic infrastructure citizen participation is necessary. Citizens must realize they have to have a proactive role in creating a strong community. Participation in a community includes activities like voting in local elections, serving on boards, attending public hearing meetings, and being an active volunteer in community-based organizations.

Comparatively, the Westside respondents have different opinions than those from other areas. Over $45 \%$ of Westsiders disagreed that most people who live here participate in neighborhood or community organizations, while only $37 \%$ of others disagreed. While the majority overall agree that all community 
members have equal opportunities to participate in decision-making, only $47 \%$ of Westsiders agreed as compared to $60 \%$ of others. In regard to residents working with government, business, and nonprofits to solve, $52 \%$ of the Westside respondents disagreed, while $37 \%$ of others agreed. Only $33 \%$ of Westside respondents agreed that it is honorable to serve in public office, while over $51 \%$ of those living in other areas agreed.

Survey comments pointed out that there is not a significant amount of citizen involvement in the community. The citizens who are involved are usually older and they participate in most community activities. Respondents feel the younger generations should be more involved.

\section{Recommendations}

Overall, the data suggest that residents in Fairmont are not as involved as they could be, and Westside respondents have a less positive attitude than respondents living in other areas. The Civic Index suggests that the community will benefit from residents taking more responsibility for their community by being involved and proactive neighbors and citizens. One way to support active participation is through neighborhood associations. 


\section{NEW ROLES FOR LOCAL GOVERNMENT}

\section{Chris Agba}

1. Our city government shares the neighborhood's vision for the future.

$24 \%$ Agree

$58 \%$ Disagree

$17 \%$ Don't Know

2. Our city government shares decision-making with residents.

$15 \%$ Agree

$66 \%$ Disagree

19\% Don't Know

3. Our city government is responsible and accountable to the residents.

$33 \%$ Agree

$54 \%$ Disagree

$13 \%$ Don't Know

4. City services are provided equally to all groups and neighborhoods.

$26 \%$ Agree

$58 \%$ Disagree

$15 \%$ Don't Know

5. Our city government works with businesses and community organizations on my neighborhood's challenges and opportunities.

$26 \%$ Agree

$56 \%$ Disagree

$20 \%$ Don't Know

\section{Comments and Ideas}

- I've seen some of this somewhat. But it will be helpful if the city would get more involved and in commonly

- I called our city about the diaper of Windmill Park. The commit "we don't have the money, I would hate to shut it down" sounds like a threat if we come be requested them he do the work needed.

- But are they (city govt really to ques. 3)

- Probably not for quest. 4

- The make decisions and tell us after. We just have to deal. A lot of times seems they use their position as leverage to force their ideas

- We need to privately organize and have our private representations go to city council meetings

- The organizations have to come together and force the hand of government

- Bring business to Fairmont everyone is growing around us

- Our community doesn't share our neighborhood vision nor include us in the planning 


\section{Interpretation}

It is the responsibility of local government to encourage broad-based citizen participation. Such engagement creates a sense of ownership and interest among residents and fosters the will to contribute funding and volunteerism toward programs that develop, nurture, grow, and promote both economic and social development for the entire community.

The majority of respondents have negative perceptions of local government. The majority (nearly 53\%) do not believe the City shares their neighborhood's vision for the future, with these sentiments being worse among Westside respondents than other areas; over $58 \%$ as compared to over $43 \%$. Nearly $64 \%$ of respondents feel left out of the decision making process; nearly $66 \%$ of Westsiders and $60 \%$ of those from other areas. Nearly $56 \%$ also felt the city government is not responsible and accountable to its residents and over $57 \%$ do not feel that city services are provided equally across all areas. Finally, 50\% of all respondents do not believe the City works well with businesses and other community organizations to meet neighborhood needs. The difference between the Westside respondents and others is striking here; nearly $55 \%$ as compared to $42 \%$. The overarching perception of respondents from the Westside neighborhoods is worse, reflecting a sense of disenfranchisement from the City, which may be misinterpreted as apathy.

\section{Recommendations}

From the perspective of collaborative governance, new roles for local government include building and unifying all sectors in the community by helping them work together in harmony. This kind of approach does not only create a sense of belonging, but it also empowers and stimulates collaborative partnership among residents. The City of Fairmont can use these survey results as a motivation for a renewed commitment to public engagement, collaboration, and responsiveness. 


\section{NEW ROLES FOR COMMUNITY ORGANIZATIONS}

\section{Bre Kreutzer}

1. Community organizations include the people they serve in setting priorities and planning programs and projects.

\section{0\% Agree}

$37 \%$ Disagree

\section{$23 \%$ Don't Know}

2. Community organizations collaborate to get needed resources rather than compete for them.

$38 \%$ Agree

\section{$39 \%$ Disagree}

\section{$24 \%$ Don't Know}

3. Community organizations work to resolve "turf issues" in our community.

42\% Agree

$29 \%$ Disagree

$29 \%$ Don't Know

4. Community organizations work with the city and county governments and businesses to reach shared goals. $30 \%$ Agree

\section{$39 \%$ Disagree}

\section{$32 \%$ Don't Know}

\section{Comments and Ideas}

- questions 2 - 4 was answered with somewhat

- I think these are somewhat could be better

- probably not (for quest. 2 to 4 )

- Have seen several campaigns/projects to involve different groups. DAC is very wonderful with getting needed things for participants and reaching large number of people

- The resources to reach the community aren't used through television, radio, and newspaper.

- We also have internet activities to inform the communities and reach a better spectrum.

\section{Interpretation}

Community-based organizations are the key to creating change in neighborhoods by identifying needs unique to the area and providing services to meet those needs. In recent years, cutbacks in federal funding for community organizations have made resources scarce. Many community organizations have begun to lose sight of the broader goal and have started to compete for these resources in order to keep their particular organization afloat. This competition can be detrimental to communities and should be replaced with collaboration among organizations.

The statistics from the civic index survey in Fairmont indicate the majority of community members have mixed emotions of whether or not community organizations are actively fulfilling their obligations to the public. Each question of the survey yields majority results that are very close to the alternate opinion, including a large 
percentage of "Don't Know" answers. This indicates that community-based organizations are not doing a good job with public relations and outreach.

Overall, respondents from the Westside have a more negative view of community organizations. For example, only $25 \%$ of Westside respondents feel that community organizations work to resolve turf issues within their neighborhood compared to $53 \%$ of respondents from other Fairmont neighborhoods. Only $35 \%$ the Westside respondents feel as though community organizations include the people they serve in setting priorities in planning and projects whereas $49 \%$ of others agree. In regard to collaborating rather than competing for resources, $42 \%$ of Westside respondents disagreed as compared to $33 \%$ of other Fairmonters. Finally, almost half of Westside community members (49\%) feel as though community organizations do not work with the city and county governments and businesses to reach shared goals, while only $19 \%$ of respondents from other areas have this view. The more positive comments made in the survey may not necessarily reflect the experiences of the Westside respondents.

\section{Recommendations}

These survey results reveal a need to improve the public image and responsiveness of community organizations, particularly those serving the Westside neighborhoods. Participatory planning is an effective way to achieve both objectives simultaneously. Community-based organizations also need to become more collaborative in providing services-with one another and with government agencies. By focusing on each organization's strengths, decreasing overlaps in services, and filling gaps in service provision, communitybased organizations could become a leading force in community and economic development in the Westside neighborhoods. 


\section{NEW ROLES FOR BUSINESS}

\section{Daniel Eades}

1. Our Chamber of Commerce is active and highly visible in the community.

$19 \%$ Agree

\section{$54 \%$ Disagree}

$27 \%$ Don't Know

2. Our downtown Main Street program is active and highly visible in the community.

45\% Agree

$40 \%$ Disagree

$15 \%$ Don't Know

3. Businesses participate in broad community improvement efforts.

$26 \%$ Agree

49\% Disagree

$25 \%$ Don't Know

4. Businesses play a charitable role in our community, such as making donations to charities and community organizations.

$35 \%$ Agree

40\% Disagree

$24 \%$ Don't Know

5. Businesses encourage employees to volunteer in community activities.

$30 \%$ Agree

49\% Disagree

$21 \%$ Don't Know

\section{Comments and Ideas}

- No outreach from the Chamber of Commerce or local businesses

- Without social media they would not be informed

\section{Interpretation}

Businesses provide financial and human capital resources for sustaining communities' civic infrastructure and undertaking community development efforts. Unfortunately, community responses to the civic survey suggest that local businesses are generally not viewed as active contributors to the overall health of the Fairmont community; this was especially true for Westside respondents.

The Chamber of Commerce was not regarded as active or visible in community development activities (54\% of responses) but Main Street Fairmont was regarded more positively. However, there were noticeable differences between the views of Westside residents and the larger Fairmont community. Nearly half (47\%) 
of Westside respondents did not feel that the organization was active in the community. Conversely, 56\% of respondents from outside the neighborhood felt the organization was active and visible.

Responses indicate that businesses do not participate in community improvement efforts (49\% of respondents). The majority of respondents (49\%) indicated that businesses did not encourage their employees to volunteer in community activities. Views on charitable giving were mixed: $40 \%$ of respondents disagreed with the statement "Businesses play a charitable role in our community;" however Westside residents were more inclined to disagree (49\%) than other community residents (24\%). This suggests that Westside residents' primary employers may be less involved in charitable giving than the broader Fairmont business community.

\section{Recommendations}

The National Civic League notes that businesses are key contributors to overall community health. Their involvement has traditionally been limited to charitable giving; however, for communities to fully benefit, businesses must think beyond their walls and bottom-line, integrating employees and leaders into the activities of local governments, schools, and non-profits. The results of the civic survey suggest that development organizations should play a more visible role in the community and use communication tools like social media to highlight their role in community development efforts. Additionally they should move beyond hubs for business-to-business connections and work to link their members with community organizations, especially those in traditionally underserved neighborhoods like the Westside. Once these links are established, employees and corporate leaders are encouraged to share both monetary resources and talents in ways that strengthen the capacity and effectiveness of local governments and organizations; serving in leadership positions, contributing monetary resources, and actively planning for the economic future of the community. 


\section{CROSSING GOVERNMENT BOUNDARY LINES}

\section{Dakota Morris}

1. The right type and amount of community services are provided by city, county, and state government agencies.

$26 \%$ Agree

\section{$53 \%$ Disagree}

$21 \%$ Don't Know

2. Our city government works well with neighboring communities.

$28 \%$ Agree

$46 \%$ Disagree

$26 \%$ Don't Know

3. Our city, county, school district, and other local authorities work well together on regional issues.

$28 \%$ Agree

46\% Disagree

$26 \%$ Don't Know

4. State agencies help our city meet challenges and opportunities.

$26 \%$ Agree

\section{$52 \%$ Disagree}

\section{$22 \%$ Don't Know}

\section{Comments and Ideas}

- The city, county, etc. need to get more involved by making self known.

- I think city government works better in other communities.

- Give to all who do nothing, take away from those who work here.

- Probably not (comment in reference to questions two and three).

- They have no money.

\section{Interpretation}

Ideally, government may be more responsive when the various levels of government work together to respond to complex issues. These issues cannot be resolved solely on a municipal basis. State, county, municipal, and other local governments should work in conjunction with one another to address the complex issues which arise. As this occurs, leaders may develop an attitude of cooperation leading to a more inclusive regional government structure, ongoing forms of dialogue monitoring accountability and implementation of regional plans, and healthier communities throughout the region.

Respondents were asked about attitudes toward county government, municipal government, the local school district, and state agencies. The questions were designed to identify whether or not the governments serving the community were working well with the community and one another. The survey responses overwhelmingly demonstrate strong disagreement with the assertion that government is effectively providing services and working successfully with the community across all levels of government. "Disagree" was the highest response 
for each question at $53 \%, 46 \%, 46 \%$, and $52 \%$ for the four questions, respectively. It is interesting to note however, that the Westside respondents tended to have a more negative view toward government than those outside of the Westside communities. In particular, there is a significant difference between Westside and other respondents in regard to city government. Only $19 \%$ of respondents from the Westside neighborhoods agree that their city government works well with neighboring communities, while respondents from other neighborhoods report $46 \%$ agreement.

\section{Recommendations}

The ultimate goal would be to see respondents to a future survey reflect agreement that their governments at each of the various levels are working well together to address issues and provide services needed by the community. This would most likely be a reflection of a shift away from a municipal-only approach toward a more regional approach to solving complex issues. Government would then be more effective across government boundary lines. 


\section{BRIDGING DIVERSITY}

\section{Amy Loomis}

1. Our community works together across racial, ethnic, economic, and other group lines.

$38 \%$ Agree

\section{$50 \%$ Disagree}

$12 \%$ Don't Know

2. All racial, ethnic, economic, and other groups are involved in important community decisions.

$32 \%$ Agree

\section{$50 \%$ Disagree}

$18 \%$ Don't Know

3. The leadership of the community reflects the diversity of the community.

$41 \%$ Agree

$45 \%$ Disagree

$14 \%$ Don't Know

4. Our community responds quickly and strongly to discrimination, racism, and racist acts.

$29 \%$ Agree

\section{$53 \%$ Disagree}

$18 \%$ Don't Know

\section{Comments and Ideas}

- In 45 yrs. I have attend one video at fmt clinic when I was employed

- I have witnessed two bullying at Rivesville middle and the staff turned their backs. I was shocked! I am glad that children are being educated in the class rooms in efforts of discrimination

- Racism is real and evident and not just due to attention on today media

\section{Interpretation}

Healthy inter-group relations result in greater cohesiveness, understanding, unity, and empathy among citizens. These attitudes foster the ability to work together to build a stronger community. Because the Westside neighborhoods are racially diverse, it is particularly important that community efforts be inclusive of all perspectives in order to identify and work towards common goals.

Respondents are divided over whether or not their community works together across racial, ethnic, economic, and other group lines: $53 \%$ of Westside residents and $44 \%$ of respondents living outside of the Westside do not agree that racial, economic, and other groups are involved when it comes to important community decisions. This suggests that more work needs to be done to include all groups into community planning and action opportunities and prevent disenfranchisement.

$53 \%$ of residents outside the Westside agree that the leadership reflects their diversity. In contrast, $53 \%$ of Westside residents do not feel that the leadership of the community reflects their diversity. This suggests that the community's leaders may not fully represent or understand the needs of the Westside. $53 \%$ of respondents overall and $58 \%$ of Westside respondents feel that the community does not respond quickly and 
strongly to discrimination, racism, and racist acts. Many respondents (18\%) don't know how the community responds to racist acts. This suggests that the community can do more to increase awareness of and responsiveness to racial injustice.

\section{Recommendations}

The data suggest that Fairmont is underperforming in bridging diversity among its residents. Efforts to support diversity must be part of comprehensive community building efforts. Inter-group relationships must transcend personal and interest group agendas and create forums for civic participation, provide avenues for communication, and seek input from a broad spectrum of the community. Cross-cultural initiatives leverage power when groups and individuals mobilize around such issues as justice, education, socio-economic development, health, and job development. Proactive approaches to building and strengthening inter-group relations are the best way to foster cross-cultural understanding.

There are a number of activities for promoting diversity and unity that have proven successful in other places. For example, the community can organize an Awareness Week to promote diversity, peace, brotherhood, anti-bullying and/or multicultural sharing. This event can involve the City Council, local businesses, and several community organizations coming together to offer free public events focusing on respect, racism, anger management, the earth, and cultural diversity. A fair can include activities such as puppet shows, storytelling, cultural talent, movies, and games.

Schools can raise awareness of bullying and discrimination through workshops for teachers and administrators on how to adequately discuss and handle situations of bullying and discrimination. Programs for youth and teens can foster community dialogues, promote civil discourse, and promote teen leadership. The City can offer programs or create boards or commissions that promote citizen's legal rights and responsibilities as residents of the city, with a focus on human rights. The City can commit to an initiative recruiting women and minorities into high-level leadership and law-enforcement positions. Mentorship or workshop programs can be offered to increase candidate eligibility. 


\section{SHARING INFORMATION}

\section{Michelle Sloane}

1. Residents have the information they need to make good decisions and choices.

$32 \%$ Agree

\section{$53 \%$ Disagree}

\section{$15 \%$ Don't Know}

2. The news media provides our community with helpful information about our most important challenges, opportunities, and priorities.

$35 \%$ Agree

\section{$52 \%$ Disagree}

$13 \%$ Don't Know

3. All residents have access to information technology like the internets.

$41 \%$ Agree

$45 \%$ Disagree

$14 \%$ Don't Know

4. Community leaders regularly share information and ideas with residents.

$24 \%$ Agree

\section{$59 \%$ Disagree}

\section{$17 \%$ Don't Know}

\section{Comments and Ideas}

- I think the information is available

- Probably no (for quest 1 and 4)

- I have seen nothing in the news with the exception of election time

- Our city officials aren't doing enough to help the low-income people

- The info is out there but not always known. Not everyone can afford technology or have transportation too areas that do

\section{Interpretition}

According to the Civic Index guide, sharing information and fostering dialogue leads to improved cooperation and consensus. Residents can access information through a variety of means including public records, news media, the internets, and informal community channels. The media shares responsibility for disseminating information and reporting fairly and objectively. Informed residents offer a greater diversity of perspectives and opinions that will in turn lead to greater quality in life of Fairmont for all residents.

Over half of all survey respondents $(53 \%)$ disagreed with the statement that residents have the information they need to make good decisions and choices, however $7 \%$ more of Westside residents than other Fairmont residents disagreed with this statement. Similarly, most respondents $(52 \%)$ disagree that the news media provides adequate information, while significantly more Westside residents disagreed with this (59\%) than other Fairmont residents (41\%). Overall, respondents were somewhat mixed on whether all residents have 
access to information technology ( $45 \%$ disagree while $41 \%$ agree), but the majority of Westside residents $(51 \%)$ disagreed that there is sufficient access, while most of who live outside of the neighborhood $(46 \%)$ believed that access is sufficient. Most strikingly, $59 \%$ of all respondents disagree that community leaders regularly share information and ideas with residents. While write-in comments were few, the statements support the overall sentiment in the survey responses.

\section{Recommendations}

These findings indicate that local leaders should increase efforts to communicate with residents on the Westside so that they are informed of Fairmont's priorities and of opportunities for residents to participate. One notable issue is access; most respondents did not believe they have access to information technology, so local leaders should use a variety of ways to engage residents. Responses also indicate that residents feel informed only during election time, indicating that the media also has an opportunity to expand their reach, such as reporting on day-to-day issues that relate to all residents in Fairmont, inclusive of the Westside. Improving communication will result in more informed residents who will be motivated to participate in efforts that directly influence their community and Fairmont at large. 


\section{REACHING AGREEMENT}

\section{Ashley Morgan}

1. Our community stays on top of challenges and opportunities, rather than waiting until it's an emergency situation.

\section{$34 \%$ Agree}

\section{$52 \%$ Disagree}

$14 \%$ Uncertain

2. Our community leaders bring residents together to share opinions openly.

$30 \%$ Agree

\section{$53 \%$ Disagree}

$17 \%$ Uncertain

3. All stakeholders in our community-residents, government, businesses, and community organizations-are included in decision making.

$22 \%$ Agree

48\% Disagree

$30 \%$ Uncertain

\section{Comments and Ideas}

- I agree you need to get involved but if meetings are held where only a few show there is a need to find more input.

\section{Interpretation}

According to the Civic Index, healthy communities understand that disagreement is to be expected and actually provides opportunities for creative problem-solving. These communities work through disagreements by exploring and integrating the differences in opinions. It is important for community leaders to facilitate discussions with residents in order to reach consensus, develop programs, and build communities.

The majority of respondents (52\%) disagree that the community is proactive in problem solving, including $58 \%$ of respondents from the Westside as opposed to $43 \%$ of respondents from other areas. The majority of all respondents $(52 \%)$ disagree that the city brings all residents together to hear their concerns and opinions, including $63 \%$ of Westside respondents as compared to $43 \%$, of others. Nearly a majority of all respondents $(48 \%)$ disagreed that all stakeholders are included in decision making, including $54 \%$ of Westsiders as compared to $38 \%$ of other residents. These responses are supported by comments that indicated that community leaders need to find more ways for people from across Fairmont to be involved in order to reach consensus.

\section{Recommendations}

Fairmont appears to be a community that is not working through disagreements among stakeholders in the most effective manner. Community members do not feel that their voices are being heard. In response, community leaders in Fairmont could come together and hold open forums across the city to provide an opportunity for residents to voice their concerns. This requires an understanding that disagreement is going to 
happen and an ability to embrace it as an opportunity for creativity and innovation. Conflict resolution and conflict transformation can be facilitated in order to identify common goals and begin the challenging but fulfilling process of working together. This approach can be more effective when starting at the neighborhood scale and working out into larger groups in an incremental fashion. 


\section{ONGOING LEARNING}

\section{Gaillynn Bowman}

1. Our community has a sense of tradition and draws from that history in making decisions.

$38 \%$ Agree

\section{2\% Disagree}

$20 \%$ Don't Know

2. Our community uses lessons learned from past experiences to make better decisions for the future.

\section{$41 \%$ Agree}

$40 \%$ Disagree

$19 \%$ Don't Know

3. People see their work in our community as ongoing and long-term, despite ups and downs.

\section{$44 \%$ Agree}

$34 \%$ Disagree

$22 \%$ Don't Know

\section{Comments and \|deas}

- I feel that newcomers to Fairmont and truly want to contribute to improvement are soon finding out that the ones in power here all say in any decision. "politics as usually". Also I forward that it is not "what you know, it is who you know" its very sad.

- We need more forward thinkers.

\section{Interpretation}

Strong communities possess the ability to solve problems by using knowledge gained from past experiences, positive and negative, and then incorporating those critical lessons into future plans and endeavors. A community's history provides a wealth of knowledge derived from facing obstacles and overcoming difficulties in order to ensure success.

The results indicate that the largest percentage of respondents disagree that the community draws from its sense of tradition and history when making decisions. However, while $50 \%$ of Westside community respondents disagree, only $28 \%$ of respondents living in other areas disagree that the community uses its wealth of knowledge. The greatest number of responses overall agree that the community learns from past experiences and see community work as ongoing. However, $52 \%$ of Westside respondents disagree that the community learns from past experiences as compared to $19 \%$ of others. Continuing the trend, $44 \%$ of Westside respondents disagree that people see their community work as ongoing, despite ups and downs, while only $17 \%$ of respondents in other areas disagree. These results may indicate a desire for change to make progress, which is supported by the comments made. But these results may also indicate that Westsiders wish to see their unique history taken into greater consideration in community planning. 


\section{Recommendations}

These different perceptions of the community's ability to draw positively on tradition while learning lessons from previous experience are significant. It may be beneficial to document the specifics of Fairmont's history in order to help the community as a whole benefit from its past-both in terms of celebrating unique and shared histories and learning from previous mistakes. 


\section{EDUCATING RESIDENTS TO MEET COMMUNITY CHALLENGES}

\section{Leah Cunningham}

1. All students receive effective education in school about how government works.

$22 \%$ Agree

\section{0\% Disagree}

$18 \%$ Don't Know

2. Training is available to people in my neighborhood about how government works.

$16 \%$ Agree

\section{$56 \%$ Disagree}

$28 \%$ Don't Know

3. People in my neighborhood are offered enough opportunities to volunteer in community and government activities.

$30 \%$ Agree

48\% Disagree

$22 \%$ Don't Know

\section{Comments and Ideas}

- Some fall through the cracks. Some teachers only do minimal for children in school system so have inside view.

\section{Interpretation}

Residents are the human capital of a community, offering knowledge, skills, and attitudes. Empowering citizens to become involved in the decision-making process is crucial to the health of a community's civic infrastructure. Both private and public institutions must strive to ensure citizens are empowered and have an active role at the decision-making table. There must be lifelong opportunities to learn about good citizenship and ways to participate in community governance. These opportunities may include civics courses, internships, volunteer opportunities, focus groups, leadership development, and service on citizen advisory boards.

According to survey respondents, there is little happening in Fairmont to help develop and engage these human resources. With the vast majority of respondents either disagreeing with or not knowing about these statements, there appears to be a lack of engagement in civics education by government and the public schools. In summary, one in five residents feel that students receive effective education in school about how government works. About one in seven feel that training is available to neighborhood residents about how government works, and a little less than a third feel there are enough opportunities to volunteer in community/government activities. These negative opinions are even stronger in the Westside neighborhoods. For example, only $12 \%$ of the respondents in the Westside felt that there was adequate training available to those in the neighborhood about how government works, as compared to $22 \%$ of respondents living in other neighborhoods. 


\section{Recommendations}

Research shows that when given the opportunity, residents tend to engage in community-building activities. Therefore, it is essential to develop residents' capacity to actively participate in the governance process. In order to generate positive community outcomes, citizen education must become a top priority. Indicators of this commitment can include: (1) a specific number of school credits dedicated toward citizen education; (2) a high rate of diverse participation in adult citizen education programs; and (3) a high proportion of citizen education alumni participating in public decision making bodies. Promoting the Fairmont 101 program, and possibly expanding the initiative to include leadership and youth development programming could help accomplish these objectives. Community-based organizations can also contribute through board and volunteer training. 


\section{BUILDING LEADERSHIP IN THE COMMUNITY}

\section{Bob Riddle and Marissa Angellatta}

1. Our community has programs to develop and encourage new leaders.

$27 \%$ Agree

\section{$51 \%$ Disagree}

$22 \%$ Don't Know

2. Leadership program participants reflect the racial, ethnic, economic, and other groups in our community. $31 \%$ Agree

\section{3\% Disagree}

$26 \%$ Don't Know

3. Our city has a program to help neighborhoods organize for action.

$25 \%$ Agree

\section{4\% Disagree}

$31 \%$ Don't Know

4. Members of city boards and commissions receive training to serve in their roles.

$24 \%$ Agree

\section{$38 \%$ Disagree}

\section{$38 \%$ Don't Know}

\section{Comments and Ideas}

- When do our "other" like low income people- are able to run for offices and are elected to make a difference in the community

- If I am not aware of programs, then maybe not

\section{Interpretalion}

Many cities work with civic clubs and chambers of commerce to deliver leadership development programs that become the training ground for civic leaders. Fairmont could gain valuable information on building leadership from the National Civic League. The Civic Index calls for inclusive leadership that reflects the diversity of the community. It suggests that rather than being in charge, leaders should encourage participation from community members and facilitate discussions about meeting community needs. Through this approach leaders will be able to collaborate more effectively within the community, thus mitigating hostility and community disagreements.

With very low levels of agreement to the statements in this section of the survey, the data reveal there is a lack of encouragement and development of inclusive leadership in Fairmont. With the vast majority either disagreeing about availability or not knowing about leadership training, leaders may not be receiving proper development for success. Nearly $48 \%$ of respondents from the Westside neighborhoods do not believe leaders represent the diversity of the community, as compared to about $35 \%$ of respondents from other areas. Similarly $50 \%$ of Westsiders disagree that the City has programs to help build neighborhood leadership, as compared to just over $35 \%$ of respondents from other areas. This trend continues in responses 
to preparation for service on boards and commissions, with over $45 \%$ of Westsiders disagreeing as compared to $27 \%$ of other respondents.

\section{Recommendations}

Based on promising practices in the Civic Index, three recommendations can be made to the City of Fairmont. First, all different groups in the community should be actively encouraged to engage in leadership, which can begin with neighborhood organizing. Second, the community needs to provide leadership development programming, which can be done through partnerships among the City, business groups, and local colleges and universities. Third, training and development should continue in formal leadership positions with City boards and commissions. Leadership training should develop facilitative skills. Ultimately good leaders will listen, look for common ground, and remain open in creating plans, providing leadership opportunities for everyone in the community. 


\section{SUMMARY}

\section{Margaret Stout}

As noted in the introduction, indicators of a vital community include: a shared community identity and vision for the future; interactive roles for residents, government, community organizations, and businesses; bridging group boundaries of all types; cooperating by sharing information, reaching agreement, and learning from experience; and educating community members and developing leadership from all walks of life. In each aspect of civic infrastructure in Fairmont, there is room for improvement.

Through Fairmont's competition for the America's Best Communities award, community leaders have already established four strategic areas of development that will contribute greatly to civic infrastructure. In particular, the Great Neighborhoods goals and strategies will lay the groundwork for many aspects of the recommendations made herein. The pilot program in the Westside neighborhoods will model an approach to establishing a shared neighborhood identity and vision for the future, continuing into strategic planning that will consider interactive roles for residents, government, community organizations, and businesses in implementation. The methods used will establish participatory, collaborative practices for sharing information and reaching agreement that will build experiential knowledge and skills. Program and project plans developed through a logic model approach will lend themselves well to evaluation for ongoing improvement. Through a combination of community workshops, experiential learning, and responsibilities for outreach and organizing, community members will better understand the process and practices of self-governance, building leadership skills along the way. While not the only effort that can and should be made, this Fostering Fairmont project promises to make a great start toward building strong civic infrastructure.

\section{REFERENCES}

League, National Civic. 1999. The civic index: Measuring your community's civic health. Denver, CO: National Civic League. 


\section{Purpose}

A community profile provides key information about a particular geographic area and its people

$\square$ This profile provides baseline data for community visioning and planning efforts

$\square$ Continuing over the next 18 months!

\section{COMMUNITY PROFILE}

\section{What's included?}

We us a community capitals structure

$\square$ Natural Environment

$\square$ Cultural

- Human

$\square$ Social*

$\square$ Political

$\square$ Organizational

$\square$ Financial

$\square$ Built Environment

- * *o be considered in the Spring semester...

\section{Natural Environment Capital}

The natural features and environmental assets in the neighborhoods...

Bob Riddle and Lisa Lagana

\section{Topography}

\section{Natural Environment Capital}
Topography
$\square$ Soil
Climate
Open Space
Natural Resource Extraction
Environmental Quality 


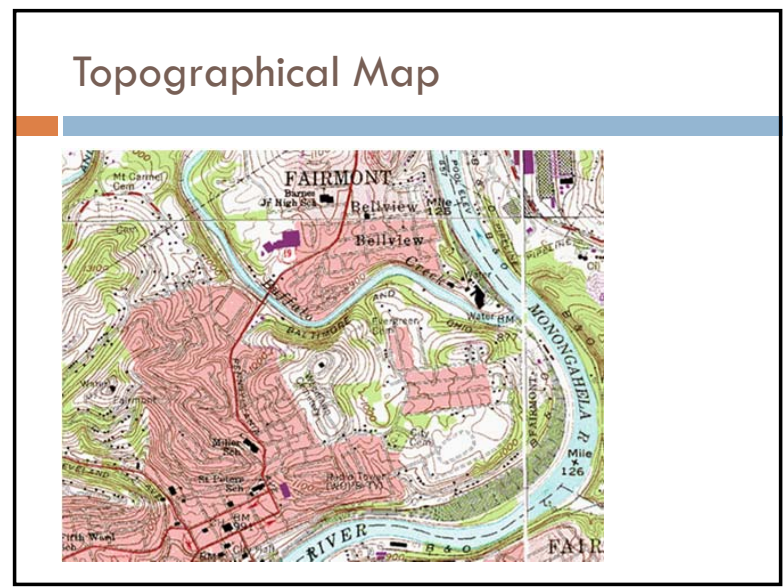

\section{Soil}

$\square$ Monongahela-Zoar Allegheny Soils
$\square$ Moderate to well-drained soils
$\square$ Very shallow soil, close to bedrock
$\square$ Shadyside
$\square$ Westmoreland Silt Loam
$\square$ Sterling Heights
$\square$ Culleoka \& Westmoreland Silt Loam
$\square$ The Ave
$\square$ Urban Land Culleoka
$\square$ The Dish
$\square$ Allegheny Silt Loam

\section{Climate}

\section{$\square$ Avg. temp}

$\square$ Low 42 degrees

$\square$ High 62 degrees

$\square$ Avg. precipitation

口 Rainfall - 39 inches

$\square$ Snowfall - 31 inches

$\square$ Avg. humidity $76 \%$

$\square$ Avg. wind speed $19 \mathrm{mph}$

$\square$ Growing season average 144 days

\begin{tabular}{|l|}
\hline Natural Open Space \\
$\square$ Forested areas \\
$\square$ Trails \\
$\square$ Wildlife watching \\
$\square$ Waterways \\
$\square$ Fishing \\
$\square$ Boating \\
$\square$ Swimming \\
\end{tabular}

\section{Integrated Open Space}

$\square$ Windmill Park

ㅁ 20 acres open fields

- Accommodates baseball, football, soccer, and basketball

$\square$ Children's playground

$\checkmark$ Covered picnic tables

$\square$ Many vacant lots

$\square$ Community gardens

$\square$ Pocket parks

$\square$ New development

\section{Planned Trails}

$\square$ Mon River Trail South (Rail Trail)

$\square$ Starts at Prickett's Fort State Park

- 5 miles North of Fairmont

$\square$ Connects to Morgantown

$\square$ Future plans to connect to Fairmont

- Marion County Connector Trail

- Accessible from Windmill Park 


\section{Monongahela River, Buffalo Creek}

$\square$ Boating, kayaking, and swimming $\square$ Minimum average depth 9.49 feet

$\square 61$ degrees

$\square$ Water Quality Concerns

$\square$ Acid mine drainage

$\square$ Eutrophication (nutrient accumulation)

口 Invasive species

$\square$ Fishing

$\square$ Bluegill, catfish, crappie, carp, bass, perch, muskie, drum, gar, sauger

\section{Natural Resource Extraction}

$\square$ Historical, not ongoing

$\square$ Evidence of strip mining and subsidence

$\square$ Areas of neighborhoods "filled"

$\square$ Fairmont Coke Works (1918-1979)

$\square$ A high carbon fuel product from bituminous coal

ㅁ 1993 Environmental Protection Agency started cleanup

of site and 2 on-site landfills

$\square$ 2015: cleanup is nearly complete

口 Future Brownfields Redevelopment Plans

- Volcano Island indoor water park \& resort

- Other development possibilities

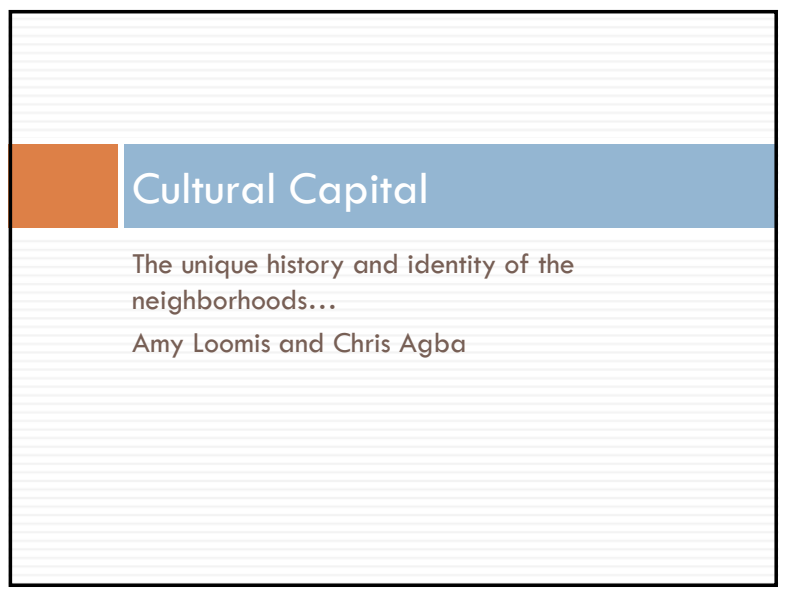

\section{Culturally Diverse Immigrants}

\section{Regional Characteristics}

$\square$ The West Fork, Tygart, and Monongahela Rivers

$\square$ Employment opportunities for all

$\square$ 1800s shipping and transportation jobs

$\square$ Navigable waterways and railroads

$\square$ Resource extraction

$\square$ High-quality coal, natural gas, glass, timber 


\section{Italian Cultural Influences}

$\square$ Organized crime headquartered in East Fairmont

$\square$ The Black Hand

$\square$ Famiglia Vagabonda (Wandering Family)

$\square$ Bootlegging, extortion, prostitution, narcotics

$\square$ May have contributed to rise in drug use and decline of

Westside neighborhoods (70s-80s)

$\square$ Invention of the Pepperoni Roll!

\section{Percent African American Residents}

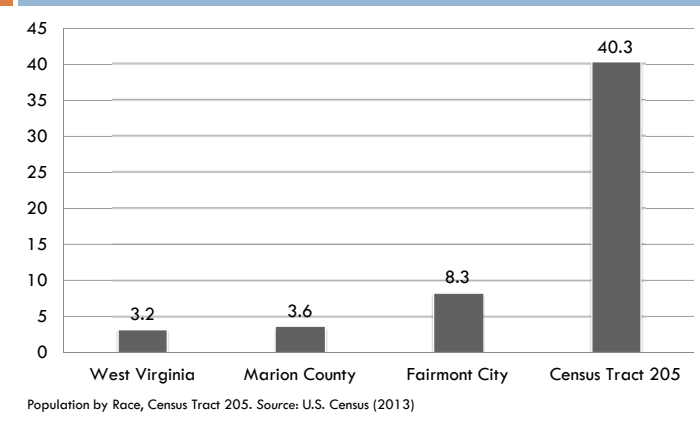

\section{An Historically Complex Mix}

Shadyside

$\square$ Historically more African American

$\square$ Sterling Heights

口 Historically more Caucasian

$\square$ The Maple Avenue area

$\square$ Historically more Caucasian

$\square$ Jackson Addition

$\square$ Historically African American

$\square$ Bellview

ㅁ Historically Caucasian

\section{African American Cultural Influences}

$\square$ Westside neighborhoods

- Shadyside

$\square$ Sterling Heights

$\square$ The Maple Avenue area

$\square$ Jackson Addition

$\square$ Primarily U.S. Census Tract 205

口 Over $40 \%$ African American/Black

a Fairmont overall- $8 \%$

口 State overall-3\%

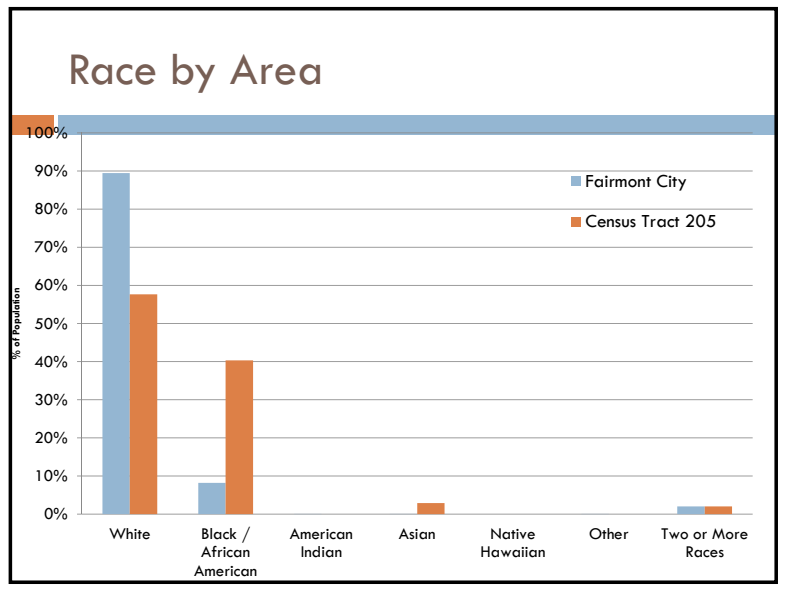

\section{Historic Economic Activities}

$\square$ A cultural tradition of self-sufficiency and mutual aid

$\square$ Home-based businesses

$\square$ African American-owned businesses

$\square$ Westside neighborhood businesses 


\section{Self-Sufficiency and Mutual Aid}

A long-standing African American tradition

Traditional African American cultural emphasis

$\square$ Communal solidarity

Mutual aid

$\square$ Mutual respect

$\square$ Mutual support

$\square$ Churches, civic and social organizations, founding of Dunbar school parallel these values and traditions!

\section{Supplemental Income}

Part-time jobs

$\square$ Cleaning

$\square$ Seamstress/tailor

$\square$ Maintenance

$\square$ Handyman

$\square$ Low-paying jobs

口Country Club

\section{Home-Based Businesses}

Homes-based shops and service businesses serve community

$\square$ Ms. Ann's snow-cones

$\square$ Ms. Charlotte's candy

$\square$ Home-based entrepreneurs

$\square$ Daycare

$\square$ Lawn care

$\square$ Accountancy

$\square$ Hair and beauty

\section{African American-Owned Businesses}

$\square$ Neighborhood (50s-70s):

$\square$ Parker Bequty School

$\square$ Whit's Restaurant, Mr. Fat's Restaurant

$\square$ Filling station

$\square$ Blacksmith

$\square$ Saw Robeson Convenience Store

$\square$ Gym

$\square$ Record shop

$\square$ Barbers

\section{Other Neighborhood Businesses}

30s-50s: Many family businesses, mostly immigrant-owned

$\square$ Maple Avenue toward Jackson Street

$\square$ Norwood Street Groceries, Jack's Groceries, Debatos Store

- Pacifico's Italian Deli

- Marty's Restaurant

- Mylan Drugstore and Beer Garden

$\square$ Concessions and school supplies stores

$\square$ 70s and beyond...

$\square$ \# of businesses on the decline starting 1958

$\square$ Business owners retired and closed shop

$\square$ New businesses did not open in their place

\section{Social Activities}

$\square$ Faith community

$\square$ Civic and social organizations

$\square$ Business meeting places

$\square$ Neighborhood park 


\section{Faith Community}

$\square$ Church traditionally had an important and central role in community life

$\square$ Trinity United Methodist is the oldest

口 Its 146 years old!

$\square$ Once one of the leading churches in the community

$\square$ Morning Star now has the largest congregation

$\square$ Since the 60s, the church has declined in position $\square$ Aging congregations, passing of older worshippers

$\square$ Aging pastors do not reach the youth

\section{Civic and Social Organizations}

$\square$ Settlement House

$\square$ Social services

$\square$ Black Elks \& Daughter Elks \# 148

$\square$ A social center!

$\square$ Restaurant and alcohol

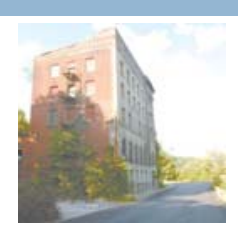

$\square$ Dancehall with live music weekly

$\square$ Apartments

$\square$ Black American Legion

$\square$ Scholarships, social dances, and holiday events

\section{Business Gathering Places}

$\square$ Westside spots

$\square$ Club Modi's

$\square$ Ann Ford

口 Mary Phillip's Chatterbox

$\square$ Nearby spots

$\square$ Rose Tea Room

$\square$ Theaters

- Fairmont Theater

- Lee Theater

- Virginia Theater

\section{Windmill Park}

$\square$ The center of social activities then...

a Formerly Testa Fairgrounds

$\square$ County fairs, softball games, carnival rides

$\square$ The center of social activity today!

$\square$ Now a city-owned park

$\square$ Some criminal activity...

$\square$ Residents maintain that it always has been safe

$\square$ Frank Hines Football Field dedication

口 October 11, 2015

\section{Local Sports Tradition}

$\square$ Dunbar School as the center of athleticism $\square$ Historic match between Dunbar High and Fairmont Senior

$\square$ 60s: "Pop" Warner football league

$\square$ Hills Bulldogs

$\square$ FOP Moosejets

$\square$ Idamay Black Diamonds

$\square$ 80s: Bulldogs as 612 MAC's youth team

$\square$ Hershel Walker, Henry Rome, and Frank Hines

$\square$ 2014: Bulldogs youth football restored

\section{Historic Buildings}

$\square$ Dunbar School

$\square$ Thomas C. Miller School

$\square$ Woodlawn Cemetery
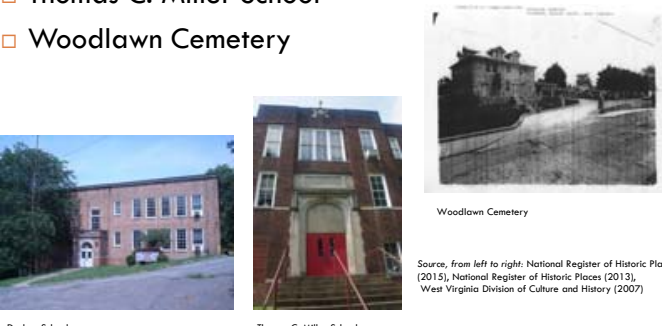

Woodlown Cemetery

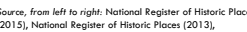

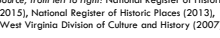




\section{Dunbar School}

$\square$ Dunbar School

$\square$ Founded 1867

- Original buildings constructed by the African American community!

$\square$ One of the first African American schools in West Virginia

$\square$ African American school until desegregation in 1955

$\square$ Not all teachers found placement after integration

$\square$ Existing structure built in 1928...

$\square$ Historic Register

$\square$ Now owned by the Dunbar School Foundation

\section{Thomas C Miller Public School}

Built in 1914

Annex added in 1928

$\square$ Reflection of population doubling from 1900 to 1910

$\square$ Will be converted into senior living

\section{Evergreen Cemetery}

$\square$ A perceived need for an African American Cemetery

$\square$ Est. 1935 by John Williams

\section{Black History Museum}

Fairmont's rich African American history repository at the Dunbar School facility

$\square$ Under development by Charlotte Meade

\section{Woodlawn Cemetery}

$\neg$ Est 1875

- Private burial ground

$\square$ Governors, legislators, veterans dating back to Revolutionary War

$\square$ Policy prevented African American burials until integration

$\square$ New graves can be added today but must comply with the original design intent

\section{Who's Who?}

$\square$ The Meade Family

$\square$ One of Fairmont's first families

$\square$ John Darcus and Fred Stubbs

$\square$ African American Union Organizers

$\square$ Dewey Fox

$\square$ Organized the Fairmont branch of the NAACP

$\square$ Gregory Hinton

$\square$ Fairmont City Council and Mayor

$\square$ Lawyer and FSU Professor 


\section{Who's Who?}

W. O. Armstrong

$\square$ Dunbar Principal

$\square$ Contemporary of W.E.B. Du Bois

$\square$ George "Spanky" Roberts

a First of the Tuskegee Airmen

$\square$ Johnnie Johnson

$\square$ Blues musician

$\square$ Rock and Roll Hall of Fame

Professional Athletes
Who's Who?

$\square$ Professional Baseball

口 "Toothpick" or "Sad" Sam Jones

-1948-1967 many teams, many leagues!

$\square$ Ted Echols

- Chicago Cubs 1972

$\square$ Professional Football

口 Calvin Eugene Turner

- Tampa Bay Buccaneers 1987

$\square$ Rashod Kent

- Houston Texans 2003
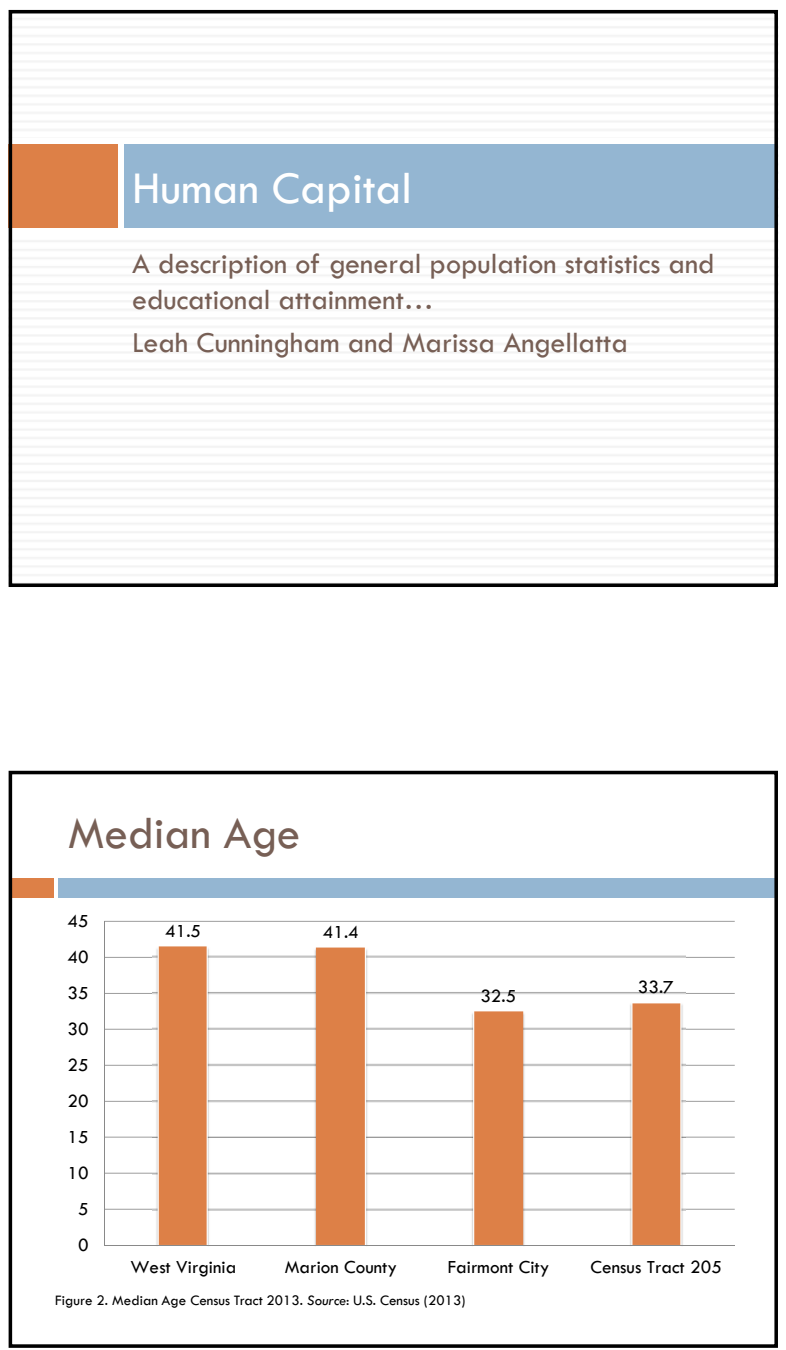

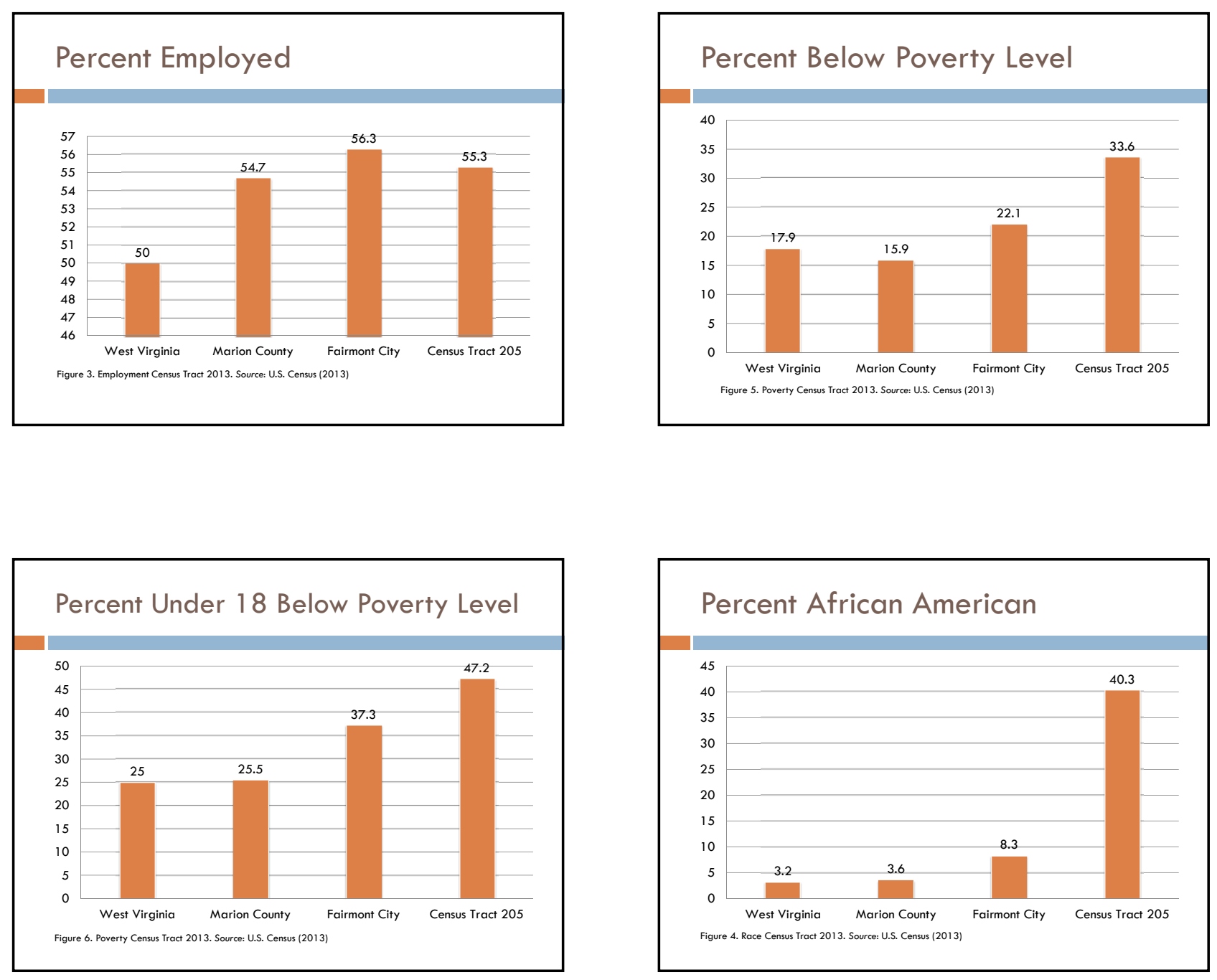

\section{Population Characteristics}

Fairmont overall has experienced a decline in population after 1970

口 "Brain Drain" phenomenon

$\square$ Census Tract 205 is unique

$\square$ Significantly higher poverty levels

$\square$ Concentration of African American residents

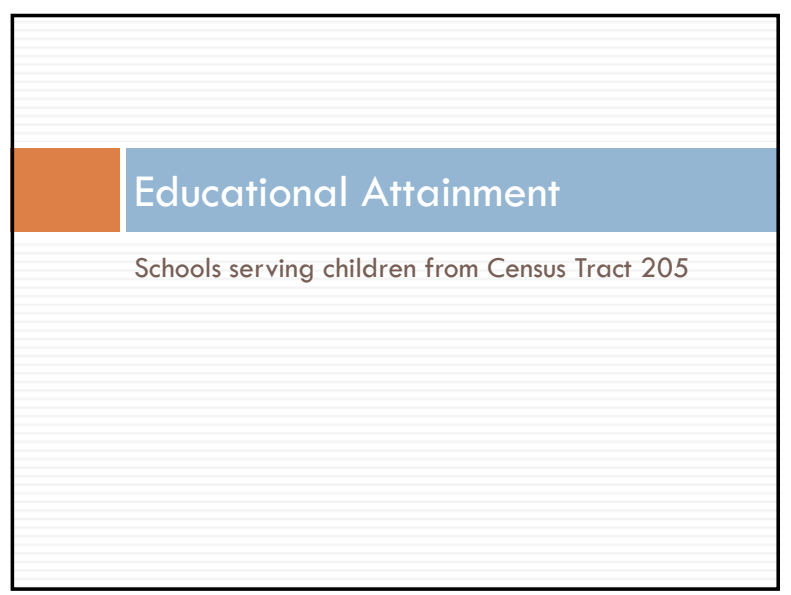




\section{High School Graduate or Higher}

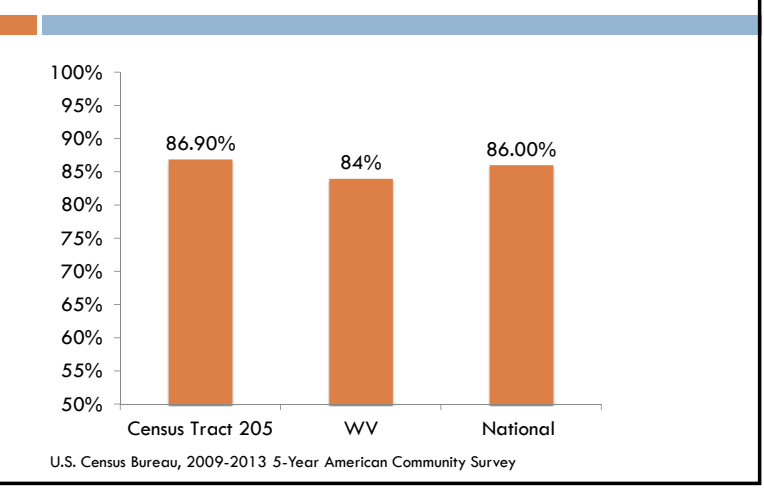

\section{School District Characteristics}

$\square$ Marion County Board of Education

$\square$ Superintendent of Schools, Gary Price

$\square$ Shifting standardized tests

$\square$ WESTEST

$\square$ WESTEST 2

$\square$ West Virginia Summative Assessment

$\square$ West Virginia Next Generation Standards

$\square$ Higher expectations in mathematics and ELA

\section{Bachelor's Degree or Higher}

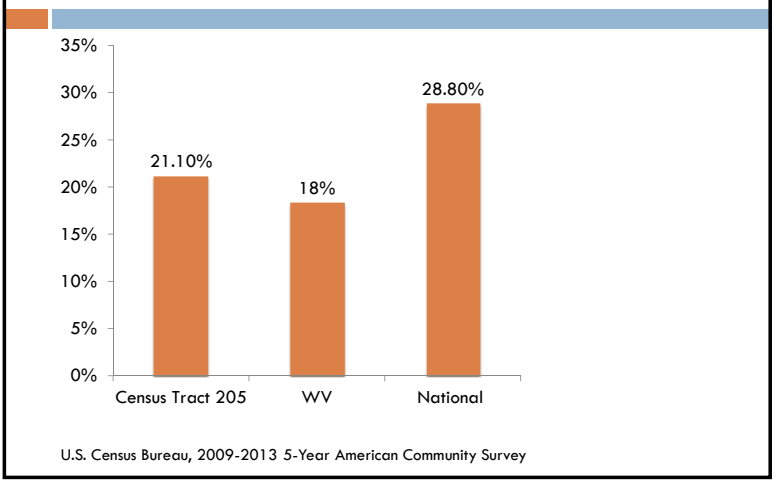

\section{Neighborhoods' Schools}

$\square$ Youth from Census Tract 205 attend...

$\square$ Watson Elementary

$\square$ West Fairmont Middle School

$\square$ Fairmont Senior High School

\section{Federal Title I Policy and Programs}

$\square$ Improving the Academic Achievement of the Disadvantaged

$\square$ To ensure that all children have a fair, equal, and significant opportunity to obtain a high-quality education

$\square$ To ensure that all children reach minimum academic achievement standards

$\square$ Schoolwide programs to improve curriculum $\square 40 \%$ or more students from low-income families

\section{West Virginia Accountability Index}

$\square$ Assigns points to schools for multiple measures of student performance

$\square$ Statewide general test

$\square$ Summative assessments or reading/language arts and mathematics

$\square$ Graduation rates for high schools

$\square$ Attendance rates for elementary and middle schools

$\square$ WVAl School Designation based on the scores from Annual Measurable Objectives (AMOs) 


\section{WVAI Designations}

\section{$\square$ Success}

$\square$ The school has met its target score, and the majority of its student subgroups are making academic progress.

$\square$ Transition

$\square$ The school has met its target score or has demonstrated that a majority of its subgroups are making academic progress.

$\square$ Support

$\square$ The school has not meet its target score and has not demonstrated that a majority of its subgroups are making sufficient academic progress.

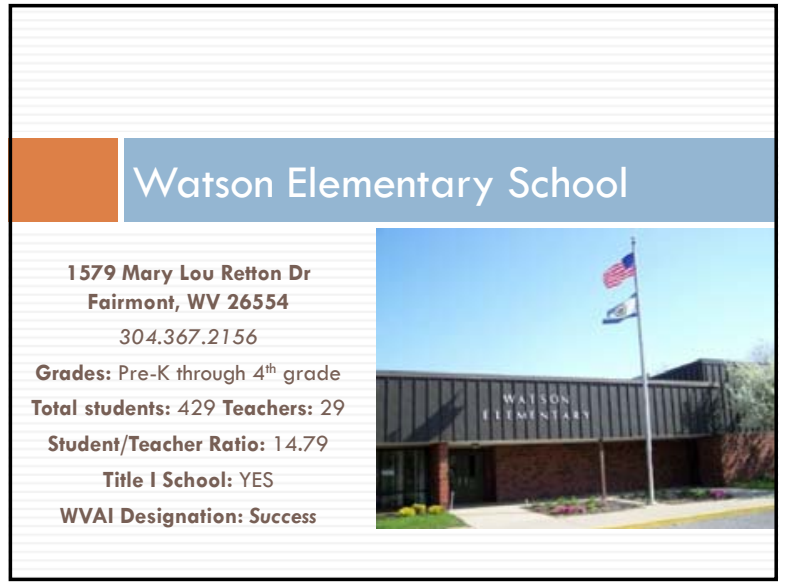

\% Low Socio-Economic Status by Race

\section{Enrollment by Race}

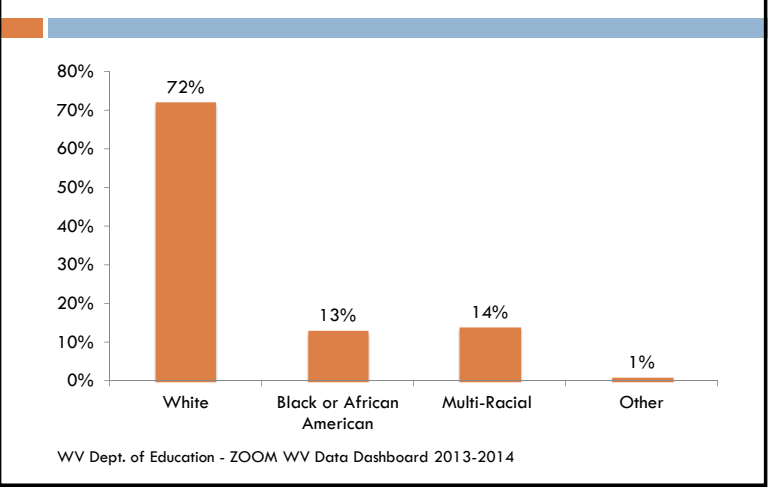

\section{\% Meeting Grade Level Expectations}

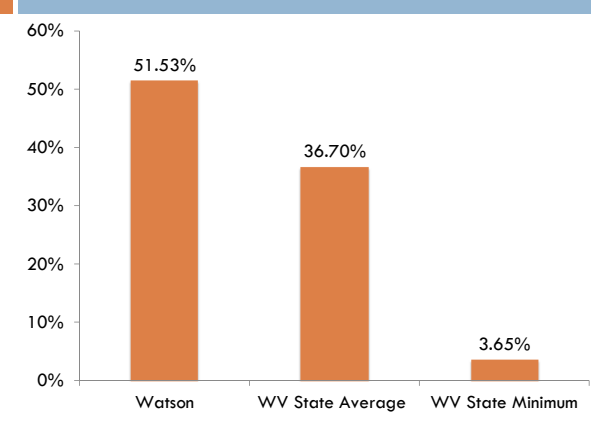

WV Dept. of Education - ZOOM WV Data Dashboard 2013-2014
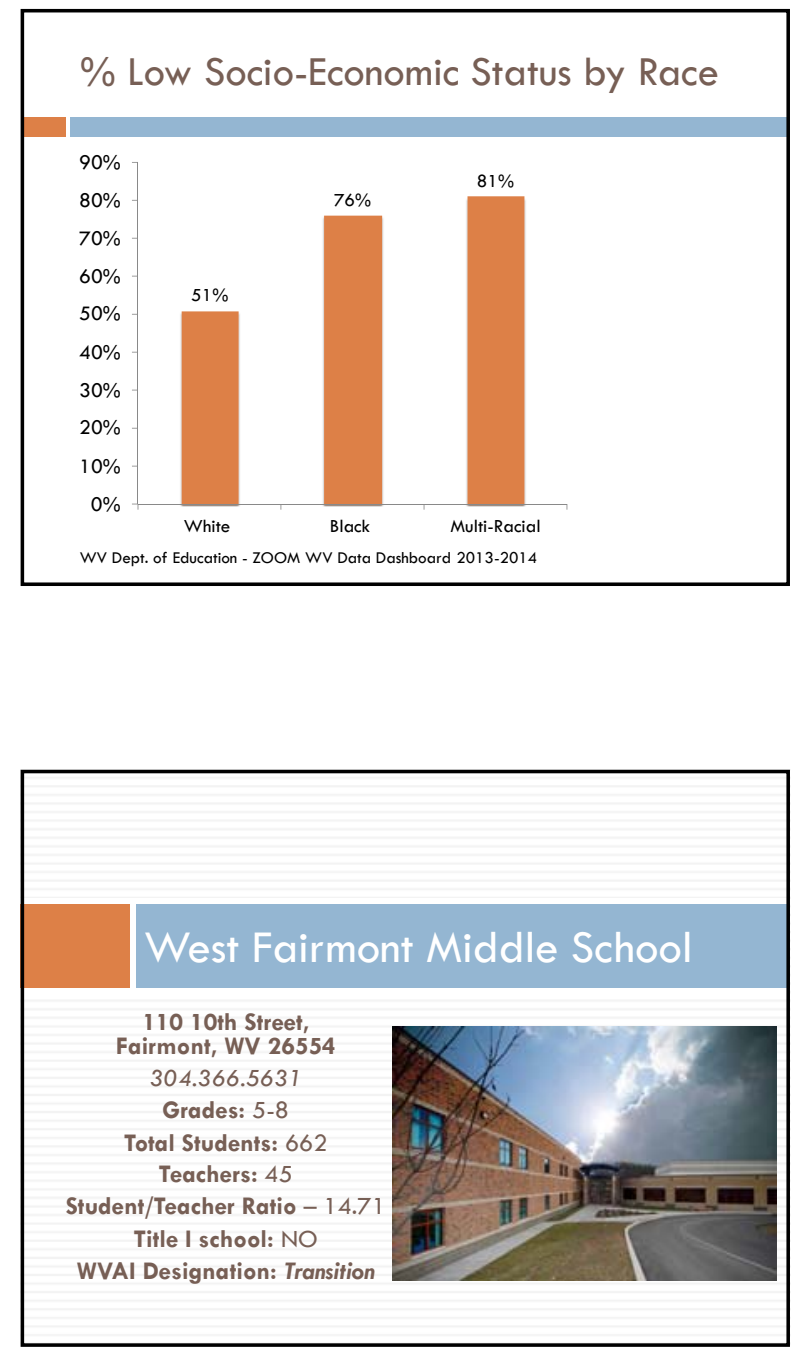

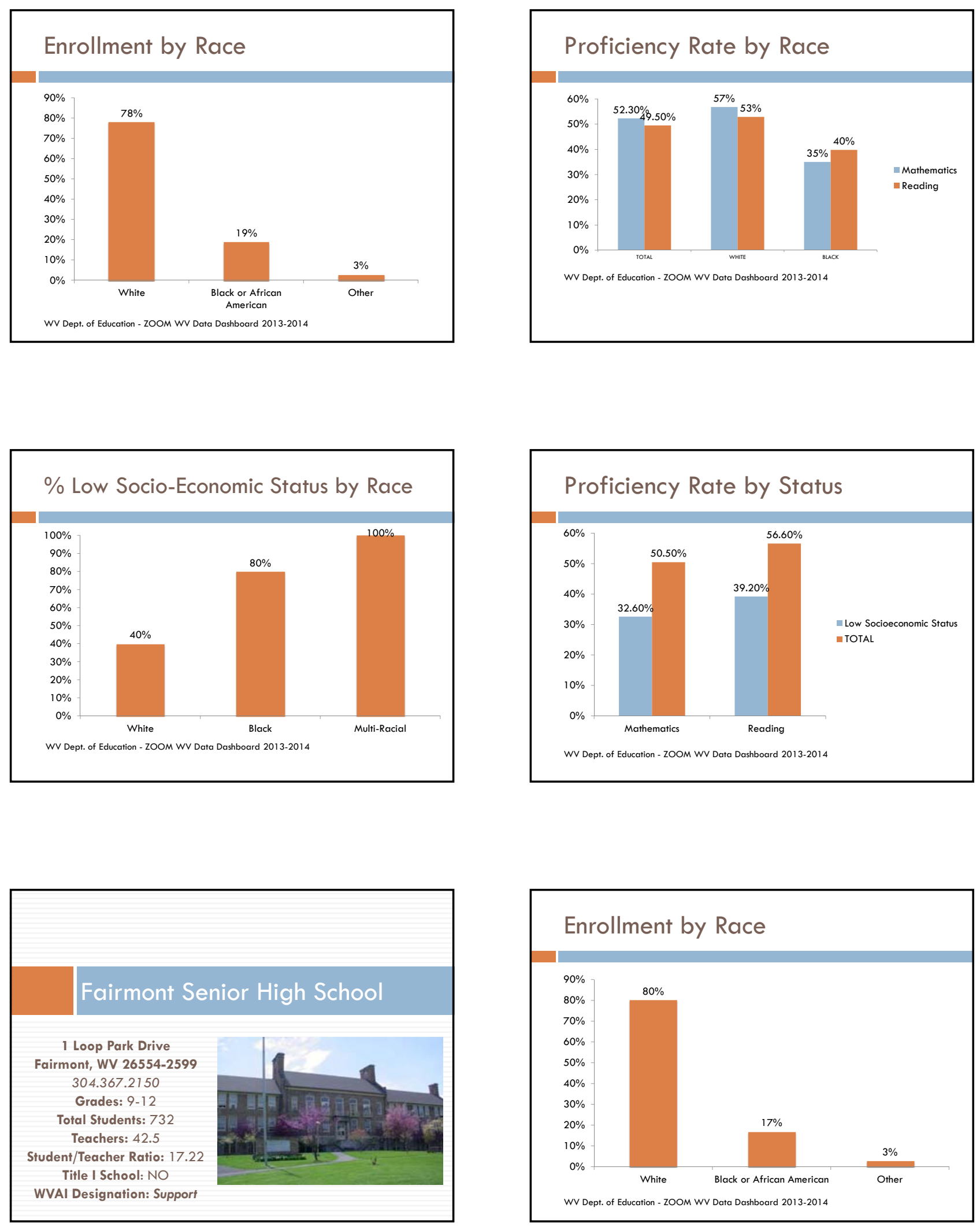

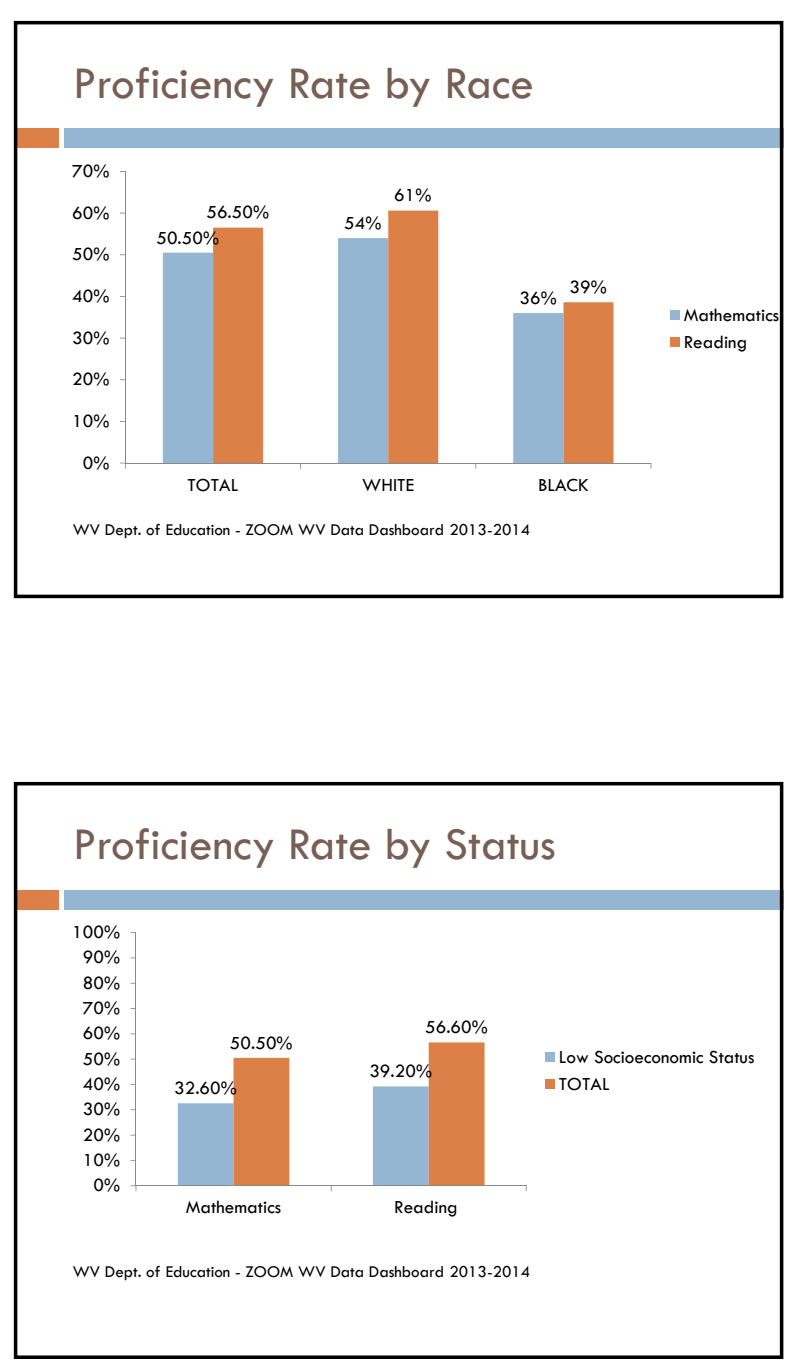

\section{Educational Attainment}

Students from Census Track 205 experience a decline in educational attainment as they progress in school

$\square$ Watson Elementary

$\square$ Title I school

$\square$ Success Designation (highest)

$\square$ West Fairmont Middle

$\square$ No Title I

$\square$ Transition Designation (middle)

$\square$ Fairmont Senior High

$\square$ No Title I

$\square$ Support Designation (lowest)

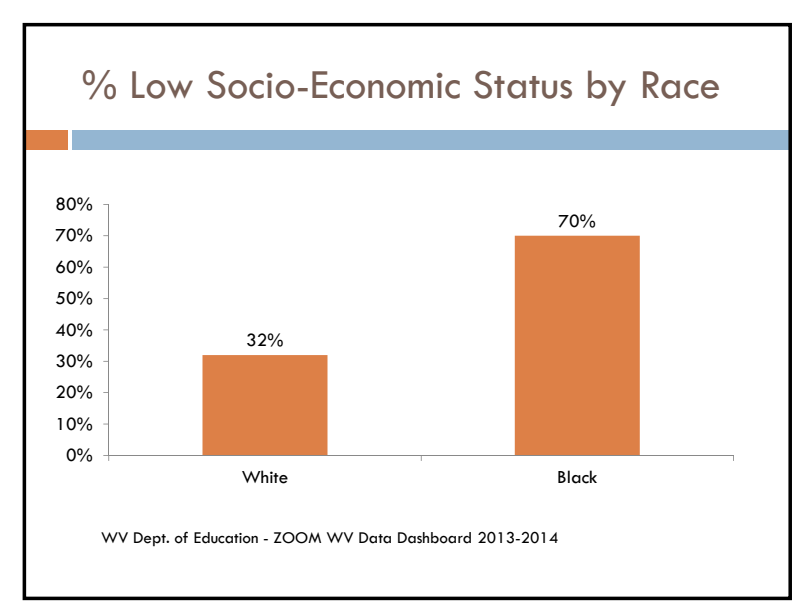

\section{High School Graduation Rate}
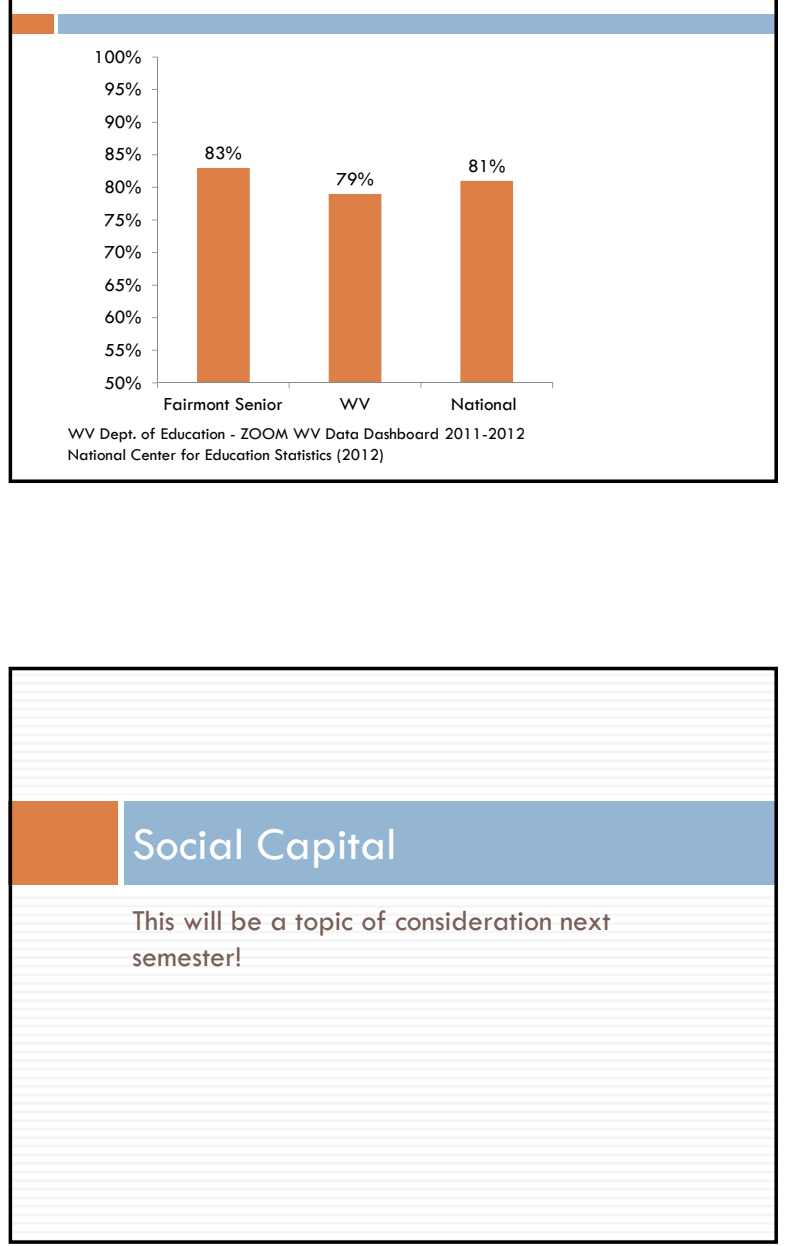


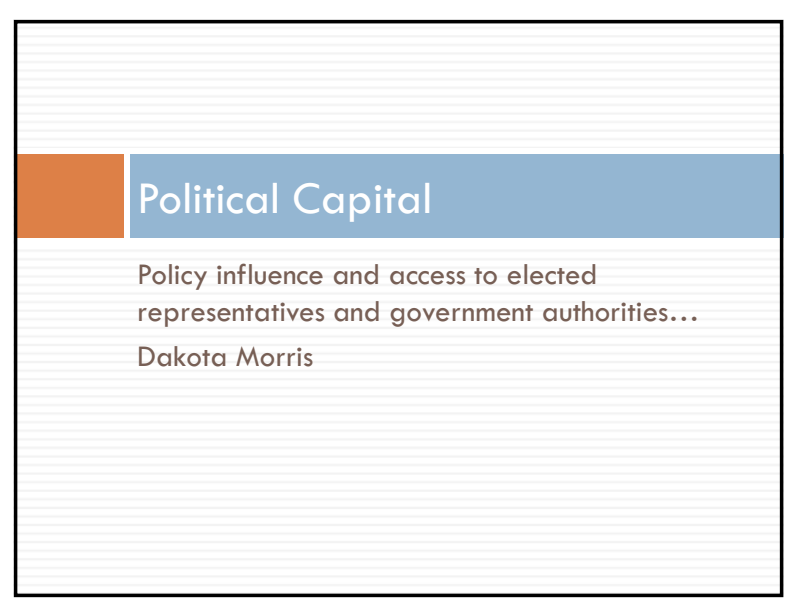

\section{Federal and State Representation}

$\square$ Federal Representatives

- Senator Joseph Manchin III (office located in Fairmont)

$\square$ Senator Shelley Moore Capito

$\square$ Representative David McKinley

$\square$ WV $13^{\text {th }}$ Senatorial District

$\square$ Senator Roman Prezioso

$\square$ Robert Beach

$\square \mathrm{WV} \mathrm{50} 0^{\text {th }}$ Delegate District

$\square$ Linda Longstreth

- Tim Manchin

$\square$ Mike Caputo

\section{Relevant Government Authorities}

Federal and State Delegates

County Government

$\square$ School District

$\square$ Municipal Government

$\square$ Municipal Court

\section{Marion County Government}

$\square$ County Commission

$\square$ Assessor

$\square$ Sherriff

- County Clerk

$\square$ Marion County Health Department

$\square$ Marion County Department of Homeland Security and Emergency Management

\section{Marion County Commission}

$\square 3$ members serve six year rotating terms

$\square$ Magisterial Districts

$\square$ Paletine

$\square$ Middletown

$\square$ West Augusta

$\square$ Meets on Wednesdays at 10:00 AM.

\section{Assessor and Sherriff}

$\square$ The Assessor determines the value of real and personal property each fiscal year

$\square$ The Sherriff serves not only as the chief law enforcement officer of the county but also as the tax collector and Treasurer 


\section{County Clerk}

$\square$ Issues licenses

$\square$ Marriage, hunting, fishing

$\square$ Issues certified copies of vital records

$\square$ Birth, death and marriage certificates

$\square$ Chief election officer of the county

$\square$ Voter registration and election results

$\square$ Bookkeeping

\section{Health and Safety}

$\square$ Marion County Department of Health

$\square$ Provides public health services

$\square$ Marion County Department of Homeland Security and Emergency Management

$\square$ Helps organizations prepare for and cope with disasters and emergencies as they occur

\section{Marion County School District}

Board of Education members:

$\square$ President Richard Pellegrin

$\square$ Dr. Babette Sims

$\square$ Janette Crespenzi

$\square$ Thomas Dragch

- Mary Joe Thomas

$\square$ Superintendent of Schools

$\square$ Gary Price

$\square$ Meets first and third Mondays of each month at 6:00

PM in Fairmont.

\section{City Council}

9 members from 9 districts

$\square$ Elected at large

$\square$ Westside districts'

口5: Fran Warner(yellow)

$\square$ 4: Bill Burdick (pink)

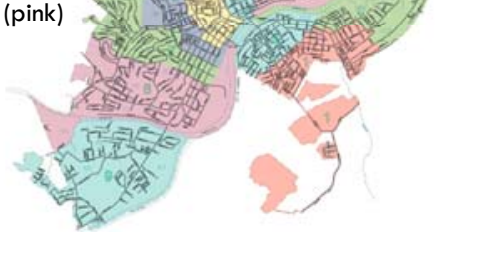

\section{Fairmont Municipal Government}

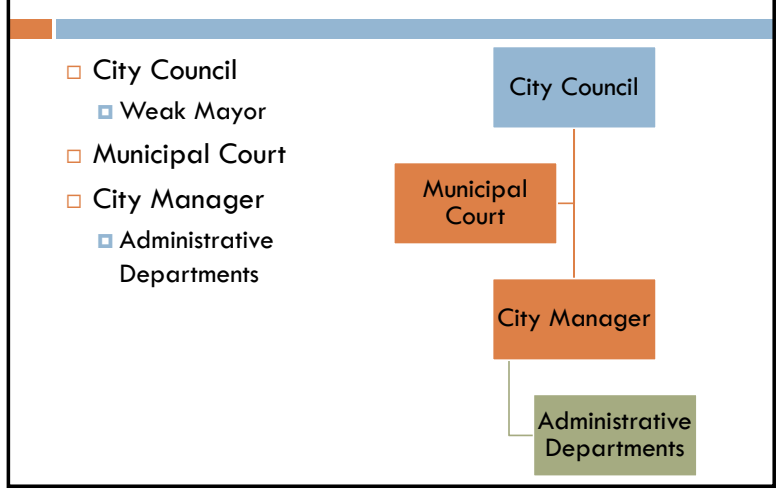

\section{Mayor}

$\square$ Ron Straight

$\square$ Mayor elected by the Council (weak)

$\square$ Serves as chair of the City Council meetings

$\square$ Represents the City Council at public events

$\square$ No veto power

$\square$ No administrative authority 


\section{Municipal Court}

$\square$ Municipal Judge is appointed by the City Council

$\square$ Must be an attorney is good standing of the Marion County Bar Association

$\square$ Serves a 4 year term

$\square$ Criminal jurisdiction over city ordinances

$\square$ Criminal jurisdiction of a West Virginia magistrate $\square$ Within the City's and Fairmont Police Department's jurisdictions

\section{City Manager}

Robin Gomez

Appointed by City Council

$\square$ Serves as Chief Administrative Officer for the City

$\square$ Prepares agendas for City Council meetings

$\square$ Participates in City Council meeting discussion but possesses no voting power

\section{Administrative Departments}

$\square$ Legal Departments

$\square$ City Attorney

$\square$ Department of Building Inspection and Rental Registration

$\square$ Administrative Departments

$\square$ City Clerk

$\square$ Marketing and Communications

$\square$ Finance Department

ㅁ Human Resources

$\square$ Purchasing

$\square$ Operations Departments

口 Planning and Development Department

a Public Works

$\square$ Utilities

$\square$ Water and Wastewater

\section{Legal Departments}

$\square$ City Attorney: Kevin Sansalone

$\square$ Serves as legal counsel to City Council and City Manager

$\square$ Provides legal opinions for the city

$\square$ Prepares and reviews contracts and agreements

$\square$ Researches and prepares city ordinances

$\square$ Department of Building Inspection and Rental

Registration: Inspector Ken Fletcher

$\square$ Enforces building codes and rental

$\square$ Issues building permits

口 Provides necessary forms, applications, and assistance

\section{Administrative Departments}

\section{$\square$ City Clerk: Janet Keller}

$\square$ Provides staff support to City Council

$\square$ Takes minutes of meetings

$\square$ Files and stores legal documents

$\square$ Publishes notices

$\square$ Provides clerical service to Police and Fire Civil Service Commissions

$\square$ Serves as the Chief Election Official of Municipal Elections

\section{Administrative Departments}

$\square$ Marketing \& Communications: Hanna Weaver, Mgr.

$\square$ Upcoming events and news related to the City

$\square$ Fairmont 101 citizen education program

$\square$ Finance Department: Eileen Layman, Director

$\square$ Business licensing

$\square$ Taxation

$\square$ City service fees

$\square$ Human Resource Department: Debra Erdie, Asst. $\square$ Manages City employment

$\square$ Purchasing: Paula Friend, Coordinator $\square$ Manages bids and procurement 


\section{Operations Departments}

Planning \& Development: Mark Miller, City Planner

口Advises City Council, the Planning Commission, and Urban Renewal Authority on zoning and land use regulations, comprehensive city planning

$\square$ Prepares and manages grants and other funding opportunities for the city

$\square$ Manages parks and recreation facilities

$\square$ Public Works: Ron Miller, Director

$\square$ Manages and maintains city streets and signage

\section{Utilities}

$\square$ Utility Manager: David Sago

$\square$ Water Department: Chip West, Superintendent $\square$ Operates filtration and delivery of water to households and businesses

$\square$ Manages the meter department for billing

$\square$ Wastewater Department: Billie Johnson, Superintendent

$\square$ Manages and maintains the sewer system

$\square$ Operates wastewater treatment

$\square$ Supports engineering and field services needs of other City departments

\section{Public Safety}

Police Department: Chief Steve Shine

$\square$ Law enforcement

D.A.R.E.

$\square$ Fire Department: Chief James Emerick

$\square$ Fire prevention and suppression

$\square$ Vehicular Rescue

$\square$ Hazardous Material Spills

\section{City Boards and Commissions}

22 boards, commissions and authorities

ㅁ 14 are defined within the Code of Ordinances

\section{City Boards and Commissions}

$\square$ Personnel Appeals Board

$\square$ Police Civil Service

Commission

- Fire Civil Service Commission

$\square$ ICC Board of Appeals

$\square$ Safety Review Board

$\square$ Fairmont Audit Committee

$\square$ Fairmont Airport Authority

$\square$ Fairmont Parking Authority

Fairmont Sanitary Sewer

Board

$\square$ Fairmont Water Board
Planning and Zoning Commission

Board of Zoning Appeals

Arts \& Humanities

Commission

$\square$ Historic Landmarks Commission

$\square$ Historic Preservation Review Committee

Fairmont Parks Commission

$\square$ Urban Renewal Authority

\section{Regional Boards and Commissions}

$\square$ Fairmont/Morgantown Housing Authority

$\square$ Fairmont-Marion Transit Authority

$\square$ Marion County Parks \& Recreation Commission

- Marion County Public Library Trustee Board 


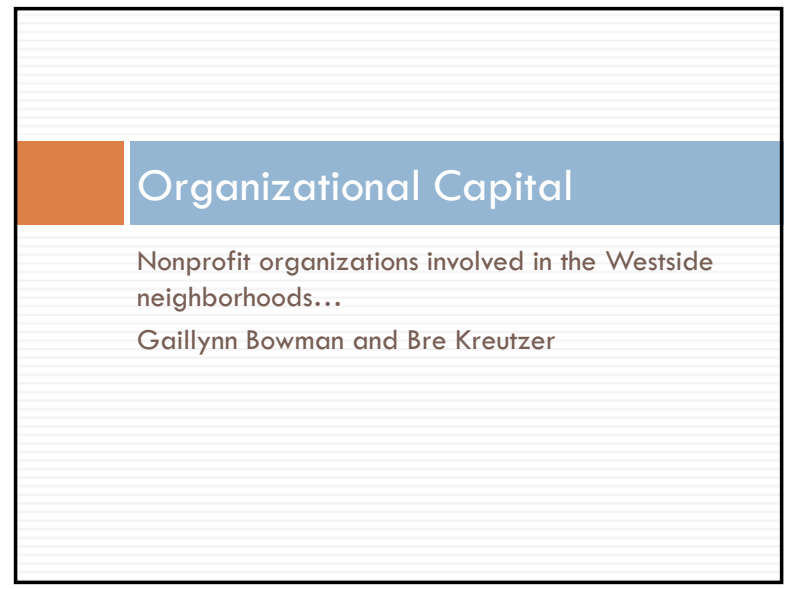

\section{Faith Community}

Serves the community via:

$\square$ Providing a common moral foundation

$\square$ A sense of identity and belonging

$\square$ Social activities

$\square$ Youth programming

$\square$ Outreach to senior citizens

口Employment opportunities

\section{Types of Organizations}

Faith Community

$\checkmark$ Civic Organizations/Chapters

$\square$ Community-Based Organizations

$\square$ Nonprofit Community Development Organizations

$\square$ Universities and Colleges

\section{Congregations}

$\square$ Churches within the Westside neighborhoods

$\square$ Morning Star Baptist Church

$\square$ Women of Purpose Ministry

$\square$ Mt. Zion Baptist

$\square$ Temple of Christ

$\square$ Church of God MPGT

$\square$ Churches widely attended by Westside residents

$\square$ Christian Love Ministry

$\square$ Trinity United Methodist

\section{Freemasons}

$\square$ No longer active

Membership groups designed to be of service to the community and provide mutual benefit to members

$\square$ Informal associations

$\square$ Chapters of national organizations 


\section{African American Order Eastern Star}

$\square$ Associated with the Freemasons

$\square$ Founded in 1874

$\square$ Oldest sorority-based Black women's organization in America

$\square$ Still active in Fairmont's Westside

$\square$ Meets twice a month during the summer

\section{NAACP}

$\square$ National Association for the Advancement of Colored People

$\square$ Marion County Chapter

$\square$ Mission: to ensure the political, educational, social, and economic equality of rights of all persons and to eliminate race-based discrimination

a Particularly pertinent to the Westside's historically African American community

\section{Dunbar School Foundation}

Founded in 2008 by Houston Richards

$\square$ Seeks to preserve the heritage of the community school built in 1928

口 Predominantly African American until integration in 1955

$\square$ Seeks to renovate and preserve the building to house inclusive community activities

$\square$ Currently developing a repository for the Marion County African American History Museum

\section{West Side Robotics}

\section{Fairmont Community Youth Development Center (FCYDC)}

$\square$ Youth development organization

口 Previously 612 MAC (Madison Avenue Center) (to 2011)

a Re-established in 2014

$\square$ Mission

To provide children with a safe place to spend time with other youth during leisure time as well as provide programming contributing to the development of Fairmont's Westside youth

$\square$ Programs

$\square$ Youth sports leagues

$\square$ Mentorship and tutoring in Marion County

$\square$ Began programs with Fairmont Senior High School

$\square$ Students act as mentors to students at Jayenne

Elementary and West Fairmont Middle School

$\square$ Provides training, support, and equipment to teams who wish to participate in robotics competitions $\square$ LEGO League tournaments

$\square$ Enhances STEM (science, technology, engineering, and math) education

$\square$ Operates out of Dunbar School ancillary building
- Established in 2009 by Willie James to serve youth 


\section{Nonprofit Development Agencies}

$\square$ Organizations established specifically for community and economic development activities

$\square$ Economic development purposes included in Financial Capital
Fairmont Community Development Partnership

$\square$ Established in 1992

$\square$ A NeighborWorks America strategic partner

口 Funded by the Federal Home Loan Bank, US Housing and Urban Development, USDA, and WV Development Office

$\square$ Develops quality, affordable housing in Fairmont

$\square$ Both construction and rehabilitation

- Owner-occupied housing

- Rental housing

- Commercial buildings

$\square$ Home-ownership counseling

$\square$ Supports general neighborhood improvement

\section{Fairmont-Morgantown} Housing Authority

$\square$ Quasi-governmental nonprofit organization

$\square$ Programs...

$\square$ New housing construction

$\square$ Housing rehabilitation services

$\square$ Commercial real estate services

$\square$ Rental assistance

$\square$ Residential property management

$\square$ Community development supports

$\square$ Housing counseling

$\square$ Recently awarded contract from City of Fairmont

$\square$ Renovate Miller School as senior housing

\section{Marion County Habitat for Humanity}

$\square$ An affiliate of Habitat for Humanity of West Virginia

Headquartered in Fairmont

Mission...

$\square$ To put God's love into action by bringing people together to build homes, communities, and hope

$\square$ Builds and remodels affordable housing

$\square$ Active in the Westside neighborhoods

\section{Colleges and Universities}

Institutions of higher education often provide faculty outreach and student service learning in communities
Blighted, Abandoned, Dilapidated Buildings

A small volunteer group inspired by the WV Redevelopment Collaborative

$\square$ Northern Brownfields Assistance Center at WVU

$\square$ Creating an inventory of structures that need to be demolished or renovated to support community revitalization

$\square$ Will help establish programs to address various scenarios found 


\section{Pierpont Community/Technical College}

$\square$ Campus in downtown Fairmont

$\square$ Two-year degree programs

$\square$ Education toward good paying jobs

$\square$ Transfer education to four-year institutions

$\square$ Affordable tuition rates

$\square$ Academic programs

$\square$ Business, Aviation \& Technology

$\square$ Health Careers

口 Human Services

$\square$ Workforce Education

\section{Fairmont State University}

$\square$ Located in south Fairmont

$\square$ Baccalaureate programs

Wide variety

$\square$ Master's degree programs

$\square$ Education and Teaching

$\square$ Criminal Justice

Business Administration

$\square$ Architecture

$\square$ Community outreach and service learning

$\square$ Architecture design studios

$\square$ The Black Student Union

- Tutoring and school supplies to Fairmont Youth Community Development Center

\section{West Virginia University}

$\square$ Located in Morgantown

$\square$ All level degree programs

$\square$ Extension Service programs in every county

$\square$ Various departments conduct community outreach and service learning

$\square$ Department of Public Administration's Fostering Fairmont initiative!

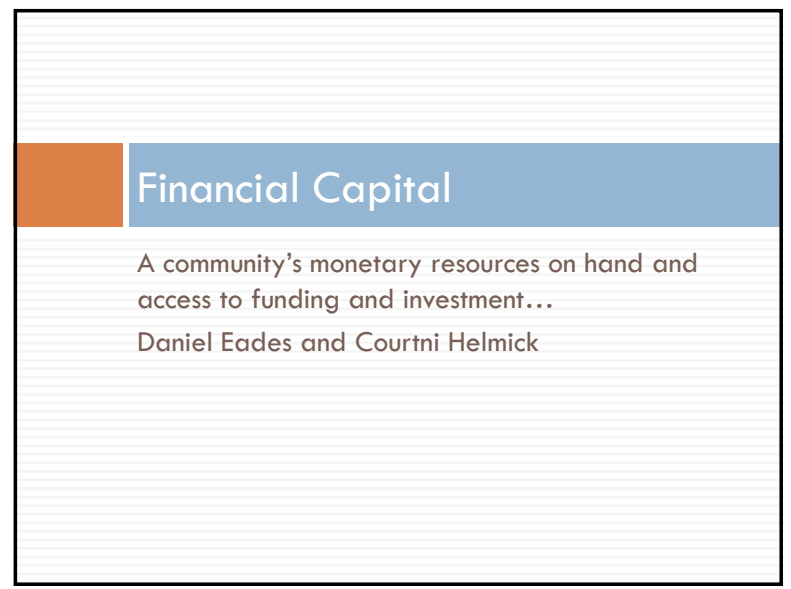

\section{Sources of Income}

\section{Financial Resources}

$\square$ Individual income, savings, credit

$\square$ Business investment, credit

$\square$ Governmental tax revenue, grants-in-aid

$\square$ Civic and social entrepreneurship, volunteerism

$\square$ Nonprofit grants, charitable giving

$\square$ Assets to leverage

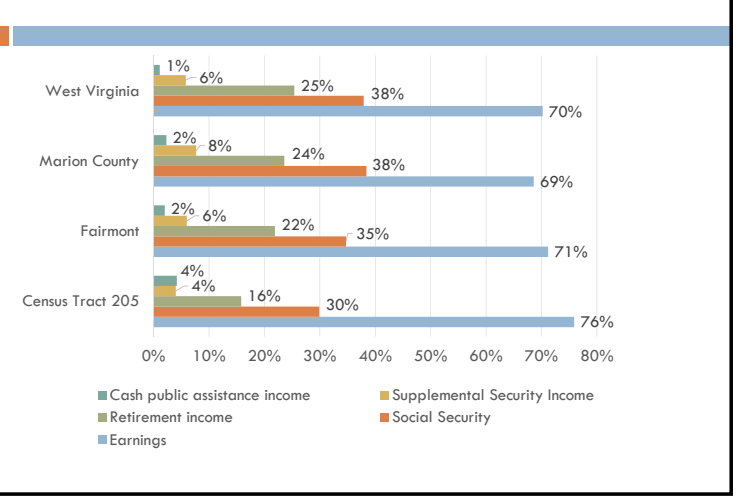



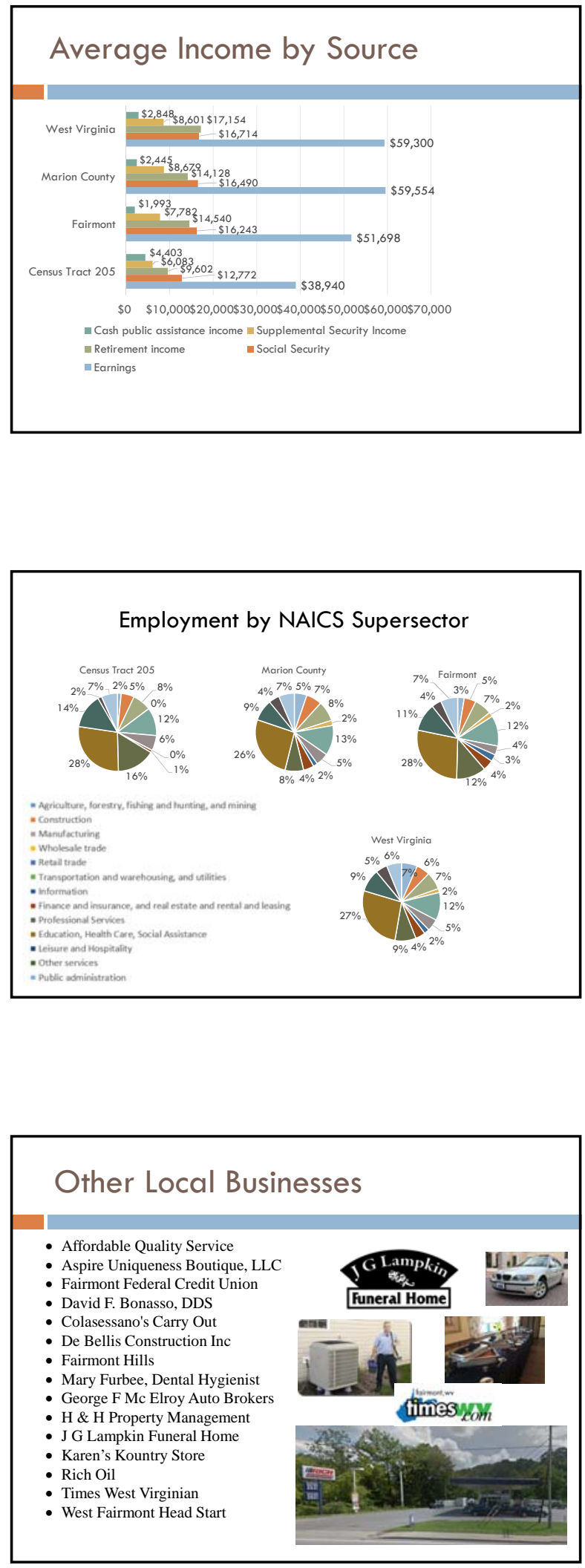
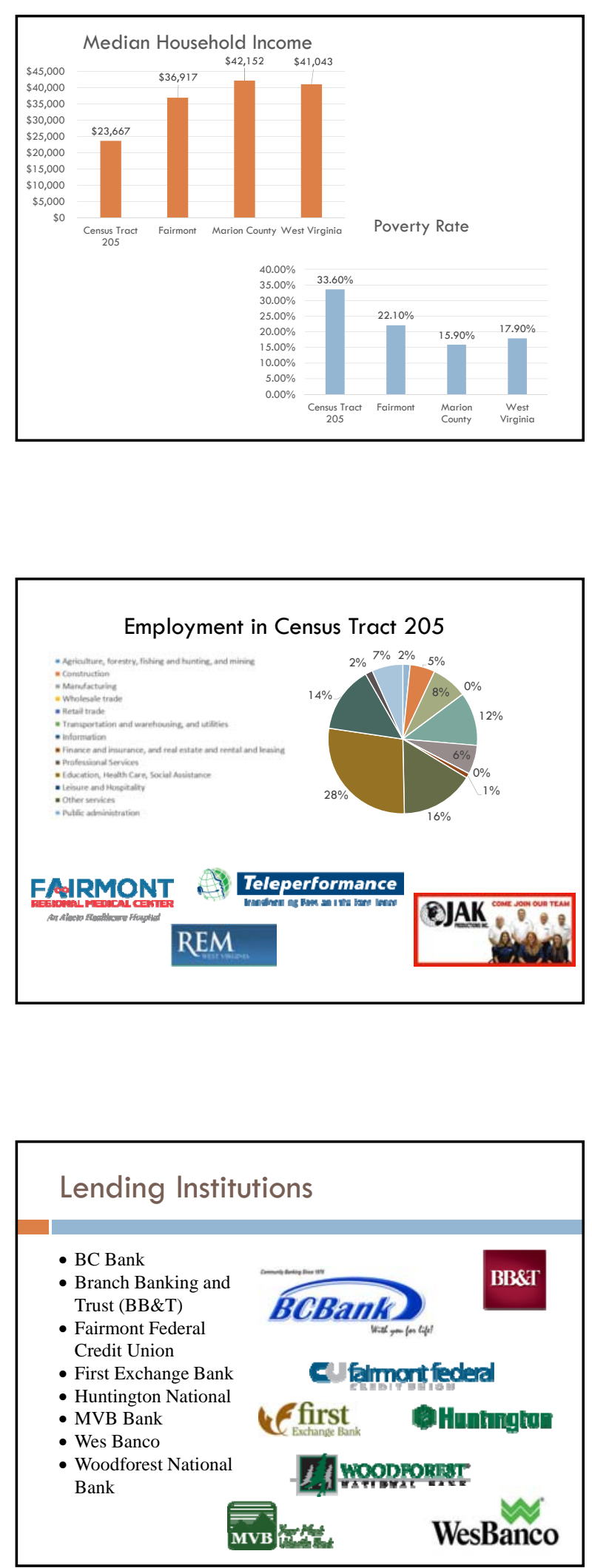


\section{Economic Development Organizations}

- The Marion County

Chamber of Commerce

- Marion Regional

Development Corporation

- I-79 Development Counci

- High Technology

Foundation

- Fairmont Renaissance

Corporation

- Vandalia Heritage

Foundation

- Fairmont Urban Renewal

Authority

- Main Street Fairmont

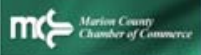

DEVELOPMENT

DOUNCIL

WNHTC

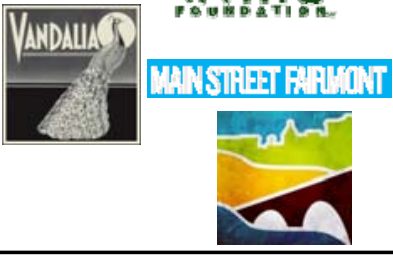

\section{Mainstreet Fairmont}

$\square$ Community and economic development organization $\square$ Volunteer driven

$\square$ Creating efforts to improve the overall quality of life in Fairmont

$\square$ Working though America's Best Communities Competition on a four pillar initiative to revitalize the community

$\square$ Working to connect businesses with the Westside Action Coalition for Windmill Park improvements

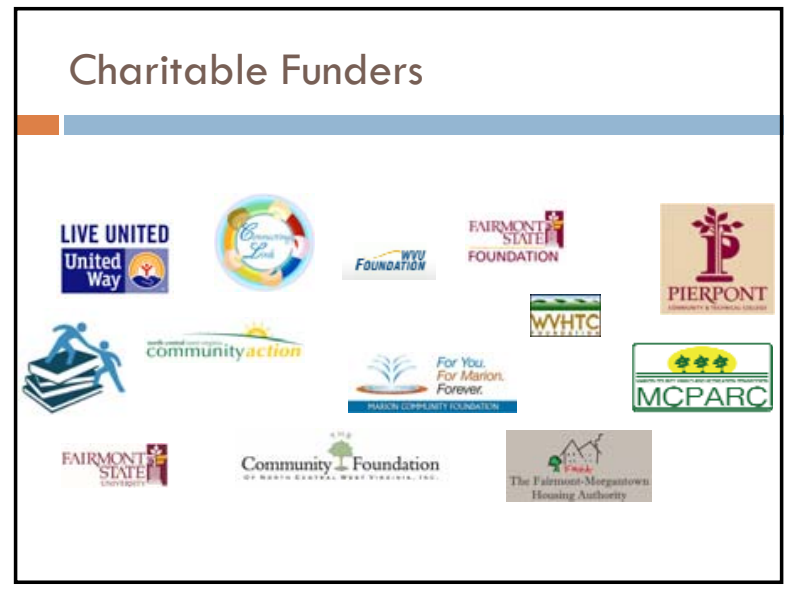

\section{Built Environment Components}

\section{$\square$ Infrastructure}

Water and sewer systems, solid waste management power and communications utilities

$\square$ Roads, sidewalks, trails, lighting

$\square$ Structures

$\square$ Commercial and industrial buildings

$\square$ Housing

$\square$ Park amenities

\section{Water and Sewer Systems}

$\square$ Water Treatment Plant

$\square$ Sewer System and Wastewater Treatment Plant
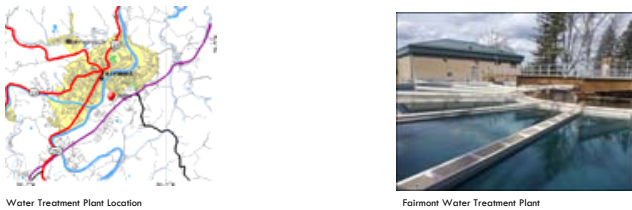

Foimmont Water Treatment Plant 


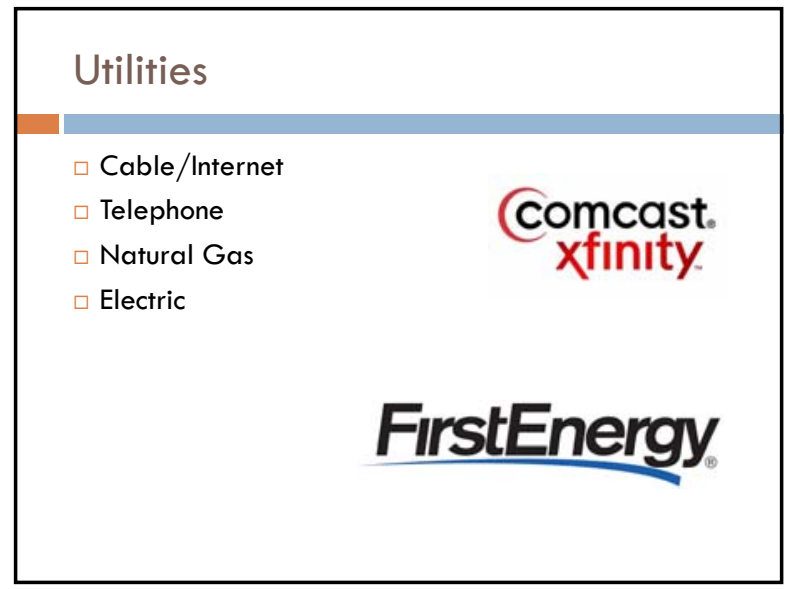

Streets and Circulation

Roadways

口 Gateway Connecter

口 Route 250

$\square$ Route 19

$\square$ City streets

$\square$ Fairmont Municipal Airport 口 Frankman Field

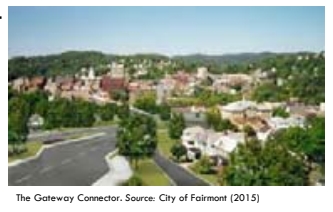

Solid Waste Management

Marion County Solid Waste Authority

$\checkmark$ Garbage Collection (Fee-Based)

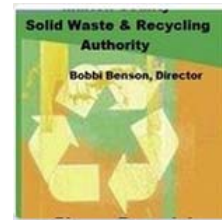

\section{Zoning and Land Uses}

Zoning designates allowed land uses

Zoning districts in the neighborhood:

$\square$ General Residential

$\square$ Neighborhood Residential

$\square$ Recreation

$\square$ Main Corridor Commercial

$\square$ City Center

口 Industrial

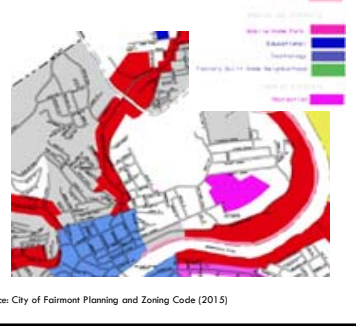

\section{Basic goods businesses}

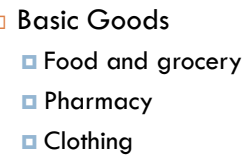

$\square$ Food and grocery

$\square$ Pharmacy

$\square$ Clothing

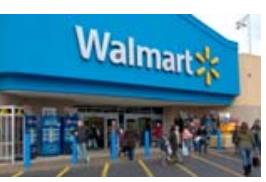

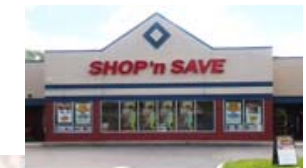

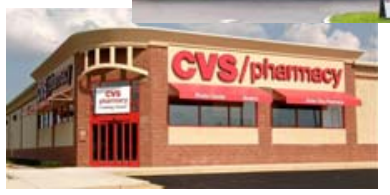

\section{Basic Services}

$\square$ Basic Services

$\square$ Health Care

$\square$ Senior homes

$\square$ Beauty and hair care

口 Laundry

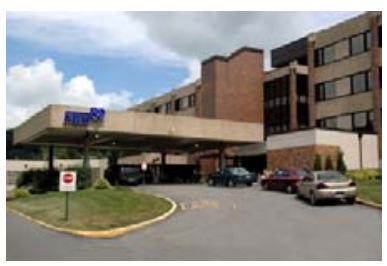




\section{Professional Services}

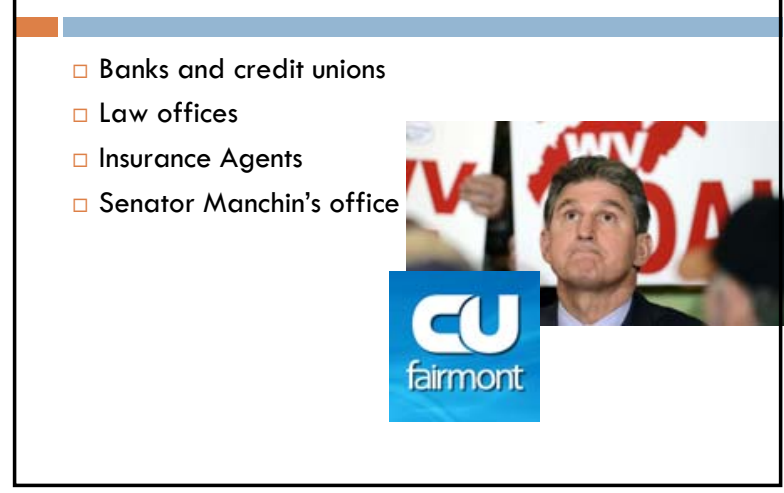

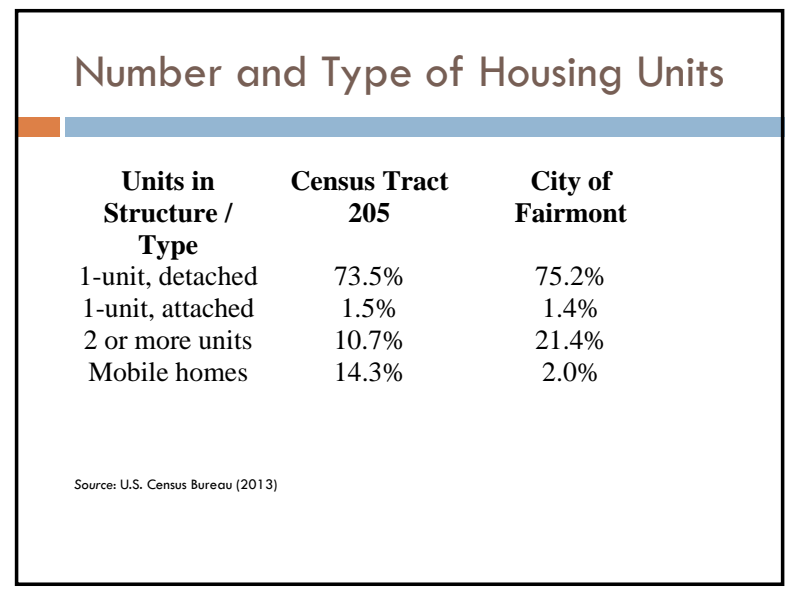

\section{Ownership Rates}

$\square$ Higher in Census Tract 205

口 $72.1 \%$ as compared to $67.5 \%$.

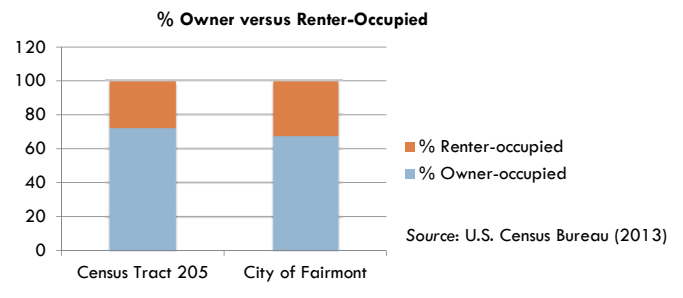

\section{Other Goods and Services}

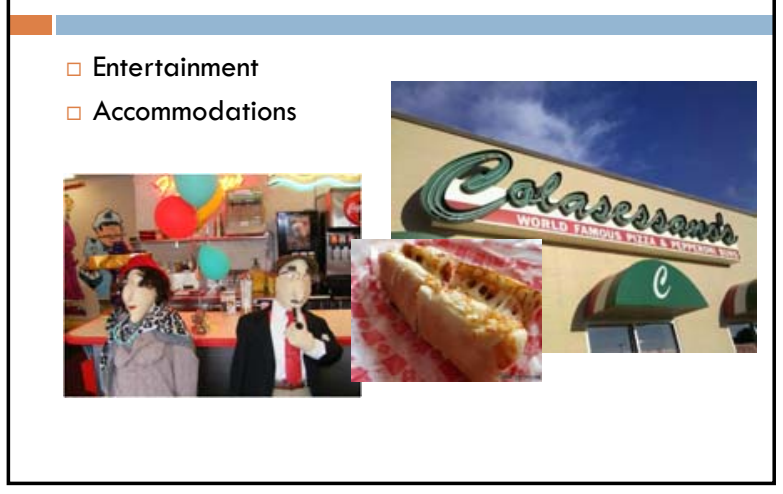

\section{Vacancy Rates}

$\square$ Significantly higher in Census Tract 205

口 $20.9 \%$ of units versus $13.9 \%$ in Fairmont.

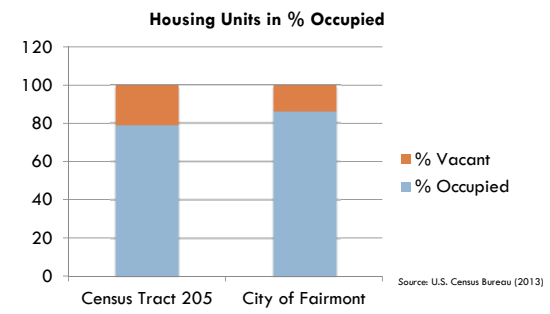

\section{Home Values}

$\square$ Fairmont as a whole has a larger percent of homes valued in the highest brackets

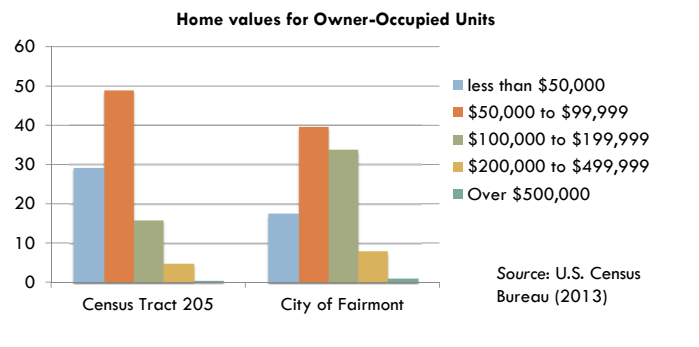




\section{Housing Affordability}

$\square$ "Families who pay over 30 percent of their income for housing are considered cost burdened and may have difficulty affording necessities such as food, clothing, transportation and medical care." -HUD (2015)

$\square$ Neighborhood residents will have trouble being able to afford other necessities.

\begin{tabular}{|l|c|c|}
\hline $\begin{array}{l}\text { Those who spend } 30 \% \text { or more } \\
\text { of income on housing costs }\end{array}$ & Census Tract 205 & City of Fairmont \\
\hline Homeowners & $39.4 \%$ & $20.1 \%$ \\
\hline Renters & $73.5 \%$ & $61.0 \%$ \\
\hline
\end{tabular}

\section{Building Condition}

BAD Buildings Team Inventory

ㅁ $19.6 \%$ are in the Westside neighborhoods

$\square$ Second only to Norwood

Number of BAD Buildings by Neighborhood

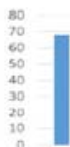
Executive Summary (2015)

\section{Blight Concentration}

BAD Buildings Team Inventory

$\square$ Ogden Ave, Spruce Street, Pennsylvania Ave, Robinson Street, and Spring Street

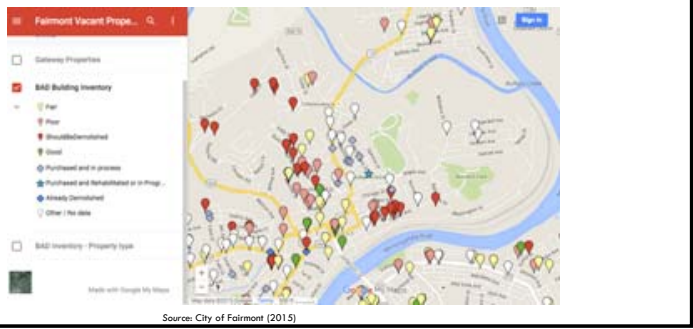

\section{Building Age}

\section{- Matches Fairmont overall}

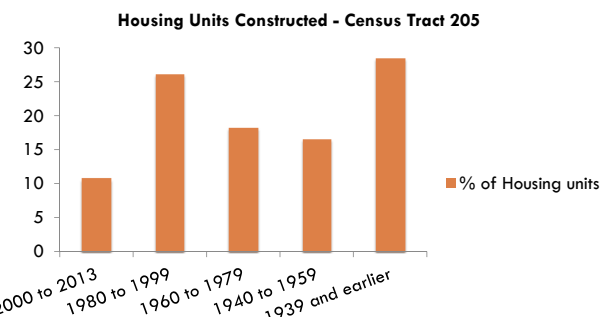

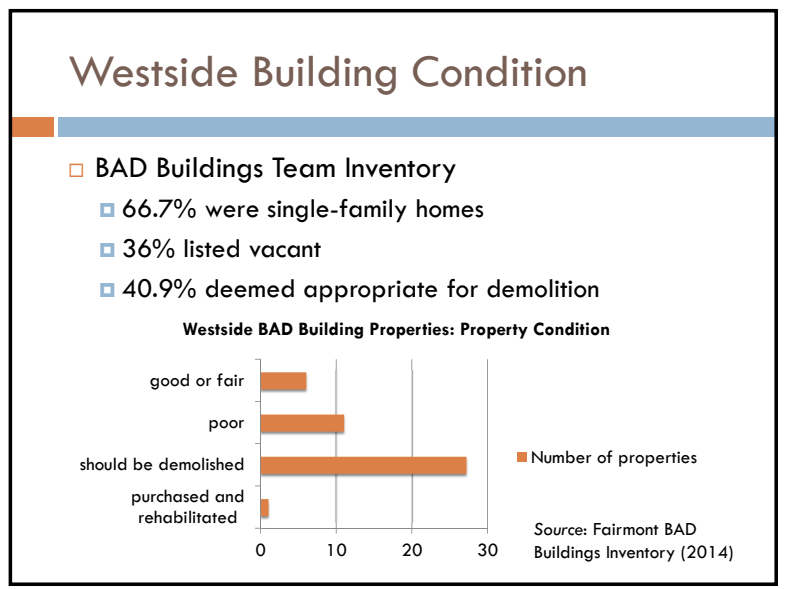

\section{Access to Utilities}

$\square$ A significantly higher \% of Tract 205 houses lack complete plumbing and have no telephone services

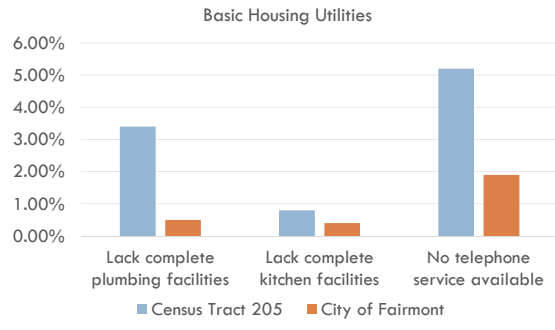



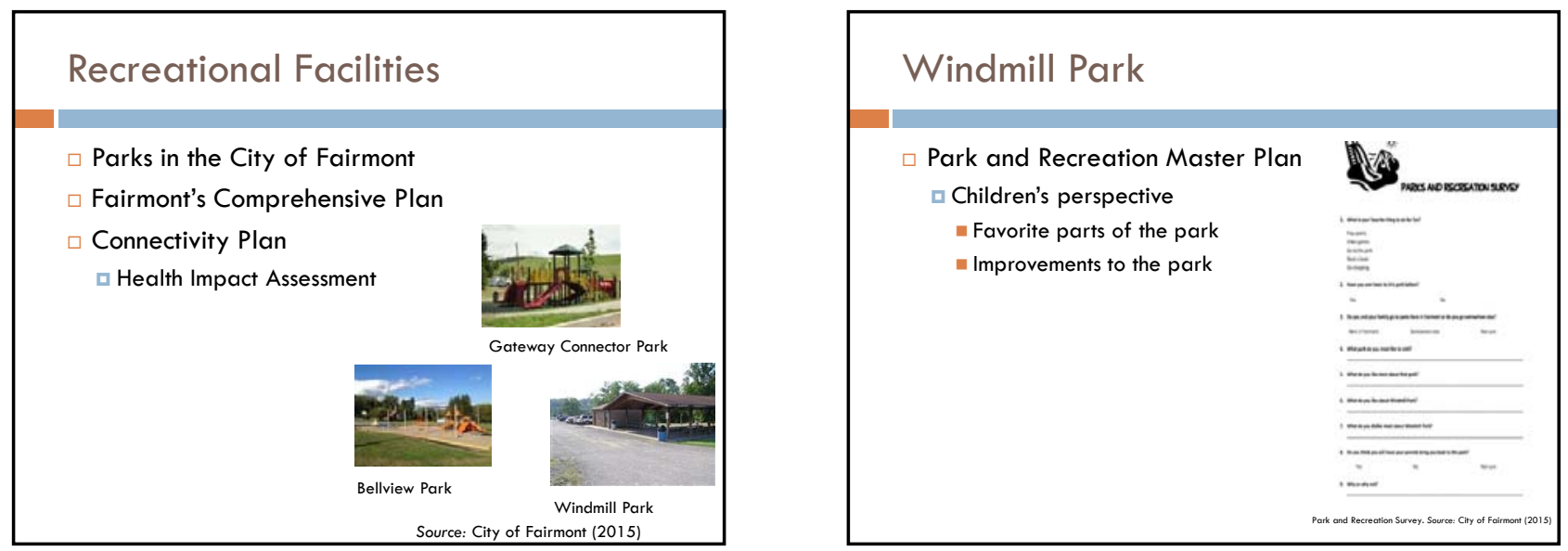


\section{NEIGHBORHOOD ACTION PLAN}

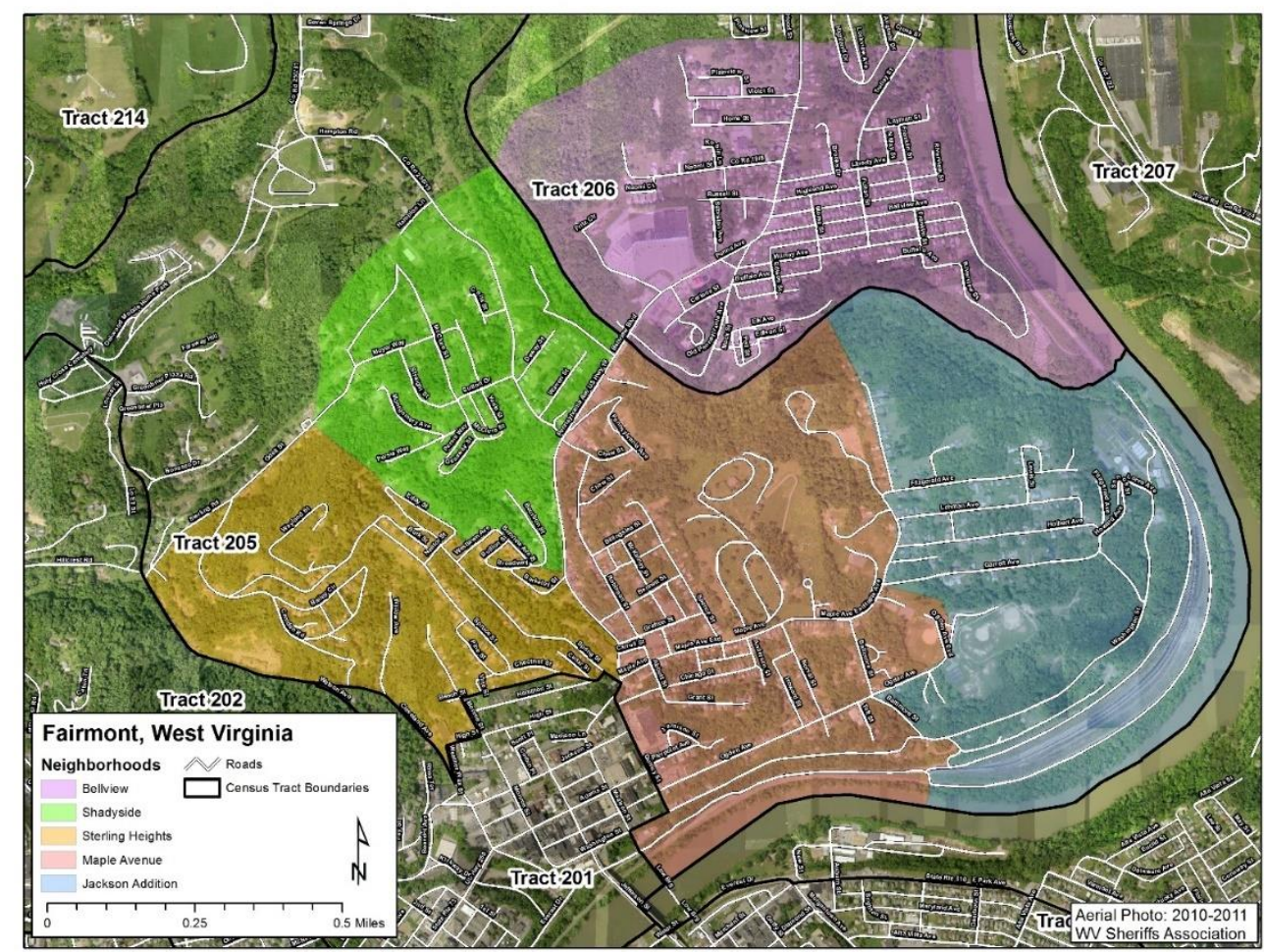

\section{Fairmont, WV: Westside Action Coalition}

This plan summarizes the results of the community planning workshop held October 15, 2016. However, the information used to draft goals, objectives, and strategies also includes all previous Fostering Fairmont project data: Community Profile, Community Survey, Community Visioning Conversations, Neighborhood Walkabout field inventories, and all other stakeholder discussions. 
Submitted by:

Margaret Stout

Associate Professor

Department of Public Administration

John D. Rockefeller IV School of Policy and Politics

West Virginia University

PO Box 6322 / 325 Willey Street

Morgantown WV 26506-6322

304-293-7978

Margaret.Stout@mail.wvu.edu

Student Facilitators and Planners:

Chris Agba

John-Michael Aurednik

Phillip Avis

Leah Cunningham

Emily Hawkins

Allyson Hoch

Amy Loomis

Robert Riddle

Shanequa Smith

Ben Spurlock

Kelsey Staggers 


\title{
Neighborhood Action Plan
}

\author{
FAIRMONT, WV: WESTSIDEACTIONCOALITION
}

\section{PROJECT BACKGROUND}

\section{Margaret Stout}

In spring 2015, a group of community members from the west side of Fairmont decided they wanted to improve the quality of life in their neighborhoods. These community members realized that if they received the technical assistance needed to guide their passion for improving their community, they could become a driving force for community and economic development. Collectively, these group members also serve on the boards of the Fairmont Community Youth Development Center, the Dunbar School Foundation, and the Marion County NAACP. This core group formed the Westside Action Coalition (WAC), an expanding group of neighbors and representatives from community-based organizations who are willing to work together in a collaborative effort to build community and economic sustainability within their community. The area of focus includes several Westside neighborhoods: Jackson Addition, Maple Avenue, Sterling Heights, Shadyside, and parts of Bellview. The WAC invites other community members, businesses, agencies, and government representatives to join this growing movement to foster community and economic development in these neighborhoods.

The WAC is receiving technical assistance through a two-year agreement with West Virginia University (WVU) faculty and students who specialize in community and economic development. This initiative is called the Fostering Fairmont project, which is designed to assist community members who want to see the assets in their community be put to better use. The project's purpose is to equip neighbors with the tools necessary to enhance their neighborhood through learning, mobilizing, planning, and then acting on the strategies necessary to enhance their community. The Fostering Fairmont project includes four phases:

- The first phase began in fall 2015. Activities focused on learning about the community through community stakeholder meetings, neighborhood tours, and secondary research. This information was compiled in a Community Profile report, which is a powerful tool for learning about the community's assets and conducting resource development. Workshops were also provided to build community capacity for understanding local governance, community development, and community organizing.

- The second phase was initiated in spring 2016 with a dual focus. The first objective was to equip the WAC with a Public Engagement Plan that contains information about the Fostering Fairmont project, guidance on how to effectively engage community members, and a list of stakeholders and resources that can assist residents with their community enhancement initiatives. The second objective was to document the vision residents have for their neighborhoods. This was achieved by facilitating Community Visioning Conversations. The information gathered from these conversations identified shared values, visions, and ideas about community issues and potential action.

- In fall 2016, the third phase brought community members, businesses, agencies, and government representatives to the table with experts on tap to develop a Neighborhood Action Plan, which will be used to guide residents and partners in their collaborative efforts to strengthen their community socially, economically, and physically. This phase included field inventories guided by community stakeholders. 
- In spring 2017, the fourth phase will focus on action. Community stakeholders will prioritize the strategies in the Neighborhood Action Plan, select projects to launch, and work collaboratively to implement them. Stakeholders will learn about how they can work together effectively and what part they can play in making the community's vision a reality.

The Fostering Fairmont project is designed to follow the theory of asset-based community development $(A B C D)$. The $A B C D$ approach establishes a positive outlook by focusing on capacities rather than deficiencies, empowers residents to create positive change within their community "from the inside out", and emphasizes the importance of relationships in achieving shared purpose (Kretzmann \& McKnight, 1996). The successful implementation of a neighborhood action plan depends on the level of community capacity, which is the synergy created by combining human, social, organizational, and political resources (Chaskin, 2001). Therefore, building community capacity through training and technical support is key to the success of any community development initiative. Leader mentoring, community meetings, and learning workshops are used to build community capacity. This community development approach employs inclusive, participatory, and collaborative methods that are most democratic and effective (IAP2, 2007; Kaner et al., 1996). The technical assistance providers work with the community, rather than simply doing things for it, or worse, to it.

To understand a community's capacity, the $A B C D$ approach begins with assessing community assets, emphasizing the human and social capacities in place. The Fostering Fairmont project uses the more comprehensive community capitals framework (CCF) (Flora, Flora and Fey, 2003), which identifies and analyzes the key elements that contribute to a community's vitality and provides insight to how each asset can be used to grow and strengthen other assets within a community (Emery \& Flora, 2009). The CCF works well in participatory practice because both planners and community stakeholders identify community assets, combining inside and outside perspectives.

Specifically, we consider the CCF capitals: natural; cultural; human; social; political; financial; and built types. Following comprehensive community initiatives (Chaskin, 2001) and collaborative approaches to community development list (Chrislip, 2001), we add organizational capital to this set. Natural capital consists of environmental resources, geographic location, natural beauty, and climate. Cultural capital comprises the history, traditions, worldview, and language of residents. Human capital includes the skills and abilities used to access knowledge and resources, identify effective practices, and provide leadership that "leads across difference" in an inclusive and participatory manner. Social capital represents the relational connections among individuals and organizations that enable communities to function more cooperatively and effectively. Political capital includes the access to power and the ability to influence public policy either directly or through representatives. Organizational capital includes the collective capacity for action of groups serving the community. Financial capital includes the resources available to invest in development. Built capital is the man-made infrastructure within a community, including buildings, roads, sidewalks, and utilities.

The community capitals framework was used in the Community Profile to provide information about the neighborhoods and was used to guide development of the Public Engagement Plan. This framework was also used to analyze the responses from participants in the Community Visioning Conversations and to guide asset identification and creative combinations during the field inventories and planning workshop. 


\section{References}

Chaskin, R. (2001). Building community capacity: A definitional framework and case studies from a comprehensive community initiative. Urban Affairs Review, 36, 3, 291-323.

Chrislip, D. D. (2002). The Collaborative Leadership Fieldbook. San Francisco: Jossey-Bass.

Emery, M., \& Flora, C. (2006). Spiraling-up: Mapping community transformation with the community capitals framework. Community Development, 37, 1, 19-35.

Flora, C. B., Flora, J. L., \& Fey, S. (2003). Rural communities: Legacy and change. Boulder, CO: Westview Press.

International Association for Public Participation (IAP2). (2007). Spectrum of public participation. Louisville, CO: International Association for Public Participation.

Kaner, S., Lind, L., Toldi, C., Fisk, S., \& Berger, D. (1996). Facilitator's guide to participatory decisionmaking. Gabriola Island, BC: New Society Publishers.

Kretzmann, J. P., McKnight, J. (1993). Building communities from the inside out: A path toward finding and mobilizing a community's assets. Evanston, IL: The Asset-Based Community Development Institute, Institute for Policy Research, Northwestern University. 


\section{THE PLANNING PROCESS}

On September 17, 2016, the Fostering Fairmont project team convened with community stakeholders to complete field inventories during a Neighborhood Walkabout. The destinations guiding the team members' routes included: (1) the places identified during the Community Visioning Conversations Sense of Place Dialogue, (2) the Brownfields, Abandoned, and Dilapidated (BAD) Buildings inventory, (3) the Fairmont-Morgantown Housing Authority property inventory, and (4) the Fairmont Community Development Partnership property inventory. As shown on the map in Figure 1, these features represent natural and built assets to be leveraged or improved to enhance the quality of life in the Westside neighborhoods. Descriptors of each feature can be found in Appendix A.

\section{Neighborhood Walkabout}
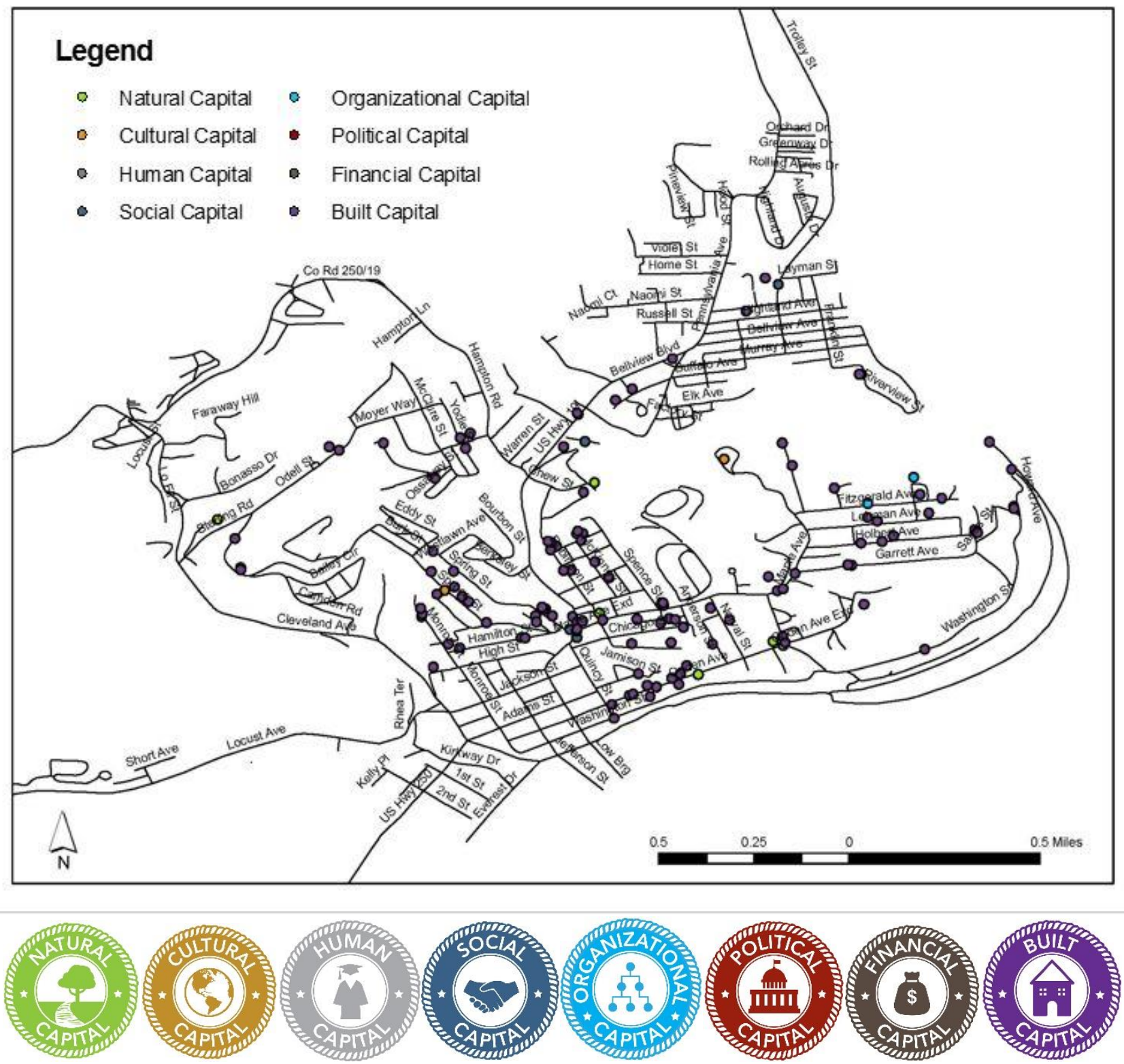
On October 14, 2016, the Westside Action Coalition hosted an evening Pizza and Performance Party in which neighbors were invited to share stories about neighborhood life and their hopes and dreams for its future. While the 12 adult participants engaged in informal conversation early in the evening, 14 youth from the Fairmont Community Youth Development Center's programs joined the party later in the evening, telling their stories and sharing some fun dance and cheerleading moves.
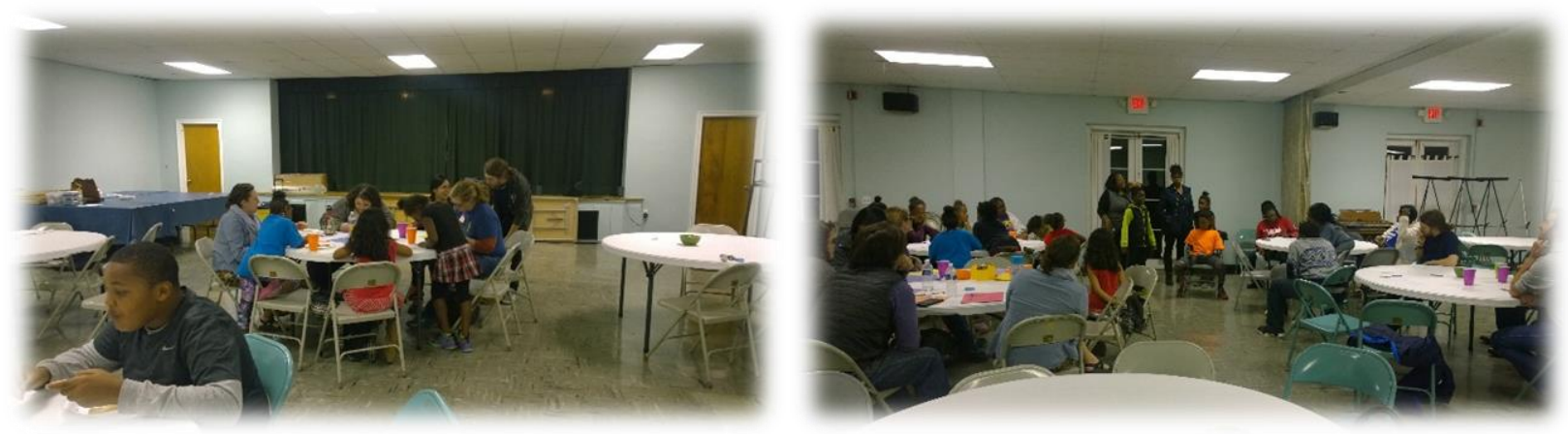

On October 15, 2016, the Fostering Fairmont project team facilitated an all-day neighborhood planning workshop organized around a Community Enterprise Game. While only seven community members participated in the session, they were highly engaged and productive. As explained by the facilitator, a community enterprise can include any type of project, program, group, or organization that has a purpose that will fulfill a community need. The enterprise could be operated by a for-profit business, a nonprofit organization, or a voluntary coalition.

The Community Enterprise Game began with the Name That Asset! exercise, during which participants named every asset they could think of according to the Community Capitals Framework employed throughout the project (see Appendices B and C). WVU team members who had participated in the Neighborhood Walkabout and previous stakeholder meetings and events also contributed assets.
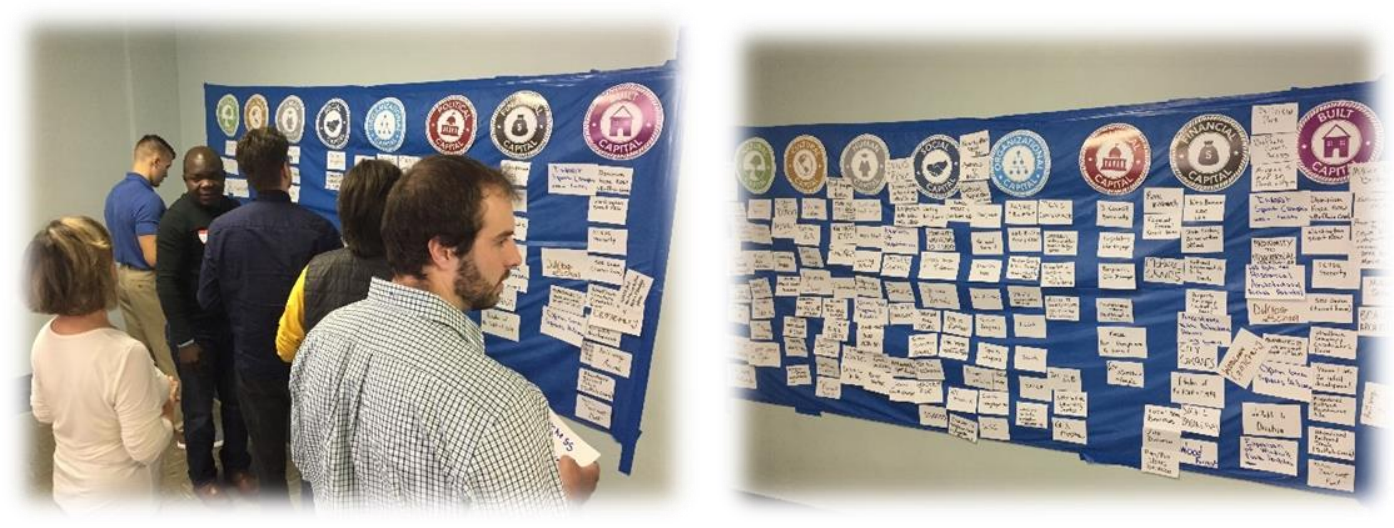

In the Mix it Up! exercise, participants were asked to combine neighborhood assets in creative ways to produce Community Enterprise proposals. Individual planning and discussion took place in three small groups. Worksheets helped participants think through which assets could be combined for the greatest community impact (see Appendix D). 


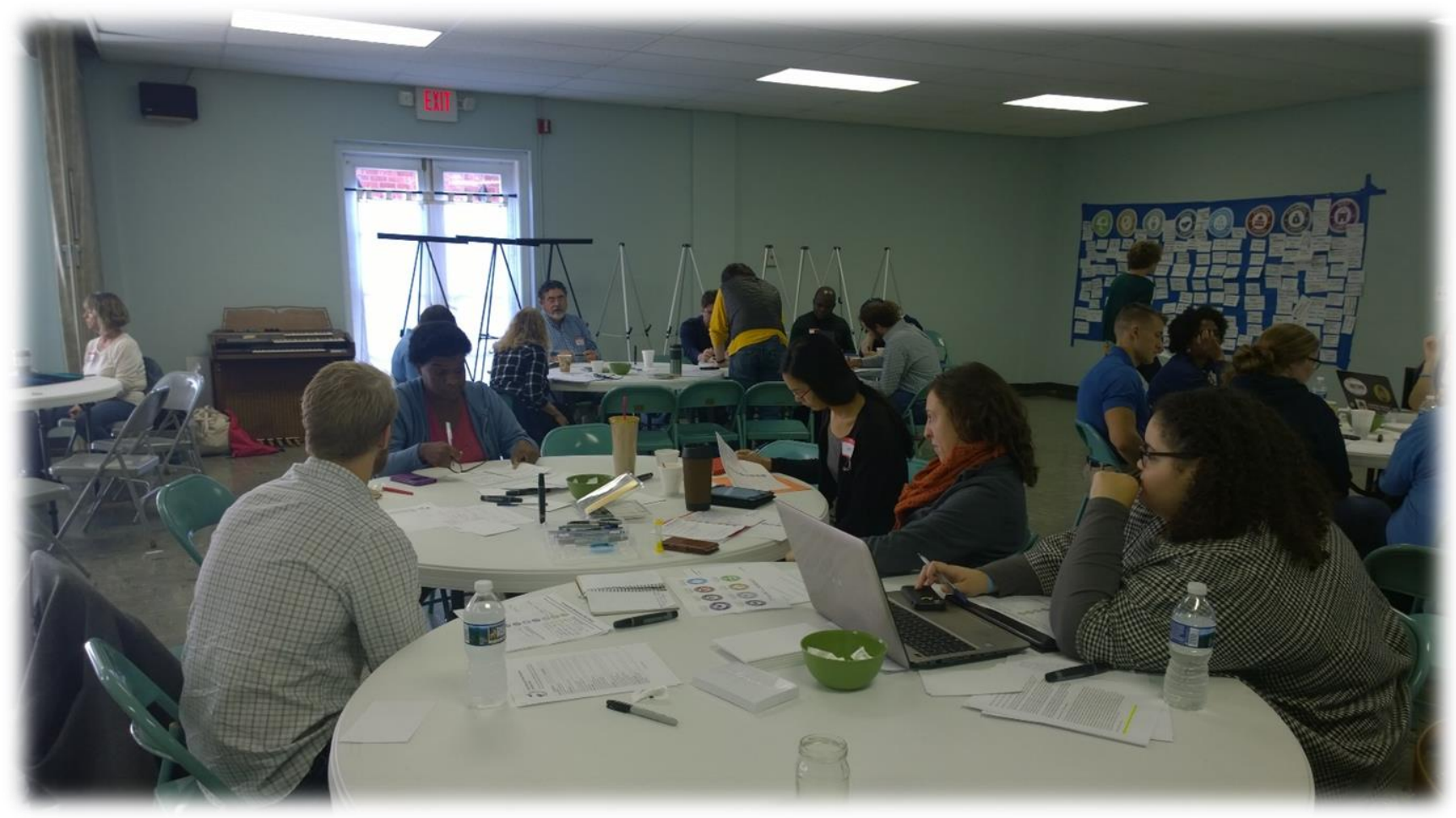

The enterprise ideas generated by participants were:

- Indoor recreation center at Windmill Park (FCDP property expansion)—possibly with YMCA

- Enhancement of Windmill Park amenities (master plan with WVU Landscape Architecture)

- Community center at Dunbar School with a vast array of youth, adult, and senior programs

- Urban agriculture and community gardens on vacant FCDP lots

- Cooperative convenience market and green grocer at the FCYDC property

- Bed and breakfast at 500 Ogden Avenue

- Pocket park overlook next to 500 Ogden Avenue (Pierpont coal mine, Palatine Park)

- History walk through Civil War, coal field, and African American cultural sites

- Hiking trail to Buffalo Creek from Jackson Addition (Dominion Gas right-of-way)

- Rail trail along Buffalo Creek (abandoned line in the City of Fairmont Connectivity Plan)

Each participant was asked to pitch their idea during the Promote It! exercise. The other participants provided feedback and creative ideas to augment the enterprise, fleshing out each proposal.

After the pitches were finished, participants voted on their favorite idea in each of three categories: social, economic, and physical development. Each winning enterprise received further attention during a facilitated strategic planning session called the Startup Lab.

The results of the neighborhood planning workshop were considered in development of the Neighborhood Action Plan elements below, along with all previous information collected throughout the Fostering Fairmont project. These resources include: 
- Community Profile

- Community Survey

- Community Visioning Conversations

- Neighborhood Walkabout

- Stakeholder meetings and conversations 


\section{COMMUNITY VALUES AND VISION}

Drawing from the results of the Community Visioning Conversations and community feedback to the draft report, the following values guided development of the Neighborhood Action Plan:

\section{Naturall Capitall}

- We value both neighborhood and regional parks and open spaces for recreation.

\section{Culturall Capitall}

- We value Fairmont's historic character and sites.

- We value our history as a largely African American community.

- We value ample opportunities for arts and entertainment.

\section{Human Capital}

- We value formal educational opportunities and attainment, including training for entrepreneurship.

- We value lifelong learning through both youth and senior development programs.

\section{Sociall Capitall}

- We value our families and home lives.

- We value a sense of community supported by spaces and opportunities for community activities.

- We value a sense of safety and security supported by adequate law and ordinance enforcement.

\section{Organizationall Capital}

- We value the public and community-based organizations serving our neighborhoods.

\section{Politicall Capital}

- We value civic education and adequate information about what local government is doing.

- We value adequate political representation and influence over public decision making.

- We value productive government-community relations.

\section{Financiall Capital}

- We value adequate employment opportunities, including small business ownership.

- We value equitable and adequate investment from public and nonprofit partners in the Westside neighborhoods.

\section{Built Capitall}

- While we value regional shopping opportunities and activities in downtown Fairmont, we deeply value neighborhood-based businesses.

- We highly value quality public recreation facilities.

- We value home ownership and well-maintained residential neighborhoods.

- We value well-maintained circulation infrastructure for both people and cars. 


\section{Vision Statement}

Together, these values tell a story about what the Westside neighbors envision for their future-a target for neighborhood action strategies:

We envision neighborhoods with adequate and equitable investment in both people and place, so that our youth will enjoy the quality of life that we enjoyed several decades in the past-one with family-owned homes, small local businesses serving our basic needs, neighborhood schools and churches, excellent community parks and recreation centers, ample employment and entrepreneurship, and pride in our shared history as a largely African American community.

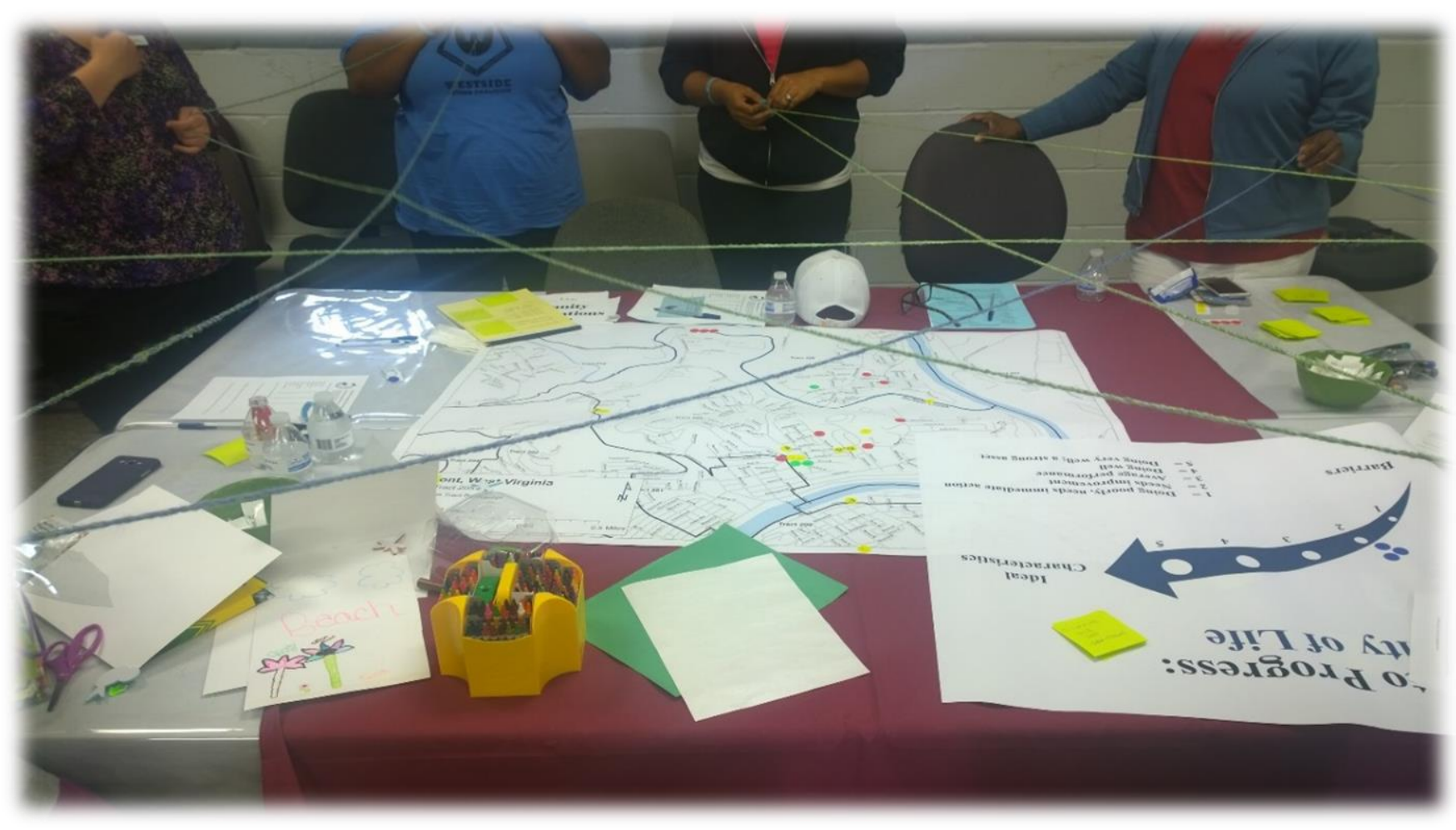




\section{SOCIAL DEVELOPMENT}

\section{Emily Hawkins, Allyson Hoch, and Amy Loomis}

Social development activities prioritize human needs and social and economic justice in the pursuit of a high quality of life. Based on community data, the goal of the Social Development section is to increase the capacity of individuals, families, and neighborhoods to thrive. To achieve this goal, the Westside Action Coalition will focus on: (1) increasing a sense of belonging and solidarity among neighbors, (2) celebrating the largely African American heritage, (3) expanding and improving youth development opportunities, (4) improving leisure and development opportunities for adults and seniors, and (5) improving the variety of housing options. A review of academic and practice literature identified promising practices that are responsive to these objectives.

\section{Sense of Bellonging}

The National Civic League suggests that communities benefit from residents being more involved and proactive neighbors and citizens. Community building activities that increase mutual understanding and trust and bridge group boundaries help develop a shared community identity and sense of belonging. Furthermore, collaboration among community organizations, businesses, and individuals will allow Westside residents to pool resources, avoid program duplication, establish long-term community connections, and draw on talent from diverse sources to create high quality programs. Collaboration among the Westside's many churches and community-based organizations is vital in fostering a sense of belonging within the neighborhoods. The Westside Action Coalition should continue to host fun and purposeful community events that bridge diversity, build community, and encourage interfaith collaboration.

\section{Celebrating African American Heritage}

Discussions throughout the Fostering Fairmont project have clearly indicated that cultural identity and history should be considered and celebrated. For example, the area's Civil War history, Civil Rights era events, historically Black schools and cemetery, and Black-owned businesses are all deeply valued. Indeed, residents report that the loss of those schools and businesses after desegregation are still felt today with a decline in African American educators, mentors, and leaders in the community. While often paired with painful memories, this cultural history is rich in ideas for healing and rebuilding, as well as potential for cultural tourism. Therefore, every part of the Neighborhood Action Plan should consider how to celebrate, leverage, and augment this cultural heritage.

\section{Community-Based Programming}

Westside residents have consistently articulated a need for expanded community programming for youth, adults, and seniors. Program design should be sensitive, equitable, and responsive to the varying needs of residents. Particularly for youth living in poverty, extracurricular activities are needed to boost educational achievement and attainment, develop a positive sense of identity and healthy peer relations, and to prepare for adult life. While the Fairmont Community Youth Development Center offers a few programs, they are underfunded, understaffed, and lack adequate facilities and equipment. This organizational asset needs capacity building to provide sufficient affordable, accessible, and regularly scheduled youth programming. Youth and parents desire hands-on learning and creative cultural 
expression, sports and physical activities, life skills education, and leadership. Mentorship of youth is highly desired, as residents report a significant loss of African American role models and educators following desegregation. However, the Westside Action Coalition should engage youth more significantly in specific program design.

In regard to adult and senior programming, Westside residents have expressed the need for basic and continuing education, life skills, financial literacy, leadership and civic engagement, expanded social and leisure activities as well as educational enhancement and workforce development (for the latter, see the Economic Development section). They also wish for at least some of these activities to feature intergenerational programming to meet the community's civic participation and mentorship needs as well as hobby and leisure interests. While these types of programs may exist elsewhere in Fairmont, partnerships that bring programming into the neighborhood at affordable costs are desired.

Given Dunbar School's history as the heart of the community, Westside neighbors would like the building to house these various social development programs. Because completion of renovations necessary to support occupancy may take some time to fund and complete, programs could be hosted in the immediate term at the Fairmont Community Youth Development Center and the Dunbar School Annex.

\section{Housing Options}

Housing is a foundation of healthy family life and neighborhood stability. Ensuring that housing is of adequate quality, diverse in type, high in owner-occupancy, and affordable for a range of incomes achieves these outcomes equitably. However, maintaining this balance while avoiding displacement through gentrification or encroachment of more lucrative commercial land uses is a constant challenge for housing policy. Residents within the Westside neighborhoods have stated a desire to simultaneously maintain housing affordability, increase owner-occupied housing, and remedy dilapidated houses that lower home values and neighborhood charm.

In the recent past, development in the neighborhoods by both the Fairmont-Morgantown Housing Authority (FMHA) and the Fairmont Community Development Partnership (FCDP) has overemphasized lowincome rental housing. To increase owner-occupied housing while maintaining housing affordability over time, infill development could include use of a Community Land Trust. This will maintain the affordability of a portion of owner-occupied housing over time, thereby protecting against overall gentrification. These protections against home loss through increased property values will enable incentivizing market-rate infill housing development to remedy the problem of dilapidated houses, as well as other infill development to expand available owner-occupied housing types such as small-lot homes and townhomes.

\section{Sociall Development Action Plan}

Based on this overview of community assets and preferences, the overall goal for social development is to improve the capacity of individuals, families, and neighborhoods to thrive. Based on responsive promising practices, the action plan for achieving this goal is broken down into the following objectives and strategies. 
1. Increase a sense of belonging and solidarity among neighbors.

1.1. Encourage collaboration among voluntary organizations (e.g., churches, coalitions, neighborhood associations, civic groups).

1.2. Host regular social events that bring neighbors together for fun.

1.3. Host purposeful community building events (e.g., bridging diversity, community coalitions, interfaith activities, beautification and service projects).

1.4. Improve local political representation.

1.4.1. Develop a redistricting proposal for City Council districts with the NAACP.

1.4.2. Partner with NAACP to deliver civic development programming, including hosting speakers, workshops, voter drives, and candidate forums.

2. Celebrate the neighborhoods' African American heritage.

2.1. Create and curate the Marion County Black History Museum.

2.1.1. Partner with the West Virginia Division of Culture and History.

2.1.2. House the Museum at the renovated Dunbar School building.

2.2. Coordinate delivery of the "sense of place" curriculum developed by the WVU Community Resource Management team.

2.2.1. Host the program at the Dunbar School Annex until the Museum is available.

2.3. Develop interpretive signage and materials for cultural tourism purposes.

2.3.1. Partner with the Tourism Division of the West Virginia Department of Commerce (see Economic Development section).

2.4. Ensure that racial equity is considered in all future planning and decision making by the City of Fairmont and community-based organizations serving the neighborhoods.

2.4.1. Members of the Westside Action Coalition will maintain consistent advocacy efforts.

3. Expand and improve youth development opportunities in the neighborhoods.

3.1. Host youth programs at the Fairmont Community Youth Development Center and the Dunbar School Annex until the Dunbar School building becomes available.

3.2. Provide educational enhancement programs.

3.2.1. Partner with Energy Express Marion to provide summer literacy and nutrition programs.

3.2.2. Partner with Learning Options, FSU Black Student Union, Harrison County YMCA, and Marion County or Mountaineer Boys \& Girls Club to develop after school educational enrichment opportunities, including tutoring, literacy, and robotics.

3.3. Provide creative arts programs.

3.3.1. Partner with local arts businesses such as Joe $N$ Throw to develop arts programming.

3.4. Provide recreational programs.

3.4.1. Partner with MCPARC and Adventure WV to provide outdoor recreational activities. 
3.4.2. Partner with Harrison County YMCA and MCPARC to provide year-round access to team sports and physical activity.

3.4.3. Create indoor intergenerational recreation programs, including gaming options such as video gaming and chess.

3.5. Provide adult mentoring programs.

3.5.1. Partner with FSU's Black Student Union, Harrison County YMCA, and Marion County or Mountaineer Boys \& Girls Club to provide adult mentoring following the Quality Life Initiative model developed by the Coalfield Development Corporation.

3.6. Provide youth leadership programs.

3.6.1. Partner with Boy/Girl Scouts and Adventure WV to provide leadership training.

4. Improve adult and senior leisure and development opportunities in the neighborhoods.

4.1. Host programs at the Fairmont Community Youth Development Center and the Dunbar School Annex until the Dunbar School building becomes available.

4.2. Provide basic and continuing education programs.

4.3. Provide adult recreation and leisure activity programs.

4.3.1. Develop or recruit programs based on participant requests.

4.4. Provide civic leadership training to complement Fairmont 101.

4.4.1. Work in partnership with the NAACP and other civic groups to develop training.

5. Improve the variety of housing options in the neighborhoods.

5.1. Advocate for ongoing availability of affordable rental housing and improved management.

5.1.1. Add tenant associations and activities to management plans for FMHA and FCDP rental housing.

5.2. Increase sustainable homeownership through financing, homeowner education, and ongoing maintenance assistance.

5.2.1. Work with the Fairmont Community Development Partnership to develop programs modeled after Habitat for Humanities' homeowner support methods.

5.3. Ensure ongoing affordable owner-occupied housing through mechanisms such as a Community Land Trust.

5.3.1. Work with the Fairmont Community Development Partnership to develop programming.

5.4. Increase the availability of market-rate owner-occupied units in strategic locations (see Physical Development section).

5.4.1. Recruit developers who build the type of housing desired.

5.5. Advocate for a new zoning ordinance for small single family homes on lots that have been cleared through demolition (see Physical Development section).

5.6. Increase the quality of housing through rehabilitation programs and financing.

5.6.1. Work with the Fairmont-Morgantown Housing Authority or the Fairmont Community Development Partnership to develop programs. 


\section{ECONOMIC DEVELOPMENT}

\section{Leah Cunningham, Kelsey Staggers, and Ben Spurlock}

A key foundation for a high quality of life is a vibrant and stable economy that provides sufficient individual and family income while minimizing the cost of living. A strong local economy is generated by an economic base that brings outside resources into the community, while limiting the resources that leave the community. Therefore, the more that can be done with assets at hand and the more ownership can be retained within the community, the better. This approach to community economic development is sometimes referred to as "economic gardening," which often requires creativity. Supporting such planning and growth requires expanding the capacity of individuals and groups to maximize talents and skills for innovation, production, and trade. These development activities require effective, collaborative institutions focused on advancing mutual gain for the public and private sector.

Economic development is a necessity for improving the quality of life in the Westside neighborhoods. While residents were once employed in high-paying blue-collar jobs associated with a strong economic base in natural resource industries, the transition toward high-tech industries and white collar jobs has left many behind in the lowest paying service jobs. While the unemployment rate is extremely low, poverty rates are very high. Furthermore, the neighborhoods have lost many basic goods and service businesses, making in more expensive and inconvenient to live in the area. In response to these conditions, residents desire an increase in minority-owned local businesses and entrepreneurship, and fulfillment of basic needs and services, and workforce development for existing and new employment opportunities.

\section{Enterprise Development}

Locally-owned businesses, particularly women and minority-owned businesses, were once a staple in the Westside neighborhoods. To rebuild the economic base of small businesses in the neighborhood, entrepreneurial development programming, financing, and incubation are needed. While general small business training and support should be provided, following an economic gardening approach, enterprises that draw upon local assets, fulfill basic goods and service needs, and potentially lower the cost of living should also be identified and encouraged. Furthermore, enterprise models that increase worker income and create youth employment opportunities are desirable. Based on resident input, these would include: businesses that will serve future tenants of the Miller School senior living adaptive reuse development project, a cooperative convenience store and green grocer, outdoor recreation associated with adjacent waterways and planned rail trails, cultural tourism associated with local sites, urban agriculture on vacant lots, construction trades associated with demolition and infill development, and solar or wind power generation.

\section{Workforce Development}

While workforce development programs from federal and state agencies are abundant, they are not necessarily accessible for Westside neighbors, particularly those currently working multiple jobs to make ends meet. Therefore, the Westside Action Coalition should work toward bringing programs and services to the neighborhoods. Training should be designed to meet underemployed residents where they are in pursuit of available higher paying jobs or entrepreneurial opportunities. This training should support the enterprise development priorities identified by the community, in addition to opportunities available in 
the I-79 Technology Park and various public agencies and institutions located in Fairmont. In terms of local enterprise training, models provided by the Coalfield Development Corporation are particularly promising.

\section{Economic Development Action Plan}

Based on this overview of community assets and preferences, the overall goal for economic development is to increase individual and family incomes within the Westside neighborhoods. Based on responsive promising practices, the action plan for achieving this goal is broken down into the following objectives and strategies.

1. Increase the number of locally-owned and operated businesses.

1.1. Partner with the WVU Entrepreneurship and Innovation Law Clinic to deliver entrepreneurship programs.

1.1.1. Deliver services at the Fairmont Community Youth Development Center and/or the Dunbar Annex until the Dunbar School building renovation is completed.

1.1.2. Once the Paul Laurence Dunbar Community Center is operating, transform the Fairmont Community Youth Development Center into a Westside Community Enterprise Center.

1.1.3. Seek support from the West Virginia Small Business Development Center (WVSBDC), and the U.S. Small Business Association (SBA).

1.2. Promote use of the Excelerator business incubator in partnership with the Fairmont Community Development Partnership and WesBanco.

1.3. Promote the use of cooperative enterprise models that increase worker income.

1.3.1. Place a WVU AmeriCorps VISTA volunteer with the Community Action Lab to provide technical assistance and capacity building for this type of enterprise.

2. Increase the availability of basic goods and services businesses in the neighborhoods.

2.1. Establish a cooperative convenience market and green grocer.

2.1.1. Renovate the accessory building at the Fairmont Community Youth Development Center to house the market.

2.2. Recruit senior-oriented service businesses to support the forthcoming adaptive reuse of Miller School.

3. Develop enterprises associated with neighborhood assets and needs.

3.1. Develop urban agriculture enterprise.

3.1.1. Partner with the Fairmont Community Development Partnership to replicate the Coalfield Development Corporation Refresh Appalachia agricultural entrepreneurship program.

3.1.2. Seek funding from the USDA Rural Development Program.

3.2. Develop wind and solar energy enterprise.

3.2.1. Partner with statewide initiatives such as WV SUN and Solar Holler.

3.2.2. Seek funding from the Rural Energy for America Program Renewable Energy Systems \& Energy Efficiency Improvement Loans \& Grants. 
3.3. Expand deconstruction and demolition enterprise to support BAD Buildings Team efforts.

3.3.1. Encourage the City of Fairmont to partner with FCDP to acquire and clear dangerous properties for redevelopment using the Property Rescue Initiative loan program from the West Virginia Housing Development Fund.

3.3.2. Encourage local businesses like Mike Jecker or Reclaim Company LLC to expand operations in Fairmont.

3.4. Develop cultural tourism enterprise.

3.4.1. Establish a Marion County Black History Museum (see Social Development section).

3.4.2. Establish a Civil War Walk through associated historic sites (see Social Development section).

3.5. Develop outdoor recreation and tourism enterprise.

3.5.1. Work with the WVU Entrepreneurship and Innovation Law Clinic to complete market feasibility studies for outdoor recreation businesses associated with the Buffalo Creek access points, the future Rail Trail, and the potential ATV park at the historic Roundhouse site (see Physical Development section).

4. Increase workforce readiness across a wide range of occupations.

4.1. Provide general workforce development training.

4.1.1. Deliver services at the Fairmont Community Youth Development Center and/or the Dunbar Annex until the Dunbar School building renovation is completed.

4.1.2. Once the Paul Laurence Dunbar Community Center is operating, transform the Fairmont Community Youth Development Center into a Westside Community Enterprise Center.

4.1.3. Provide resource and referral to available workforce development programs...

4.1.4. Partner with WorkForce West Virginia; Governor's Guaranteed Work Force program, Temporary Assistance for Needy Families (TANF), WV Women Work, and the State Workforce Development Board to bring training to the neighborhood.

4.2. Provide training related to urban agriculture.

4.2.1. Partner with Coalfield Development Corporation to replicate the Refresh Appalachia: Agricultural Entrepreneurship Program.

4.3. Provide training related to solar energy.

4.3.1. Partner with Solar Holler and Coalfield Development Corporation to replicate the Center for Mining the Sun apprenticeship program that leads to an associate's degree as well as NABCEP solar certification.

4.4. Provide training related to deconstruction and construction.

4.4.1. Partner with Fairmont Community Development Partnership and local businesses like Mike Jecker or Reclaim Company LLC to replicate the Coalfield Development Corporation's Quality Jobs Initiative.

4.5. Provide training related to science, engineering, and technology.

4.5.1. Partner with I-79 Technology Center businesses, Fairmont State University, and Pierpont Community College for training programs. 


\section{PHYSICAL DEVELOPMENT}

\section{John Michael Aurednik, Phillip Avis, Chris Agba, Bob Riddle}

The natural and built environment is the foundation a community relies upon to sustain itself socially and economically. Beyond resource extraction, natural capital can enable recreation for residents and visitors alike. Built capital supports the needs of people, businesses, and other organizations. Together, the possibilities enabled by the natural and built environment determine both social and economic development. Therefore, identifying constraints and opportunities among nature, people, and economic activities helps to determine strategies for sustainable community growth.

Ultimately, the goal of physical development in the Westside community is to increase public and private investment in sustainable natural and built environments in the Westside neighborhoods. Due to a history of disinvestment in the area, plans for physical development must be culturally competent, equitable, and consider a vision shared by most residents. Westside neighbors have expressed many preferences for physical development, including public facilities, parks and open space, transportation and circulation, and safe places.

\section{Projected Land Use}

Land use planning is the first step toward desired development because it indicates the local jurisdiction's intent for public investment and preferences for private investment. Land use planning identifies how each parcel of land will be used, considering its relation to other parcels, public infrastructure, transportation, and other essential services. Zoning classifications and associated property rights are awarded without variance according to land use plans, therefore planning for future land use poses a challenge when proposing changes that do not fit current zoning rights. Planning decisions about these changes should be responsive to the neighborhood's residents, businesses, and property owners. This is particularly important in communities that have not felt a sense of agency and voice in previous development decisions.

Throughout the Fostering Fairmont project, residents of the Westside have expressed a sentiment that public investment has been lacking and that development decisions have not been responsive. As shown on the Projected Development Map (see Figure 1), residents desire public facilities as well as residential and commercial development in strategic areas that will not change the character of the existing neighborhoods. This land use map is based on all sections of the Neighborhood Action Plan and can be used in developer recruitment efforts by the City of Fairmont and in project planning by the Fairmont Community Development Partnership and Fairmont-Morgantown Housing Authority. 


\section{FIGURE 1: PROJECTED DEVELOPMENT MAP}

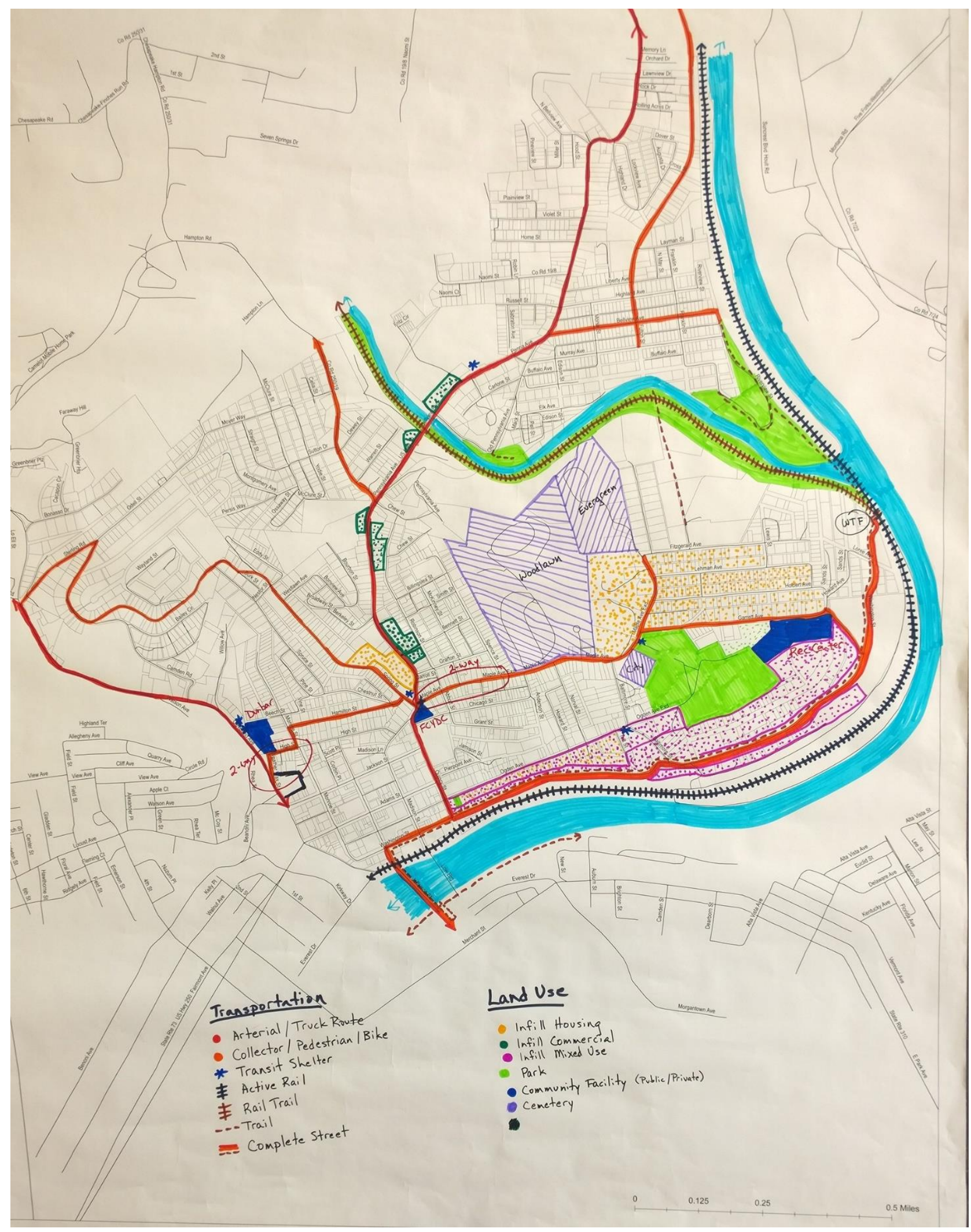




\section{Public Facilities}

Public facilities include utilities, water, sewer, transportation, communications, schools, and recreation facilities. It is essential to provide the infrastructure and facilities needed for a community to thrive. Such projects must account for future land use, population growth, demographic patterns, and zoning. Although these facilities do not create growth, they do guide and encourage growth and therefore shape the quality of life in communities. Some of the public facilities recommended herein serve the needs of existing residents, while also incentivizing development in strategic areas. Because schools are located outside of the planning area, and because most utility and communications infrastructure is maintained by private companies, they are not addressed directly. While water and sewer systems are maintained by the City of Fairmont, neither service came up in community comments. Therefore, we focus on the public provision of transportation infrastructure and recreation facilities.

\section{Transportation and Circulation}

Transportation and circulation are vital to physical development. The ease and convenience of movement of people and goods from one place to another within a community contributes to quality of life. Adequate routes and facilities for automobiles, trucks, emergency vehicles, transit, pedestrians and bicyclists are necessary. Recent transportation policies encourage "complete streets" that support walkable communities to promote health, safety, comfort, sociability, accessibility, and attractiveness.

Westside residents have identified a lack of pedestrian and bicycle facilities, as well as insufficient connections from the neighborhood to downtown for both cars and commercial trucks, particularly those traveling to and from the Wastewater Treatment Facility. Residents seek better circulation via streets, sidewalks, and identified truck routes, as well as trail linkages to Buffalo Creek and the Monongahela River. They also seek increased street capacity and connections should development intensify in strategic areas. Because some of these facilities will be very costly to build, planning and resource development should begin now.

As shown on the Projected Development Map (see Figure 1), changes are indicated to better accommodate both vehicles and pedestrians/bicyclists. In terms of vehicular transportation, circulation is impeded by one-way traffic zones on key neighborhood collector streets and routes to public facilities such as parks, future community centers, and cemeteries (see Maple/Garrett Avenue and Weatherwax/High Street). Furthermore, Washington Street needs to be rebuilt as an identified truck route between downtown and the Wastewater Treatment Facility. If designed as a complete street, this reopened route could incentivize private development on the mostly vacant hillside between Ogden Avenue and Washington Street.

In terms of pedestrian and bicycle circulation, sidewalks and proper lighting should be provided on neighborhood collector streets leading to and from Route 19. The addition of shade trees, traffic calming features, and public art would enliven these streets as the heart of each neighborhood. Complete street design would enable the City to seek funding from alternative sources related to community health. In addition, pedestrian access routes could be made on both sides of Buffalo Creek. From the south bank it could connect to Windmill Park via the Dominion Hope right-of-way to Fitzgerald Street, to Washington Street, to Garrett Avenue. From the north bank it could connect to Old Pennsylvania Avenue via an extension. 
Plans should also be considered for bicycle traffic. This could be accomplished by having established bike routes on both sides of the Monongahela River with access points at Garrett Avenue to Washington Street, through the Wastewater Treatment Facility and the at-grade railroad crossing. A connection can also be made from the Buffalo Creek rail trail to Palatine park via on-street routes along Washington Street to the Jefferson Street Bridge, to a ramp from Merchant Street to Water Street. The on-street routes would include signage such as "Share the Road" and "Bicycle Route" to warn motorists to take care.

Finally, to better serve transit riders, it would be beneficial to install bus shelters with public art elements at key public facilities such as the Dunbar School, Windmill Park, and Fairhills Plaza.

\section{Parks and Open Space}

Parks and recreation facilities encourage healthy lifestyles and build community by accommodating social gatherings and interactions. These facilities have positive impacts on air, water, tourism, and property values that cumulatively result in a greater quality of life and sense of belongingness. Westside residents have expressed a lack of adequate parks and recreation facilities. Residents would like to see upgrades to Windmill Park sports fields, courts, track, outbuildings, concession stands, sidewalks, parking, and lighting, along with the addition of a dog park and other outdoor activities. They also want to see an indoor recreation center constructed in or adjacent to Windmill Park to accommodate gym and pool facilities. This could be accomplished through public-private partnerships. A master plan that considers all these potential improvements is recommended.

Vacant lots amidst development provide small open spaces that should be considered for temporary or permanent use as pocket parks or community gardens/urban agriculture sites. Activity deters behaviors like dumping and overgrowth that depress values of adjacent properties. However, open space also includes natural areas and greenways that provide routes and destinations for outdoor recreation and provide essential linkages between habitat areas, allowing wildlife to thrive even in urban areas. The Westside neighborhoods are blessed with the Monongahela River and Buffalo Creek, along with an abandoned rail line that provide many opportunities to expand usable open space and generate regional rail trail connections. Given that neighborhood youth are fond of riding ATVs and dirt bikes illegally on the streets and private property, it would be wise to designate some of this open space for this purpose. The planned Marion County Connector rail trail will extend from Mannington to Morgantown, and from there to both Pittsburgh and Washington, D.C.

Finally, the Westside neighbors wish to complete an adaptive reuse of Dunbar School as a community center hosting a wide range of youth, adult, and senior programming. This could be accomplished through public-private partnerships.

\section{Safe Places}

Physical development decisions should consider both building and community safety. In terms of building safety, it is clear that City of Fairmont code enforcement officers have not been able to achieve objectives given the plethora of Brownfield, Abandoned, and Dilapidated (BAD) Buildings in the Westside neighborhoods. While the legalities of enforcement are constrained by West Virginia Code, stepped up prevention could be accommodated through creative staffing approaches. In terms of community safety, building and landscape design should follow Crime Prevention Through Environmental 
Design (CPTED) guidelines. These tactics modify the physical environment to help people take control of spaces where they live and work. The four basic principles of CPTED are: natural surveillance through visibility and lighting, territorial reinforcement through borders and fences, natural access control through landscape deterrents, and target hardening through the use of adequate locks or other barriers to entry. Of these, enabling natural surveillance encourages neighbors to look out for one another, thereby building a sense of community.

\section{Physicall Development Action Plan}

Based on this overview of community assets and preferences, the overall goal for physical development is to increase public and private investment in sustainable natural and built environments in the Westside neighborhoods. Based on responsive promising practices, this goal will be achieved through the following objectives and strategies.

1. Increase desired residential and commercial development in strategic areas.

1.1. Create a Projected Development Land Use Map based on all sections of the Neighborhood Action Plan.

1.1.1. Identify viewsheds where there is greater potential for infill development opportunities.

1.2. Use land use map in developer recruitment efforts with the City of Fairmont and the Fairmont Community Development Partnership.

2. Improve circulation for all forms of transportation.

2.1. Rebuild Washington Street as a Complete Street and identified Truck Route between downtown and the Wastewater Treatment Facility.

2.2. Design and build safe pedestrian routes to and from Route 19, including sidewalks, pedestrian lighting, shade trees, and public art.

\subsubsection{Create a Multimodal Circulation Map.}

2.3. Install "Share the Road" and "Bicycle Route" signage along identified pedestrian routes.

2.4. Establish pedestrian access routes to both sides of Buffalo Creek.

2.4.1. Connect the Buffalo Creek Rail Trail to Windmill Park via on-street bike routes from the Wastewater Treatment Facility to Washington Street, to Garrett Avenue.

2.4.2. Connect Fitzgerald Street to Buffalo Creek via the Dominion Hope right-of-way access road.

2.4.3. Connect Old Pennsylvania Avenue to Buffalo Creek via an extension.

2.5. Establish pedestrian/bicycle access routes to both sides of the Monongahela River.

2.5.1. Establish an access point via Garrett Avenue to Washington Street, through the Wastewater Treatment Facility, and across the at-grade railroad crossing.

2.5.2. Connect the Buffalo Creek Rail Trail to Palatine Park via on-street routes along Washington Street to the Jefferson Street bridge, to a Merchant Street ramp to Water Street.

2.6. Eliminate one-way traffic barriers to circulation on neighborhood collectors and routes to public facilities. 
2.7. Install bus shelters with public art elements at key public facilities.

2.7.1. Include the Dunbar School stairs (Barrackville Route); both entrances to Windmill Park (Jackson Addition Route); and Fairhills Plaza (Fairview/Rivesville Routes).

3. Expand parks and public facilities to meet informal education, recreation, and leisure programming needs (see Social Development section).

3.1. Expand Windmill Park to Garrett Avenue through the Fairmont Community Development Partnership lot.

3.2. Generate a master plan for Windmill Park improvements.

3.2.1. Work with the WVU Landscape Architecture program, the City of Fairmont, and the Marion County Parks and Recreation Commission.

3.3. Design and build an indoor recreation center on Garrett Avenue.

3.3.1. Establish a partnership among the City of Fairmont, Marion County Parks and Recreation Commission, and the YMCA.

3.3.2. Work with Fairmont State University's Architecture program for conceptual design.

3.4. Design and build the Francis H. Pierpont Overlook pocket park next to the historic house at 500 Ogden Avenue.

3.4.1. Work with the WVU Landscape Architecture program and the City of Fairmont.

3.5. Design and build an ATV park at the abandoned Roundhouse site.

3.5.1. Work with the WVU Landscape Architecture program, the City of Fairmont, and a private operator.

3.6. Formalize Buffalo Creek use areas as public pocket parks.

3.6.1. Including: (1) the railroad trestle location, (2) the end of the Dominion Gas right-of-way, and (3) the extension off Old Pennsylvania Avenue.

3.7. Develop the first section of the Buffalo Creek Rail Trail.

3.7.1. Complete the section from the Wastewater Treatment Facility (active freight railway) to the Johnny Johnson Bridge.

3.8. Design and renovate the historic Dunbar School building and site as the Paul Laurence Dunbar Community Center.

3.8.1. Establish a partnership between the Dunbar School Foundation and the Fairmont Community Development Corporation.

3.8.2. Work with Fairmont State University's Architecture program and WVU's Landscape Architecture Program for conceptual design.

4. Increase the safety of private and public spaces.

4.1. Demolish or rehabilitate buildings on the BAD Buildings Team inventory list.

4.1.1. Establish a partnership between the City of Fairmont and the Fairmont Community Development Partnership, using Property Rescue Initiative funding from the West Virginia Housing Development Fund. 
4.2. Form a property code enforcement prevention team of retirees and youth who wish to work part-time for the City of Fairmont without benefits.

4.3. Advocate with the City of Fairmont to add Crime Prevention Through Environmental Design (CPTED) to its zoning and design review policies and procedures.

4.3.1. Ensure guidelines improve visibility, lighting, and security in private developments.

4.4. Increase visibility and lighting in and around public facilities. 


\section{APPENDIX A. NEIGHBORHOOD WALKABOUT FEATURES}

\section{Naturall Capital}

Buffalo Creek Access, Pocket Parks, and Trails

- Wastewater Treatment Facility

- Dominion Hope right-of-way

- Old Pennsylvania Avenue trail

- Johnny Johnson Bridge (Pennsylvania Avenue) trail

- Abandoned Railway (Marion County Connector Trail)

- Abandoned Roundhouse Site

Parks and Pockef Parks

- Windmill Park

- Bellview Park

- 502 Ogden Avenue

- Bellview Avenue "triangle"

\section{Cultural Capital}

Cemeteries

- Evergreen

- Fairmont City

- Woodlawn

Historic Buildings

- Dunbar School

- Miller School

- Barnes School

- Woodlawn Cemetery Caretaker's Home and Chapel

- 500 W. Ogden

\section{Sociall Capital}

\section{Churches}

- Church of God

- Church of God MPGT

- Fairmont Christian Assembly

- Highland Methodist

- Miles Chapel and Divine Café 
- Morning Star Baptist

- Mount Zion Baptist

- Temple of Christ

- Ultimate Health Mind and Body Recreative Ministry

\section{Social Services}

- Barnes Learning Center

- Head Start

- Fairmont Community Youth Development Center

- Women, Infants and Children (WIC) Office

\section{Criminall Activity (Drugs)}

- Spring/Maple/Quincy/Pennsylvania Avenue intersection

\section{Financiall Capital}

\section{Affordable Housing}

- 211-233 Billingslea Street (FMHA)

- 600-612 Carlone Street (FMHA)

- 100-110 Maple Avenue (FMHA)

- 609-621 Ogden Street (FMHA)

- Spence at Maple (FCDP)

\section{Local Businesses}

- Brite Wash Laundry

- Funeral Home

- Skate-A-Way

- Sno-Cone Stand

- TRANSFLO Service Bulk Transfer Terminal

\section{Built Capital}

- 201 Billingslea Street

- 527 Boydson Street

- 120 Cedar Street

- 137 Chestnut Street

- 139 Chestnut Street

- 313 Chicago Street

- 323 Chicago Street

- 327 Chicago Street 
- 334 Chicago Street

- 109 Chew Street

- 395 Garrett Avenue - Old Carriage House

- 403 Garrett Avenue

- 238 Grant Street

- 260 Grant Street

- 216 Hamilton Street

- 344 Hamilton Street

- 350 Hamilton Street

- 17 Holbert Avenue

- 292 Holbert Avenue

- 396 Holbert Avenue

- 401 Holbert Avenue

- Holbert Avenue and Garrett Avenue Alley

- 235 Lehman Avenue

- 320 Lehman Avenue

- 324 Lehman Avenue

- 214 McKinney Street

- 640 Monroe Street

- 642 Monroe Street

- 644 Monroe Street

- 403 Montgomery Avenue

- 102 Odell Street

- 140 Odell Street

- 414 Odell Street

- 518 Ogden Avenue

- 523 Ogden Avenue

- 524 Ogden Avenue

- 527 Ogden Avenue

- 600 Ogden Avenue

- 601 Ogden Avenue

- 605 Ogden Avenue

- 553 Pierpont Street

- 320 Persis Way

- 312 Robinson Street

- 406 Robinson Street

- 813 Sand Street (marked Howard)

- 221 Spring Street

- 227 Spring Street

- 609 Spring Street

- 613 Spring Street

- 123 Spruce Street 
- 126 Spruce Street

- 130 Spruce Street

- 211 Spruce Street

- 221 Spruce Street

- 98 Sterling Road

- 99 Sterling Road

- 315 Sutton Drive

- 37 Williams Street

- 320 Yodie Street

\section{Vacant FCDP Lots}

- 129 Abbott Street

- Baltimore Street near Ogden Avenue

- 115 Billingslea Street

- 115 Chew Street

- 162 Fitzgerald Avenue

- 163 Fitzgerald Avenue

- Loree Avenue near Wastewater Treatment Facility

- 201 Maple Avenue

- 309 McKinney Street

- 813 Ogden Avenue

- 400 Robinson Street

- 404 Robinson Street

- 407 Robinson Street

- 414 Robinson Street

- 109 Wheeling Street

\section{Vacant Lołs}

- Windmill Park entrance dead end road

- 700 block Maple Avenue

\section{Key Circulation Routes}

- Maple/Garrett

- Weatherwax/High/Monroe/Hamilton/Spring

- Hampton

- Bellview/Riverview

- Fulton/Trolley

- Washington Street

- Quincy Avenue Pedestrian Bridge 


\section{COMMUNITY CAPITALS}

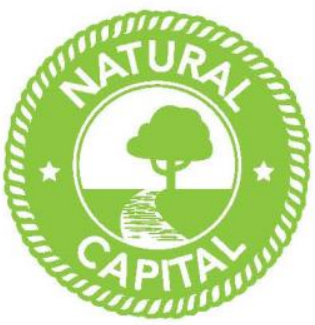

Natural Capital

The geography, climate, natura resources, and natural beauty of a place

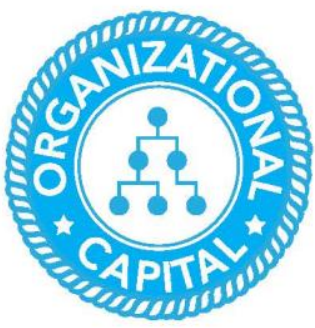

Organizational Capital The structure, policies, plans, and track record of existing groups

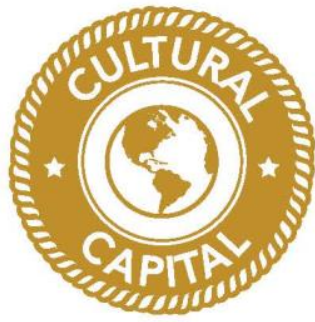

\section{Cultural Capital}

The traditions, history,

language, and creativity of the people

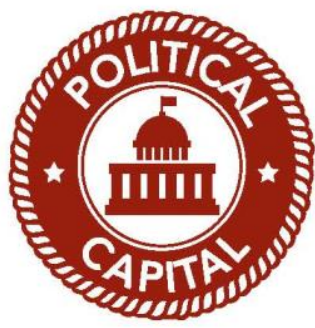

Political Capital The ability to make or influence public policy at local, county, and state levels of government

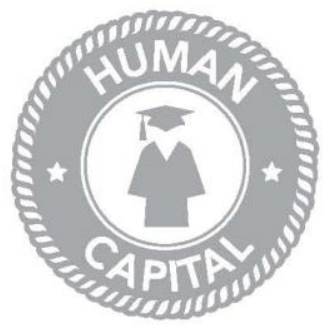

$$
\begin{aligned}
& \text { Human Capital } \\
& \text { The skills, knowledge, abilities, } \\
& \text { and attitudes of individuals }
\end{aligned}
$$

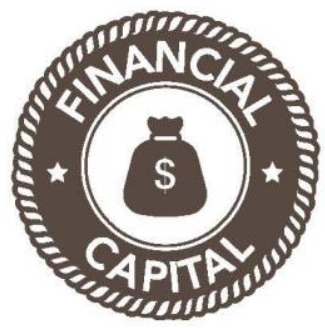

Financial Capital The ability to access funding, investment, lending, and income

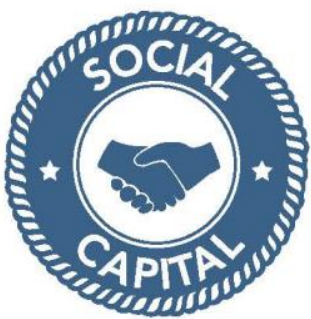

Social Capital

The relationships that enable bonding among individuals and bridging across groups

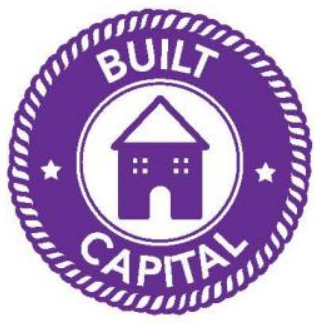

Built Capital The trails, sidewalks, lights, roads, bridges, buildings, and utility systems 


\section{APPENDIX C. ASSETS IDENTIFIED DURING THE PLANNING WORKSHOP}

\section{Naturall Capitall}

- Scenic land $\times 2$

- Amazing hilltop/side views $\times 2$

- Mon River X 2

- Access to river

- Ogden and Washington $\times 2$

- Scenic Views on Ogden Ave.

- Washington St. overlook and access

- Washington Street Right-of-way

- Windmill Park

- Expansion potential at Windmill Park

- Open Green Space Utilization

- Community garden

- Green spaces on Holbert Ave and Ogden

- Lots near Windmill

- Farmable vacant lots

- Vacant lots $\times 3$

- Bellview Park $\times 2$

- Buffalo Creek Access

- Buffalo Creek

- Kayaking possibilities - Buffalo Creek

- Fishing/swimming opportunities

\section{Culturall Capitall}

- African-American history/culture $\times 2$

- Civil war history $\times 2$

- Woodlawn cemetery x2

- Governor Pierpont burial site

- Dunbar school x3

- History of Diversity

- History

- Pepperoni Rolls

- First Father's Day

- Windmill Park fairground history

- Rich in immigrant history

- Historic buildings

- Evergreen cemetery (was 1 or $1^{\text {st }}$ black cemetery in WV)

- Evergreen Cemetery

- History Negro baseball league

- Appalachian Identity 
- Diversity

- Brothers' cooking

- Cultural Appreciation (music, dance, etc...)

\section{Human Capitall}

- Ms. Charlotte

- Neighbors who care and do

- Caring neighbors

- Business owners who care and do

- Community leaders who care and do

- Youth/adults interactions with older adults

- Old People

- Children Play

- Affordable sports/activities

- Optimistic attitudes

- Skills from elders

- Community willingness to change

- Awareness of opportunities

- Awareness of needs

- Dance, Music \& Cheerleading

- Parents/others support kids

- Good principals and teachers

- Youth still enjoy outside vs. computer/screens

- Youth who want to grow

- WV work ethic

- Fundraise

- Access to Fairmont schools

- Engaged youth

- After school program

- Retired teachers

- Diverse youth programs and activities

\section{Sociall Capital}

- Strong sense of collaboration

- Neighbors who know each other

- SAFE neighborhoods

- Safe streets - people outside

- Church youth groups

- Youth sports

- Youth activities

- Outdoor activities 


\section{Organizationall Capital}

- Independent groups working on projects

- Head Start

- Learning Options

- Churches + Church Communities (4x)

- Fairmont State $(2 x)$

- WV Foodlink

- Churches in neighborhood - Highland Ave other church

- Westside Robotics

- 612 MAC

- Westside Action Coalition (WAC)

- Women's Club (took lead in neighborhood PRESERVATION)

- NAACP

- Dunbar School Foundation

- Church Congregations

- Boy Scouts of America

- Sports Leagues

- Senior Programs

- Fairmont Community Development Partnership

- PAWV (Preservation Alliance)

- WV Robotics

- Marion County Black History Team (Charlotte Meade)

- Highland Ave. Methodist

- Bad Buildings Team/NBAC

- Fairmont State University

- FCYDC "The Mac"

- Pierpont College

- Dominion Hope

- Men's Conference

- Fairmont Christian Assembly

- Access to Soup Opera, etc. Opportunities for service

- Woodlawn now has an active board and strategic plan

- The Hub

- Alternative Learning Center (Barnes School)

\section{Politicall Capital}

- Active Delegates

- Legislators who engage

- House of Reps

- Responsive City Manager

- Quick Grabs

- Senator Manchin + Gayle 
- County Commission - Palatine Park

- City of Fairmont- Limited

- 3 Council Districts

- Zoning $=$ Penn + Washington zones for commercial

\section{Financiall Capital}

- Main Street Fairmont

- Woodforest Bank

- State Historic Preservation Office

- WesBanco CDC and CRA

- Fairmont Federal Credit Union

- MCPARC Grants

- City Grants

- Assistance with dilapidated houses still occupied

- Property Recovery Initiative loans

- National Endowment for Arts Grants

- BBW Laundry

- Bridge in Bellview

- Dominion Hope Right of Way to Buffalo Creek

- Bank Investments

- Attention of the FCDP and FMHA

\section{Built Capital}

- Dilapidated Building List in GIS database

- GIS Map/Data

- Vacant Lots for Infill Development

- Proximity to State Building + Departments

- Close to downtown

- Walkable to Downtown

- Proximity to Educational Opportunities

- Proximity to state parks

- Access to Dick Ritter - Fairhillls Plaza owner

- Fairhills Plaza and businesses

- Skate-a-way

- History of family-owned businesses

- Local Small Businesses

- Small Businesses

- Colassenos

- Broken Egg

- 24/7 Laundromat

- Small businesses along boulevard

- $B B Q$ restaurant 
- Former cornerstore (Maple)

- Ms. Ann (snowcones)

- Older Businesses

- Mom/Pop Stores Businesses

- Roller rink (Skate-Away)

- Entrances to town - except rt.19

- Expansion of Windmill Park Facilities

- Windmill - (Needs Additional facilities, Horseshoe Pit, Track, Update Playground Equipment)

- Water Treatment Plant

- Abandoned Railroad Track (Buffalo Creek)

- Abandoned Railroad Roundhouse Site

- Woodlawn Cemetery Caretakers House

- Woodlawn Cemetery

- Dunbar School

- Million Dollar Bridge

- 500 Ogden (Turret House)

- 500 Ogden Ave - Historical Architectural Rehab Potential

- FCYDC Property

- Active Railway Access

- Beauty of Architecture

- Miller School

- Bellmont Hotel

- Old Post Office in Bellview

- Access to $5^{\text {th }}$ St. Park + Gym

- East West Stadium

- "Urban" area for Marion County 


\section{APPENDIX D. ENTERPRISE PITCH SHEET}

\section{Community Enterprise Pitch Sheet}

What specific assets will you use to make this happen?

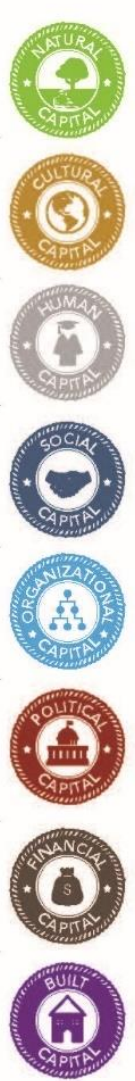

What do you seek to do and why? Do you have a name for your enterprise?

What is your name and what are you willing to do to make it happen? 